\title{
Gods, Goods and Big Game: The Archaeology of Labrador Inuit Choices in an
} Eighteenth- and Nineteenth-Century Mission Context

\author{
Beatrix Joy Yvonne Michelle Arendt
}

Charlottesville, Virginia

B.A. Anthropology and Art History, Emory University, 1999

M.A. Anthropology, University of Virginia, 2006

A Dissertation presented to the Graduate Faculty of the University of Virginia in Candidacy for the Degree of

Doctor of Philosophy

Department of Anthropology

University of Virginia

December 2011

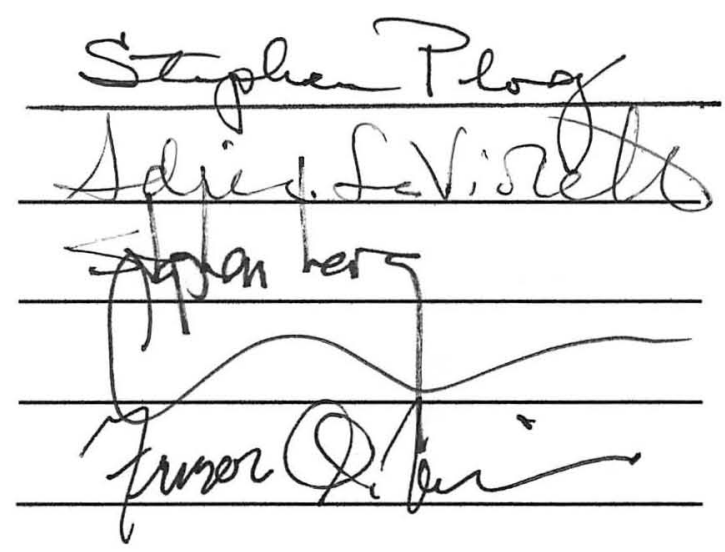


(C) Copyright by

Beatrix Joy Yvonne Michelle Arendt

All Rights Reserved

December 2011 


\begin{abstract}
This archaeological project investigates the long-term economic and social impact of German Moravian missionaries on Labrador Inuit culture, by exploring changes in eighteenth-and nineteenth-century Inuit material culture and architecture near the mission town of Hopedale, Labrador. My analysis archaeologically examines three sites in northern Labrador region that include Adlavik, a mid-eighteenth century Inuit sod house settlement, Anniowaktook, a late eighteenth century Inuit settlement, and the Inuit village associated with the mission at Hopedale, Avertôk. The research draws together archaeological, faunal, and ethnohistorical data to define changes in Inuit economic and subsistence strategies.
\end{abstract}

This research examines whether changes to Inuit domestic space, subsistence practices, economic structures, and religious traditions during the Moravian period were due in part to earlier eighteenth-century organizational patterns. This dissertation evaluates the hypothesis that the Moravians disrupted an earlier Inuit social organization where Inuit leaders who could both trade with Europeans and coordinate local hunting groups experienced greater accessibility to desired trade goods. By offering Inuit easier access to desirable resources including European goods, the Moravians were able to challenge existing Inuit authority.

Excavated Inuit sod houses were differentiated according to artifacts related to trade, hunting, and domestic production; however the lack of a marked differentiation between households with respect to the abundance of valued goods suggest that Inuit settlements followed a more egalitarian organization based on a division of labor. 
Further, the Moravian missionaries employed a systematic strategy that included economic and social variables towards changing Inuit perception associated with appearances, healing, taboos, and the role of the shaman. This study demonstrates that the process of culture change involves bilateral influences leading to the reorganization of Inuit society after the arrival of the Moravians, including Inuit adaptation and missionary coercion. 
In memory of my uncle,

Wolfram Rüdiger Arendt, who passed away before defending his thesis. 


\section{Table of Contents}

Abstract iii

Dedication $\quad$ V

List of Figures $\quad$ vii

List of Tables $\quad$ xiii

$\begin{array}{ll}\text { Acknowledgements } & \text { XV }\end{array}$

Chapter 1: Identifying Missionary Influence on Native Societies 1

Chapter 2: Early Inuit Predecessors for the Development of Social Organization 25

Chapter 3: First Contact: Europeans in Labrador 70

Chapter 4: The Moravian Church in Europe and Labrador 107

Chapter 5: Identifying Social Influence in the Moravian Documents 151

Chapter 6: Introduction to the Sites: Avertôk, Adlavik and Anniowaktook 193

Chapter 7: Inuit Material Culture and the Definition of the Artifact Categories 263

Chapter 8: Locating Evidence for Inuit Social Organization in the Material Remains

Chapter 9: Conclusions and Future Research 365

Appendix A: The Hopedale Archaeology Project 380

Appendix B: Explanation for the removal of Anniowaktook House 3 and the Avertôk houses from the correspondence analysis 404

Appendix C: Faunal Data $\quad 414$

$\begin{array}{ll}\text { Bibliography } & 424\end{array}$ 


\section{List of Figures}

Figure 2.1: Summary of cultural phases of house styles, the appearance of snow house villages, and harpoon heads of the Thule.

Figure 2.2: Plan map of Oakes Bay 1.

Figure 2.3: Plan of Uivak Point 1.

Figure 2.4: Plan of Eskimo Island 1 and 2.

Figure 2.5: Plan of Eskimo Island 3.

Figure 4.1: The Moravian settlement at Hopedale founded in 1782 (print 1791).

Figure 4.2: Chart of the richness scores, or number of different types of goods imported for sale in the trade store from 1788-1823.

Figure 4.3: Graph of Hopedale and Avertôk population.

Figure 5.1: Richness scores of the food category from the trade lists from 1788 through 1804.

Figure 5.2: Richness scores for the hunting category at the trade store from 1788 through 1804.

Figure 5.3: Richness scores of the hunting category from the Trade and Missionaries' Lists.

Figure 5.4: Richness scores for the manufacturing category at the trade store from 1788 through 1804.

Figure 5.5: Richness scores of manufacturing from both the Trade and Missionaries' List.

Figure 5.6: Richness scores for the clothing category at the trade store from 1788 through 1804.

Figure 5.7: Black and white photograph of four Christian Inuit women and a child. 169

Figure 5.8: Color postcard of a "heathen” Labrador Inuit woman in traditional clothing.

Figure 5.9: Richness scores for imported items from the Missionaries' Lists from 1782 through 1813. 
Figure 5.10: Linear regression of richness scores of the Missionaries' List from 1782 through 1813 with the three periods identified.

Figure 5.11: Richness scores for the food category from the Missionaries’ Lists from 1782 through 1813.

Figure 5.12: Richness scores for the clothing category from the Missionaries’ Lists from 1782 through 1813.

Figure 5.13: Richness scores for the writing category from the Missionaries' Lists from 1782 through 1813.

Figure 6.1: Junius Bird's plan drawing of Avertôk including all excavated and unexcavated houses.

Figure 6.2: Photograph of three unexcavated sod house remains at Avertôk.

Figure 6.3: Photograph of the excavation of the large midden in front of a large sod house.

Figure 6.4: Map of Labrador with site locations and Hamilton Inlet.

Figure 6.5: Plan of sod house settlement on Anniowaktook Island with test units from 2007.

Figure 6.6: Plan drawing of Anniowaktook House 1.

Figure 6.7: Outline of a Avertôk sod house drawn by medical doctor Eliot Curwen who visited Hopedale in 1893.

Figure 6.8: Pie chart of botanical remains found in Anniowaktook House 1.

Figure 6.9: The Anniowaktook House 1 midden excavation in 2008: a 2 x 2 m unit excavated directly outside of House 1 's entrance tunnel.

Figure 6.10: Plan drawing of Anniowaktook House 4.

Figure 6.11: Profile of the west wall of House 4 at Anniowaktook Island.

Figure 6.12: Pie chart of botanical remains found on the sleeping platform at Anniowaktook House 4.

Figure 6.13: Unit N1E2. Floor of Anniowaktook House 4. 
Figure 6.14: Possible lamp stand and hearth located in unit N4E1 of Anniowaktook House 4.

Figure 6.15: Hopedale student James Karpik holding a soapstone lamp fragment found inside a House 3 on Anniowaktook Island.

Figure 6.16: Map of Labrador coast with the location of Adlavik encircled in red. 226

Figure 6.17: Plan drawing of Adlavik by S. Loring and L. Rosenmeier. 227

Figure 6.18: Plan drawing of Adlavik House 1. 230

Figure 6.19: Entrance tunnel into Adlavik House 1 facing north. 231

Figure 6.20: West profile of the Adlavik House 1 midden. 232

Figure 6.21: Plan view of the shell midden in Adlavik House 4. 234

Figure 6.22: Screenshot of Context Form from Access database. 236

Figure 6.23: Screenshot of the Artifact Table from the Access database. 236

Figure 6.24: A collection of beads from the Adlavik assemblage. 244

Figure 6.25: 95\% confidence intervals for mean ceramic dates for house deposits. $\quad 254$

Figure 6.26: $95 \%$ confidence intervals for mean ceramic dates at midden deposits. 255

Figure 6.27: Occurrence seriation of four house deposits. 256

Figure 6.28: Occurrence seriation of the six midden deposits. 257

Figure 7.1: Example of a soapstone pot form Avertôk House 6. 270

Figure 7.2: Example of a soapstone lamp from Avertôk House 1. 272

Figure 7.3: Examples of a soapstone toy lamp from Adlavik House 1, and toy pots from Adlavik House 4.

Figure 7.4: Example of a child's snow knife made out of baleen from the Avertôk midden.

Figure 7.5: Fragment of a small ulu knife with bone handle and iron blade Anniowaktook House 4 midden. 
Figure 7.6: Sewing implement or possible thimble guard found in Anniowaktook House 1 midden.

Figure 7.7: Image of a needle case and accessories from the Nunavut Inuit.

Figure 7.8: Lead ulu pendant found in the entrance tunnel of Anniowaktook House 4.

Figure 7.9: An example of a nail pounded into a harpoon head from Anniowaktook House 4.

Figure 7.10: Examples of iron forms cut from strap metal or sheet metal from Adlavik House.

Figure 7.11: Example of a whale bone snow knife from the midden of Anniowaktook House 1.

Figure 7.12: Example of a collection of bone artifacts. Example of a collection of bone artifacts, including a (1) handle to a man's knife, (2) a toggle, (3) a wound plug, (4) a harpoon head, and (5) a game piece or pendant from Adlavik House 1.

Figure 7.13: Lead fishing weights or possible parka trim from Adlavik House 1 and House 2.

Figure 7.14: Slate harpoon head from Anniowaktook House 4.

Figure 7.15: Feature 1 on the sleeping platform in Anniowaktook House 1.

Figure 7.16: Normandy stoneware fragments found on rock located approximately 100 meters east of a cave burial on Anniowaktook Island.

Figure 7.17: Photograph of an Inuit woman smoking a pipe.

Figure 7.18: Black and white photograph of an Inuit winter house with several children standing out front.

Figure 7.19: Inuit woman's seal skin parka decorated with glass beads and pewter spoon bowls.

Figure 7.20: Correspondence analysis of artifact types and assemblages of Anniowaktook and Adlavik. 
Figure 7.21: Plot of the artifact types inertia values against their rank.

Figure 7.22: Plot of correspondence analysis of Anniowaktook and Adlavik with sheet metal and soapstone hollow vessels removed.

Figure 8.1: Image of a white whale identifying the parts for distribution.

Figure 8.2: Hunting Index Values with $90 \%$ Confidence Intervals by ranked site.

Figure 8.3: Author standing directly behind a stone fox trap near Adalvik.

Figure 8.4: Hunting Index value with $90 \%$ confidence intervals over time.

Figure 8.5: Linear regression of Hunting Index.

Figure 8.6: Trade Index scores for midden deposits at Anniowaktook and Adlavik plotted over time.

Figure 8.7: Trade Index Scores with a 90\% confidence interval plotted over time. 356

Figure 8.8: Manufacturing Index values with nails removed and a $90 \%$ confidence interval.

Figure 8.9: Trade Index Values plotted against Hunting Index Values.

Figure A.1: Plan map of the Hopedale Moravian mission and unit locations.

Figure A.2: Students viewing photographs at the Archaeology Open House.

Figure A.3: Community members viewing artifacts from the summer's excavation at the Archaeology Open House.

Figure A.4: Community Day on Anniowaktook Island, 2009.

Figure A.5: Poster 1 donated to the Hopedale School.

Figure A.6: Poster 2 donated to the school.

Figure B.1: Correspondence Analysis plot of all assemblages and artifact types. $\quad 407$

Figure B.2: Scatterplot of Inertia values of assemblages. 408

Figure B.3: Scatter plot of inertia values of all artifact types.

Figure B.4: CA scatterplot after soapstone hollow vessels (SSHollow) were removed. 
Figure B.5: Scatter plot of inertia values of all artifact types after soapstone hollow vessels removed (SSHollow).

Figure B.6: Scatter plot of inertia values of all artifact types once soapstone hollow vessels removed (SSHollow).

Figure B.7: CA scatterplot after weights, whet stones, lamps and soapstone hollow vessels were removed. 


\section{List of Tables}

Table 2.1: House dimensions and the entrance passageways in meters at Oakes Bay 1.

Table 2.2: House dimensions and the entrance passageways in meters at Uivak Point.

Table 2.3: House dimensions and the entrance passageways in meters at Eskimo Island.

Table 5.1: Inventory of items that made up each category which identifies various domestic and activity areas at the mission.

Table 5.2: Kendal Tau Correlation Coefficient for the richness scores of Clothing, Domestic, Hunting, Manufacturing and Tool subgroups from the Trade Lists.

Table 6.1: List of Avertôk house types and descriptions and possible occupation period as identified by Bird (1945).

Table 6.2: Total area excavated at Anniowaktook.

Table 6.3: Total area excavated at Adlavik.

Table 6.4: Table of beads from Adlavik and Anniowaktook.

Table 6.5: Table of raw counts of the tobacco pipe stems by bore measurements.

Table 6.6: Estimated date for Adlavik and Anniowaktook using three different formulas for pipe stem diameters.

Table 6.7: Ceramic ware types that contributed to the mean ceramic date collected from the DAACS MCD list, Parks Canada, and the Florida Museum of Natural History Digital Types Collection.

Table 6.8: Raw counts of the ceramic types found in each deposit.

Table 6.9: Table of estimated mean dates (EMD) based on evaluations of the diagnostic beads, bore diameter mean dates, MCDs, and a temporal order as determined by the occurrence seriation.

Table 6.10: Table of raw counts of tobacco pipe stems and ceramic types at each deposit used in calculating the EMDs. 
Table 7.1: Material frequency by house and deposit type. 268

Table 7.2: Raw counts of the artifacts included in the domestic category. 269

Table 7.3: Raw counts of artifacts included in the manufacturing category. 282

Table 7.4: Raw counts of artifacts included in the hunting category. 288

Table 7.5: Raw counts of artifacts included in the trade category. 292

Table 7.6: Average number of items by volume excavated in each category at Adlavik and Anniowaktook.

Table 7.7: Kendall Tau correlation using the transformed (log) counts of the domestic, hunting, manufacturing and trading categories from all deposits at Anniowaktook, Adlavik and Avertôk.

Table 7.8: Kendall Tau correlation using the transformed (log) counts of the domestic, hunting, manufacturing and trading categories from all deposits at Anniowaktook and Adlavik, with the Avertôk deposits omitted.

Table 8.1: Table of NISP of the seal, caribou and whale faunal material identified in the test units at Anniowaktook House 1 and House 4.

Table 8.2: Table of NISP of the seal, caribou and whale faunal material identified at Anniowaktook House 4.

Table 8.3: NISP of seal, caribou, walrus, and whale faunal material from Adlavik House 1 midden.

Table 8.4: Table of whales spotted, killed or found by Inuit in the Avertôk/Hopedale area as recorded by the Moravian diaries.

Table C.1: NISP of faunal material from Adlavik House 1 midden.

Table C.2: Distribution of specimens by class at Anniowaktook.

Table C.3: NISP and MNI of identified specimens at Anniowaktook by house and midden.

Table C.4: Faunal frequencies at Anniowaktook by context and level. 


\section{Acknowledgements}

This project would not have been possible without generous financial support from a number of institutions and organizations. Funding for this dissertation was made possible by the National Science Foundation Dissertation Improvement Grant, the Smithsonian Predoctoral Fellowship, a Canadian Embassy Doctoral Fellowship, the Arctic Institute of American Grant-in-Aid, two Explorers Club Exploration Grants from the Washington, D.C. and New York groups, the Lewis and Clark Research Fellowship from the Philosophical Society, a Museum Studies Grant from the American Museum of Natural History, three Archaeological Research Grants from the Provincial Archaeology Office in Newfoundland, and three Inuit Youth Employment Summer Strategy Grants for Summer Employment for Students from the Nunatsiavut Government.

I have been extremely fortunate to receive advice, support, and encouragement from a great number of people without whom this project would never have seen the light of day. I am especially grateful to my committee chair, Steve Plog, for his continued guidance and encouragement during all levels of this project. Despite my regional interests being far different from his own, he took me on as a student and tirelessly helped me develop this project through numerous conversations, appraisals, and comments on many rough (and I do mean rough) drafts. He has gently yet persuasively, pushed me to strive to achieve a high level of scholarship. He has been a good friend and excellent mentor over the years, and without his guidance, I would not have been nearly as successful in achieving this end. 
I would also like to thank Fraser Neiman, who continuously challenged me to improve the questions I asked, to enhance the quality of my research. It was during the years prior to graduate school, while working for Fraser at Monticello where I grew to understand the true significance of statistics in archaeology. It was his mentoring that helped me realize my own potential. Also, I have been fortunate to have met Adria LaViolette early on in my graduate career. She has served as a friend and mentor throughout the years. Her comments, suggestions and amazing ability to understand and improve upon my occasionally convoluted sentences served to exponentially improve the quality of my work. I also must extend my thanks to Christian McMillen, who agreed to serve on my committee during the final stages of this project. His thoughtful and artful comments on all parts of the project, and especially on mission history, were invaluable.

A good portion of this dissertation would not have been possible without the help, wisdom and wit of Stephen Loring. He was the one who lured me to Labrador, despite the flies, mosquitoes and polar bears. I have been honored to have been able to learn from Stephen these past twelve years, as he taught me so much more than the difference between Ramah and Mugford chert; he showed me the beauty embedded within the stories of every hill, every stone and every town in Labrador. His passion and appreciation for this remote land is contagious and I am lucky to have such a great friend and mentor in him. I thank him for guiding me through this challenging, yet phenomenal, journey.

I must thank Cynthia Zutter for providing the archaeobotanical analysis of Anniowaktook houses. It was through her reports and our email exchanges that I have 
come to appreciate the significance of botanical research in the area. I also would like to thank James Woollett and his exceptional zooarchaeology students — Céline DupontHébert, Félix Gagné and Lindsay Swinarton at Université Laval in Quebec City, Canada — for conducting the faunal analysis for this dissertation. My conversations with Jim have also helped me better understand the seasonal flow of life in Labrador, and the central spiritual and social role that seals played in historic Labrador.

A number of individuals provided valuable advice and support during my time at the Smithsonian as a Fellow and they deserve recognition. William Fitzhugh has been a wonderful proponent of my research in Labrador. Through our many conversations, I was able to refine my questions regarding the various groups of Europeans that visited the Labrador coast. I was lucky enough to have my fellowship overlap with Christopher Wolff's tenure. His knowledge of prehistoric northern Labrador was invaluable and his advice and friendship during the final years of this project that helped me reach the finish line. I am also indebted to Laurie Burgess, who helped me navigate through the extraordinary literature on glass beads; she also generously provided her expertise in identifying some of the lesser known specimens in my collection. There were a number of other Smithsonian colleagues who provided invaluable support, advice and always a good laugh throughout the years including, Ann Kaup, Noel Broadbent, Joan Gero and Dorothy Lippert.

I was lucky to have worked with a number of bright Smithsonian interns and researchers who volunteered their time and suggested some important final touches on this project. Those include Sarah Dickey, who was an immense help in researching and 
designing the posters and teacher handbooks donated to the Labrador schools; Anna Eschelman, who finalized the Adlavik catalog and provided an incredibly high level of digital expertise in making the images; and Juli Six, who provided many of the excellent photographs of objects for this dissertation.

I must thank many other individuals at institutions that provided me with support and guidance during the earlier stages of my project. This includes Paul Peuker and Lanie Radkow of the Moravian Archives in Bethlehem, Pennsylvania, and Lorraine Parsons of the Moravian Archives in London, England. Anibal Rodrigeuz was also helpful during my tenure at the American Museum of Natural History in New York City, by providing access to Junius Bird’s Avertôk collection and helping me navigate the various ambiguous written records.

I find myself indebted to many people from Hopedale, Makkovik, and Happy Valley-Goose Bay, Labrador. They were instrumental at all levels of this project. In particular, I would like to thank Judy Dicker, the entire Town Council and the Hopedale Nunatisavut Office for their administrative assistance and general interest in the project; David Igloliorte and Juliana Flowers of the Agvituk Historical Society for their constant counsel and support in promoting archaeology in Hopedale; Ross Flowers, Clarence Vincent and Rex Flowers for shuttling me and my crew out to Anniowaktook Island regardless of the weather; Teena and Gil Flowers and Doreen Blanchard for the soft beds, hot meals, and warm hearts and for providing me with a home away from home; and Roberta and Bernie Andersen, Randy Edmunds and Lori Dyson from Makkovik for 
helping with some of the logistics of establishing a community archaeology program in Hopedale, and for always being ready with a warm smile and a great story.

I would also like to thank Heather Angnatok at Nunatsiavut Government, and Jaime Brake, Delphina Mercer and Stephen Hull from the Provincial Archaeology Office in Newfoundland for their direction and assistance with funding and legal issues as well as general support. The majority of this work would not have been completed without the dedication and resilience of my field crews from 2007 to 2009. This included Ashley Abel, Benjamin Abel, Christopher Abel, Trevor Broomfield, Kelsey Hunter, Amalia Jararuse, Mary Jararuse, Selma Jararuse, James Karpik, Nathan Karpik, Bobby Nochasak, and Delano Torarak.

My many years as a graduate student at the University of Virginia (UVA) were challenging. Yet it was a wonderful time in my life that I will always cherish. Much of that is due to a number of brilliant scholars who shared this experience with me. Professors Susan McKinnon, Patti Wattenmaker, Rachel Most, Fred Damon and Peter Metcalf pushed me to achieve a level of scholarship I never thought I was capable of reaching. While the faculty at the UVA anthropology department served me exceptionally well, I would have never made it through without the support, friendship, and wisdom of some exceptional current and former graduate students. In particular, I must thank Jillian Galle, Sherri-Lynn Colby Bottle, Carrie Heitman, Beth Bollowerk, Adam Watson, Abby Holeman, Amy Nicholos-Belo, Lydia Watson and Matt Pawlowicz. Recognition must go also to members of my family. They have been a true and constant source of support. My in-laws, Evelyn and David Speedie provided unwavering 
encouragement. Evelyn, in particular, took the time to read various sections and offered invaluable editorial comments that significantly improved many of my chapters. My parents, Ulli and Volker Arendt, helped me translate many of the German Moravian documents, as well as cheering me on through both the highs and lows. And of course, I must extend my final thanks to my husband, Sam. He truly shared in my work by traveling with me to Labrador to endure the bugs and weather and help run the Hopedale Archaeology Project. His steadfast support and belief in me was all that I had at times, but it was all that I needed. 


\section{Chapter 1: Identifying Missionary Influence on Native Societies}

\section{Introduction}

The Inuit of Labrador, Canada had been in intermittent contact with European whalers, fishermen and traders since the sixteenth century, but altered many of their hunting and religious traditions after the arrival of German Moravian missionaries in 1771. Prior to the Moravians' arrival, researchers argue that Inuit male heads of household held positions of authority as boat owners, hunters and shamans to organize kin, dominate exchange, and accumulate wealth through European trade goods (Jordan 1977; Kaplan 1983, 1985a; J. G. Taylor 1974). Those who could both trade with Europeans and coordinate local hunting groups experienced greater accessibility to desired trade goods or food and, as a result, accumulated more of the items. But the Moravians’ establishment of three permanent residences in northern Labrador in the eighteenth century eventually disrupted the Inuit social system by offering Inuit men and women easier access to desirable resources including European goods and foods. After living a semi-nomadic life for hundreds of years, many Inuit settled at missions, converted to Christianity, and participated in a European market economy by the end of the nineteenth century

To study this profound transformation to Inuit culture, social systems, and economy, I adopt a regional approach building on existing archaeological and ethnohistorical research of Labrador, Canada (Auger 1989; Graburn 1969; Hawkes 1916; Jordan 1977; Kaplan 1983; Kleivan 1966; Loring and Arendt 2009; Rollmann 2002; Stopp 2002; Whitridge 2004b; Woollett 1999). My project uses historic mission 
documents and the archaeological record to compare the social and economic transformations of three eighteenth-century Inuit sod house villages and one late eighteenth, early nineteenth-century Inuit mission village. I explore whether earlier Inuit social systems that emphasized the role of local leaders, who accumulated and shared local and traded resources during times of scarcity, played a fundamental role in how the Inuit engaged with the Moravians in the late eighteenth and early nineteenth centuries. In doing so, I address the following questions: How does artifact distribution differ among individual Inuit households, and among eighteenth and nineteenth century Inuit settlements? Is there material and faunal evidence supporting the presence of individual Inuit leaders within communal house settlements who were traders and whaling captains, or held other positions of authority? How did new European forms of religion, material culture, and trade influence Inuit negotiations of their tribal organization and cultural practices?

Changes to Inuit domestic space, subsistence practices, economic structures, and religious traditions during the Moravian period were due in part to earlier eighteenthcentury organizational patterns. Inuit leadership relied on knowledge of the land and the accumulation of particular resources, such as boats, which could then be shared for a greater social good (Jordan 1977; Kaplan 1985a; J. G. Taylor 1974, 1975). My intention is to focus on identifying relationships within a system where values are flexible and change according to individual and group needs (Crumley 1995:4).

Prior archaeological research has primarily focused on trying to understand how Inuit converted to Christianity (Brice-Bennett 2003; Hiller 1967, 1971a; Rollmann 2002; 
J. G. Taylor 1975). Less attention has been paid to why Inuit chose to convert and move to missions in the nineteenth century, especially considering the limited cultural and social repercussions the previous 400 years of European contact had on Inuit culture (Cabak 1991; Loring 1998a). Further, changes in seventeenth- and eighteenth-century Inuit culture are not widely discussed as they relate to nineteenth-century settlements. Instead, research on the Moravian sites focuses on the resulting effects of colonialism on Inuit culture. I argue that understanding Inuit choices to move their settlements to missions, convert to Christianity, and adopt European practices requires identifying the social system prior to the Moravians’ arrival, and that information will help develop new models to explain Inuit choices during the nineteenth century. Understanding past Inuit engagements with colonial structures will further clarify Inuit social organizations, group interrelations, and Native identities.

\section{History of Culture Contact Studies}

We know that Native societies responded to the introduction of European trade goods long before the responses were noted in written observations (Deetz 1991), and that such trade resulted in social transformation among indigenous groups (Wolf 1982; Worth 2002). Studies of culture contact seek to determine how such activities operated as a mechanism for social change (Cusick 1998; Frink 2003; Voss 2008; Wolf 1982). Rather than accepting that indigenous peoples experienced culture change identically across all cultures, the processes of change developed in a number of ways from full cultural and social domination by one group over another to a bilateral exchange of ideas 
and goods that evolved into a blending of cultures (Said 1978). The colonial experience was not a single moment of transformation; it was a constantly interpreted process through a social life of shared community activities such as trade, labor, and political alliance (Deagan 1983; Lightfoot 1995, 2005; Lyons and Papadopoulos 2002; Saunders 1998). Applying a diachronic research approach reveals the complexity of culture contact events as an exchange of cultural ideas that influenced the formation of both Native and European societies over time (L. Ferguson 1992; Lightfoot 1995, 2005; Rothschild 2003).

Although contemporary scholars offer a more fluid interpretation, early anthropological research approached the study of culture contact differently. Evon Vogt (1969), for example, viewed colonialism as an economic enterprise with important political and sociocultural functions. Vogt understood colonial situations as a confrontation between two distinct entities which resulted in the eventual domination by the colonial powers to replace indigenous culture (Dommelen 1997:308). His anthropological perspective created and reified a dichotomy between colonizer and colonized (Rothschild 2003:10; Said 1978).

Early archaeologists also perpetuated the notion of this static power structure by explaining material changes as a direct result of European contact. Identified as the theory of acculturation, this approach focused on the adoption of Western values and materials as a result of contact between peoples of different culture (Cusick 1998). Researchers used the acculturation model to describe a loss of traditional culture, the 
adoption of Western values, and the acceptance and incorporation of ideas or technologies from an external source.

However, some early archaeological works on culture contact treated acculturation in a more holistic fashion (Foster 1960; Spicer 1961). These approaches recognized the role of the Native groups in accepting or rejecting cultural attributes. George Foster (1960), for example, explained why some cultural traits from Spanish culture transferred to the New World while others did not. He argued that one culture, the recipient culture, selects, rejects, or transforms material culture from another donor culture. He proposed Spanish culture was conveyed to the New World in the form of traits which the Native groups actively incorporated or rejected (Cusick 1998:133).

Edward Spicer (1961) was one of the first who aimed to construct a diachronic ethnography of culture contact. He studied 12 Native American groups from Arizona and New Mexico to trace cultural, linguistic, political, economic and religious transformations introduced by Spanish missionaries. Spicer claimed that conflicting interests between the Spanish missionaries’ and the mining towns revolved around religious objectives as opposed to economic goals. As a result, both sides influenced Indian culture.

Later critics, however, found the acculturation approach, even the more nuanced approaches of Foster and Spicer, flawed in their premise of unidirectional culture change; the theory essentialized indigenous cultures and assumed change occurred identically across cultures. The approach further assumed that the less powerful always lost their culture to the dominating group (Rothschild 2003; Singleton 1999). Both Foster and 
Spicer therefore have been criticized for over-determining the influence of Europeans on Native cultures and not recognizing both Native and European transformations. In contrast, critics have argued that processes of change can develop in a number of ways from full cultural and social domination by one group over another, to an equal exchange of ideas and goods evolving into a blending of cultures.

These critiques stemmed in part from Edward Said's (1978) comment on the historical discourse and beliefs he calls “Orientalism.” Said’s work highlighted that academic and political work rested on an assumption regarding current depictions of Arabic nations. He argued that Western discourse about Arab cultures actually created, rather than examined the divide between such cultures. Continuous political domination over the East led the West to appropriate Arab and Asian culture history and identity. In doing so, Western politicians could depict the Arab as irrational, unpredictable, dishonest and threatening. In doing so, Western ideals were established as superior (Said 1978:8). Scholars, politicians, and other writers did not question this conclusion, thus reproducing this power structure in their work (Said 1978:3). Rather than ignoring cultural differences, Said called for the critical evaluation of differences between cultures and the rejection of racialized cultural constructions.

The post-colonial criticism generated by Said and pursued by others (Bhabha 1994; Spivak 1987) pushed archaeologists to consider the individual experience and unequal power relations within a colonial setting and how that becomes expressed in the archaeological record. I see five key conclusions of colonization studies of the last 25 years that are particularly important to this archaeological and ethrnohistoric study of 
Labrador Inuit: culture contact is a two-way cultural exchange; understanding colonialism requires understanding Native contexts; different colonial groups affected Native groups differently; missionaries had a unique role as colonizers; and colonialism had an ongoing effect on Native cultures. Because these five conclusions are important to the present study, I discuss them more fully below using a wide range of regional archaeological examples, given the limited amount of data available from Labrador sites regarding the study of colonialism.

First, transformations during the colonial period were a two-way exchange of culture where Europeans used local materials and labor and indigenous populations consumed European goods in non-European contexts. One example was Leland Ferguson's (1992) study of African-American slaves on a South Carolinian plantation that examined changes in the use of both European and locally-made ceramics. By identifying objects considered European that appear in slave households, Ferguson argued that slaves were transforming European materials for African purposes as a form of resistance against white American ideology. He made an analogy to the linguistic model of the Creole where the lexicon of one language merged with the structure of a second language. While artifacts or objects appeared European or American, their use or the underlying cultural structure ("grammar") remained primarily African (L. Ferguson 1992:xlii).

Second, understanding the social organization within Native groups clarified differences seen in the archaeological record. For instance, Kathleen Deagan (1974, 1983) found that differences between upper and lower economic classes of Spanish and 
Native societies residing at seventeenth- and eighteenth-century Spanish missions in Florida was a more useful distinction than a simple dichotomy between Native and European. Distributions of European trade goods, households, and burials suggested a pattern of differential access to European goods by specific individuals. Supported by documentary evidence, the data revealed non-random distributions concentrated in contexts associated with Native elites who had greater contact with Europeans (Chaney and Deagan 1989; Deagan 1985).

Third, not only did Native groups respond differently to colonial forces, different colonial enterprises affected both European and Native cultures in various ways. In her description and comparison of Spanish-Pueblo and Dutch-Mohawk interactions, Nan Rothschild (2003) showed how European groups differentially affected Native cultures. The Spanish arrived in New Mexico with the intention of introducing Christianity and European civilization to the Pueblos. Their demands for religious and economic conversion unified the Pueblos to resist the Spanish, leading to the Pueblo Revolt of 1680. Spanish who arrived after the Revolt altered their expectations for conversion and stopped enforcing an enculturation program (Liebmann and Preucel 2007; Liebmann 2008). The Spanish maintained their presence due to a political interest in preserving the territory and keeping other Europeans out (Rothschild 2003:225). The new Spanish generation incorporated local materials and practices into the Spanish lifestyle. The result was a society that retained aspects of both Spanish and Pueblo cultures and created archaeological deposits combining both Pueblo-made pottery and Spanish metal. 
In her discussion of the Dutch-Mohawk, Rothschild (2003) shows how the interactions differed from the Spanish situation in New Mexico since the Dutch interests were purely economic. Unlike the Spanish colonial efforts to convert and acculturate the Pueblos, the Dutch and Mohawks lived separately, interacting only to trade fur. The Dutch did not seek to change Mohawk culture; they saw the Mohawk as the providers of a commodity. To develop their control of the fur-bearing region of the Hudson, the Dutch provided large quantities of European goods to guarantee exclusive trade with the Mohawks. While the Mohawks incorporated European goods into their way of life, they modified the European items to fulfill Mohawk needs. Iron replaced stone and was used for cutting and piercing, while goods such as colorful glass beads were incorporated into an existing symbolic system (Rothschild 2003:225). When fur availability decreased and Dutch profits declined, the Dutch ended their trade relationship with the Mohawks. As a result, the Mohawks lost their ability to achieve their new material goals, and the Dutch felt no moral responsibility to provide any services or continue trade.

In both the religious (Pueblo) and economic (Mohawk) situations, Rothschild revealed the significance of different social and cultural variables affecting culture change. Changes seen to the Pueblo and Mohawk cultures were more the result of Spanish and Dutch religious and economic goals. Pueblo culture underwent change due to Spanish missionaries desire to convert and civilize, even if they were not always successful. Changes to Mohawk culture were the result of economic dependency as created by the Dutch. 
The fourth conclusion of direct relevance to this study echoes Rothschild's observation that missionaries played a significant role in exporting European culture. Anthropologists Jean and John Comaroff (1992) demonstrated in their analysis of English Christian missions in South Africa that missionary activities actually reshaped social and personal practices through an extension of western capitalism and the import of European goods. As scholars before have shown (Durkheim 1912; Weber 1958), religion was an intimate part of South African social relations, production, and politics. Although missionaries believed and intended to convert only through the teaching of Christianity, they were more persuasive by reconstructing a "living culture by the infusion of alien signs and commodities into every domain of [Native] life" (Comaroff and Comaroff 1992:36). It was not just the introduction of materials that imposed change, but the meaning and significance tied to those objects that disrupted established social systems.

Lastly, the effect of colonialism is not static and continues to shape Native societies. For example, in his attempt to follow how the introduction of European materials and society influenced changes to Native organization, Kent Lightfoot (2005) applied a diachronic approach to his study of Spanish missions and Russian merchants in seventeenth- and eighteenth-century California. His study traced their interaction with Native California people and how Native peoples dealt with colonial aftermath (Lightfoot 2005:11). He used historical and archaeological sources to understand how the different colonial experiences directed culture change, and how this influenced federal recognition of some Native groups and not others. 
Similar to Rothschild’s work, Lightfoot investigated the distinguishing factors that identified the mission colonial enterprise from that of the merchant. He identified these factors as conversion on the one hand and civilization on the other. Missionaries engaged in a specific enculturation program designed to teach Native populations Christian doctrine and the importance of European worldviews (Lightfoot 2005:6). Missionaries differed from merchants since they viewed Native populations as more than a cheap commodity and were interested in moral transformations; merchants engaged with Native peoples from an economic perspective.

Using Native and colonial texts along with the archaeological record, Lightfoot identified the complexity of both missionary and merchant situations and how resistance to the colonial message became expressed in Native contexts, especially residential spaces. For instance, neophytes living at the mission chose to portray themselves as devout Christians publicly, while privately maintaining traditional rites. Native populations living near Russian merchants chose to adopt and modify only those European cultural practices that were similar to their own. In both cases, Native Indians of California were part of a significant cultural transformation that led to new kinds of Indian identities, social forms, and tribal relationships (Lightfoot 2005:236). Lightfoot establishes this historical context to argue that the social forms and tribal organizations that emerged both shaped and directed future developments for the Native populations (Lightfoot 2005:210).

Since missionaries’ goals differed from merchants in that missionaries contacted indigenous populations with the principal motive of changing their religion, it is 
important to identify the methods missionaries used towards reaching that goal. Religion, not economics, was the driving force behind change. Many missionaries studied and incorporated indigenous culture to successfully transpose it with a Christian ideology and European lifestyle; however, the study of missionization also includes how both missionaries and Natives peoples negotiated the evangelical and acculturative programs (Van Buren 2010:159). In an effort to build on the conclusions discussed above and identify the material evidence for culture change at missions, I study the missionaries’ methods to identify what and how elements were infused into Native culture.

I see missionization as the process of introducing new religious ideas via direct and indirect approaches. For instance, the construction of mission buildings and churches stands as an obvious statement of Christianity, while the syncretism of indigenous ritual practices or symbols within this Christian tradition creates a hybrid form requiring the interaction of both groups. Only limited research on missions in Labrador exists (Cabak 1991; Cabak and Loring 2000; Loring and Arendt 2009); therefore I intend to identify some examples of the direct and indirect methods of missionization from other regions to highlight how such processes led to culture change and how it is represented materially. Specifically, I focus on the use of architecture and domestic artifacts to convey meaning about Christianity and influence identity formation.

\section{Approaches to Missionization}

The mission buildings are the most noticeable feature of the local landscape that reveals direct missionary influence on local cultures. The earliest work conducted on 
mission sites in California, the Southwest, and Mexico served as architectural reviews, as many of these studies were part of preservation efforts that required accurate information for reconstruction purposes (Baer and Rudinger 1958; Kubler 1940, 1948). George Kubler’s (Kubler 1948:54-55) study of Mexican missions proposed that construction was based on a prescribed course to replicate an ideal established by the home church in Spain. Focusing on the size of the church, its architectural footprint, the decorative façades, and associated buildings, Kubler argued that variability is evident only in the attempts to standardize form to accommodate the different cultural environments.

Similarly, W. J. Murtagh’s (1998) work on Moravian missions in Bethlehem, Pennsylvania and Herrnhut, Germany argued that a Moravian focus on architectural features and urban planning intended to perpetuate a Christian ideal established at the original church in Germany. The Moravians deliberately designed the missions and settlements to surround the church and then replicated this plan at most missions. The plan physically conveyed the idea that the church centered the community. The organization of buildings both reiterated and helped maintain a Moravian-centric society led by the ideological rule of the church (Murtagh 1998).

Steven Wernke (2007) also investigated this relationship between the built environment and the process of missionization and the intended messages. Wernke emphasized that Spanish missionaries in Peru relied on analogs with existing Native practices as means to convey Christian doctrine. By incorporating indigenous religious symbols, the missionaries referenced the same idolatry they were sent to abolish. The analogies prevented the complete eradication of the Inca symbols and practices, which 
were incorporated into the new Christian tradition. Wenke identified chapels at each of the four major Inca settlements, which he argued links the early chapels with indigenous centers of power and public ritual. The friars intended to associate their chapel with the Incan state, and at the same time, use its grand size and distinct Spanish-style architecture to set it apart from the surrounding landscape. The interactions between the colonial and indigenous populations created a hybrid space that was neither controlled entirely by the Spanish nor the indigenous population (Wernke 2007:179). Despite Spanish goals to completely eradicate indigenous idolatry practices, the incorporation of local Incan state and ritual spaces became a necessary means towards conveying Spanish Christian ideals within an existing structure.

However, the inclusion of foreign cultural traditions with a direct approach did not necessarily equate with Native peoples converting. Missionaries often introduced new types of clothing, foods, and raw materials to indigenous populations with the hope that physical changes implied religious transformations. Yet anthropologists and archaeologists have struggled with determining and assessing belief and its manifestation in human behavior as evidenced by the consumption of material culture. By identifying evidence of foreign material in Native contexts, are Native peoples truly converting to Christianity or merely retaining traditional beliefs under the veneer of a superficial acceptance of Christianity?

To further understand the degree to which the introduction of new forms influenced cultural and ideological change in a more implicit fashion, archaeologist Paul Farnsworth devised a measure calculating rates of material change using the 
archaeological record. Farnsworth (1992) created artifact classifications to determine the degree to which California Indians maintained traditional cultural continuity at California missions. Using excavations from three California missions, Farnsworth separated artifacts into ten categories according to whether they were a newly introduced or traditional form. His categories included completely new forms representing new cultural elements, new forms made from traditional materials, traditional forms made with imported materials, and unmodified traditional forms (Farnsworth 1992). By calculating the percentage of the forms in each category, Farnsworth argued that deposits exhibiting higher concentration of "hybrid" artifacts represented a higher intensity of exchange and vice versa (Farnsworth 1992:26-27). Analysis of the sub-assemblages from neophytes’ barracks at Soledad, San Antonio and La Purisima along with historical records, suggested that the neophytes maintained cultural tradition despite varied degrees of success claimed by the Spanish in imposing cultural and religious beliefs.

Locating how the Moravian social organization influenced Inuit identity formation in the archaeological record proved difficult. One way archaeologists have sought to do this in the past was isolating groups according to gender. This proved particularly productive in the case of Labrador, since historical data show that Inuit women were the first to move to missions and convert. Interested in why women would move to missions, Melanie Cabak’s (1991) research focused on gender issues at the mission. Cabak examined what elements attracted Inuit women to settle at the missions and how these influenced larger patterns of culture change. She analyzed material culture from a midden at the first Moravian mission in Nain. A rise in European household items 
led Cabak to conclude that Inuit women were introducing more European goods into the household because the domestic realm was traditionally the woman's space. Further, new economic opportunities introduced by the Moravians made Inuit women more influential figures in social and religious events. Inuit women were responsible for certain economic endeavors and created a social space for themselves beyond the house. These changing social roles allowed women to introduce new materials and foodstuff freely into their households, thus serving as a catalyst for larger cultural changes (Cabak 1991).

Elizabeth Graham (1998) also considered archaeology and material culture studies as a means of better understanding a group’s shared experience of becoming Christian. She summarized mission research in the Spanish-occupied territories of North American and Mayan Mesoamerica to show that the regional variety is a direct result of the contribution of local cultural features. More specifically, she argued that Spanish friars acknowledged the flaws of applying a universal Christian structure, and included Indian subsistence strategies and local ceramic manufacturing techniques in their mission to assist in the conversion process. For Christianity to succeed outside the European domain, it needed to adapt and incorporate local elements. Thus, the inclusion of preHispanic elements led to local populations permanently accepting and including Christianity (Graham 1998:54).

The aforementioned studies on colonialism and missionization sought to identify how new religious ideas were introduced, and how Native peoples adjusted to the 
introduction of new physical and ideological colonial structures and the associated moral beliefs associated with missions. These approaches have shaped the discourse within archaeology to a great extent. Current research no longer over-determines the role of colonizers and recognizes the active role of the indigenous groups in culture change (Gosden 2001; Ferris 2011).

Furthermore, research on missionization explored direct and indirect ways missionaries sought to introduce a new ideology and, ultimately, a new identity. Despite the infusion of buildings, materials, and symbols, the missionary encounter was a mutual process that led to the development of new hybrid identities incorporating European and local religious and social practices. The mission still serves as the catalyst towards revitalizing previous cultural traditions while Native groups incorporate new influences and rejecting others (Liebmann 2008:364).

Yet many of the studies focus on the moment of contact and the resulting material expressions by both indigenous and colonial groups. They do not articulate how social or cultural systems established before contact influenced decisions to engage with Europeans, and they are limited in explaining group choice to incorporate one characteristic versus another. Archaeologists employing agent-based studies only consider the synchronic transformation, rather than placing it the proper historical context (Kristiansen 2004:85).

For instance, Deagan $(1985,1989)$ identified economically distinct groups at the Spanish mission, but she did not track how pre-contact social organization may have played a role in determining which African or Caribbean groups rose to higher social 
status. Rothschild (2003) successfully isolated the variables that distinguish mission from merchant colonial encounters but did not investigate how pre-colonial Native social structures or hierarchies influenced Native choice to engage with either of those groups. Nor did Deagan recognize the flexible nature of colonialism where negotiation and reformation of identities by settlers fell beyond the binary categories originally presented (Hantman 1990; Voss 2008).

Furthermore, Farnsworth (1992) attempted to identify the degree of conversion equated the consumption of European goods with ideological shifts. Individuals are instrumental in the process of change; however, societal changes require the adoption of beliefs and behaviors by groups of people (Van Buren 2010:177). Identity formation is just one factor that motivates human behavior. A better understanding of the colonial encounter requires investigating the many conditions that shape individual and group behavior and how that is mediated on the colonial landscape; economic, political, social, spiritual and environmental factors all contribute to those individual and group choices. Native beliefs played a paramount role in determining Native reactions to Europeans before and after contact (Trigger 1991:1206).

While Cabak (1991) and Lightfoot (2005) both take a diachronic approach which is missing in Farnsworth's work, they only examined post-encounter effects. Cabak offered an alternative interpretation of the historical record regarding Inuit agency in a colonial situation yet only focused on the post-contact period. She did not question or investigate the role Inuit women played in the households prior to the Moravians, beyond ethnographic descriptions. 
Furthermore, Lightfoot provided a description of the California Indians, but it was only a historical one; he did not elaborate on how Native social systems established before the missionaries’ and merchants’ arrival influenced their adoption of Spanish and Russian culture. While he noted that syncretism of Native and colonial structures gave way to Native peoples adopting to certain cultural attributes, he did not identify those same Native structures.

To build upon the theoretical approaches reviewed above, I incorporate a diachronic analysis that examines change within Inuit cultural structures by comparing pre-contact and post-contact sites. This method transcends the boundary between prehistory and history and shows the changes seen to Inuit culture were part of a larger trajectory of culture change that began prior to the Moravians’ arrival (Lightfoot 2006).

In this study I use archaeological data from three Labrador Inuit sites to address questions regarding evidence for social organization and the factors that influenced culture change. I suggest that changes encountered in Inuit and Moravian cultures were the result of relying and adapting pre-contact systems to entirely new circumstances for both groups. Inuit engaged with the Moravians by applying a flexible framework of an earlier social structure, while the Moravians tried to impose certain European and Christian systems regarding market exchange and private property. Through the combination of multiple factors — including the Moravians’ permanent presence in Labrador, the centralization of local Inuit groups, the increase of disease, and the presence of goods and materials that benefit the entire community — Inuit and Moravians systems collided to create a new social and cultural landscape. 
This dissertation is an archaeological and historical study of the process of Inuit culture change in the late eighteenth and early nineteenth century. I use data collected from eighteenth- and nineteenth-century Labrador Inuit house sites in conjunction with Moravian historical trade lists. Data from Inuit households offer archaeologists a chance to study the subtle transformations of the colonial situation and bridge the gap between grand theories of culture change and the events at the group level. I discuss excavations at Hopedale conducted by Junius Bird in 1934, Adlavik Island in Long Tickle south of Makkovik conducted by Stephen Loring of the Smithsonian Institution from 1999-2003 and archaeological excavations I conducted on Anniowaktook Island from 2007-2009. The Hopedale site encompasses both pre- and post-Moravian habitants as the Hopedale mission was settled near the Inuit sod house settlement of Avertôk. The two mideighteenth-century Inuit sod house settlements located on Anniowaktook and Adlavik Islands date to the period prior to the Moravian missionaries' arrival and serve as the foundation for my research. By studying the artifact, faunal, and botanical materials of the two earlier sites, I establish a model for Inuit economic and cultural practices. I investigate whether there was an Inuit social system that recognized individual group leaders as represented through the uneven distribution of goods and resources, and compare that to the Moravian historic documents.

The mission differs from other colonial situations in that it actively seeks to engage local populations with the culture change process based in the matter of faith. What makes the Labrador situation unique is that the Moravian missionaries expected conversion could succeed with Inuit solely incorporating Christian teachings into their 
daily lives without disrupting other elements of their culture. Several studies around the world have demonstrated the special characteristic of the independent Moravian settlements (Fienup-Riordan 1991; Gollin 1967; Lewis 1985; Lydon 2009; Sensbach 1998, 2005; South 1999; J. G. Taylor 1975). This study contributes to the research that has just begun to explore the daily and institutional negotiations of power and meaning at Labrador missions through archaeological contexts (Arendt 2010; Cabak 1991; Cary 2004; Loring 1998b; Loring and Arendt 2009).

\section{Structure of the Dissertation}

In the following chapters, I investigate the long-term economic and social impact of German Moravian missionaries on Labrador Inuit culture, by examining changes in eighteenth- and nineteenth-century Inuit material culture and foodways near the mission town of Hopedale, Labrador.

In Chapter 2 I summarize the culture history of the prehistoric Thule and historic Inuit groups in the Arctic and their migration into Labrador. I focus more specifically on the archaeological evidence for social organization which preceded the appearance of different forms of community leadership, including the trading captain in the historic period. Better comprehension of social formations and subsistence practices of the immediate descendants of the early historic Inuit offers clues as to how Inuit reacted to a constantly changing landscape.

In Chapter 3 I discuss the European explorers, whalers and traders that visited the coast of Labrador and review documented interactions with Inuit. I focus on European 
impressions of the Inuit to establish the complex and hostile environment into which German Moravian missionaries encountered.

Following the historical review of European groups in general, in Chapter 4 I turn to a specific discussion of the history of the Moravian church and its development of foreign missions in Labrador. The church’s dominant presence in Labrador and the incorporation of an elaborate international trade was the result of earlier economic and political events in England and Germany. I focus on one Moravian mission, Hopedale, the Moravian’s third mission station in Labrador settled in 1782. Hopedale was settled explicitly to expand the church's reach to southern Inuit and help develop a trade that rivaled other European trading interests.

Chapter 5 summarizes ethnohistorical research conducted at the Moravian Archives in Bethlehem, Pennsylvania. I use correlation and regression analysis on the import of foreign goods to Hopedale for the first 30 years of its existence to establish to what degree local markets influenced Inuit consumption practices. In addition to the trade lists, I analyze Moravian impressions of the presence of centralized Inuit leadership by studying the original letters which were sent back to the Moravians churches in Germany and England. Critically evaluating historical documents in relation to the archaeological record helps evaluate interpretations generated from historical contexts, and offers additional evidence of social organization, customs, and beliefs (Lightfoot 1995; Stahl 1993; Whiteman 1986).

Chapters 6 and 7 introduce and analyze the three Inuit sites that contributed to this study. I review methodologies, architectural findings and general artifact descriptions for 
the three sites and establish a dating index using tobacco pipes, beads and ceramics. Following the archaeological description in Chapter 7, I develop methods to estimate discard rates and artifact distribution at Adlavik, Avertôk and Anniowaktook throughout the eighteenth century by describing four general artifact categories created to help identify household activities and access to exotic goods. The organization of these categories is then tested by using correspondence analysis to verify whether the artifacts fall along a functional gradient as predicted.

Chapter 8 establishes the four hypotheses used to identify a model that explains eighteenth-century Inuit social organization and whether it was status-based. Abundance indices, correlation and correspondence analysis methods are used to identify patterns within and between sites that identify unique deposits in order to test whether an Inuit social hierarchy is expressed through material accumulation. Specifically, I look at artifact material and form in different deposits to identify whether Inuit were participating in a coastal trade network that provided access to particular materials and goods, or whether Inuit accessed goods through independent means such as raiding European posts. These models also are used to identify whether artifact patterns connote changes to Inuit subsistence or social strategies.

Elemental to testing these hypotheses in Chapter 8 includes a brief summary of the faunal analysis conducted by Dr. James Woollett of Laval Université in Quebec City, Canada. The faunal material is used to test whether household assemblages differentiate by degree of participation in hunting as reflected in the abundance of particular faunal material. These analyses reveal the degree of uniformity in species within and between 
sites, but identify variability in consumption practices. Patterns identified reveal differences in faunal assemblages between houses which may be the result of individual group preferences rather than the structure of larger social network as previously believed.

Following the summary of the analysis, Chapter 9 draws together the historical and archaeological data collected and discusses the project's local importance in Labrador, Canada. I summarize the conclusions from this project and discuss directions for future work. 


\section{Chapter 2: Early Inuit Predecessors for the Development of Inuit Social Organization}

About 800 years ago, Inuit migrated eastward from the northwest Alaskan territories, displacing earlier Dorset Paleo-Eskimo and the Innu who lived along the Labrador coast (McCullough 1989; McGhee 2007; Morrison 1981). Known as the Thule, this prehistoric group of Inuit traveled eastward to take advantage of expanding bowhead whale populations in the central Canadian Arctic, create new and better trade routes to access valuable metals including copper and iron further east, as well as social pressures, increased warfare and territoriality in the Bering Strait (Maxwell 1985:252; McGhee 2007; Park 1997; Sabo and Jacobs 1980). Gradually over time, subtle changes occurred to Thule houses, tool construction, subsistence practices, and social organization. The Thule ancestors' cultural transformation into what is characterized as the Historic Inuit offers initial clues as to the social and economic predecessors for later Inuit cultural and social structures.

Ethnographic, linguistic, biological, and archaeological data indicate that Inuit societies across the Arctic from Alaska to Labrador and Greenland share a recent common ancestry, arising from the repeated Thule migrations east (Gulløv and McGhee 2006; Marchani et al. 2007; McGhee 2009; Schledermann and McCullough 1980). Archaeological evidence provides little information regarding the size and frequency of movement; however, the initial Thule Inuit population migration from Alaska must have been substantial to account for the number of sizable early Thule winter villages and material culture identified throughout the Canadian Arctic (McGhee 2009; Friesen and Arnold 2008). 
As a result, all Inuit societies across the Arctic can be used for modeling social organization and human behavior in this given environment, even though the Arctic itself is a varied set of environments with different sorts of resources. The danger, however, in using specific analogies is projecting too much onto the archaeological record, which results in a distortion of the historical particularities of past societies (Plog 1990; Whitridge 1999). Yet an analytic foundation is necessary to develop comparisons and contrasts with respect to established archaeological theories.

This chapter investigates the social precursors that led to the development of a social hierarchy that privileged prominent Inuit who organized trade with Europeans and local hunting groups, and as a result, accumulated more goods. I focus on archaeological evidence for the existence of household organization in each of the three periods as seen through (1) sod house organization, ${ }^{1}(2)$ hunting strategies and complex tool construction, and (3) the presence of non-local materials suggesting the presence of a trade network. More specifically, evidence for trade networks can include two different means of provisioning as outlined by Lewis Binford (1980) — one where acquisition was based on a formal strategy or "collection" that involved specialized individuals, and the other which included less complex “foraging” strategies where movements coincided with the seasonal appearance of various resources.

Evidence for household organization as illustrated by a combination of the aforementioned categories varies between and even within each period; however,

\footnotetext{
${ }^{1}$ While Inuit lived in igloos (snow houses) during winter months and skin tents during the spring and summer, I focus on the archaeology of sod houses which were occupied during the fall and winter months. The majority of archaeological research in the Arctic focuses on sod houses as they tend to have the best preservation and produce a substantial archaeological footprint.
} 
identifying the general differences in the archaeological material between the periods might reveal the evolution of social organization and how indigenous groups confront and negotiate cultural and environmental stresses.

\section{Thule Inuit (AD 1000-1550)}

Archaeologists have identified two distinct periods within the Thule culture that correlate to two successive eastward migrations, the Classic and Modified periods. While their exact temporal spans continue to be debated, most archaeologists agree that the Classic Thule Period began around AD 1000 in the Central Arctic (Gulløv and McGhee 2006; McGhee 2007) and ended in the mid-fourteenth century (Friesen and Arnold 2008; Grier 2000; Park 1997; Savelle 1984, 1987). Changes to settlement patterns, material culture, and subsistence practices that began around AD 1350 mark the beginning of the Modified Period, which will be described in more detail later in this chapter (Clark 1979; Coltrain et al. 2004; Grier and Savelle 1994; Henshaw 2000; McCartney 1979; Savelle 1987) ${ }^{2}$. The Modified period is less defined by strict temporal boundaries and likely represents the process of cultural change and development within the Thule culture as a whole. By identifying the specific differences of the periods, it will help trace the process of culture change, and how that appears in Labrador. In particular, architectural or material distinctions separating Classic and Modified Thule Periods are not as pronounced in Labrador thus requiring separate attention in this chapter.

\footnotetext{
${ }^{2}$ Researchers also have referred to this period as the Later Expansion, Pioneer Phase, Late or Developed Thule period. I chose to employ Modified Thule since it best reflects the subtle shifts in cultural traditions that represent this post-Classic period.
} 
Classic Thule (AD 1000-1350)

Researchers have attributed specific archaeological features to the Classic Period including settlement patterns near resource rich areas, multiple semi-subterranean houses, a kitchen extension, and a sophisticated and diverse material culture assemblage. Aligning these cultural features with the Classic Thule is based on their presence across the Arctic, from Alaska, the Beaufort Sea coast, Amundsen Gulf, Coronation Gulf, Baffin Bay and the Smith Sound region around the same time (Park 1997:274).

\section{House Organization}

Thule settlement size ranged from a couple of semi-subterranean sod houses to over 60 houses or temporary camps located in rich ecological areas where only a few of these houses were occupied simultaneously (Fitzhugh 1994; Kaplan 1983:462; Woollett 2003:47). The later and larger Thule sites likely consisted of villages of up to a dozen houses, only half of which were occupied, and those by small groups of families. Nevertheless, maintaining these larger settlements would have been advantageous for ecological reasons; success in hunting large sea mammals required a large number of hunters (Morrison 1983; Park 1988; W. Taylor and McGhee 1979). While the Thule would organize into small groups to hunt other animals such as caribou or construct fishing weirs, residents of the multi-house settlements primarily hunted bowhead whales (Balaena mysticetus). A single successful hunt would provide an enormous amount of food and fuel to supply a sizable group throughout the winter. 
Thule houses were made of stone, whalebone, wood, and skins, with paved stone floors, raised sleeping platform, and long tunnel entryways. Houses were either covered with turf or skin roofs, and were seasonally occupied during September or October until April or May (Le Mouël and Le Mouël 2002:179). Early structures were lobate and oval shaped as seen in Figure 2.1 and had only 12 to $20 \mathrm{~m}^{2}$ of interior floor space suggesting they were occupied by single family units (Kaplan 1983:220-223). Communities often returned and reused the temporary settlements, indicating the area’s abundance and availability of resources.

A characteristic specific to the Classic Thule house in higher latitudes was the kitchen extension, a space separated from the main house located between the entrance passage and living area. The kitchen extension was reached through a short passage off the main living area and held an open hearth (McCartney and Mack 1973; McGhee 1994; Morrison 1987, 1991; Reedy-Maschner and Maschner 1999). Researchers Le Mouël and Le Mouël (2002) hypothesized that the extension’s separation from the main dwelling area served a functional purpose, keeping smoke and cooking debris out of the main living area. 


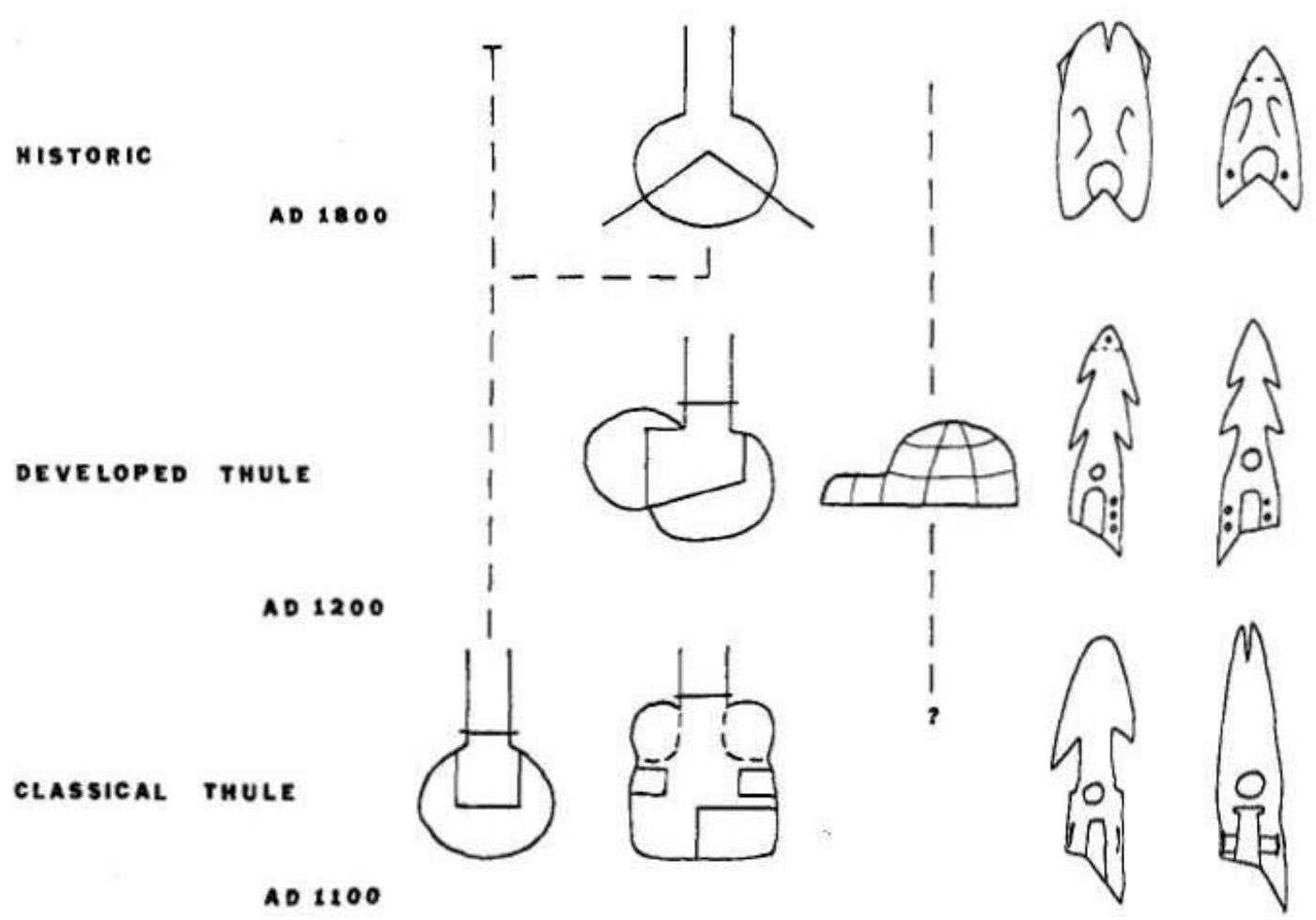

Figure 2.1: Summary of cultural phases of house styles $(\wedge$ indicates qarmat or a house covered by skins and not sod), the appearance of snow house villages, and harpoon heads of the Thule (Dawson 2001:460). "Developed Thule” refers to what I designate as the Modified Thule.

Artifact distributions within houses revealed presence of a gendered differentiation of space and labor. Hunting was considered a male activity and required different tools, such as marine mammal hunting equipment, while artifacts associated with food preparation and clothing manufacture, such as ulus or U-shaped knives, lamps and beads, were generally used by women. The distribution of these tool types identified gendered activity areas, such as kitchens, and served to spatially organize the house (Whitridge 1999:286; 2008:302). 


\section{$\underline{\text { Hunting and Tool Construction }}$}

Hunting was a prominent part of Thule culture, as evidence by their specialized hunting technologies and highly crafted tools. Evidence for dog sleds such as sled runners and toggles, and watercraft such as kayaks indicate that the Thule moved across the land and water in an effort to expertly exploit their environment. Their extensive toolkit included a wide variety of seasonally specific hunting and fishing equipment such as bone and antler harpoons, bow drills, ulus, bird darts, and barbed fishing spears. In addition to using bone, antler and baleen, a wide variety of tools were made from schist, slate, and stronger materials such as nephrite were used for harpoon heads, pointed blades for men’s knives, and semi-circular blades for the ulus. Stone also served as a valuable resource for both domestic purposes, particularly the use of soapstone for lamps and cooking pots.

As noted above, the primary game hunted by the Classic Thule were large sea mammals such as the bowhead whale for the vast food and materials it provided. Whales required a communal hunting strategy and could be a dangerous endeavor given their size and strength. The reward of a successful hunt not only included a surplus of food and blubber, as well as bone for tools and architectural elements, but also status and prestige.

The best archaeological example for a complex social organization based on the whale hunt is Peter Whitridge’s (1999) analysis of a Classic Thule site in Somerset Island in the high Arctic. ${ }^{3}$ Whitridge developed a model explaining artifact and settlement distributions of a complex social network based on ethnographic research of historic

\footnotetext{
${ }^{3}$ Peter Whitridge (1999) dates the sites to A.D 1200-1400. Although this overlaps with the Modified Thule period, its inclusion in the Classic Thule section is based on Whitridge's assessment of the material.
} 
North Alaskan Iñupiat whalers, where hunting was considered predominantly a male activity even though the entire community participated.

Whitridge maintained that North Alaskan groups were unified by a powerful and influential leader whose ability to successfully organize a whaling crew successfully was important in establishing his status as leader. Leadership also required an accumulation of goods especially the umiak, a large multi-person boat needed for the hunt. However, the ability to redistribute goods was also critical. If the hunt was not successful then the leader was expected to distribute stored food extra material and skins, or needed tools to support the group.

Whitridge used the detailed ethnographic description from North Alaska Iñupiat whaling communities to organization and interpret his archaeological data from the Somerset Island Thule houses. The spatial configuration and patterning of five Thule houses and their associated artifacts strongly implied the presence of social organization and gendered division within and between the houses. For example, excavations revealed households differentiated according to participation in whaling and access to whaling products, and that these factors would predict other aspects of status including dwelling size, abundance of adornment items, and proximity to ritual spaces (Whitridge 1999:326).

Some Thule groups moved further south into the eastern Arctic areas such as Nunavut and Labrador, and they hunted a variety of sea and land mammals when whale hunting was less productive and predicable (McGhee 1984; Savelle 1987; Whitridge 1999). Archaeological evidence indicates that Thule groups supplemented their diet with smaller marine mammals, mostly significantly seals and walrus, as well as fish, caribou 
and avian species, with these resources appearing to gain importance in later Historic Inuit economies (Maxwell 1985; Whitridge 1999:83; Woollett 2003).

\section{Trade Networks}

Researchers have documented elaborate prehistoric trade networks extending across the Arctic from Chokotka to Greenland (Fitzhugh and Crowell 2009; McGhee 1984; Schledermann and McCullough 1980; Whitridge 1999). Various metals, including copper and iron, were likely accessed through trade with other Inuit and Indian groups in the region, as well as Norse visitors who were believed to have visited the High Arctic as early as the thirteenth century (McCartney and Mack 1973; McCartney 1988). The difficulty in acquiring some of the aforementioned materials needed for tool or house construction probably led to the development of some kind of trade network as evidenced by the presence of other foreign materials in the archaeological record (Maxwell 1985; Whitridge 1999). Archaeological deposits from Thule sites in the central Arctic revealed unexpectedly high amounts of metal. A few natural iron sources do occur in the Arctic including telluric iron in Disko Bay in Greenland. But source studies for iron found in Thule sites on Somerset Island linked it to the Cape York meteorite ${ }^{4}$ located in northwest Greenland (Fitzhugh and Crowell 2009; Kaplan 1983; Maxwell 1985; McGhee 2007; Pringle 1997:766; Whitridge 1999).

\footnotetext{
${ }^{4}$ The Cape York meteorite is one of the largest meteorites in the world, and was found in Savissivik, Greenland. The meteorite collided with the earth over 10,000 years ago and served as a vital source of iron for Inuit. American Arctic explorer Robert E. Peary located the meteorite in 1894 and transported it to New York City. He sold it to the American Museum of Natural History, where it is still on display, for $\$ 40,000$ (Huntington 2002).
} 
Although only a small quantity of iron has been found at most Thule sites, its presence far from its source suggest that the Classic Thule were engaging in some form of trade or exchange. Whatever the manner by which resources were accumulated, the various materials found in the Thule toolkit suggest investment of time and energy towards accessing and collecting goods; yet the degree to which it was organized or reason for the Thule migration continues to be debated.

\section{$\underline{\text { Summary of Classic Thule }}$}

An intricate toolkit indicates that the Thule were excellent hunters able to exploit a variety of local resources. Whaling played a central role. The large-scale labor resources required to hunt whales are apparent in the populations represented by the large Classic Thule sod house villages. Uneven artifact distribution throughout the villages further indicated that Classic Thule settlements had a social organization that revolved around the accumulation of select portions of the meat, skin and bones as determined by one's role in the whale hunt. Further, social spaces were also defined by gendered divisions, where men hunted and women processed food and maintained the domestic space. While the presence of some level of trade was evident, insignificant evidence suggests that trade and hunting were related or determined social status; instead, Classic Thule Inuit social organization was heavily determined by one's role in the whale hunt. Modified Thule (AD 1350-1550)

A second migration of Inuit crossing the central Arctic in the mid-fourteenth century defined the start of what archaeologists refer to as the Modified Thule period. 
Coinciding with the rise of a Neo-boreal cooling (also known as the Little Ice Age), the Thule were confronted with significant ecological challenges not experienced by the earlier Classic Thule culture. The Modified Thule had slightly different subsistence practices since the group focused on new ecological niches and likely adopted different social networks as a response to climatic changes. By AD 1400-1500, Modified Thule groups had abandoned much of the central Canadian Arctic sites and colonized new territories further east in southern Greenland, Labrador and Quebec (Rowley 1994:582). However, some archaeologists argue that these changes were not solely the result of new environmental conditions, but rather internal cultural changes already underway (Sabo and Jacobs 1980:493).

Identifying the reason for the cultural shift — abrupt or gradual — and its duration has been more difficult. Archaeologists determined distinct changes to cultural and subsistence features that occur at different times and in different ways throughout the Arctic region. In the following section, I identify the most prominent changes to occur during the Modified period as seen in the archaeological record. I also discuss the dominant ecological and cultural theories as to why a shift in subsistence practices and social networks occurred.

Three notable changes that distinguished the Modified Thule period from the Classic Thule period were (1) smaller winter villages, (2) the appearance of stone graves, (3) the simplification of a once intricate toolkit, and (4) the intensification of fishing and winter sealing. These changes, which are each considered below, are in part the result of 
internal cultural adjustments due to a variety of environmental factors, and the technological influences from other Native groups in the region.

\section{House Organization}

The first notable change in Modified Thule settlements was the shift to smaller villages and the inclusion of less permanent dwellings including igloos. Villages that once consisted of many single-room houses were abandoned in favor of settlements with fewer but larger oval-shaped houses that incorporated kitchens into the main space rather than as a separate extension. Internal house areas ranged from approximately $5 \mathrm{~m}^{2}$ to $24.5 \mathrm{~m}^{2}$ on the larger end, with most averaging around $12 \mathrm{~m}^{2}$ (Bird 1945; Cox 1977; Fitzhugh 1980; Kaplan 1983:795; Schledermann 1971; Woollett 2003:48).

After the fourteenth century, sod houses took on a cloverleaf structure which included two or more family units in each lobe with a separate sleeping platform joined by a common floor area or passageway (Merbs 1997:249) (see Figure 2.1). The shift in house construction suggests that an earlier communal organization was maintained yet the new division represents a more complex residential component where families retained some level of independence. Multiple family units remained associated with a larger single social system by occupying separate yet connected living space.

Perhaps the most significant archaeologically identifiable addition to Thule culture that suggests changing social expressions was the inclusion of burial practices. Bodies were wrapped in animal-skin clothing or caribou skin and placed in a flexposition on the ground surface (Sabo and Jacobs 1980:492-493). Located in the vicinity 
of a sod house settlement, stone tombs were constructed on the surface, around an individual's body, making sure not to rest any stones on the corpse so as not to disturb or harm the soul of the deceased. This careful attention to the deceased was part of a new development in social expression and organization. In addition, individuals were buried with highly valued artifacts, such as slate or nephrite end-blades, bone harpoon heads, and drills, affirming their individuality within society and social prominence (Maxwell 1985:289).

\section{Hunting and Tool Construction}

Although identifying specific ecological or cultural catalysts for differences between the Classic and Modified Thule cultures continues to be debated, archaeologists agree that there were enough significant changes in the material culture to indicate larger social shifts. The third feature used to identify Modified Thule Inuit culture was the homogenization of the toolkit and a shift in harpoon head construction. Harpoon heads with angle-cut basal spurs, lashing slots on either side of rectangular open foreshaft sockets, and grooved lateral basal edges with squared shoulders at the juncture of the base and midsection shifted to rounded double-barbed blades, open foreshaft sockets with

drilled lashing holes (see Figure 2.1) (Wenzel 1994). This technological change appeared to coincide with a shift away from a whale economy, thus requiring particularly durable tools towards a more diverse marine-oriented economy.

McGhee argued that the technological simplification and decline in craftsmanship seen during the later phases of the Thule period were related to an economic shift from 
hunting whales to hunting seal and summer fishing. The decline in stylistic uniformity and a loss of craftsmanship was probably related to a breakdown of social order along with prolonged environmental uncertainty (Savelle 2002:83).

The final change to Modified Thule culture was a move away from whale hunting to focus on seal and fish. The change to hunting strategies was the result of new environmental conditions that severely affected bowhead whale range and required Thule to constantly change ecological niches (Jacobs 1979; Maxwell 1985; McCartney 1979; Schledermann 1976). The shift away from whale hunting would have affected all areas of Thule life given the social significance placed on the organization of the whale hunt, and the whale as a primary resource for food, heat and light from the blubber, and for raw materials like whale bone and baleen, seen in the Classic Thule period. Hunting seal would require less group labor and thus households could remain relatively independent from one another.

Nonetheless, cooperative hunts did continue. Thule built igloo communities on the ice where men would hunt seals from the breathing holes, or holes in the ice where seals surfaced for air, and shared their catches communally. This shift to collaborative seal hunting maintained the similar complex social organization seen among the Classic Thule but allowed for the Modified Thule to be more mobile in hunting different species. Identifying the reason that Modified Thule shifted their efforts away from whale hunting and towards other resources has been the focus for many researchers. Explanations can be classified into two types: (1) those based on climatic and ecological explanations and (2) those that rely on cultural explanations. 
Many archaeologists consider climate change the primary cause for this subsistence shift (Maxwell 1985:304). The region saw colder temperatures and more extensive ice coverage as a result of the Little Ice Age. Greenland and Baffin Island experienced advancing glaciers and an increase in drifting pack ice throughout the region. The decreasing temperatures and subsequent rise in sea-ice shifted whale migrations further out to sea, reducing the range of available whales as they no longer entered the High Arctic waters. The increasing pack ice would have made boat hunting hazardous or even impossible (Finkelstein et al. 2009:452). In the more southerly latitudes, the persistence of fast ice along the shore would have hindered launching kayaks, therefore shortening the deep-sea hunting season.

Recent paleoclimatic studies from the Baffin region suggest that areas east of Baffin Island did not experience the same cooler temperatures as the west (Finkelstein et al. 2009). Dissimilarities found in the climatic histories surrounding the Melville Peninsula suggest that the eastern Arctic climate was more variable then expected (Clark 1979). Given this new evidence, it seems likely that the Modified Thule migrated into areas with less ice and more resources. Those areas tended to be along the coast where the Modified Thule could take advantage of different local ecological niches for dietary and raw material needs (Henshaw 2000).

Excavation of Modified Thule houses in the western Hudson Bay area identified varied faunal assemblages suggesting that different ecological niches other than whaling and sealing were exploited (Clark 1979:94). The faunal assemblage associated with winter houses suggests that Modified Thule traveled out on the sea-ice in the winter to 
hunt seals, and returned to the islands and promontories in the spring to access a wide array of fish and birds. Thule also traveled into the interior to intercept migrating caribou during the late summer and early fall. The presence of fish, bird and caribou in the Modified Thule assemblages and the conspicuous absence of whale bone suggest that new resources replaced the once dominant whale (McGhee 2007). The variety of species also points to longer settlement occupations where Thule could exploit their new ecological niches year round.

\section{$\underline{\text { Trade Network }}$}

The aforementioned studies focused on subsistence practices and did not address the related cultural implications; however, it was probable that a shift away from whaling was also tied to larger cultural changes. Archaeologist Robert McGhee (1994, 2007) argued that changes seen to Thule culture were not solely the result of an abandonment of the whale hunt, but included a shift to focus on trade. McGhee and others, argue that the movement of the Thule people eastward was not the result of changing whale migration patterns, but rather an instead an interest in acquiring metal (McCartney and Mack 1973; McGhee 2007). The quick Thule migration east was to access meteorite iron from Cape York, Greenland which they fashioned into carving knives, engraving tools and small blades (Buchwald 2005:22; McCartney and Mack 1973). Cape York iron has been found as far west as Ellesmere Island, Somerset Island and areas around Hudson Bay suggesting the presence of extensive trade or interaction networks with other eastern Native groups (Morrison 1991:241). 
Additional evidence for the existence of trade between Thule settlements was the movement of soapstone westward. Soapstone, critical for the manufacture of lamps and kettles, was found in areas west of known sources (Giddings 1952; Morrison 1991:242). Soapstone replaced less durable ceramic vessels common among Alaskan and western Inuit, yet its presence in only a few western sites indicate that trade was limited (Whitridge 2007). Nevertheless, the extent of an elaborate and deliberate trade network of the Modified Thule has yet to be determined. The movement of materials, instead, may have been tied to opportunities during Inuit migration rather than an organized system.

\section{Summary of Modified Thule}

Material evidence used to identify the Modified Thule culture differs slightly between regions as adaption to environmental and social circumstances changed. The most significant changes that identify the cultural period include mortuary practices, a move away from a whaling economy, and smaller settlements. These corresponding changes suggest the later Thule migration encountered a change in social organization, as large organized Inuit whaling villages shifted to smaller, more mobile bands.

\section{Thule in Labrador}

The various settlements of Thule in the eastern Arctic make the application of a uniform schema of chronological sequences problematic and previous attempts toward interpretation have not always been met with acceptance (i.e., McGhee 1984). The Thule 
movement into Labrador was part of a general shift that took place in the 1500s where settlements in the Central Arctic were abandoned in favor of sites in the southeast.

Identifying Thule sites in Labrador have been difficult because cultural features characteristic of early Thule in the central Arctic, such as clover-leaf houses (Whitridge 1999) or detached kitchen wings (Fitzhugh 1977:31) persist at later Thule sites further east, making their utility as definitive chronological markers problematic. Nevertheless, using archaeological evidence from houses, tools, and faunal remains may point to the existence of similar social organization at Labrador Thule sites and offer insight into the evolution of Inuit culture as it migrated into Labrador.

Archaeologists believe that the Thule expansion along the Canadian Arctic moved south along Greenland’s coast and the eastern Canadian coasts of Hudson Bay, eventually arriving in northern Labrador by the thirteenth century (Fitzhugh 1972:132). In Labrador, Thule groups came in contact with the Late Dorset Paleo-Eskimo population residing in the region and seemed to have borrowed or even assimilated some cultural traits (Cox 1977). Given this overlap and that Thule reoccupied Dorset sites, absolute dating of colonizing Thule sites in the region has been problematic (Hood 2008:11). Radiocarbon dates from Thule occupation in northern Labrador range from AD 10001400 (Fitzhugh 1994) and more recent research suggest that most sites probably date sometime after AD 1250-1300 (Fitzhugh 2009:130; Kaplan 1983, 1985a). Despite the lack of clear temporal periods in Labrador, Thule groups occupied the north coast, and expanded along the south coast by the 1550s settling in Voisey Bay, Hopedale, Makkovik and Hamilton Inlet, and settlements at Twin Island in the Strait of Belle Harbor (Auger 
1989; Barkham 1980; Fitzhugh 1981:601; Jordan 1974; Whitridge and Woollett 2008;

Woollett 2010b). The Thule occupation in Labrador appears brief, perhaps lasting only a century. This relatively short duration gave way to a significant cultural transformation in the eighteenth century where Inuit houses increased in size and more European goods appeared in Inuit archaeological deposits.

\section{$\underline{\text { House Organization }}$}

As noted above, many of architectural features associated with the earlier Classic Thule period appear along side those from the Modified Thule period in Labrador. Recent excavations in northern Labrador in 2007 and 2008 at Green Island near Saglek found two small groups of loosely clustered houses (Woollett 2010b). The easternmost house located at a slightly higher elevation had a clover-leaf structure, typical of the Modified Thule period. In addition to the house's paved floor, a raised sleeping platform with vertically placed slabs, and a large interior cooking platform directly adjacent to the entrance tunnel, the house also had an artifact collection that consisted primarily of slate tools which signals an earlier occupation. A second house at Green Island exhibited many similar features as the house discussed above, also having a paved interior floor, sleeping platform, lamp stands, interior alcoves, and stone-lined storage compartments; however, a small collection of flakes and slate tools and a thin organic deposit revealed the house only had a single occupation of relative short duration. This stands in sharp contrast to the dense and deep deposits associated with eighteenth-century Inuit houses, which will be discussed in more detail later in this chapter. Due to the interior house 
architecture, the presence of slate and nephrite flakes, and a notable lack of European artifacts, the site exhibited Classic Thule features typical of Labrador which dates to the fifteenth century (Whitridge 2004a, 2007).

Similar architectural features were also found at a later Thule site in northern Labrador. A multi-period Inuit winter village at Nachvak had an occupation period spanning from the Classic Thule to the early Historic period (Peter Whitridge, personal communication 2010). The Nachvak village site consisted of 16 sod and whale bone houses with the earliest Thule occupation dating to the fifteenth century. The Thule section of the site included a clover-leaf house, similar to the one from Green Island. Yet the reoccupation of one lobe after initial occupation, the high proportion of ground stone in the form of soapstone vessels and slate blades, and a small sample of metal suggested the site also had a later post-contact occupation (Fitzhugh 1981). The combination of the earlier architectural features with later artifacts highlights Inuit pattern of reoccupying houses in resource-rich areas and the difficulty in assigning specific features to regional and cultural periods.

The most extensive research of the Thule occupation in Labrador was conducted by the Torngat Archaeological Project during the 1980s that surveyed the entire Labrador coast including Killinek, Saglek, Hebron, Okkak, Nain, and Seven Island Bay. Surveys of house ruins and stone artifacts found at Sculpin Island, Bouverie Island along the northern Nain archipelago, Iglosiatik Island located south of Nain and west of Voisey's Bay, Skull Island, Questlet Island and south to Hamilton Inlet revealed Thule occupation continued along the entire Labrador coast (Kaplan 1983). Multiple large, rectangular and 
semi-subterranean sod houses were clustered together in small villages along the entire Labrador coast (Fitzhugh 1981:39; Kaplan 1983). Houses varied in size, often 5 x 3 m to 9 x $5 \mathrm{~m}$ with approximately 5 to $7 \mathrm{~m}$ long entrance passages and had flat stone floors, internal wood structures, raised sleeping platforms and stone lintel doorways to help keep out the cold. Most of these houses exhibited multiple occupations with an array of materials and forms diagnostic of the Modified Thule period including ground slate flakes and nephrite tools (Kaplan 1983:462).

Thule sites appear as far south as Hopedale where research conducted in 1934 by Junius Bird (1945) identified a number of sod house settlements that exhibited architectural and archaeological elements of the Thule culture. Bird argued that most of the earlier Thule houses were small and round occupied by a single family, had flat stonelined floors, and were succeeded by larger square or rectangular two-family houses (Bird 1945; Fitzhugh 1972:60-61). Bird's excavations revealed that the Thule houses had a raised sleeping platform along the back of the house, and a single storage space or alcove at the front of the house near the entrance tunnel or next to the sleeping platform. Bilobed houses, with two separate residential areas sharing a single entrance tunnel — a common style among the Modified Thule — appeared in the southern region although without regularity. Bird only identified three bi-lobed houses at the five sites he investigated in the Hopedale region. 


\section{$\underline{\text { Hunting and Tool Construction }}$}

Similar to their Central Arctic neighbors, Labrador Thule hunted throughout the year and exploited a variety of ecological niches. Faunal evidence from Nachvak and Green Island indicated that Labrador Thule hunted a variety of animals, including fish, birds, seal, and caribou as well as focusing resources on larger baleen whales (Whitridge and Woollett 2008:150). Thule used tents or sod houses with skin roofs (qarmat) during the warmer months from April-August which allowed them to remain mobile to follow seal or larger sea mammals, or caribou further inland.

As noted above, most of the artifacts found resemble those from other Thule sites throughout the Central Arctic, including slate and nephrite knife blades and drilled triangular end blades. Yet a distinct absence of soapstone from the Nachvak and the earliest component of Green Island sites suggest that occupants were recent arrivals to the region and not familiar with available resources (Whitridge and Woollett 2008).

Tools from sites collected from the Hopedale region reflect the variety of the Thule toolkit including whale bone snow knives, wooden sealskin plugs, whetstones, and narwhal scrapers. In addition, this toolkit resembled cultural features similar to other Thule sites from Greenland and Baffin Island suggesting some degree of cultural continuity from northern regions (Ramsden and Rankin 2010).

\section{$\underline{\text { Trade Networks }}$}

Recent research suggested that the Thule in the Central Arctic were in contact with Greenland Norse prior to the AD 1500s, and the migration south was a result of 
seeking new opportunities to trade with Europeans (Ramsden and Rankin 2010). Radiocarbon dates show that the earliest Thule sites in the Canadian Arctic coincide with the Greenland Norse first reporting contact with Inuit around the mid-thirteenth century. The sudden move from the high Arctic to northern Labrador corresponded to the decline of Norse settlements in Greenland at around AD 1500 (Ramsden and Rankin 2010). Central Thule were already in contact with Norse, so their migration south into Labrador may have been to meet new Europeans for the purpose of trade (Balikci 1984; Damas 1984; Park 1997). The rise of a European presence in the south led to the development of new residential and migration patterns which will be discussed in more detail in the following Historic Inuit section.

\section{Summary of Labrador Thule}

Labrador Thule sites exhibit some characteristics similar to sites in the Central Arctic; however different resource availability and environment conditions in Labrador led to subtle changes as seen in the material remains. Even as the Thule adjusted to their surroundings and incorporated new materials such as soapstone and iron, they maintained some traditions from the earlier period, including slate tool construction and the cloverleaf house style. Their ability to adapt and exploit their new surroundings allowed the Thule to colonize as far south as the Hopedale region. 


\section{Historic Inuit (AD 1650-1800s)}

Historic accounts document that eighteenth- and nineteenth-century Inuit of central Canadian Arctic followed similar winter settlement patterns and house constructions as their northern Thule ancestors (Kaplan 1985a). As noted earlier, the Inuit of Canada are the direct descendants of the Thule. The arrival of European whalers and explorers in the early sixteenth century marked the beginning of radical changes to Inuit material culture, settlement patterns, and social organization. By the seventeenth and eighteenth centuries, the Inuit population in central and southern Labrador grew by two-thirds as Inuit moved south to gain better access to the new exotic goods either under either friendly or hostile circumstances (Kaplan 1983:331). Some Inuit were actively trading fur, walrus ivory and marine mammal products in exchange for European raw materials, such as iron, lead, and copper. They also sought manufactured products including guns and glass beads, tobacco and alcohol, and food. Other Inuit accumulated European materials by collecting those left behind after Europeans abandoned their settlements. There were still other Inuit that raided European sites, one of the reasons for the eventual erosion of the relationship between Europeans and Inuit.

The Moravian missionaries arrived in the midst of this turmoil in the lateeighteenth century with the hopes of bringing salvation and civilization to the Inuit. As a result, Inuit social habits changed again in response to the Moravian incentives and inducements. Inuit became more settled, moved into wooden houses, and relied more on Europeans for food. In the following section, I review the Inuit cultural transformation prior to Moravian missionaries’ arrival, focusing on the arguments for why Inuit changed 
settlement patterns and engaged in an emerging European trade market. While I discuss changes to sod house organization, hunting patterns and tool construction, I center the following discussion on the archaeology of trade and the connection to the emergence of a hierarchical social organization needed to facilitate the new economic exchange system. Evidence for this shift serves as the basis of the model for social organization that will be tested in subsequent chapters.

\section{$\underline{\text { House Organization }}$}

Few seventeenth-century Inuit houses have been identified along the Labrador coast, thus offering limited information regarding exactly how settlement size and subsistence practices changed during the period preceding the historic Inuit (LeMoine 2001:128). Kaplan (1983) argued that the lack of seventeenth-century sites in coastal Labrador may be the result of a declining Inuit population. Ultimately, the archaeological implication of this demographic shift saw eighteenth-century sod houses and assemblages alter from the single family houses described above.

The most commonly noted changes between the Thule and Historic Inuit in Labrador were in house and household size. Earlier Thule houses were smaller, rounder houses with short entrance tunnels that accommodated a single, nuclear family, as evidenced by the presence of a single lamp platform (LeMoine 2001:128) and a shorter sleeping platform. These earlier houses may have been less evident on the landscape as their walls would erode over time or were reused in the construction of later houses. 
Conversely, Historic Inuit incorporated larger, rectangular houses that had long sleeping platforms extending across the entire back of the house and multiple lamp stands suggesting multiple families sharing a house (Woollett 2010a:249). Ethnohistorical evidence collected by J. G. Taylor (1974) using the original Moravian diaries determined that typical late-eighteenth-century winter Inuit household comprised of multiple closelyrelated nuclear families consisting of a father and his married sons. In some cases brothers also shared houses which led Taylor to conclude that sod households were patrilocal in organization (J. G. Taylor 1974:74). Historical records from the Moravians suggest that larger, multifamily houses continue to be used in and around Hopedale from 1787 to 1801 . The addition of the larger house style and the larger families may be the result of Inuit returning to communal hunting practices during extreme climatic variability and unpredictability. It may also point to the addition of a new social organization in response to the changing social conditions brought about by the presence of Europeans and the availability of European raw materials and manufactured products

One site indicative of the above is the Oakes Bay settlement located on Dog Island just east of the site of the Moravian mission at Nain. Oakes Bay had both a seventeenth- and eighteenth-century component (Woollett 2003, 2010a) (Figure 2.2). The site consists of seven houses, of which three (Houses 1, 2 and 3) are rectangular structures with dimensions ranging between 12 to $13.5 \mathrm{~m}$ in length and with long entrance tunnels. Three other ruins (Houses 4, 5, and 6) are smaller, ovoid sod houses that range 7 to $9 \mathrm{~m}$ in length. Their smaller dimensions along with their indistinct walls only $0.5 \mathrm{~m}$ high, suggest that the latter houses had an earlier occupation (Kaplan 1985b). 
The final ruin (House 7) was found truncated between Houses 1 and 2, indicating it was an earlier structure covered by the more recent house structures. A summary of the houses dimensions are in Table 2.1.

A series of excavations between 2000-2007 by James Woollett (2003, 2010a) revealed general interior architectural features of each of the house except House 7, based on test units placed in each house and its associated midden. Houses 1, 2 and 3 all had sleeping platforms along the rear and side walls. House 3 also exhibited a cavity in the north end of the western wall of the entrance passage, suggesting the presence of an alcove or storage area (Woollett 2003:285). Earlier test excavations of House 3 conducted in 1984 by William Fitzhugh also uncovered a series of wood timbers, which were believed to be the remains of a collapsed sod roof (Woollett 2003:313).

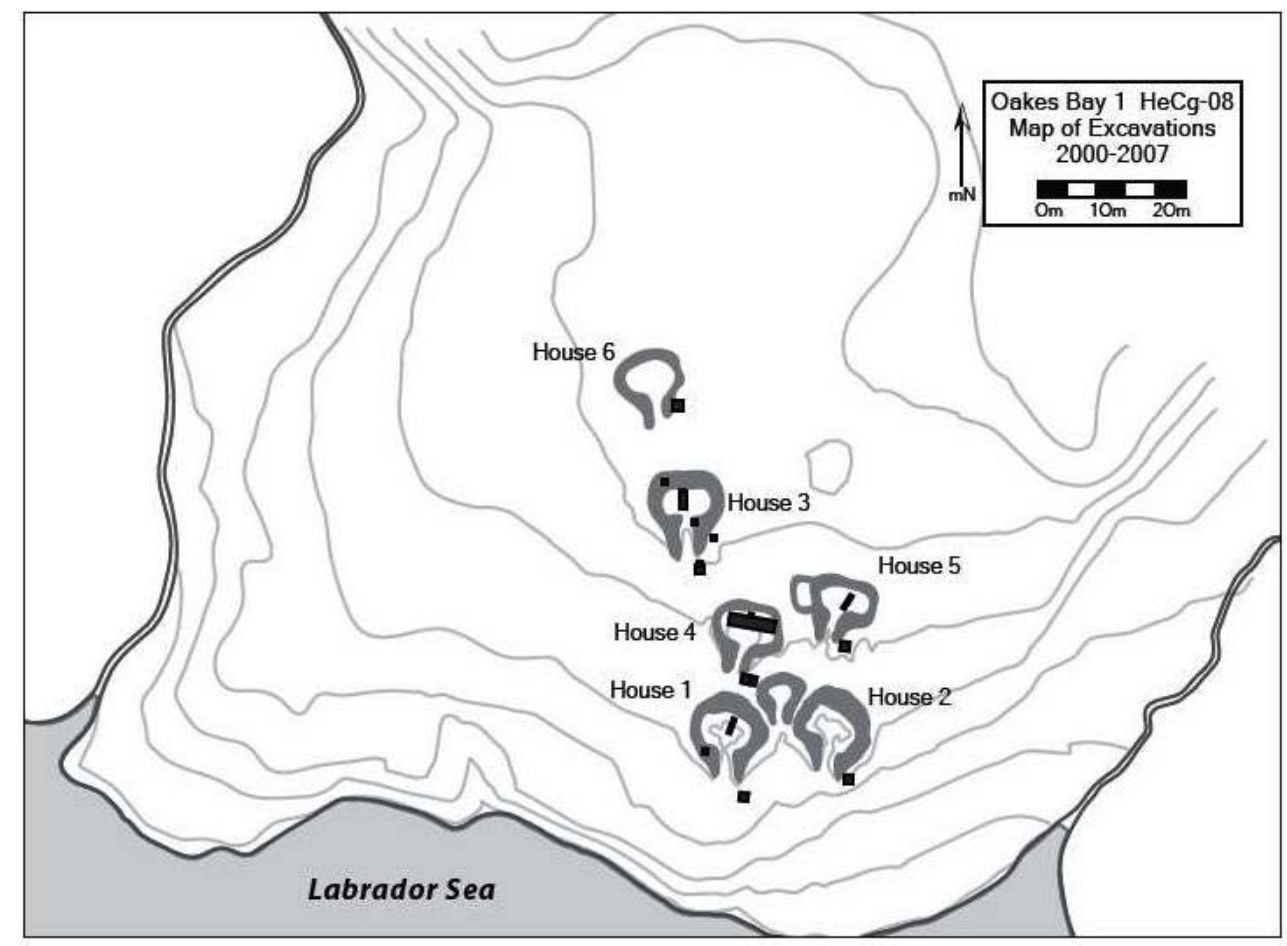

Figure 2.2: Plan map of Oakes Bay 1 (Woollett 2010:249, Figure 2). 


\begin{tabular}{|c|c|c|c|}
\hline Oakes Bay 1 & $\begin{array}{c}\text { House } \\
\text { Dimension (m) }\end{array}$ & $\begin{array}{c}\text { Entrance } \\
\text { Passageway } \\
\text { Length (m) }\end{array}$ & $\begin{array}{c}\text { Approximate } \\
\text { Occupation } \\
\text { Period }\end{array}$ \\
\hline House 1 & $13 \times 11$ & 10 & $18^{\text {th }}$ century \\
\hline House 2 & $15 \times 9$ & 9 & $18^{\text {th }}$ century \\
\hline House 3 & $12 \times 8$ & 9 & $18^{\text {th }}$ century \\
\hline House 4 & $12 \times 9$ & 6 & Mid $17^{\text {th }}$ to early $18^{\text {th }}$ century \\
\hline House 5 & $11.5 \times 8$ & 7 & Mid $17^{\text {th }}$ to early $18^{\text {th }}$ century \\
\hline House 6 & $9 \times 6$ & 6 & $*$ \\
\hline
\end{tabular}

Table 2.1: House dimensions and the entrance passageways in meters at Oakes Bay 1 (data from Woollett 2003:284-292 and 2010b:249-250). *House 6 was presumed to have a similar date as Houses 4 and 5; however no datable artifacts were recovered. No measurements were given for House 7 , so it is not included.

Another site located in northern Labrador with evidence for seventeenth and eighteenth century occupations was Uivak Point 1 , approximately $7 \mathrm{~km}$ northeast of the Okkak mission (Figure 2.3). The site consists of nine large, semi-subterranean sod houses of varying size (see Table 2.2) located in an extremely resource rich area providing excellent access to migrating whales and seals in the spring and fall. Similar to Oakes Bay 1, house sizes and architectural styles at Uivak Point vary between the houses suggesting different residential periods. For instance, Houses 8 and 9 were smaller, round houses with low walls. House 8 was partially covered by House 5, further indicating its earlier construction. House 4 was a smaller, rectilinear house that may have been an earlier house incorporated into House 2, or a rare example of a bi-lobed house. While all the houses had sleeping platforms extending across the length of back or side walls, some houses exhibited features common to multi-family houses such as multiple lamp stands found in House 1. 


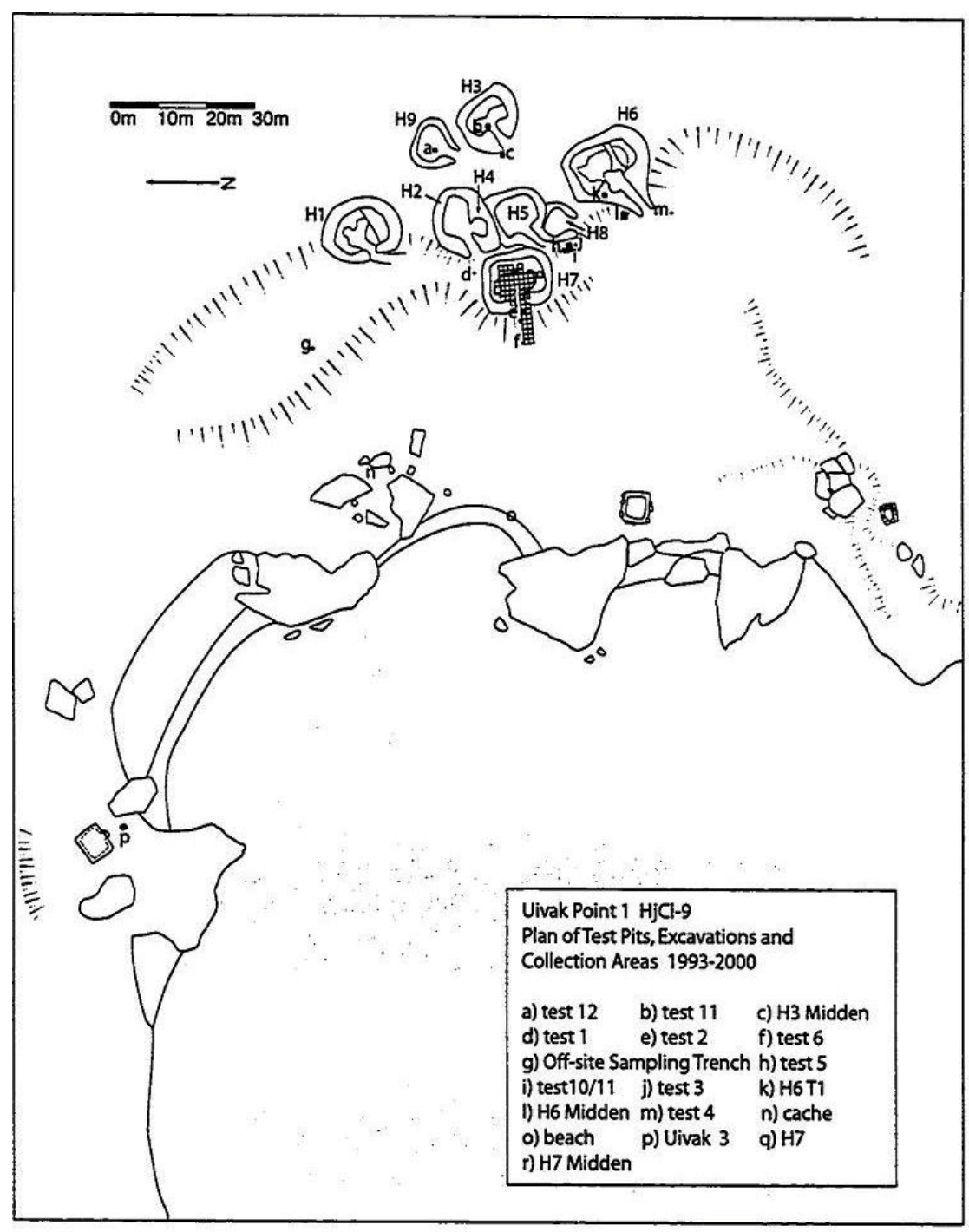

Figure 2.3: Plan of Uivak Point 1 (Woollett 2003:299). 


\begin{tabular}{|c|c|c|c|}
\hline Uivak Point 1 & $\begin{array}{c}\text { House } \\
\text { Dimension (m) }\end{array}$ & $\begin{array}{c}\text { Entrance } \\
\text { Passageway } \\
\text { Length (m) }\end{array}$ & $\begin{array}{c}\text { Approximate } \\
\text { Occupation } \\
\text { Period } \\
\end{array}$ \\
\hline House 1 & $15 \times 14$ & $3-4$ & Not excavated \\
\hline House 2 & $12 \times 10$ & 4 & Not excavated \\
\hline House 3 & $11 \times 7$ & 4 & $\begin{array}{c}\text { Earliest phase, } \\
\text { perhaps } 17^{\text {th }} \text { century }\end{array}$ \\
\hline House 4 & $4 \times 3$ & - & Not excavated \\
\hline House 5 & $11 \times 10.5$ & 7 & $1750-1830$ \\
\hline House 6 & $17.5 \times 10.5$ & 9 & $\begin{array}{c}1750 \text { to } \\
\text { early } 19^{\text {th }} \text { century }\end{array}$ \\
\hline House 7 & $14 \times 10$ & 3 & $\begin{array}{l}\text { Early Phase: } 1750-1790 \\
\text { Later Phase: } 1775-1806\end{array}$ \\
\hline House 8 & $9 \times 9$ & - & $1750-1830$ \\
\hline House 9 & $10 \times 7$ & $3-4$ & Not excavated \\
\hline
\end{tabular}

Table 2.2: House dimensions and the entrance passageways when identified at Uivak Point (data from Woollett 2003:302-321, 386).

Other houses at the site exhibited some unique architectural features not necessarily associated with the larger, communal house settlements. House 6 was the largest house, but had a turf partition built across the southern portion of the house, perhaps a modification to reduce the overall house size during reoccupation (Jordan and Kaplan 1980:42). House 7 revealed a considerable use of whale bone as structural elements for the walls, sleeping platform, and as roof posts, common among the Thule Inuit houses, but less so with eighteenth-century houses. A substantial amount of European artifacts were found in House 7, indicating a later occupation. Artifacts found in the top and bottom layers of the sleeping platform effectively bracket the use of the sleeping platform between 1785 and 1792, indicating that the house was likely occupied regularly during that period (Woollett 2003:397). 
Arguably, one of the most important sites in Labrador with an eighteenth-century occupation is Eskimo Island situated in the southwest end of the Narrows in Hamilton Inlet. Three clusters of large sod houses with long entrance tunnels exhibit the largest amount of European material found at an Inuit site on the Labrador coast to date. The density of material strongly indicates that residents were heavily active in the central trade, accumulating an incredible variety of European goods. The location of Eskimo Island in the Narrows provided excellent opportunities to engage with European ships traveling down the Strait. The three sites are located within $170 \mathrm{~m}$ of one another and had an occupation that spanned from the sixteenth to the late eighteenth century based on an elaborate artifact assemblage that included a large amount and great variety of European goods (Jordan 1978; Kaplan 1983) (Table 2.3).

Despite their proximity to one another, the house groupings exhibit slight architectural differences within and between each grouping, again suggesting multiple occupations. The most uniform of all sites, identified as Eskimo Island 1, has three single-roomed sod houses built in a line with all entrance tunnels facing south. Houses 1 and 3 were not tested, but excavations in House 2 revealed a raised sleeping platform extending along the back wall covered by wooden planks and surrounded by several lamp stands with heavy charring (Kaplan 1983:425). The presence of multiple lamp stands along the long sleeping platform suggests several families occupied House 2. Artifacts found during excavation identify House 2 as being occupied during the eighteenth century. 
The three houses at the second site called Eskimo Island 2 located 27.43 m east of Eskimo Island 1 also face south, but are slightly smaller and have internal partitions creating a separate chamber along the eastern side of Houses 4 and 5 (Figure 2.4). House 6 is located behind Houses 4 and 5 which were built next to one another. Limited excavations in House 5 by Richard Jordan (1974) revealed a stone paved floor and a sleeping platform running along the back and side walls. A sleeping platform covered by fir boughs and broad planks was surrounded by several heavily charred lamp stands, indicative of multiple families (Woollett 2003:264). Reanalysis by Susan Kaplan (1983) of the approximately 2000 European artifacts found in the three houses determined that Houses 4 and 6 were occupied during the eighteenth century, while House 5 had a slightly later eighteenth- to early nineteenth-century occupation.

Lastly, Eskimo Island 3 consists of four semi-subterranean sod houses approximately $85 \mathrm{~m}$ northwest of Eskimo Island 1. Unlike the other house clusters, the four houses are the smallest houses on the island, are widely spaced, and not aligned. Houses 3 and 4 were considered to have the earliest occupation at Eskimo Island 3. House 3 was not excavated but its proximity and architectural similarity to Houses 1, 2 and 4 suggests its late sixteenth- to early seventeenth-century occupation (Kaplan 1983:425). 


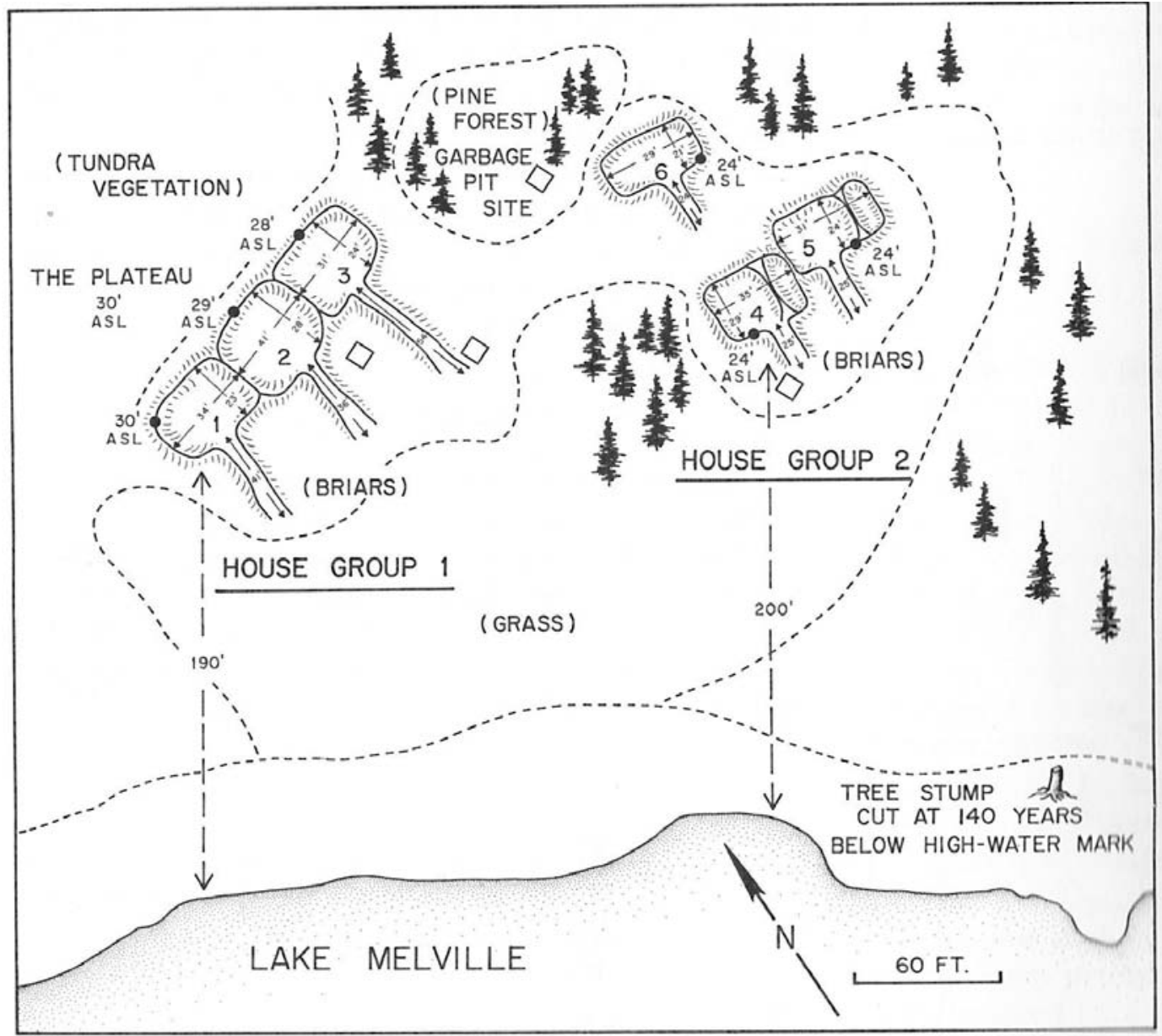

Figure 2.4: Plan of Eskimo Island 1 and 2 (Fitzhugh 1972:83). 


\begin{tabular}{|c|c|c|c|c|}
\hline Site & House & $\begin{array}{c}\text { House } \\
\text { Dimensions (m) }\end{array}$ & $\begin{array}{c}\text { Entrance } \\
\text { Passageway } \\
\text { Length (m) }\end{array}$ & $\begin{array}{c}\text { Approximate } \\
\text { Occupation } \\
\text { Period } \\
\end{array}$ \\
\hline \multirow[t]{3}{*}{ Eskimo Island 1} & House 1 & $6.9 \times 10.2$ & 12.5 & Not excavated \\
\hline & House 2 & $8.4 \times 12.3$ & 11 & $18^{\text {th }}$ century \\
\hline & House 3 & $7.2 \times 9.3$ & 16.46 & Not excavated \\
\hline \multirow[t]{3}{*}{ Eskimo Island 2} & House 4 & $8.7 \times 10.5$ & 7.62 & $18^{\text {th }}$ century \\
\hline & House 5 & $7.2 \times 9.3$ & 7.62 & $\begin{array}{c}\text { Late } 18^{\text {th }} \text { to } \\
\text { early } 19^{\text {th }} \\
\text { century }\end{array}$ \\
\hline & House 6 & $6.3 \times 8.7$ & 7.31 & $18^{\text {th }}$ century \\
\hline \multirow[t]{4}{*}{ Eskimo Island 3} & House 1 & $8 \times 5$ & 4 & $\begin{array}{l}\text { Mid-17 th to } \\
\text { early } 18^{\text {th }} \\
\text { century }\end{array}$ \\
\hline & House 2 & $5.4 \times 9.6$ & 9.3 & $\begin{array}{c}\text { Late } 16^{\text {th }} \text { to } \\
\text { early } 17^{\text {th }} \\
\text { century }\end{array}$ \\
\hline & House 3 & $6 \times 4.8$ & 6 & $\begin{array}{c}\text { Late } 16^{\text {th }} \text { to } \\
\text { early } 17^{\text {th }} \\
\text { century }\end{array}$ \\
\hline & House 4 & $8 \times 8$ & None & $\begin{array}{l}\text { Late } 16^{\text {th }} \text { to } \\
\text { early } 17^{\text {th }} \\
\text { century }\end{array}$ \\
\hline
\end{tabular}

Table 2.3: House dimensions and the entrance passageways at the Eskimo Island (data from Fitzhugh 1972:83-84; Jordan n.d.; Kaplan 1983:413-425).

House 4 was also considered to have an early occupation based on the nearly 200 artifacts recovered, including bone artifacts, soapstone lamps and some late sixteenth to early seventeenth-century European goods similar to Basque artifacts (Woollett 2003:272). Excavations of House 4 revealed a high density of wood beams used for the interior architecture, and a raised sleeping platform which was covered by a thin layer of twigs (Jordan n.d.). 
Excavations in House 1 revealed a stone lined floor, a rear sleeping platform, a lamp stand near the entrance adjacent to a storage pit, and had heavy density of bones, hide and charred fat (Jordan n.d.). Jordan believed that the roof was constructed with wood beams supported by posts, based on the dense layer of timbers overlaying the floor within the house and entrance tunnel (Woollett 2003:271). Based on the trade artifacts recovered from House 1, it has a late seventeenth- to early eighteenth-century occupation. House 2 is the largest of the four houses at Eskimo 3 and the most complex, as it has a second chamber extending from the southwest corner (Figure 2.5). This chamber is separated from the main house lacking any direct passage to the main part of the house. The house may have been a clover-leaf or a bi-lobed house similar to those from the Modified Thule period, or an older structure underlying House 2 (Jordan 1978). Jordan dated the side chamber to the late sixteenth- to early seventeen-century period, thus representing the earliest occupation at the site.

The change in architectural styles seen in most northern and central settlements at Oakes Bay and Eskimo Island were also evident in the Hopedale region. Junius Bird’s two-month survey of the Hopedale region in 1933, located between Oakes Bay and Eskimo Island, suggest Inuit along the entire coast were shifting away from the smaller single-family dwellings to the larger, rectangular houses with raised platforms and multiple lamp stands (Richling 1993). A more thorough discussion of the house architecture at Avertôk will occur in Chapter 6, but it is worth noting here that Bird proposed that the shift to larger communal houses was a defensive strategy due to rising 
Inuit apprehension of the increasing presence of Europeans along the coast (Bird 1934:179).

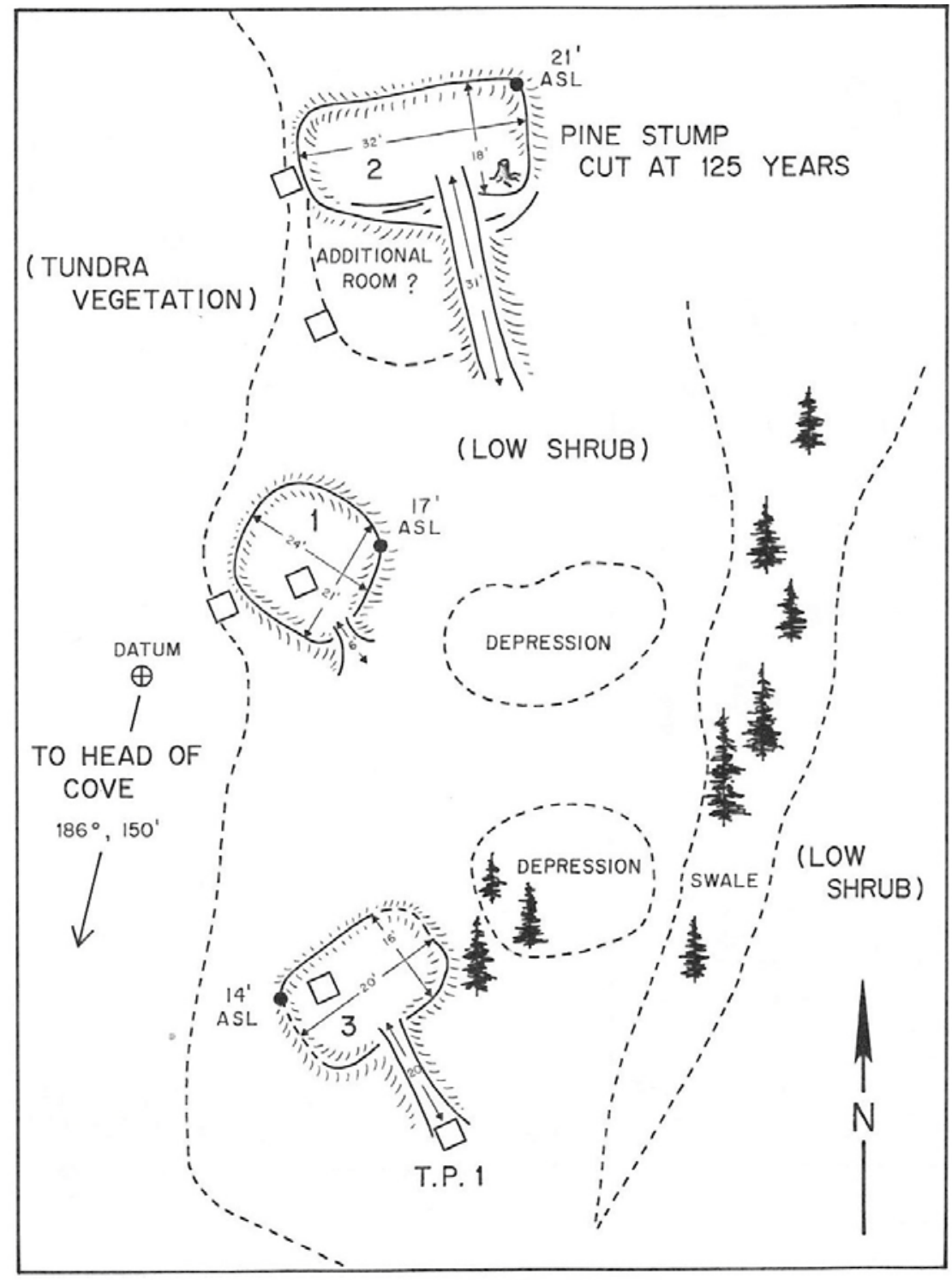

Figure 2.5: Plan of Eskimo Island 3. Note the presence of a possible additional room in House 2 (Fitzhugh 1972:84). 


\section{$\underline{\text { Hunting and Tool Construction }}$}

Previous researchers have argued that reasons for the shift to larger households was either the result of an adaptation to environmental stresses or an adjustment to changing social and cultural elements (e.g., Jordan 1977; Richling 1993; Schlederman 1976). I intend to tease out the evidence for both lines of argument, first focusing on the environmental factors as tied to hunting patterns in this section, followed by a discussion of the cultural factors in the subsequent section.

Peter Schlederman (1972) argued that the shift to larger households evolved as an adaptation to environmental stresses. Deteriorating climatic conditions during the seventeenth century led to a period of decline in whales, a critical resource for the ancestral Thule population (Coupland 1996). Frozen seas directly impacted whale migration patterns, and the resulting variability made whale hunting unpredictable (Woollett 2010a:255). The decline of dependable whale hunting would have created serious provisioning problems for less productive households (Schlederman 1972). The shift to an alternative food source such as seals placed pressure on households with less accomplished hunters, making those households more susceptible to starvation. Consolidating households and forming larger labor groups offered a level of economic security by allowing for a broader distribution of meat. Schledermen thus framed the formation of the larger houses in purely evolutionary terms.

Most of the subsistence activities employed by the Inuit included a social component, particularly the whaling and large-scale fishing or sealing which required at least 12 men to ensure success (J. G. Taylor 1974:84). Especially during seasons of 
simultaneous subsistence activities, larger households could combine resources and engage in more diverse resource collection than smaller ones (Coupland 1996:122). Due to food sharing practices among many Inuit groups, larger communal households would experience greater sharing of food and other resources than those with single-family units. Sharing resources offset the inadequacies of limited fuel supplies; therefore evidence of communal houses indicates a decrease in resources and increased reliance on the group (Schlederman 1975:35-36). Pooling resources, employing a food-sharing network, and relocating winter settlements to inner islands to be closer to additional resources such as seal and caribou and — in Labrador — to wood, could have served to reduce stress.

Recent research based on earlier ethnographic and historic data, suggested conclusions inconsistent with these ecological arguments; instead, communal houses were shown to be reasonably stable and productive subsistence economies, and were not experiencing ecological stress (Woollett 2003:639, 2007:81). Analysis of faunal remains at Uivak Point and Oakes Bay reveal an abundance of seal remains, particularly harp seals. The deposits also included secondary taxa such fish, birds, mussels, caribou, foxes and dogs, but none of which were consumed to the same degree as seal.

Whale bone was also present at the site, but many of the elements found represented adult individuals which were likely collected from stranded or beached carcasses. Whale hunting from earlier Thule sites suggest Inuit whaling efforts focused on yearlings or immature whales that were easier to hunt and recover (Woollett 2003:595). Ethnohistoric evidence collected by J. G. Taylor (1974) identified that whale 
hunting occurred regularly in areas north of Okkak, but less so in central Labrador and around Hamilton Inlet. In central Labrador, whale bones recovered at Eskimo Island were used as raw materials and structural components of the houses; however, they comprised less than $1 \%$ of the entire faunal assemblage and no particular evidence of whale hunting was apparent in the faunal or artifact assemblages (Woollett 2003:633). It was more likely that the objectives of the Eskimo Island residents were to exchange whale products obtained from Inuit living further north, and traded in the emerging trade market with Europeans, rather than collecting more whale products (Kaplan 1985a:59).

Many of the artifacts associated with hunting during this later period also reflect the array of tools needed for hunting and processing a greater variety of species from the land and the sea, such as sealing harpoon foreshafts, caribou spears, bows and arrow for hunting birds and caribou, fishing leisters or three-pronged spears, ground slate, stone knives, and strips of baleen for lashing, along with bone and wooded sled and boat parts. Yet the greatest difference in the later assemblages from the Thule predecessor was the heavy inclusion of European materials, especially metal. Often metal was incorporated and refashioned into more traditional forms where spikes and nails were hammered out into endblades, and iron rivets were used to manufacture or repair other items. In many cases, forms were not modified, such as fish hooks, lead weights and corks used as floaters. Eventually, firearms were also incorporated into the Inuit toolkit, as evidenced by the presence of lead shot and gunflints. 


\section{$\underline{\text { Trade Networks }}$}

A second perspective to understanding the formation of the larger communal houses uses cultural data. More recently, the model that has gained greater acceptance by researchers is that the trade of local products including ivory and baleen for European goods promoted the development of an increasingly hierarchical Inuit social structure that emerged with the increase in European presence on the Labrador coast (Kaplan 1985a). Ethnohistorical evidence identified the presence of individual men with clear authority as boat owners, whale hunters, shamans, mediators, or trading captains (Kleivan 1966; J. G. Taylor 1974). These leaders used existing social roles of authority to organize kin, dominate exchange, and accumulate wealth (Jordan 1977).

Focusing on trade as a factor encouraging communal houses, Kaplan (1983) documented changes seen in prehistoric and historic Inuit settlements. She used ethnographic and archaeological data to define the function of long-distance trade networks maintained by prominent Inuit traders (Kaplan 1983). Settlement patterns and resource distribution at eighteenth-century Inuit settlements indicated that Inuit moved south to acquire European goods then returned north to trade. Although the Inuit population steadily grew from the seventeenth to the eighteenth century (Kaplan 1983:331), the rise of violence and disease in the south led to a loss of men. The skewed gender ratios may have provided opportunity of those remaining to form polygynous, multi-family households (Kaplan 1985a:62).

These larger family groups may have been traveling together and meeting with other familial groups. J. G. Taylor (1974:18) identified that the average size of a 
July/August camp in the late-eighteenth century was approximately 158 persons per camp. This was significantly larger population may have been a coalescence of several camps, since other seasonal camps included approximately 36 persons residing at sod house camps and 27 residing at spring tent camps (J. G. Taylor 1974:18). The purpose for the larger group may have been two-fold: providing strength in numbers during trade and corresponding with seal or caribou migrations (Stopp 2002:82).

Inuit assemblages became increasingly diversified throughout, and sites located closer to European settlements yielded more trade items than sites located farther north (Kaplan 1983). European material appear in every known eighteenth-century Inuit site; however, Eskimo Island stands apart from other sites as its substantial and diverse collection of European objects denote a community that appear to be interested in accumulating items perhaps for trade elsewhere. House 2, the only house excavated at Eskimo Island 1 had approximately 10,000 European artifacts, including gun parts and ammunition, an axe head, knives and parts of two swords, as well as European ceramics, glass and 9000 beads (Jordan 1977, 1978; J. G. Taylor 1974). The large quantities of European goods and particularly the hunting items suggest that Eskimo Island residents were amassing these goods primarily for trade, as well as for their own use (Whitridge 2008:302).

The assemblage found at Eskimo Island supported the argument of a complex Inuit trading system that originated in the south and moved north along the Labrador coast. Eskimo Island was uniquely situated to provide access to the incoming Europeans who were establishing a number of posts in central Labrador, while allowing Inuit to 
maintain many of their basic subsistence practices. The location near ice-free zones, called polynayas, in the Narrows offered Inuit access to harp, ring and harbor seals, as well as other marine and terrestrial resources which could be shared in communal houses during periods of economic hardship. The establishment of large multi-house settlements in Hamilton Inlet allowed Inuit to exploit trading opportunities with Europeans while maintaining important subsistence practices.

The array and quantity of European goods at the Eskimo Island houses suggests the development of a new social organization where surplus was valued. Jordan (1974) argued that the development of surplus led to the rise of individuals with status based on their success as traders and their aptitude in interacting with Europeans. Maintaining strong social and economic alliances with these leaders could be beneficial to community members during periods of resource scarcity or economic hardship.

Due to limited contact with Europeans to the north and rising Inuit demand for European goods, Inuit leaders who were boat-owners took on this new role as traders (Kaplan 1985a:62). These traders connected disparate households and settlements into single economic units and established a dominant trade network (Kaplan and Woollett 2000). Local goods such as sealskin and ivory were traded south, and European goods traded north up the coast brought tobacco pipes, beads and metal (Kaplan 1985a:62).

The presence of European goods in eighteenth-century Inuit sites further north indicates Inuit ability to accumulate these goods; however, the extent of this Inuit trade network progressing to northern sites remains unknown since limited archaeological research at sites participating in an exchange network has been conducted (e.g., Kaplan 
1985a). Further, no clear material evidence tie northern sites to the southern traders. Inuit acquiring goods directly from Europeans was infrequent as the majority of the traders congregated at southern posts, yet small numbers of Europeans traveled north to engage in trade with Inuit and hunt whales. There were a number of ways Inuit could collect European goods and they may not have relied on formal trading relations.

Two alternatives to trading included raiding European sites in search of desired materials, or the more indirect measure where Inuit visited abandoned European sites and collected discarded or cached items. The origins for tensions between the Inuit and Europeans appear to be European incursions into Inuit resource areas, particularly salmon rivers and traditional sealing regions, and Inuit raids increased the level of conflict (Stopp 2002:83).

Few researchers discuss the role of site foraging as an alternative to raiding or trading as a means towards accumulating European materials. Stemming from Binford's (1980:5) theory of foraging as a mode for subsistence, I use foraging in a similar vein where Inuit integrate seasonal moves among a series of resource patches that included abandoned European sites. After a season of hunting, fishing, whaling and trading, Europeans returned to their native country abandoning their temporary settlement along the Labrador coast. Inuit would encounter materials the previous European residents deemed trivial, such as extra nails or barrel hoops, or were simply thought lost. Perhaps the result of the continued aggressions led Inuit to seek alternative means towards accumulating desired materials without engaging the Europeans. 
Subsistence and trading activities of the eighteenth century introduced a new level of economic prosperity that caused new social problems (Kaplan and Woollett 2000). The increasing presence of Europeans, especially Moravian missionaries, offering easier access to goods increased the desire for European materials. As European goods saturated the local market, acquiring goods became less costly, and the importance of the intermediary role played by Inuit community leaders was diminished, leading to organizational change in Inuit culture. Access to European trade goods was no longer reserved for the most powerful and may have added to the decline of the communal settlements. The final abandonment of the communal house as an organizing structure appears to have coincided with the beginning of the Moravian period (post-1760s) and the introduction of a market economy.

\section{$\underline{\text { Summary of Historic Inuit }}$}

Evidence suggests that seventeenth-century Inuit lived in smaller single family homes and were able to acquire limited quantities of European goods. Archaeological data indicate that Inuit shifted their residential patterns in the eighteenth century to include large multi-family houses during the winter months, though the ecological and cultural features for the change to larger houses continues to be debated. Communal hunting during the spring and fall seal migration along with the rise of a coastal trade, suggest that Inuit lived in the large multi-family houses to benefit from those who were successful hunters and traders (Jordan 1977; Kaplan 1985a; J. G. Taylor 1974). 


\section{Chapter Summary}

This chapter provided an overview of Thule and Historic Inuit culture history as it pertains to Labrador and the development of social structures according to house organization, hunting and tool construction, and trade networks. The goal of this chapter was to discuss archaeological evidence for economic and cultural features associated with the Classic Thule, Modified Thule, and Historic Inuit groups and the ways in which those features changed over time. This section also introduced theoretical propositions as to why Inuit culture changed as it related to the eastward migration, climatic events, the arrival of Europeans, and the development of trade.

Many changes seen to Inuit houses and settlement patterns in the seventeenth and eighteenth century coincide with the rise of various European groups along the coast. In the following chapter, I review which European groups visited the coast, discuss the social and political environment that may have influenced the changes discussed above, and how their interaction differed from the Moravian missionaries who arrived later.

Better comprehension of how previous Inuit groups addressed climatic change and incorporated foreign ideas and materials offers insight into the development of specific cultural and social forms. Although direct analogy to prehistoric cultures can be problematic, studying earlier patterns of change can offer new avenues for research previously not considered in studying recent Inuit culture change. Compiling archaeological evidence for house organization, changing subsistence practices, tool construction, and the presence of trade helps develop a model for Inuit social organization and possible explanations for its transformation over time. 


\section{Chapter 3: First Contact: Europeans in Labrador}

The rise of a European and American presence along the Labrador and Newfoundland coasts during the sixteenth to eighteen centuries had a deep and lasting effect on Inuit culture. This chapter focuses on the activities of the Basque, Dutch, French, American, and English fishermen, traders and government officials and their policies. Using primary and secondary sources, I shed light on the economic and political developments in the region as well as European impressions of the Native peoples with whom they engaged in trade. Specifically, I study the effects of European colonialism on Inuit culture and how the mercurial relationship led at least a few Inuit to engage more exclusively with Moravian missionaries than European traders located in Hamilton Inlet.

Each foreign group had its own purpose for being in the region, and its own attitude and policies towards Native Americans. I intend to tease out those differences in this chapter, and highlight how they combined to create a complex and hostile social environment prior to the arrival German Moravian missionaries in the 1770s. I focus on the arrival of the Europeans from the sixteenth century until the arrival of the Moravian missionaries in the eighteenth century for four reasons. First, previous researchers believed that the earliest Europeans to visit Labrador were the Norse, developing trade with the Inuit of Labrador as early as 986 A.D. (Zimmerly 1975). Archaeological and historical records suggest Norse settlements were in Newfoundland at L'Anse aux Meadows around 1003 AD (McGhee 1984; Wallace 2006). Although Leif Eriksson apparently sailed down the Labrador coast and named it "Markland," archaeological or historical evidence of a Viking presence in Labrador has yet to be recovered. Due to a 
lack of evidence for contact between the Norse and Native peoples in Labrador, the following section will focus on the post-Norse European exploration and settlement of Labrador and Newfoundland, which developed after the fifteenth century.

Second, the oldest commercial corporation in North America, the Hudson Bay Company (HBC) originally entered the Hudson Bay region in northern Canada as a venture in 1668 but did not establish any trading stations in Labrador until the nineteenth century. The HBC believed that Labrador held no potential for the fur trade, since it was a "barren tract of land with few inhabitants, few beaver, few furs of any kind, and but little merchandise” (Rich 1960:621). But in 1811, the threat of Moravian missionaries establishing a mission and trade store in Ungava Bay in Quebec renewed the HBC’s interest in Quebec and Labrador (Loring 1992:124). Although the HBC played a significant role in developing trade relations with Native groups in the nineteenth century, their late arrival extends beyond the purview of this dissertation; therefore the HBC is not discussed in the following chapter.

Third, many European trading policies focused initially on the Newfoundland coast, and not Labrador. Although cultural and environmental differences existed between Labrador and Newfoundland, Europeans approached Labrador as if it were an extension of Newfoundland. Understanding and analyzing the conflicts between the various European and Native groups in Newfoundland helps explain the hostility and aggression in the entire region.

Finally, it is important to identify which Europeans arrived before the Moravian missionaries and the manner of each group's interaction with Native peoples. This is 
critical to the analysis of social changes experienced later by the Inuit as identified in the archaeological and historical records. The relationships between Europeans and Native groups led to volatile situations at times, thus providing clues as to why Inuit chose to engage with certain traders and missionaries and not with others.

A limited number of records distinguish difference between the Beothuk, Innu, and Algonquin (referred to as Indians in the historic documents) and Inuit (referred to as Eskimos in the historic documents), all of whom inhabited Labrador and Newfoundland. Rather than try to identify which specific group earlier explorers and fishermen came into contact with, I use the same identification as recorded in documents (i.e., Indian versus Beothuk; Eskimo versus Inuit). The term “esquimao” and its variants were used in historical documents to refer to a number of Native peoples including the Micmac and Montagnais as well as the Inuit (Fitzhugh 2009:131; Martijn 1980; Pastore 1994:23). In adopting this approach, my intent is to document Native/European interactions and, when available, specific examples of Inuit/European interactions. Rather than try to cover all the instances of Native-European contact, I aim to examine the activities, policies, and attitudes of the Europeans to clarify the colonial process in Labrador during the early historic period.

\section{The Basque}

While individual explorers from Spain, France, and England traveled along the coast of Labrador at the turn of the sixteenth century, the earliest Europeans to establish seasonal occupation and economic operations in southern Labrador were the Basques. 
Originally fishing for cod in the strait between Labrador and Newfoundland in the 1520s, the Basques shifted their attention to the whales that migrated regularly through the Strait of Belle Isle. This shift proved profitable, for the Basques and their Labrador whale trade helped trigger an economic growth in Europe in the late sixteenth century (Proulx 1993:17). However, Basque industry saw a rapid decline as European wars, local competition and declining whale stocks resulted in the Basque abandoning the region.

The earliest documentation of a whaling industry in Labrador is 1547 when the Basque established a whaling station along the southern Labrador coast at Red Bay. Soon thereafter, four other whaling ports were established. By the 1570s, 20 southern Basque ships hunted whales seasonally in this area (Proulx 1993:19). During the peak years from 1584-1587, they Basque oversaw a large and lucrative operation. Their whaling industry had 15 ships hunting in the waters around Labrador and produced anywhere from 14,000 to 18,000 barrels of whale oil every year (Barkham 1984:516; Turgeon 1998:597). Demand for oil was high due to industrial needs such as for oiling wood and street lamps from predominantly English markets such as Bristol, Southampton, and London (Barkham 1977:579, 1978).

Even as the market flourished and oil remained a profitable commodity, environmental and social variables led to a decline of the Basque whaling industry. Over-hunting of whales and climatic disturbances likely affected the numbers of whales the Basque encountered. The whalers followed fewer whales out to open waters which led to smaller catches than in previous years (Barkham 1984:518; Turgeon 1998:593). By the 1580s ships were returning to Europe half-empty. 
Violence was the primary social factor affecting the decline of the Basque whaling industry. Piracy and raids by Dutch and English ships and the Inuit forced the Basque to move their enterprises further south to the Gulf of St. Lawrence, the St. Lawrence River and into Norwegian waters (Barkham 1984:518). The Dutch and English were unrelenting towards their competitors by disrupting and sabotaging the Basque industry. On rare occasions, the Basque also were attacked by Inuit who were interested in acquiring European raw materials such as iron. Three such cases were documented in Jesuit parish records kept between 1575 and 1618 where Basque were attacked and killed by “Eskimaos” (Barkham 1984:518). Another report written in 1625 by Basque historian Lope de Isasti identified “Eskimaos” attacking Basque ships, killing and eating the men (Isasti 1850:154 in Barkham 1984:518). Although it is unclear as to the true extent of the Inuit incursion based on only a few documented attacks, the constant assaults by both Europeans and Natives contributed to the demise of the Basque presence in the Strait of Belle Isle. The Basque turned their attention to areas further south and around Northern Europe, where they remained until the end of the seventeenth century (Barkham 1984:518).

Closer examination of the historical record revealed that such attacks by Inuit on Europeans were not unprovoked. A combination of three social factors may provide justification for Inuit hostility. First, Jesuit parishioners living in Labrador during the late sixteenth century and early seventeenth century note that Inuit hostility was likely a form of opposition to the European presence (Turgeon 1998). The sudden influx of Basque whalers stressed a delicate environmental and cultural balance established by the Inuit. 
Basque likely infringed upon traditional Inuit hunting grounds and over-fished those areas which caused tensions.

Second, the Basque were known for engaging in trade with other rival Native groups, such as the Innu, Montagnais and Algonquian (Turgeon 1998). Basque historian Isasti (1850:154 in Barkham 1980:514) identified one group as “montañeses” who spoke Basque and helped prepare the fish on shore in exchange for bread, biscuits and cider. These Indians also helped by warning the Basque of approaching Inuit (Barkham 1984:518). The Basque also developed amicable relationships with the Innu, who helped the Basque process whale oil and traded furs for iron tools. With the fur trade assuming more significance in the last quarter of the sixteenth century, these relationships developed even further. English sea captain Richard Whitbourne stated in reference to Indian cooperation with the Basque and French whaling industries that "naturall Inhabitants of the Countrey...report to them to be an ingenious and tractable people (being well vsed:) they are ready to assist them with great labour and patience, in the killing, cutting and boyling of Whales; and making the Traineoyle, without expectation of other reward, then a little bread, or some such small hire” (Whitbourne 1620). Perhaps by developing working relationships with the other Native groups, the Basque aligned themselves with Inuit rivals.

Lastly, the European notion of superiority heavily influenced Basque perception of Native groups. Historical documents are saturated with descriptions of Native peoples and particularly Inuit groups as wild, savage or heathens. Previous anthropological and historical research attests to this cultural assumption of superiority (Fagan 1984; 
Lightfoot 2006; Obeyesekere 1997). The common European belief was that Native groups were inferior due to their pagan religions and lack of technology. Conversely, some Natives believed Europeans were gods or demons and not to be trusted (Sahlins 1985). Such presumptions carried over whenever Europeans and Natives interacted, making for less than amicable relations.

The height of recorded hostilities coincided with the end of the Basque's tenure in Labrador in the late sixteenth to early seventeenth centuries. It seems unlikely that small bands of Inuit would attack well-armed Basque outposts of more than 500 men during the peak of the Basque whaling period (Barkham 1980:56). Inuit probably raided scaleddown settlements or those abandoned after the Basque returned to Europe late in the fall, stealing boats and leaving fishing stations and shore-side facilities in ruins.

The Basque never established permanent year-round settlements, opting for seasonal off- and on-shore operations. Upon season's end, the Basque covered their oilrending try-works and their shelters, leaving much in their camps intact while taking the rendered whale oil, fish and trade goods back to Europe. Elaborate on-shore operations included cooper workshops, ovens, and dwellings for the workers, constantly required shipments of building materials for building and maintaining blubber-rendering facilities (Barkham 1978:9-11; Tuck 1982; Tuck and Grenier 1981). Archaeological excavations at the southern Labrador Basque site at Red Bay recovered a great numbers of nails, wood barrels, lead, ceramic tiles, ceramic jars, cooking vessels, plates and majolica-ware vessels indicating the presence of industrial and domestic activities (Fitzhugh and Phaneuf 2008; Tuck and Grenier 1981). Many materials such as tiles, tools to construct 
ovens, and equipment to construct oil barrels were also desired by many Native groups including the Inuit, and have been occasionally found at Inuit sites in northern Labrador.

Some recent archaeological finds, however, counter these earlier versions of Basque/Inuit hostilities. Located in the Quebec Lower North Shore, the partially submerged Mécatina Basque site reveals a potential economic collaboration between some Inuit families and the Basque. Ongoing excavations at Mécatina in Hare Harbor conducted by William Fitzhugh of the Smithsonian Institution provide revelations of Basque-Inuit activities previously unknown. The site was a frontier zone used by a variety of groups for obtaining resources, such as whale products, fish, fur and timber, and was a central location for multi-national competition (Fitzhugh and Phaneuf 2008). Creating favorable relations with Native groups would offer the Basque an economic and strategic advantage over its European competitors. Not only would such relationships allow the Basque to access goods and additional labor, it ensured limited or no raiding while they were gone.

Excavations at Hare Harbor thus suggest the Basque-Inuit connection was more complex than historical documents show. While a wide range of European materials was found, excavations at Mécatina uncovered a number of Inuit artifacts, including soapstone lamps, children's toys, oil lamps, and Inuit tools in the same place as the Basque on-shore industry. In the summer of 2008, excavations revealed the floor and sunken entryway of an Inuit sod house within the Basque site. Further survey and excavations of the area revealed an eighteenth to nineteenth century Inuit tent ring, suggesting continuous Inuit occupation in the area during the Basque’s seasonal 
operations (Fitzhugh and Ford 2008). Debate continues over whether the eighteenthcentury European component associated with the Inuit occupation was in fact Basque (Stephen Loring, personal communication 2011).

Stratigraphic evidence also revealed evidence for extensive burning that suggest the site was attacked, burned, and possibly overtaken (Fitzhugh and Phaneuf 2008). A 1729 report by French merchant Martel de Brouaguge of Brador detailed an Indian massacre of an Inuit family and the burning of the Inuit house in Mécatina. While evidence is still being uncovered to verify the archaeological findings, both pieces of evidence reveal the contentious relationship among many Native groups in the region: hostility over competing interests for resources that began long before the Europeans' arrival. What makes this particular situation unique is that a French rival of the Basque incited the Indians to attack (Fitzhugh and Ford 2008). The collusion of various European and Native groups living on the coast highlights the theory that the growing hostilities were not the result of a single colonial event. Rather, it was a case of separate groups attempting to meet their own needs.

As excavations continue at Hare Harbor, more information will shed light on the Inuit/Basque/European relationship. The evidence strongly suggests that contact between Inuit and Basque could have been at the very least a cordial one and instrumental in the Basque whaling enterprises. Fitzhugh argues that the Inuit winter house contexts include Basque material culture, suggesting that the Basque employed an Inuit family as hunters, fishermen, and site custodians during the winters (Fitzhugh and Ford 2008; Fitzhugh et al. 2011). 
The aforementioned attack seems to mark the end of the Basque/Inuit relation at Hare Harbor, with the Basque returning the following season to build a blacksmith shop on top of the burned Inuit house remains. No additional evidence of Inuit material culture appears at this level throughout the site (Fitzhugh and Ford 2008).

Limited documentary evidence suggests the Basque were one of the earliest European groups to exploit Labrador's resources. The early interest in whales brought the economic potential in the region to the attention of the rest of continental Europe, helping to spur an economic growth in the region and abroad in the seventeenth century. However, increasing competition in the whaling industry by other European nations compromised the Basque’s ability to successfully hunt and procure whales. Their inability to sustain relationships with Native groups further hampered their chances of survival, as the Basque soon became the focus of hostile raids. Although recently uncovered evidence suggests the Basque attempted to build working relationships with Inuit in the eighteenth century, it stands as a single incident in a long history of violence.

\section{The Dutch}

Arriving in northeast Canada in the early 1600s, the Dutch appear to have been interested in exploiting Labrador resources for economic reasons. However, only limited documentation exists of the Dutch enterprises in Labrador during the seventeenth century. A collection of research by historians Jan Kupp and Simon Hart on Dutch activities in Labrador from the Amsterdam archives, provides as the only information available regarding Dutch whaling and trading industries. The following section reviews 
Kupp and Hart's work focusing on the political and economic significance of the Dutch presence in Labrador and its role in the European global market.

Identifying the economic potential of a New World trade in the seventeenth century, Dutch businessmen created two companies in 1614 that sought to control both land and sea trade (Kupp and Hart 1976:4). The first, the New Netherlands Company, was formed to control the New York fur trade, while the second, the Northern Company, sought to continue whaling and trading in the North Atlantic with Labrador serving as the western-most limit (Kupp and Hart 1976:4). Dutch activities remained seasonal and no attempt was made to establish permanent settlements or develop trade with the Inuit (Kaplan 1983:163; Kupp and Hart 1976). Notes by Dutch mapmaker Joris Carolus during a 1615 journey to $80^{\circ} \mathrm{N}$ latitude briefly discussed interactions between Europeans and Native peoples as unfriendly. Carolus failed to go into detail, simply stating that the Natives were "heathens and wild Cannibals” who engaged with the Europeans in a hostile manner (Kupp and Hart 1976:8).

Nevertheless, the Dutch merchants eventually recognized the global demand for Native trade goods and incorporated elements of a local trade in Newfoundland (Kupp and Hart 1976:5). They placed their focus on developing Newfoundland and not Labrador, since they felt Labrador did not offer economic appeal. By the 1630s, Dutch merchants were using more cost efficient cargo ships and gained better access to Spanish trading ports, giving them a significant advantage over other European nations (Cadigan 2009:50). 
The English feared the growing presence of the Dutch in the region prompting fierce competition with the Dutch. English policies, such as the Acts of Trade and Navigation of the 1660s requiring English merchants to use only English registered ships, was a direct economic attack against the Dutch (Cadigan 2009:50). Unable to establish permanent settlements along the Newfoundland coast to compete with the growing English and French presence, the Dutch abandoned their efforts and turned towards developing Labrador.

As the entire whaling industry slowly declined toward the beginning of the seventeenth century, the rise of fishing and trading in the area became increasingly more profitable. The Dutch moved their emphasis from fishing and whaling near Greenland towards developing the industry in Davis Strait. A Dutch charter company was expected to first trade and fish in the Davis Strait before heading south to Labrador to trade with the Natives. The Dutch traders were expected to wait for Inuit if necessary, but they were not to sacrifice a good catch for the sake of the trade (Kupp and Hart 1976:13). ${ }^{5}$ The potential for acquisition of baleen, skins, furs and ivory seemed to overshadow the potential for hostile encounter. The local trade remained profitable and the Dutch continued to trade with the Native groups until the French Revolution (Kaplan 1983:163; Kupp and Hart 1976:10).

Despite the limited documentary evidence available, the Dutch appear to have maintained a prominent presence along the coast in the sixteenth and early seventeenth centuries. Early advantages in trade were quickly thwarted by the English, leaving the

\footnotetext{
${ }^{5}$ Although a distinction between Native groups is never made when discussing trade, it is likely the Dutch are referring to the Inuit given their coastal settlements, as opposed to the Innu who were further inland or the Beothuks who were further south.
} 
Dutch to focus on the trade in Labrador. The little documentary evidence there is suggests that Dutch merchants maintained frequent interaction with the Inuit, although the degree of such interactions is still unknown. The Dutch interest and presence seemingly waned during the latter half of the seventeenth century and their dominance was replaced by a growing French and English presence.

\section{The French}

French explorers and fishermen sailed to the northern waters around Labrador and Newfoundland from Europe during the latter half of the sixteenth century also to participate in a lucrative fishing and trading market. The French recognized the economic potential and political importance of developing a stronghold in the New World. Royal investment in individual merchants sought to establish French dominance, yet turmoil abroad and competition with the English negatively affected French development in Labrador and Newfoundland. France's dominance in the region became limited by the end of the eighteenth century.

The French were one of the first to arrive in Labrador and Newfoundland establishing a fishery by 1504, and expanding to conduct 38 and 61 expeditions in 1559 and 1560, respectively (Pastore 1994:22; Turgeon 1998:590). These numbers marked the beginning of a massive French expansion with the fishing industry as the draw. Approximately 150 French cod-fishing vessels were spotted by English navigator Anthony Parkhurst during a reconnaissance mission in 1578; however, these numbers were likely higher considering Parkhurst probably would not have been able to count the 
inshore fishing boats along the hundreds of miles of coastline (Pastore 1994:22; Turgeon 1998:591).

Nevertheless, the dramatic incursion of the French along the coasts likely led to encounters with Native peoples. Limited archaeological information suggests that Labrador Inuit traveled from northern Labrador to the Strait of Belle Isle and may have encountered Europeans as early as 1500 (Pastore 1994:23). One of the earliest recorded encounters was depicted in a 1566 woodcut of an Inuit woman and her child who were taken from Labrador by French fishermen (Sturtevant 1980). The fact that the fishermen killed the husband before capturing the Inuit woman and her child attests to the nature of Inuit-French relations during this earlier period.

In the early stages, French fishermen concentrated fishing close to shore, catching fish for "wet” and "dry” cures to satisfy a domestic French market. By the mid-sixteenth century, the French included offshore fishing to accommodate an ever-growing domestic and international demand for cured fish. The French continued to expand their enterprise along the northern waters experiencing little friction from English fishermen who also fished similar waters. But the free trade changed by the end of the seventeenth century when French fishers experienced increasing involvement by the French and English governments. The French presence both on and off shore started to impede other European territorial interests in Newfoundland and Labrador, and tensions abroad were played out in the North Atlantic waters.

Warring between the French and English in Europe accounted for some of the difficulties experienced by the French in the New World (Trudel 1978:102). France 
refused to allow many of their fishing boats to sail to Newfoundland for fear of encounters with English warships (Trudel 1978:102). Attacks and counter-attacks between French and English colonies on the coast of Newfoundland resulted in the destruction of many French and English settlements and fisheries and perpetuated a state of armed conflict between the colonial settlers that continued into the eighteenth century (Trudel 1978:102).

Tensions continued to develop between the two countries until the 1713 signing of the Treaty of Utrecht to help end the War of the Spanish Succession. The Treaty gave the British sovereignty over Newfoundland, requiring the French to abandon their Newfoundland settlements and turn over fishing grounds (Kaplan 1983:165; Rowe 1980:314). Forced out of Newfoundland fishing waters, the French turned their attention to developing fishing and trade along the Labrador coast, an area they already knew well.

French familiarity with Labrador was due to expeditions conducted before the establishment of the 1713 Treaty. In 1659, explorer Louis Jolliet surveyed the Labrador coast, traveling as far as $56^{\circ}$ north (Rompkey 2003:23). His descriptions of the land and the Inuit serve as some of the earliest accounts of Labrador Inuit life. In addition to describing cold-season sod houses seen along the coast, he presented an image of Inuit being well supplied with European goods, such as wooden boats with sails, screws, nails, knives and cloth. He felt that the Inuit practiced a duel economy based on local subsistence and European trade (Delanglez 1948). The wide array of European commodities led Jolliet to assume the Inuit did not have regular commercial relations 
with any single European group, but traded with all the Europeans in the region (Kennedy 2009:31).

Jolliet had his first encounter with Inuit in July of 1647 and according to historian John Kennedy’s interpretations of Jolliet's letters, it was quite clear that the Inuit were experienced traders (Kennedy 2009:31). A small party led by two Inuit men approached Jolliet's boat in large two-mast fishing boat approximately 40 feet long. The trading party encouraged Jolliet to enter the harbor, leaving their guns, bows and arrows at a distance from the transaction where they exchanged European knives for fur pelts (Kennedy 2009:30). Such descriptions by Jolliet showed French traders the potential of a new market in Labrador, a virtually untouched trading and fishing grounds where little competition existed.

Trade opportunities in Labrador accommodated a booming European demand for furs, seal and whale oil, baleen, and whale bone (Stopp 2002). The French recognized that previous interactions between European traders and Native people led to the current hostile situation and tried a different approach. To prevent any disruptions in the trade economy, the early French proved enlightened in recognizing and respecting Native nations, and as allies of the French crown (Stopp 2002). Historical data from 1712 claimed that French authorities expected trade with Inuit to be peaceful and profitable (Trudel 1978:107). The policies seemingly worked as French interactions with Native groups occurred with such regularity that the prominent trade language was French (Cadigan 2009; Patterson 1994:126). 
It isn’t entirely clear how often the French traded with Inuit or if it was always amicable. Letters and memoirs from the early 1700s suggest that Inuit did trade with the French, yet only sporadically (Trudel 1978:107). The King of France in 1734 prevented cod fishing boats to trade with Inuit, claiming that exclusive trading rights were reserved for land grantees (Trudel 1978:107). Furthermore, not all fishermen conducted trade with Inuit in a cordial manner. While some fishermen who settled in the area tried to attract Inuit for purposes of trade, others attacked Inuit to drive them away from their posts (Trudel 1978:108). During the later half of the eighteenth century, relations had declined so rapidly that French sailors were told to shoot Inuit on sight (Palliser to Lord Hillsborough, 20 Oct 1768, Pro, CO 194/28, fos 25-6; Memoirs of James Haven 465n).

The historical documents also vary in how Natives were described, with some praising their cooperation and others describing the Inuit as "extremely savage, inapproachable, ferocious and cruel, fleeing at the sight of Europeans and killing them whenever they can” (PAC, MG1, C11A, Vol. 109:58). With such dissimilar approaches, it’s no surprise Inuit were hesitant or aggressive with the visiting French.

Nevertheless, the French continued to develop shore-based fisheries into the eighteenth century with the hopes of entrenching their position and further regarding the Inuit trade industry. The first of such expeditions was made by explorer and Canadian grantee Augustin Le Gardeur de Courtemanche in 1702 (Gosling 1910:131). As part of a larger French plan to establish permanent settlements, seasonal fisheries, and trade with the Inuit, Courtmanche was granted a ten-year concession for land spanning from the north shore of the St. Lawrence to Hamilton Inlet (Rompkey 2003:24). Courtemanche’s 
idea was to develop an independent fishery and Native trade, despite expressed fears by local fishermen of Inuit attacks. He made it his personal enterprise to make peace with the Inuit and garner respect by establishing himself as a dominant figure prepared to defend coastal fishermen and himself against attacks (Gosling 1910:134).

Courtemanche believed the success of a French industry in Labrador rested on both the successful development of the fishing industry and building amicable relationships with Native groups, especially the Inuit. He felt that preventing conflicts between Inuit and European fishermen would contribute to France’s commercial success. By developing a positive and friendly trade environment for Inuit, France would gain access to valuable goods, such as skins, furs, ivory, oil and feathers, as well as the everimportant fishery. Such access would give France significant economic advantage over other European countries that maintained the area was dangerous (Gosling 1910:141).

Other French merchants echoed Courtemanche’s belief arguing that the best way to optimize trade with the Inuit was by civilizing the Inuit. This sentiment was articulated in an anonymous French memoir from 1715 concerning Labrador:

The Esquimaux, if civilized, will render important services to the French through the fishery and by the chase they carry on in their country, they being very adroit both in the one and in the other. They will bring skins, furs, walrus tusks, fish-oils, eider-down, feathers for beds, having on their coast an infinity of birds with fine and very good plumage. Thus the Esquimaux will contribute to render commerce on the Labrador both large and lucrative for the establishments in these countries. I forgot to say that it is necessary to use every conceivable means to induce them to come and establish themselves in villages near the French, the advantages of which, both for themselves and the French, it is unnecessary to detail, as they can be sufficiently appreciate. Their proximity need not be feared, as they are not warlike but lazy and timid. (Anonymous Memoir 1715, p. 3698 in Zimmerly 1975:46-47) 
Courtemanche agreed claiming that it would open opportunities for industrial development in Labrador, and strongly advised the French government to develop additional settlements along with agricultural and resource exploration along much of Labrador's coast.

After Courtemanche’s death in 1717, his son, François Martel de Brouage, tried to continue his father's legacy of promoting trade with the Inuit by appealing to French authorities to forbid captains to trade firearms with the Inuit. His appeals were successful and in 1734, an ordinance was passed instructing traders not to trade firearms, ammunition or alcohol with the Inuit or be liable to a fine and imprisonment. This measure seems to have positively affected French-Inuit relations over the next two decades (Auger 1989:35). However, French-Inuit trading never fully developed into a stable financial market and Inuit aggression continued be a burden.

In 1743, French merchant Louis Fornel sought to further expand French fishing stations in Labrador and undertook a bold expansion. He led an expedition north traveling as far as Hamilton Inlet, and engaged Inuit in trade. Fornel had trepidations given the Inuit reputation for attacking and murdering Europeans, and remained cautious during all encounters. His diary details his first encounter with Inuit in Hamilton Inlet revealing the apprehension of the entire crew as well as the Inuit fear of the Europeans.

Having shifted our anchorage, we then put our artillery in readiness and prepared our arms in order to be always on the defensive in case of an attack, and to avoid being taken by surprise during the night. Not venturing to board us, the said Eskimaux landed on a neighbouring island where they uttered cries, raising their oars and saying in their jargon, "Tout Camara Troquo balena, non Characo", which means "No war, I am your comerade, let us trade whale"....Three Eskimaux then jumped into their canoes and came on board where they showed us great affection. I 
remarked that the presence of our small artillery and of our arms frightened them to such a degree that all their bodies were trembling for fear of them and to such an extent that they naturally bled from the nose without striking themselves, which I found very queer. I had some gifts distributed to them, which seemed to please them. (4 July 1743 from Narrative of a voyage by Sieur Louis Fornel to La Baye des Eskimaux, 16 May to 27 August 1743 in an English translation of the Original French Narrative from Documents of the Enquiry into the Labrador Boundary by the British Privy Council)

Despite his apprehension, Fornel remained successful in trading with Inuit and opened additional trading posts at North West River and Rigolet that same year (Kaplan 1983:167; Rompkey 2003:24).

The hostile environment that led to Europeans taking up arms upon seeing Inuit was due to a complex situation that involved competition over seal resources and territory. First, fishermen established settlements on Inuit hunting grounds and took away a valuable and fundamental Inuit resource. They believed Inuit were savages and murderers and felt the need to protect their sovereignty by killing the Inuit indiscriminately. Settlers and fishermen ignored recently passed French guidelines recognizing aboriginal rights and fair and proper treatment of Inuit (Jaenen 1991:35; Kaplan 1983:167; Trudel 1978:105, 118). In turn, Inuit attacked French establishments, raided supplies, destroyed cabins and murdered Europeans (Kaplan 1983:167). The situation grew to such an extreme that the French commandant station in Labrador, Augustin Le Gardeur de Tilly, Sieur de Courtemanche noted in 1705 that "According to the Savages, the Eskimos made the Europeans leave” (Barkham 1984; Proulx 1993:21). The Inuit who moved south to access French trade in Hamilton Inlet encroached upon Innu territory. The Innu and Inuit had a violent rivalry extending prior to the arrival 
of the Basque. Oral histories suggest that the animosity and bloodshed between the two groups spilled over at Eskimo Island located in Hamilton Inlet possibly continuing into the late-eighteenth century (Rompkey 2003:25). As a result of the developing fisheries and increasing competition with Innu, some Inuit returned north while the Innu withdrew into the interior.

Events across the Atlantic Ocean also affected the Labrador and Newfoundland trade. The French were drawn into the Seven Years War between Prussia and Britain, which eventually made its way to the North American shores between 1754 and 1763. Later called the French and Indian War, French forces allied with various Native American groups to fight against the English, who were trying to expand their territory along the entire Eastern seaboard from Newfoundland to Georgia. France ultimately lost possession, resulting in England's conquest. The shift in power marked by the Treaty of Paris signed in 1763 changed the commercial landscape of Newfoundland yet again, affecting France's hold on Canada and North America and its significance as a colonial power.

The Treaty left France with fishing rights around Newfoundland and denied access to Labrador, resulting in a decline in France's presence and influence in the region (Auger 1989; Rowe 1980; J. G. Taylor 2009:87). Other national and international conflicts such as the American Revolution (1775-1783) and the French Revolution (1789-1799) required attention drawing both financial and labor resources away from the Labrador and Newfoundland market. As the French retreated, the English increased their involvement in the fishing markets and militarily prevented French merchants from 
trading trade with Inuit (Auger 1989:35). Yet the English newcomers could not communicate with the Inuit as the French before them had, which led to misunderstandings and the return to a cycle of violence.

Nevertheless, France maintained fishing and trading industries in Labrador given its economic promise. The signing of the Treaty of Paris in 1814 after the Napoleonic Wars reinstated France's rights to the Newfoundland/Labrador fishery. The restoration of the French Shore along southern Labrador gave the entire Labrador fishery an economic boost in the nineteenth century (Gosling 1910; Hutchings and Myers 1995:52). French harvests composed $27 \%$ of the entire Newfoundland fishing industry and rose to almost 50\% of the total catches in Labrador and Newfoundland by 1890 (Hutchings and Myers 1995:52). France remained a prominent component of the southern Labrador and the Newfoundland fishing industry until 1904, when it finally relinquished the shores to Newfoundlanders (Hutchings and Myers 1995:52).

France’s economic ability to maintain a presence in the Labrador and Newfoundland fishing industry fluctuated throughout the centuries as a result of internal and external political conflicts. The French quickly recognized the economic significance of developing a trade with the Inuit and tried to encourage a civilized engagement with all Native groups. A rise in Inuit violence towards French merchants likely led to the belief held by many Europeans that the Inuit were a hostile group, and continued distrust between the two groups grew. Attempts to develop friendly trade with the Inuit were made by independent merchants, yet the absence of that sentiment among 
other French fishermen eventually returned the prevailing social interaction to one of hostility.

\section{The New Englanders}

A neglected chapter of Labrador and Newfoundland maritime history lies in the exclusion of a New England fishing and trading industry. New Englanders fished in waters along the east coast of Newfoundland and later along the south coast. They developed a trade with Native populations and settlers as early as the 1640s, maintaining a presence until the Revolutionary War (Kennedy 1995:47). The profits coming from the large numbers of New England whalers who hunted in the Gulf of St. Lawrence and in the Strait of Belle Isle helped fund the newly formed American Colonies (Gosling 1910:6; Kennedy 1995:44). However, continued tensions with England and poor relations with Native peoples led New England fishers to withdraw from the region by the mid-nineteenth century.

The 1630s marked the beginning of New England's link with Newfoundland as ships from Old England to New England often stopped at Newfoundland (Pope 2004:151; Prowse 1895); however, New Englanders did not extend into Labrador until the eighteenth century. A steady and prominent trade developed by 1652 between New England and Newfoundland, and there was no need to expand these markets into Labrador until the signing of the Treaty of Paris (1763), when Newfoundland fell completely under British control (Prowse 1895:153). 
Growing tensions with the American Colonies led the British to try to limit the New England presence along their Newfoundland shores. As a result, the New Englanders moved their fishing enterprises to southern Labrador because they knew that it was relatively ungoverned, thereby deliberately violating newly instituted British policies (Rompkey 2003:27). The British quickly recognized the New Englander’s financial and strategic advantage by maintaining a near monopoly of the southerly Labrador waters and moving to exclude them from the fishery entirely.

The newly appointed English governor of Newfoundland, Sir Hugh Palliser, sought to control the flux of American whaling vessels that fished in British waters illegally and interfered with the British trade. Apparently, the New Englanders were aggressively seeking to obstruct the British fishery by illegally fishing for cod, selling to the French, and destroying British shore facilities (Rompkey 2003:27).

Another one of Palliser's concerns revolved around the New Englanders' harsh treatment of and attacks on the Inuit since it directly affected the British interest in developing a trade (Innis 1940:70; Kennedy 1995:49). Palliser believed a strong and successful British industry in Labrador and Newfoundland required establishing friendly relations with Inuit. Governor Palliser wanted to limit the New Englanders’ attacks on Inuit, end destruction of British property, and prevent New England fishers from selling cod to the French on the French Shores (Gosling 1910:329-330; Rompkey 2003:27; Whiteley 1964:39). In a 1765 letter to the British Board of Trade, Palliser argued that "strict measures must be taken for preventing [the Americans] doing mischief on the 
coast and from carrying on the cod fishery in the government, which is ruinous to the British cod fishery” (Palliser 1765).

Peace talks between the Americans and the British after the American Revolutionary War repaired much of the resentment caused by Palliser. The 1783 Treaty of Paris permitted American fishers to fish, dry and cure fish in parts of Labrador and Newfoundland that were once British territories (Kennedy 1995:49). The signing of the Treaty also gave New Englanders unrestricted rights to much of the Newfoundland coast. In return, the Americans agreed not to interfere with the fisheries along the French Shore located on the western shore of Newfoundland (Gosling 1910:10-11; Kennedy 1995:49).

The Americans remained a prominent element of the Newfoundland fishery well into the nineteenth century, as an estimated 2,500 American ships continued to fish off the coast of Newfoundland in the Grand Banks. Although that number declined to 530 vessels by 1820, the Americans remained productive by taking 530,000 quintals ${ }^{6}$ of fish compared to the 134,000 quintals taken by Newfoundland and English ships that same (Rowe 1980:469; Tocque 1895:254).

However, such growth proved unsustainable. Depleted fishing stocks and new tensions with Newfoundlanders over access to fishing grounds led New England fishers to withdraw from the region. By the 1840s, American prominence in the Labrador and Newfoundland fishing and trading industry was all but absent (Kennedy 1995:59).

New England played a significant role in the global prominence of the Labrador and Newfoundland fishery and trade markets in the seventeenth and eighteenth centuries,

\footnotetext{
${ }^{6}$ A quintal is equal to 100 kilograms or 220.5 pounds.
} 
linking the North Atlantic and New England economies (Pope 2004:150). Yet the regulations instituted by the British after 1763 appear to have enhanced general hostilities in the area. New England attacks on British fishing stations and aggression toward the Inuit appear to be part of a larger attempt to impede the British industry. Although the American presence in the region declined, the tension created with the British and Inuit added to the overall hostile environment.

\section{The English}

The arrival of the English in Labrador and Newfoundland added yet another level of competition to the region. Like the Europeans before them, English interest in eastern Canada began in the late fifteenth century with an attempt to locate the Northwest Passage. Despite their failed attempts to identify a thoroughfare to Asia, the English realized the region's economic and strategic potential for themselves. Soon thereafter, droves of fishers and traders arrived along the coasts of Labrador and Newfoundland and attempted to develop their own independent market.

The earliest explorer credited with identifying Newfoundland on behalf of England was Venetian navigator Zuan Cabotto, better known as John Cabot (Pope 2004:13). Cabot explored the eastern coast of Newfoundland and parts of Labrador in 1497 for the English King Henry VII and a group of Bristol merchants interested in trading opportunities. Cabot's diaries offer some of the earliest descriptions of the region, including the presence of fishermen, perhaps the Basque, already visiting the area. 
Recognition of the trade potential with Native populations did not occur until some time later, as contact with Inuit did not happen until almost half a century after discovery. The first documented Englishman to contact Inuit of Baffin Island was Sir Martin Frobisher who originally sailed the northern waters in 1575 to 1578 in search of the Northwest Passage. While sailing down a strait he thought was the Northwest Passage, Frobisher came in contact with Inuit. Initial interactions between Frobisher's crew and the Inuit were friendly but turned violent when Inuit, seemingly unprovoked, killed five of Frobisher's men. The incident offers a clue to the state of affairs already present between Europeans and the Inuit in the late sixteenth century (Fitzhugh and Olin 1993).

Frobisher returned to England immediately, but he was not empty-handed. During this trip, he picked up a stone that he thought contained elements of gold. His serendipitous find spurred on a new period of interest for continued explorations in Labrador (Gosling 1910:104). Although a series of expeditions in search of ore sailed after Frobisher’s discovery, no more gold was found (Fitzhugh and Olin 1993).

The exploration generated new pronounced efforts for colonization by the English (Gosling 1910:108). Having lost several thousand pounds to Frobisher’s expeditions, Queen Elizabeth reconsidered her rights to industrial investment in the New World and thought permanent settlements might serve a better economic and political need. Attempts to sail to Newfoundland and establish a colony began in 1577 . None succeeded until 1583 when Sir Humphrey Gilbert established St. John’s, Newfoundland as the first English possession of land on the American continent (Gosling 1910:113). Although the 
English did not go further north in Labrador than the Strait of Belle Isle and the area of Cape Charles, the British laid claim to the entire eastern seaboard of North America (Auger 1989:36).

Documentary evidence suggests the English did not enter the Newfoundland fishery until the second half of the seventeenth century (Starkey and Haines 2001:8). English settlement along the northern shores of Newfoundland between 1620 and 1680 allowed for the British to capitalize on the waning Basque whaling industry. By the end of the seventeenth century, the English were well established within the Newfoundland industry only to be eclipsed by the French (Pope 2004:19).

England's initial investment in the industry was small, sending only 11 ships from 1500-1550 to develop the fur trade and participate in the Newfoundland cod fishery. Realizing the economic potential, English investment grew into a full-scale enterprise with more than 150 ships entering the northern waters by 1600 (Hutchings and Myers 1995:48). English proprietors began to settle colonies with the hopes of economic diversification and development of the fishery that would challenge the existing commercial network (Pope 2004:40). By 1660, resident fisherfolk were well established on the English shore and by 1680 resident fishers were catching and processing about a third of the fish exported by the British fishery (Pope 2004:40).

This sudden arrival of English fishermen settling along the Newfoundland shore intensified the competitive atmosphere. The fishery was a common-property resource with unmarked boundaries and unconventional property rights. Competition among all fishermen over access to resources commonly led to conflicts between migratory and 
settled fishermen, where fishermen stole boats or destroyed each other's fishing stages (Pope 2004:71). The disruptive behavior of the immigrants might be attributed to cultural incompatibilities, but the confrontational nature seems to be rooted in the industry (Pope 2004:71).

Adding to the local difficulties, England was engaged in frequent wars with various countries. In 1623, the treaty of war with Spain caused England to place an embargo on fish exports to that country. English civil war and continued conflicts with Spain and Holland during the 1650s further disrupted the fishing and trade industry, with only 43 ships sailing for Newfoundland in 1684 (Pope 2004). By the end of the seventeenth century, the English fishery was on the brink of collapse.

The English shore-fishery began to recover at the end of the 1720s. After the signing of the Treaty of Utrecht in 1713, England gained significant control over the eastern seaboard and established its stronghold in Newfoundland (Rompkey 2003:23). In addition, increasing demand throughout Europe and the development of sedentary fishery allowed the British fishery to return the industry to prominence by the 1760 s.

The tensions among the French, Americans, and British over access to these lucrative fishing and trading resources never receded, however, and also occurred in the lesser known Labrador industry. As discussed earlier, the French, British and Americans attacked and deliberately obstructed each other’s industry. Managing such conflicts was fundamental to ensuring a successful British fishery and became the new English government's main focus. 
Sir Hugh Palliser sought to make Labrador a similarly robust fishing industry as Newfoundland. He believed that maintaining British dominance in the fisheries was vital to the United Kingdom's naval predominance (Whiteley 1964). Palliser wanted to gain control of the area by prohibiting the French from trading with Inuit as well as forbidding the English from attacking the Inuit (Auger 1989:37). In particular, he was concerned about the notoriously poor treatment of Inuit by New England fishermen and whalers. He sought to promote civility between all Europeans and the Inuit because he feared the tumultuous relationship would lead to the demise of the British fishing industry. Palliser strongly believed that a successful fishery was dependant upon Inuit cooperation (Whiteley 1964). He also thought if he could establish friendly relationships with the Inuit and convert them into loyal British subjects (Whiteley 1964:29), the Inuit would not attack English ships and would become allies in a fur and oil trade (Zimmerly 1975:50).

Palliser's efforts toward creating this harmonious relationship only helped to slightly curtail the chaos that prevailed in the Labrador and Newfoundland fishery. For example, after Palliser conducted friendly negotiations with the Inuit by sending a group of Moravian missionaries to question the Inuit regarding their culture (J. G. Taylor 1972), he learned that Massachusetts fishermen were responsible for plundering Inuit sites and murdering Inuit families. He contacted the Governor of Massachusetts in 1766 to express his displeasure with the behavior of the Massachusetts fishermen (Rowe 1980:467). Palliser felt such offenses required regulation. His actions also may have been a response to the smuggling occurring between New England, English and Newfoundland ships. 
The illegal smuggling resulted in approximately $£ 400,000$ of lost revenue for Labrador and Newfoundland by the start of the American Revolution (Rowe 1980:467).

To end the smuggling and aggressive behavior of the fishermen, Palliser set out to enforce new regulations by building Fort York in the center of the action at Chateau Bay in 1767. The fort was not well received by many in the region including the Inuit, who attacked the fort soon after it was built (Rompkey 2003:27). The English and French Canadian, and New England fishermen also felt the policies restricted their rights to trade and fish. Their outright opposition resulted in fort closure 12 years later (Auger 1989:37; Gosling 1910:191; J. G. Taylor 1974:21).

While government officials had limited success reaching out to Inuit for the purpose of trade, independent merchants succeeded far better. Englishman Captain Nicholas Darby established a whaling fishery in 1765 on Seal Island, Cape Charles near the southern end of Labrador (Kennedy 1995:26). Darby employed Inuit as whalers, hoping to civilize the Inuit (Kennedy 1995:26). However, other Inuit mistook Darby for a New Englander and focused their raids on his settlement in retribution for New England hostility against the Inuit. The raids continued over the following years, and eventually led to the downfall of Darby’s fishery. Most notable was an Inuit attack after an extremely successful season, leading to damages to boats and equipment in excess of $£ 4000$ (Gosling 1910:201; Kennedy 1995; J. G. Taylor 1974:21).

Despite Darby’s earlier hardships, he returned to Labrador and became involved with net-sealing. He planned to market seal oil through a Quebec merchant. This particular business relationship attracted the attention of British troops, who were 
authorized to prevent any trading with the French. The soldiers seized Darby's merchandise and demolished Darby's entire station and enterprise, leaving him destitute (Kennedy 1995:28).

More successful merchants such as Captain George Cartwright effectively developed friendly relationships with local populations. Originally commissioned by Palliser in 1768 to conduct an exploration in Labrador, Cartwright took over Darby’s abandoned station in 1770 and attempted to establish a salmon fishery and trade with the Inuit and Indians. He remained in the area for 15 years, trading in furs, fish and seals, and maintained friendly relations with Montagnais Indians and Inuit. This was an impressive feat considering the centuries of injustices committed by Europeans (Rowe 1980:468; J. G. Taylor 1974:22). Cartwright’s success emboldened other English and Newfoundland fishers and traders to venture further north along Labrador's coast.

Historian John Kennedy argued that Cartwright played a significant role in moving relations between Inuit and Europeans from hostile to harmonious (Kennedy 1995:41). Cartwright felt the best way to establish a strong trading network with the Inuit required understanding Inuit culture. Many of his early expeditions between 1770 and 1772 offered valuable descriptions of Inuit culture and the coastal trading network. His attempts to understand Inuit culture and the Labrador landscape led him to set up a tent and live among the Inuit for weeks at a time to gain their confidence (Kennedy 1995:42; Stopp 2008:27). This interaction also taught him about building Inuit-style houses, games and religious rites. He felt such information could provide traders with an important foundation for friendly trading. However, Cartwright was also known for 
sexually exploiting Inuit women ${ }^{7}$ and contributing to Inuit taste for alcohol by making it a mainstay at his posts (Kennedy 1995:45).

Despite Cartwright's success as a trader, the increasing presence of other European and American merchants in Labrador impeded his market share. A few years after establishing a trading post in Sandwich Bay in 1775, Cartwright suffered a severe loss of approximately $£ 14000$ when several of his servants plundered his posts and joined a Boston privateer’s crew (Rampkey 2005:33). By 1784, Cartwright was bankrupt and forced to return to England, thus ending his sixteen year tenure in Labrador (Stopp 2008:31).

Cartwright's enlightened approach toward understanding Inuit culture as a means of promoting trade eased many of the tensions built up from the previous years. With Cartwright's absence, however, trading became a dangerous and unpredictable enterprise again. Although trade continued to play a significant part in the economic progress desired by all European nations, the history of hostilities with Europeans ran deep for the Inuit and Indian peoples of Labrador and Newfoundland and attacks began to occur again.

In an effort to ease these tensions, Governor Palliser moved the focus toward encouraging and legislating the development of seasonal fisheries in southern Labrador and confining Inuit to the north. A timely proposal by German Moravian missionaries

\footnotetext{
${ }^{7}$ Evidence suggests Cartwright had an Inuit son. A 1782 Moravian missionary diary from Nain described an account where Inuit who were trading along the south-central coast met Cartwright and saw his son (Stopp 2008:30). Historical archaeologist Marianne Stopp argues that this may have been a misunderstanding, miscommunication or a mistranslation of the true relationship between Cartwright and the boy (2008:30); Cartwright may have been a guardian, rather than a father.
} 
offered to help Palliser reach this goal. The Moravians offered to develop a mission in northern Labrador to Christianize and civilize the Inuit (Hiller 1971a; Kaplan 1983:169).

After a failed attempt by the Moravians in 1752, Moravian missionary Jens Haven revived interest in a new mission to Labrador in 1764 and met with Governor Palliser to seek financial and administrative support. Haven argued that the Moravians’ interest in converting Inuit coincided with Palliser's wishes to moderate Inuit hostilities thereby promoting favorable trade relations. Haven believed trade with Inuit could develop if Inuit were given proper encouragement and tools such as boats, fishing hooks and knives (Whiteley 1964:32). Recognizing the importance of establishing a stable Inuit community and the potential for placing permanent British settlements in the center of that region, Palliser supported the missionary’s proposal.

Despite Palliser's backing, negotiations remained contentious. English authorities were suspicious of the Moravians’ request for 400,000 acres of land (100,000 acres for each of the four settlements) to develop missions and a fishery. They feared it would interfere and compete with the English industry (Whiteley 1964:38). But the missionaries wanted the land-grant to insure their efforts would not be undermined by traders establishing posts in their purview. The Board of Trade, a British government agency that regulated trade, finally honored the Moravians’ request for land in 1769 (Brice-Bennett 1981:18; Hiller 1971a:841; Kaplan 1983:170).

The British maintained a prominent presence in the Labrador fishing and trading industry into the nineteenth century; however, their monopoly in the industry came to an end after the 1770s. The British never sought to establish resident fisheries, which served 
as the crux for the entire Labrador and Newfoundland industry. Furthermore, independent merchants and companies began to take control of the trading industry. Even as their economic standing in the region waned, Britain kept possession of Newfoundland and Labrador until 1949 when they finally became a Canadian province.

England played a significant role in the development of the Labrador and Newfoundland industries. In particular, independent merchants were able to develop working relationships with Inuit. Yet these relationships rarely lasted once the merchant left the area. The English were merely another foreign group whose cultural biases and economic interests added one more layer to a complex cultural entanglement.

\section{Summary}

Europeans who came to Labrador in search of a passage to the Orient found instead a viable economy with fishing, whaling and trading. Through the early historic period, European markets demanded North Atlantic products of fish, baleen and oil, and developed an increasing curiosity about the exotic cultures of the New World. As early as 1578, European ships sent between 350 and 380 ships crewed by approximately 8,000 to 10,000 men to the Labrador and Newfoundland waters (Turgeon 1998:593). This amount of foreign traffic resulting in the introduction of new products undoubtedly created stress for an Inuit social system in flux.

As the European nations met in the Labrador and Newfoundland waters, rivalries heightened. The sudden influx of foreign fishers and traders in the area created a tense situation where survival required gaining the economic upper hand. In many cases, that 
meant deliberate attacks on other Europeans and their Native allies. While seen as a commodity, the Inuit also became a casualty. As a result, Inuit took violent measures to protect themselves against increasingly aggressive European methods to gain access to goods they desired and the Inuit needed, such as seals. The historical and limited archaeological record showed that the European presence dramatically affected Native peoples and their culture. Some researchers argued this sudden rise of Europeans served as the primary reason for supplanting Inuit further north, heightening desire for trade goods, and introducing disease (Stopp 2008:11). Regardless of the specific affect the European presence had on Native cultures, this review has showed the magnitude of the European presence in the Atlantic region. Not surprisingly that presence would affect Native culture and serve as the catalyst for future changes in Inuit culture.

Nevertheless, attempts were made by Europeans to engage with Inuit on peaceful terms. Both the French and English sought to protect Native rights by enacting administrative regulations forcing fishermen and whalers to treat Native peoples civilly even if it was to protect their own trading interests. The best attempts at establishing peaceful trade relations with Native populations were made by independent merchants who saw the potential for a Labrador trade market. For instance, some Basque hunters employed Inuit to hunt whales and protect their settlements. France’s Courtmanche believed in developing a friendly trade environment to access valuable goods. England's Cartwright was arguably the most successful in establishing amicable relations with Inuit by learning about their culture and living with them. Each individual group understood the necessity and profitability of maintaining friendly relationships with the Inuit in order 
to access highly desire goods. Nevertheless, most merchants prioritized economic gains over social benefits, ultimately seeking the means to fulfill their own interests.

The economically competitive setting that developed during the seventeenth and eighteenth century may have expanded the Inuit social order to include trading as an element towards elevating individual status. Understanding this social and economic environment in the early historic period sets the stage for the Moravian arrival and offers hindsight for why the missionaries were successful in converting and trading with Inuit. I turn now to a description of the history of the Moravian church and its presence in Labrador. 


\section{Chapter 4: The Moravian Church in Europe and Labrador}

In this chapter, I focus on three major topics: the development of the Moravian church, the development of the Hoffenthal mission (hereafter identified as Hopedale) ${ }^{8}$ in Labrador, and the economic and social ramifications of mission development on Inuit culture. While the Moravians were similar to European traders in many ways, my intention here is to show how the Moravian missionaries differ from the other Europeans with whom the Inuit are in contact. Understanding the differences will highlight why the Moravians were successful in converting Inuit and influencing grander social change. By tracing the history of the missionaries in Europe and establishing why they chose to convert the Labrador Inuit specifically, I will show how their direct and indirect methods of missionization ultimately led to wide-scale culture change for the Inuit.

The Moravians, or Unitas Fratrum (Unity of Brethren), are Protestant missionaries claiming ties to the fifteenth century reformer Jan Hus. Despite Hus’ public execution in 1415 by the Roman Catholic Church as a message to all Protestant sects, the Moravians remained part of the European religious landscape until the CounterReformation in the 1600s. At that time the Brethren fled to Poland, effectively decentralizing their church. They maintained only a few congregations in Bohemia, Moravia and central European towns. These exiles, known as the "Hidden Seed," were led by Czech bishop John Amos Comenius who believed the church would once again rise to prominence (Hutton 1922:108).

\footnotetext{
${ }^{8}$ Hoffenthal was the original German name for the mission, meaning "the valley of hope.” This name was used until the early 1900s when it was changed to Hopedale, the English version of the name. Known today as Hopedale, I use the English name for sake of consistency throughout the chapters.
} 
Facing persecution, the exiled group of evangelical Protestants from Germany formed a renewed church in 1722 on the estate of Count Nicholas Ludwig von Zinzendorf, a sympathetic Pietist. Under his leadership, the Moravians established a commune near the German-Polish border based on principles they felt all societies should adopt: diligence, work, order and prudence. The Moravians envisioned spreading the Gospel throughout the world and they became one of the first Protestant churches to promote foreign missions when they established themselves in the West Indies in 1732. Their success at converting slave and indigenous populations led to a global expansion that included Greenland, the United States, Central and South America, Tibet, India, South Africa, and Labrador.

I begin with the origins of the church abroad, as it establishes the foundation for the economic and social reasons for Moravian settlement in Labrador in 1771. In discussing the development of the Moravian missions in Labrador, I will focus on Hopedale, the third mission established along the coast in 1782. Initially, the Moravians approached the Native Inuit in Labrador by offering to bring them salvation without changing any aspect of Inuit culture. However, the missionaries quickly realized that converting Inuit required dismantling their existing ideological system and limiting Inuit contact with non-Christians, as well as other European traders. I will trace the Moravian church’s systematic campaign to persuade Inuit to convert to Christianity by undermining Inuit spiritual authority and gaining control of their access to European manufactured products. 


\section{Zinzendorf and the Development of the Moravian Brethren}

Count Nicholas Zinzendorf offered asylum to exiled Moravians in 1722 at his estate in Berthelsdorf, Germany. They called their new home Herrnhut, meaning "in the care of the Lord” (Sensbach 1998:24; Sommer 2000). Originally, Count Zinzendorf offered shelter only, but he eventually became responsible for refashioning the settlers into a global missionary force (Sensbach 1998). Some of the doctrines Zinzendorf established are still followed by Moravian congregations today. In this section, I study Zinzendorf's influence on the formation of the Moravian church in Germany and England during the early eighteenth century. The principles established by Zinzendorf remained fundamental to all future missions, especially that in Labrador.

Zinzendorf's religious beliefs as a Lutheran were closely aligned to those of the Moravians, particularly regarding one’s relationship to God. Both Zinzendorf and the Moravians believed religion was a personal matter and that individuals should experience God with their heart, rather than through rational understanding about God (Sensbach 1998:25). Zinzendorf felt that this relationship was essential to becoming a Christian and could be achieved by everyone. He undertook an active role in the overall social, cultural, and economic reorganization of the Moravian church by providing detailed clerical instructions for the congregation to follow.

First, Zinzendorf drew up a list of 42 statutes regulating social, religious and economic conduct under his patronage (Sensbach 1998:25). He recommended the creation of a Council of Elders who would oversee these spiritual activities (such as ensuring the strict separation between single people of the opposite sex) and approve 
marriages and most economic endeavors. The regulations called for the creation of a rigorous community organization with hierarchical social controls, with Zinzendorf at the top. These principles reflected Zinzendorf's vision that the group’s identity outweighed the individual's. As a community, together they would pursue the common goal of serving Christ (Lewis 1985:36; Sensbach 1998:26).

In addition, Zinzendorf created a significant economic institution called the General Economy, which he envisioned would reduce the church's exposure to exterior influences and thereby ensure spiritual purity. Zinzendorf visualized a self-sustaining economy with the church community divided into groups according to the various trades that provided the settlement with all the basic necessities: food, clothing and housing (Gollin 1967:148). If the Moravians could remain self-sufficient and establish a degree of independence from the outside world, he felt they would be removed from state obligations or colonial interests. This independence would allow the Moravians to pursue their religious goals without the intrusion of non-Moravian resources and influences (Gollin 1967:149). From inception, the settlement was expected to strive for economic self-sufficiency.

Zinzendorf also guided the community to become more open in its acceptance of other denominations. His willingness to admit new dominations led to rapid growth at Herrnhut as the settlement became a haven for all persecuted Christians. Inspired by their ability to unite disparate groups under the name of Christ, the Moravians believed that especially through foreign missions they could pursue their fundamental objective of 
spreading Christianity around the world and bringing salvation to individual souls (Hiller 1969:10).

Zinzendorf's visit to Copenhagen in 1732 sparked the beginning of global mission work. During this visit he met Antony Ulrich, a converted African slave from the West Indies. Ulrich spoke of his sister and brother, both of whom were slaves on the Dutch island of St. Thomas, and their desire to learn Christianity (Hutton 1922:161). Impressed with Ulrich’s account, Zinzendorf returned to Herrnhut with renewed conviction to pursue foreign mission work. Later that year, two Moravian volunteers sailed for St. Thomas, thereby becoming the first Protestant church representatives to establish foreign missions.

Mission work was done out of a concern for the salvation of those who might otherwise be forgotten, such as African slaves in the Colonies and Native North Americans. The ultimate goal of the Moravian mission was to teach Christianity to the heathen. Converts were not necessarily expected to become members of the Moravian church, but simply to become Christians (Hiller 1971a:13). The Moravians were not the first to pursue mission work; unlike other missionaries of the time, however, the Moravians’ explicit goal was not predicated on transforming every aspect of local indigenous culture or tied to economic or political colonial endeavors.

The missions eventually created financial challenges for the church. Due to Zinzendorf's belief that missions should remain sovereign, missionaries were expected to follow the General Economy model and remain self-sufficient without engaging in business with non-Moravians (Rollmann 2009a:58). The idea was to teach the heathens 
the importance of good work ethics by working for their own living (Weinlick and Frank 1989:79). Even as each mission maintained separation from external economic sources, they relied heavily on the main Herrnhut church for financial support, thus placing a significant burden on the German church. Reported annual expenses for foreign missions increased from $£ 3,000$ in 1800 to $£ 83,000$ by 1898 (Hutton 1922:488). The German church did not always have the finances available, thereby requiring individual missions to incur debt with local traders which they, in turn, passed on to the church.

To help alleviate the financial strain and allow the missionaries to focus on their evangelical activities, the Moravians established three societies: the Dutch “Brethren’s Society for the Spread of the Gospel among the Heathen” founded in 1738, which sent parcels to Surinam; the English "Society for the Furtherance of the Gospel” founded in 1741, which sent parcels to Labrador; and the American "Society of the United Brethren for Propagating the Gospel among the Heathen” founded in 1745, which sent parcels to the West Indies (Hutton 1922:189). Each society supplied specific foreign missions with food and clothing and helped raise public interest and support for the church's missionary work abroad.

With the new societies established, the Moravians sought to expand their mission development to include Greenland, South Africa, and North America. Their interest in pursuing missions in North America led them to seek connections with the Church of England in London. The Moravians sought recognition and blessing from the Church of England's archbishop, which they felt would make it easier for missionaries to enter the Colonies and establish settlements (Podmore 1998). Zinzendorf also hoped to establish a 
Moravian world headquarters in London since it served as a crucial location between the Continental and New World settlements, which included Labrador (Podmore 1998:228). During Zinzendorf's repeated visits to England from 1737 to 1745 he developed contacts that benefited missionaries in the English colonies and strengthened the church’s popularity in England (Podmore 1998:27, 2007:34).

As Zinzendorf hoped, the English church played a prominent role in the development of foreign missionary activities. In particular, the new Society for the Furtherance of the Gospel (hereafter SFG) based in England helped garner financial and emotional support for the Moravian missions prior to and during their time in Labrador (Hiller 1978:17). The SFG also held monthly meetings to collect funds and report on missionary activities worldwide. Initially the SFG played a minor role, but by the end of the eighteenth century it oversaw all missionary activities in Labrador.

The German Moravian church’s new presence in English religious life brought prominence along with criticism and opposition. The church faced a scandalous accusation in 1753 when a prominent Methodist leader accused Zinzendorf of unscrupulous and dishonest business dealings. Embarrassed and humbled by the scandal, the English Moravian church secluded itself, choosing to focus its efforts on new missionary endeavors abroad instead of further English expansion. New congregations did emerge throughout England in 1755, but the emphasis was placed on chapel congregations instead of entire English settlements. The SFG also sought to "renew and reform” itself in order to play a more active role in the direction of the church and its missions (Hilller 1978:18). 
Despite the common theological connection between the English and German Moravian churches, cultural differences led to the formation of two vastly different approaches to church and mission development. Moravian historian Colin Podmore (1998, 2007) has argued that the two fellowships fundamentally differed in their world view such that the English libertarian spirit conflicted with the authoritarian German leadership. As a result, the German and English fellowships never fully united.

The English Brethren's distrust of Zinzendorf after the crisis of 1753 led the congregation to withdraw from the German church and downplay his role in the development of the Moravian church in England and at certain missions. They dismissed many religious features associated with Zinzendorf (Podmore 2007:50). Although the English church always considered itself part of the Moravian church, its disillusionment with Zinzendorf influenced the future direction of the English church and many of its missions, including those in Labrador. The English church took responsibility for most of the economic matters of the mission particularly relating to trade, while the German church directed all matters of faith.

Zinzendorf's death in 1760, following the scandal in 1753, ushered in a new era of leadership in the Moravian church. The eventual successor to Zinzendorf, August Gottlieb Spangenberg, took measures to restore the church’s good name and inspire confidence both within and beyond the congregation (Mason 2001:11). Spangenberg implemented a range of reforms that abandoned many of Zinzendorf's previous methods, resulting in a redirection for both the English and German churches. For instance, the German church was led by a unified central authority rather than a single individual, and 
an emphasis was placed on promoting mission work as a method of regaining worldwide respect.

Spangenberg believed one way to generate widespread respect was by creating a collective leadership rather than maintaining concentrated authority in a single voice. He helped form the Unity’s Elders’ Conference (UEC), a collective leadership of 12 elected Elders to oversee, direct, and administer all general affairs of the Unity (de Schweinitz 1859:86). The UEC was a centralized authority that took a more democratic approach toward handling church policies and issues than had been evident under Zinzendorf's rule.

The UEC also oversaw all publications to avoid any future offenses as experienced in the period prior to 1753. The church originally published very little about the mission except for a few letters and German journals (Mason 2001:17). David Cranz’s book published in 1765 about his year working with Greenland Inuit sparked a new potential for positive publicity about foreign missions. In it Cranz reported on Moravian efforts to reach out to isolated heathens overseas, and received much praise from Zinzendorf critics (Mason 2001:17). The feedback signaled a shift in public perception and encouraged the church to invest in more publications. As a result, the church published the Periodical Accounts Relating to the Missions of the Church of the United Brethren, Established Among the Heathen, a collection of summaries of life at foreign missions in 1790. The Periodical Accounts helped the church garner moral and financial support from congregations and private individuals, and became a prominent means of communication for the Moravian church. 
While the Moravian church changed significantly after Zinzendorf's death, many of his ideas about a structured religious community remain embedded in the church's fabric. Although Spangenberg reorganized and redirected the church’s focus, he maintained Zinzendorf's goal to bringing the Gospel to previously forgotten peoples.

\section{The Labrador Missions}

The Moravians began their missionary endeavors in the 1730s but did not settle Labrador for another fifty years. They first focused on developing missions in the West Indies and the new American Colonies. The rise of a fishing and trading industry in Newfoundland and Labrador, and an opportunity to bring the Gospel to an otherwise ignored indigenous community eventually enticed the Moravians to pursue developing missions in Labrador in the 1750s.

The Moravian interest in Labrador originated with exploration by Johann Christian Erhardt, a German mariner and Moravian missionary. Erhardt learned to appreciate Inuit culture — including learning Inuktitut — during his time as a missionary at the Moravian's second mission in Greenland in 1747 and 1749 . He was convinced that the Labrador Inuit were “one nation with the Greenlanders” (Ellis 1748). His conviction that the two groups were related originated from the accounts of explorers in search of the Northwest Passage. Their writings described North American Inuit as having similar cultural features, and clothing and language the same as those from Greenland (Rollmann 2009a:56). Erhardt recognized that their Greenland experience presented the Moravians 
with a unique advantage. Knowledge of Inuit language and customs provided them with access to Inuit who otherwise did not have contact with missionaries.

In 1752, Erhardt and four other missionaries set out to establish a mission to the Inuit on the central Labrador coast. They built the first mission house in Nisbet Harbor, Labrador (Cary 2004). Erhardt assumed that the Labrador Inuit would receive the Moravians with similar excitement as had their Greenland brothers; however, the missionary and his crew were killed by a party of Inuit during their attempt to establish a settlement in Labrador. Zinzendorf was never in full support of the expedition due to the missionaries' intention to include trade in their evangelical endeavors, and the failed voyage simply reinforced his doubts (Hiller 1967:36). Tales of the massacre followed by the outbreak of the Seven Years War in Europe extinguished any enthusiasm for developing Labrador missions.

The church reconsidered renewing the Labrador project after Zinzendorf's death in 1760 and at the end of the Seven Years War in 1763, when Labrador and Newfoundland were claimed by the British. The Moravians’ pursuit of Labrador missions played a part in their attempts to improve the church's standing in England and worldwide. Success at the Labrador missions could restore the church's reputation which had declined, and encourage Protestantism in the new colonies.

The Labrador initiative was renewed by another Greenland missionary, Jens Haven, who felt compelled to spread the Gospel to the Inuit nation and continue Erhardt's goal of developing missions there (J. G. Taylor 2009:88). With the help of Moravians in England and the SFG, Haven proposed the idea of a new mission to 
Commodore Hugh Palliser, the newly appointed British Governor of Newfoundland in 1764.

Both the British and the Moravians actively sought to develop Labrador, but for different reasons. The Moravians wanted to bring religious enlightenment to the Inuit. The missionaries felt that by living with the Inuit, they also could teach them to be honest, obedient, industrious and loyal to the British government (Hutton 1922:171). Governor Palliser wanted to develop the Newfoundland trading and fishing industry into Labrador but found the region a hostile environment. The British and Moravians both thought that introducing Christianity, they could curb Inuit hostilities, develop the Inuit trade, and help build a successful English fishery along the Labrador coast (Mason 2001:30). Their similar interests made them convenient partners for introducing Christianity in the region.

With Palliser's assistance, Haven arrived in the Strait of Belle Isle in 1765 and met his first Labrador Inuit. According to Haven’s diary of the account, an Inuk paddled his kayak into the harbor in search of another captain (Haven 1797). Haven spoke to this Inuk in the Greenlandic language and told the surprised man that he was a friend who hoped to speak with more of his countrymen. Once the Inuit returned with more countrymen, Haven reappeared dressed in Greenlandic Inuit clothing. Upon seeing him, the Inuit cried, “Here is an INNUIT (or countryman of ours)” (Haven n.d.).

Because of his willingness to engage Inuit in their language and dress, Haven enjoyed a special dialogue with the Inuit that did not extend to all Europeans. The Inuit disassociated him from his European shipmates and their material belongings, and saw 
him as a friend. Haven even visited Inuit in their homes despite his fear of facing a similar demise to that of his predecessor, Erhardt (Hiller 1967:41). Haven understood that by approaching the Inuit in this way, he might become incorporated into their culture, something other Europeans had less success accomplishing because of their unwillingness to accommodate other worldviews.

Haven’s approach exemplified many of the Moravian ideals of mission development as laid out by Zinzendorf. The missionary’s explicit goal was not predicated on transforming every aspect of local indigenous culture; instead, the intention was for the Inuit to remain self-sufficient and maintain many of their traditions, including hunting, dress, and diet (Brice-Bennett 1981). The Moravians hoped the Inuit would use Christianity to fulfill their religious and spiritual need, while maintaining other Inuit traditions (Schattschneider 2009:144).

The Moravians were also aware of British economic interests and conducted a study of the potential for trade development among the Inuit. Upon Haven's return to St. John's, Newfoundland, he sent the report to Palliser. Although an established market with the Inuit did not exist at the time, Haven believed that with a little encouragement the Inuit could be a source of commerce (Whiteley 1966:32). Haven followed up on this economic report with a questionnaire to identify elements of Inuit culture in 1765 that would support trading activities (J. G. Taylor 1972). The questionnaire collected answers from a small group temporarily encamped at Chateau Bay in southern Labrador. While it did not offer a complete picture of Inuit culture, the questionnaire identified possibilities for trade, mainly fish, whale and seal oil, in exchange for boats, fishing hooks, needles, 
and knives (Whiteley 1966:33). After hearing and reading about Haven's success,

Palliser sent a positive report to the Board of Trade, which was responsible for

overseeing the United Kingdom's trade endeavors.

Despite the favorable report, the Board of Trade was slow in granting permission.

The British were suspicious that the Moravians would develop a trade monopoly with the Inuit. Their mistrust originated from additional Moravian requests for land grants along the Labrador coast totaling 400,000 acres, and a petition to acquire the same rights as British subjects to trade and fish. The Moravians argued that the quantity of land was “only in order to keep Europeans at a distance \& to give Room enough for all the Eskimaux to be at Peace \& in quiet in the Land that they might be induced to settle near the Missionaries, which would be the only possible means, according to [their] many years Experience of doing good effectually” (Benham 1856).

Once assured that the Moravians would not seek a monopoly and would allow English traders who "conformed" to their regulations to use their harbors, the Board of Trade granted the Moravians permission to establish their first mission on May 3, 1769 (Mason 2001; Petition of Moravians to the Board of Trade. PRO, CO 194/16 (pt 1), fos 81-5. February 23, 1765). The Moravians met with two prominent Inuit leaders, Tuglavia and his wife Mikak ${ }^{9}$ who helped the missionaries identify their future settlements and were

\footnotetext{
${ }^{9}$ Mikak played a fundamental role in the establishment of the Moravian missions in Labrador and influencing Inuit acceptance of the Moravian missionaries (Stopp 2009). The daughter of a prominent shaman, Mikak's first encounter with the Moravian missionaries was when her family invited the missionaries, Jens Haven and Christian Drachart, to stay with them in 1765 (J. G. Taylor 1983, 1984). Later, she traveled to England with her children, in 1768 after being captured by the English at Fort York. While in England, she learned how to read and write and was a prominent proponent for the establishment of a Moravian church in Labrador (Petrone 1992:52). She was an object of great curiosity in England; there was a portrait painted of her wearing extravagant dresses and jewels (Cadigan 2009:68). After returning to Labrador in 1769, she helped the Moravians raise funds and establish their first mission at Nain
} 
helping the Moravians locate and settle their first mission in November 1771, called Nain, and later Hopedale (Rollmann 2010:19).

Before building their mission, the Moravians proceeded with a systematic purchase of land from the Inuit. They first sought verbal permission from local Inuit to purchase their land and move among them, followed by missionaries documenting the men's names as proof of purchase in exchange for gifts such as fishing hooks (Rollmann 2009b:118). The document was intended to serve as a reminder to future generations that the land had been bought. To further demonstrate legal purchase, the Moravians made an announcement declaring full control over the land, including reserving the right to prohibit individuals to live among them who did not meet their ethical qualifications. This final act included a solemn ceremony during which two boundary stones were strategically placed to delineate their land, thus marking the area Moravian.

The events were intended for two audiences. First, the Moravians used the ceremony as a way to prove to the English government that they were a prudent and legitimate group. Second, it was an overt cultural demonstration of Moravian power and ownership. It served to define what was considered proper, legal and Christian versus what was improper, unlawful and godless.

It is impossible to discern whether the event held similar importance for the Inuit; however, it did mark a clear shift in the way the Moravians decided to approach the Inuit and their conversion. Haven took care to be more sympathetic to the Inuit by dressing in 
their clothing and speaking Inuiktituk, but later, the Moravians made no similar effort during their claim of the land.

Historical documents fail to record Inuit impressions of the events or how the introduction of foreign concepts such as private property and ownership clashed with Inuit communal organization. Inuit culture practiced a belief of distribution of food and tools, especially during times of need. There was no single owner of an object; rather tools and food were distributed throughout the community according to one's role in the household, during the hunt, or in times of need (Graburn 1969). The European notion of ownership countered this collective aspect of Inuit culture. Regardless of how it was interpreted, the ceremony marked the beginning of a complicated relationship between the Moravians and Inuit that led to future miscommunications.

After founding Nain in 1771, the Moravians realized that the location was not ideal for interacting with Inuit. Originally, the Moravians thought Nain was suitably located since it could be reached by Inuit from the north and the south; however, Inuit only visited Nain during the summer to fish. The area did not offer year-round subsistence. Inuit who did offer to stay only did so under the presumption that the missionaries would provide food, something the Moravians strongly opposed (SabathyJudd 2009:136).

Furthermore, the time spent in Nain showed the Moravians that a single site would not suffice in spreading the Gospel. The Moravians needed multiple missions along the coast to accommodate Inuit who lived further north and south, and who 
followed a seasonal subsistence round. They believed that additional missions near frequently visited areas could reach more potential Inuit converts (Rollmann 2009b:120).

The Moravians therefore settled two other missions they hoped would offer them new opportunities to reach Inuit. The second mission settled in 1776 was located north of Nain at Okkak in the hope of contacting Inuit living to the north. A series of explorations conducted during the summer of 1775 determined that Avertôk would serve as an ideal location for the Moravian's third mission south of Nain. The location had a fresh water source, good anchorage for ships, and was in close proximity to a large Inuit sod house settlement.

In 1777, the Moravians conducted a similar land exchange ceremony as in Nain with Inuit living at Avertôk (Brice-Bennett 2003:35). In exchange for the land, the Moravians gave the Inuit knives and fish hooks. The transaction was acknowledged by a proclamation with seven Inuit signing their names. Upon completing the transaction, the missionaries again placed boundary stones marking the northern and southern extent of the area for the new mission, which they called "Hoffenthal." Construction of the mission did not begin for another four years, as the Moravians awaited official approval and funding from the German church (Brice-Bennett 2003:36). By 1782, missionaries Jens Haven and his wife along with William Turner and Christoph Wolff became the first Moravian occupants at Hopedale. 


\section{The Campaign to Convert}

The mission's location next to the Avertôk village offered definite advantages that the Nain site lacked (Figure 4.1). The presence of a variety of animals, the proximity to the winter sea ice edge (sina), and a more hospitable landscape with resources meant more Inuit remained in close vicinity throughout the year, rather than traveling to more distant resource localities (Hiller 1967:99). Despite the immediate access to potential converts, few Inuit abandoned their shamans and spiritual traditions in favor of Christian and European customs. The main reason for this impasse could be traced to the influences from southern traders and shamans. The Moravians believed by providing local alternatives to trade and religion, they could disrupt the southern trade and influence of the shamans over the Inuit. The Moravians underestimated how deeply embedded these influences were in the Inuit cultural fabric and that much more than a simple replacement was required.

Three distinct periods in Hopedale history reflect how the relationship between the Moravians and Inuit changed due to a number of circumstances. The first period, from 1782 to about 1790, was a time when the Moravians were building and developing the Hopedale mission and trying to establish a presence among local Inuit. The Moravians struggled to convince Inuit to abandon their spiritual traditions in favor of Christianity.

The second period began in the 1790s when the Moravians saw a steady rise of Inuit visiting their mission, perhaps as a result of rising European occupation in the south (Stopp 2009:61). A sudden flux of Inuit converts in 1804 is identified as the "Great 
Awakening." The final period follows the "Great Awakening,” as many Inuit began to alter aspects of their lifestyle by attending church services and participating in mission activities. Inuit continued to maintain fundamental hunting practices particularly the caribou hunt in the fall. The Moravians needed the Inuit to follow traditional subsistence practices to accumulate food to ensure the missionaries' survival. When Inuit were away from the watchful eye of the Moravians, baptized Inuit often returned to practicing traditional spiritual activities. This volatility frustrated the missionaries, who hoped the Inuit would maintain their redemptive state and serve as wards of the church.

What caused the Moravians the greatest frustration was the Inuit continued travels south. Prior to the Moravian missionaries’ arrival in Labrador in 1771, Inuit traveled south to raid or trade with the French, Dutch, and English. A long-distance trade route connecting settlements along the coast was in existence by the eighteenth century (Kaplan 1985a:62; J. G. Taylor 1974). European trade goods taken north became rarer and more expensive the further north they went. Presumably, those who could acquire such goods rose to prominence within Inuit society (Hiller 1971a; Kaplan 1985a; J. G. Taylor 1974; W. Taylor 1966).

The Moravians disapproved of Inuit traveling south since it took Inuit families away from the mission for weeks if not months. They believed that during these trips, Inuit “plunged themselves, not only into spiritual, but outward misery and ruin” (P.A. 1790:50). The Moravians felt European traders encouraged Inuit to participate in unsavory and unchristian activities by granting them access to undesirable and "useless European” goods, such as alcohol (Packard 1891:304). The Inuit, on the other hand, 
found these trips south exceedingly valuable as the Inuit "could get a large boat there for a small price, and plenty to eat as the Europeans caught the seals in nets and gave away the flesh for nothing; and they gave them also bread and rum at a low rate” (The Moravians in Labrador 1835:154). In particular, the Inuit focused on trips to Sandwich Bay where Captain George Cartwright operated summer and winter trading stations from 1775 until 1786 (Brice-Bennett 2003:38).

To counteract this unsavory behavior and limit the consumption of goods, the Nain Moravians sent a letter to southern Europeans in 1783 via Inuit a traveling south. The missionaries hoped this letter would portray the Moravian intent of converting Inuit, and to implore the Europeans not to engage with those Inuit who exhibited their heathen customs stating, “we would beg all gentlemen not to trust any of our [baptized] more than others for [some] of them not attending our advise have lost that blessing which they had [partaken] of by Holy Baptism and have turned back to their heathenish customs” (Letter from Nain Missionaries to Southern Europeans Traders. 1783. Letter on file at the Moravian Archives, Bethlehem, Pennsylvania, Acc. No. 38750-38753).

In a 1790 letter to Moravian officials in Europe, Hopedale missionaries David Kruegelstein, Stephen Jensen, Samuel Towle, and Suen Andersen wrote that they felt the Inuit would "bring no good from a place where they are allowed to indulge every evil inclination without restraint” (P.A. 1790:50). The southern traders provided a lack of religious structure and a bounty of forbidden goods which concerned the missionaries. Nevertheless, many Europeans ignored the Moravians’ call to disengage with the Inuit. 


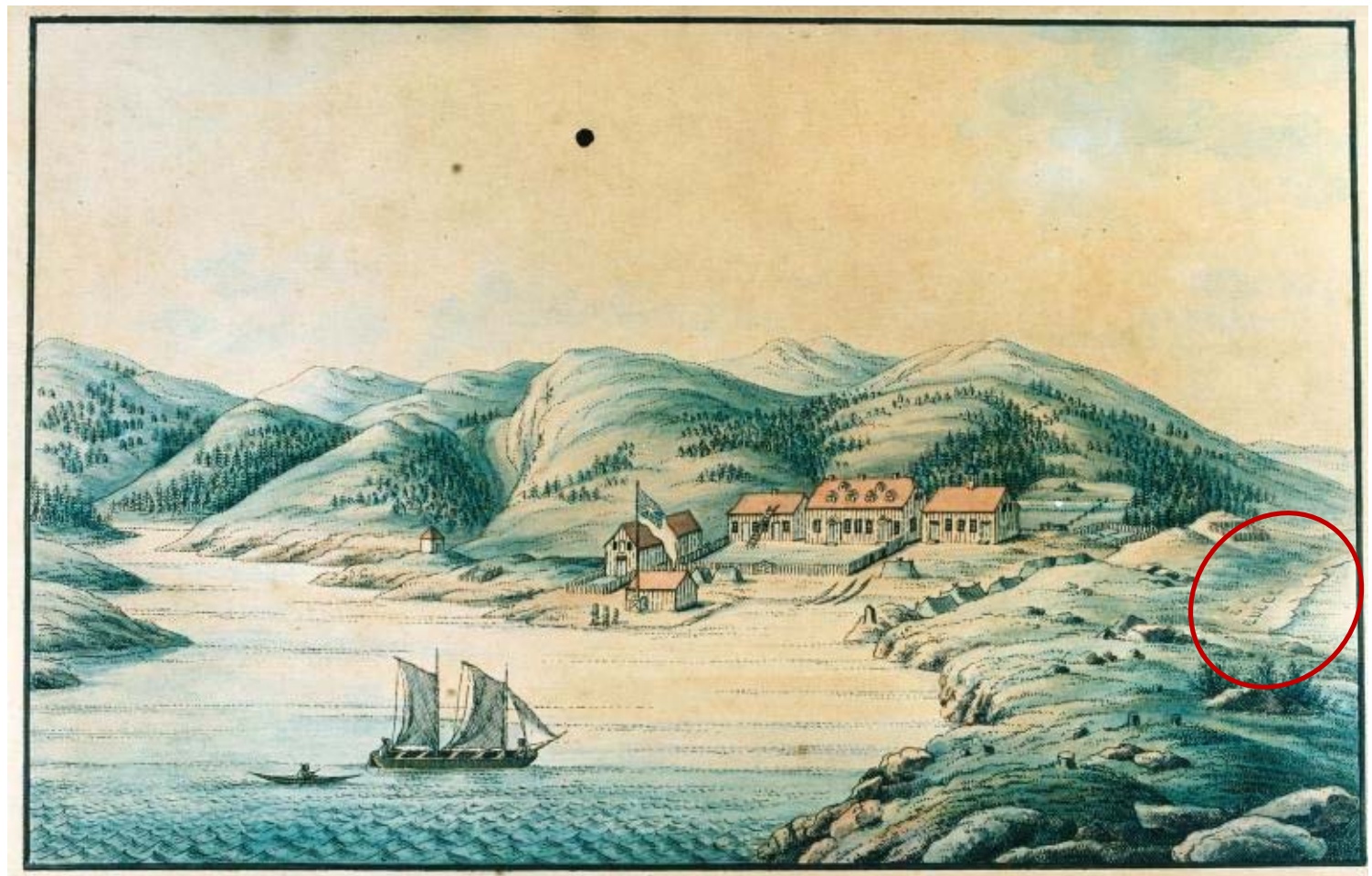

Figure 4.1: The Moravian settlement at Hopedale founded in 1782 (print 1791). The print shows the mission buildings, a ship and a kayak in the harbor, and Inuit tents along the coast to the right of the mission buildings. The ship appears to be a traditional Inuit umiak with the addition of two masts serving as an interesting example of Inuit adapting European technology. Encircled in red are the Avertôk ruins, arguably the earliest depiction of an archaeological site in Labrador. (From "The Labrador Inuit Through Moravian Eyes" website at http://link.library.utoronto.ca/inuitmoravian/digobject.cfm?idno=P0746. Original print in Unity Archives, Herrnhut.)

To counter the southern traders and establish a sustainable economic system, the Moravians began their own trading operations. They were careful to separate trading from religious pursuits and maintain a strictly economic relationship with the Inuit, by neither giving nor receiving presents and requiring Inuit to pay for services or goods rendered. They hoped that the convenience of accessing European goods at nearby missions as opposed to making the long journey south would attract continuous Inuit 
trade (Hiller 1971:847) and ultimately lead to conversion. The Moravians originally did not sell or trade firearms or European foods items in an attempt to preserve traditional Inuit subsistence practices and limit Inuit dependence on European materials. While this stance on guns and food later changed, Inuit must have been frustrated by these limited trading policies because their travels south continued (Brice-Bennett 2003:38).

Labrador historian James Hiller identified the period after the settlement of Hopedale beginning in 1783 as the start of Inuit disillusionment with the Moravians (Hiller 1971:135). In British trader George Cartwright’s journal from 1783, he notes that he is trading with Inuit who "expressed a great dislike to the Moravians, and assured [him] that they would not live near, or trade with them more” (Cartwright 1792:11). The apparent shift in the Inuit demeanor towards the Moravians had been developing for the previous twelve years, since the settlement of the first mission in Nain in 1771. Hiller argued the Moravian's creation of a structured and organized community that enforced strict rules on economic policies soured the Inuit impression of these newcomers. Inuit were not interested in complying with Moravian rules and constraints, and chose to travel south. The only thing that seemed to keep Inuit at the missions was hunger or a fear of death as hostilities and disease grew in the south with the influx of European traders (P.A. 1792:158).

The Moravians were troubled by their lack of influence over Inuit behavior, particularly Inuit drinking, smoking, and gun use. Inuit often returned from trips praising the southern Europeans for providing such goods cheaply while allowing them to live according to Inuit customs (Hopedale Diary, April 6, 1787. Diary on file at the Moravian 
Archives, Bethlehem, Pennsylvania; Hiller 1971:138). Such decadent descriptions of the south continued to draw Inuit away from the northern areas and the missions. Large portions of Inuit communities moved south, leaving the Moravians to watch their congregation dwindle. Two large groups left the Hopedale area in 1787 and 1788, while Okkak missionaries reported in the summer of 1791 over a hundred Inuit joined families from Nain and Hopedale to head south on a trading expedition (Hiller 1971:139). Yearly counts of congregations reported by the Moravians show that in 1785 and 1786, a number of baptized Hopedale Inuit went south “where they bought fire-arms, [and] associated with the Heathen” (P.A. 1790:n.50). In 1791, only 47 Inuit lived at the Hopedale mission while 96 Inuit resided in Avertôk. Hopedale numbers decreased five years later to 38 Inuit living among the missions and 54 living at Avertôk (P.A. 1791, 1796). The lack of a steady Inuit population in Hopedale at the mission suggests that the Moravians struggled to retain Inuit based on religious conversion alone and were in competition with the southern traders.

Forced to alter their approach, the Moravians sought to encourage Inuit settlement by stocking more desirable items such as guns, lead shot, gun powder, and canvas for sails in the company store by 1788 (Annual lists of trading goods wanted for Hopedale store, 1788-1866. Original documents on file at the Moravian Archives, Bethlehem, Pennsylvania, Acc. No. 37237-37238). The missionaries also had another motive: they wanted to establish the mission as a viable economic institution by sending trade items such as fur, ivory and oil back to Europe for sale. Many in the German church disliked the incorporation of a trading store for fear it would corrupt Inuit while simultaneously 
distracting the missionaries from their true purpose. But the missionaries, especially those at Hopedale, felt they had to combat a growing economic competition from southern traders who were populating the coast north of Hamilton Inlet. The Moravians felt they needed to limit Inuit exposure to the negative influences of European traders.

Lists requesting goods for the Hopedale trade store from 1788-1818 reveal that while the variety of goods waxed and waned considerably from year to year, the Moravians required constant replenishment of specific goods, especially lead bullets and nails. The invoice list from 1789 reveals considerable quantities of decorative objects such as beads, quilting needles, and “rivets for copper work" (Annual lists of trading goods wanted for Hopedale store, 1788-1866. Original documents on file at the Moravian Archives, Bethlehem, Pennsylvania).

But Inuit tastes changed almost a decade later as the fur and trading industry became more lucrative. This shift was reflected in the Moravian trading store, with the Moravians importing fewer decorative items and more manufacturing and hunting items including seven- inch files, gun flints, and nails. A brief examination of the invoice lists for the trading store from 1788 to 1818 (Figure 4.2) reveals that the variety, or richness, of the number of individual items available for sale in the Trade Store patterns neither increased nor decreased over time. Richness scores represent each unique item imported, and not the total quantity of goods imported, as the Moravians did not always provide accurate measurements. These scores are tracked by assigning a value of one to each item only once. While a closer analysis of the richness scores for the Trade Store will occur in Chapter 5, it is worth noting here that the annual fluctuation of the types of 
goods being imported for sale in the Trade Store is a reflection of the Moravians adjusting their requests, in part, according to Inuit demand.

The missionaries actively sought new ways to introduce products to entice Inuit to participate in the Moravian local economy. One way they tried to increase yields was through lending Inuit hunting tools such as seal nets, where hunters could catch more seals than hunting by kayak or at breathing holes (Williamson 1964:34). Besides providing products for export to European markets, the net assisted Inuit in collecting seal products, which the Moravians believed to be the basis of Inuit health and well-being (Williamson 1964:33). But many Inuit preferred not to eat the drowned seals caught in nets, and continued traditional means of seal hunting with kayak, gun, and harpoon to supplement other food sources, such as caribou and char (Stephen Loring, personal communication 2005).

Nets were rarely used prior to the 1790s, but a shipment of new nets and twine by the SFG in to Hopedale 1799 appears to be due to a shift in the use and success of seal nets (Hiller 1971:143). The Moravians relied on help from the Inuit to capture the large number of fall migrating harp seals, and then render the blubber into oil for import to European markets, which was an essential part of their economy. But the draw for the Inuit may have been the access to a proportion of the hunt when extremely successful, as well as payment or merchandise from the trade store for their labor in the blubber yard. 


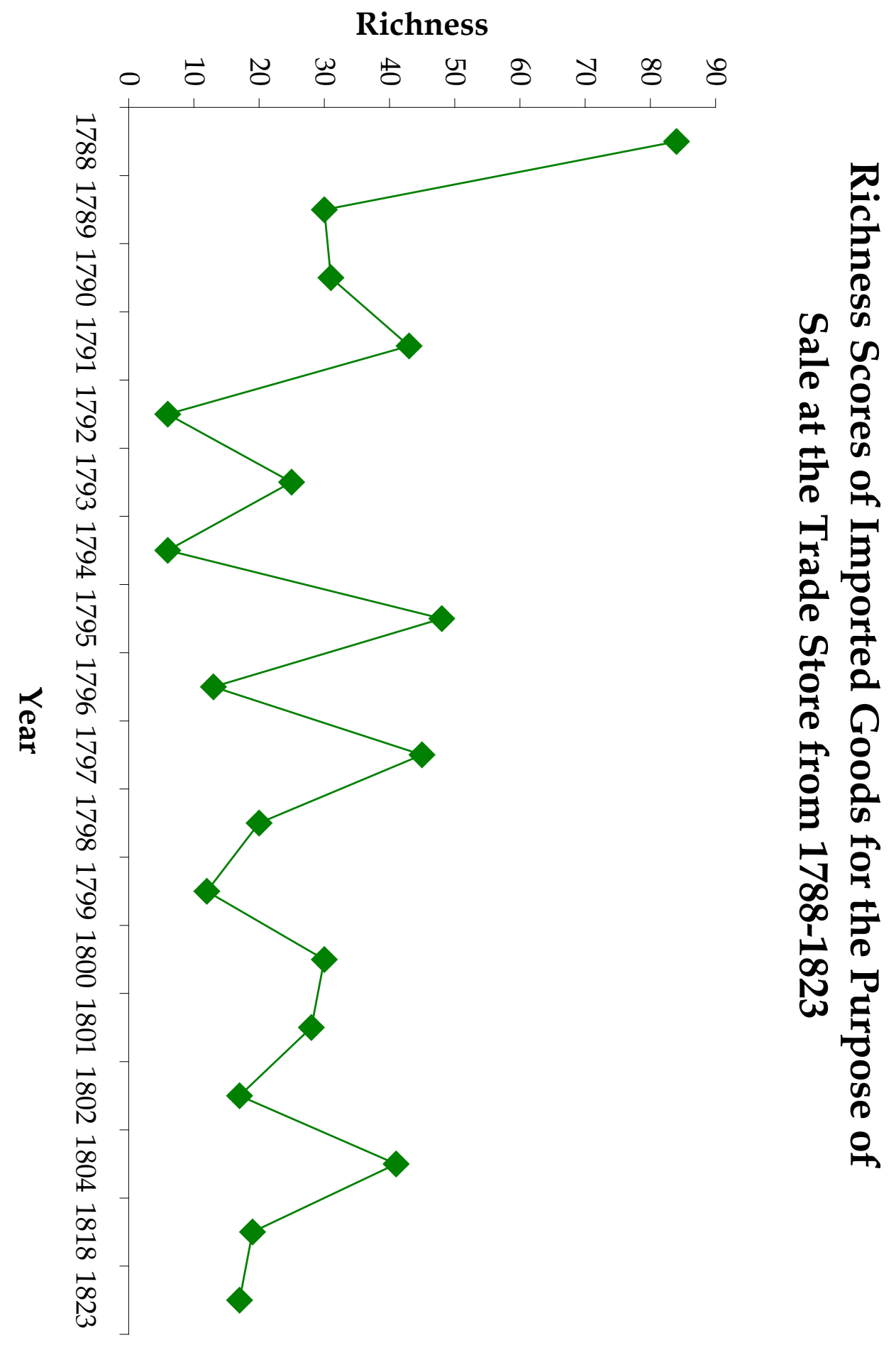

Figure 4.2: Chart of the richness scores, or number of different types of goods imported for sale in the trade store from 1788-1823. 
Access to these trade goods usually came at a cultural cost. Although the Moravians attempted to keep trade separate from other religious endeavors, the missionaries gave sermons in every other venue. They hoped to dissuade Inuit from their nomadic practices, and to encourage them to settle in the vicinity of the missions, and embrace the Moravian Christian way of life. Evidence that Inuit continued to travel south throughout the eighteenth and early nineteenth century strongly suggests that these religious demands overshadowed the benefits that came with living at a mission, including economic security and access to goods during difficult times (Hiller 1971:144). While wage labor presented an entrée into Inuit society, the Moravians quickly realized that conversion required a fundamental ideological shift on behalf of the Inuit. To convince Inuit that Christianity was the only true religion, the Moravians adopted a campaign to undermine traditional Inuit notions of spirituality.

To succeed in their efforts to create a diligent, European Christian community in Labrador, the Moravians first had to address obstacles presented by certain Inuit customs. Many of these demands or strategies often imposed European logic on an alternative Inuit worldview. The Moravians used multiple approaches to remedy what they believed to be a dysfunctional Inuit system. They did not understand that Inuit culture did not differentiate between natural and supernatural worlds; rather these worlds coexisted (Birket-Smith 1959:160). Introducing changes to Inuit culture, such as modifying hunting strategies or undermining existing religious practices, disregarded this Inuit system that recognized a social cohesion based on a symbiosis with the natural world. 
One fundamental change the Moravians pursued was encouraging Inuit to settle at missions and modify their lifestyle of feast or famine. The Moravians tried convincing Inuit to store meat and fish caught in the summer in preparation for winter famine. Storing meat was not a new practice for Inuit. They already made use of stone-lined storage pits in prehistoric and early historic sod houses or external storage caches located near settlements (Bird 1945; Morrison 1983; Park 1999; Schledermann and McCullough 2003; Whitridge 1999). However, the Moravians urged the Inuit to reserve far greater volumes of food than was their practice.

The Moravian insistence on more storage went against core Inuit values, particularly sharing after the hunt. The consumption of meat after the success of a large hunt or during times of shortage played a significant role in social cohesion and communal sharing. The redistribution of meat was part of a system of reciprocity where groups were obligated to give to each other in similar ways. These forms of giving followed particular rules of consumption (Graburn 1969:68).

Food sharing was a significant part of Inuit social strategies and served to promote relations among various families and dispersed settlements (Damas 1972). Feasting also operated as an Inuit social mechanism where the products of successful hunts were shared within villages and with visitors from settlements where hunting had not been as successful (Damas 1972; Henshaw 2000; J. G. Taylor 1975:61). Inuit respected generous individuals; those who freely gave away their goods and food were considered rich while those who hoarded were held in lower esteem (Graburn 1969:70). 
The Moravians also failed to recognize the significance of the hunt to a subsistence-based society. Inuit hunted a variety of sea and terrestrial resources such as seal, caribou and fish throughout the year. For the Inuit, the hunt was an important subsistence and social element. Hunting caribou and seal were highly respected activities in Inuit society especially among men; the hallmark of an Inuit leader was his success as a hunter.

Large cooperative hunts often provided the majority of the meat and clothing for the remainder of the year, especially the summer caribou hunt (J. G. Taylor 1969). Hunting the large herds often required the assistance of the entire household or settlement to corral caribou, and skin and process hides and meat before returning to the settlement. Inuit would travel inland to find the caribou.

The Moravians were conflicted with the Inuit decision to follow caribou. On the one hand, the missionaries relied on these seasonal hunts for food for their own survival. On the other hand, the seasonal hunts exposed Inuit to the influences of non-converted Inuit and interfered with other potential financial. The missionaries feared that the newly converted Inuit would be exposed to the unsavory influences of non-converted Inuit, such as drinking alcohol, and slide back into their "heathenish” tendencies (J. G. Taylor 1975). The missionaries also relied on the Inuit to assist in other forms of subsistence as part of their economy, particularly sealing which occurred in the fall and winter (Hiller 1971:150). Seal hunting could not begin before the caribou hunters returned, which often extended into the fall and pushed the start of the hunt late into the season (Hiller 1971:150). 
As early as 1778, missionaries tried to convince Inuit to change their hunting strategies and remain along the coast to fish cod rather than follow the caribou (1778 Okkak Diary in J. G. Taylor 1975). The Moravians felt fishing was more efficient and economically productive than caribou hunting because caribou was not considered a viable item for trade in foreign markets. The Moravians reasoned that both adults and children could fish, and fish could be dried in large quantities and stored for the winter months (Brice-Bennett 2003:52). The Moravians overlooked Inuit aversion towards fishing due to its social stigma as an undignified livelihood. It was considered women's work (Cabak 1991; Hiller 1971:152; Kleivan 1966; P.A. 1859:23:85, 1869:27:59). Nevertheless, the Moravians’ persuasion likely contributed to the eventual decline of the late summer caribou hunt (Taylor 1975). The summer-fall caribou hunt previously was significant for skins. With European clothing and canvas replacing skins, Inuit no longer needed the caribou hunt.

In their dismissal of Inuit customs, the Moravians displayed a disregard for a worldview that intertwined nature and culture, as revealed by Inuit taboos. For instance, Inuit respected the period immediate after death as liminal and dangerous. Work stopped after the death of a seal or person for up to four days to respect the passing of the soul from the living to the dead. Not allowing this transition to occur could result in the dead wandering the earth and disrupting future hunts.

The Moravians instead viewed this inactivity as wasteful, irrational and unproductive. They could not accept that Inuit settlement life was centered on a spiritual connection to their land that adhered to specific customs and taboos related to hunting, 
animals, and other daily activities. The Moravians failed to recognize that if Inuit did not adhere to these customs that honored and respected the connection, they put the entire community in danger.

Inuit taboos also interfered with Moravian hunting schedules, thus further frustrating the missionaries. The most important Inuit taboo separated products and activities associated with animals from the land on the one hand and the sea on the other. Elsewhere in the Arctic, Inuit believed that products and activities associated with land and sea animals had to remain separate to preserve cosmic order (McGhee 1977; Oosten 1976; Pearce 1987). For instance, all work on caribou skin had to be completed before the first seal hunt, and the meat of caribou and sea mammals could not be cooked in the same vessel or eaten on the same day. Hunters were not permitted to hunt caribou and seal simultaneously and seal meat could not be eaten while caribou skins were tanning or being sewn. Weapons also were separated according to the type of hunt, as only caribou blood could be applied as glue to arrows used in caribou hunting (McGhee 1977:146).

Convincing Inuit to convert to Christianity involved more than just adopting European economic and social norms; the Moravians realized they had to supplant traditional Inuit beliefs with the Christian way of thinking. Three aspects of Inuit life were targeted: shamans, taboos and healing.

The Moravians sought to undermine Inuit religious leaders, shamans or angakoks. In the beginning, the shamans welcomed the Moravians as potential trading partners and helped them locate their settlements. Eventually, the shamans were viewed as representatives of the wicked traditions the missionaries wanted to replace. The 
Moravians started questioning Inuit spiritual beliefs and animism, and ridiculed common taboos and practices. They spoke out against the shamans and their methods, belittling and questioning the authenticity of their powers, and challenging them to replicate their magic (Brice-Bennett 2003:37; Hiller 1971:168).

The Moravians also challenged the significance of taboos, claiming they were unnecessary hindrances that disrupted progress in collecting food. Able to survive in Labrador, the Moravians proved one could live in Labrador while disregarding taboos. A more striking image was the converted Inuit who also ignored taboos and found hunting success, despite angkok claims that their irresponsibility caused communal-wide hunting failure (Hiller 1971:169).

Lastly, the Moravians provided alternative healing methods by introducing western medicine. Having doctors or missionaries with medical knowledge reside at each mission, the Moravian provided a service to sick Inuit. When successful, Inuit deemed the doctors great men, speaking highly of them to other community members (P.A. 1797:135). Yet Inuit often expected instantaneous cures and “when [the Inuit] perceive[d] that the useful medicines [were] slow in their operation, they [felt] a great inclination to try the old way, and [were] apt to place much confidence in the mutterings and woeful grimaces of the sorcerers” (P.A. 1797:135).

One method of countering fluctuating Inuit allegiance was to offer an ultimatum: Inuit were granted access to western medicine only if they did not mix old customs with Moravian medicine, nor seek the help of the angakok. "[If] they used or caused sorcery to be used, [the Moravian's] medicines would do them no good and [the missionaries] 
would not meddle in the cure, but if they used [their] medicines orderly, and begged [the] Saviour to help them, they certainly would be cured if He found proper” (Nain Diary, March 3rd, 1781. Diary on file at the Moravian Archives, Bethlehem, Pennsylvania). Maintaining a clear separation between traditional Inuit and Christian methods played an important role in linking medicine with religion and replacing shaman practices with Moravian ones (Wilson 2000).

Such aggressive methods eventually led to an Inuit response. In the spring of 1786, Kapik, a prominent shaman leading the Avertôk Inuit near the Hopedale mission called a meeting to convince local Inuit to stop revealing their customs and practices to the Moravians (Brice-Bennett 2003:39; The Moravians in Labrador 1835:156). Kapik did not appreciate the Moravian efforts to replace traditional Inuit practices with Christian customs, thereby undermining his authority. As a result, Inuit living in and around Avertôk avoided the missionaries, and the mission saw a steady decline in converts until the 1800s.

Despite the missionaries' repeated attacks on the shaman's status and authority, the angakok maintained a hold on the religious imagination of the Inuit community during the early period (1782-1790). Inuit were not accustomed to the organized and structured methods of the Christian religion, or the Moravian’s social organization and habits. Many of the Moravians’ methods were foreign to Inuit, such as medical procedures (i.e., bleeding, enemas), while other practices countered Inuit customs, including excessive food storage and breaking of taboos. Inuit were not willing to cast aside their traditions so quickly. 
The Moravians persisted in their efforts throughout the second period (17901804) and eventually were rewarded. Kapik, the Avertôk shaman who had organized an Inuit resistance to Moravian activities, chose to convert to Christianity in 1799. Kapik’s change of heart apparently occurred after witnessing an unusually large meteorite shower, which was interpreted as the sign of the apocalypse as predicted by the missionaries (The Moravians in Labrador 1835:183). While the sudden ideological shift by Kapik appears to be tied to a changing economic landscape that saw the end of the Inuit entrepreneurs, Kapik moved his entire household to Hopedale. He joined the congregation there, eventually being baptized in December of 1804 (P.A. 1806:108-109). His action seemed to motivate a larger movement as all three missions saw a rise in Inuit residents. Once a small village with a population of 77 Inuit, the mission grew to include 125 Inuit inhabitants by the end of 1805 (Brice-Bennett 2003:40), leading to Avertôk’s abandonment by 1807 (Kleivan 1966). By the beginning of the 1800s, all three missions had grown to 288 Inuit members, more than in any of the previous years (The Moravians in Labrador 1835:184).

Kapik’s baptism marked the beginning of a great Inuit transformation to accept Christianity, which, as noted above, the Moravians identified as the Great Awakening of 1804. The Moravians capitalized on Kapik’s conversion in their letters and reports to the German church representing it as a pivotal victory toward wide-spread conversion. The Great Awakening grew to become a widespread movement by Inuit throughout Labrador to adopt Christianity. Communities living in the vicinity of Nain and Okkak saw a similar rise in Inuit conversion and movement to the missions (Brice-Bennett 2003:40). 
The Moravian's earlier campaigns to challenge the shamans and insist that Inuit who were living at the mission convert, eventually led to significant transformations in Inuit cultural traditions and social structure within and beyond the mission boundaries. At the beginning of the mission settlement in 1782, more non-converted Inuit lived near the mission than those considered part of the congregation. That ratio shifted by 1788 when more congregation members lived at the mission than non-converted Inuit (Figure 4.3).

Kapik’s baptism and the Great Awakening appear to correspond with a larger Inuit migration north that occurred throughout the 1790s, with women as the most active participants (Cabak 1991:59). The rise of French and English pioneers along the southern coast coincided with an increase in disease-related deaths among Inuit. Furthermore, the region saw an increase in violent encounters between Europeans and other Native groups as competition for resources and land increased. The hostile environment in the south led many Inuit to seek shelter in northern settlements, even as traders continued to populate the northern shores (P.A 1790:202). 


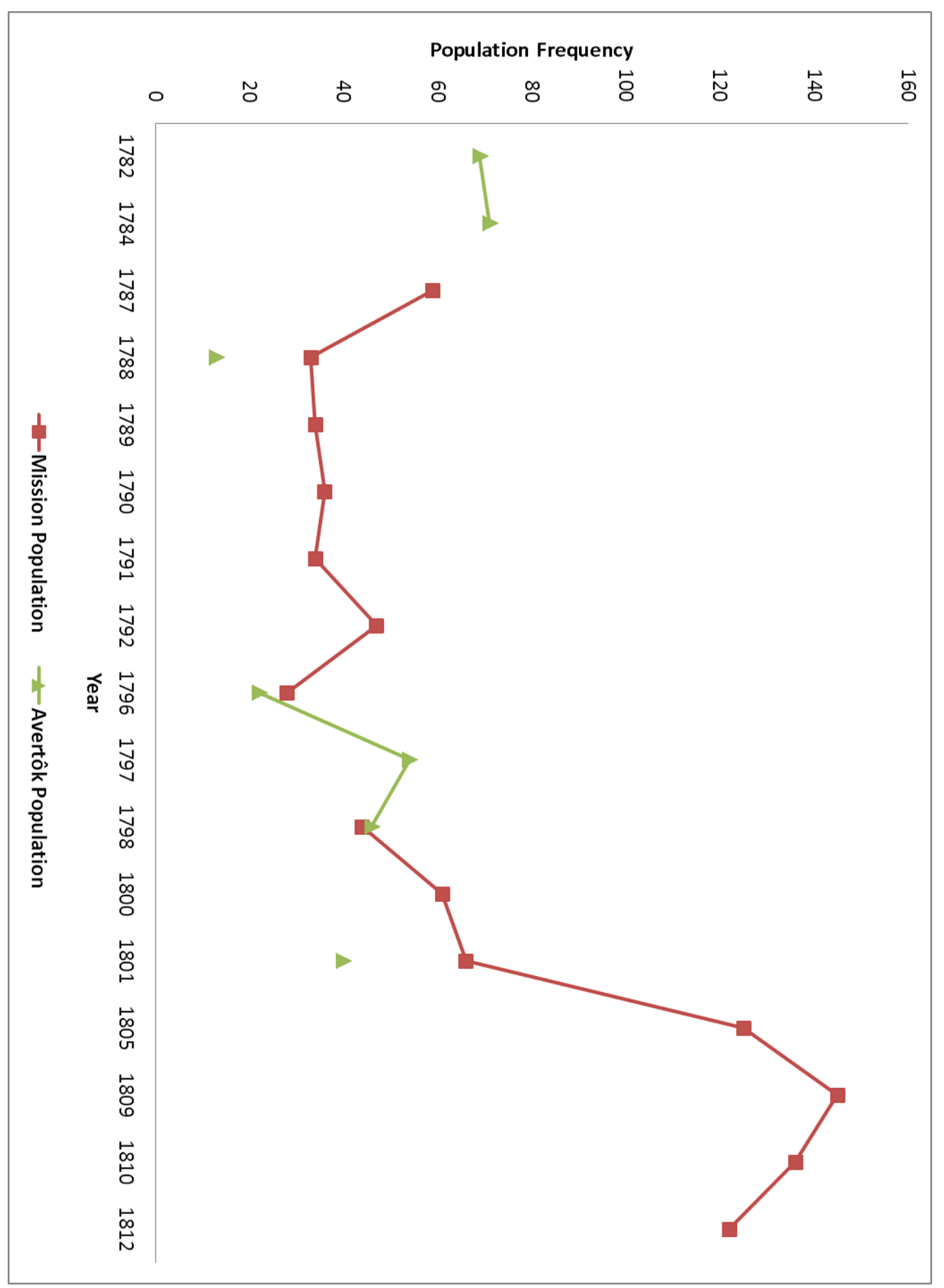

Figure 4.3: Graph of Hopedale and Avertôk population (Hiller 1967:207; Kleivan 1966). 
By electing not to head south, Inuit interacted and traded locally with the Moravians. The convenience of access to European goods at nearby missions compared to the long and dangerous journey south led to continuous Inuit trade, and ultimately led to the end of Inuit interregional traders (Hiller 1971:847; Stopp 2009:61). The Moravians offered food during scarce times, alternative medicines, and cheaper goods that occasionally rivaled southern traders. This increased interaction with the missionaries exposed the Inuit to Moravian doctrine all the more. While not all customers became converts, the economic strategies and the demographic shift probably played a part in the conversion of a few Inuit.

The Great Awakening served as a historic marker for significant demographic shifts throughout much of Labrador as Inuit began moving to the missions and converting to Christianity. The Moravians’ carefully strategized campaign to undermine shamans combined with ongoing disease and violence along the southern coast led Inuit to reconsider some of their earlier practices and traditions. While traditional hunting remained an important element of Inuit livelihood, Inuit began incorporating new practices that were in line with Moravian cultural, social, and economic principles.

\section{After the Great Awakening}

In the years following the Great Awakening, all three Labrador Moravian missions experienced a dramatic influx of new converts, many of which were women (Cabak 1991:59). The missions saw rapid population growth as Inuit living in the immediate areas moved closer to the mission and became part of the congregation. As a 
result, Inuit culture underwent a variety of changes in dress, subsistence practices, and even dietary habits to reflect Moravian influence. Adopting the European material culture did not determine ideological conversion, however, and many Inuit continued to uphold subsistence and spiritual traditions.

Initially, Hopedale missionaries saw significant changes in Inuit habits. Some Inuit radically altered their behavior and began participating in Christian activities such as attending church and praying at home (Brice-Bennett 2003:40; P.A. 1806:107). Inuit were also included in the daily maintenance of the mission and helped expand the mission to accommodate the needs of a growing settlement. The missionaries were skilled craftsmen, excelling as carpenters, bakers, tailors, teachers, weavers and gardeners. Inuit converts learned these new skills and took on these roles as workers and gardeners. The transition from semi-nomadic hunter to wage-earning laborer appeared most readily in the Inuit material culture where European objects necessary to abide by a Protestant work ethic, such as clocks, became more abundant in Inuit contexts (BriceBennett 2003:70; Cabak 1991). By 1839, Hopedale Inuit were incorporated into the mission economic landscape and helped physically and symbolically to build the mission at Hopedale and along the Labrador coast.

Further evidence of Inuit incorporation into the growing Moravian community centered on self-governance. The missionaries created new positions within the congregation for Aboriginal leaders who were “men of strong and good character” called kivgats (Williamson 1964:34). These individuals were prominent and devout Inuit men who served as chapel servants or church helpers monitoring social and community affairs 
(Brice-Bennett 2003:69). As church leaders, they continued many traditional roles of the Inuit leader by providing guidance and mediating disputes, but they also incorporated religious and spiritual advice. This role became a fundamental element of the church's development, and by the 1860s, the Moravians were actively seeking "Native Assistants" (Nationalgehülfen) who would assist and work alongside the missionaries (Rollmann 2010:22). The Moravians came to recognize that overcoming what they considered heathenish ways required a subtle transformation of the traditional Inuit social structure.

Women also played a significant role in the developing congregation and were some of the most active participants in the awakening (Brice-Bennett 1981). Women were attracted to the mission due to an interest in Christianity as well as the community benefits, such as childcare, educational opportunities, and homes for the elderly and widows (Cabak 1991:62). By empowering women and giving them new opportunities previously unavailable, the Moravians found a new avenue of conversion. Appointing men and women as chapel servants reaffirmed their authority and afforded them respect from within the Inuit community. The success of this strategy is evident in the unity of the Inuit community with a new Moravian leadership.

Inuit choosing to live near the missionaries after the abandonment of Avertôk in 1807 were the first to incorporate European, wooden style houses. Rather than multifamily households sod and stone houses, Inuit families moved into single-family log houses. Inuit began replacing most sealskin jackets and pants with cotton and flannel clothing by the mid-nineteenth century, as these were more comfortable especially during the warmer summer months (Brice-Bennett 2003:70); however, traditional sealskin or 
caribou hide outfits were not completely replaced as hunters often preferred those to the less durable European cotton or wool clothing.

One change the Moravians tried to prevent was an Inuit incorporation of European foods. The Moravians imported many provisions such as flour, coffee, biscuits, molasses and some vegetables for their consumption; however, they also distributed the food to Inuit when food was otherwise scarce. The Inuit were only offered these goods during periods of famine. The Moravians tried to limit distribution of European foods because they believed it would lead to Inuit dependency upon the missionaries for food. Furthermore, the missionaries believed the sugars and starch would weaken Inuit strength and resilience to diseases (Brice-Bennett 2003:71). The missionaries wanted Inuit to continue hunting and remain self-sufficient, only coming to them for spiritual guidance.

For some Inuit, living at missions was a matter of convenience. Several Inuit remained near missions only to trade, while other Inuit only resided at the mission during the winter season when weather restricted hunting activities. Inuit gathered at the mission from Christmas to Easter to celebrate religious festivals and attend instructional classes offered by the missionaries (Brice-Bennett 2003:43), but left in the early spring to hunt seal and caribou. Occasionally, non-converted Inuit from the north came to the mission to visit family and friends living at the mission and engage in trade, but rarely stayed. The Inuit seemed to find a balance between the two religions that the Moravians found unsettling. 
In particular, Inuit following traditional hunting practices continued to present the Moravians with a conundrum. On the one hand, allowing Inuit to hunt caribou provided food for the entire community and reduced Inuit dependence on Moravians. On the other hand, Inuit were no longer under the missionaries’ watchful eyes and were exposed to other non-converted Inuit and their heathenish practices.

The Moravians hoped the Inuit would disengage themselves from these traditional customs and permanently settle at the mission and convert. But as a northern Inuit from Nachvak explained to Okkak missionaries, "they could not possibly leave their native country, where they could get a sufficient quantity of food, whereas [at the mission] the people were often in danger of starving, and every summer many died of diseases” (P.A. 1797:127). Allowing Inuit to retain their hunting practices to avoid their becoming dependent upon the missionaries, the Moravians were the source of their own frustrations.

Despite increased Inuit engagement with the Moravian activities, the missionaries felt compelled to convince Inuit to fully accept Christianity and the devout and diligent Moravian lifestyle. But many Inuit did not agree with accepting Moravian authority, especially since they experienced a looser social organization where individual heads of households, hunters and successful tradespeople led the community. An 1806 letter from Hopedale to the German church reported in the Periodical Accounts revealed the missionaries aggravation with non-converting Inuit claiming that, [t] he necessity of true conversion was often represented to them in the most urgent terms. But as they have no mind to forsake their heathenish ways, and our words, as they say, only make them uneasy, they fly as fast as possible from the sound of the Gospel, many 
however with a secret conviction of its truth. We hope that it is not all in vain...(P.A. 1806:89)

The missionaries' efforts were not all in vain, as some accounts reported successes. Detailed descriptions written in Moravian letters and diaries described the manner in which Inuit came to them seeking refuge from the evil of their former ways, often times involving a prominent member of Inuit society. One such account of the son of a prominent shaman Angukualak who chose to move to Hopedale was detailed in an 1806 Hopedale diary:

I thought I saw a very deep dark cavern, the descent to which was a narrow steep chasm. In this horrible place, I discovered my mother, my relations, and many other whom ... who had led a very wicked life on earth, sitting in great torment, and exhibiting a dreadful appearance. ... From that moment I found no rest any where, but having heard that true believes lived at Hopedale, I resolved to come hither, and with my whole family, to be converted to Jesus...(P.A. 1806:119-120)

Many of these letters were read by other Moravians worldwide, including Elders responsible for approving funding and supply shipments. Accounts such as these played a significant role in garnering both local and foreign support for the Moravians’ endeavors. The Hopedale Moravians were motivated to highlight positive events to garner financial and moral support from the entire Moravian community. Prominent members of the Inuit community such as Angukualak’s son and Kapik served as powerful local spokesmen and influential examples of the missionaries' influence. More importantly, these reports legitimized the missionaries' work in Labrador. 


\section{Summary}

This chapter presented the history of the Moravian church as derived from German and English Moravian manuscripts. What began as a small religious sect in Germany evolved into an international church and mission enterprise that reached the shores of Labrador. Studying the origins of the Moravian church and its eclectic leader Count Zinzendorf served as the foundation for understanding the development and eventual success of the Moravians in Labrador.

The history of the Moravian church in Germany and England was tumultuous, eventually leading to a significant cultural divide. Zinzendorf's unique vision of unifying all Christians under a single religion was at odds with the belief of others in the church, leading to the English Church seeking a separate direction. This divide manifested itself in the Labrador missions, as much of their financial and material support came from the English-based SFG, while the German church maintained religious authority.

The cultural transformation that occurred at Hopedale was a process that involved Inuit and Moravian negotiation of the other's culture as well as their own. The missionaries came to Labrador with the belief that they would only change Inuit religion without altering Inuit culture or subsistence practices, but they underestimated the intricacy of spirituality within Inuit culture. The Moravians’ permanent presence and insistence on a European lifestyle, which countered Inuit traditions, led many Inuit to consider alternative options such as trading with Europeans to the south.

Eventually, the Moravians recognized that converting Inuit required changing

fundamental Inuit traditions, including taboos, clothing and household organization, and 
challenging the leaders who upheld them. They attempted to understand and incorporate elements of Inuit culture; however, they simultaneously used that knowledge to undermine prominent shamans and generate a new social structure based on prominent Inuit church leaders. As more and more Inuit chose to live near and work with the Moravians, new cultural features including nuclear households, wage labor, a market economy, and Christian customs were incorporated into the Inuit routine. The changes that took place were part of a broader social process where Inuit negotiated missionary actions and policies and emerged with different identities than those that were evident when the Moravians’ first arrived. 


\section{Chapter 5: Evidence for Missionization in the Moravian Documents}

As discussed in Chapter 4, the Moravians were not consistent about how they interacted with the Inuit. Initially, they sought to introduce Christianity, expecting Inuit to remain self-sufficient and continue traditional subsistence hunting and fishing practices. Over time, the Moravians began introducing not only religion and moral order, but also at Inuit insistence, European raw materials, manufactured products, and foods. By the beginning of the nineteenth century, Inuit were incorporated into a global market economy where the export of local goods resulting from Inuit labor such as seal oil, dried fish, ivory, and fur were exchanged for iron tools, guns, cloth and ceramics.

In the following chapter, I review the Moravian historical documents to track potential evidence for direct methods of missionization employed by the Moravians. While the missionaries primarily focused on demonstrating the power of God's word to the Inuit, they believed they were also responsible for ensuring Inuit progression towards civilization. The introduction of established Western institutions such as schools, medicine, and even etiquette was intended to raise Inuit up from their squalor and reach a social ideal founded firmly in Christian as well as Enlightenment theories (Lydon 2009:6). The common belief of the time was that political, moral and intellectual progress was tied directly to material progress, and that material development corresponded to intellectual development (Bury 2004). Similarly, the progress of religious enlightenment among the Inuit was measured by their progress towards civilization via material markers, such as the consumption of particular goods. 
This section reviews the analysis I conducted of the original German and English Moravian documents tracking the import of European material. The approximately 120 letters and probate lists dating between 1782 to 1813 in the collections at the Moravian Archives in Bethlehem, Pennsylvania offer insights into the introduction of the material effects of the Moravian's new economic and religious ideas. The documents analyzed here make up a small fraction of the records kept by the Moravians, including information on economic, religious, and daily practices in the forms of diaries, letters, minutes, and various inventory lists. Given the hundreds of thousands of documents available in the Archives, I chose to focus only on the request lists for the trade store and the invoice lists for the general mission, as these documents offer insight into the development of the mission and the nature of the evolving relationship between the missionaries and Inuit.

Identifying the diversity of the goods imported would be ideal; however, quantifying imported goods for comparison proved difficult, since the shipping records include a variety of measurements, some of which could be quantified accurately (i.e., yards and grams) while others less so (i.e., rolls of yarn or small barrels). Furthermore, certain items were sent over in great quantities, such as 40 gallons of vinegar and 650 cucumbers, and would overshadow the rare but perhaps important classes. Given the difficulty in identifying variation in sample sizes, this analysis examines the number of different types of goods which were being imported to the Hopedale store each year. I am thus measuring richness rather than diversity or evenness (Plog and Hegmon 1993). Richness is the number of types (or species) per sample and does not take the total 
number of individuals into account. I track the richness of imported goods sent from Europe to the mission over time as proxy evidence for identifying changing consumption and production habits by both Inuit and Moravians during the first few decades of the Moravians’ tenure at Hopedale.

The presence or absence of goods, or richness values, are tracked over the first 30 years from 1782 until 1813, as these were the formative years of the mission’s development. If the Moravians were undermining an Inuit social hierarchy where prominent Inuit men accumulated a greater variety of goods by offering Inuit men and women easier access to desirable resources, then I expect to see import richness scores increase over time. However, changes to the variety of goods being imported or requested by missionaries fluctuate according to the popularity of the mission among Inuit and appears to coincide with the rise of hostilities in the south. While overall richness scores did not reveal a steady trend over time, the analysis highlights the complex nature of the missionization process and the evolution of the mission.

The analysis presented here examines two different Hopedale mission invoice lists. The first list which is called "Trade Lists" focuses on goods requested specifically for sale from 1788 to 1804 at the trade store. This was not a shipping probate list reflecting items actually shipped; instead it was the list of items requested by the store managers. The second list which is called “Missionaries' Lists” focuses on all the goods being imported to the mission from 1782 to 1813, which also included specific requests by individual missionaries. These are the probate lists that record all of the items shipped from European to the mission. 
A distinction between the two types of list is important as it has implications regarding interpretive significance. Prior to any shipment to a foreign mission, German church Elders or the SFG reviewed all missionary requests. Occasionally, items were refused by church officials because it was not available, too expensive, or considered inappropriate. Thus, lists requesting items such as the Trade Lists did not guarantee that all items were sent to the mission; however, comparisons between similar letters of requests by the missionaries and probate lists when available showed that mission requests for goods were frequently honored. I note this distinction to show that the Trade Lists were not shipping probate lists and their analysis may include a small margin of error in the event an item was requested but not sent.

Richness scores were calculated by assigning a score of 1 to each unique item as recorded by the Moravians. For instance, the Moravians were careful to note various colors and types of fabrics of cloth or the length of a nail, as these items served a specific purpose. The types of cloth varied based on it use for clothing or domestic purposes (e.g. tablecloth), while the length of nail differed according to its intended use such as a roofing nail or a flooring nail. In an effort to capture these distinctions, each time a unique item was listed (e.g. 9 inch nail, red wool, etc.), it received a unique value. After individual items were identified and total richness scores were calculated, items were grouped into 14 subgroups that reflect the various domains and activity areas of the mission including food, clothing, the construction activities (Table 5.1). Combining the goods into subgroups eliminates the noise caused by plotting the hundreds of items separately and allows general patterns to emerge more clearly. 


\begin{tabular}{|c|c|}
\hline Group & Items included \\
\hline Food & Garden seeds, spices (including hops), fat, tea, and honey. \\
\hline Equipment & $\begin{array}{l}\text { Items used for packaging or vessels to transport goods, such as } \\
\text { barrels, casks, bottles, kegs, tape, straw (for packing). }\end{array}$ \\
\hline Tools & $\begin{array}{l}\text { Hammers, nails, files, axes, buckets, iron, rope, other locks, } \\
\text { carpenters pencil. }\end{array}$ \\
\hline Construction & $\begin{array}{l}\text { Items used in the actual construction of the mission including } \\
\text { window glass, wood, bricks, lights, roofing material, door locks, } \\
\text { tar. }\end{array}$ \\
\hline Manufacturing & $\begin{array}{l}\text { Materials predominantly used towards the production of another } \\
\text { object or substance, such as white lead, oil used for tanning or } \\
\text { paint, ockum, scrap metal, copper, sheet metal, iron hoops and } \\
\text { nail rod. }\end{array}$ \\
\hline Writing & Books, chalk, quills, ink, sealing wax. \\
\hline Clothing & $\begin{array}{l}\text { Various colors and types of cloth, wool, flannel, gloves, sewing } \\
\text { needles, buttons. }\end{array}$ \\
\hline Hunting & $\begin{array}{l}\text { Shot, powder, flint, boats, oars, nets, knives, fox traps, gun parts } \\
\text { (e.g. springs), corks for nets. }\end{array}$ \\
\hline Domestic & $\begin{array}{l}\text { Items usually found inside the home, such as bells, fire billow, } \\
\text { frying pan, box locks, plates, forks, coal, corks for bottles, } \\
\text { cupboard locks, down, tablecloths, keys, children's toys. }\end{array}$ \\
\hline Other & $\begin{array}{l}\text { Items sent over for a specific purpose such as an English flag, } \\
\text { cannon, canvas. }\end{array}$ \\
\hline Luxury & Tobacco, alcohol (wine, rum, ale), watch, chocolate. \\
\hline Hospital & $\begin{array}{l}\text { Items used in the hospital including medicine, potash, } \\
\text { peppermint water. }\end{array}$ \\
\hline Church & $\begin{array}{l}\text { Items used only by the church including wafers, chapel books, } \\
\text { and chalice. }\end{array}$ \\
\hline Unidentified & Anything that was illegible. \\
\hline
\end{tabular}

Table 5.1: Inventory of items that made up each category which identifies various domestic and activity areas at the mission. 


\section{Trade Lists}

As discussed in Chapter 4, the variety of goods requested by the Moravian missionaries to sell in the trade store did not increase over time yet appeared to correlate with Inuit demand (see Figure 4.2). Closer analysis of the types of items being requested may offer insight into the shifting consumer demands and how the Moravians tried to manipulate or curb Inuit demand by providing or limiting certain items.

The introduction of the trade store by Moravians was the result of their struggle to convince the Inuit, through preaching, to settle and incorporate new religious traditions and hunting methods. Inuit showed indifference towards the missionaries’ message and recommendations, growing increasingly hostile towards impositions on their way of life. Withdrawing from Hopedale, Inuit continued to travel south during the early years of the mission to trade with other Europeans, listen to shamans, and "live the summer season in sinful practices” (LaTrobe 1800:527; PA 1790:50).

During the 1790s, changing circumstances abroad and increasing disorder in southern Labrador forced the Inuit to reconsider their trips south. Many Inuit returned to their northern settlements and restricted their travels south as early as 1794 due to food shortages, disease outbreaks, and increased hostilities with the Europeans. Missionaries noted that fewer and fewer Inuit were praising the benefits of traveling south (PA 1794:259). The Europeans introduced new deadly diseases to the region, such as typhoid, influenza, and measles, affecting indigenous and missionary populations alike. Foreign wars such as the French and American Revolutions also led to heightened 
tensions locally among various European groups and Native peoples who were fighting for similar resources.

Such dramatic changes to Inuit demographic patterns in the 1790s likely placed more demand on the missionary trading posts. In response to this shift and the potential for new converts, the Moravians began to provide more European goods specifically desired by Inuit. The request lists for the Hopedale trade store revealed that the missionaries ordered more knives, tobacco, fox traps, nails, tools, children’s toys, gun powder, and shot by 1791 (Annual Invoices of Trading goods wanted at the Mission stores, Hopedale, 1788, 1791. Original documents on file at the Moravian Archives, Bethlehem, Pennsylvania, Acc. No. 37237-37238, 37247-37248). Some of these items, such as tobacco and gun powder, were previously considered unacceptable trade goods as they perpetuated bad habits and advocated gun-use among the Inuit, an item the missionaries just ten years earlier, did not allow for fear of increased violence and overhunting (Brice-Bennett 1981:24). The chance to increase trading opportunities and come in contact with more Inuit outweighed these earlier concerns.

Nevertheless, richness scores for requested items for the purposes of trade do not reflect an expected increase in demand for European goods over time given the aforementioned external influences. Instead, I believe the fluctuation in the richness scores is the result of the missionaries focusing on importing certain groups of goods each year. Annual peaks followed by dips suggest that large amounts of goods were requested for stockpiling which were then traded or sold to Inuit over a period of years. Some subgroups exhibited this trend more dramatically than others. 
One subgroup that had limited effect on the overall richness score was food. This was due to the Moravians’ desire not to import European food for fear Inuit would become dependent on the missionaries. The missionaries only imported specific foods, such as peas, biscuits and bread. As a result, food richness scores remain low throughout the 30 year period examined ( $\mathrm{n} \leq 3$ ) (Figure 5.1). The limited variety emphasizes the Moravian intention to control access to food.

In an effort not to influence Inuit dietary habits, I believe the Moravians imported greater amounts of hunting equipment, such as lead shot, gunflints, and nets to encourage Inuit hunting. The spikes followed by significantly lower richness scores for 1791, 1797 and 1801 suggest an accumulation for surplus purposes (Figure 5.2). Peaks in the richness score for those years were the result of requests for a variety of gun flint, gun springs and ammunition, including shot and powder. The Moravians originally were reluctant to sell firearms to the Inuit, but found by offering guns in the trading store by 1785 they could curtail Inuit travels south to Hamilton Inlet (Stopp 2009:61; J. G. Taylor 1977).

In addition to preventing Inuit from becoming too dependent upon the missionaries for food, the Moravians provided sufficient variation of hunting tools because they missionaries relied on the Inuit to help supplement their own food supply as well as develop their blubber industry. More tools associated with hunting were being made available at the Trade Store and were not being sent for the missionaries’ personal use as recorded by the Missionaries’ Lists (Figure 5.3). As will be discussed later in this chapter, the Missionaries' Lists had, in general, greater richness scores than the Trade 
Lists, indicating that the missionaries were requesting a greater variety of materials and goods for their personal use. However, that was not the case for the hunting category where the Trade Store had more variation in the types of hunting tools then were being sent to the missionaries.

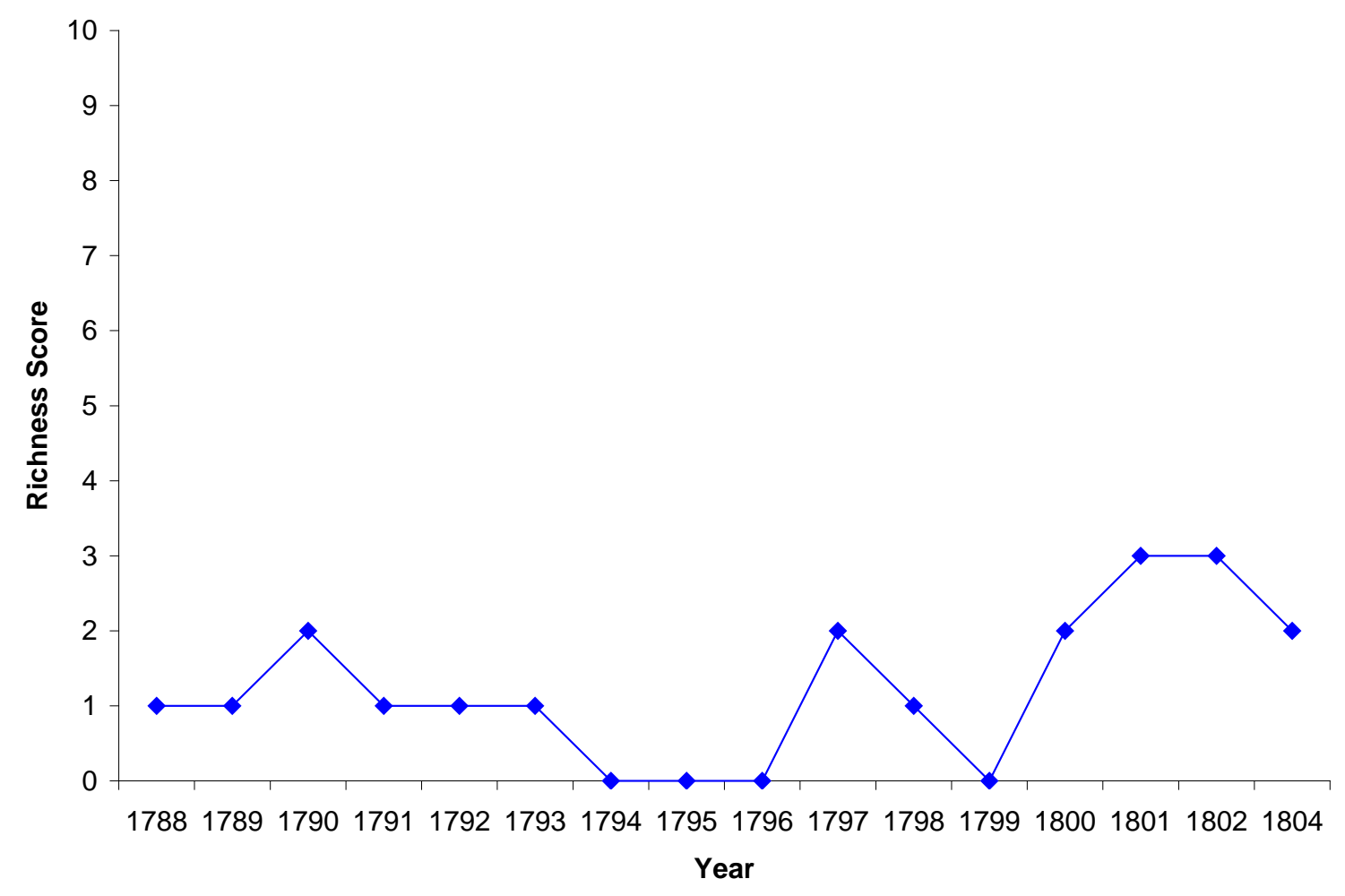

Figure 5.1: Richness scores of the food category from the trade lists from 1788 through 1804. 


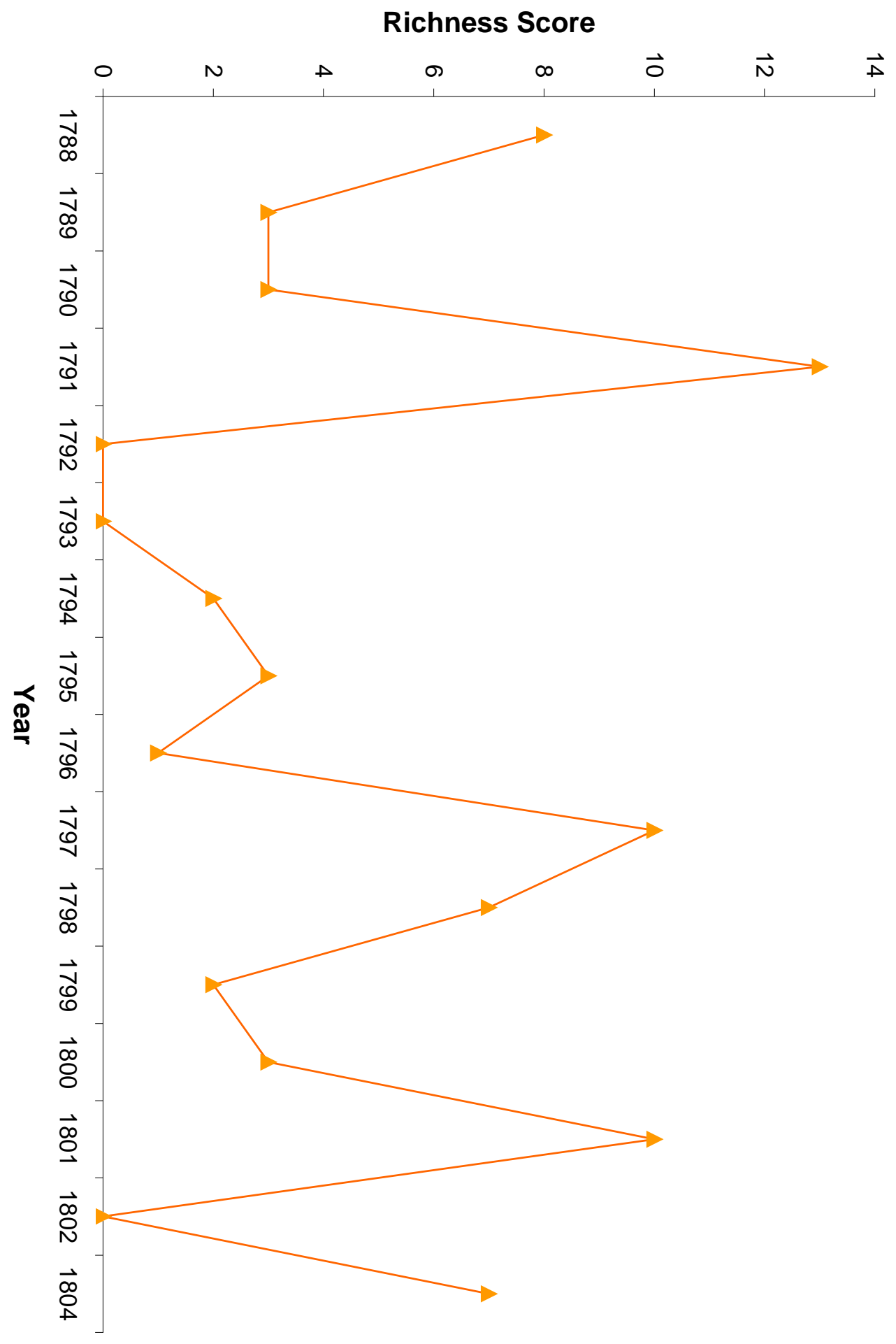

Figure 5.2: Richness scores for the hunting category at the trade store from 1788 through 1804. 


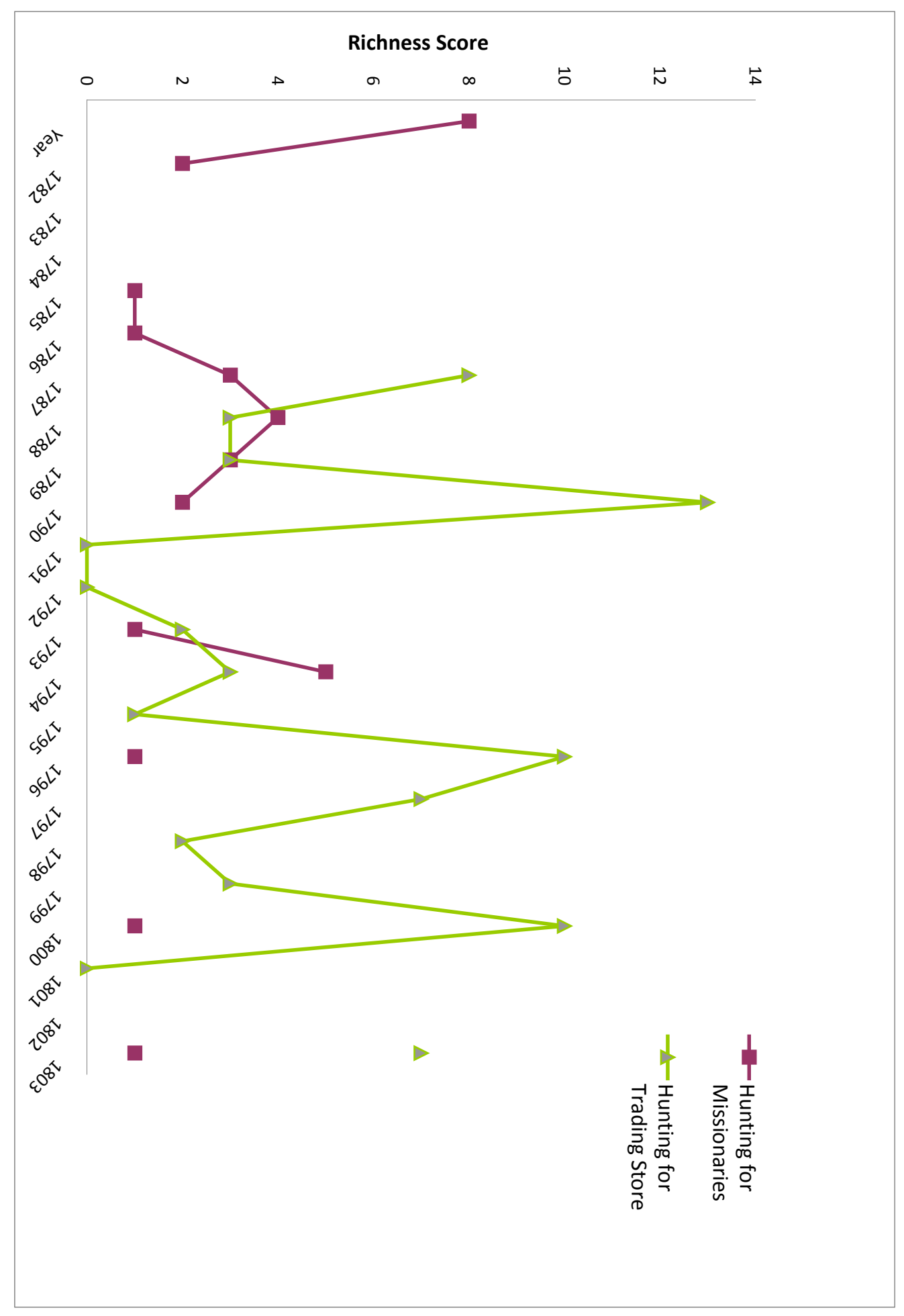

Figure 5.3: Richness scores of the hunting category from the Trade Lists and the Missionaries’ List charted over time. 
Inuit also acquired material, such as sheet and strap metal which could be used to make harpoon heads or knife blades. These materials are subsumed under the manufacturing category and included items such as nail rod, lead, sheet metal, iron wire, tin and pewter, many of which were being traded by southern traders. Yet a majority of the items included in this list were oil, saltpeter (potassium nitrate) for the blacksmith, salt for preserving fish and meat, tar used for sealing seal nets, and hoop rivets for the barrels that stored the oil rendered from seal blubber, all of which were specific to an export industry. The high richness score seen in 1788 corresponds to opening of the trade store, thus requiring an initial surplus of a variety items including those that met Inuit demand. Following 1788, manufacturing scores stay relatively low (n < 8), but many of the materials being requested were primarily used for collecting or shipping products for import, such as salt for brining fish, grease for shotguns, and hoop barrel (Figure 5.4). The missionaries are also requesting manufacturing items, as detailed in the Missionary Lists. But as Figure 5.5 reveals, with the exception of a few years $(1789,1793,1798$, 1801 and 1803), a greater variety of manufacturing items are being requested for sale in the trade store than for use by the missionaries. Unlike patterns seen earlier in the decade where the Moravians appear to be accommodating to Inuit desires, the inclusion of the manufacturing items indicate the Moravians were encouraging the pursuit of economically viable hunting strategies that aligned more with the mission's financial needs.

The shifts seen in both the hunting and manufacturing categories exemplify the various and often conflicting messages the Moravians sent. On the one hand, the 
Moravians were trying to entice Inuit to remain near the mission and receive goods from the missionaries in exchange for animal skins. On the other hand, the Moravians were trying to guide Inuit subsistence strategies to align with the mission's economic goals, while not allowing the Inuit to become dependent on the missionaries for food. The strict control and confusing limits on goods continually frustrated the Inuit and led many to become disillusioned with the missionaries.

Another imported material that symbolized the Moravian shift from "simply" Christianizing Inuit to actively civilizing the Inuit was the inclusion of clothing. Items and materials related to the production of clothing had some of the highest richness scores, thus greatly influencing the overall trend seen in Figure 4.2. For instance, 1795 had the highest richness score due to a request for 11 different kinds of needles varying in length and thickness, and nine different colors of rolls of cloth and ribbons suggesting the Moravians were encouraging clothing manufacture (Annual Invoices of Trading goods wanted at the Mission stores, Hopedale, 1795. Original documents on file at the Moravian Archives, Bethlehem, Pennslyvania, Acc. No. 37254-37255) (Figure 5.6). Different sized needles were needed to accommodate different types of hide and cloth, and sewing styles. Thicker needles were needed for hide or canvas, while thinner or smaller needles were used for refined stitching details. 


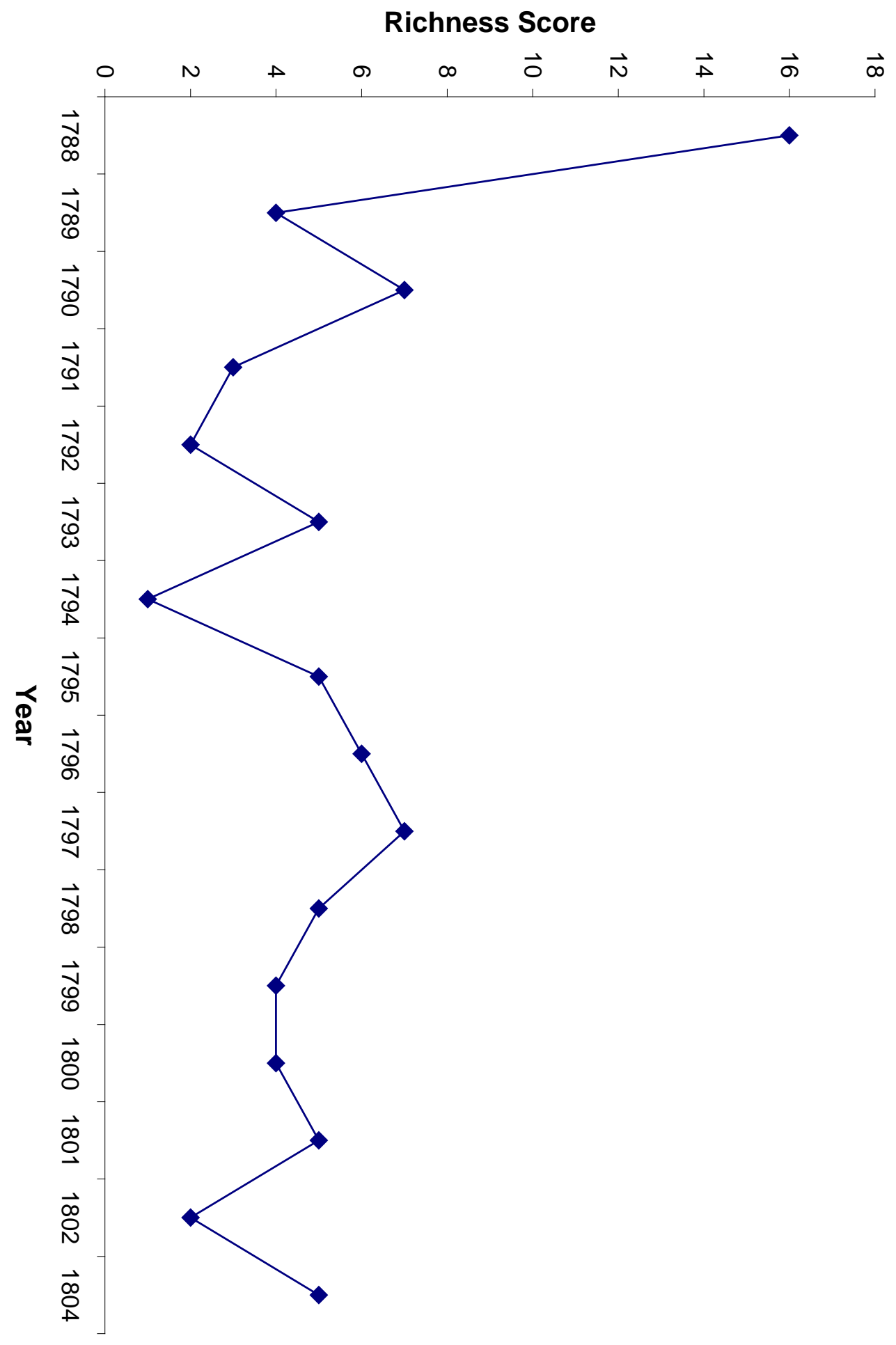

Figure 5.4: Richness scores for the manufacturing category at the trade store from 1788 through 1804. 


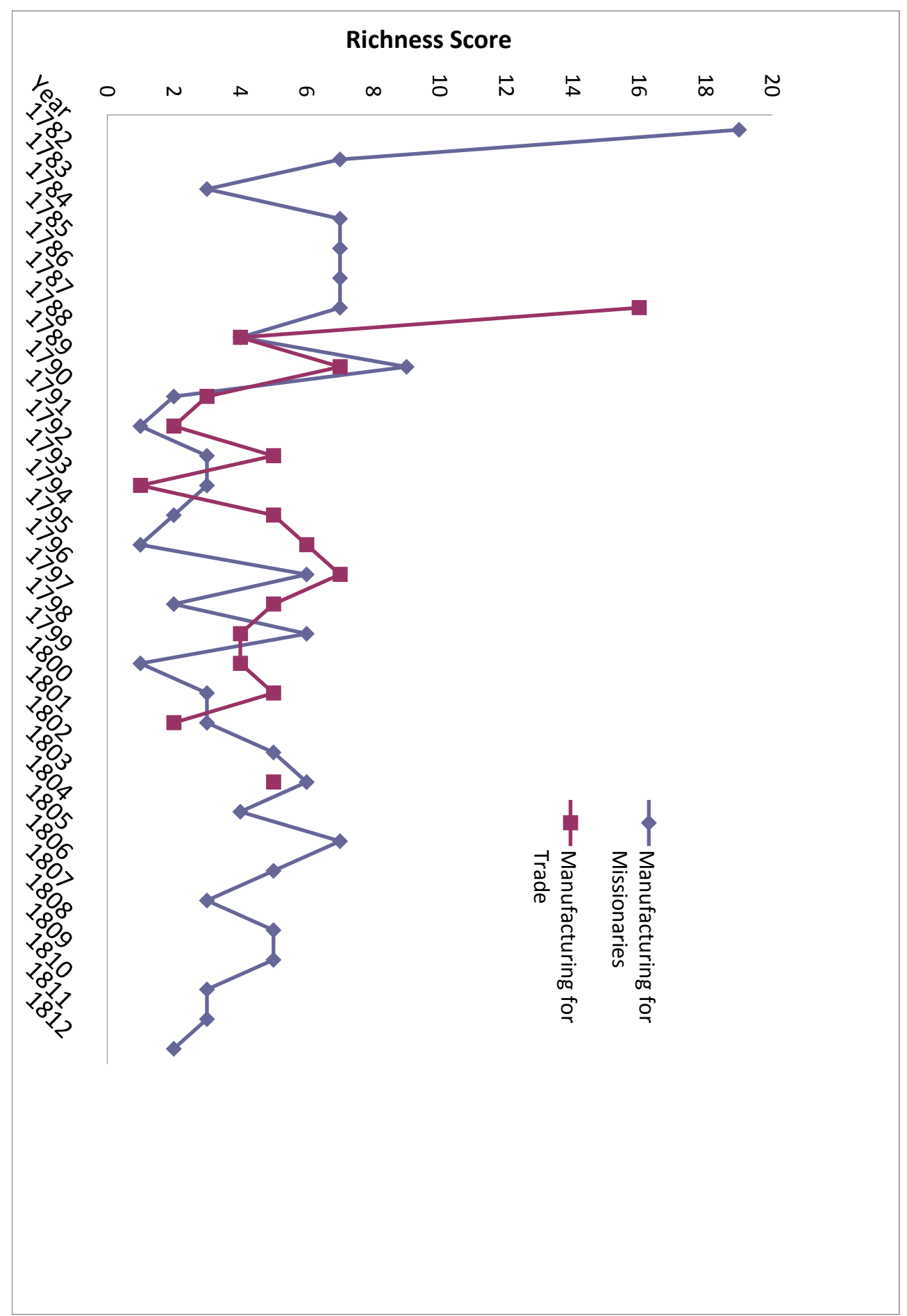

Figure 5.5: Richness scores of manufacturing from both the Trade List and the Missionary Lists over time. 


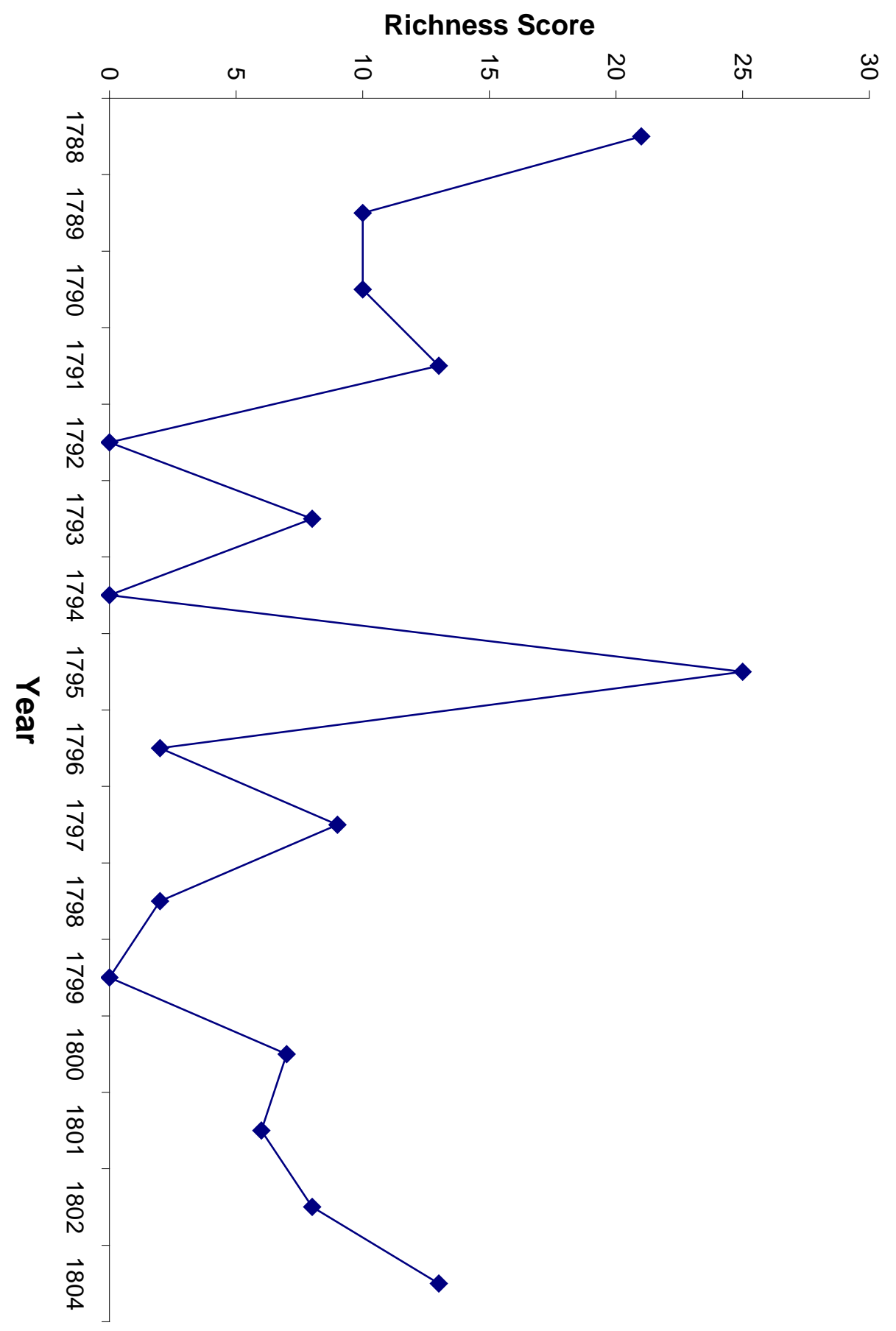

Figure 5.6: Richness scores for the clothing category at the trade store from 1788 through 1804. 
Needles would have been most readily used by female Inuit seamstresses, a position that garnered a great amount of respect from within the Inuit community. Wellmade clothing was a fundamental part of Inuit social life and research of nineteenth century patterns at Nain identified the rise of the seamstress within the Moravian community as a position of status (Cabak 1991:141). Prior to the Moravians’ arrival, Inuit women played a critical social role in maintaining the household, procuring hides, making suitable clothing that simultaneously honored the animal spirit, and keeping the lamps burning.

An example from another hunter-gatherer society in the subarctic, the North Alaskan Iñupiat, clearly articulates this tie. A man's responsibility was to treat the animal properly during the hunt, but it was the Iñupiat woman’s skill in constructing clothing from animal skin that ultimately determined her husband's success as a hunter (Bodenhorn 1990:64). The woman’s labor in butchering animals and preparing hides made her responsible for the well-being of the animal. While this spiritual association with animals was lost when Inuit started incorporating European cloth to replace animal hide, the status associated with Inuit women as seamstresses and the social significance associated with clothing manufacture carried over into the historic period. Men and women alike wore the hooded parkas or atiqik that maintained Inuit style yet incorporated European materials. The blending of Native and European cultural preferences commonly occurs in culture change process, and inclusion of European materials represents one example of the material expression of this subtle transformation. 
The Moravian’s inclusion of each needle size and ribbon color goes beyond their normal penchant for meticulous detail; the sudden rise in richness suggests Inuit requests for various needles led the Moravians to order a surplus to meet Inuit demand. The Moravians often accumulated a surplus of goods to be able to trade to Inuit over a number of years without having to rely on the unpredictable annual shipment from England for these particular items.

After 1799, the clothing scores appear to increase more regularly over time. While the time period was limited due to incomplete archival material, the steady trend in clothing richness post-1800 coincides with the growth of the mission population (see Figure 4.3). Inuit continued to wear their traditional fur parkas during the winter months, but replaced the thicker hides and fur with the European cloth during the spring and summer seasons (Cabak 1991:143). The Inuit maintained their traditional style of dress, but the lighter material proved more comfortable during the warmer weather.

The social role of seamstress and an Inuit demand for the lighter-weight cloth helped the Moravians promote their vision of the clean Christian Inuit that would stand in opposition to the traditional Inuit who were dirty, unkempt and heathen. By encouraging Inuit to change their style of dress served to establish a dichotomy between the devout, industrious, and Christian Inuit who lived in single-family homes at the mission, dress in European-styled clothing, and regularly attended services (Figure 5.7) (Loring 1990:212).

Alternatively, unconverted Inuit or "Heathen Eskimos” were depicted as nomadic individuals that visited the mission annually for trade (Figure 5.8). They were idolatrous, unkempt individuals who practiced polygamy, wore animal skins and ate raw meat 
(Loring 1990:214). By presenting these images as a contrast, the Moravians created the acceptable appearance of Christian Inuit which happened to incorporate different materials being sold at the trade store.

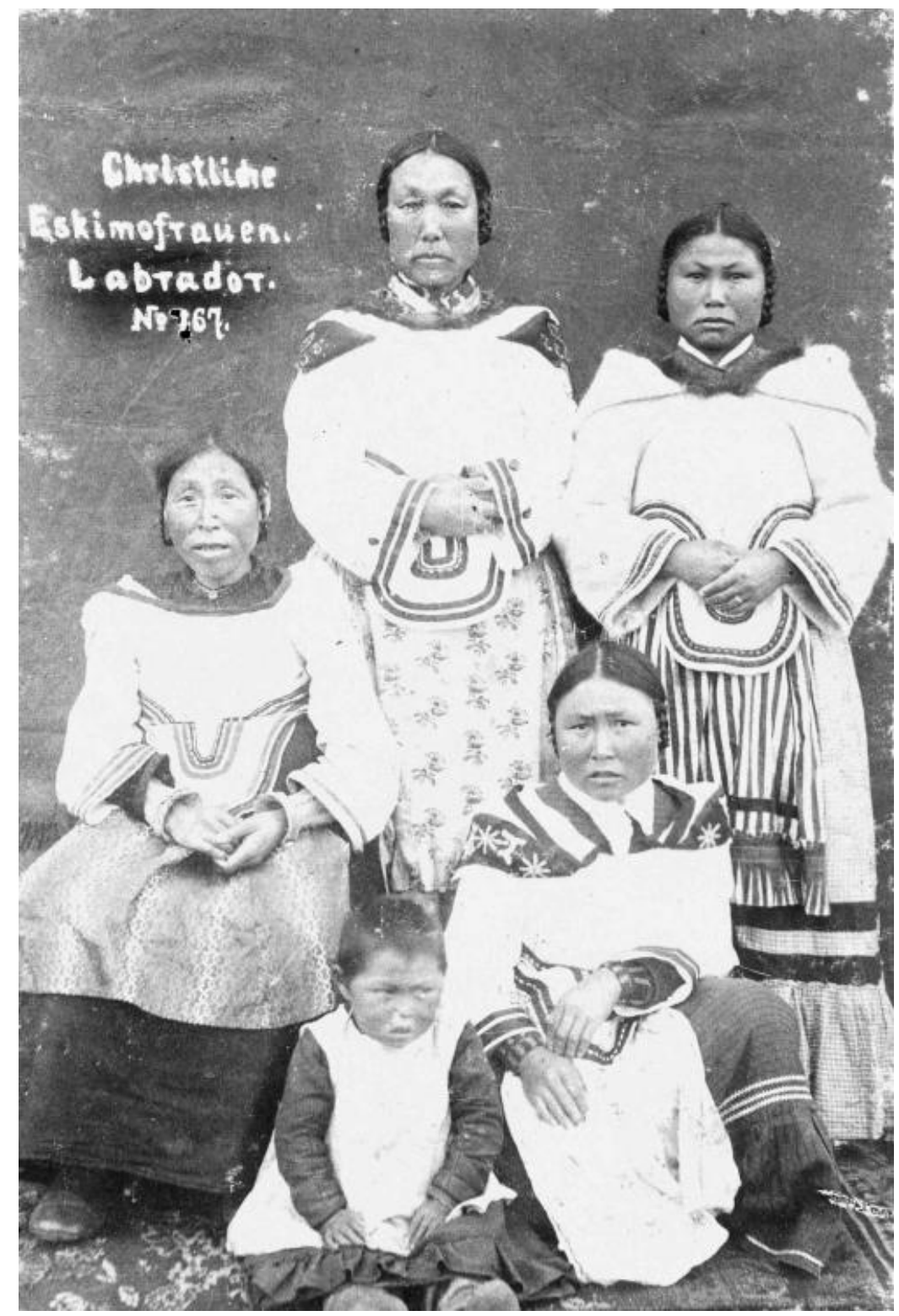

Figure 5.7: Black and white photograph of four Christian Inuit women and a child between 1884 and 1902 from the Paul Lundberg collection. Note the use of European materials with the Inuit style parka (Source: Labrador Inuit Through Moravian Eyes http://link.library.utoronto.ca/inuitmoravian/index.cfm). 


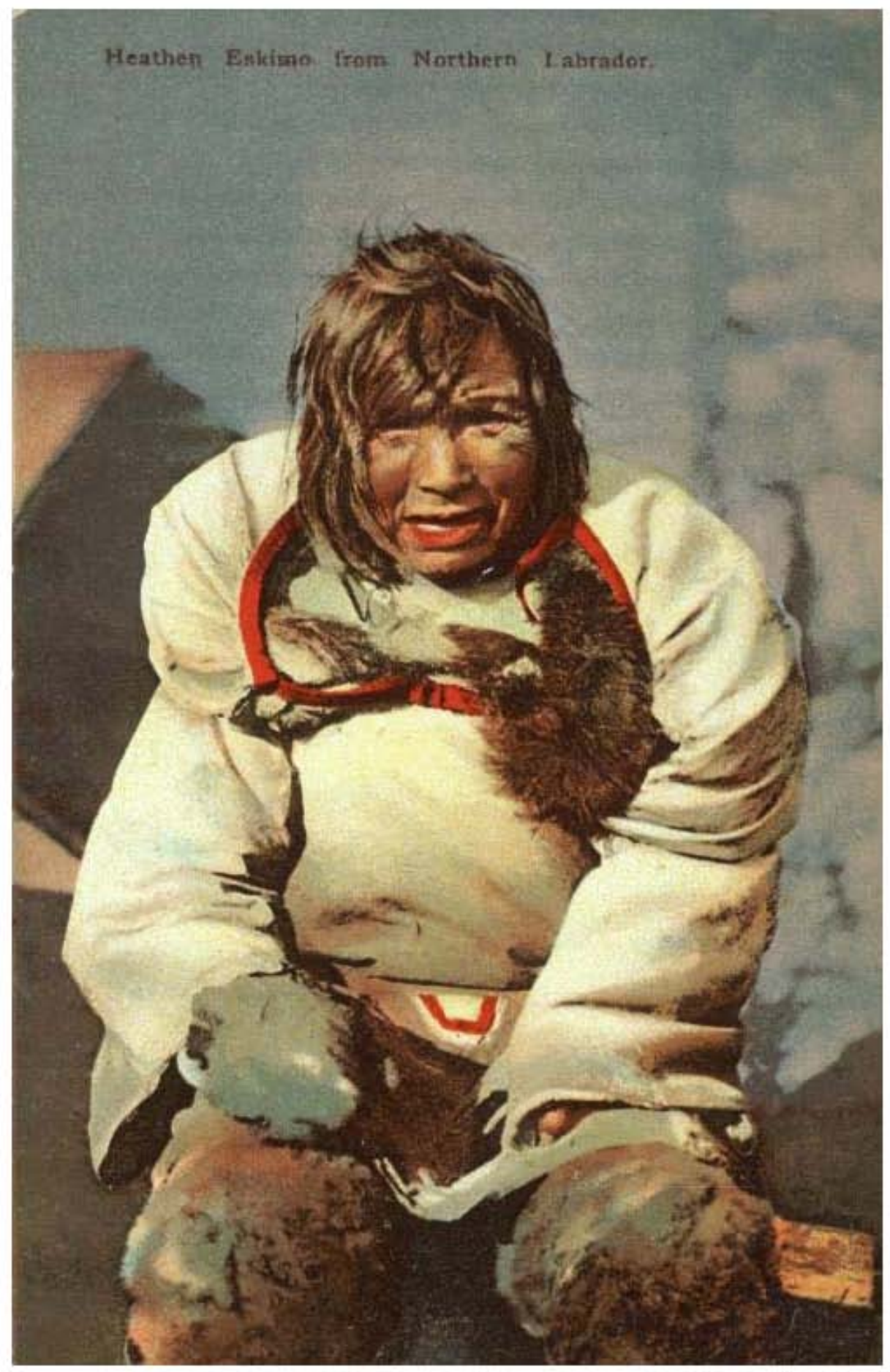

Figure 5.8: Color postcard of a "heathen” Labrador Inuit woman in traditional clothing circa 1910 from Mary Schwall collection (Source: Labrador Inuit Through Moravian Eyes http://link.library.utoronto.ca/inuitmoravian/index.cfm). 
While the Moravians hoped the adoption of European materials signaled a shift towards Inuit accepting other elements of European civility and Christianity, the byproduct of this change was that Inuit began to replace traditional fur and hide clothing with cloth that was only available at the trade store. The Moravians provided Inuit with clothing, leading the Inuit to rely less on the summer caribou hunt for skins and hides (Cabak 1991:171). If Inuit no longer needed to process furs and hides for their clothing since cotton and wools became more plentiful at the trade store, then reliance on male hunters would also decrease. Inuit subsistence strategies would shift away from hunting animals as a resource for food and clothing, and focus on hunting animals as a commodity for trade and export. As a result, the Moravians unintentionally made Inuit dependent on them — the one thing they hoped to prevent — in their attempts to create a Christian Inuit.

The Trade Lists reveal the subtle attempts by the missionaries to manipulate Inuit consumption habits. The Moravians did not increase the variety of goods over time as expected; instead, a specific selection of goods was requested by the Moravians at certain times. Calculating a Kendall tau correlation, a non-parametric test that measures the association between two categories, between all of the categories shows a strong correlation between richness scores of the Clothing and Domestic categories as seen in Table 5.2. Kendall tau measures the strength of correlation between the variables and is carried out on the ranks of the data and falls between the range of -1 to +1 . The advantage of Kendall tau is that the distribution has better statistical properties and there is a direct interpretation in terms of probabilities of observing concordant and discordant 
pairs (Conover 1980). The correlations calculated here suggest that the Moravians were simultaneously requesting clothing and items for the home to be sold at the Trade Store at approximately the same rate. Additionally, the clothing and tool categories, and the domestic and tool categories exhibited moderately high correlations between each respsective pair.

The Trade List shows that some items were being made available as a response to Inuit demand, but other materials were also presented with the hope of introducing European values. The missionaries set forth to "civilize” the Inuit by remaking both the person and the home. They emphasized the role of Christianity in the introduction of specific goods to inculcate European culture (Comaroff and Comaroff 1992). In short, clothing, tools and domestic items would produce a new kind of Inuit identity that aligned with the strong work ethic, evangelical imagination and ultimately, the Moravian ideal.

\begin{tabular}{|c|c|c|c|c|c|}
\hline \multicolumn{6}{|c|}{$\begin{array}{c}\text { Kendall Tau b Correlation Coefficients, } N=16 \\
\text { Prob > |tau| under HO: Tau }=0 \text { at } \alpha=0.1\end{array}$} \\
\hline & Clothing & Domestic & Hunting & Manufacturing & Tools \\
\hline Clothing & 1.00000 & & & & \\
\hline Domestic & $\begin{array}{r}0.60882 \\
0.0022\end{array}$ & 1.00000 & & & \\
\hline Hunting & $\frac{0.34398}{0.0800}$ & $\begin{array}{r}0.32081 \\
0.1120\end{array}$ & 1.00000 & & \\
\hline Manufacturing & $\frac{0.34240}{0.0803}$ & $\begin{array}{l}0.24420 \\
0.2247\end{array}$ & $\begin{array}{c}0.29493 \\
0.1377\end{array}$ & 1.00000 & \\
\hline Tools & $\begin{array}{r}0.52920 \\
0.0067\end{array}$ & $\begin{array}{r}0.53292 \\
0.0079\end{array}$ & $\frac{0.35781}{0.0711}$ & $\frac{0.38357}{0.0522}$ & 1.00000 \\
\hline
\end{tabular}

Table 5.2: Kendal Tau Correlation Coefficient for the richness scores of Clothing, Domestic, Hunting, Manufacturing and Tool subgroups from the Trade Lists. The highlighted coefficients indicate moderately correlated categories and underlined coefficients indicate weak correlations between categories at $\alpha=0.1$; the remaining correlations were not statistically significant. 
The Trade Lists highlight the Moravians’ attempt to rapidly incorporate Inuit into a larger European economic system. Initially, the Moravians attracted Inuit to trade at their store by providing items desired by the Inuit, but quickly shift to include materials that would only benefit Inuit who adopted economic endeavors introduced by the Moravians, such as sealing and fishing. Unfortunately, interpretation of the Trade Lists is limited as they only represent the Moravians’ approach to introducing new cultural features, and not the degree to which Inuit adopted those materials in their daily lives. The trade store was the most likely venue for Inuit acquisition of European goods, but not the only way. The Moravians note in the diaries that they gave gifts from their private supply. Missionaries gave clothing and toys as rewards to Inuit who were learning the Gospel. They also provided food to help starving Inuit during times of scarcity. A more comprehensive look at all goods available at the mission and not just the Trade Store reveals the extent material was available to Inuit who lived or visited the mission.

\section{Missionaries’ Lists}

These lists represent the catalog of goods shipped from England to Hopedale from 1782 to 1813 sent specifically for development and maintenance of the mission. These were the probate lists and record the items received by the missionaries. When the richness scores were tracked over time, it revealed there was an overall weak correlation between the richness of goods being imported and time (Figure 5.9). The linear regression, which measures how well a linear equation describes the relationship between time and imported items, shows there was a weak association that decreased over time ( $r$ 
$=-0.354)$. Unfortunately, linear regression is greatly influenced by outliers, unequal variances, non-normality, and nonlinearity. Studying the differences between actual values and the predicted values, the residuals, revealed where the regression did not fit (Drennan 1996; Shennan 1988), and highlight the presence of three separate trends from 1782 to 1790,1791 to 1804 , and 1805 to 1813 , suggesting there are non-linear trends in the data and that a linear regression model is not the best fit (Figure 5.10).

The first period showed a decrease of richness values from 1782 to 1790, with the most significant drop-off in 1783. The richness score from 1782 is clearly an outlier, particularly since it represents the mission's first year when the majority of materials and food were sent by the church. The fluctuation of the richness scores of the subsequent years suggests that there is no correlation with time. Even so, the scores from these eight years are higher on average than any other period. The first decade represents the foundation of the mission, a time when many of the mission buildings were still under construction, thus requiring a greater amount of materials and tools. The higher richness scores during this period again reflect the missionaries’ need for basic goods, foods, and materials to help establish the mission.

The second period from 1791 to 1804 was marked by its lower scores but gradual increase over time. The final period between 1805 and 1813 showed little correlation to time as yearly imports fluctuated (Figures 5.10). Closer analysis of the separate periods suggests that specific historic events discussed in Chapter 3 (i.e., the rise of Europeans along the Labrador coast) may have influenced these shifting patterns. 
As already noted, the richness value from 1782 has a higher than expected score, thus influencing the overall correlation score. In 1782, the mission received its very first shipment that included a wide variety of items necessary for the initial development of the mission. The subsequent richness scores were lower and oscillated from year to year, neither rising nor falling over time. These scores were primarily influenced by the import of European foods and clothing. Given that many of the Hopedale missionaries had never lived in Labrador or in an Arctic climate, the great amount of variety being imported may reflect the missionaries’ attempts to continue a European lifestyle with which they were familiar. The richness scores may also reveal the missionaries’ apprehension and anticipation of the difficulties they will undoubtedly endure while living in such a new and foreign environment.

The second period reflects a steady increase of the variety of materials imported to Hopedale over time, culminating in 1804, the year the Moravians deemed as the Great Awakening. This rise coincides with a gradual increase in the mission population (see Figure 4.3) which I argued in Chapter 4 was the result of increased hostilities occurring in the south and a sudden and serious food shortage that lasted into the 1800s. Settling at or near the mission which could provide food and goods was a promising option for many Inuit. 


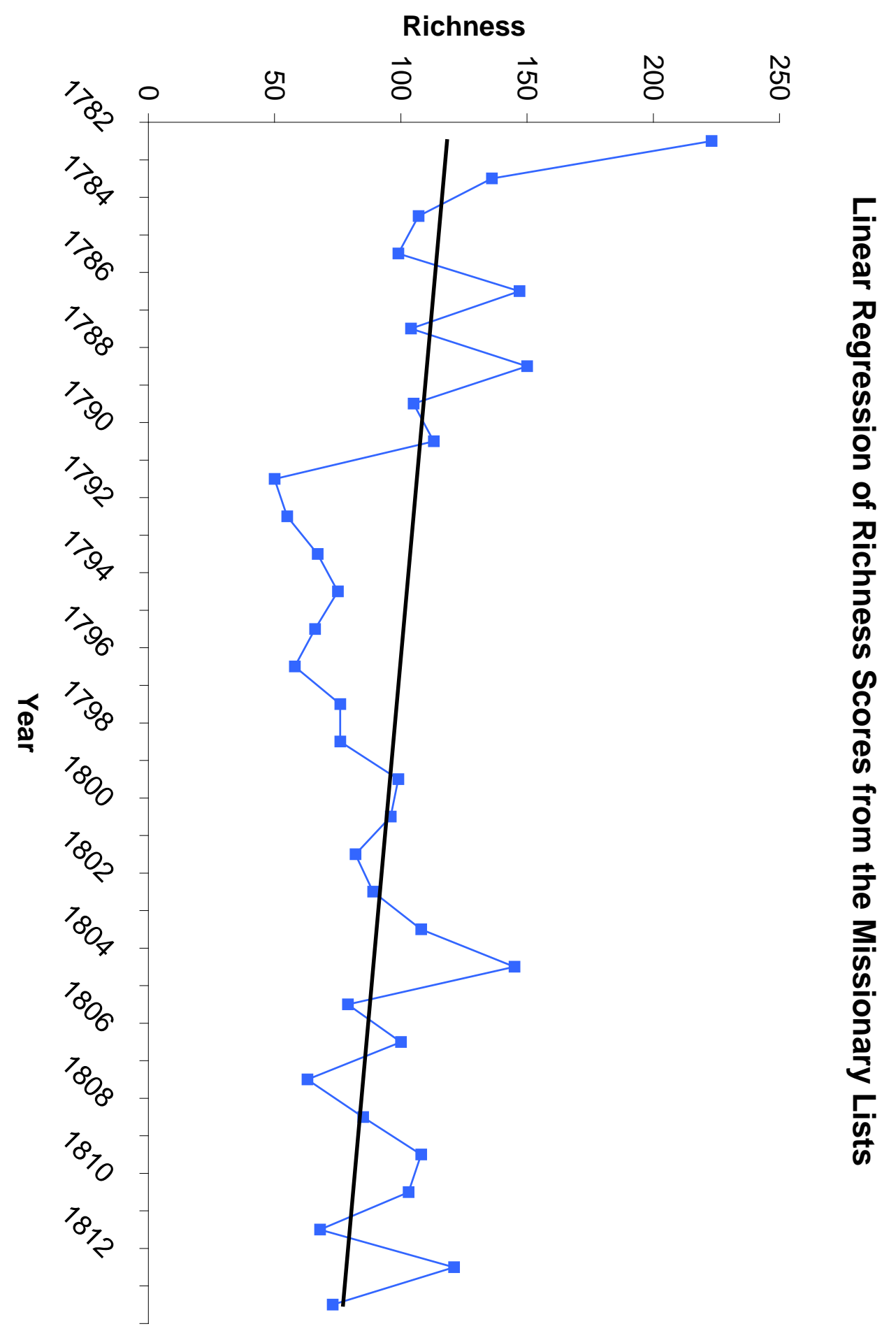

Figure 5.9: Richness scores for imported items from the Missionaries’ Lists from 1782 through 1813. 


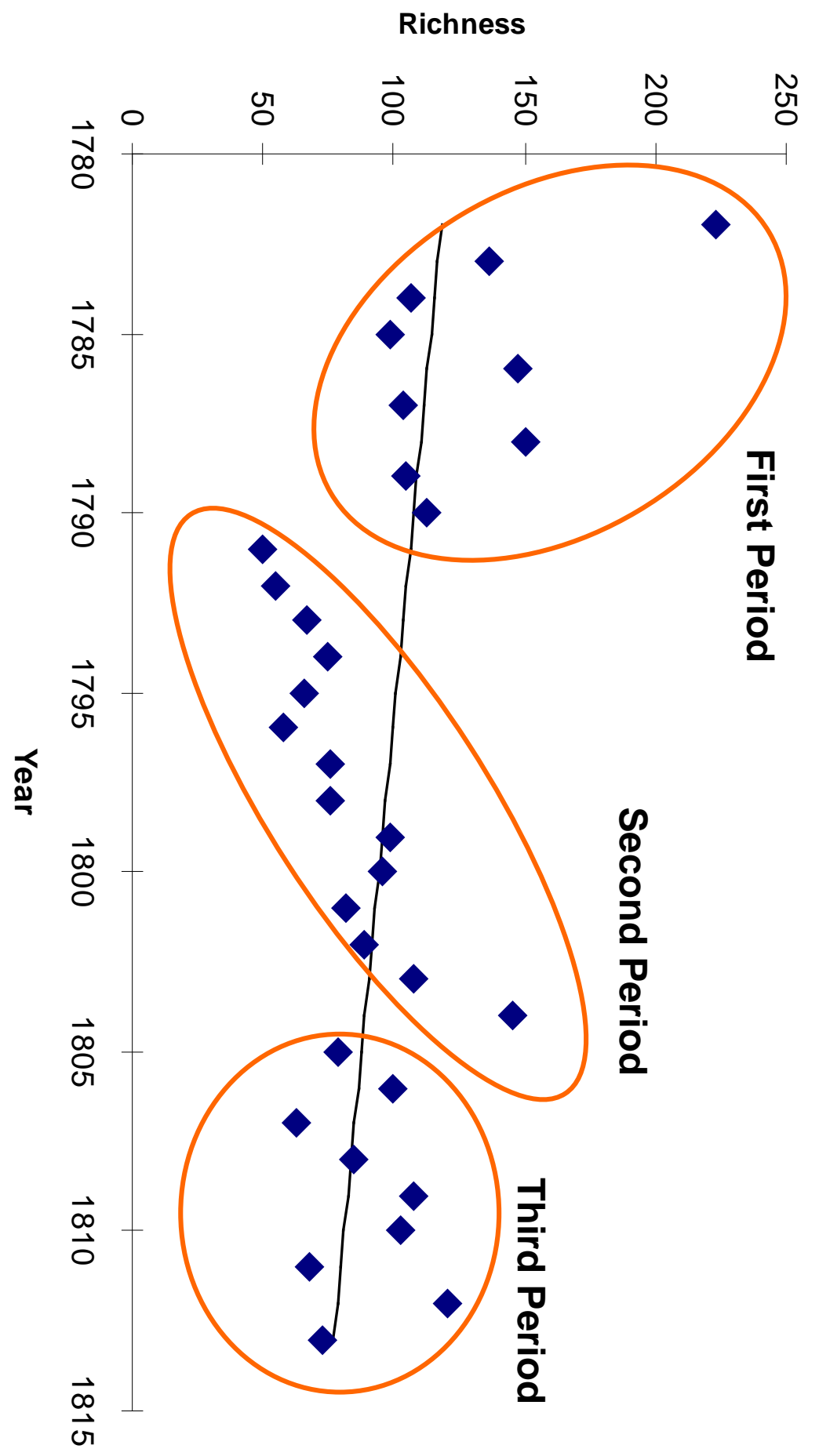

Figure 5.10: Linear regression of richness scores of the Missionaries’ List from 1782 through 1813 with the three periods identified. 
Recalling that a fundament aspect to Inuit culture was the practice of sharing, Inuit may have been settling near the Moravians to gain access to otherwise depleted resources, especially food, with the expectation that they would be shared. By occasionally sharing their food and other goods with Inuit, the Moravians may have been perceived by Inuit as participating in acceptable Inuit practices. This act may have helped to promote the mission as a viable option among Inuit, leading to the rise of the mission population and perhaps the conversion of at least a few people.

As more Inuit chose to move to the mission and settle, the missionary population also had to grow to accommodate the needs of a larger congregation. Annual letters written by missionaries to members of the Moravian church in Germany note the arrival of many new missionaries (George Schmidtmann to Brother LaTrobe, September 18, 1797, The Moravian Archives, London, England). Lists of the number of missionaries residing at Hopedale were not collected; however, the number of missionaries listed as receiving items on the Missionary Lists doubles from four to eight from 1791 to 1804. While not all of the Moravians living at Hopedale are listed on these probate lists as receiving items, the records suggest that the rise of the richness scores was due in part to the requests of new missionaries who sought the comforts of home. The import invoices for this period included specific requests by missionaries, such as additional pieces of clothing and luxury items for personal consumption including tobacco and ale. The richness scores for this second period highlight the development and growth of the new Hopedale mission. 
The final period identified from 1805-1813 does not indicate a strong correlation with time; however, the scores were higher than the second growth period, suggesting a period of stability after an era of growth. The post-Great Awakening period was a time when the Moravians were a well-established institution in Labrador and exerted new efforts to convert more Inuit. The higher richness scores suggest that items being imported were to meet the demands of the larger missionary community and emergent Inuit congregation.

Analysis of the overall richness scores from the Missionaries’ Lists identify three periods that offer a general overview of the transformation and evolution of the Hopedale mission that underwent a period of development followed by growth and stability. Yet a better understanding of what individual categories of items are being imported is needed to understand what areas the Moravians focused on as avenues towards influencing Inuit to convert and adopt European behaviors. The remainder of this chapter focuses on identifying the categories of items that influenced the overall Missionaries’ List richness scores and how they played into a larger Moravian ideal.

One area where significant change appeared was in the development of the mission as an economic enterprise. Beyond the church congregation, Inuit were becoming a fundamental part of the mission’s economy as their labor helped produce commodities exported to the European market. Participating in this capitalistic economy and displaying a good work ethic was an important part of the Moravian Christian ideal, where one's worldly work intended to benefit both the individual and society (Weber 1958). By employing Inuit to hunt for seals or at the blubber factory, the Moravians 
could also monitor Inuit behavior and keep temptations at bay, especially those provided by the southern traders and non-converted Inuit.

Inuit were becoming an important part of the work force, providing the majority of the wage labor for production of oil, skins and later, fish. Over time, Inuit gained more opportunities to garner wages or bartering-status at the trading store. Seal oil and pelts became extremely valuable on the export market and their profits helped fund the Hopedale mission. Thus, the relationship between the missionaries and the Inuit was becoming more symbiotic as each relied on the other for products or goods.

Despite attempts to incorporate and use local resources for food, the missionaries continued to rely on imported food from Europe. Richness scores from the non-local foods were three to four times higher than those from the Trade Lists and were imported with regularity throughout the first 30 years. The Moravians imported a wide variety of food items including beef, pork, spices, vegetables, sugar, sauerkraut, nuts, butter, flour, and rice. The marked difference in food richness scores between the Missionary Lists and the Trade Lists reveals that imported food was intended solely for missionary consumption and not to be distributed to non-converted Inuit.

Even though foreign food was being imported with some regularity, the overall correlation between the variety of food from the Missionaries’ Lists and time was low ( $r$ $=-0.26$ ), as scores fluctuated yearly (Figure 5.11). One reason for the annual shift may be tied to seasonal hunting difficulties. Hunting in Labrador can be very unpredictable with constantly changing weather patterns due to atmospheric circulation, ocean currents, and the presence of sea ice along the entire Labrador coastline, all of which affect the 
coastal ecosystem and animal migrations. While migration patterns would affect which animals Inuit and missionaries would come in contact, the presence of ice could influence accessibility. For instance, stable, solid sea ice can link islands with the mainland, providing access by foot or sled to a variety of habitats previously only available by boat. On the other hand, unstable ice such as shifting pack ice or melting ice in the spring can prevent people from accessing those same productive hunting or fishing areas. Thus, the different environmental factors added a level of complexity to hunting strategies that did not always lead to hunting success; this resulted in the Moravians relying on imported food, which they often shared with the Inuit.

Food shortages or scarcity occurred regularly at all Labrador missions. Even though the missionaries relied on the Inuit to help acquire local resources, I suggest the Moravians compensated for anticipated shortfalls by ordering a surplus of food based on years when local hunting was less successful. Archaeological research from a nineteenth-century Moravian deposit in Nain indicated that the missionaries were incorporating local resources, especially seal and caribou (Cabak 1991; R. Ferguson 2003), but that they rarely met the appropriate amount need to feed an entire mission and its congregation. The Moravians frequently wrote letters to their family members and the German church detailing their frustration with hunting and fishing in the subarctic landscape, perhaps an attempt to justify their demands for imported food. 


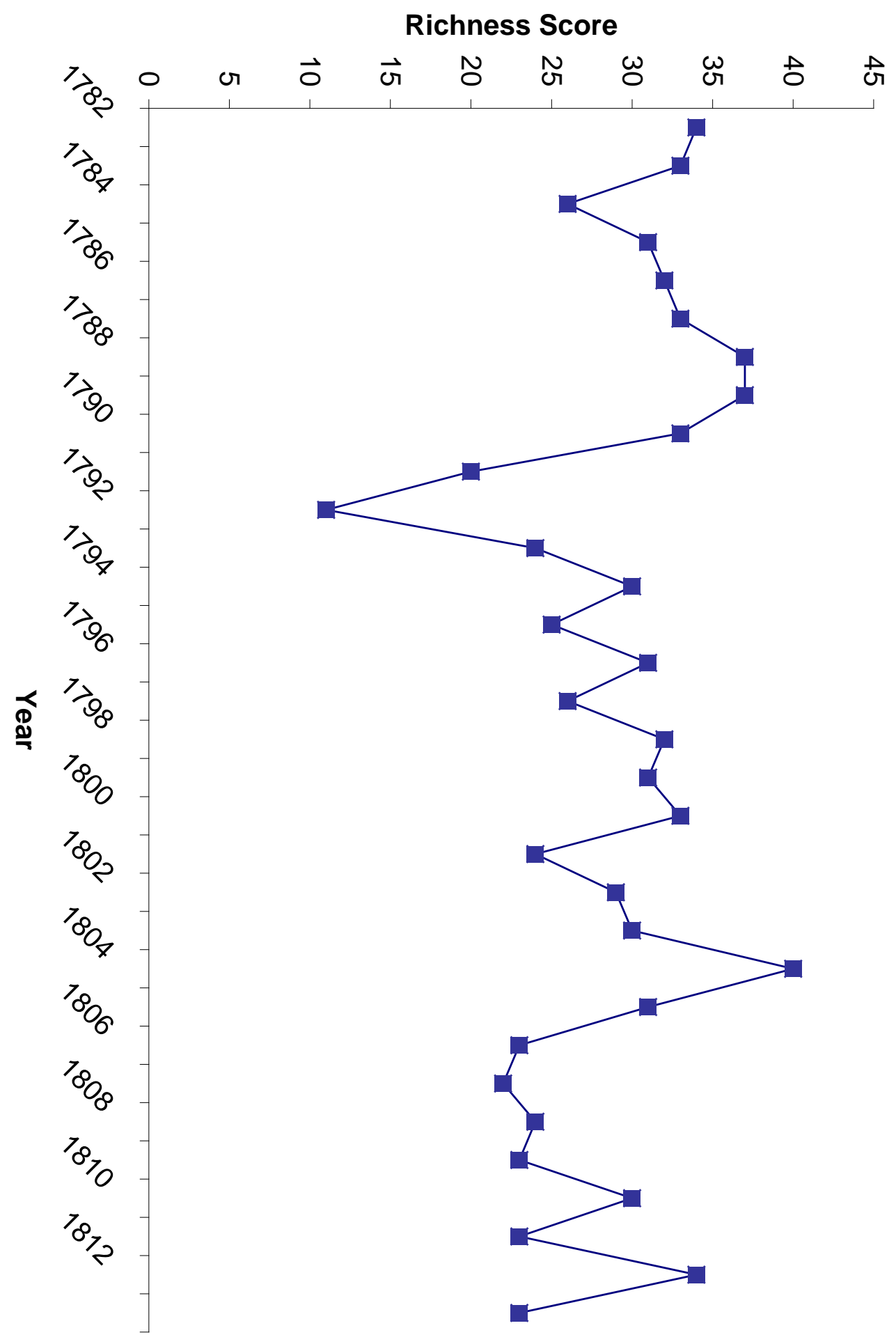

Figure 5.11: Richness scores for the food category from the Missionaries' Lists from 1782 through 1813. 
The years in which the Moravians recorded unproductive hunting trips coincided with years that exhibited high richness scores, and vice versa. For instance, years when Hopedale missionaries received a lower variety of food items such as in 1792 and 1795, they documented successful hunting seasons. The Periodical Accounts note that hunters caught enough partridges, caribou, and seals to last throughout the season, thereby requiring fewer supplements (PA 1792:156, 1795:350). Years exhibiting higher than average scores such as 1790 and 1812 coincide with documentation for poor hunting seasons (PA 1790, 1812:259).

The dilemma with importing European food was that it was intended to satisfy missionaries’ needs and not be shared with Inuit, who were expected to continue consuming traditional foods. Yet the prevalence of starvation at all Labrador missions combined with the missionaries’ belief they were there to help Inuit reach salvation, often led the Moravians to share their personal supply of food. In 1800, they report Inuit living near the Hopedale mission suffered from hunger since they did not store enough food for the winter. The Moravians claim in their annual report from 1801 in the Periodical Accounts that,

Most of what our [Inuit] people had laid in...the spring in 1800, was consumed in autumn, as they could get nothing in the interval, and their attempts upon the thin ice were mostly unsuccessful. The poor sick people had hardly any thing to eat, which made their situation truly deplorable, and we could not but lend them assistance. (PA 1801:11)

Such acts of charity also would influence the need for additional food supplies the following year, leading to slight increases in richness scores as the missionaries tried to replenish their personal stocks. While the missionaries frequently engaged in this type of 
assistance, the jump in richness scores for food appears to be most heavily influenced after community-wide famines.

While the Moravians tried to limit Inuit access to European food to some extent, the missionaries' decision to share their personal food supplies in an effort to prevent starvation among potential converts set a precedent. The Moravians did not realize that their actions reinforced a social organization where the community leader shared resources. A result of unintentionally abiding by Inuit social rules led to the missionaries' continued frustration with Inuit asking for food during times of scarcity, rather than store more food.

The attempt to restrict Inuit access to food did not extend to all Europeanmanufactured goods. In fact, they were more liberal with providing access to materials used for the manufacture of clothing. As noted in an earlier section of this chapter, the Moravians provided a variety of cloth and sewing implements for the Inuit at the trade store. Similarly, the Missionaries’ Lists reflected a great variety of clothing, cloth and sewing equipment; however, the Moravians did incorporate traditional Inuit clothing given its durability and warmth to withstand the harsh Labrador winters. A 1789 letter from a Hopedale missionary to an English Moravian discussed the benefit of traditional seal skin clothing in enduring the colder winters, commenting that it might be useful in European climates (David Kriegelstein to Secretary Benjamin LaTrobe, June 7, 1789, The Moravian Archives, London, England). Despite the utility of Inuit clothing, the Moravians' displeasure with the smell of the garments and the labor required to procure the hides may have led missionaries to opt for the use of cottons, flannels, and wools. 
But the Moravians also did not leave significant changes to chance, and were forthright with their wishes for Inuit to change their physical appearance and incorporate cleanliness by distributing clothing to women and orphans living at the mission (Cabak 1991:87, 141). The missionaries hoped that those who dressed in European clothing and lived in single family homes would serve as an example for the wild unconverted heathen.

Given this penchant for transforming Inuit into a civilized society, I expected to see a rise in clothing richness scores over time as more Inuit converted and accepted the new European style. Yet the variety of clothing related items did not correlate with time $(r=+0.095)$ (Figure 5.12); rather two distinct trends emerge. From 1784 to 1789 and again from 1796 to 1804, clothing richness scores increased over time. Reasons for the rise of scores during the later period from 1796 to 1804 may be tied to the mission’s period of growth, yet reasons for the rise seen from 1784 to 1789 is less clear. This earlier trend coincides with the initial development of the mission, and may be the result of Moravians wanting European-styled clothing rather than adopting the less-hygienic Inuit style. Missionaries’ may have been attempting to use material culture to help deliver messages reflecting European ideals tied to Christian ones.

The Moravians exposed Inuit to a variety of other skills common among European societies including reading and writing. As discussed earlier, the Moravians were meticulous record keepers, documenting every element of the economic, social and religious life of the mission, as well as maintained regular contact with the English SFG, the German Church, and other missions worldwide by contributing to the Periodical 
Accounts. This part of mission life was captured in my classification of elements related to record keeping such as reams of paper, ink, and quills called the "Writing” category. As writing was a constant and necessary part of the mission, I expected to either see a constant amount of writing-related materials being sent annually, or peaks and valleys of the richness scores as the missionaries accumulated materials for surplus. Figure 5.13 shows the richness scores for the "Writing" category and the presence of peaks and valleys in the latter half period analyzed, however, another interesting trend appeared.

From 1785 to 1796, the Writing category showed a decrease of the variety of imported items over time. Since writing did not decline during this period as evidenced by the thousands of documents in the archive, the decline of richness scores may instead suggest that the certain items needed constant replenishment, such as ink, or starch to make paper, while other items were ordered less frequently but in greater quantities, such as quills or pencils. For instance, from 1803 to 1809, a single order of 100 quills was imported annually. Since the mission Inuit population rose to just above 140 individuals during this period, and writing became an important part to learning the Scripture, the constant request for quills may be an attempt to replace the heavily used item.

After 1800, the writing category exhibited the highest scores on average although it fluctuated annually. While I believe this fluctuation suggests the Moravians attempt to build a surplus, I also believe more Inuit were engaged in writing or learning how to write. In 1790, the Moravians established a school at Hopedale to teach Inuit children to read and write (PA 1790:94). Unlike other missionaries of the time, the Moravians did not require Inuit to learn German or English; instead, the Moravians taught classes in 
Inuktitut, the Inuit language. The introduction of written texts and the publication of an Inuktitut reader in 1790 serve as the first examples of the Inuit language being translated into written form. Initially, classes were small as Inuit continued to take their entire family when traveling along the coast to trade or hunt. But after the 1804 Great Awakening and the Hopedale mission saw a rise in converts, more writing materials were needed to accommodate the growing mission and its school. 


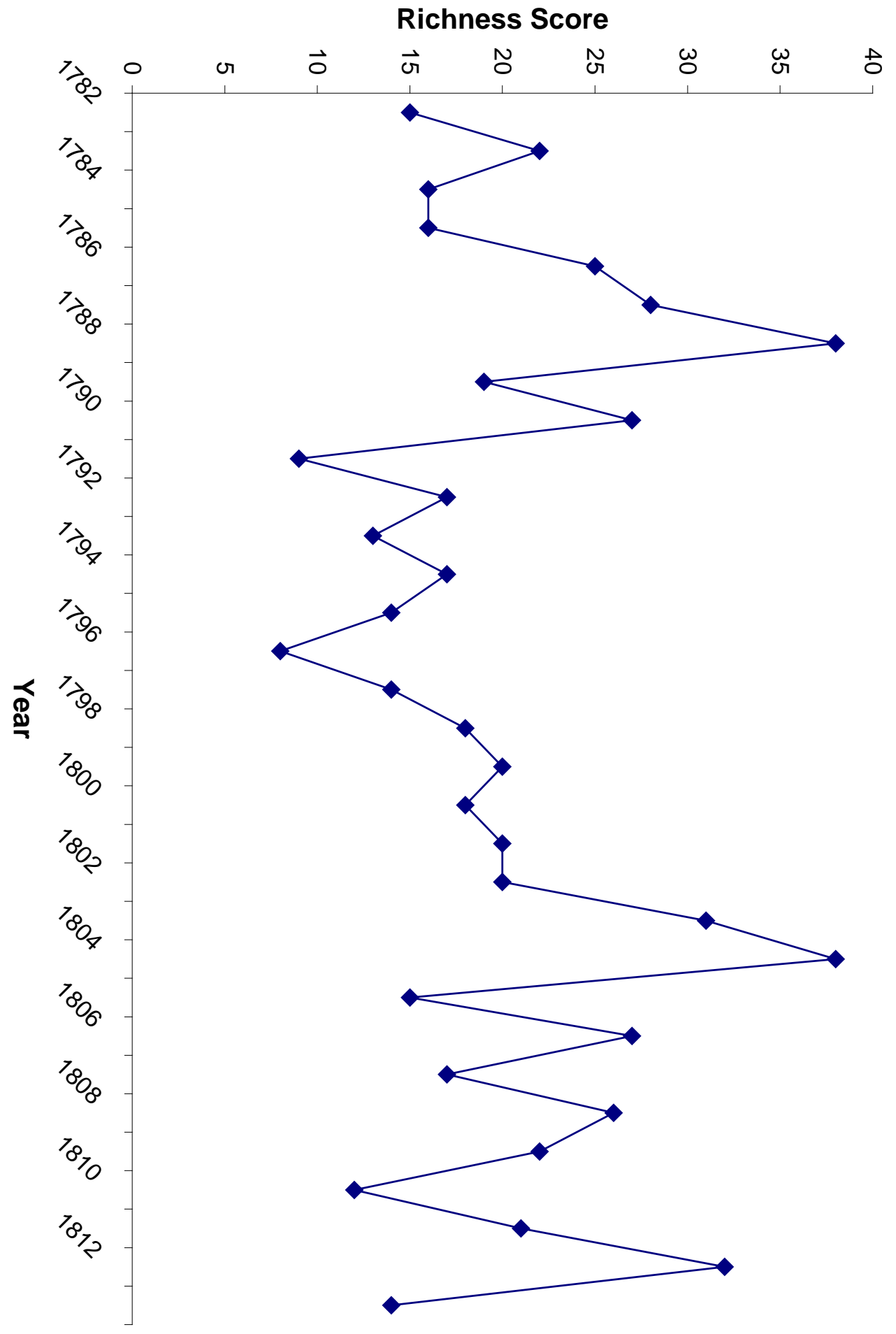

Figure 5.12: Richness scores for the clothing category from the Missionaries’ Lists from 1782 through 1813. 


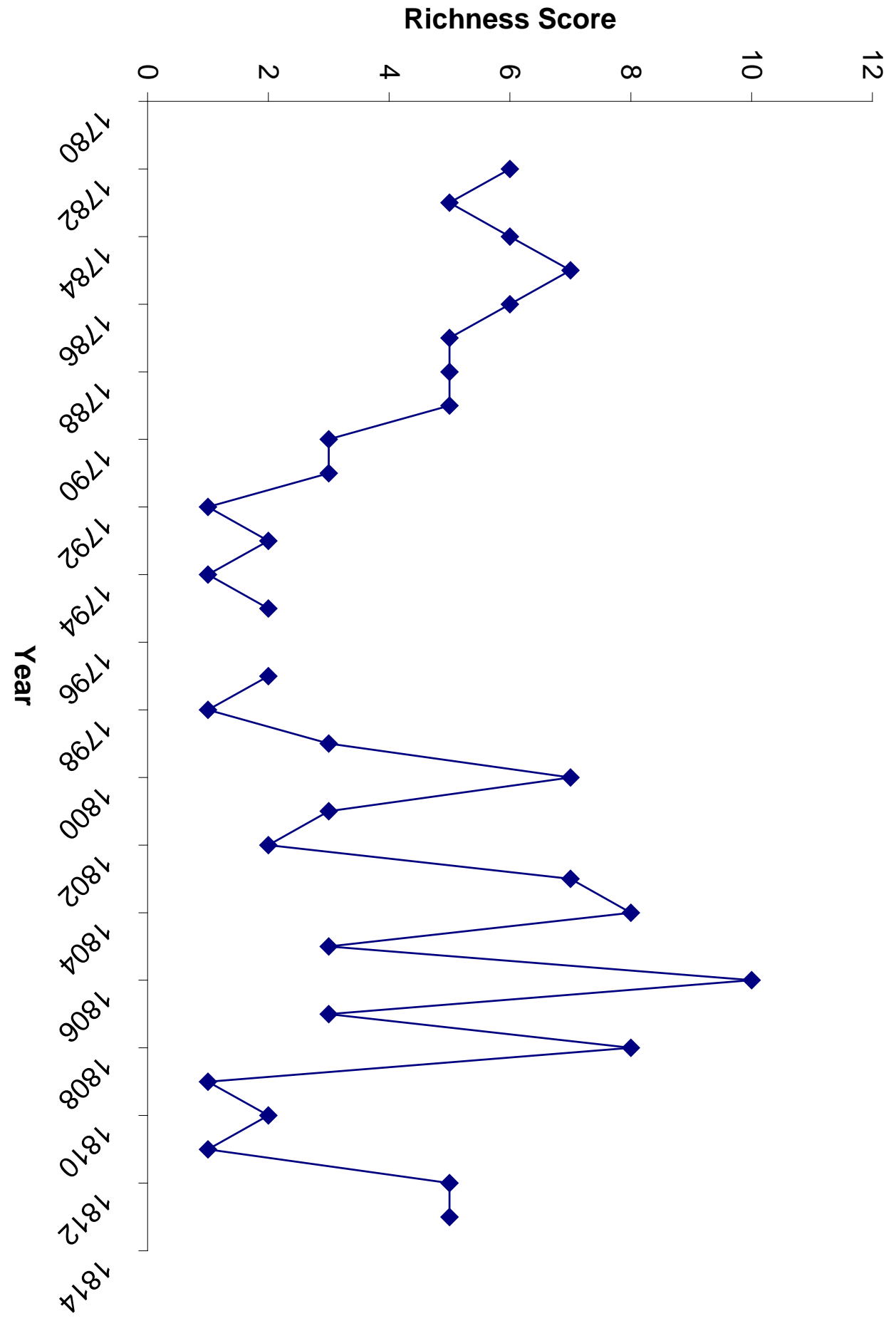

Figure 5.13: Richness scores for the writing category from the Missionaries’ Lists from 1782 through 1813. 


\section{Chapter Summary}

The analysis of the Moravian historical documents highlights the development of the Labrador mission and the missionaries’ attempt to build it into a structured European society. Rather than attempt to dismantle an existing social hierarchy, the documents reveal that the Moravians tried to carefully control the cultural and religious transformation by restricting Inuit access to some items but making other items readily available. For instance, the Moravians offered a very limited variety of European foods in the trade store, but provided a greater assortment of materials used for hunting. By limiting access to foreign foods, the Moravians hoped Inuit would maintain traditional subsistence practices and related material culture. While the Moravians may have initially used goods to attract Inuit to the mission, their subsequent control of the distribution of goods intended to convey a specific Christian message tied to a European sensibility.

Converting Inuit also meant civilizing them, or introducing a European lifestyle which included particular ideals about cleanliness, appearance, and a Protestant work ethic. These European ideals opposed the delicate yet intricate Inuit structure; changing one component, such as Inuit clothing, had multiple repercussions in other arenas of Inuit life. The Moravians’ insistence on Inuit wearing clean clothes or participating as wage labor in the blubber and fishing industry directly influenced what animals Inuit hunted, ultimately changing their subsistence practices. 
The import richness scores revealed the Moravians' calculated approach to converting Inuit and how those goals shifted over time with the growth and development of the mission. Originally, the Moravians approached Inuit via an emic tactic that sought to gradually introduce Christianity as an alternative to the shamans. The Moravians provided items in the trade store that Inuit wanted.

But Inuit lives were characterized by mobility and a degree of independence that defied a Moravian sense of the Christian community (Lydon 2009). Eventually, the Moravians imposed new methods of hunting, styles of clothing, and living based on Western standards of civilization, thereby ignoring Inuit social mores that abided by a natural and spiritual relationship with the land and each other. But changing conditions in the south led some Inuit to remain in the north and consider the new materials and ideas of the Moravians.

While these historical documents offer substantial details and descriptions of Inuit and their culture, the interpretations are still through a European lens. These inventories and records only capture the moment when these items arrived in Hopedale, providing little information regarding object use or reuse by Inuit or the Moravians. Examining the historical record alone can only provide the potential insight into the lifestyle changes that accompanied the Moravian presence. As the mission landscape changed with the arrival of new Moravians and goals regarding conversion and civilization methods changed over time, the flow of materials and information shifted to reflect those new ideas. Some Inuit adopted and adapted to the new order, while others did not. Identifying whether explanations for these differences was rooted in a pre-existing Inuit 
social hierarchy requires understanding the social situation prior to the Moravian’s arrival, as preserved in the archaeological record. 


\section{Chapter 6: Introduction to the Sites: Avertôk, Anniowaktook, and Adlavik}

This project proposes to bridge the temporal gap in research on the early historical period by using evidence found at eighteenth-century sites to shed light on Inuit practices in the nineteenth century. Previous research on Labrador Inuit sites largely focused either on early historic or Moravian sites; rarely were sites from the two periods compared or discussed simultaneously. A better understanding of the situation before the Moravian's arrival will provide information on Inuit social structures already in place and help develop new models to explain Inuit choices during the nineteenth century. This chapter introduces the sites used in the following study focusing on excavation and collection methods, house organization, and general artifact description.

\section{Research Areas}

The artifact assemblages included in this study consist of two collections from sites near the Hopedale Moravian mission, Avertôk and Anniowaktook Island, and one site located approximately 120 kilometers south at Long Tickle in the Adlavik Islands. The Avertôk and part of the Anniowaktook Island sites were first excavated by Junius Bird in 1935 and are stored at the American Museum of Natural History. I conducted additional excavations at Anniowaktook Island as part of the Hopedale Archaeology Project (HAP hereafter) during 2007-2009. The Adlavik site was excavated between 1999-2003 by the Central Coast of Labrador Community Archaeology Project centered in Makkovik. Stephen Loring of the Smithsonian Institution and Leah Rosenmeier of the Peabody Museum of Archaeology oversaw the excavation and curation of materials from 
Adlavik. Artifacts from Adlavik and Anniowaktook are on loan from the Newfoundland Provincial Archaeology Office and are at my research lab at the Museum Support Center (MSC) at the Smithsonian’s National Museum of Natural History. All artifacts were washed and analyzed and then cataloged in an Access database. Material type (ceramic, composite, faunal, metal, organic, and stone) and form were tabulated for all artifacts. Additional information on quantity, specific material (e.g., iron, refined earthenware, whale bone), manufacturing technique, completeness, evidence of burning, postmanufacturing modification, decoration, and object measurements including weight was also recorded.

All faunal material underwent initial inspection and was counted before being sent to James Woollett of Laval University in Quebec City, Canada for additional identification. Flotation samples were collected from the Adlavik and 2007-2009 Anniowaktook Island excavations and sent for botanical analysis to Cynthia Zutter of McEwen College of Edmonton, Canada. The following section reviews the various methodologies employed at each site, and summarizes contextual information associated with the houses.

Avertôk (GiCb-03, GiCb-04, GiCb-05)

In 1935, American archaeologist Junius Bird conducted a series of excavations in the Hopedale region as part of an extensive study of prehistoric Inuit life. Bird examined five sites and excavated 45 houses out of the 88 he identified in the region. Only two of these sites are used in this study, Avertôk and Anniowaktook Island. Avertôk, meaning 
“the place of bowhead whales,” had 22 sod houses (Brice-Bennett 2003:15), and Bird excavated nine (Figure 6.1). This collection serves as the only remaining evidence of the original sod house settlement since recent town development at Hopedale has destroyed the sod houses and their related middens (Arendt 2008; Penney 2002). He characterized each house according to size and occupation period by type, which I summarize in Table 6.1. Type Ia tended to be the smallest, most similar to early Thule houses. Type Ib was a two-family structure with a rectangular outline and two sleeping platforms. Type III was a larger rectangular multi-family house with extended sleeping platforms along the rear and side walls (Bird 1945:128). Bird determined that Types II and III houses had later occupations based on the architectural design and related artifacts.

Bird excavated the houses with shovels in a single level, noting a scarcity of artifacts at most houses (Bird 1945:131) which may have been the result of earlier collecting by an American scientific exploration from Bowdoin College in 1891 (BriceBennett 2003:26). Since Bird’s primary interest was in reconstructing pre-contact Inuit life, he saved few European artifacts. He claimed that five houses and one associated midden at Avertôk exhibited artifacts dating to post-Moravian contact. Because of his interest in early Inuit technology, Bird made only a passing reference to the many European artifacts found, collecting only a small sample when they were present. Bird did note that the Avertôk midden located north of the mission building exhibited much European material as well as bones and mussel shells. His decision not to collect European artifacts makes these collections from Avertôk and Anniowaktook problematic for accurately describing early historic Inuit consumption and discard patterns. 
Due to the sampling strategy Bird employed, the occupation periods at Avertôk remain somewhat of a mystery. Bird did not suggest specific time periods, but rather offered generalizations regarding the approximate period when the houses were occupied based on house size and type. Ethnohistoric evidence suggests that the Avertôk settlement was occupied continuously until and through part of the Moravian occupation (Kleivan 1966; J. G. Taylor 1974). However, not all houses were occupied simultaneously as indicated by modification to the main floor plans at Houses 8 and 9 . Avertôk Houses 1 and 3 appear to have been occupied into the historic period as Bird collected a small sample of European artifacts as a manner of noting their presence in the assemblage. The fact that he did not collect European objects from any other house may suggest that the remainder of the Avertôk houses did not have any; therefore the other houses were likely abandoned prior to the arrival of the Moravians. I will describe all of the excavated houses; however, only Avertôk Houses 1 and 3 are used in the subsequent dating analyses. 


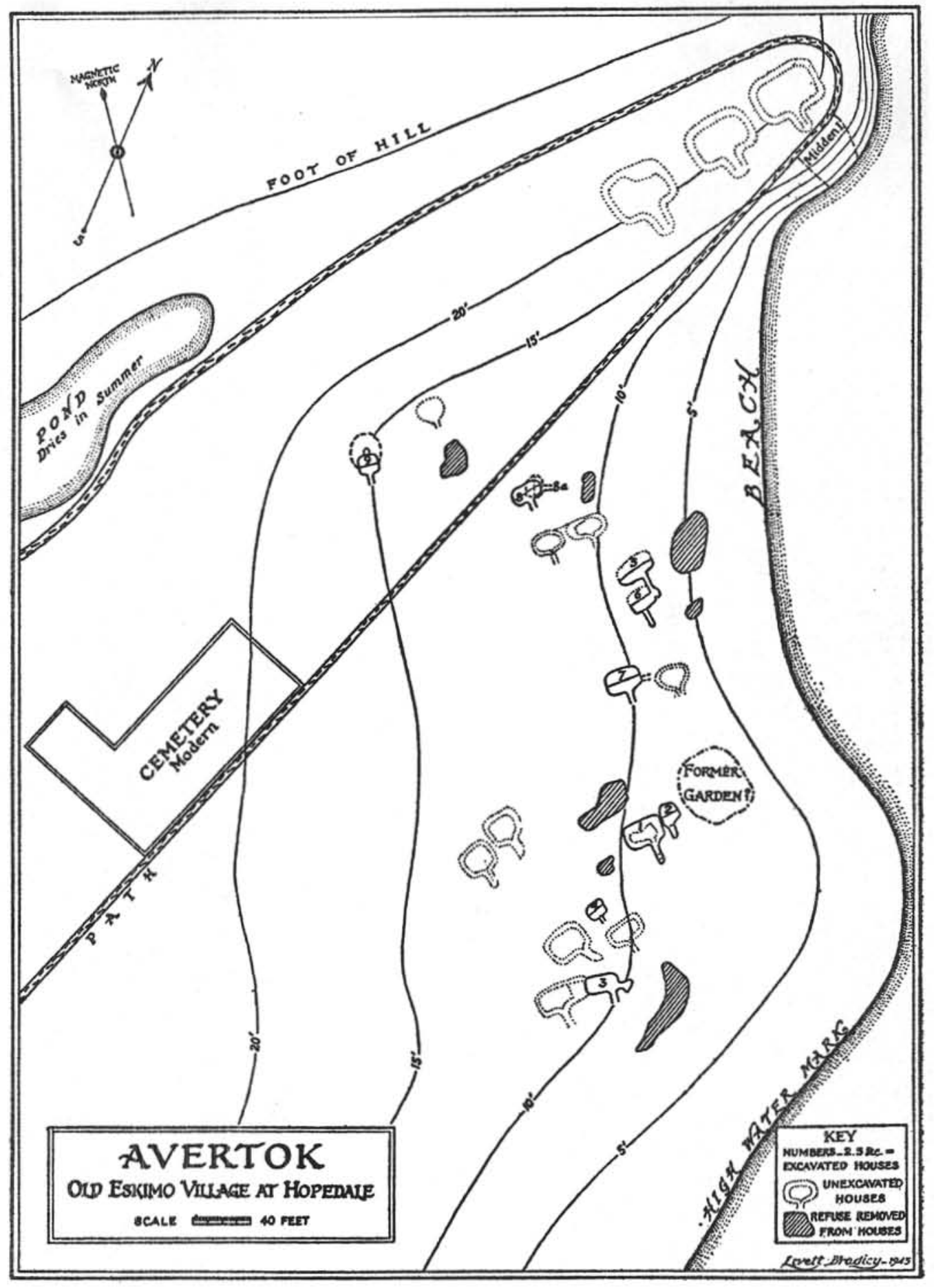

Figure 6.1: Junius Bird's plan drawing of Avertôk including all excavated and unexcavated houses (Bird 1945:130). 


\begin{tabular}{|c|c|c|c|}
\hline Avertôk & House Type & House Description & Occupation Period \\
\hline House 1 & Type III & Large, rectangular house & Contact \\
\hline House 2 & Type Ia & $\begin{array}{l}\text { Smallest house; similar to } \\
\text { Thule type; rounded corners; } \\
\text { single sleeping platform; } 1 \text { or } 2 \\
\text { shallow meat pits }\end{array}$ & $\begin{array}{l}\text { Earliest, } \\
\text { possibly pre-contact }\end{array}$ \\
\hline House 3 & Type Ib or Ic & $\begin{array}{l}\text { Larger, roughly square house; } \\
\text { single sleeping platforms; } \\
\text { single deep meat storage pit; } \\
\text { possible second room used in } \\
\text { second occupation }\end{array}$ & Contact \\
\hline House 4 & Туре Ib & $\begin{array}{l}\text { Larger, roughly square house; } \\
\text { single sleeping platforms, } 1 \text { or } \\
2 \text { lined recesses near front edge }\end{array}$ & Early contact \\
\hline House 5 & Type Ib & $\begin{array}{l}\text { Larger, roughly square house; } \\
\text { single sleeping platforms; } 1 \text { or } \\
2 \text { lined recesses near front edge }\end{array}$ & Early contact \\
\hline House 6 & Type Ib & $\begin{array}{l}\text { Larger, roughly square house; } \\
\text { single sleeping platforms; } 1 \text { or } \\
2 \text { lined recesses near front edge }\end{array}$ & Early contact \\
\hline House 7 & Type Ia & $\begin{array}{l}\text { Smallest house; similar to } \\
\text { Thule type; rounded corners; } \\
\text { single sleeping platform; } 1 \text { or } 2 \\
\text { shallow meat pits }\end{array}$ & $\begin{array}{l}\text { Earliest, } \\
\text { possibly pre-contact }\end{array}$ \\
\hline $\begin{array}{l}\text { House } \\
8 \mathrm{a} / \mathrm{b}\end{array}$ & Type Ia & $\begin{array}{l}\text { Smallest house; similar to } \\
\text { Thule type; rounded corners; } \\
\text { single sleeping platform; } 1 \text { or } 2 \\
\text { shallow meat pits }\end{array}$ & $\begin{array}{l}\text { Earliest, } \\
\text { possibly pre-contact }\end{array}$ \\
\hline House 9 & Type Ib & $\begin{array}{l}\text { Larger, roughly square house; } \\
\text { single sleeping platforms; } 1 \text { or } \\
2 \text { lined recesses near front edge }\end{array}$ & $\begin{array}{l}\text { Prehistoric; } \\
\text { Paleo-indian } \\
\text { (descendants of the } \\
\text { Innu) }\end{array}$ \\
\hline Midden & Type III & Large, rectangular house & Contact \\
\hline
\end{tabular}

Table 6.1: List of Avertôk house types and descriptions and possible occupation period as identified by Bird (1945). 


\section{House 1}

Characterized as a Type III house by Bird, House 1 was believed to have the latest occupation, one that overlapped with the earliest period of the Moravian mission due to its high quantity of European artifacts. The house was a large rectangular structure approximately 9.24 x $5.91 \mathrm{~m}$, with a $5.5 \mathrm{~m}$ long entrance tunnel located southwest from House 2 and near a former garden. Bird did not record many architectural features, but noted the presence of a raised dirt sleeping platform, a flat slab stone floor, a meat cache near the front of the house by the entrance tunnel, and a box hearth located to the right of the entryway. He also noted a conspicuous lack of glass or ceramic artifacts, suggestive of an earlier pre-Moravian period (Bird n.d.).

\section{House 2}

House 2 was located northeast of House 1 and was one of the smaller houses excavated by Bird, measuring 4.75 x 4.75 m. Characterized as a Type Ia, Bird argued this house was a Thule house and one of the older houses at the site based on an architectural style similar to other Thule houses in the eastern Arctic (Bird 1945:131). The round house had an entrance tunnel and a single sleeping platform near the back of the house. Two meat caches were located on either side of the house near the front of the house. A single lamp stand was located next to one of these meat caches along the eastern wall. 


\section{$\underline{\text { House } 3}$}

Bird characterized House 3 as Type Ib suggesting that its architectural style was similar to the Type Ia although it was larger at $6.1 \times 5.76 \mathrm{~m}$ and slightly more rectangular. The house had a raised sand sleeping platform extending across the rear half of the dwelling with a stone-lined recess along the front edge. A flat stone floor extended beyond the platform to the front of the house. House 3 exhibited a single meat cache approximately half a meter in diameter near the front of the house and by the entrance tunnel. Bird also took note of the many bone hunting artifacts, lamps, and cooking pots found throughout the house floor and in the tunnel, as well as the presence of some European objects such as iron nails, a cast iron pot, glass, and ceramics.

Bird believed that House 3 had been reoccupied during the Moravian period and the original $3.05 \mathrm{~m}$ long entrance tunnel was removed, along with all the walls. The paved floor was covered by an 8” midden mottled with shell and bone. Within the house, Bird identified a series of small postholes which were possibly used to strengthen sod walls with wooden stakes (Bird 1945:134). House 3 exhibited some of the best preserved and highest amounts of hunting materials.

\section{$\underline{\text { House } 4}$}

House 4 was also classified as a Type Ib larger and more rectangular in shape than Type Ia houses. A paved entryway approximately $3.05 \mathrm{~m}$ long led into the main house that was approximately 5.18 x $3.65 \mathrm{~m}$. A raised sand sleeping platform ran along 
the back of the house and two recesses were dug out towards the front edge of the platform, possibly as a lamp stand or as alcoves. The house had a paved stone floor with a fragment of a soapstone pot used as a paving stone (Bird n.d.). It also had a single meat cache in the wall next to the entry tunnel.

\section{$\underline{\text { Houses } 5 \text { and } 6}$}

These houses served as two more examples of Type Ib and exhibit a similar rectangular architectural style, each with a paved entry tunnel and interior, and a raised sleeping platform. Both houses also contained a meat cache located towards the front of the dwelling next to the entry tunnel. House 5's sleeping platform extended along the eastern wall and two recesses were located near the front edge of the platform. A lamp stand was resting on top of the platform. House 5 measured approximately 6.1 x $4.75 \mathrm{~m}$ with a 3.65 m paved tunnel, while House 6 dimensions were approximately 7.62 x 3.65 m with a 5.18 m entrance tunnel. The entry tunnel of House 5 opened up into the wall of House 6 indicating that they were not occupied contemporaneously.

\section{$\underline{\text { House } 7}$}

Classified as a Type Ia, House 7 fell into the category of the smaller, Thule type houses. House 7 was a rounder 3.65 x $3.65 \mathrm{~m}$ house with an approximate $4.27 \mathrm{~m}$ long entrance tunnel. The raised sleeping platform took up much of the back of the house and two shallow meat caches were located on either side of the entrance tunnel. Bird observed that the house underwent a period of rebuilding and the entrance tunnel was 
moved to face southeast. Many of the original paving stones of the entrance and floor were removed and the original walls were disturbed. Bird's House 7 map plan provides only a rough estimation, rather than an accurate drawing.

\section{$\underline{\text { House } 8}$}

House 8 was built on top of an earlier house (which Bird identified as $8 \mathrm{~b}$ in his map) with a similar layout and identified as a Type Ia house. The house's main dwelling area was approximately 4.88 x $3.96 \mathrm{~m}$ with a $3.05 \mathrm{~m}$ entrance tunnel. The layout was similar to other Type Ia houses with a raised sleeping platform along the back wall and a meat cache located near the front of the house. Because Bird did not record any stratigraphic distinctions separating the two houses, artifacts were cataloged together.

\section{$\underline{\text { House } 9}$}

Another example of a Type Ib squared house was House 9 measuring approximately 3.05 x $3.05 \mathrm{~m}$ with a $2.13 \mathrm{~m}$ entrance tunnel. The interior house had a paved flat stone floor and a meat cache along the western wall. Bird noted that House 9 differed from the other houses in that it had a floored entrance tunnel with wooden posts running parallel with its axis, and had absolutely no iron artifacts (Bird n.d.). It appears that the house construction disturbed an earlier Point Revenge ancestral Innu site, although no evidence of the earlier structure remained. Bird identified a dense concentration of 585 Ramah chert flakes, one quartz flake, and 27 stone tools in a circular area approximately $4.27 \mathrm{~m}$ in diameter along the northern half of House 9 (Bird 
1945:134). Bird did not provide much discussion of House 9's architectural features, yet based on the abundance of stone material referred to it as the "stone culture lodge" (Bird 1945:134). The archaeological evidence suggests that this house was in fact occupied by earlier Point Revenge. Since this house appears to be associated with ancestral Innu group and not the Inuit, I choose not to include it in subsequent analysis.

\section{$\underline{\text { Midden }}$}

Located towards the northern end of the site, three large rectangular sod houses sat along a steep slope near the base of a hill (Figure 6.2). Bird drew a sketch map of the three sod houses and excavated a $274 \mathrm{~m}^{2}$ portion of a midden located outside the third northern-most house (Bird 1945:131) (Figure 6.3). Bird identified the midden deposit as black, unstratified earth mottled with deteriorating bone and a considerable amount of mussel shell. The midden deposit and depth varied due to the slope of the hill and was 51 $\mathrm{cm}$ at its maximum depth. The midden was composed mostly of European objects including iron, glass and ceramics; however, Bird discarded most of these artifacts, only noting their presence. 


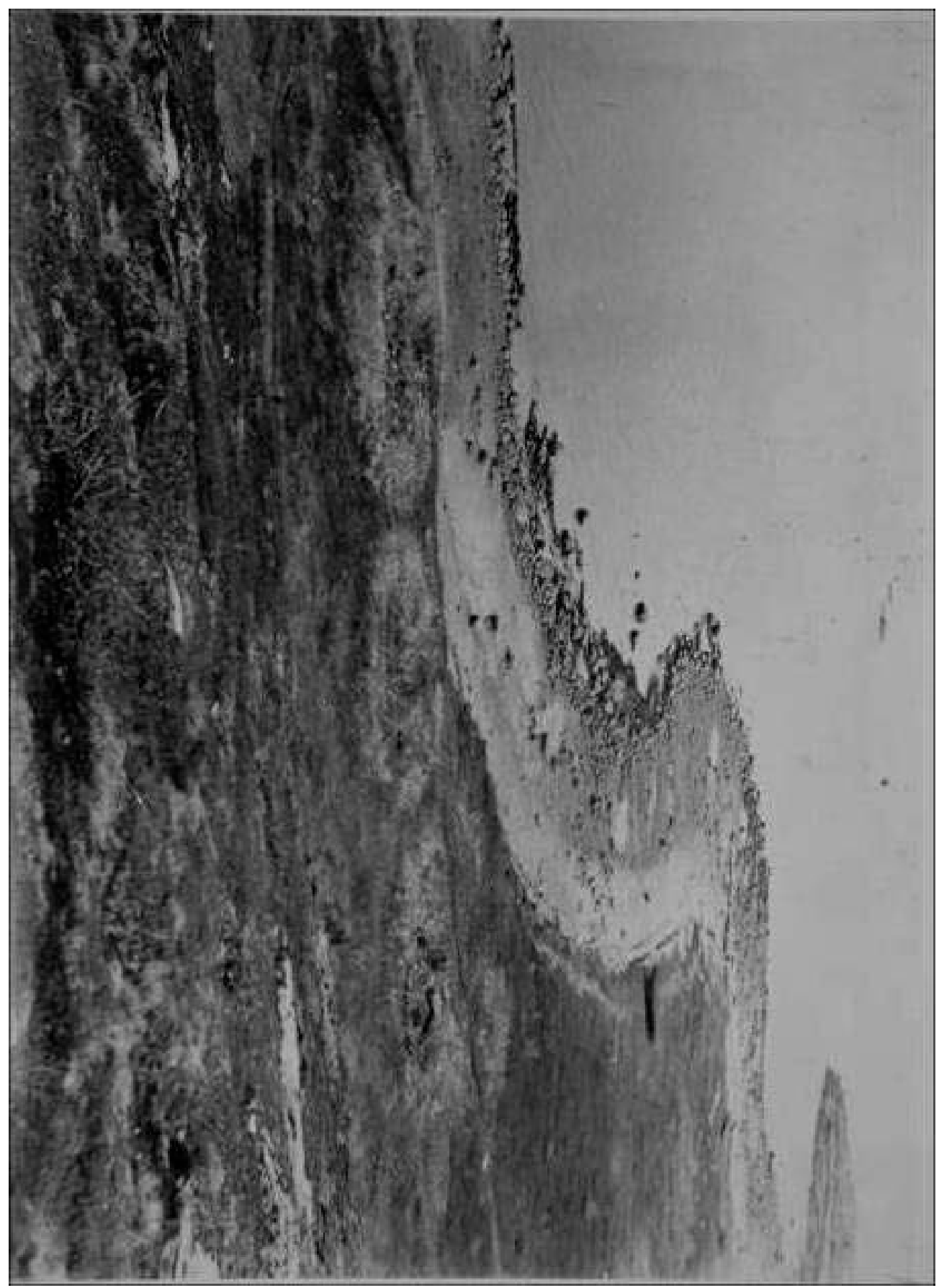

Figure 6.2: Photograph of three unexcavated sod house remains at Avertôk. These remains are the northern-most houses located on Bird's map in Figure 6.1. Photo by Junius Bird, 1933 located in the American Museum of Natural History Archives in New York. 


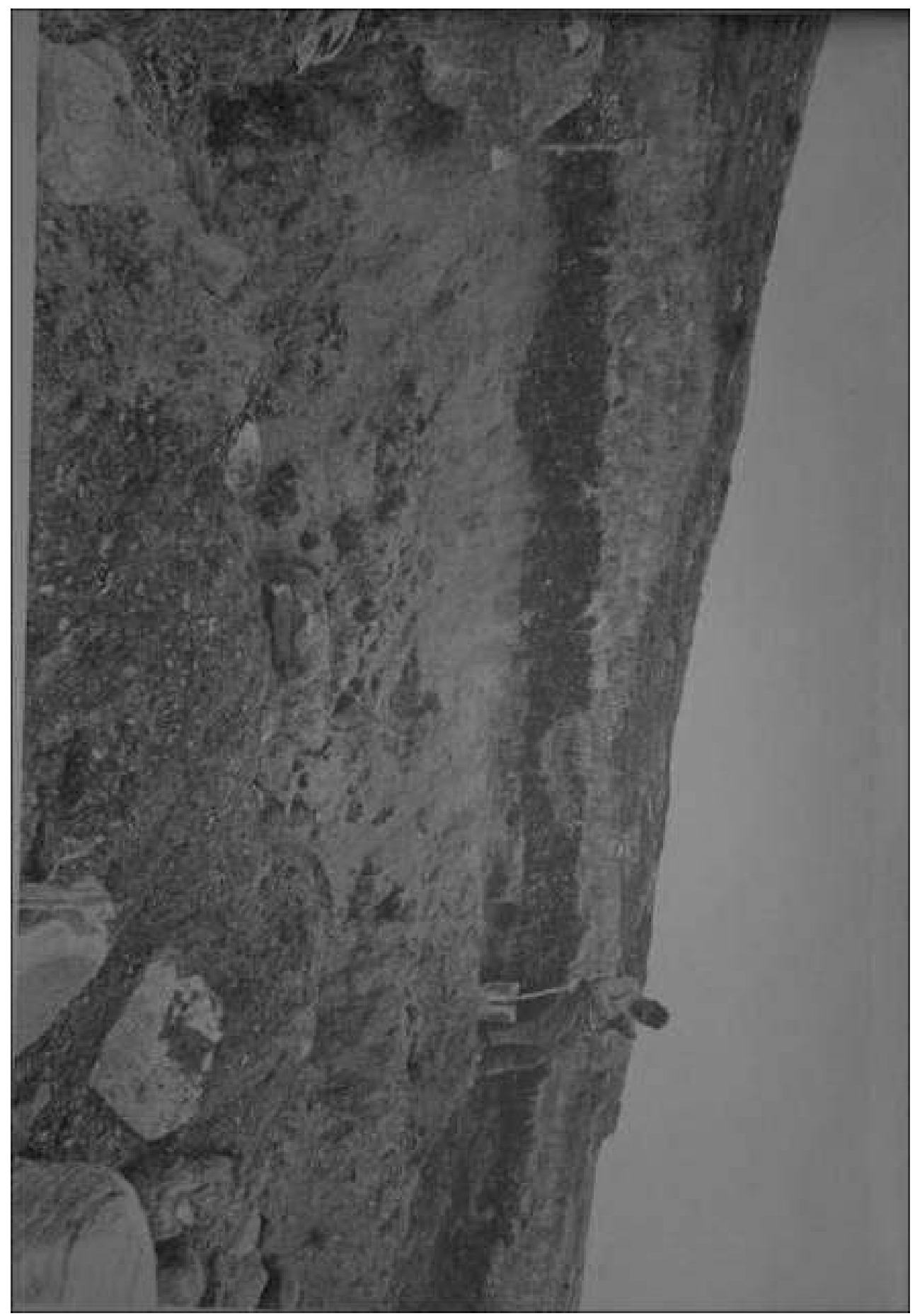

Figure 6.3: Photograph of the excavation of the large midden in front of a sod house at Avertôk seen in Figure 6.2. Note the thickness of the midden profile and the amount of material exposed. Photo by Junius Bird, 1933 located in the American Museum of Natural History Archives in New York. 
Anniowaktook Island (GgCi-02)

Bird also conducted archaeological surveys on islands surrounding Hopedale and identified Inuit sod houses that may date to the Moravian period (Bird 1945) (Figure 6.4). Although most eighteenth- and nineteenth-century Inuit families lived within approximately 30 to $55 \mathrm{~km}$ of the mission station (Brice-Bennett 1977:103), little research has been done to examine how island residences were part of the Moravian purview. To begin to understand the extent to which Moravian influence permeated the Labrador coast, I investigated a site on neighboring Anniowaktook Island where Bird identified four Inuit sod houses he dated to the Moravian period (Bird 1945:159) (Figure 6.5). More recent scholarship questions that assertion, suggesting that the site has an earlier date based on Bird’s physical descriptions of the artifacts (Kaplan 1983:450).

In summer 2007 I excavated two 1 x $1 \mathrm{~m}$ test units outside two of the four sod houses identified by Bird. The units were excavated by trowel and artifacts were collected within each quadrant by arbitrary $10 \mathrm{~cm}$ levels. All excavated material was screened through $1 / 4$ ” steel mesh and artifacts were bagged according to unit and stratigraphic level. Plans were drawn of the top of each stratigraphic level before excavation, as well as a final floor plan of all excavated units. Profiles were drawn of the western and northern exposed house walls, and the west wall of the test unit in the midden. The test units revealed a very high quantity of sea mammal fauna and European artifacts. A piece of Normandy stoneware and some wrought nails found in the midden outside of House 1 place occupation of the site into the eighteenth century, but did not confirm Bird's claim. 


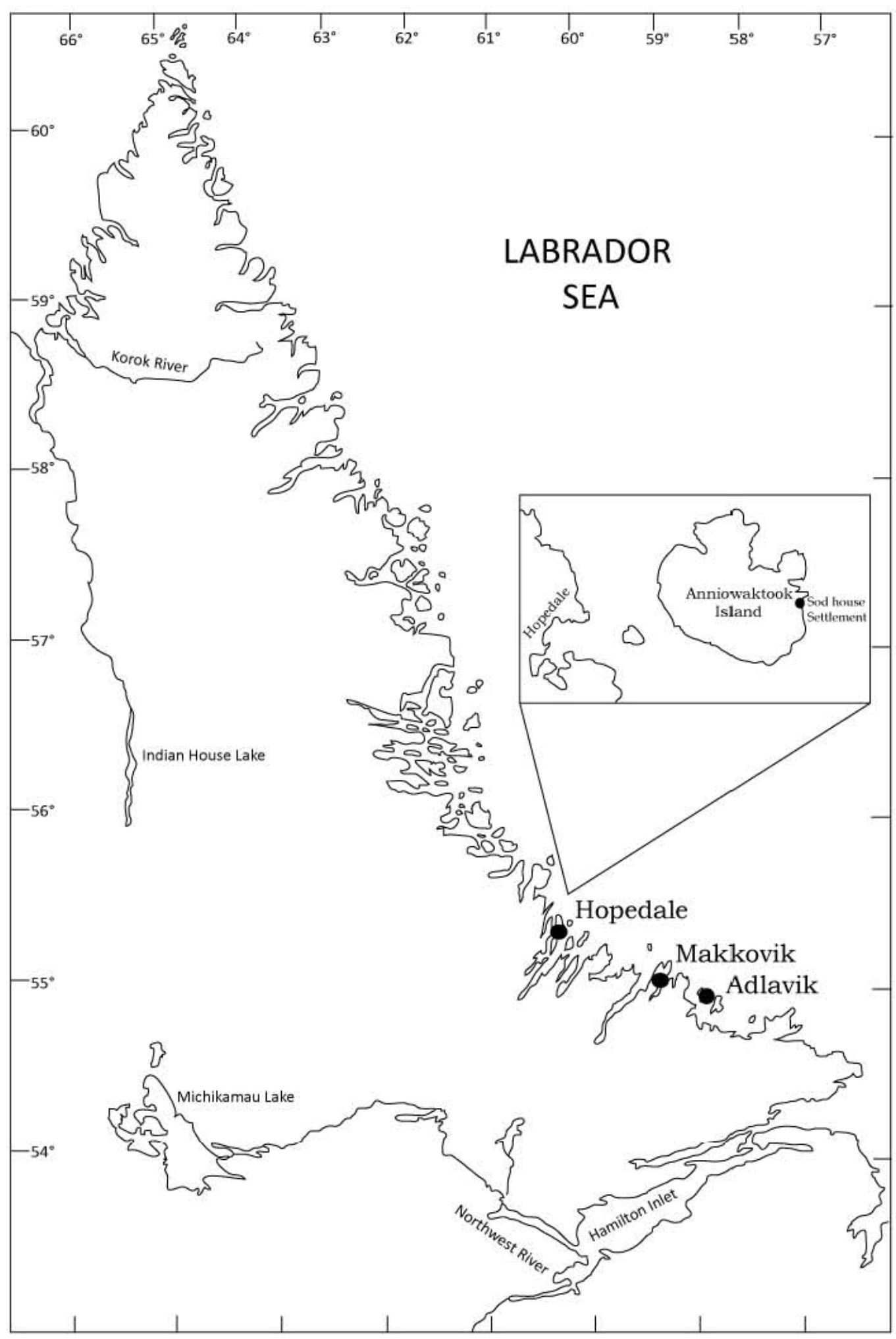

Figure 6.4: Map of Labrador with site locations and Hamilton Inlet. 


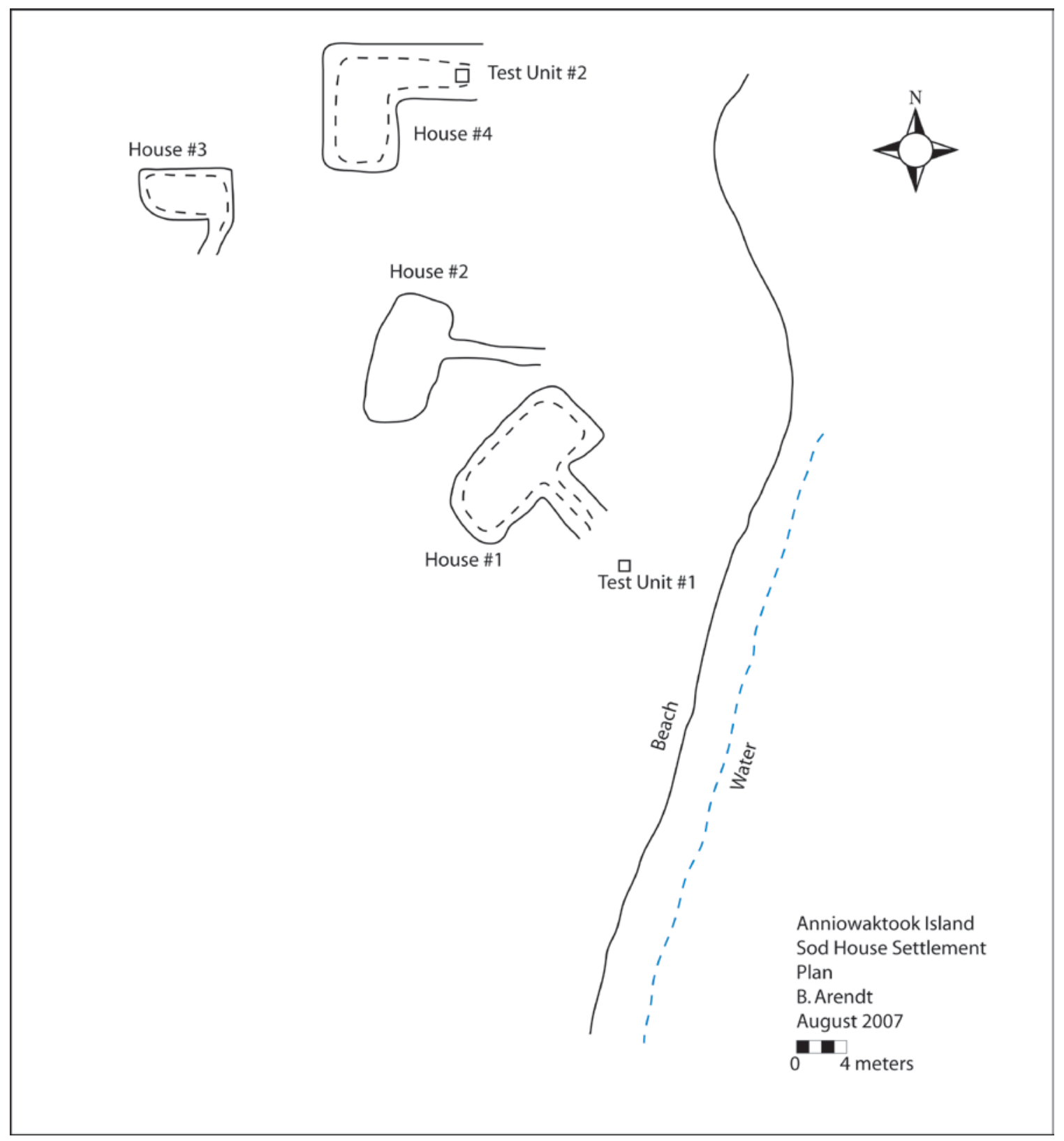

Figure 6.5: Plan of sod house settlement on Anniowaktook Island with test units from 2007. 
I returned to the site in summer 2008 and 2009 to run HAP, a community archaeology program I discuss in greater detail in Appendix A. With the help of ten local Inuit students, half of the interiors of House 1 and House 4 were excavated. In 2008, we excavated House 1. The largest house at the site, House 1 measured 10.6 x $4 \mathrm{~m}$ and had a $9 \mathrm{~m}$ entrance tunnel with a southerly orientation, common for winter houses. Sixteen $1 \mathrm{x}$ $1 \mathrm{~m}$ units were placed across the interior of the house predominantly in the western half, and one $2 \times 2 \mathrm{~m}$ unit was placed in the midden located just southwest of the entrance tunnel. A datum was set on the top of the northeast corner wall of the house, from which all elevations for House 1 and midden were taken.

Excavations during 2009 focused on House 4 located northeast of House 1. House 4 was a 9 x $5 \mathrm{~m}$ house with a $6 \mathrm{~m}$ entrance tunnel oriented east and onto a bedrock ledge overlooking the water. A series of nine $1 \mathrm{x} 1 \mathrm{~m}$ units were placed north-south in the interior of the house and an additional five $1 \mathrm{x} 1 \mathrm{~m}$ units were placed east-west leading into the entryway tunnel. A datum was set at the top of the northwest corner wall of the house and all elevations were taken from that point.

We excavated all units by trowel and excavated material was screened through 1/4" steel mesh. A summary of the area excavated can be found in Table 6.2. Excavations followed natural stratigraphic levels, but each level did not extend beyond $10 \mathrm{~cm}$ in depth. Excavation ceased when we reached sterile soil or the flat stone floor. A simple plan of the top of each unit's level was sketched onto the provenience sheets. After excavations were complete, a plan view of the excavated area was drawn. 
We collected artifacts and faunal remains from each unit and bagged them separately according to stratigraphic level. While the majority of large architectural stones were left in place a few that appeared to be out of context were removed to continue excavation. These stones were counted and weighed before being placed outside the house. Large quantities of fire-cracked-stones were also found; stones larger than a fist were counted and weighed before being discarded.

\begin{tabular}{|c|c|c|c|c|}
\hline Site & Context & $\begin{array}{l}\text { Depth } \\
\text { Excavated (m) }\end{array}$ & $\begin{array}{l}\text { Area } \\
\text { Excavated }\left(\mathrm{m}^{2}\right)\end{array}$ & $\begin{array}{l}\text { Total } \\
\text { Excavated }\left(\mathrm{m}^{3}\right)\end{array}$ \\
\hline \multirow[t]{4}{*}{ Anniowaktook } & House 1 & 5.94 & 16 & 95.04 \\
\hline & House 1 Midden & 0.62 & 5 & 3.1 \\
\hline & House 4 & 4.21 & 14 & 42.1 \\
\hline & House 4 Midden & 1.15 & 4 & 4.6 \\
\hline
\end{tabular}

Table 6.2: Total area excavated at Anniowaktook.

Organic material occurred throughout both excavations but was poorly preserved. Wood was commonly used as structural wall-supports or flooring but the general poor condition required samples either to be left in situ, or mapped and removed to continue excavations. Organic matter including hide, leather and fur was collected, and locations recorded. Photographs were taken when wood or organic material was found in situ. We took samples only when wood or organic remained intact and appeared relatively wellpreserved. Faunal remains were placed in paper bags to allow air flow so samples could dry slowly. Faunal remains were dry brushed in the field and later cleaned using a tooth brush and water and dried in my lab at the MSC. 
In addition, we took $2 \mathrm{~L}$ soil samples from select locations within the house to be analyzed by ethnobotanist, Dr. Cynthia Zutter from McEwen College in Edmonton, Canada. These included four samples from the sleeping platform, five samples from the area just above the flat slab stone floor, three from the midden (one sample for each stratigraphic level), and one sample outside the house to serve as the control. Two $1 \mathrm{~L}$ soil samples were taken from two features and later wet-screened in the lab and examined for small artifacts which I analyzed.

\section{$\underline{\text { House } 1}$}

Approximately one-third of the interior and one unit in the entrance tunnel of House 1 were excavated (Figure 6.6). The focus on the interior of the house was to establish when the house was occupied, determine whether single or multiple families lived in the house, and locate activity areas. The majority of the entrance tunnel was not excavated; however, excavations at Adlavik found that deposits in entrance tunnels were similar to the midden. As Inuit traveled through the tunnel they carried materials on their way to be discarded, often dropping a few on the way, or tracking them in on their shoes when returning into the house. Since the midden was also being excavated, I chose not to excavate the entrance tunnel.

Early in the project, we noticed a few unexpected discrepancies with House 1. First, House 1 had only a thin layer of sod (less than $10 \mathrm{~cm}$ thick) indicating that either the collapsed sod roof had already been removed or the house was a qarmat, a sod house 
with a skin or canvas roof. The roof was likely held up by a few wooden posts. A center posthole with a wood post in situ confirmed that conclusion. Wood planks were also found throughout the house. Some planks were used as internal wall support, while others were laid on top of the dirt sleeping platform to provide a flat surface (Figure 6.7). Second, excavations revealed that a portion of the house had been disturbed by earlier archaeologists or looters. Approximately one-third of the northeastern section of the house had been dug down to sterile sand and then boulders werethrown into the southeastern half of the house; therefore we focused excavations on the western, undisturbed portion of the house. 


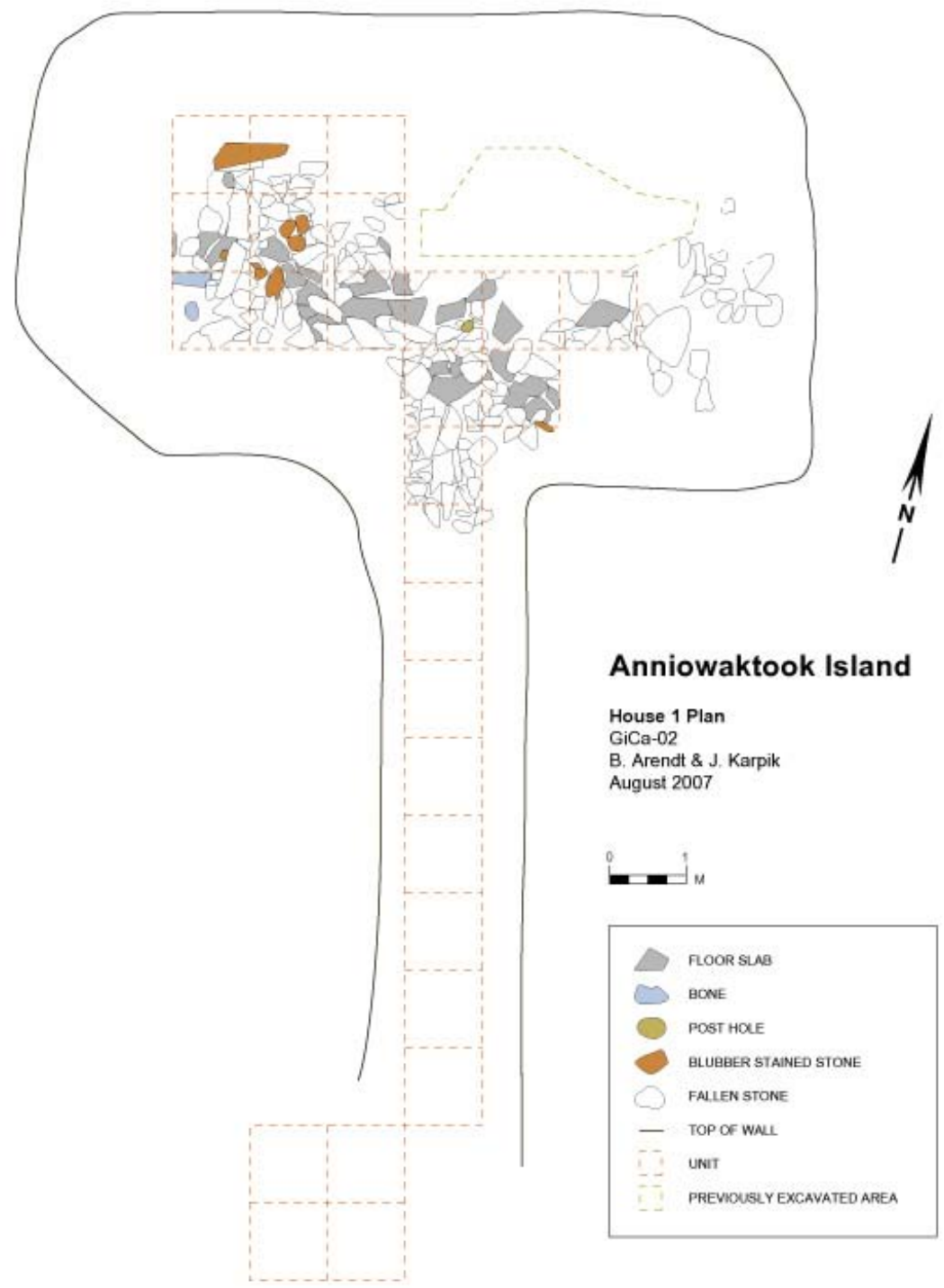

Figure 6.6: Plan drawing of Anniowaktook House 1 (modified by Anna Eschelman 2009). 


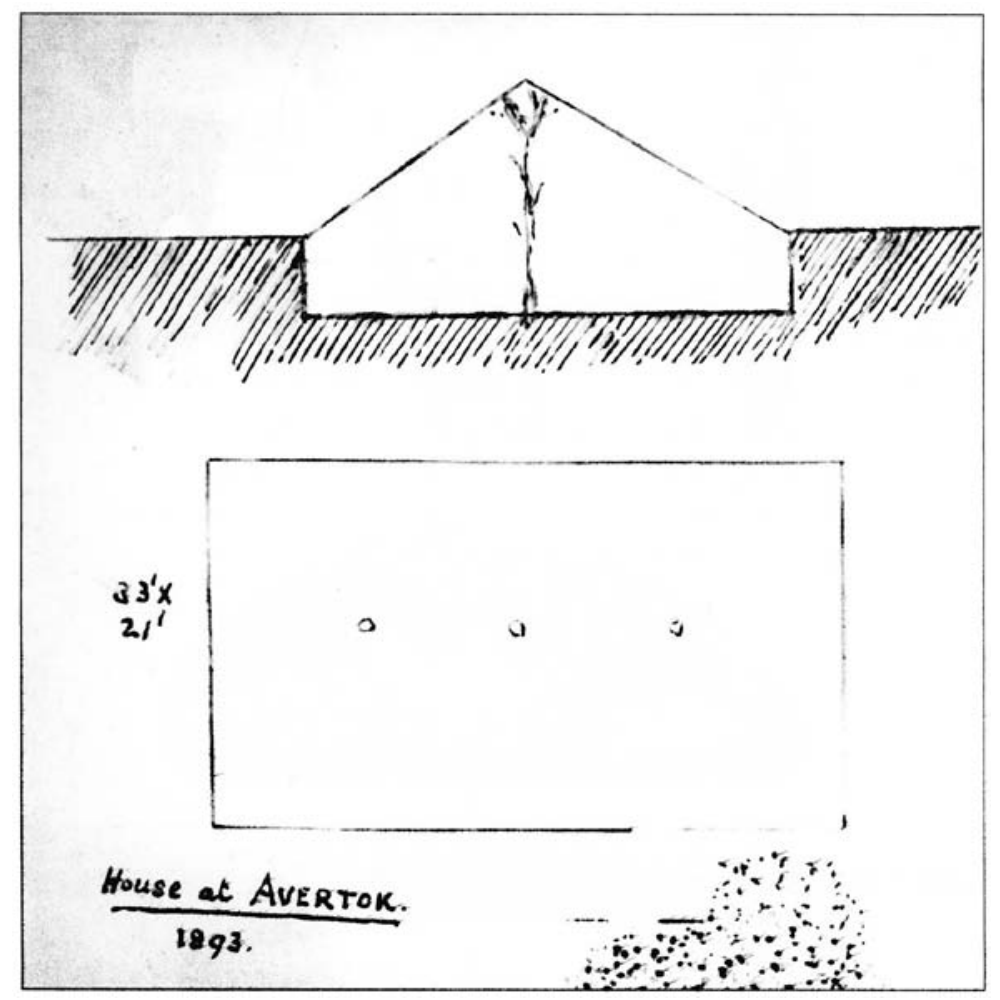

Figure 6.7: Outline of a Avertôk sod house drawn by medical doctor Eliot Curwen who visited Hopedale in 1893. Note the detail of a tree or branch serving as the center support (Brice-Bennett 2003:32).

The raised sleeping platform was encountered along the north and west wall of the house and was identified in the three most northern units. Raised turf indicated that a sleeping platform ran along the entire back wall. Unlike other historic botanical samples from Uivak Point and Oakes Bay, the sleeping platform was not covered with pine needles for insulation; instead, archaeobotanical analysis conducted by Cynthia Zutter identified the majority of plant remains found on the platform as edible plants, especially crowberries (Figure 6.8). In addition, a large cluster of burned stones located directly south of the platform and a flat, blubber-stained lamp stand resting on top of the platform suggest this area was the main cooking and living area for at least one family. 
An interior meat cache was located in the southwest corner of the house, near the sleeping platform and exhibited the highest concentration of sea and land mammal fauna inside the house. The area appeared to have been sectioned off from the rest of the house by the linear placement of a few very large stones.

A portion of the midden located outside the house was excavated and produced the majority of the artifacts found (Figure 6.9). Few objects were found complete, but the array of artifacts including a toy soapstone lamp, iron nails, ceramics, sheets of lead, glass and a few thousand sea mammal bones, shed light on the consumption and discard practices of Inuit from the early historic period, which will be discussed in Chapter 8. Furthermore, the range of artifacts found also included tobacco pipe fragments, glass beads and French stoneware shards suggested household members were actively trading with Europeans. However, no diagnostic artifacts indicating trade with the Moravians such as nineteenth-century ceramics werefound.

The large faunal assemblage and the large number of fire-cracked-stones and burned stones found in the midden, suggest house cleaning episodes. The largest of these stones were counted and discarded.

Unfortunately, the disturbance to House 1 as a result of earlier looters or unrecorded excavations by Bird compromised the archaeological integrity of the house. Evaluating House 1's context and artifact information required compiling comparable data from other areas of the site. 


\section{House 1 Sleeping Platform $\mathrm{N}=327$}

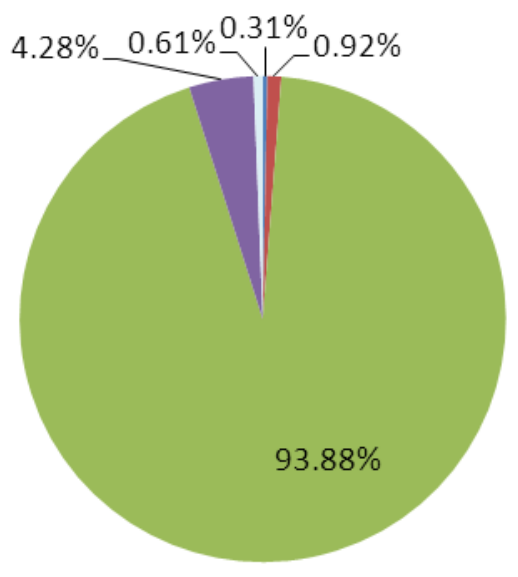

1. Coniferous

- 2. Fuel Plants

3. Edible Plants

4. Other Useable

5. Weeds

Figure 6.8: Pie chart of botanical remains found in Anniowaktook House 1.

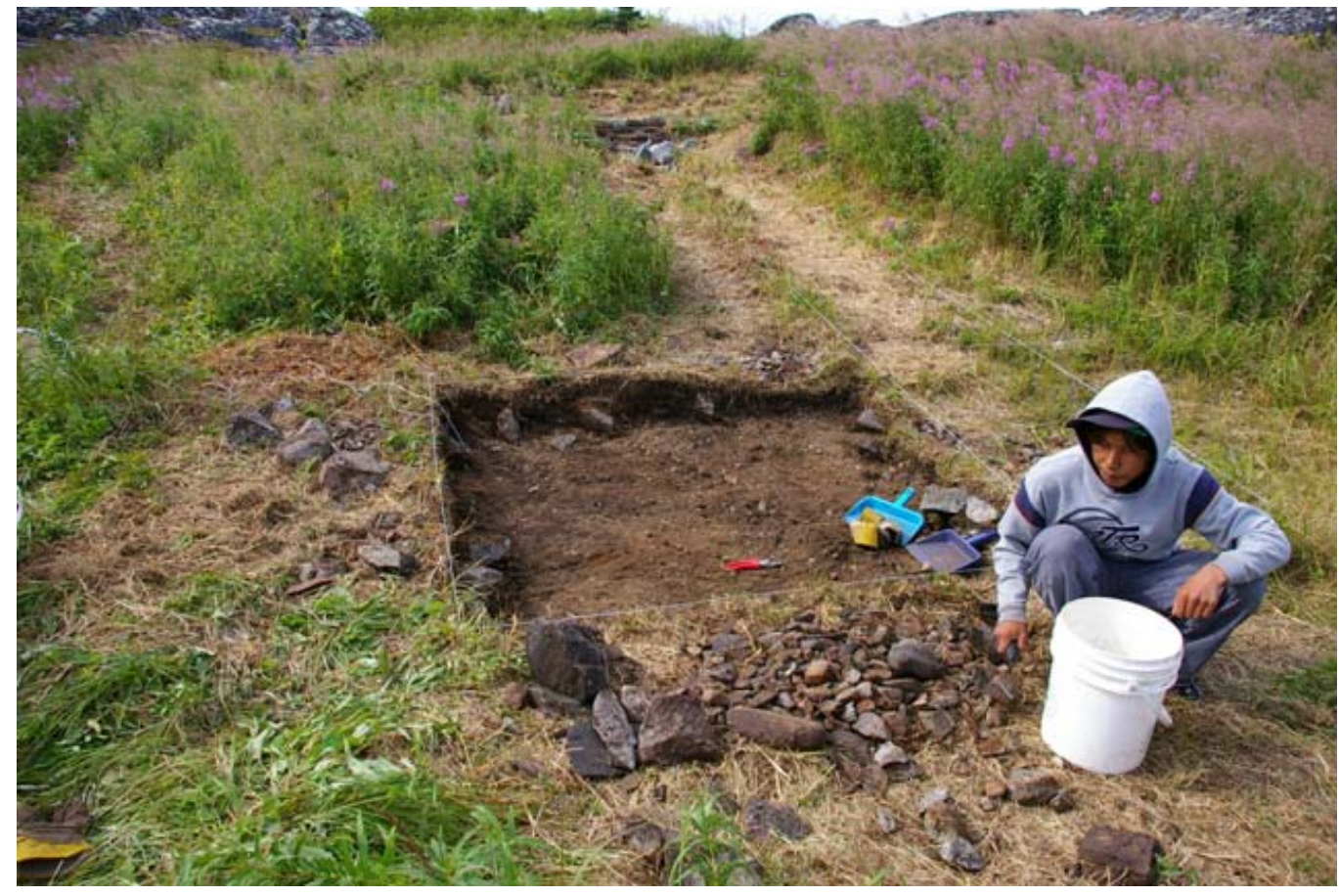

Figure 6.9: The Anniowaktook House 1 midden excavation in 2008: a 2 x 2 m unit excavated directly outside of House 1's entrance tunnel. 


\section{$\underline{\text { House } 4}$}

I returned to the site in 2009 to excavate a second house, House 4. Conclusions from the 2007 survey suggested that materials from House 4 were contemporaneous with House 1; therefore I hoped excavation of House 4 would offer additional insight into whether the houses had a similar late eighteenth-century occupation (Arendt 2008).

The northern half of the units exhibited a thin layer of sod before reaching the occupation level and, eventually a flat stone floor. Deposits along the northern half were no more than $20 \mathrm{~cm}$ deep. As seen in House 1, a shallow layer of soil suggested that sod was not the roofing material (Mary-Rousselière 1979; Park 1988); instead, the sod houses may have been covered by skin roofs. Unfortunately, we were not able to locate a posthole in the center of the house to substantiate that claim. Another possibility was that the sod was removed to be used in another house construction; however, preliminary surveys conducted in Houses 3 revealed a lack of sod on the floor suggesting that none of the houses at the site used sod for their roofs. ${ }^{10}$

Excavations in the southern half of House 4 revealed that a midden approximately $40 \mathrm{~cm}$ thick was deposited in the house post-abandonment and covered the earlier occupation level and stone floor (Figure 6.10). This later midden indicated that there were at least two separate occupations at the site and not all houses were inhabited in simultaneously. The later midden was full of sea and land mammal bones, shell and nails, and a few artifacts, such as an iron ulu knife blade. The practice of using earlier

\footnotetext{
${ }^{10}$ House 2 could not be compared as the interior was completely overgrown with alder trees.
} 
house pits as midden dumps was also evident at Avertôk’s House 9 and at Adlavik Island, which will be discussed later.

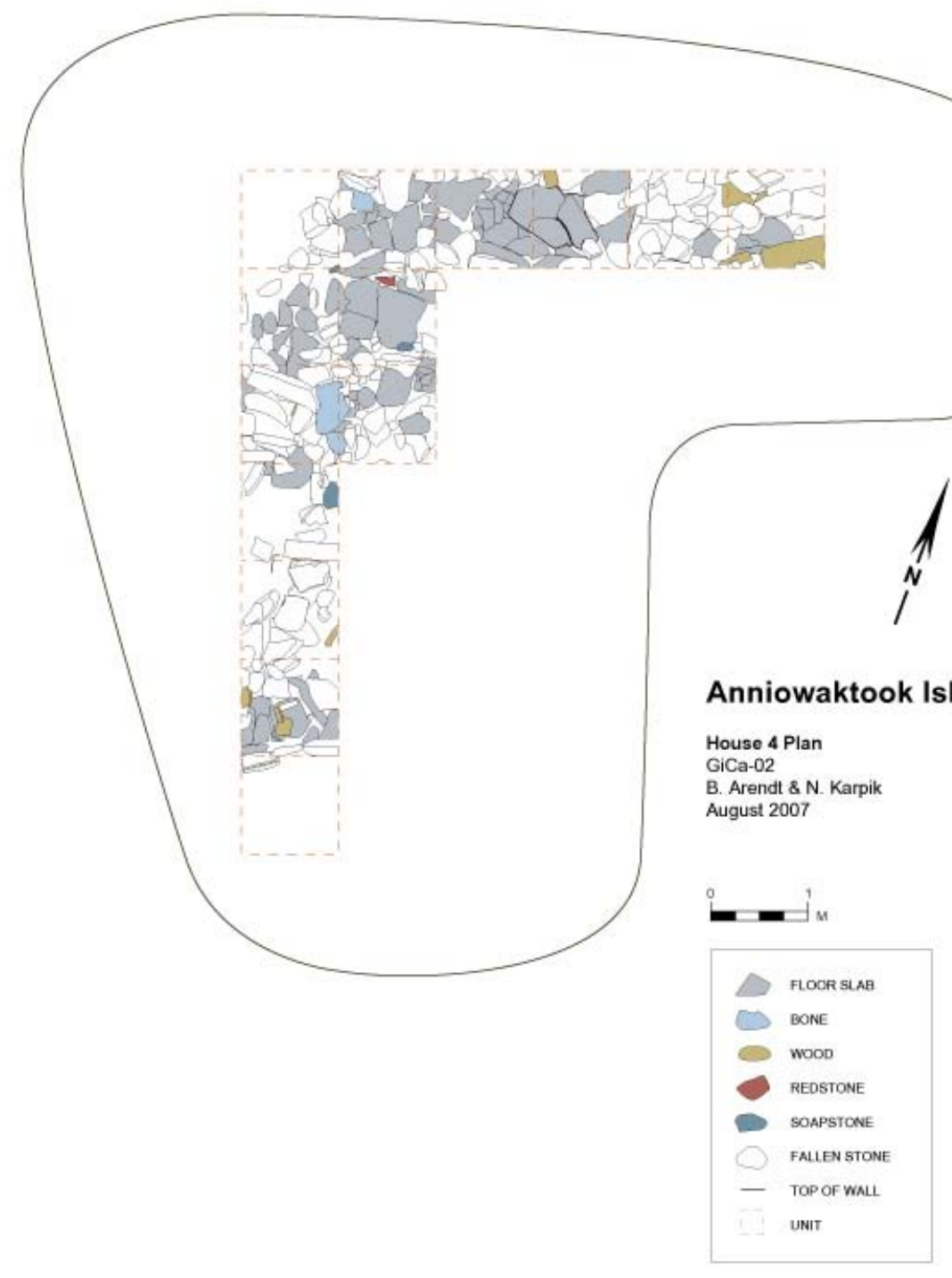

Figure 6.10: Plan drawing of Anniowaktook House 4 (modified by Anna Eschleman 2009). 
Excavations revealed additional evidence suggesting House 4 was one of the earliest houses occupied at the site. Unlike House 1, a considerable amount of whale bone was found inside the house, whereas some archaeologists argue that whale hunting was replaced by seal hunting during the historic period (Jordan 1977; J. G. Taylor 1974, 1977, 1988). Large whale bones fragments were found at the occupation level, including a section of cut whale bone placed as part of the floor (Figure 6.11), a whale bone scapula and vertebrae found near the center of the house, and a scapula found in the entrance tunnel. The amount of whale bone found in this assemblage did not seem particularly unusual given Hopedale was an important place for whaling; however, the greater number of larger intact bones differed from House 1. The prominence of whale bone and baleen in Bird's collection from House 3 suggests Inuit activities in the area included, if not depended on, whaling for resources.

Architectural features and activity areas also identified within the house included a sleeping platform located along the southern wall, a hearth, and a cold trap in the entryway. As in House 1, archaeobotanical analysis identified an unusually high amount of crowberries which are usually collected in the fall, on the sleeping platform (Figure 6.12). Unlike House 1, the sleeping platform was located along the southern wall of the house, approximately $3 \mathrm{~m}$ away from what appeared to be the central cooking area. The possible hearth was located in the center of the house near the whale bone previously mentioned (Figure 6.13). A large quantity of charcoal was located in the vicinity as well as a large piece of deteriorating green soapstone (Figure 6.14). Two charcoal samples were taken, and fire-cracked-stones were counted, weighed and discarded. 


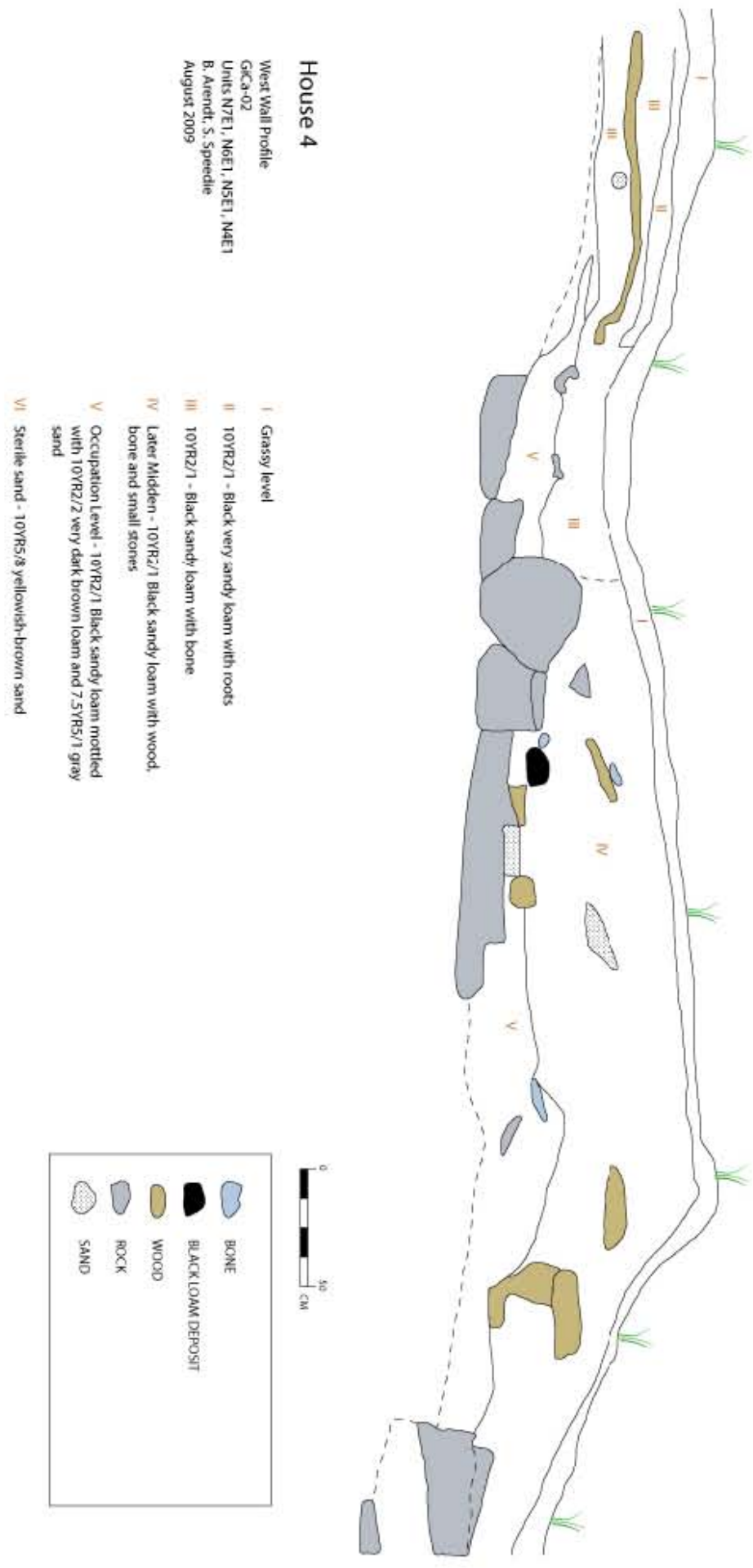

Figure 6.11: Profile of the west wall of House 4 at Anniowaktook Island. Note the presence of a later midden fill (Level IV) above the occupation level (Level V). 


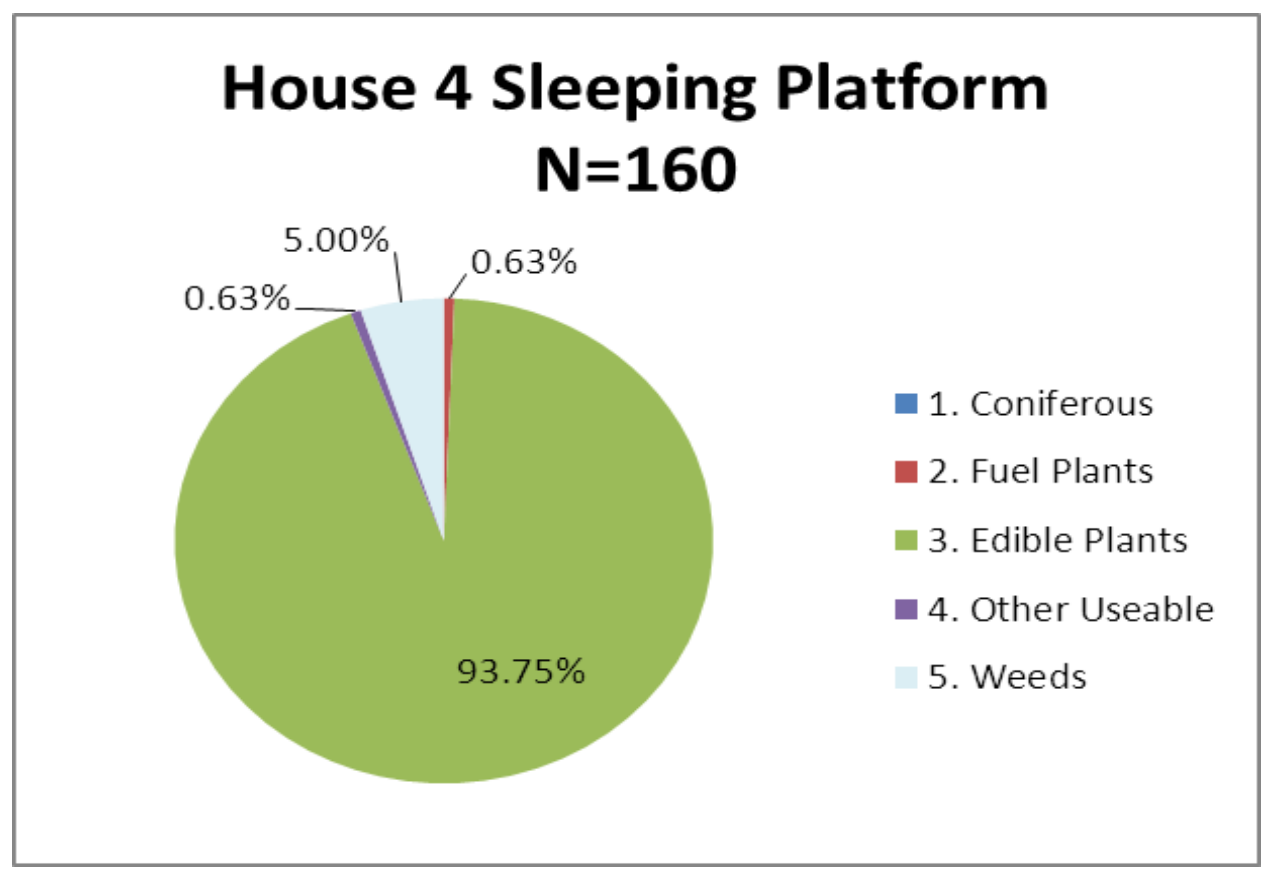

Figure 6.12: Pie chart of botanical remains found on the sleeping platform at Anniowaktook House 4.

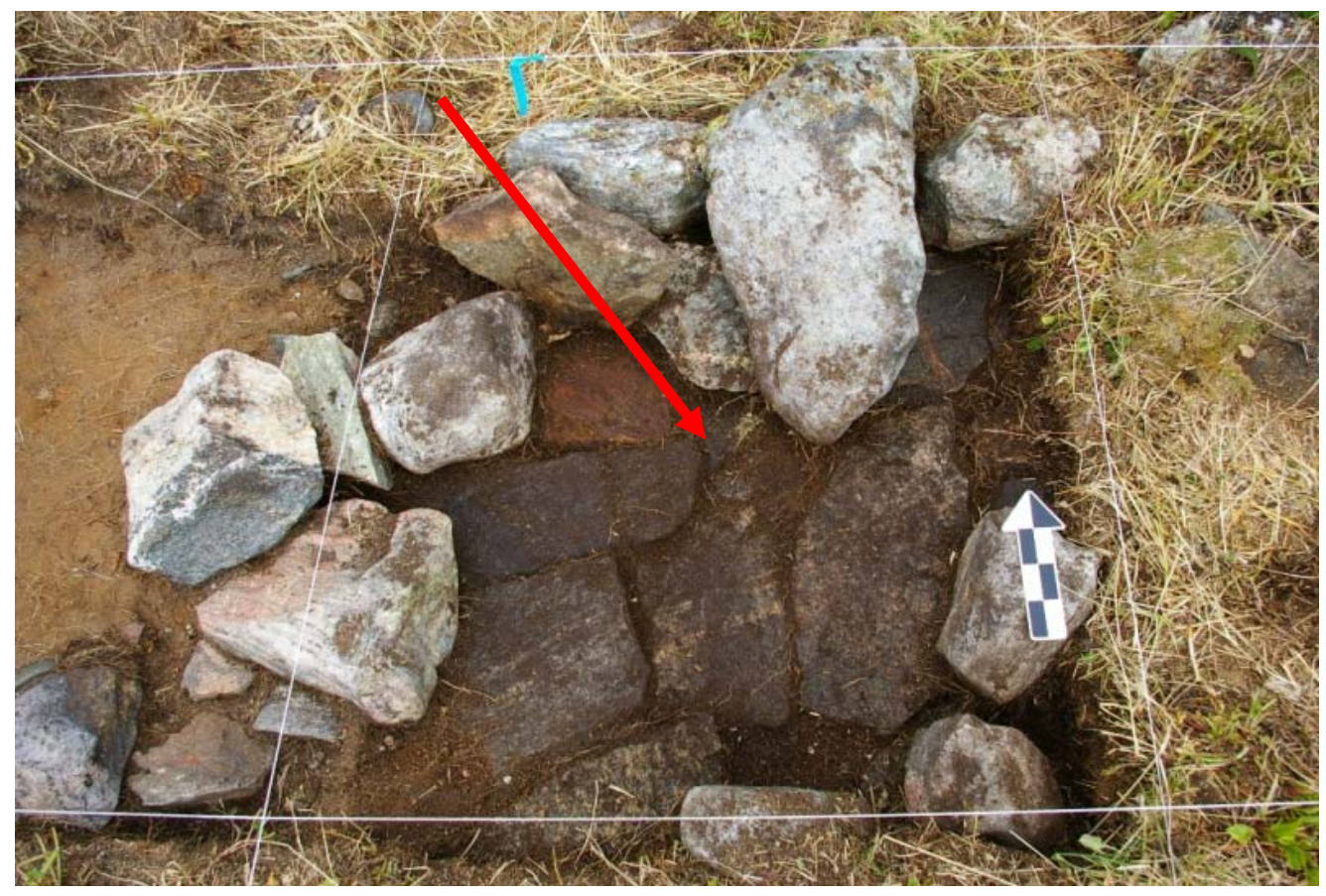

Figure 6.13: Unit N1E2. Floor of Anniowaktook House 4. The red arrow is pointing to a fragment of whale bone which was cut to fit into the corner of the floor. 


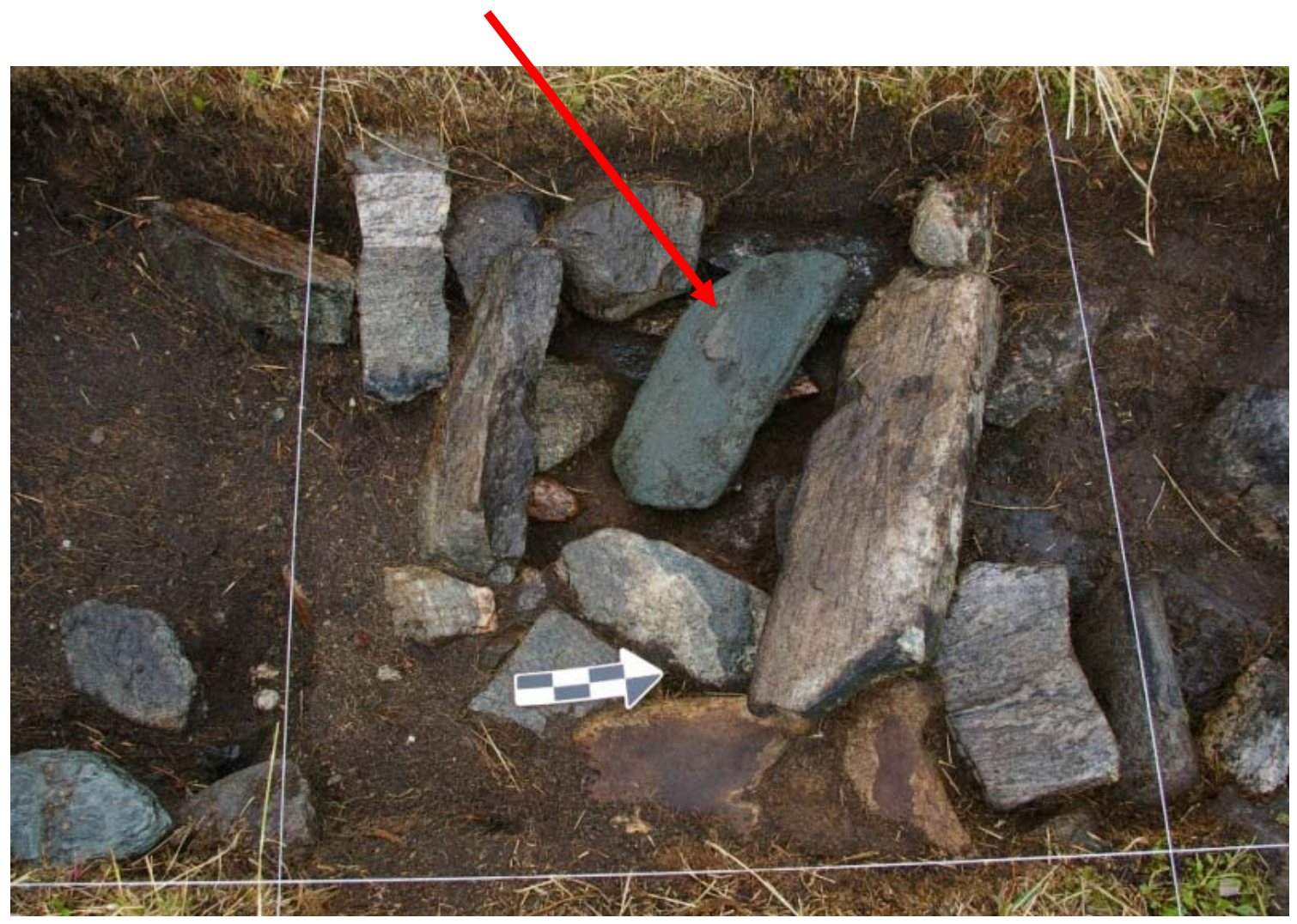

Figure 6.14: Possible lamp stand and hearth located in unit N4E1 of Anniowaktook House 4. The red arrow is pointing to the large fragment of soapstone possibly used for cooking. A whale bone scapula fragment lies along the eastern wall next to the north arrow .

Initially, the function of this large fragment of poor quality soapstone was unclear. During an Archaeology Open House when members of the Hopedale community visited the site, a Hopedale community member informed me that hunters still put a large piece of soapstone in the fire and cooked their meat on the stone instead of directly in the fire. Given its location near charcoal, surrounded by slightly burned stones, the poor quality green soapstone found in House 4 likely served this cooking purpose. 


\section{$\underline{\text { Unexcavated House Ruins }}$}

The interior of the two remaining houses were not excavated at Anniowaktook as a means of preserving the site for future generations. I briefly describe them here.

House 2: Located just north of House 1, House 2 was approximately 10 x 5 m with a $7 \mathrm{~m}$ long entrance tunnel that ended near the northeastern corner of House 1. Despite being completely overgrown with alders and vegetation, House 2's rectangular walls were still apparent. The house appeared to be a single room structure, similar to the other houses at the site. Given the density of vegetation, additional observations could not be made and I determined excavations would be too time-consuming.

House 3: Bird excavated a 9.1 x $4.6 \mathrm{~m}$ area of the midden located outside the entrance tunnel of the northernmost house in the settlement, offering a brief description of the house and its artifacts (Bird 1945:157-159). Bird collected only 25 artifacts, but notes the presence of a few European materials, such as tile and brick, as well as an absence of beads and other trade goods. Based on this observation, Bird determined the site was occupied prior to the 1800s (Bird 1945:159).

The house was a sub-rectangular single room structure located due north of House 2 and west of House 4. The house was built against the side of the hill, using the hill's bedrock to serve as the western-most wall. The interior was completely overgrown and surrounded by approximately 1.5 m high walls, which were a combination of natural bedrock and piled stone. As noted above, House 3 only had a thin layer of vegetation resting on the floor, suggesting that the house had an alternative covering such as canvas 
or skins. A few artifacts appeared on the surface including a soapstone lamp (Figure 6.15), suggesting future excavations may provide further clarification into the overall site occupation.

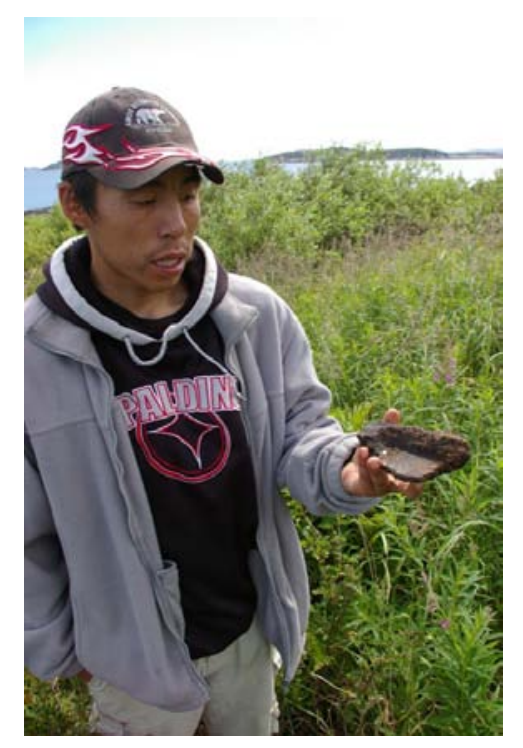

Figure 6.15: Hopedale student James Karpik holding a soapstone lamp fragment found inside a House 3 on Anniowaktok Island in 2007.

Adlavik (GgBq-1)

Stephen Loring of the Arctic Studies Center at the Smithsonian Institution began fieldwork at Adlavik in 1999 and conducted seasonal excavations with Leah Rosenmeier of the Peabody Museum of Archaeology in Andover Massachusetts and Brown University until 2003 (Figure 6.16). Located 24 km south of the Moravian’s sixth mission station, Makkovik (est. 1896), and approximately $120 \mathrm{~km}$ south of Hopedale the site was a settlement of four sod-houses tucked into the well-protected Adlavik harbour (Figure 6.17). Surrounding the Inuit sod-house site were a number of nineteenth century 
houses used by fishermen and a trade store, which may have been the source for a few of the nineteenth-century artifacts found scattered across the site.

Stephen Loring and William Fitzhugh first located the four earthen-walled semisubterranean sod houses in 1987. Loring and Rosenmeier conducted a multi-year summer field school for local Inuit students. Each season focused on identifying the occupation periods and architectural features of each of the four houses. The seasons would begin with a series of test unit excavations within the houses and their associated middens, followed by expansive focused excavations, during which the majority of House 1 and its associated midden were excavated (Table 6.3). Test units were excavated as a single level while units in the midden were excavated at $10 \mathrm{~cm}$ intervals, with changing stratigraphy or deposits noted. Loring returned to House 1 in 2003 to conduct a surface collection in the previously excavated units. Artifacts collected in the 2003 season surface collection had washed out from between the stone floor and from the wall and were cataloged as a separate level.

\begin{tabular}{|l|l|r|r|r|}
\hline Site & Context & $\begin{array}{l}\text { Depth } \\
\text { Excavated } \mathbf{( m )}\end{array}$ & $\begin{array}{l}\text { Area } \\
\text { Excavated } \mathbf{( m}^{\mathbf{2}} \mathbf{)}\end{array}$ & $\begin{array}{l}\text { Total } \\
\text { Excavated } \mathbf{( m}^{\mathbf{3}} \mathbf{)}\end{array}$ \\
\hline Adlavik & House 1 & 7.42 & 27.94 & 207.3148 \\
\hline & House 1 Midden & 3.41 & 9.0595 & 30.8929 \\
\hline & House 2 & 1.18 & 4 & 4.72 \\
\hline & House 3 & 3.23 & 5 & 16.15 \\
\hline & House 4 & 2 & 7.5 & 15 \\
\hline & House 4 Midden & 1.37 & 7 & 9.59 \\
\hline
\end{tabular}

Table 6.3: Total area excavated at Adlavik. 


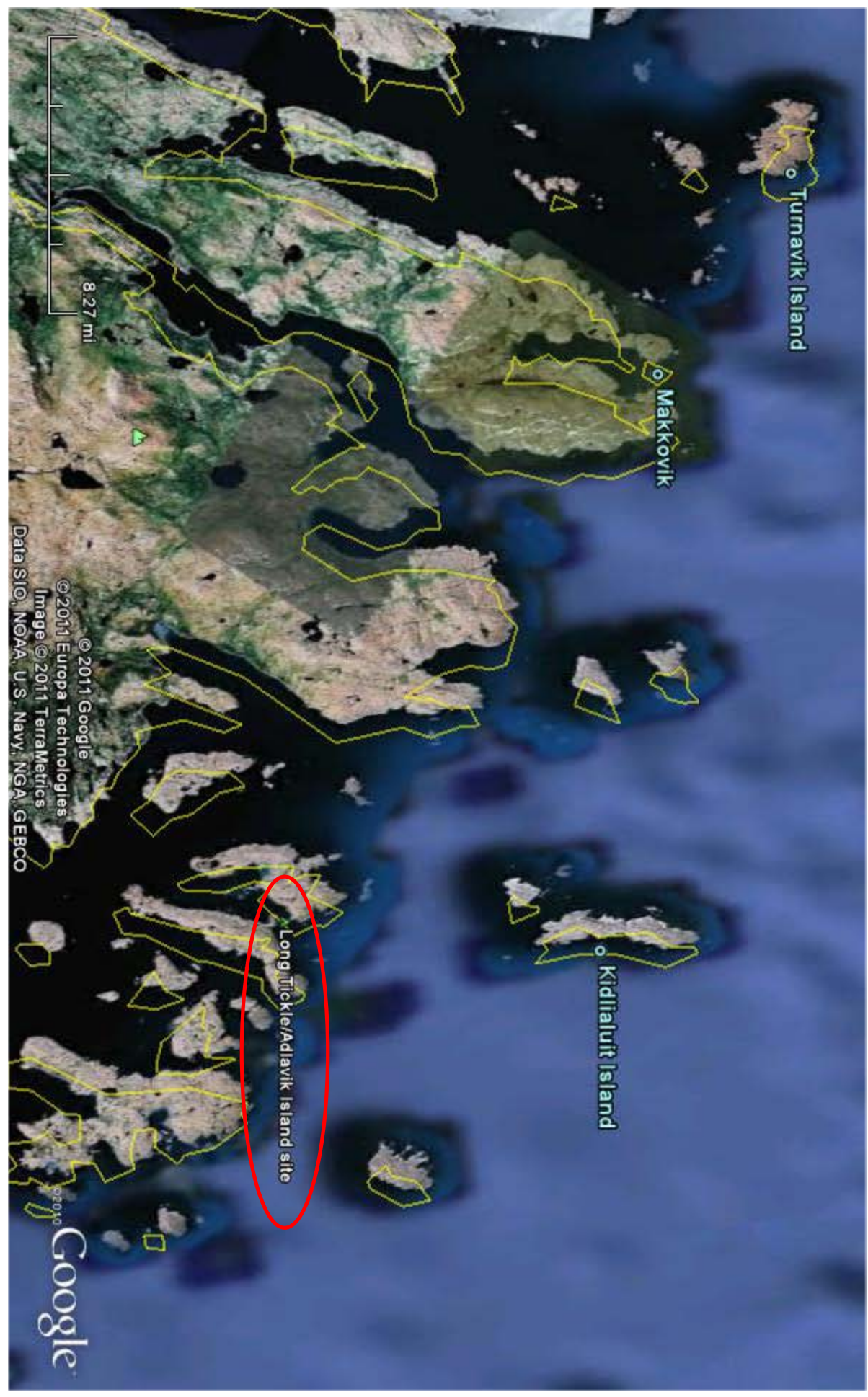

Figure 6.16: Map of Labrador coast with the location of Adlvik encircled in red (Google Maps 2011). 


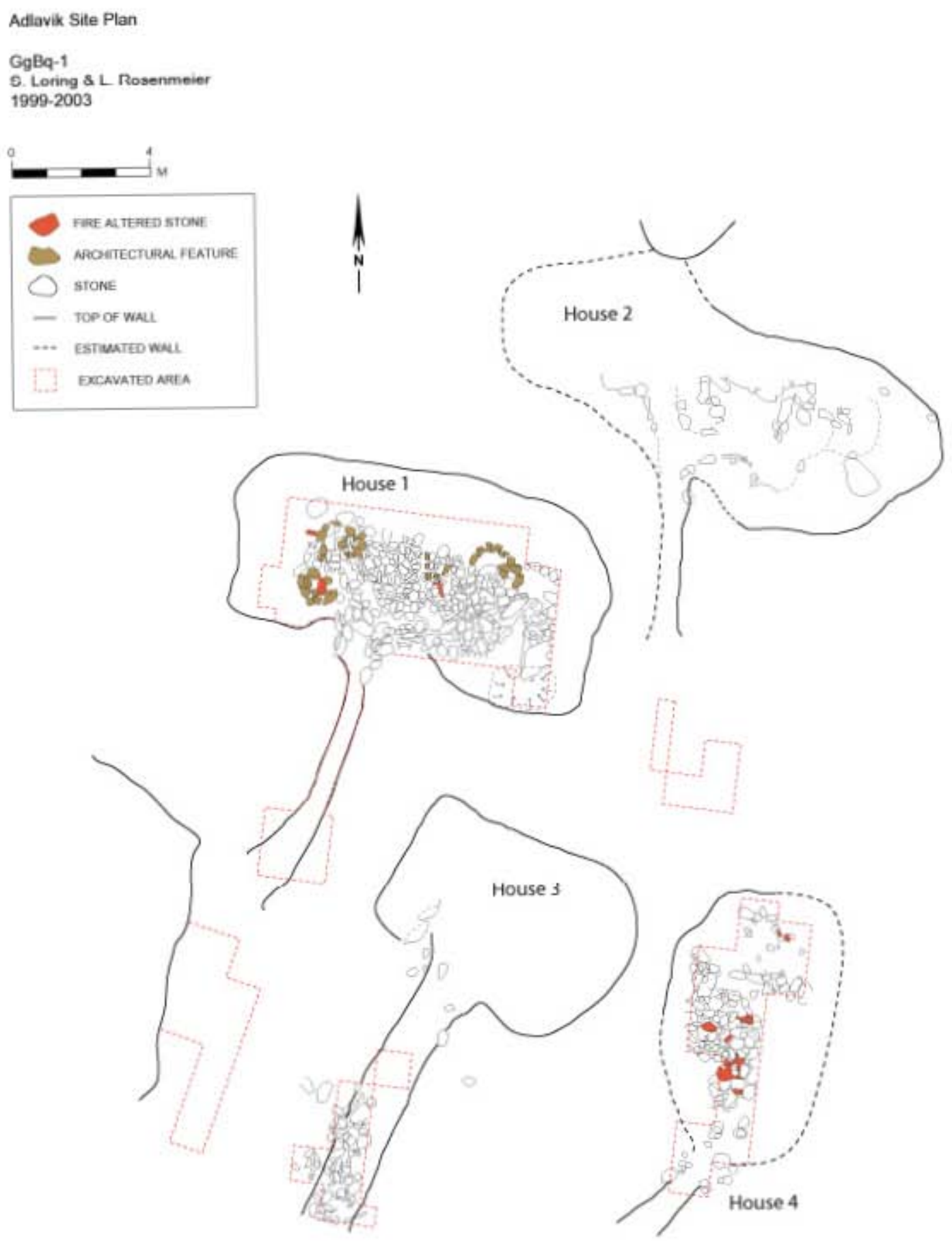

Figure 6.17: Plan drawing of Adlavik by S. Loring and L. Rosenmeier (modified by Anna Eschelman 2009). 


\section{House 1}

House 1 was completely excavated over three field seasons and proved productive in artifact and faunal material. The $7 \mathrm{~m}$ long entrance passage led into a large rectangular room measuring 10 x 5.5 m (Figure 6.18). Beneath a top sod layer was a series of tumbled wall boulders and a floor consisting of flat stone slabs mottled with a dark organic loam that contained cultural material. Some preserved wood planks probably serving as the interior house structure were also found just beneath the sod.

Excavation revealed a preserved flat slab stone floor at approximately $15-20 \mathrm{~cm}$ below the surface. Large boulders were found resting on the floor throughout the house, but they were probably a result of wall-fall. The floor was raised above the entrance tunnel in an effort to keep the interior of the house warmer, since warmer air rises and cooler air settles (Figure 6.19). The sleeping platform which ran along the back, northern wall of the house was also raised.

A few architectural features identifying activity areas were located in the house. Located along the back wall on the eastern edge of the sleeping platform was an Mshaped food storage wall. Three circular or semi-circular low stone walls were also found near the sleeping platform. Two were located along the western wall, and the third was located just west of the M-shaped feature. Each of the three features had an associated lamp-stand, suggesting their use as cooking areas. Finally, a large depression located in the front eastern corner of the house may have been a general storage area or meat cache. 
The midden was located near the southern end of the entry tunnel. Composed mostly of a black organic loam, House 1's midden had two distinct shell separated by dark organic midden deposits. A large amount of fire cracked stones were also found throughout the midden, which were counted and weighed before being discarded. The midden also contained the largest amount of faunal material (Figure 6.20).

\section{House 2}

Only a small portion of the House 2 midden was excavated during the 2003 season. No excavations were conducted within the house that was approximately $13 \mathrm{x}$ $5.5 \mathrm{~m}$ in size, but the exposed rocks were mapped (see Figure 6.17). Three $1 \mathrm{x} 1 \mathrm{~m}$ units and one 2 x 0.5 m unit were excavated approximately 2 m south of House 2's entryway. A dark loam deposit with a dense concentration of organic material including bone, rotten wood, animal fur, and baleen confirmed its use as a trash deposit. Additional $1 \mathrm{x} 1 \mathrm{~m}$ units were placed south of the midden to determine the extent of the deposit.

\section{$\underline{\text { House } 3}$}

A series of seven $1 \times 1 \mathrm{~m}$ units were excavated in the entry way tunnel and midden associated with House 3 located approximately 3 m southeast of House 1 . The interior of the house was not excavated but a rough plan of the exterior house walls was made. The house measured approximately 6.5 x $5 \mathrm{~m}$ with a $7 \mathrm{~m}$ entry way. Earlier test units exposed large architectural boulders along the tunnel as well as a high density of cultural material and whale bone. The associated midden exhibited a large amount of 
preserved wood, charcoal, and fire-cracked rock while ash and unidentified organic deposits appeared in later levels. The area near the beginning of the entry tunnel may have served as a storage area or cache for bones and blubber. All units were excavated to either bedrock or a buried peat level.
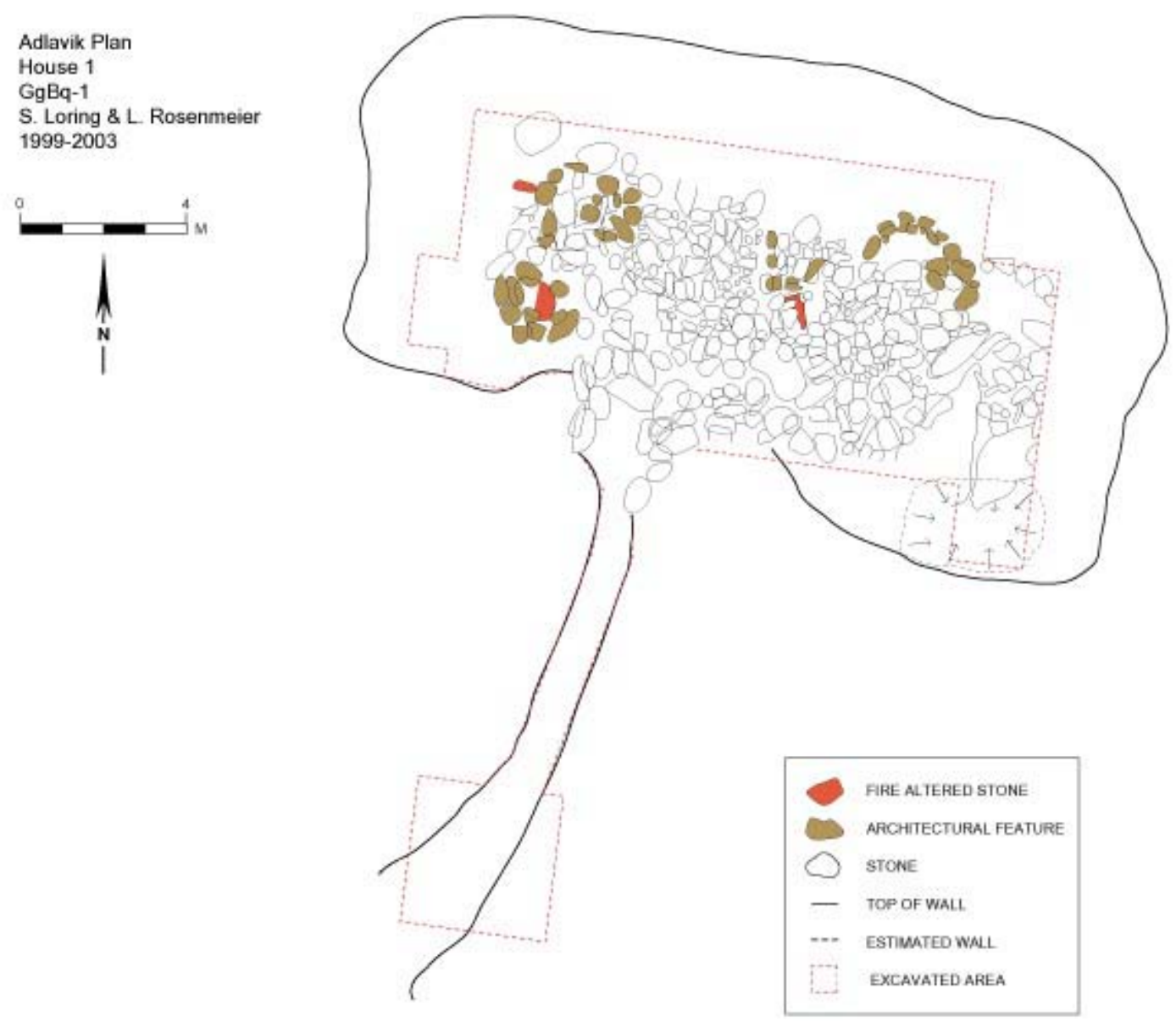

Figure 6.18: Plan drawing of Adlavik House 1 (modified by Anna Eschelman 2009). 


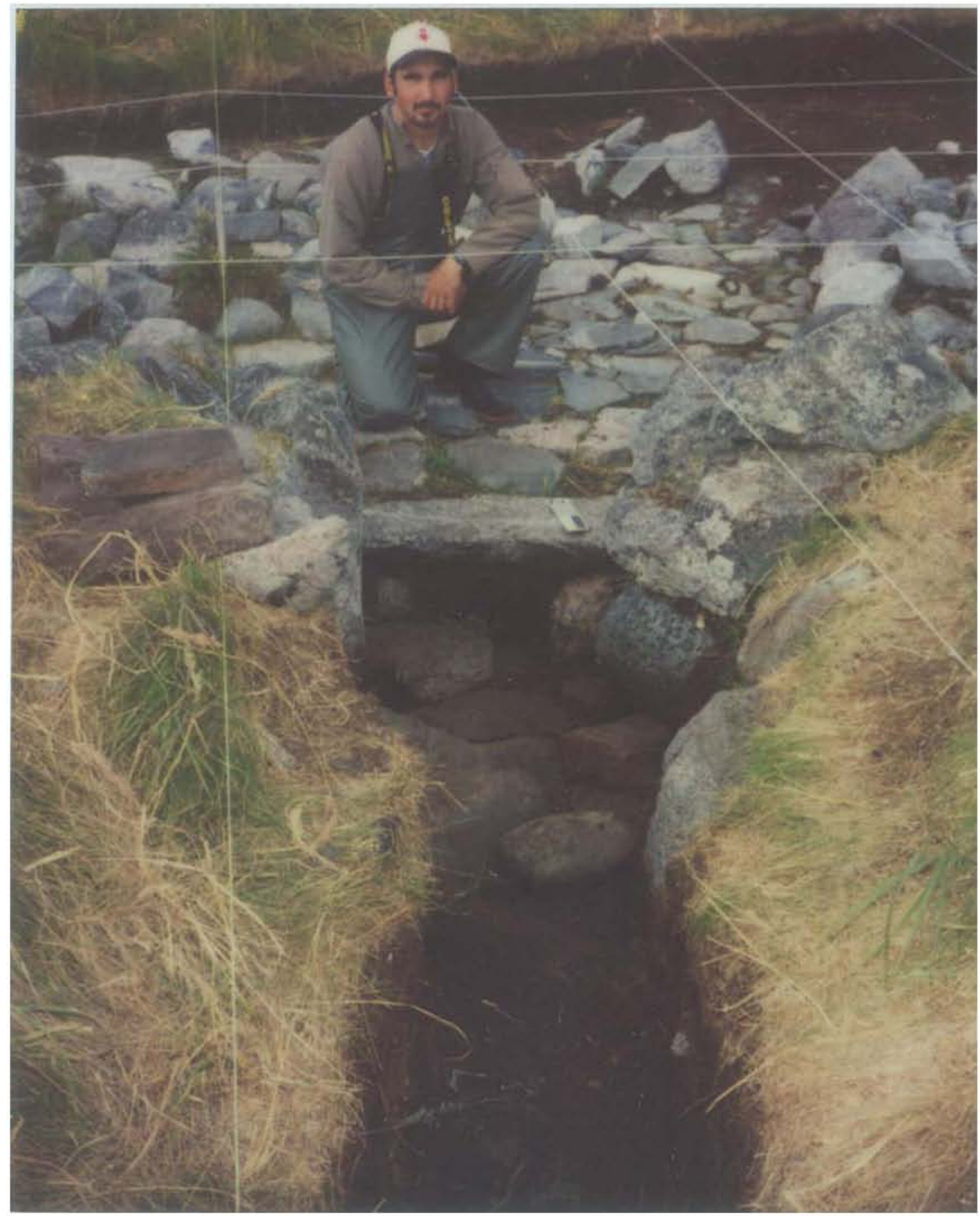

Figure 6.19: Entrance tunnel into Adlavik House 1 facing north. Jason Voisey stands on the interior house floor just beyond the entrance lintel stone. Note the raised floor platform (Courtesy S. Loring, photographer, 2000). 


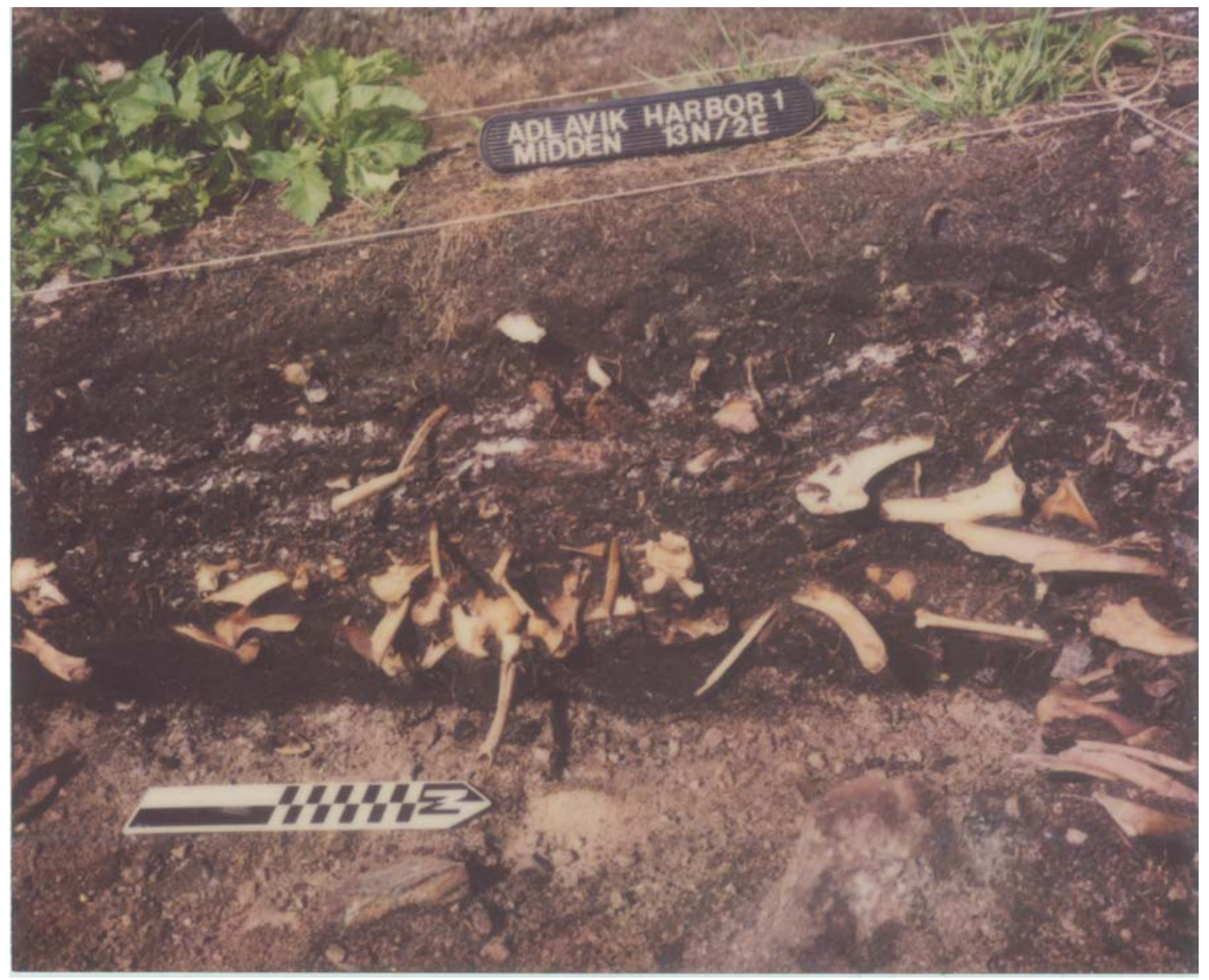

Figure 6.20: West profile of the Adlavik House 1 midden (Courtesy S. Loring, photographer, 2000). 


\section{House 4}

During the final season of excavations, test units in House 4 exposed a postabandonment midden resting above the original occupation level. House 4 was the smallest and least defined of all the houses in the settlement measuring approximately $8 \mathrm{x}$ $5 \mathrm{~m}$ and located just east of House 3. The eastern sod walls were missing, suggesting that later settlement occupants used the sod for construction of other houses. The initial $1 \mathrm{x} 1$ $\mathrm{m}$ test unit placed in the center of the house near the edge of a sleeping platform found a midden deposit with a heavy concentration of mussel shell before reaching the stone lined floor.

The shell midden was approximately 3-7 $\mathrm{cm}$ deep and located along the northeastern half of the house, cutting diagonally across the unit, separated by a line of fire-exposed stones (Figure 6.21). The midden deposit was composed of an organic loam heavily mottled with mussel shells, charcoal, ash and decomposing bone. The deposit came down on to wood logs resting on a flat stone floor. Although many of the shells were crushed possibly due to trampling, a shell sample was collected.

To identify the extent of the midden and determine the function of fire exposed rock feature, twelve additional units were added to the excavation of House 4. Shell appeared throughout the house, but concentrated mainly in the northeastern half of the house. All of the units exhibited a dark brown organic loam mottled with shell and wood. Deposits ranged from 10 - $28 \mathrm{~cm}$ deep due to the natural slope, and eventually reached a flat stone-slab floor. Excavations revealed the fire-exposed rock feature was the central hearth complex with fire-cracked rock and a thick ash deposit. The house had an array of 
well-preserved faunal and cultural material including a walrus skull, whale bone sled runner, and knife handle.

Loring believes that House 2 and House 4 were earlier than House 1 and House 3, and that residents of the later occupation salvaged the sod walls from the earlier houses (Stephen Loring, personal communication 2010). Further, he suspects the shell midden found in House 4 may be associated with the House 1 and House 3 occupations.

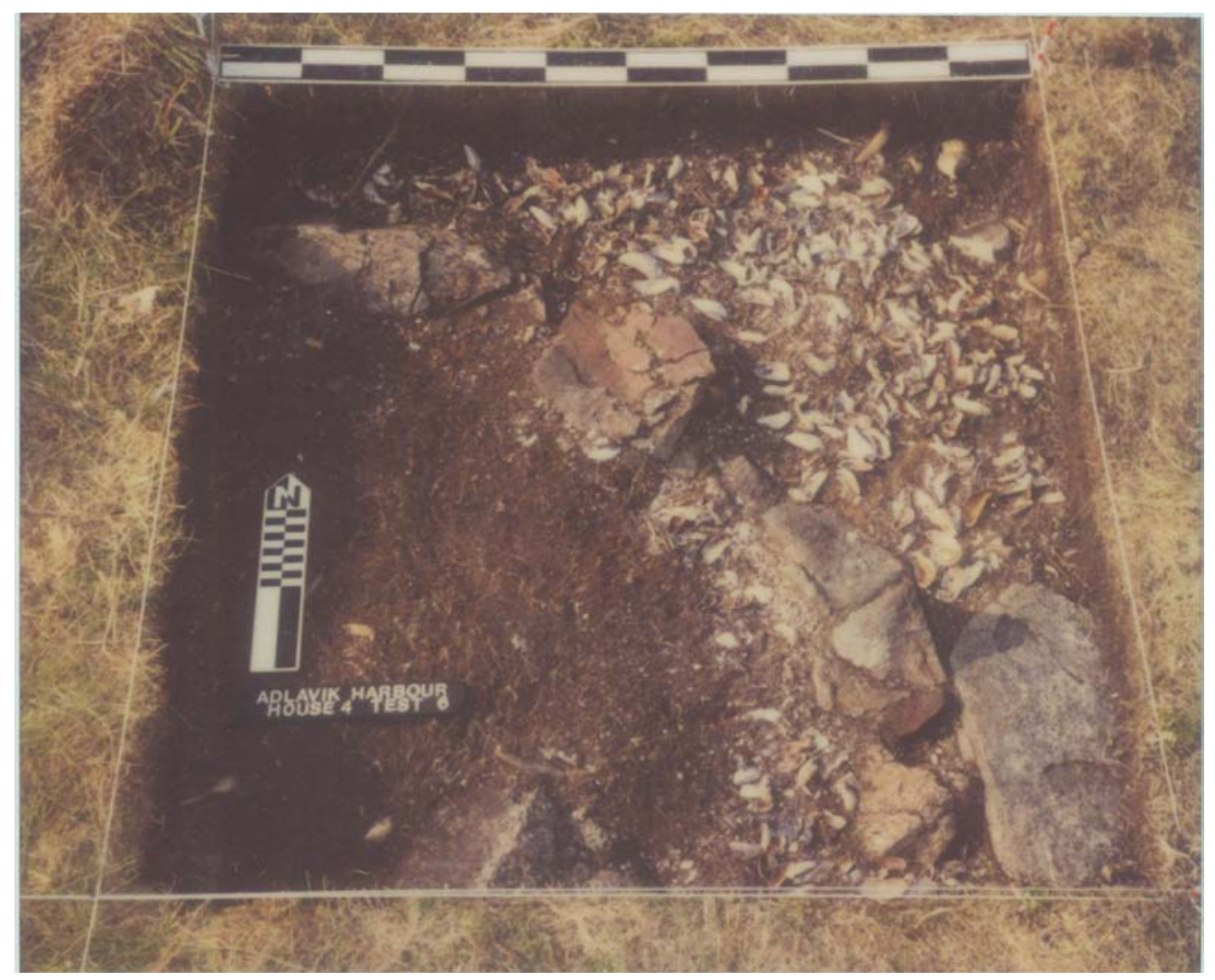

Figure 6.21: Plan view of the shell midden in Adlavik House 4 (Courtesy S. Loring, photographer, 2000). 


\section{Data Collection}

These sites provide an ideal data set for investigating diachronic changes to Inuit social and economic organization from early pre-contact to post-contact. Clues to the Native Inuit perspective and the choices they made in acquiring, adopting and using European goods can be inferred from the archaeological record. Exploring the material remains of the daily activities of the Inuit and Moravians offers insights into the local consequences of colonialism. I use the archaeological data collected from the aforementioned sites to build on previous interpretations regarding Inuit social organization and eventual changes to their culture.

To date, no comparable data set of historic Labrador Inuit sites has been compiled. Comparative analysis is important for understanding regional and temporal change of Labrador Inuit culture. However, a major challenge is ensuring consistent analytical methods for sites with different excavation strategies. Furthermore, artifacts are housed in a number of different museums spread throughout North America including Washington, D.C., New York City, St. John’s, Newfoundland, and Hopedale, Labrador and were not measured or cataloged using similar methods or classifications.

In an attempt to standardize the data from the three sites used in this project, I created an Access database to include information on artifacts and stratigraphic distinctions (Figures 6.22 and 6.23). Data recorded included contextual information such as excavators' notes as well as basic artifact information. Additional information on decoration, color, location, technique, and stylistic description were also collected. 


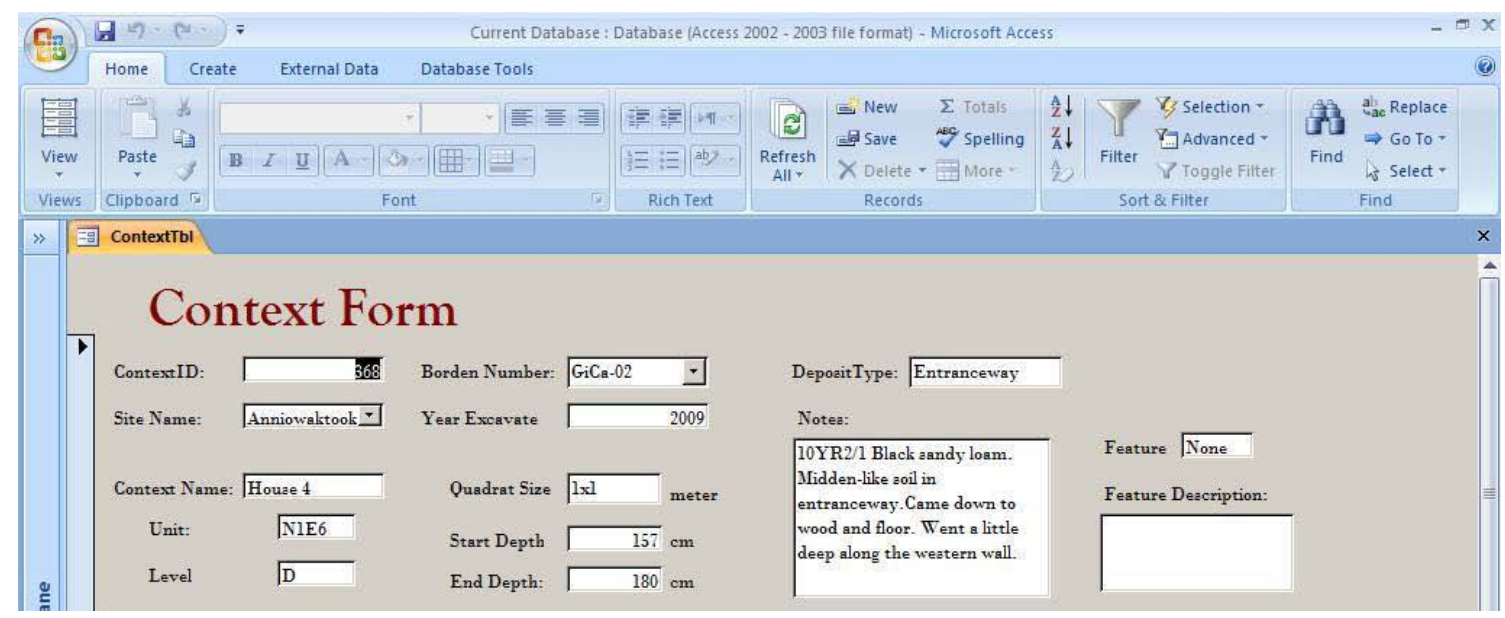

Figure 6.22: Screenshot of the Context Form from the Access database.

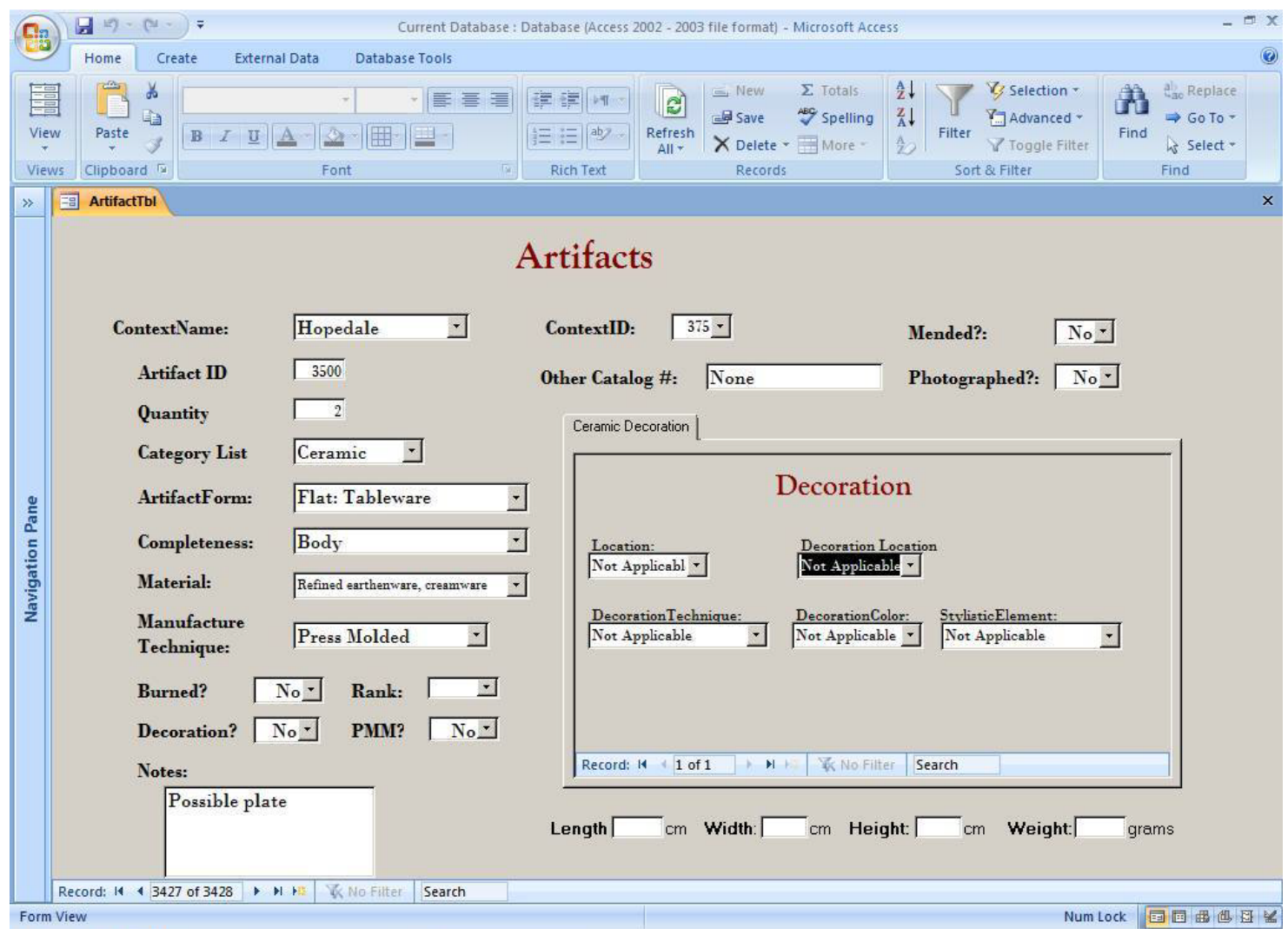

Figure 6.23: Screenshot of the Artifact Table from the Access database 


\section{Dating}

A major obstacle to evaluating temporal changes in household consumption and discard practices is the difficulty of dating sod houses. A number of factors can obscure a house’s occupation period, particularly since the Inuit often repeatedly reoccupied houses throughout the early historic periods. Such an overlap of depositional events makes reliance on only one type of absolute or relative dating problematic. Using radiocarbon to date the historic period is also problematic. The age of these sites pushes the interpretative limits of carbon dating, which has a standard deviation that exceeds the occupation period as defined by the refined historical chronologies of the recent past. Although additional complications can rise when using relative artifact-based methods, such as pipestem bore-diameters and mean ceramic dates, sufficient artifactual evidence exists to indicate that the Adlavik and Anniowaktook houses and at least three Avertôk houses were occupied in the historic period. Nevertheless, these methods are still subject to error. For instance, there can be a delay between the artifact's approximate manufacture date and its date of deposit. Therefore, I compare available dates obtained from beads, ceramic and tobacco pipestem bore-diameters to approximate a mean date range.

\section{Glass Beads}

Placing beads in a typology has often been a problem, given that beads are named in different ways varying across regions and over time. Nevertheless, attempts at bead terminology have led to a few classification systems, most prominently Kidd and Kidd 
(1970) and Karklins (1985). These classificatory systems are not intended to serve as an end in themselves, but as an analytical tool by which comparison of assemblages will reveal cultural and temporal patterns (Bundy et al. 2003).

In this study, only a small quantity of drawn and wound beads were found in the Adlavik houses and at Anniowaktook House 1, as compared to the great number and variety of beads found at Eskimo Island in southern Labrador (Jordan 1978). Drawn glass beads are cut from a glass tube that has been pulled out in a strand from a gather of glass, while wound beads are made by winding hot glass around a wire. A total of 60 beads were found within the five houses and their associated middens at Adlavik and Anniowaktook, and these represented a wide range of beads as recorded by the Kidd and Kidd (1977) and Karklins (1985) classification systems (Table 6.4). 


\begin{tabular}{|c|c|c|c|c|c|c|c|c|c|c|c|}
\hline Provenience & $\begin{array}{c}\text { Manufacturing } \\
\text { Technique }\end{array}$ & $\begin{array}{l}\text { Kidd } \\
\& \\
\text { Kidd } \\
\text { Code }\end{array}$ & Diaph. & Color & Size & Shape & Diam. & Length & Count & $\begin{array}{c}\text { Artifact } \\
\quad \#\end{array}$ & Notes \\
\hline $\begin{array}{l}\text { Adlavik } \mathrm{H} 2 \\
\text { A/B }\end{array}$ & Drawn & llb18d & Tsp & colorless & VL & $\begin{array}{l}\text { generally } \\
\text { spherical }\end{array}$ & 0.91 & 1.11 & 1 & 2230 & $\begin{array}{l}\text { Gooseberry. } \\
\text { Simple white } \\
\text { stripes }\end{array}$ \\
\hline Adlavik H1 A & Drawn & $\mathrm{Ila}$ & Tsl & Blue & $\mathrm{S}$ & Disk & 0.18 & 0.29 & 1 & 2229 & \\
\hline Adlavik H1 A & Drawn & IVa & op & white & $M$ & Disk & 0.53 & 0.58 & 1 & 2228 & \\
\hline Adlavik H1 A & Drawn & Ila & Tsl & Blue & $\mathrm{S}$ & Disk & 0.31 & 0.19 & 1 & 889 & \\
\hline Adlavik H1 A & Drawn & Ila & op & white & $S$ & Disk & 0.18 & 0.29 & 1 & 2195 & \\
\hline Adlavik H1 A & Drawn & Ila & Tsl & Turquoise & $S$ & Disk & 0.23 & 0.37 & 1 & 2184 & \\
\hline Adlavik H1 A & Drawn & IVa & op & white & $S$ & Disk & 0.18 & 0.27 & 1 & 2200 & \\
\hline Adlavik H1 A & Drawn & IVa & op & white & $\mathrm{S}$ & Disk & 0.16 & 0.30 & 1 & 2201 & \\
\hline Adlavik H1 A & Drawn & IVa & Tsl & red & $S$ & Disk & 0.18 & 0.27 & 1 & 2203 & \\
\hline Adlavik H1 B & Drawn & Ila & tsl & Blue & $S$ & Disk & 0.22 & 0.33 & 1 & 2227 & \\
\hline Adlavik H1 B & Drawn & IVa & op & white & $\mathrm{S}$ & Disk & 0.25 & 0.36 & 1 & 2219 & \\
\hline Adlavik H1 B & Drawn & la & tsl & blue & $\mathrm{S}$ & Disk & 0.21 & 0.25 & 1 & 2209 & \\
\hline Adlavik H1 B & Drawn & la & tsl & Blue & $S$ & Disk & 0.24 & 0.25 & 1 & 2214 & \\
\hline Adlavik H1 B & Drawn & IIla & op & white & $\mathrm{S}$ & Disk & 0.18 & 0.20 & 1 & 1200 & $\begin{array}{l}\text { White. } \\
\text { Compound } \\
\text { bead. }\end{array}$ \\
\hline Adlavik H1 B & Drawn & IIla & op & $\begin{array}{l}\text { Red- } \\
\text { green }\end{array}$ & $\mathrm{S}$ & Disk & 0.2 & 0.24 & 1 & 2220 & \\
\hline Adlavik H1 A & Drawn & Ila & tsl & Blue & $S$ & Disk & 0.2 & 0.30 & 1 & 1254 & \\
\hline Adlavik H1 B & Drawn & la & tsl & Blue & $\mathrm{S}$ & Disk & 0.24 & 0.25 & 1 & 2217 & \\
\hline Adlavik H1 B & Drawn & Ila & tsl & Blue & $S$ & Disk & 0.24 & 0.35 & 1 & 2218 & \\
\hline
\end{tabular}




\begin{tabular}{|c|c|c|c|c|c|c|c|c|c|c|c|}
\hline Provenience & $\begin{array}{c}\text { Manufacturing } \\
\text { Technique }\end{array}$ & $\begin{array}{l}\text { Kidd } \\
\& \\
\text { Kidd } \\
\text { Code }\end{array}$ & Diaph. & Color & Size & Shape & Diam. & Length & Count & $\begin{array}{c}\text { Artifact } \\
\#\end{array}$ & Notes \\
\hline Adlavik H1 B & Drawn & Ila & tsl & Blue & $S$ & Disk & 0.28 & 0.20 & 1 & 2215 & \\
\hline Adlavik H1 B & Drawn & Ila & op & white & $S$ & Disk & 0.23 & 0.35 & 1 & 2211 & \\
\hline Adlavik H1 B & Drawn & IVa & op & $\begin{array}{l}\text { Red- } \\
\text { green }\end{array}$ & $S$ & Disk & 0.27 & 0.19 & 1 & 2208 & \\
\hline Adlavik H1 B & Drawn & Ila & tsl & Turquoise & $S$ & Disk & 0.18 & 0.3 & 1 & 2206 & \\
\hline Adlavik H1 C & Drawn & IIIa & op & $\begin{array}{l}\text { Red- } \\
\text { green }\end{array}$ & $\mathrm{S}$ & Disk & 0.3 & 0.26 & 1 & 2216 & \\
\hline Adlavik H1 C & Drawn & $\mathrm{IVa}$ & op & white & $S$ & Disk & 0.4 & 0.3 & 1 & 2221 & \\
\hline Aldavik H3 B & Drawn & $\mathrm{IVa}$ & op & $\begin{array}{l}\text { Red- } \\
\text { green }\end{array}$ & $\mathrm{S}$ & Disk & 0.31 & 0.26 & 1 & 2212 & \\
\hline Aldavik H3 B & Drawn & - & tsl & Turquoise & $\mathrm{S}$ & Disk & 0.35 & 0.21 & 1 & 2213 & $\begin{array}{l}\text { No bore. } \\
\text { Approximate } \\
\text { measurements. }\end{array}$ \\
\hline Aldavik H3 B & Drawn & la & op & Red & $S$ & Disk & 0.18 & 0.16 & 1 & 2210 & \\
\hline Adlavik H3 B & Drawn & IIf & Tsl & $\begin{array}{c}\text { Dark red- } \\
\text { puruple }\end{array}$ & $S$ & Disk & 0.31 & 0.15 & 1 & 2223 & Paddled \\
\hline Adlavik H3 B & Drawn & Ilb18d & Tsp & colorless & $\mathrm{L}$ & Barrel & 0.61 & 0.44 & 1 & 2224 & $\begin{array}{l}\text { Gooseberry. } \\
\text { Simple white } \\
\text { stripes }\end{array}$ \\
\hline Adlavik H1 B & Drawn & $\mathrm{IVa}$ & tsl & white & $S$ & Disk & 0.4 & 0.24 & 1 & 2222 & \\
\hline Adlavik H3 B & Drawn & If & Tsl & purple & L & Barrel & 0.95 & 1 & 1 & 1288 & $\begin{array}{l}\text { Broken along } \\
\text { the bore. Six } \\
\text { straight sides }\end{array}$ \\
\hline
\end{tabular}




\begin{tabular}{|c|c|c|c|c|c|c|c|c|c|c|c|}
\hline Provenience & $\begin{array}{c}\text { Manufacturing } \\
\text { Technique }\end{array}$ & $\begin{array}{l}\text { Kidd } \\
\& \\
\text { Kidd } \\
\text { Code }\end{array}$ & Diaph. & Color & Size & Shape & Diam. & Length & Count & $\begin{array}{c}\text { Artifact } \\
\#\end{array}$ & Notes \\
\hline & & & & & & & & & & & $\begin{array}{l}\text { with two rows } \\
\text { of ground } \\
\text { facets. }\end{array}$ \\
\hline Adlavik H3 C & Drawn & Ila & tsl & Blue & $S$ & Disk & 0.25 & 0.17 & 1 & 1295 & \\
\hline Aldavik H3 C & Drawn & IIla & op & $\begin{array}{l}\text { Red- } \\
\text { green }\end{array}$ & $\mathrm{S}$ & Disk & 0.33 & 0.29 & 1 & 1296 & \\
\hline Aldavik H3 A & Drawn & IVa & op & Red-clear & $S$ & Disk & 0.25 & 0.19 & 1 & 2196 & \\
\hline Aldavik H3 A & Drawn & IVa & op & $\begin{array}{l}\text { Red- } \\
\text { white }\end{array}$ & $S$ & Disk & 0.2 & 0.14 & 1 & 2197 & \\
\hline Adlavik H3 B & Drawn & IVa & op & white & $S$ & Disk & 0.27 & 0.22 & 1 & 2198 & \\
\hline Adlavik H3 B & Drawn & IVa & op & white & $S$ & Disk & 0.29 & 0.2 & 1 & 2207 & \\
\hline Adlavik H1 A & Drawn & $\mathrm{IVa}$ & op & white & $\mathrm{S}$ & Disk & 0.25 & 0.16 & 1 & 1429 & Complex \\
\hline Adlavik H1 A & Drawn & la & tsl & $\begin{array}{r}\text { yellow- } \\
\text { gold }\end{array}$ & $\mathrm{S}$ & Disk & 0.18 & 0.21 & 1 & 1554 & \\
\hline Adlavik H1 C & Drawn & $\mathrm{Ila}$ & tsp & light blue & $S$ & Disk & 0.2 & 0.32 & 1 & 1550 & \\
\hline Adlavik H1 B & Drawn & IVa & op & $\begin{array}{l}\text { Red- } \\
\text { green }\end{array}$ & $\mathrm{S}$ & Disk & 0.34 & 0.25 & 1 & 1553 & \\
\hline Adlavik H1 A & Drawn & IVa & tsl & Yellow & $S$ & Disk & 0.3 & 0.21 & 1 & 1548 & \\
\hline Adlavik H1 A & Drawn & Ila & tsp & light blue & $S$ & Barrel & 0.45 & 0.28 & 1 & 1551 & \\
\hline Adlavik H1 A & Wound & WIIdI & Tsp & colorless & $\mathrm{VL}$ & Barrel & 1.02 & 0.72 & 1 & 1552 & Raspberry. \\
\hline Adlavik H2 B & Wound & WIIc & $\mathrm{tsp}$ & colorless & $\mathrm{VL}$ & Barrel & 1.04 & 1.05 & 1 & 1583 & $\begin{array}{l}\text { Partial. } \\
\text { Facetted. } 5 \\
\text { sides }\end{array}$ \\
\hline Adlavik H4 A & Drawn & IVa & op & white & $S$ & Disk & 0.25 & 0.19 & 1 & 1540 & \\
\hline
\end{tabular}




\begin{tabular}{|c|c|c|c|c|c|c|c|c|c|c|c|}
\hline Provenience & $\begin{array}{c}\text { Manufacturing } \\
\text { Technique }\end{array}$ & $\begin{array}{l}\text { Kidd } \\
\& \\
\text { Kidd } \\
\text { Code }\end{array}$ & Diaph. & Color & Size & Shape & Diam. & Length & Count & $\begin{array}{c}\text { Artifact } \\
\quad \#\end{array}$ & Notes \\
\hline Adlavik H4 A & Drawn & IVa & op & $\begin{array}{l}\text { Red- } \\
\text { green }\end{array}$ & $\mathrm{S}$ & Disk & 0.37 & 0.24 & 1 & 1543 & \\
\hline Adlavik H4 A & Drawn & IVa & op & $\begin{array}{l}\text { Red- } \\
\text { green }\end{array}$ & $\mathrm{S}$ & Disk & 0.35 & 0.24 & 1 & 1547 & \\
\hline Adlavik H4 A & Drawn & IVa & op & white & $S$ & Disk & 0.25 & 0.21 & 1 & 1556 & \\
\hline Adlavik H4 A & Drawn & Ila & op & white & $S$ & Disk & 0.21 & 0.24 & 1 & 1846 & Partial. \\
\hline Adlavik H4 C & Drawn & IVa & tsl & Blue & $S$ & Disk & 0.31 & 0.22 & 1 & 1785 & \\
\hline Adlavik H4 B & Drawn & Ila & tsl & Blue & $S$ & Disk & 0.35 & 0.24 & 1 & 1407 & \\
\hline Adlavik H4 B & Drawn & $11 \mathrm{~b} 2$ & op & Black & $\mathrm{VL}$ & Barrel & 1.24 & 0.76 & 1 & 1544 & $\begin{array}{l}\text { A. Speo. Single } \\
\text { white stripes. }\end{array}$ \\
\hline Adlavik H4 A & Drawn & la & tsp & Blue & $S$ & Disk & 0.29 & 0.21 & 1 & 1555 & \\
\hline $\begin{array}{l}\text { Anniowaktook } \\
\mathrm{H} 1 \mathrm{E}\end{array}$ & Drawn & IIla & op & White & $\mathrm{VL}$ & Tubular & 1.19 & 0.64 & 1 & 2416 & \\
\hline $\begin{array}{l}\text { Anniowaktook } \\
\text { H1 B }\end{array}$ & Drawn & Illa & op & Red-clear & $\mathrm{VL}$ & Tubular & 1.25 & 0.46 & 1 & 2497 & \\
\hline $\begin{array}{l}\text { Anniowaktook } \\
\mathrm{H} 1 \mathrm{~A}\end{array}$ & Drawn & Ila & op & light blue & $\mathrm{L}$ & Barrel & 0.65 & 0.71 & 1 & 2823 & \\
\hline $\begin{array}{l}\text { Anniowaktook } \\
\text { H1 A }\end{array}$ & Drawn & Ila & op & light blue & $\mathrm{L}$ & Barrel & 0.8 & 0.85 & 1 & 2824 & \\
\hline
\end{tabular}

Table 6.4: Table of beads from Adlavik and Anniowaktook. Tsp = transparent, tsl = translucent, op = opaque. The range of sizes included in this table include $\mathrm{S}=$ small (2 to $4 \mathrm{~mm}), \mathrm{L}=$ large (4 to $6 \mathrm{~mm})$, VL = very large (6 to $10 \mathrm{~mm}$ ). 
The majority of the beads found are drawn blue, white, and red-on-green seed beads, which are commonly found on eighteenth-century sites (Burgess and Sperling 2008). The red-on-green beads, sometimes called Cornaline d'Aleppo date to the 1800 s. The distinct appearance of the Cornaline d'Aleppo is based on two colors of glass - a light green or clear core is covered by a second layer of red glass — with the interior core more typically white by the 1830s (Billeck 2008:94). These beads tend to have long manufacturing spans that continued into the twentieth century and are not particularly diagnostic, yet they are commonly found in contexts associated with European-Native trading. One red-on-white was found on the surface level of Adlavik House 2 and was not included in this analysis since its relationship to the house's occupation was unclear, and may have be associated with the several nineteenth- and twentieth-century fishing villages.

A few more diagnostic beads were found that serve as better temporal markers, help place the sites' occupation (Figure 6.24). One example of a bead with a later date range is a transparent, purple bead fragment in the House 3 midden. It has at least six straight sides and two rows of ground facets. Chemical analysis of similar beads with different colors (i.e., translucent green, colorless, and dark blue) has similar compositions to known Bohemian glass recipes, and are thus identified as nineteenth-century Bohemian in origin (Burgess and Dussubieux 2007:Table 5:68; Burgess and Sperling 2008).

The Adlavik assemblage also contains an opaque black with white striped “A. Speo" bead found in House 4. These beads tend to be slightly elongated or "sagged" as a 
result of the production method, which used a pronged iron spit that was rotated in the furnace. A. Speo beads date to the mid- to late eighteenth century (Karklins 1993).

One very large gooseberry bead was found in the entry tunnel of Adlavik House 2 and a second smaller gooseberry was found in House 3's midden. Gooseberries tend to be round, colorless beads with approximately 15 white stripes. They have been found in contexts that date from the sixteenth to the eighteenth century in the mid-Atlantic and southeastern regions (Burgess and Sperling 2008; Deagan 1987; Lapham 2001; Miller et al. 1983; M. Smith 1976). Research suggests that the shape of these beads is temporally sensitive and that early sixteenth-century gooseberry beads have an oval shape but become more barrel shape by the eighteenth century (M. Smith 1983).

Beads make up a very small portion of the Anniowaktook and Adlavik assemblages and their analytical use here is limited. Nevertheless, the characteristics of the bead assemblages described above are consistent with the hypothesized mideighteenth to early nineteenth-century occupation of the houses.

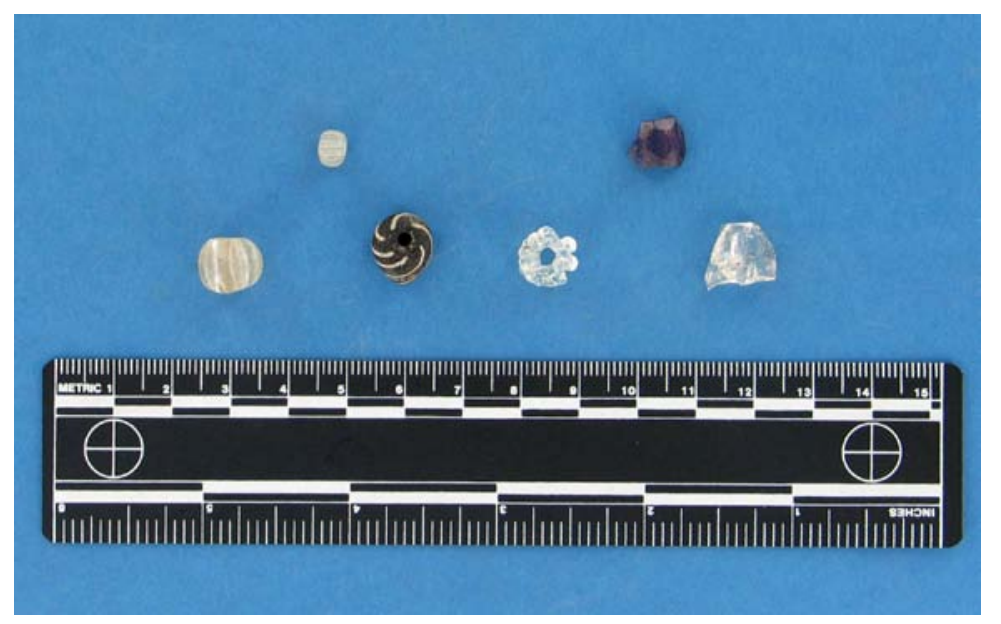

Figure 6.24: A collection of beads from the Adlavik assemblage. Top row from left to right: Gooseberry bead, purple faceted bead. Bottom row left to right: large Gooseberry bead, A. Speo, colorless raspberry bead, colorless faceted bead. 


\section{Tobacco Pipe Bores}

Tobacco pipe bore diameters have long been used in dating sites for historical archaeologists since it was discovered that the bore diameters shrank over time (Binford 1962; Harrington 1951, 1954; Omwake 1956). The earliest pipes date to about 1600 and had a bore diameter of 9/64”. Pipe bore diameters decreased to 4/64” by 1800 . This change in diameter led researchers to devise a mathematical formula that approximated manufacturing dates for pipe stems made in England between 1590 and 1800. The pipestem bore diameter measurement thus can be quantified and the regression formula employed to yield an approximate date.

Since the Moravians received all of their goods from the England-based SFG, it can be assumed that all the pipes found in Hopedale Moravian contexts were English. Given that the pipes found at the Inuit sites were similar kaolin ball-clay pipes, I assume those pipes were also manufactured in England. However, it is not clear whether all Inuit sites were abandoned prior to 1750 , when the relationship between bore diameter and date ceased (K. Smith et al. 2008).

Of the 20 pipe stem fragments found, two have bore diameters of 7/64” and 6/64” respectively, 9 have a bore diameter of 5/64”, and 9 have a bore diameter of 4/64” (Table 6.5). ${ }^{11}$ One stem with a bore diameter of $4 / 64$ ” was found on the surface of a beach near House 1 and was not included in the analysis since its relationship to the Inuit occupation was vague.

\footnotetext{
${ }^{11}$ Two pipe stems were found at two of the Avertôk houses; however, given that bore diameter measurements could not be made and historical context was uncertain, they were removed from this portion of the analysis.
} 
I use three different regression formulas since each generates slightly different approximate dates for the disappearance of pipe diameters and their duration of use. While J.C. Harrington (1951) originally identified bore size as a dating technique, Lewis Binford expanded Harrington's histogram and refined the original data to develop a statistical regression formula for estimating the pipe stem's age from the bore size. Lee Hanson (1969) tried to refine the dating again by combining Harrington's set time period with Binford’s mean date and standard deviation (McMillan 2010:18). Hanson's method created separate formulas according to different time brackets. Determining which formula to use is based on the estimated occupation dates determined by the researcher.

For the following pipes, I calculated mean dates for pipes found at Inuit houses with Hanson’s earlier bracket from 1680-1800. Although Hanson later recanted his findings based on “unwarranted assumptions” (Hanson 1971:254), recent research has found his equation useful in estimating occupation periods (McMillan 2010).

The final formula used was developed by Robert Heighton and Kathleen Deagan (1971) who agreed with Hanson that the bore diameters did not follow the linear pattern assumed by Binford's analysis; instead it followed a curvilinear pattern of change over time. They used a logarithmic equation to the fit the alleged curvilinear relationship between time and bore diameter.

By comparing the three formulas — Hanson, Binford, and Heighton and Deagan — I avoid relying on a single analytical approach or its associated problems. In some cases, however, sample sizes from Anniowaktook and Adlavik are small. Additionally, the accuracy of pipe bore diameter estimates decline towards the end of the eighteenth 
century, the anticipated abandonment date of the sites. Specific regional and temporal factors not included in the earlier formulas which were based on tobacco pipes from Virginia may not be representative of other regions, thus influencing the accuracy of the calculations (McMillan 2010:21). The extremely small sample size and that fact that at least some of the sites were occupied after 1750, puts the validity of these dates into question (K. Smith et al. 2008). Together the three formulas present a wide range of possible dates, with the majority of the mean dates pointing to a mid- to late eighteencentury occupation for the Inuit sites (Table 6.6).

\begin{tabular}{|c|c|c|c|c|c|c|c|}
\hline Site & Context & $\mathbf{4 / 6 4}$ & $\mathbf{5 / 6 4}$ & $\mathbf{6 / 6 4}$ & $\mathbf{7 / 6 4}$ & $\begin{array}{c}\text { Total } \\
\text { Stems }\end{array}$ & $\begin{array}{c}\text { Average } \\
\text { Bore } \\
\text { Diameter }\end{array}$ \\
\hline Adlavik & House 1 & & & & 1 & 1 & 7 \\
\hline & House 1 Mid & 2 & 2 & & & 4 & 4.5 \\
\hline & House 2 & 1 & & & & 1 & 4 \\
\hline & House 3 & 5 & 5 & & & 10 & 4.5 \\
\hline & House 4 Mid & & 1 & & & 1 & 1 \\
\hline Anniowaktook & House 1 & & 1 & 1 & & 2 & 5.5 \\
\hline & House 4 & 1 & & & & 1 & 4 \\
\hline & TOTAL & $\mathbf{9}$ & $\mathbf{9}$ & $\mathbf{1}$ & $\mathbf{1}$ & $\mathbf{2 0}$ & \\
\hline
\end{tabular}

Table 6.5: Table of raw counts of the tobacco pipe stems by bore measurements. 


\begin{tabular}{|c|c|c|c|c|}
\hline Site & Context & Heighton \& Deagan & Binford & $\begin{array}{c}\text { Hanson } \\
(1680-1800)\end{array}$ \\
\hline & & $\begin{array}{c}x=(-\log y \\
+1.04435) / 0.05324 \\
\text { then } \\
1600+22 x=y\end{array}$ & $\begin{array}{c}y=1931.85- \\
38.26 x\end{array}$ & $\begin{array}{c}y=1959.66- \\
44.32 x\end{array}$ \\
\hline Adlavik & $\begin{array}{c}\text { House } 1 \\
\text { House } 1 \text { Mid } \\
\text { House } 2 \\
\text { House } 3 \\
\text { House } 4 \text { Mid }\end{array}$ & $\begin{array}{l}1682 \\
1762 \\
1782 . \\
1762 \\
1743\end{array}$ & $\begin{array}{l}1664 \\
1760 \\
1779 \\
1760 \\
1741\end{array}$ & $\begin{array}{l}1649 \\
1760 \\
1782 \\
1760 \\
1738\end{array}$ \\
\hline Anniowaktook & $\begin{array}{l}\text { House } 1 \\
\text { House } 4\end{array}$ & $\begin{array}{l}1726 \\
1783\end{array}$ & $\begin{array}{l}1721 \\
1779\end{array}$ & $\begin{array}{l}1716 \\
1782\end{array}$ \\
\hline
\end{tabular}

Table 6.6: Estimated date for Adlavik and Anniowaktook using three different formulas for pipe stem diameters. 


\section{Mean Ceramic Dates and Occurrence Seriation}

Mean ceramic dates (MCDs) offer a rough temporal estimate of a ceramic assemblage based on the weighted average of the midpoints of the manufacturing dates based on documentary evidence (South 1977). MCDs are determined by the relative frequencies of types in an assemblage; proportionally more abundant types have a greater impact on the estimated date. I calculated MCDs using the tabulated data from the Digital Archaeological Archive of Comparative Slavery (DAACS) as it is a large database (with over 175,000 ceramic artifacts catalogued) and a wide variety of types.

In the DAACS list, MCD calculations were broken down to include decorative variation, such as decorative technique and applied color; general date ranges for undecorated ceramic ware types are also provided (source: http://www.daacs.org/aboutDatabase/MCDTypes.html). Although the DAACS MCD type list was created by using ceramics found on American colonial sites, the database's extensive sample size that overlap with temporal periods from this study area offers the best collection of ceramic date estimates. A few wares in the Labrador collection were not on the DAACS MCD-type list; therefore manufacturing dates for Normandy Stoneware and Rouen Plain Faience were collected from Parks Canada and the Florida Museum of Natural History Digital Types Collection respectively. Normandy Stoneware was produced in the Normandy region of France beginning in the 1600s. It was characterized by a dark purple-brown or purple-grey fabric which is often unglazed. Normandy Stoneware appeared most frequently in northern Labrador as a storage jug. Rouen Plain Faience also originated in France and has a salmon-colored hard paste with 
an exterior tin enamel glaze and interior manganese lead glaze. It had a 50-year manufacturing period from 1740-1790, and often appeared as bowls or pots, although no complete form has been found in northern Labrador. All of the types and their mean manufacturing dates are listed in Table 6.7 and the raw counts of the ceramics from each deposit are listed in Table 6.8.

\begin{tabular}{|c|c|c|}
\hline Ceramic Ware Type & Date Range & Mean Manufacturing Date \\
\hline English Stoneware & $1671-1800$ & 1735.5 \\
\hline Delftware & $1600-1802$ & 1701 \\
\hline Faience, unidentified & $1690-1765$ & 1727.5 \\
\hline Normandy Stoneware & $1690-1790$ & 1740 \\
\hline $\begin{array}{c}\text { North Devon Coarseware, Gravel } \\
\text { Tempered }\end{array}$ & $1600-1775$ & 1687.5 \\
\hline Pearlware & $1775-1830$ & 1802.5 \\
\hline Redware & $1700-1900$ & 1800 \\
\hline Rouen Plain Faience & $1740-1790$ & 1765 \\
\hline Staffordshire Slip Coarse Earthenware & $1670-1795$ & 1732.5 \\
\hline White Salt Glazed Stoneware & $1720-1805$ & 1762.5 \\
\hline Whiteware & $1830-1920$ & 1875 \\
\hline
\end{tabular}

Table 6.7: Ceramic ware types that contributed to the mean ceramic date collected from the DAACS MCD list, Parks Canada, and the Florida Museum of Natural History Digital Types Collection. 


\begin{tabular}{|c|c|c|c|c|c|c|c|c|c|c|c|}
\hline Site & Context & Delftware & $\begin{array}{l}\text { North } \\
\text { Devon } \\
\end{array}$ & $\begin{array}{c}\text { Faience, } \\
\text { unid. }\end{array}$ & $\begin{array}{c}\text { English } \\
\text { Stoneware }\end{array}$ & Normandy & $\begin{array}{c}\text { Rouen } \\
\text { Plain } \\
\text { Faience } \\
\end{array}$ & Redware & Pearlware & Whiteware & Total \\
\hline \multirow[t]{6}{*}{ Adlavik } & House 1 & & & 1 & & 8 & 3 & 1 & 1 & 1 & 15 \\
\hline & House 1 Mid & 1 & & & & 1 & 1 & 1 & & 1 & 5 \\
\hline & House 2 & & & & & 4 & & & & & 4 \\
\hline & House 3 & & & 4 & 1 & 2 & 1 & & 1 & 2 & 11 \\
\hline & House 4 & 2 & & & & & & & & & 2 \\
\hline & House 4 Mid & & & 1 & & & & & 1 & & 2 \\
\hline \multirow[t]{4}{*}{ Anniowaktook } & House 1 & & & & 1 & 7 & & 58 & & & 66 \\
\hline & House 1 Mid & & 2 & & & 1 & & 1 & & & 4 \\
\hline & House 4 & & 16 & & & & & 4 & & & 20 \\
\hline & House 4 Mid & & 18 & & & & & 2 & & & 20 \\
\hline \multirow[t]{2}{*}{ Avertôk } & House 1 & & & & & & & 1 & & & 1 \\
\hline & House 3 & & & & 1 & & & 1 & & 1 & 3 \\
\hline Total & & 3 & 36 & 6 & 3 & 23 & 5 & 69 & 3 & 5 & 153 \\
\hline
\end{tabular}

Table 6.8: Raw counts of the ceramic types found in each deposit. 
Prior to the MCD calculation, I determined that a majority of the whiteware and pearlware sherds found at Adlavik were collected from the surface level. One sherd of whiteware was found in the entrance of Adlavik House 1 at $20 \mathrm{~cm}$ below surface; however, it appears this came from a later level as a result of wall-fall (Stephen Loring, personal communication 2010). Pearlware was introduced in 1775 and manufacturing ended around 1830 when whiteware was introduced. Given the later manufacturing date ranges and that the majority of these sherds were found on the surface, I removed whiteware and pearlware from the analysis.

MCDs were calculated with a 95\% confidence interval for the remaining Inuit sites. Confidence limits were calculated by calculating a manufacturing mid-point by averaging the entire date range for each ceramic type for sherd in a single assemblage. The sum of the manufacturing midpoints is divided by the total number of sherds to calculate the mean. The standard deviation of the sum of those manufacturing midpoints was divided by the square root of the total number of sherds included in the analysis for a single assemblage, also known as standard error of the mean. The standard error of the mean is multiplied by the critical value of $t$ and then added and subtracted to the mean to generate the interval. Even though this method attempts to capture a range of error, the methods proves to be problematic since the sample sizes for some assemblages are small, resulting in a lack of temporal precision.

Calculating the confidence interval in this manner can lead to inaccurate mean ceramic dates when dominated by types with long manufacturing periods (Galle 2006:107) (Figures 6.25 and 6.26). Assemblages from Adlavik House $2(n=4)$ and 
House $4(n=2)$ and Avertôk House $3(n=2)$ were not only small, but the types had wide manufacturing spans, such as redware (1700-1900), English stoneware (1671-1800), and Delftware (1600-1802). As a result, these dates are subject to considerable error and might project a false sense of accuracy. Nevertheless, I incorporate these dates in the following analysis as a way to approximate Inuit occupation of these houses.

Given the potential error when calculating MCDs with such a small sample, I also conducted an occurrence seriation. Occurrence seriation orders ceramic ware types according to the presence or absence at a site. The seriation records the distribution of a combination of features not as objects, but rather as events (Dunnell 1970). Depending on presence-absence data instead of frequency data allows for a chronology that weighs all types evenly. Types with a low frequency in fact may be good time indicators and their presence, even if just a single example, can be crucial in understanding the complete chronology (Dempsey and Baumhoff 1963). Seriation relies on the theoretical principle that the "distribution of any historical or temporal class is continuous through time" (Dunnell 1970:308); therefore the ordering of the occurrence seriation is presumed to be chronological. In addition, the event being recorded by the seriation is a mean between the earliest and latest elements of the group, and this may not always translate into clear chronological precision. 


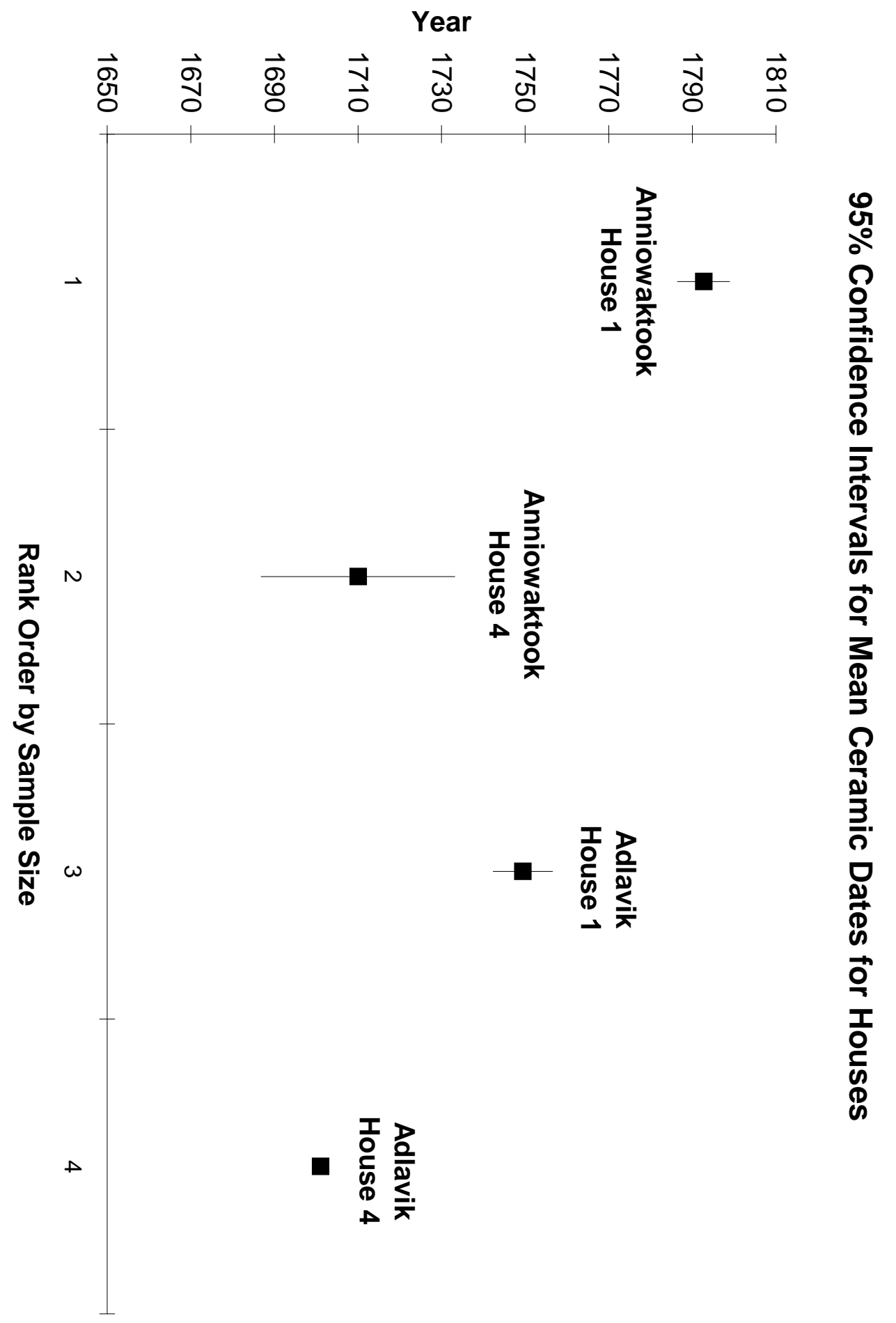

Figure 6.25: $95 \%$ confidence intervals for mean ceramic dates for house deposits. 


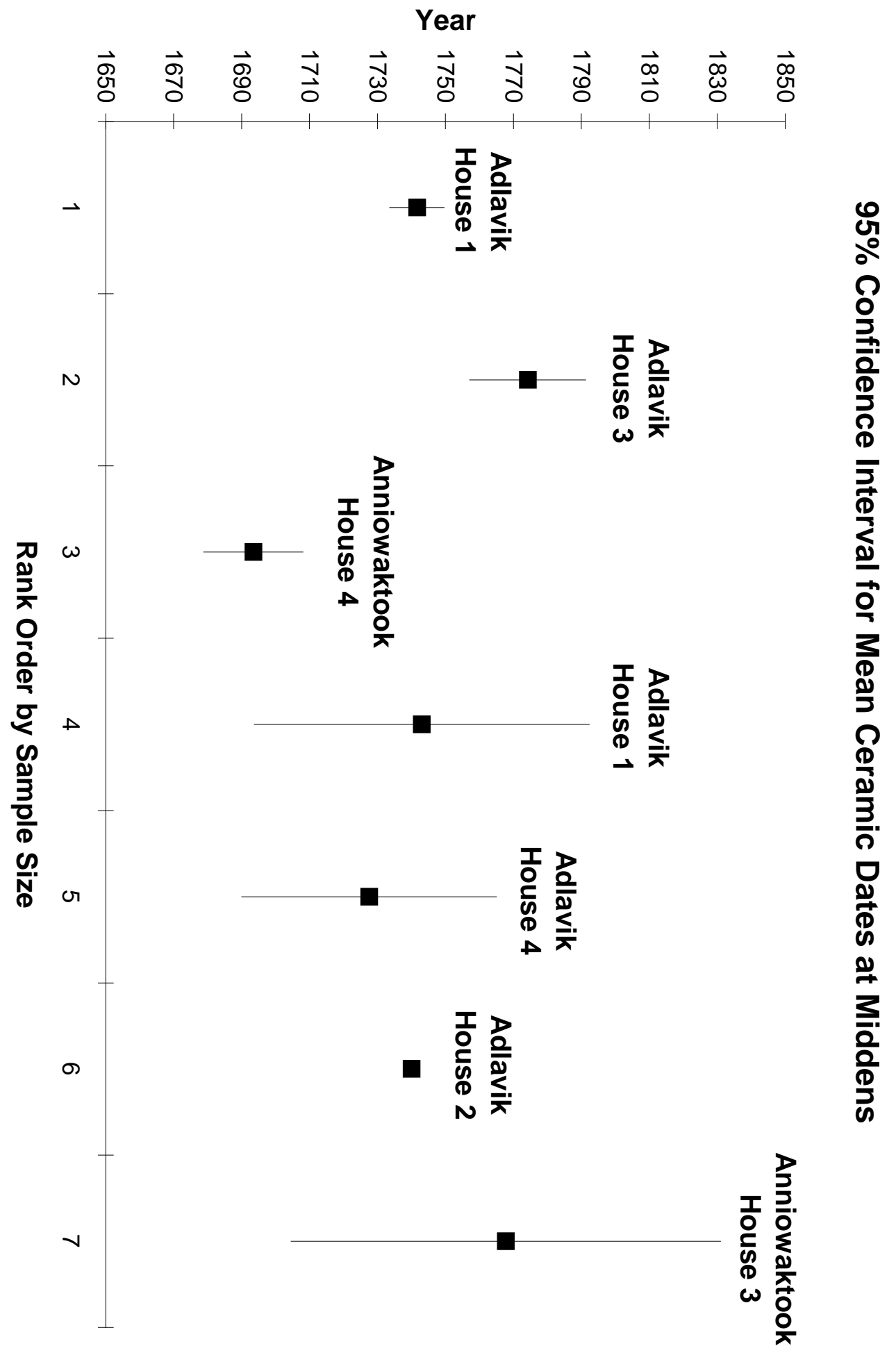

Figure 6.26: $95 \%$ confidence intervals for mean ceramic dates at midden deposits. 
All of the sites were initially grouped and ordered together, and then separated according to variation seen in the ceramic ware order. This resulted in formation of two occurrence seriations, one for the houses and a second for their middens. Once type frequencies were tabulated, I constructed occurrence serration for each type using a Microsoft Excel macro (Lipo 2001).

The first seriation represents only house deposits, indicating that Adlavik House 4 and Anniowaktook House 4 exhibited earlier materials while later ceramic types appear in the remaining three houses (Figure 6.27). The second seriation represents the midden assemblages where Adlavik Houses 1 and 4 exhibited the earliest ceramic types (Figure 6.28). Unfortunately, the limited variety of types that also have wide manufacturing spans adds to the ambiguity seen in the occurrence seriation.

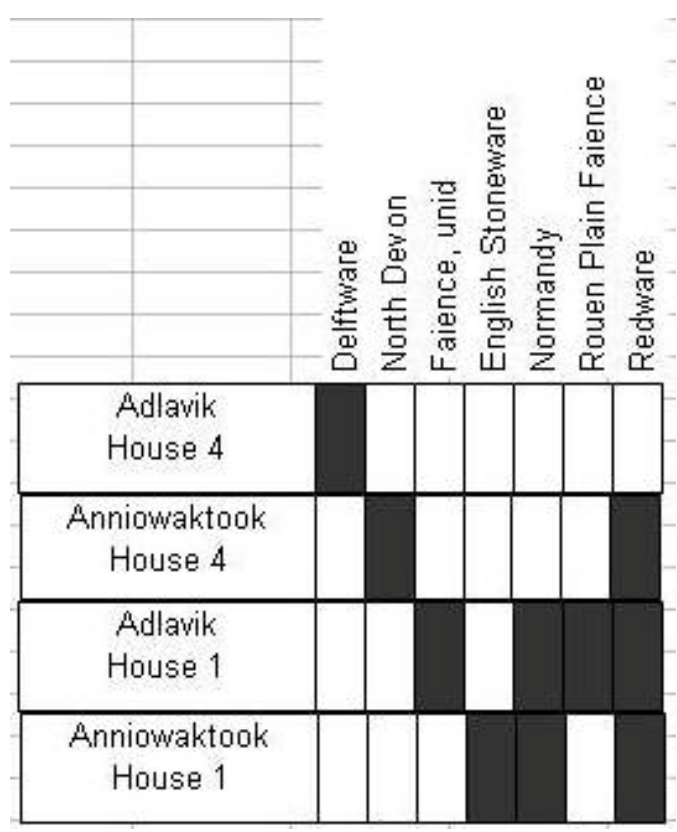

Figure 6.27: Occurrence seriation of four house deposits. The order suggests the earliest occupation occurred at Adlavik House 4 and Anniowaktoook House 4. 


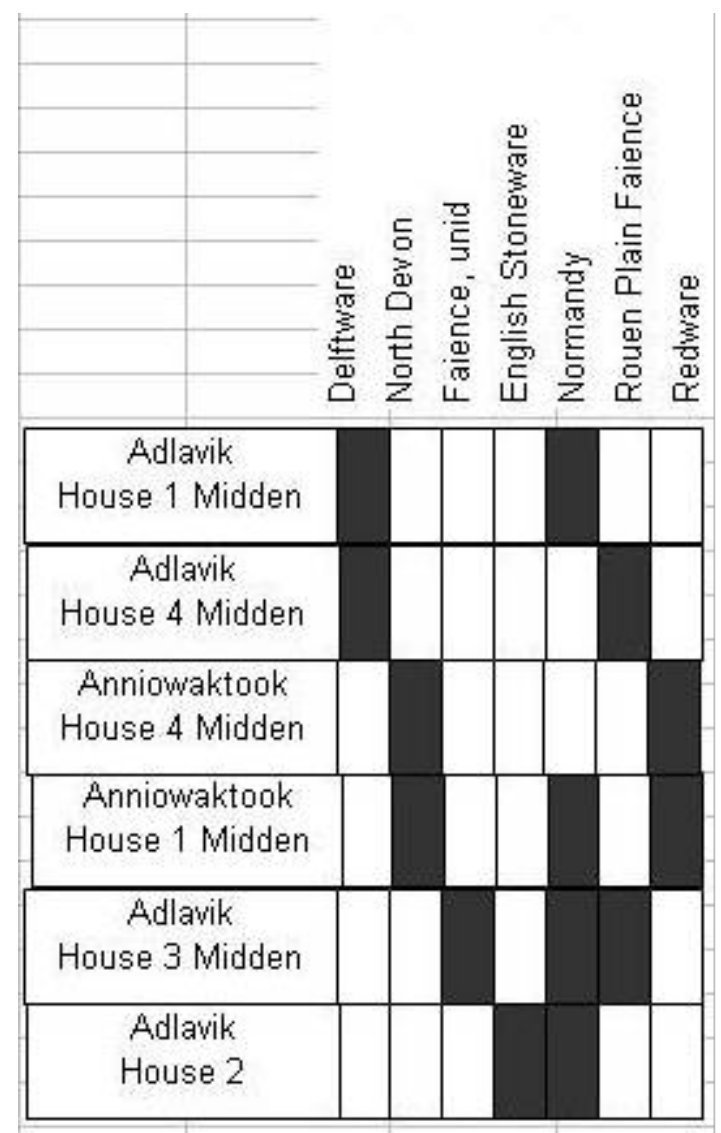

Figure 6.28: Occurrence seriation of the six midden deposits.

However, conducting independent evaluation of the seriation's dates proved to be difficult, as sample sizes of all other possible dating sources (i.e., stone tools) were either too small or not diagnostic. In addition, the small assemblages and wide manufacturing spans of certain ceramic types influenced the dates on most structures. Given these shortfalls, I chose an estimated mean date (EMD) after evaluating all of the dates generated for each house (Table 6.9).

As noted earlier, Bird's collection method did not allow for rigorous analysis of Avertôk’s occupation period. While dates or ranges could not be determined, Table 6.1 
presented earlier in the chapter summarizes house styles identified by Bird as early or late. This determination will be useful in trying to resolve whether Inuit houses exhibited different consumption or discard patterns compared to the later known Inuit houses.

The following section briefly describes my rationale for the EMDs assigned to each deposits listed in Table 6.9 based on the raw data listed in Table 6.10. Although no single method provides an accurate measure for dating these sites, particularly since sample sizes are small, evaluating historic ceramics and tobacco pipes in conjunction helps to narrow the occupation periods of the Adlavik, Anniowaktook and Avertôk houses.

\begin{tabular}{|c|c|c|}
\hline Site & Context & $\begin{array}{c}\text { Estimated } \\
\text { Mean Date }\end{array}$ \\
\hline Adlavik & House 1 & 1749 \\
\hline & House 1 midden & 1752 \\
\hline & House 2 (midden) & 1761 \\
\hline & House 3 & 1768 \\
\hline & House 4 & 1701 \\
\hline & House 4 midden & 1742 \\
\hline Anniowaktook & House 1 & 1759 \\
\hline & House 1 midden & 1743 \\
\hline & House 3 & 1774 \\
\hline & House 4 & 1710 \\
\hline & House 4 midden & 1740 \\
\hline Avertôk & House 1 & 1800 \\
\hline & House 3 & 1767 \\
\hline
\end{tabular}

Table 6.9: Table of estimated mean dates (EMD) based on evaluations of the diagnostic beads, bore diameter mean dates, MCDs, and a temporal order as determined by the occurrence seriation. 


\begin{tabular}{|c|c|c|c|c|c|c|c|c|c|c|c|c|}
\hline & & \multicolumn{4}{|c|}{ Tobacco Pipes } & \multicolumn{7}{|c|}{ Ceramics } \\
\hline Site & Context & $4 / 64$ & $5 / 64$ & $6 / 64$ & $7 / 64$ & Delftware & $\begin{array}{l}\text { North } \\
\text { Devon }\end{array}$ & $\begin{array}{c}\text { Faience, } \\
\text { unid }\end{array}$ & $\begin{array}{c}\text { English } \\
\text { Stoneware }\end{array}$ & Normandy & $\begin{array}{c}\text { Rouen } \\
\text { Plain } \\
\text { Faience }\end{array}$ & Redware \\
\hline \multirow[t]{6}{*}{ Adlavik } & House 1 & & & & 1 & & & 1 & & 8 & 3 & 1 \\
\hline & \begin{tabular}{|c|}
$\begin{array}{c}\text { House } 1 \\
\text { Mid }\end{array}$ \\
\end{tabular} & 2 & 2 & & & 1 & & & & 1 & 1 & 1 \\
\hline & House 2 & 1 & & & & & & & & 4 & & \\
\hline & House 3 & 5 & 5 & & & & & 4 & 1 & 2 & 1 & \\
\hline & House 4 & & & & & 2 & & & & & & \\
\hline & \begin{tabular}{|c|}
$\begin{array}{c}\text { House } 4 \\
\text { Mid }\end{array}$ \\
\end{tabular} & & 1 & & & & & 1 & & & & \\
\hline \multirow[t]{4}{*}{ Anniowaktook } & House 1 & & 1 & 1 & & & & & 1 & 7 & & 58 \\
\hline & \begin{tabular}{|c|}
$\begin{array}{c}\text { House } 1 \\
\text { Mid }\end{array}$ \\
\end{tabular} & & & & & & 2 & & & 1 & & 1 \\
\hline & House 4 & 1 & & & & & 16 & & & & & 4 \\
\hline & $\begin{array}{c}\text { House } 4 \\
\text { Mid }\end{array}$ & & & & & & 18 & & & & & 2 \\
\hline \multirow[t]{2}{*}{ Avertôk } & House 1 & & & & & & & & & & & 1 \\
\hline & House 3 & & & & & & & & 1 & & & 1 \\
\hline
\end{tabular}

Table 6.10: Table of raw counts of the tobacco pipes and ceramic types used in calculating the EMDs. 


\section{Adlavik House 1}

Adlavik House 1 only had one pipe stem for dating purposes. For this house, I found that the ceramic date range aligned more accurately with the stratigraphic evidence. Thus, I chose the MCD as the EMD. Adlavik House 1 midden and House 2 (midden)

The midden deposits from Adlavik Houses 1 and 2 served as the best examples where all three dating methods — beads, pipes and ceramics — aligned; therefore an average of the available dates calculated by the pipe bore diameter and MCD were used to determine the EMD.

\section{Adlavik House 3}

Adlavik House 3 date estimates from the pipe bore diameters and ceramics also aligned, but the presence of the single purple Bohemian faceted bead in the midden dating to the nineteenth century may suggest the house was abandoned later or had at least had a longer occupation spanning into the early nineteenth century; however, the bead was found between $10-20 \mathrm{~cm}$ below the surface and may have been a result of excavator error or wall fall from a later level. The EMD was calculated using an average of the MCD and pipe bore diameter.

\section{Adlavik House 4}

Adlavik House 4 had a very low sample size for ceramics $(n=2)$, but the early date is supported by the fact that a later midden was deposited in the abandoned house ruins; therefore the MCD was maintained. 


\section{Adlavik House 4 midden}

I averaged the ceramic date, tobacco pipe bore diameter, and the A. Speo bead which together support a mid-eighteenth century date for the Adlavik House 4 midden. Anniowaktook House 1

Anniowaktook House 1 had a small sample of pipes $(n=2)$, yet the ceramics from the house had an earlier MCD than those from the midden. In an attempt to accommodate this wide range, I also averaged the pipe stem date and MCD. Anniowaktook House 1 midden

The midden deposits from Anniowaktook House 1 only had ceramic evidence for dating purposes; thus the MCDs were used for the EMDs.

Anniowaktook House 3

Due to Bird's problematic sample strategy at the Avertôk houses and the Anniowaktook House 3 midden which included collecting a very small sample of ceramics, I chose the MCD as the EMD since it was the only line of evidence available. Anniowaktook House 4

Dating the Anniowaktook House 4 midden was a little more complicated, as the MCD puts the midden earlier than the occupation level for House 4. Stratigraphic evidence indicates that the midden was deposited after House 4 was abandoned, thus had a later date than the occupation level of House 4. I calculated the EMD for the Anniowaktook House 4 midden by averaging the EMDs for the three other Anniowaktook deposits (House 1, House 1 midden and House 3 midden), as the midden was deposited at around the time one of the other houses was occupied. 


\section{Chapter Summary}

This chapter provided an overview of the sites and artifacts used in this study and the methods used in acquiring estimated mean dates of occupations for most of the deposits. Although sample sizes were small, EMDs were calculated based on estimated manufacturing dates of beads, ceramics and tobacco pipes. The data indicate that the sites discussed above were occupied prior to the Moravians' establishment of Hopedale in 1782. Research conducted at Avertôk, and the Adlavik and Anniowaktook Islands reveal similar architectural features, but suggests the use of space and consumption of artifacts between the three sites differed considerably. In the following chapter, I turn to a closer examination of the specific artifact types to better understand Inuit household organization of the early historic period. 


\section{Chapter 7: Inuit Material Culture and the Definition of the Artifact Categories}

The data collected from the sites described in the previous chapter are used to test a model for an Inuit hierarchical social organization. As described in Chapter 2, the hierarchical model is a product of ethnohistoric and archaeological research suggesting that Inuit men who were successful traders and hunters rose to a position of authority. In the following two chapters, I will focus on identifying material evidence for trading with Europeans and whether it was tied to Inuit social organization. While some eighteenthcentury Inuit sod houses have been excavated, research has not been concerned with identifying archaeological patterns that define social organization. This is partially due to researchers collecting exploratory data on changing demographic patterns and testing ecological models of eighteenth century Labrador Inuit subsistence (i.e. Kaplan 1983; Woollett 2003).

Before analyzing the degree to which households exhibited evidence for social stratification within settlements, I offer general descriptions of the artifacts using categories intended to identify certain elements of Inuit life. To improve sample size, artifacts were assigned to one of four categories based on early ethnographic descriptions of Central and Eastern Arctic Inuit activities at and beyond the settlement (Birket-Smith 1959; Boas 1964; Briggs 1971; Hawkes 1916; Turner 2001), and a modified version of archaeologist George Sabo’s (1991) classification of cultural components of Thule and historic Inuit from southern Baffin Island. The four categories summarize the items that represent domestic, tool manufacturing, hunting, and trading activities. I argue that these 
categories — to some extent — capture the degree individual households participated in different activities.

These categories are not intended to capture every element of Inuit behavior and technology. My goal was to identify key dimensions of human behavior that will allow an examination of variation among households. I recognize that they are a methodological construct and Inuit use of items may have been more fluid than the rigid separation created by my discrete, mutually exclusive categories indicates.

These categories were determined, in part, by ethnographic and archaeological research that identified individuals' roles that were differentiated along gender lines. Similar to many other bands, Inuit men were responsible for hunting and providing much of the sustenance for the entire community, and women managed the domestic space, tending lamps especially in the winter, rearing children, gathering mussels, berries and birds’ eggs, and processing the meat and hides for food and clothing. While occupying separate spaces, these activities were not seen as disconnected; instead, men’s and women's activities overlapped via a spiritual realm where a woman's handling of meat and manufacture of hide clothing determined the hunter's success. Hunters did not find animals; animals gave themselves to the hunter only if their souls and bodies were properly respected. For instance, if tools or clothing were poorly manufactured or taboos ignored, then animals would not reveal themselves to the hunter. A woman's skill in sewing is every bit as important as the man's ability to hunt. The male/female interdependence is absolutely essential to the survival of the family and the community; both must be skillful to attract and ensure the return of animals (Bodenhorn 1990:65). 
Studying separate artifact categories serves as an avenue towards investigating the social organization as demonstrated by various activities at historic Inuit sites. As noted, some archaeologists have argued that social relations in Inuit communities were characterized by some degree of inequality of power and material wealth (Whitridge 1999). The means through which those items were accumulated either via foraging, raiding or trading may have resulted in differential wealth. I believe that differentiating between trading and raiding requires identifying those objects that Europeans and missionaries brought to Labrador specifically with the intention to trade with Native peoples, in contrast with manufacturing materials used to construct houses or barrels for storing oil and blubber.

The "trade category" includes all items that reflected the act of an amicable exchange between two parties rather than destructive raiding or salvaging of European sites. Early European traders noted that objects such as tobacco pipes, glass beads, buttons, and buckles were valuable trading commodities. The presence of these objects in Inuit contexts suggest that Inuit interacted with Europeans or other Inuit to trade specifically for these items. The second category I call the "manufacturing category" included materials used in the construction of tools, such as strap or sheet metal, lead, ails, and worked bone scrap. ${ }^{12}$ While the metal items could have been collected via trade, they could also be evidence for raiding. Historical records document that Inuit raided French and Basque sites in the seventeenth and eighteenth centuries for iron tools, cookware, small boats, and nails (Barkham 1984; Fitzhugh 2009; Gosling 1910; Kaplan

\footnotetext{
${ }^{12}$ Faunal material included in this category had to have more than one cut side and evidence of being worked to avoid including bone that was butchered during processing.
} 
1983; Kennedy 1995; Proulx 1993). By the late eighteenth century, Moravian missionaries were so concerned with Inuit stealing boats that they actively sought to provide Inuit materials to make and repair boats as a way to deter them from stealing (Hiller 1971b:78-79).

The final two categories included in the following analysis are the hunting and domestic categories. The "hunting category" included all forms associated with subsistence such as fishing hooks, harpoon heads, and snow knives. The “domestic category” included items such as soapstone pots, lamps, needles cases, and toys which were found in the house and associated with cooking, clothing manufacture, and child rearing activities.

\section{Artifact Categories}

A total of 2269 artifacts were assigned to the four categories from all occupational deposits including houses and associated middens. Similarities and differences in the frequencies of different categories in the various deposits at each site may reveal the degree of participation in hunting or trading activities. Further, comparisons among settlements may show whether some sites expended more effort hunting versus trading.

The fill assemblages are assumed to be related to the respective house occupation since refuse accumulated on and around the houses before abandonment, and were sealed in the houses after the collapse of the sod roof in most cases. House assemblages from the fill and occupation levels appear to be intimately related at the four houses where such designations were identified (Table 7.1). Artifacts found on the surface or in the sod 
level were not included in the following assemblage analyses, since all three sites had subsequent occupation periods after their initial abandonment. ${ }^{13}$ Middens represent discard practices and these deposits were examined separately from the house deposits. Artifacts from entrance tunnels were grouped with artifacts from the midden as they tend to have similar depositional patterns and soil composition. Middens were located directly outside of entrance tunnels and objects were likely dropped on the way to discarding them in the midden or tracked inside.

\section{Domestic Category}

A total of 335 artifacts fall into the "domestic category” (Table 7.2). Researchers have argued that the Inuit gender roles were expressed via household organization and that a woman's space was the house. As discussed above, previous researchers have shown that gendered divisions were not seen as separate but rather part of a larger interdependent system (i.e., Bodenhorn 1990; Cabak 1991; LeMoine 2007; Whitridge 1999).

${ }^{13}$ Avertok did not have any stratigraphic details recorded, therefore all artifacts were included. 


\begin{tabular}{|c|c|c|c|c|c|c|c|c|c|c|}
\hline Site & & & Materials & & & & & & & \\
\hline \multirow{5}{*}{ Adlavik } & Context & $\begin{array}{l}\text { Deposit } \\
\text { Type }\end{array}$ & Ceramic & Composite $^{14}$ & Faunal & Glass & Metal & Organic & Stone & TOTAL \\
\hline & \multirow[t]{2}{*}{ House 1} & Fill & \multirow[t]{2}{*}{10} & \multirow[t]{3}{*}{8} & 8 & 21 & 187 & 1 & 37 & 272 \\
\hline & & Occupation & & & 1 & 3 & 23 & 8 & 11 & 46 \\
\hline & \multirow[t]{2}{*}{ House 4} & Fill & 2 & & 2 & 5 & 47 & & 4 & 60 \\
\hline & & Occupation & 1 & 1 & 3 & 1 & 32 & & 2 & 40 \\
\hline \multirow[t]{4}{*}{ Anniowaktook } & \multirow{2}{*}{ House 1} & Fill & 9 & 45 & 24 & 5 & 202 & 144 & 25 & 454 \\
\hline & & Occupation & 1 & 2 & 6 & 1 & 16 & 23 & 2 & 51 \\
\hline & \multirow[t]{2}{*}{ House 4} & Fill & 16 & & 8 & & 22 & 47 & 4 & 97 \\
\hline & & Occupation & 7 & 2 & 19 & 3 & 47 & 93 & 30 & 201 \\
\hline TOTAL & & & 46 & 58 & 71 & 39 & 576 & 316 & 115 & 1221 \\
\hline
\end{tabular}

Table 7.1: Material frequency by house and deposit type.

\footnotetext{
${ }^{14}$ The database included a "Composite” material category which captured forms that incorporated multiple materials, such as a knife with an iron blade and a bone handle.
} 


\begin{tabular}{|c|c|c|c|c|c|c|c|c|c|c|c|c|c|}
\hline Site & House & $\overline{3}$ & $\begin{array}{l}\text { 咅 } \\
\text { D } \\
\end{array}$ & 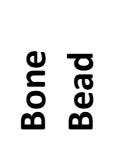 & $\frac{0}{\frac{0}{x}}$ & 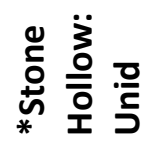 & 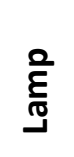 & 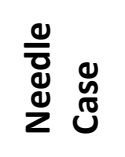 & $\begin{array}{l}\frac{1}{c} \\
\frac{\pi}{0} \\
\frac{C}{0} \\
0\end{array}$ & 茄 & ఫે & 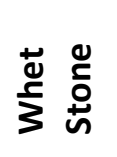 & $\frac{\mathbb{R}}{\circ}$ \\
\hline \multirow[t]{6}{*}{ Adlavik } & House 1 & & & & 5 & 2 & 3 & & & 3 & & & 13 \\
\hline & House 2 & & & & & & & & & & & 1 & 1 \\
\hline & House 1Mid & & & 3 & 1 & 6 & 1 & & 2 & & 1 & & 14 \\
\hline & House 3 & & & 2 & & 5 & & & 1 & & 1 & & 9 \\
\hline & House 4 & & & & & 2 & & & & & 1 & & 3 \\
\hline & House 4Mid & & & 1 & & 3 & 5 & & & 1 & 1 & 1 & 12 \\
\hline \multirow[t]{5}{*}{ Anniowaktook } & House 1 & & & & & 10 & 5 & & & 84 & & 1 & 100 \\
\hline & House 1Mid & & & & & 6 & 1 & 1 & 1 & & 2 & 1 & 12 \\
\hline & House 3 & & & & & 3 & & & & 3 & 4 & & 10 \\
\hline & House 4 & & & & 1 & 1 & & & 2 & & & & 4 \\
\hline & House 4Mid & & & & & 1 & 1 & & 1 & & & & 3 \\
\hline \multirow[t]{9}{*}{ Avertok } & House 1 & & & & & 3 & 8 & & 1 & 1 & & 1 & 14 \\
\hline & House 2 & & & & & 1 & & & & 1 & & 3 & 5 \\
\hline & House 3 & & & & & 25 & 7 & & 2 & 1 & & 3 & 38 \\
\hline & House 4 & & & & & 2 & & & & 5 & & & 8 \\
\hline & House 5 & & & & & 9 & 3 & & & 2 & & 3 & 17 \\
\hline & House 6 & & & & & 5 & 10 & & & 3 & 1 & 2 & 21 \\
\hline & House 7 & & & & & 2 & & & & 2 & & & 5 \\
\hline & House 8a/b & & & & & 7 & 3 & & & 6 & 1 & 3 & 20 \\
\hline & Midden & 1 & 1 & & & 17 & 5 & & & & 2 & & 26 \\
\hline TOTAL & & 1 & 1 & 6 & 7 & 110 & 52 & 1 & 10 & 112 & 14 & 19 & 335 \\
\hline
\end{tabular}

Table 7.2: Raw counts of the artifacts included in the Domestic category. *This category includes all hollow soapstone vessels. 
One of the most common activities associated with domestic space was cooking. While a majority of the initial processing of meat and hide may have occurred outside the house, the cooking of the meat and stews or liquid-based foods occurred over a hearths inside the house. Soapstone vessels used in the cooking process made up over half of the domestic assemblages at each house or deposit, signaling the availability of the material and its significance in the Inuit household. Some of the soapstone vessels have holes in the top corners which allowed the vessel to be strung with baleen or twine and suspended above a fire. Holes through the body of the vessel were also evidence of repair, with holes were drilled on either side of a fracture and baleen lashing or iron nails strung through and then sealed with tree sap or a combination of blood and fat to ensure it remained impermeable (Figure 7.1).

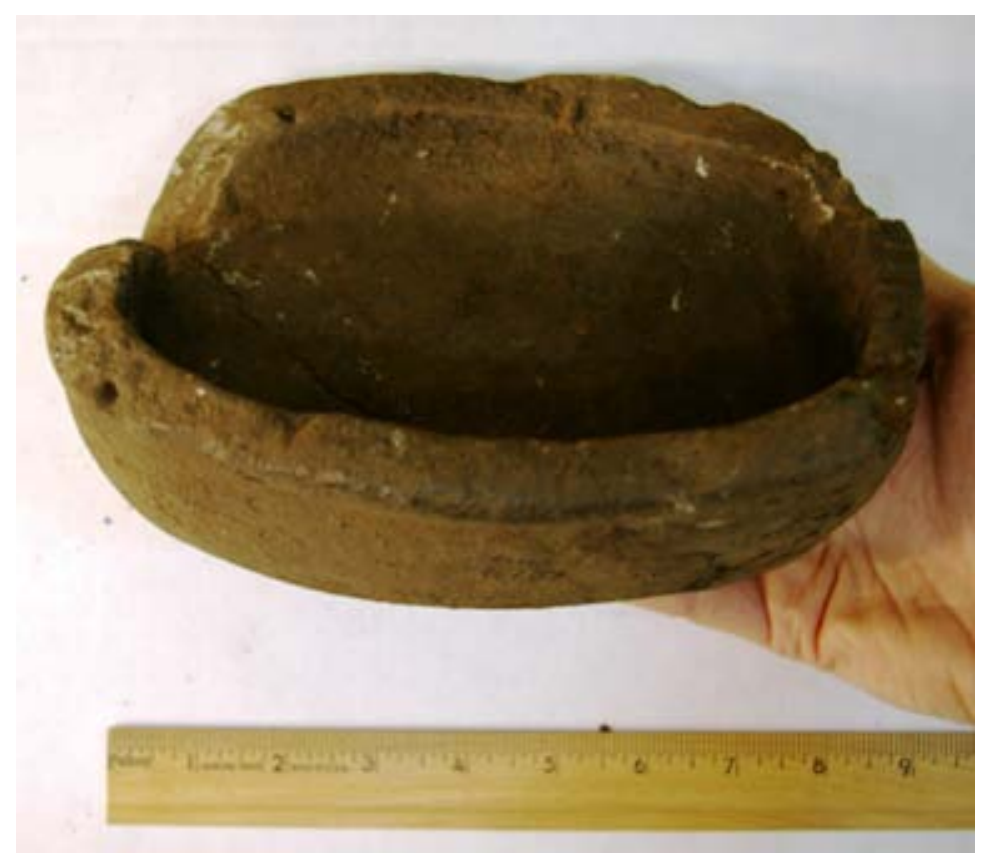

Figure 7.1: Example of a soapstone kettle form Avertôk House 6. Note drilled holes along the broken edge, which suggest repair attempts. 
Soapstone was commonly found associated with domestic activities as most lamps, pots and keetles found throughout Thule and Inuit houses were made of the material. It was commonly used since it was a local material, relatively durable, and an excellent converter of heat. As discussed in Chapter 6, a large deteriorated green soapstone slab was found near the floor and in the central hearth area of Anniwoktook House 4. The poor quality of the soapstone suggested that it was not used for vessel construction, and instead used as a cooking slab. The soapstone slab may have served as a griddle, having been heated by a fire or lamp. Rather than placing the meat into the fire, and the meat was placed on top of the stone. Due to the stone's convection properties, the meat sears more slowly. Inuit today still use stone slabs to aid in the cooking of meat when traveling out on the land (Hopedale Resident, personal communication 2009).

Soapstone was also used for lamps, which served as the central lighting and heating source in the sod house. Blubber was placed at the edge of round or crescent shaped lamps, where the heat from a wick made from cotton-weed could render the oil from the blubber (Figure 7.2). The lamp was a prized possession during a woman’s lifetime attested by it often being found in female burials (Billson and Mancini 2007). 


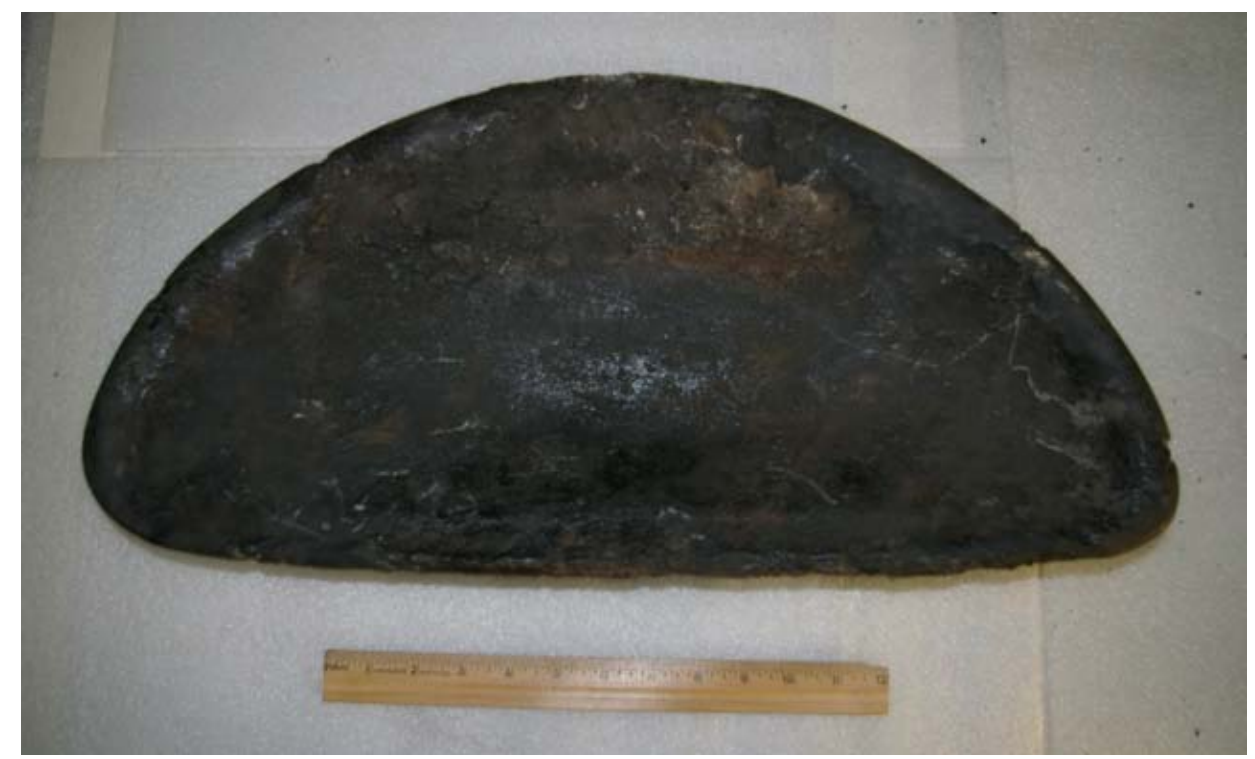

Figure 7.2: Example of a soapstone lamp from Avertôk House 1.

Miniature pots and lamps were found in nine of the twenty deposits investigated (Figure 7.3). Usually no larger than $5 \mathrm{~cm}$ in diameter, these smaller versions were considered children's toys. Toys were replicas of larger adult tools and intended to teach children their social roles (Billson and Mancini 2007:36; Hawkes 1916). The girls helped their mothers around the house, learning how to sew by making small clothing for dolls or tending their miniature lamp.

An example of a probable toy for a boy was the baleen knife in Figure 7.4. The knife is believed to be a toy, since whale baleen plates were extremely flexibly and were normally pulled into strands for lashing and sewing, and not used for cutting or carving. Boys often received harpoons and bows to test their skill on small animals, only becoming an adult after his first successful hunt. The presence of toys in a few deposits does not simply identify the presence of children in the archaeological record, but signifies the socialization process and the transference of cultural norms as well. 


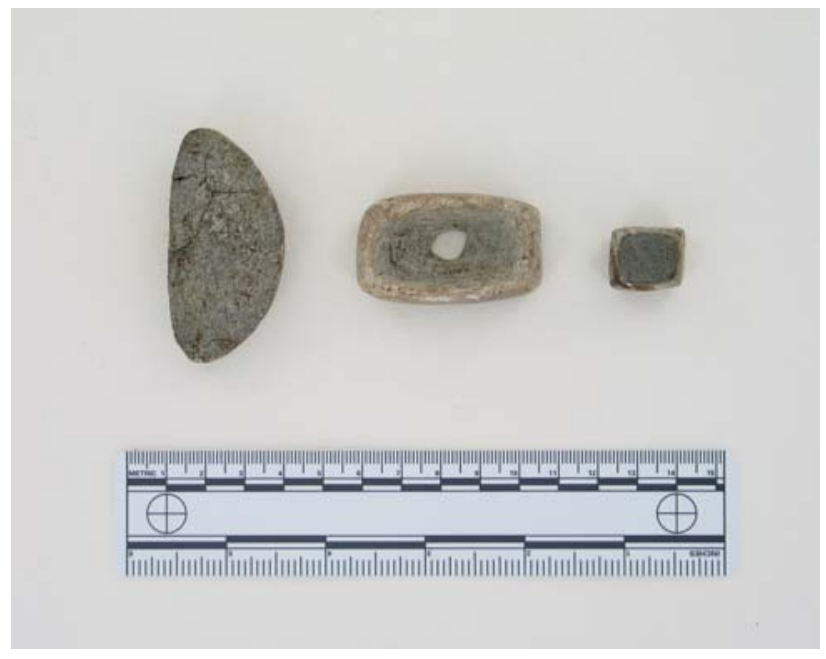

Figure 7.3: Examples of a soapstone toy lamp from Adlavik House 1, and toy pots from Adlavik House 4.

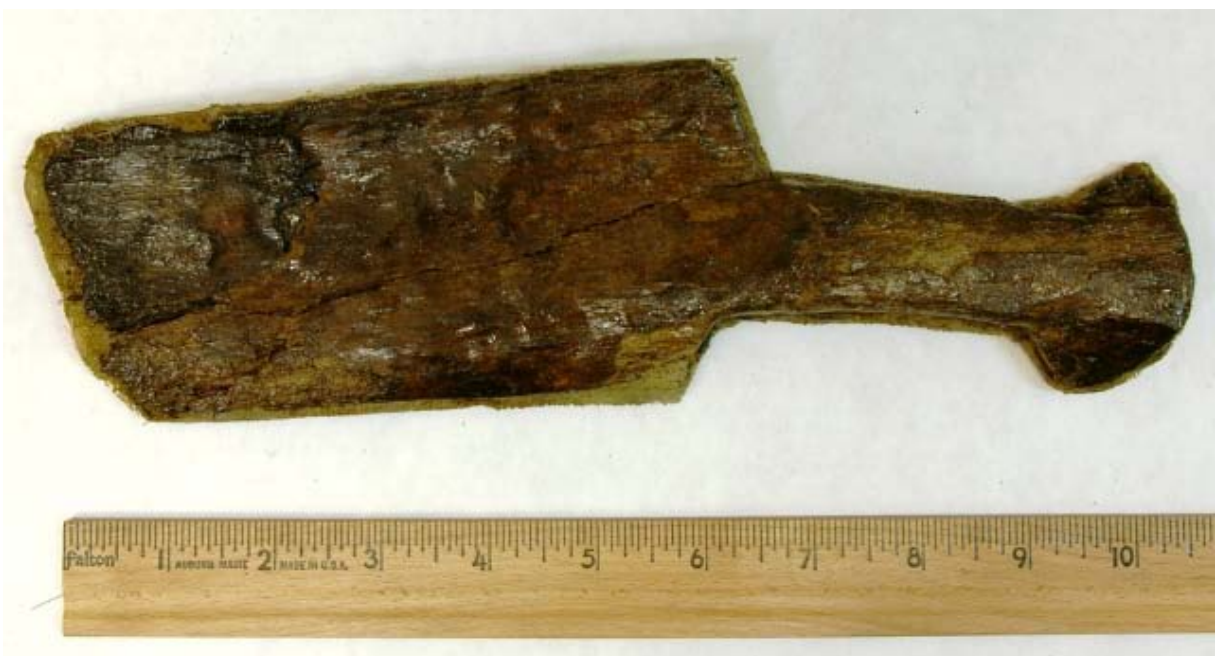

Figure 7.4: Example of a child's snow knife made out of baleen from the Avertôk midden. 
In addition to cooking, tending the hearth and supervising children, women were responsible for processing hides and manufacture clothing. Avertôk Houses 1, 3 and the midden, Adlavik Houses 1 and 4, and Anniowaktook Houses 1 and 4 had instruments needed for hide processing and clothing manufacture such as stone scrapers and ulu knives made with wood or bone handles and metal blades (Figure 7.5). These instruments allowed women to separate the meat from the hide, and clean it prior to production. Whet-stones found in half of the deposits were used to maintain the blade's sharpness.

Evidence for more refined clothing manufacture was found in the interior of Adlavik House 1, Anniowaktook Houses 1 and 4, and the midden at Avertôk, including hide scraps and sewing tools. Small samples of unfinished hide found in Adlavik House 1 and on the floor of Anniowaktook House 4 near the sleeping platform represent refuse from clothing manufacture. Due to the fragile state of the material, species identification of the samples has not been conducted.

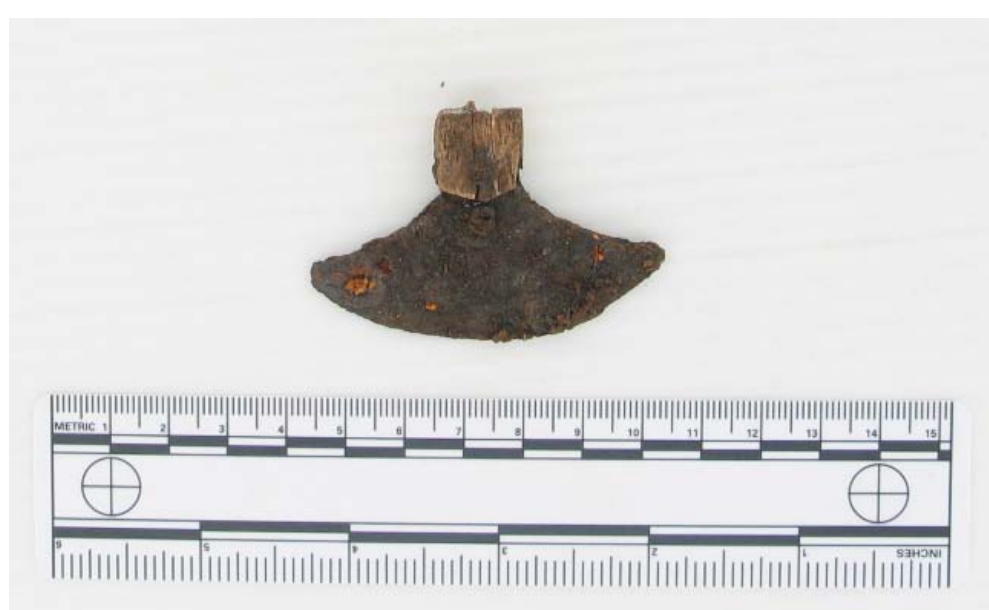

Figure 7.5: Fragment of a small ulu knife with bone handle and iron blade from Anniowaktook House 4 midden. 
Once the skin had been cleaned with a scraper or ulu knife and treated to prevent stiffening, rotting or tearing, Inuit women used a bodkin or awl to start the hole for the stitch. Bone needles used for the more refined sewing were very fragile and would break when sewing thick hide. Needles were stored in cases, which were made of hollowed out bone or ivory and could have elaborate decoration carved onto the case's exterior. A strip of hide or seal skin holding needles would pass through the case and the seamstress would pull it out of the case to insert or withdraw her needles. A thimble and a thimble guard could also be attached by braided baleen or sinew. Given the fragile nature of many of these tools, only a small sample of them were identified in the house contexts. No needles were found in any of the deposits, but a bodkin and awl were identified in the Avertôk midden and a thimble guard draw string attachment was found in the Anniowaktook House 1 midden (Figure 7.6). Few thimble guards have been found in Labrador Inuit contexts, but the find at Anniowaktook is similar to the thimble guards collected from the Nunavut Inuit (Figure 7.7).

Researchers have proposed that the butchering and processing of animals and the attention to the sewing process were out of respect for the animal and its soul. An example from another hunter-gatherer society in the subarctic, the North Alaskan Inupiat, reveals the interpretive potential for a spiritual bond between hunter and animal among Labrador Inuit. The Inupiat believed that an animal would offer itself to a hunter only if it felt that the hunter would value, respect and care for the animal's soul after death. While a man was obligated to treat the animal properly, it was the woman's skill in constructing hunting equipment and clothing from animal skin that ultimately determined 
her husband's success as a hunter (Bodenhorn 1990:64). Not his accuracy or strength, but rather his wife's ability to carefully construct hunting implements that honored the animal's spirit, determined an Inupiat hunter’s skill. This obligation extended to clothing; clothing manufacture was more than a necessity it was part of a spiritual understanding. Labrador Inuit may have held similar beliefs.

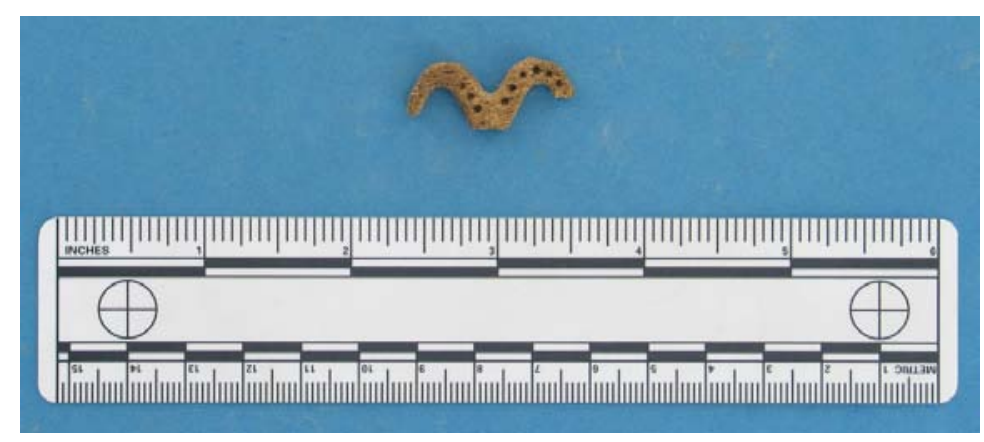

Figure 7.6: Sewing implement or thimble guard found in Anniowaktook House 1 midden.

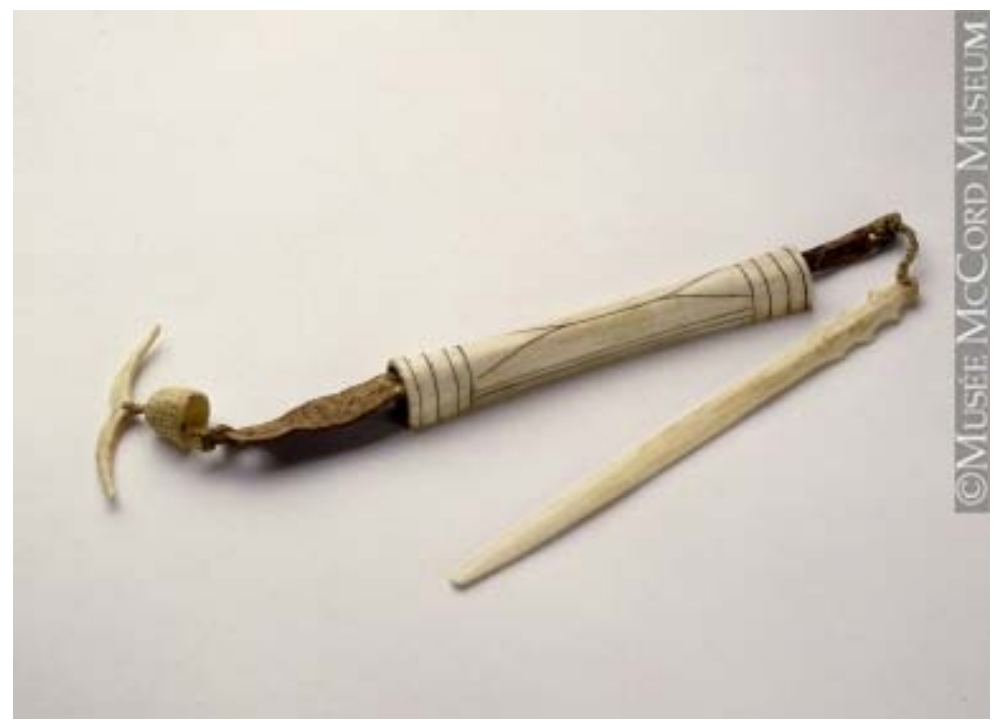

Figure 7.7: Image of a needle case and accessories from the Nunavut Inuit, courtesy of the Museé McCord Museum in Montreal, Canada. Artifact identification number ME982X.99.1-6. 
Part of that process of manufacture included decoration. Clothing was decorated with a wide variety of items including beads, bone charms, and weights. Some of the materials used for decoration, such as copper buckles, glass and metal buttons and glass beads were accumulated via trade with Europeans and will be discussed in greater detail later in this chapter under the section entitled "Trade Category.” However, a single lead charm from Anniowaktook House 4 was included in the "Domestic Category” (Figure 7.8). Although lead could only have been obtained from trading with Europeans, it was also a prominent material collected during raiding trips. Given that the final form was an ulu pendent probably used for decoration, I chose to put it into the Domestic Category for its association with clothing manufacture. The ethnographic record revealed that Inuit women from the east of Hudson Bay and Ungava north of Labrador often decorated the flap of their parka with pewter ornaments, and men used ivory ornaments to line the bottom of the parka (Hawkes 1916:39; Turner 2001).

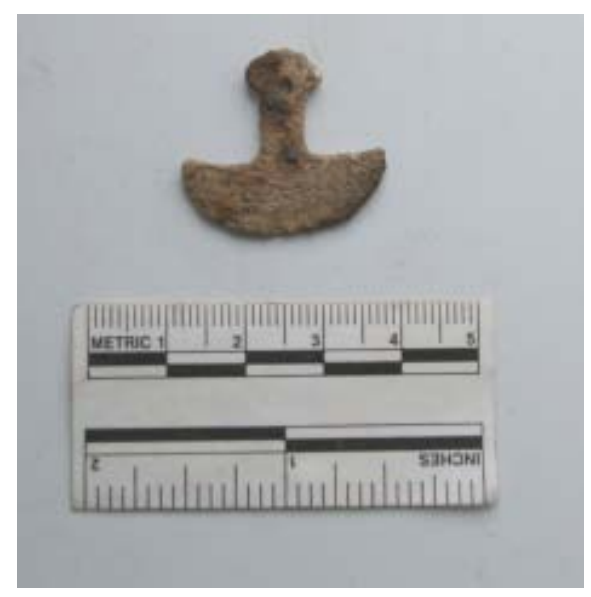

Figure 7.8: Lead ulu pendant found in the entrance tunnel of Anniowaktook House 4. 
Inuit also used faunal material for decorative purposes, as they were believed to contain the spiritual properties of animals. A total of six bone beads were found at Adlavik. A single bone bead was found in the Adlavik House 4 midden, two bone beads found in Adlavik House 3, and three bone beads were recovered in the midden of Adlavik House 1 . Bone beads make up less than $2 \%$ of the domestic assemblages from all sites (n =6). In comparison, nine times more glass beads $(n=54)$ were found at these sites, making up $25 \%$ of the trade assemblages from all sites. The lower frequency of bone beads may be indicative of Inuit replacing bone as a material with the more colorful glass beads, or may suggest bone beads were used more sparingly, perhaps due to a spiritual significance.

Another use for the faunal material was the production of amulets or charms. Animal teeth or elaborately carved animal figures were worn on the body for spiritual protection. Amulets were not reserved solely for ritual purposes or for the shaman, but were used by everyone. Labrador Inuit believed the act of carving of the animal called the spirit to embody the object and protect the individual in mundane or more precarious activities such as hunting (Hawkes 1916:135). Hunters wore amulets carved in the shape of the animals they hunted to assure a successful hunt while simultaneously respecting the animal's spirit (Fienup-Riordan 1991; Hawkes 1916). Yet amulets could lose their power and no longer protect the individual, at which time they were cast aside. Inuit continued to wear amulets into the eighteenth century to the frustration of the Moravians who noted Inuit wore amulets and charms in the hopes of warding off ailments or evil spirits (PA 1806:279). 
Unfortunately, no elaborately carved amulets were found in any of the contexts, but some tooth pendants and unidentified bone carvings with piercings were identified in a few contexts. Six possible bone pendants were found among four contexts including Adlavik House $3(n=1)$. These included a possible dog tooth and a small fish ornament with over 14 piercings in Adlavik House 1 midden $(n=2)$ (see Figure 7.12, \#5) ${ }^{15}$, two bear teeth at Avertôk Houses 3 and a walrus tooth at Avertôk House 1. More tooth pendants may have been collected at Anniowaktook or Adlavik as they likely were among faunal material sent for analysis. Again, pendants only make up a small portion of the assemblage (1.86\%), but their presence in the household deposits suggests the prevalence of certain spiritual traditions continuing into the historic period.

The artifacts discussed in this section reflect household activities overseen primarily by Inuit women. Items included in this category represent the basic realities of surviving the harsh subarctic environment, while highlighting the fundamental role the domestic space played in Inuit social life that recognized a spiritual environment.

\section{Manufacturing Category}

This category includes forms or objects that indicate the production of domestic and hunting related tools. This category is intended to capture the potential for Inuit ingenuity in reusing and refashioning metals or broken European tools, by combining local and foreign materials into useful Inuit forms. The metal forms discussed below could have been acquired through trade with European fisherman, whalers and

\footnotetext{
${ }^{15}$ This artifact may have been a gaming piece. It was included as a pendant since it had piercings that went completely through the object suggesting it was also worn.
} 
tradesmen, yet the significant amounts found in middens suggest Inuit were collecting metal in other ways, namely raiding or foraging. Not all Inuit and European interactions can be characterized as hostile and aggressive, but historical records do indicate that some of the tensions between Europeans and Inuit were the result of groups of Inuit pillaging European sites for materials and food. While historical records do not offer a clear description of the composition of these Inuit groups, it would be likely that Inuit men conducted most of these raids of abandoned European sites, since hunting groups were often comprised primarily of men. As discussed earlier, Inuit organized seasonal subsistence strategies to include visits to abandoned European settlements for the purpose of collecting cached items and building materials.

While items included in the manufacturing category indicate a level of contact with Europeans, the materials were likely modified in the domestic space to meet domestic and hunting purposes. Rather than include them in the trade category which may overemphasize the significance of trade in the historic Inuit communities, I chose to include the materials in a separate category.

The "manufacturing category" had 1566 artifacts which constituted 69\% of all of the artifacts in this portion of the analysis (Table 7.3). Ninety percent of these items were made of various metals. Metal was a versatile material as it was used in a number of ways including manufacturing of tools, mending, and adornment. When and how metal was introduced into the Inuit toolkit continues to be debated among researchers (McGhee 2007; Ramsden and Rankin 2010; Sutherland 2000), yet throughout the contact period, metal increased in demand, rapidly replacing traditional stone artifacts like harpoon 
heads, ulu knives, and men’s knife blades (Jordan 1978:176). Manufacturing items dominate Adlavik house and midden assemblages, comprising more than $61 \%$ of each of the assemblages, and $68.4 \%$ of the post-abandonment midden assemblage found associated with Anniowaktook House 4. The Anniwoaktook House 1 deposits had slightly fewer manufacturing items about $44 \%$ of both the house and midden assemblages. The Avertôk assemblages had the least amount of manufacturing items collected from only House 1 (35.5\%), House 2 (16.67\%), House 3 (23.94\%), House 6 (8.33\%) and the midden (27.12\%), the result of Bird’s discriminating collection methods. Only for House 5 assemblage did manufacturing items comprise more than half of the assemblage at $59.57 \%$. 


\begin{tabular}{|c|c|c|c|c|c|c|c|c|c|c|c|c|c|c|}
\hline Site & Context & 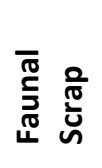 & ळ్ల & 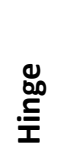 & $\overline{\overline{n \pi}}$ & $\begin{array}{l}\frac{0}{\pi} \\
\frac{5}{4}\end{array}$ & 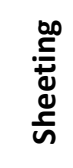 & 竞 & 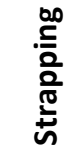 & 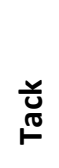 & 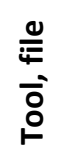 & $\stackrel{0}{\stackrel{2}{\xi}}$ & 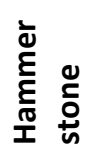 & 占 \\
\hline \multirow[t]{6}{*}{ Adlavik } & House 1 & 9 & 1 & 1 & 171 & 9 & 7 & 7 & 5 & & & & 1 & 211 \\
\hline & House 1Mid & 70 & & & 198 & & 5 & 3 & 20 & & 1 & & & 297 \\
\hline & House 2 & 2 & & & 25 & & 27 & & 3 & & & & 1 & 58 \\
\hline & House 3 & 3 & 2 & & 169 & 16 & 54 & 2 & 27 & 1 & & 1 & 1 & 276 \\
\hline & House 4 & 4 & 3 & & 48 & 4 & & 3 & 7 & & & 1 & & 70 \\
\hline & House 4Mid & 4 & 2 & & 70 & 3 & & 4 & 3 & & & 2 & 1 & 89 \\
\hline \multirow[t]{5}{*}{ Anniowaktook } & House 1 & 3 & 2 & 1 & 177 & 2 & 18 & 5 & 22 & & & 4 & 1 & 235 \\
\hline & House 1Mid & 12 & 1 & & 80 & 4 & 4 & 2 & 7 & & & 1 & & 111 \\
\hline & House 3 & 5 & & & 2 & & & & & & & & & 7 \\
\hline & House 4 & 1 & & & 67 & 2 & 6 & 2 & 1 & & & 5 & 1 & 85 \\
\hline & House 4Mid & 1 & & & 46 & 1 & & & 1 & & & 3 & & 52 \\
\hline \multirow[t]{6}{*}{ Avertok } & House 1 & 2 & & & 4 & & 1 & & 4 & & & & & 11 \\
\hline & House 2 & 1 & & & & & & & & & & & & 1 \\
\hline & House 3 & 17 & & & & & & & & & & & & 17 \\
\hline & House 5 & & & & & & & & 28 & & & & & 28 \\
\hline & House 6 & & & & 2 & & & & & & & & & 2 \\
\hline & Midden & 10 & 1 & & 4 & & & & 2 & & & & & 16 \\
\hline TOTAL & & 144 & 11 & 2 & 1063 & 41 & 122 & 28 & 130 & 1 & 1 & 17 & 6 & 1566 \\
\hline
\end{tabular}

Table 7.3: Raw counts of artifacts included in the manufacturing category 
The majority of the metal forms within the manufacturing category were iron nails which, along with iron strapping, the Inuit refashioned into hunting tools. For instance, nails were cold hammered into a variety of cutting and hunting tools, including harpoon heads, points, and blades (Figure 7.9) and used to mend broken soapstone pots. Some nails were found still embedded in wood, suggesting that the wood from boxes, barrels or trunks scavenged, rather than the nail may have been of interest, particularly for use in construction of houses or boats. Although only six nails remain in the Avertôk collection, given Bird’s collection methods more nails probably were present.

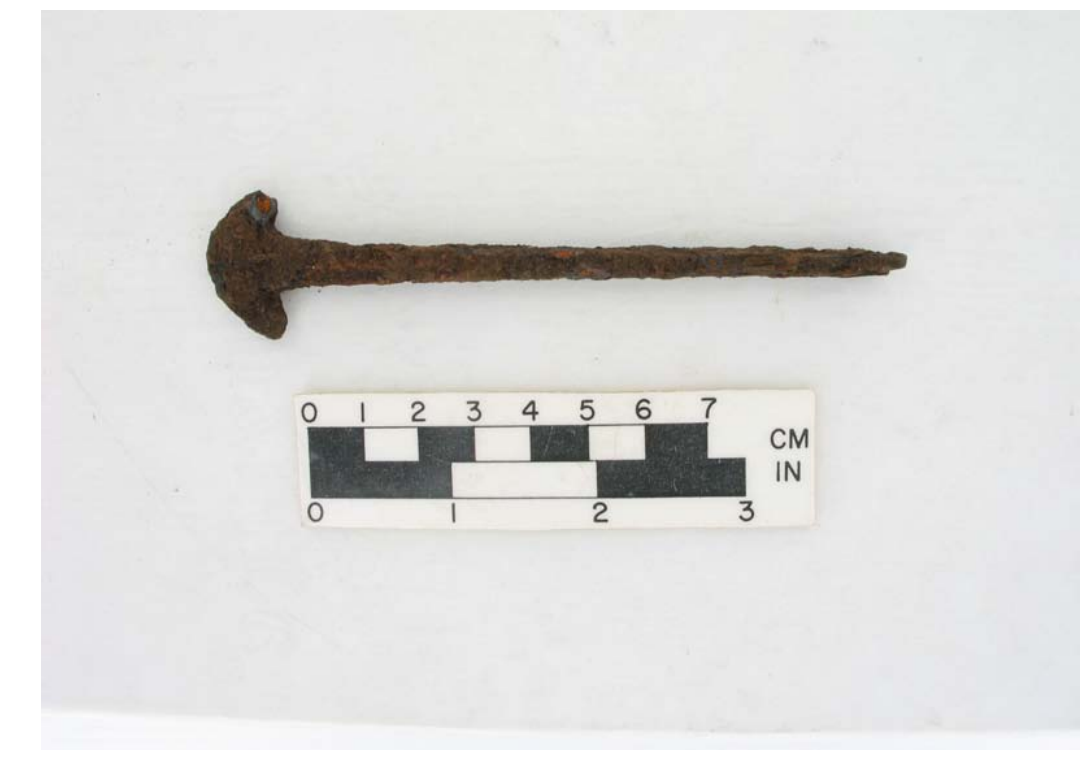

Figure 7.9: An example of a nail pounded into a harpoon head from Anniowaktook House 4 (Courtesy J. Six, photographer, 2010). Although made of iron, this form was included in the hunting category since it was found complete. 


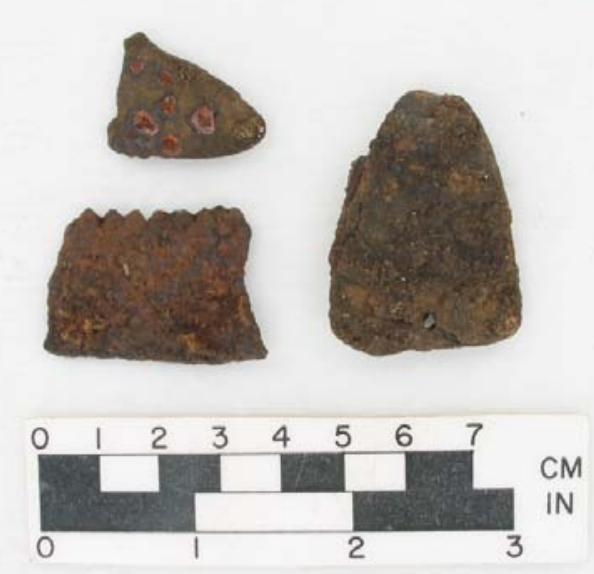

Figure 7.10: Examples of iron forms cut from strap metal or sheet metal from Adlavik House 4. From top to bottom, possible knife point or projectile point, fragment of a saw blade; right artifact: triangular pendant that may have been a projectile point or an endblade for a sealing harpoon.

Inuit used and manipulated a variety of different raw materials to produce desired tools. Iron sheet metal and strap metal ${ }^{16}$ combined to make up almost $10 \%$ of the manufacturing assemblages at the Adlavik and Anniowaktook deposits and were often cut to make blades or projectile points (Figure 7.10) (Jordan 1978:176). The majority of the iron found was heavily corroded and identifying a specific form was often difficult. Nevertheless, some of the sheet and strap metal exhibited post-manufacture modification such as refinished or cut edges. In addition to the flat metal, Inuit used wire as a substitute for leather or baleen lashing, and flattened or bent bars and nail rod to make hooks.

\footnotetext{
${ }^{16}$ Strap metal was differentiated from sheet metal. Strap metal had to be rectangular and have at least one finished edge. Sheet metal was flat metal but did not necessarily have a particular shape or any finished edges.
} 
Lead was another metal found in many of the Inuit sod house deposits that was modified to produce another form. Adlavik House 3 had the most lead artifacts $(n=23)$, particularly lead sheet or scrap. Lead was a low melting alloy that could be relatively easily manipulated at low heats, a useful trait for working in the arctic environment. The material was likely collected in the form of lead shot, sinkers, and scrap and then heated, hammered or rolled flat or into tubes to serve other domestic or hunting purposes. Lead was seen as round fishing weights, wrapped around hooks as fishing weights, rolled into tubes or manipulated into decorative pendants for parka weights as discussed in the Domestic category (see Figure 7.8). Although identifiable lead fishing weights and decorative parka pendants were classified as hunting and domestic items respectively, the lead scrap, sheeting fragments and unidentified worked forms from all the Adlavik and Anniowaktook deposits were included in the manufacturing category.

While the manufacturing category was dominated by metal forms, the second most abundant item found in all Anniwoaktook, Adlavik and Avertôk houses was faunal scrap $(n=144)$. This included all unidentified forms of faunal material that had one or more sides cut and showed signs of finishing, including the rounding of edges. These otherwise unidentified fragments may have been discarded mid-construction or were part of a larger broken tool which could not be refashioned or utilized. The Adlavik House 1 midden had the largest amount of faunal scrap $(n=70)$ suggesting a slightly elevated level of tool production using faunal material compared to the other deposits, with the next largest sample of faunal scrap from Avertôk House 3 (n = 17). 


\section{Hunting Category}

The "hunting category” included 19 different forms closely associated with subsistence such as harpoon heads, projectile points, fishing hooks, bone or ivory plugs used to stop the bleeding made by a harpoon, sled runners, toggles for dog sleds, whale bone spear shafts, snow knives used for making igloos while on the ice hunting, kayak parts, knife handles, and sled runners (Figures 7.11 and 7.12). The category included 159 artifacts from all deposits, representing 7\% of the artifacts investigated (Table 7.4). Unidentified tools due to fragmentation or excessive corrosion were not included in the category to avoid misrepresentation of function. Some tools used specifically for processing fur and hide such as ulu knives or scrapers were associated with the domestic sphere, while other tools such as a man's knife, a straight blade with a bone or wood handle, were included in the hunting category, which was predominantly male domain.

As described earlier, metal weights also had multiple functions as they were used to weigh down fishing lines, attached to hooks, or used as decorative trip on parkas. Only small metal and soapstone fishing weights measuring no more $3 \mathrm{~cm}$ in length with a single piercing near the top were included in this category $(n=5)$ (Figure 7.13). While these may have also been used to weigh down parkas, I only categorize the more decorated forms, such as the lead ulu knife found in Anniowaktook House 1 (see Figure 7.10) with the Domestic Category. Two soapstone fishing weights were found at Avertôk Houses $4(n=1)$ and House $7(n=1)$, while one lead weight was found on the floor of Avertôk House 5. Two additional lead weights were also found in Adlavik Houses 1 and 2. Although the total number of fishing weights found in all context was 
small $(n=5)$, the limited presence suggests Inuit were diversifying their diet with fish but it was not a main economic resource or activity.

Artifacts that were more indicative of the traditional sea and land mammal hunting found in Inuit households included stone tools. Inuit adeptly utilized locally available quartzite, nephrite and slate to form a variety of subsistence tools. The least frequent form found in the houses was projectile points, blades, and lances made from stone. Prior to contact with Europeans, Inuit made projectile points, harpoon heads, and most other subsistence related tools from quartzite, chert and slate, all with local sources in Labrador. The presence of a slate harpoon head near a bone foreshaft on the floor of Anniowaktook House 4 (Figure 7.14), along with a quartz biface indicated the house's earlier occupation and continued reliance on stone tools for hunting tools.

Similarly, Adlavik House 1 exhibited a very small collection of stone tools, including four quartz flakes, one Ramah chert flake, a Ramah chert scraper, and a hammer stone, while a small sample of chert flakes were also found in Anniowaktook House $4(n=3)$ and Adlavik House $3(n=2)$. All of the Adlavik and Anniowaktook deposits lacked the large amount of manufacturing debris normally associated with chipped stone, thereby indicating the household may have curated these few stone tools, but ultimately replaced the chipped stone with metals. While still found in some historic Inuit houses due to reusing sod associated with nearby Dorset sites, chert is not used by Historic Inuit. 


\begin{tabular}{|c|c|c|c|c|c|c|c|c|c|c|c|c|c|c|c|c|c|c|c|c|c|}
\hline Site & Context & 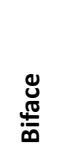 & 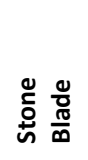 & $\begin{array}{l}\overline{\widetilde{g}} \frac{\pi}{0} \\
\sum \frac{\pi}{0}\end{array}$ & $\begin{array}{l}\frac{t}{5} \\
0 \\
3 \\
0 \\
0\end{array}$ & 蒙 & 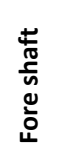 & 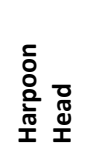 & 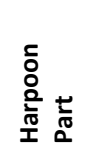 & $\begin{array}{l}\text { 음 } \\
\text { 인 }\end{array}$ & 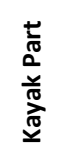 & 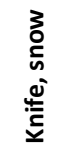 & 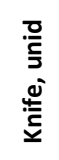 & 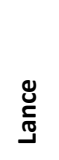 & $\stackrel{\stackrel{00}{\partial}}{\frac{0}{a}}$ & 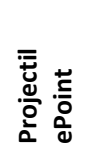 & ঠ্ঠ & $\begin{array}{l}\text { あँ } \\
\text { ڤँ }\end{array}$ & 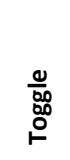 & 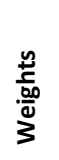 & $\begin{array}{l}\overrightarrow{\mathbb{E}} \\
\stackrel{5}{\circ}\end{array}$ \\
\hline \multirow[t]{6}{*}{ Adlavik } & House 1 & & & 2 & & 1 & & & & 3 & & & & & & & & & & 1 & 7 \\
\hline & House 1 Mid & & & 6 & & & 1 & 5 & 5 & 2 & 1 & & & & & 3 & 3 & 1 & 1 & & 28 \\
\hline & House 2 & & & 3 & & & & & & & & & & & & & 1 & & & 1 & 5 \\
\hline & House 3 & 1 & & & & & & & 1 & & & & & & & 1 & 8 & & 1 & & 12 \\
\hline & House 4 & & & & & & & & & 2 & & & & & & & & & & & 2 \\
\hline & House 4Mid & & & & & & & 1 & & 1 & & & & & 1 & & 1 & & 1 & & 5 \\
\hline \multirow[t]{5}{*}{ Anniowaktook } & House 1 & & & 1 & & & & & & 1 & & & & & & 1 & & & & & 3 \\
\hline & House 1 Mid & & & & & & & & 1 & & & 2 & 1 & & & & 1 & 1 & 1 & & 7 \\
\hline & House 3 & & & & & & & & 2 & & & & 2 & & & & & & & & 4 \\
\hline & House 4 & 1 & & & & & & 2 & 2 & 2 & & & & & & 1 & & & & & 8 \\
\hline & House 4Mid & & & & & & & 1 & & 1 & & & & & & 1 & & & & & 3 \\
\hline \multirow[t]{8}{*}{ Avertok } & House 1 & & 1 & & & & & & 1 & & & & 1 & & & & & & 3 & & 6 \\
\hline & House 3 & & & & & & & & 6 & & & 4 & 3 & 1 & & & & 1 & 1 & & 16 \\
\hline & House 4 & & 1 & & & & & & 1 & & & & & & & & & & & 1 & 3 \\
\hline & House 5 & & & 1 & & & & & & & & & & & & & & & & 1 & 2 \\
\hline & House 6 & & 1 & & & & & & & & & & & & & & & & & & 1 \\
\hline & House 7 & & & & & & & & & & & & & & & & & & & 1 & 1 \\
\hline & House $8 b$ & & 2 & & & & & & & & & & & & & 1 & & & & & 3 \\
\hline & Midden & & & 3 & 1 & & & & & 2 & 2 & 1 & 2 & & & & 1 & & 3 & & 16 \\
\hline TOTAL & & 2 & 5 & 16 & 1 & 1 & 1 & 9 & 19 & 14 & 3 & 7 & 9 & 1 & 1 & 8 & 15 & 3 & 11 & 5 & 131 \\
\hline
\end{tabular}

Table 7.4: Raw counts of artifacts included in the hunting category. 


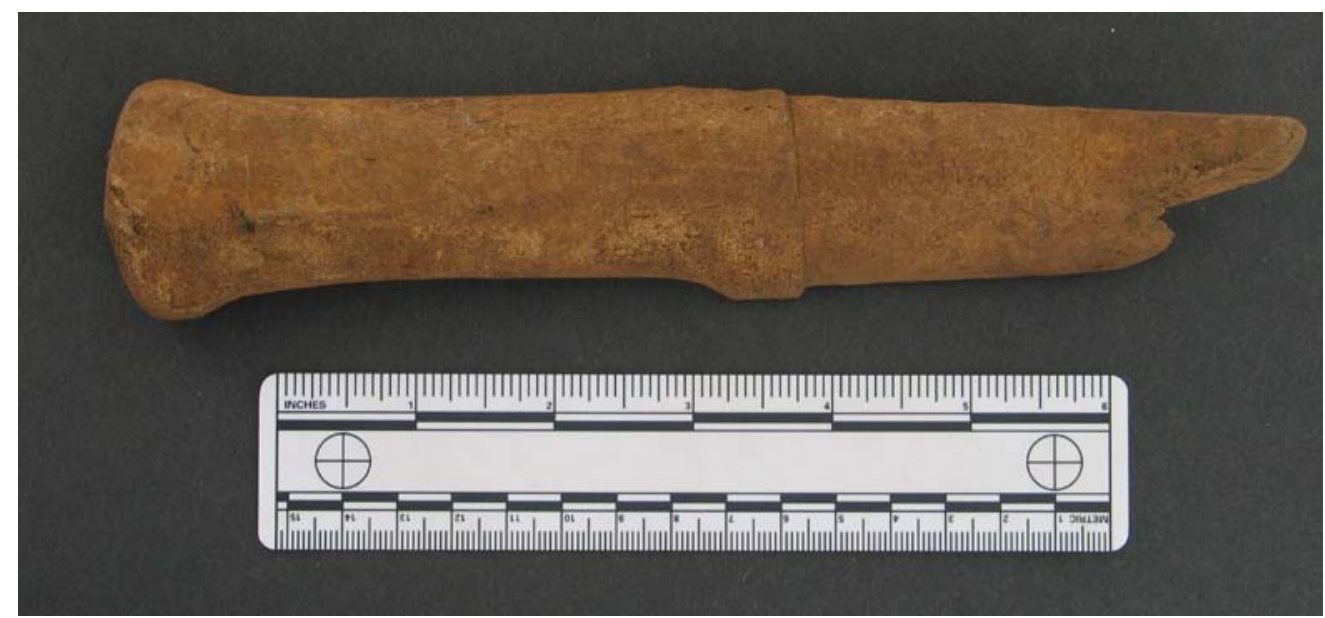

Figure 7.11: Example of a whale bone snow knife from the midden of Anniowaktook House 1 found in 2007.

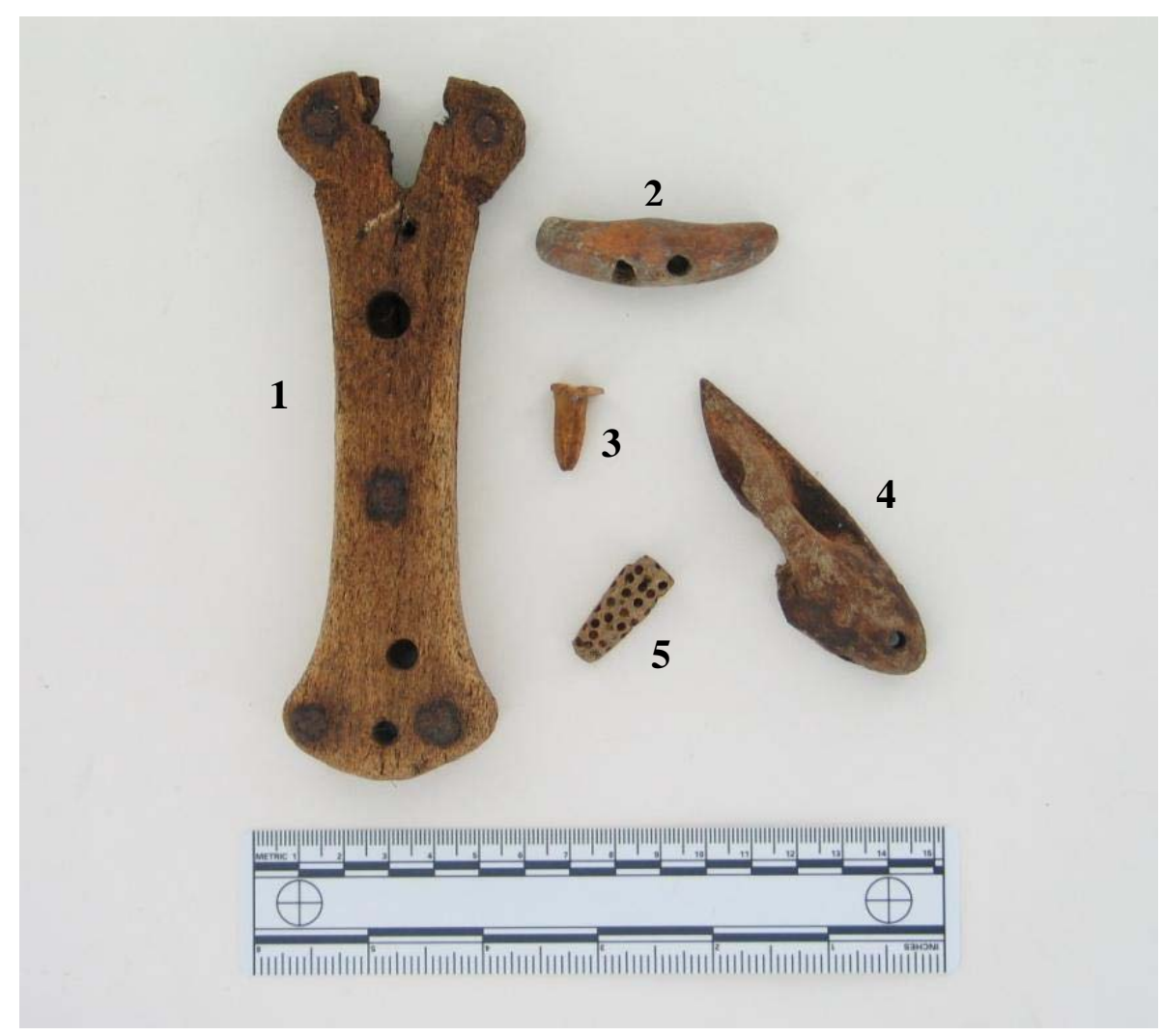

Figure 7.12: Example of a collection of bone artifacts, including a (1) handle to a man's knife, (2) a toggle, (3) a wound plug, (4) a harpoon head, and (5) a game piece or pendant from Adlavik House 1. (Courtesy J. Six, photographer, 2010; modified by author, 2011). 


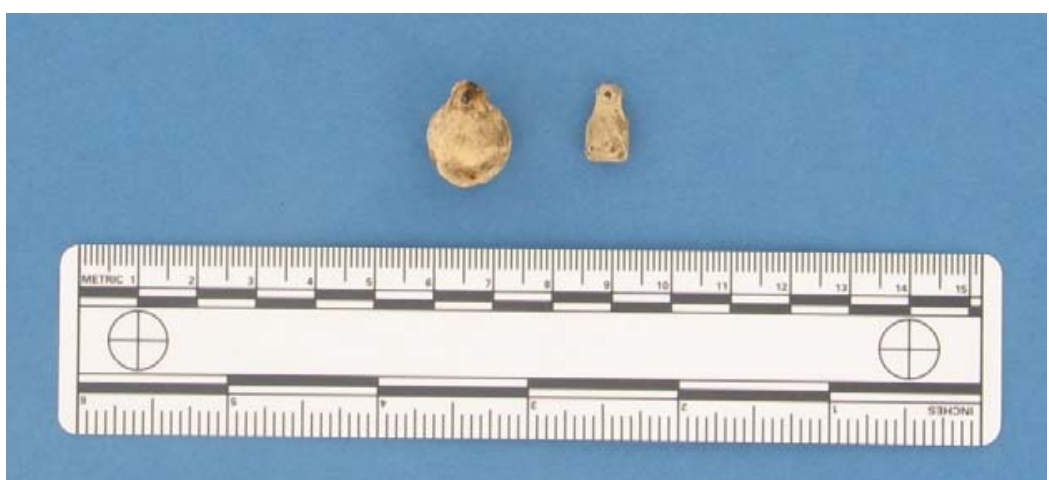

Figure 7.13: Lead fishing weights or possible parka trim from Adlavik House 1 and House 2.

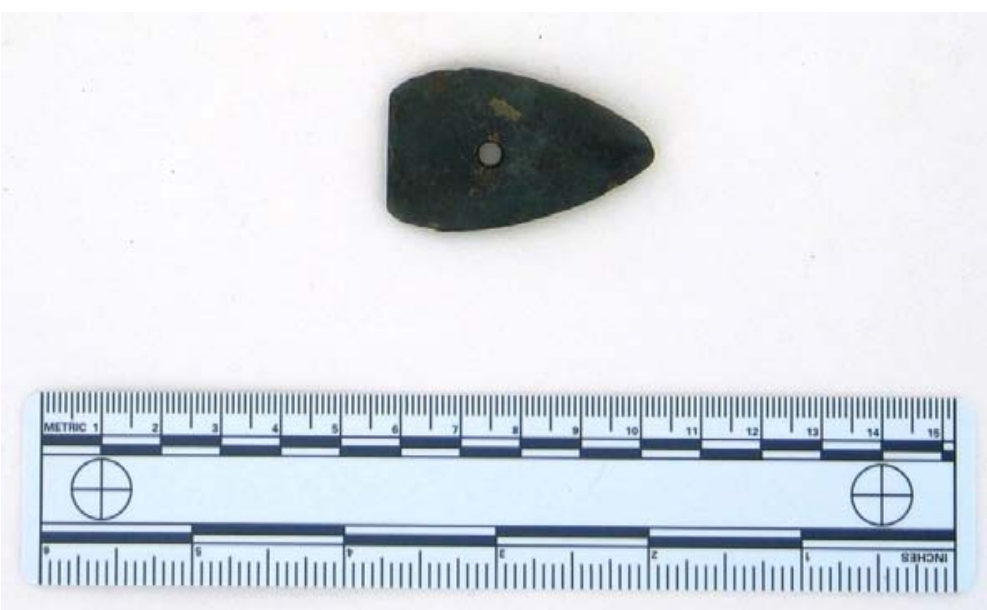

Figure 7.14: Slate harpoon head from Anniowaktook House 4.

A number of reasons may have led to the decline of ground stone tools made from nephrite and slate in Inuit deposits, particularly during the eighteenth century. First, a rise of metals along the Labrador coast during the eighteenth century was the result of a developing European trade. As metal became more plentiful along the coast and could be acquired in a central location or by a single individual, it eventually replaced most stone blades. Second, stone tools required a relatively high degree of manufacturing 
proficiency and needed constant retouching. Conversely, metal remained sharper with limited retouching. As knowledge regarding tool manufacturing and source location became less ubiquitous, Inuit found and used alternative materials.

\section{Trade Category}

Only items made of foreign materials and indicative of trade with Europeans or Inuit middlemen were included in this category. All the artifacts included in this category were found in Inuit contexts thereby implying their use and adoption into Inuit life, yet they were often modified or showed evidence of use that differed from the intended European purpose. For instance, the interior of a North Devon coarseware vessel from England was found in Anniowaktook House 4 encrusted with blubber, suggesting its use as a lamp or cooking vessel. Other items, such as lead scrap likely came from lead shot or fishing weights which was melted down and reshaped for personal adornment.

The trade category included 212 items found primarily at Anniowaktook and Adlavik (Table 7.5). With the exception of an early example of a pipe stem found in Avertôk House 9, two glass bottles in Avertôk House 3, and an iron key found in Avertôk midden, no other trade items were identified in the Avertôk assemblages. Thus the remainder of this discussion will focus primarily on the Adlavik and Anniowaktook assemblages. 


\begin{tabular}{|c|c|c|c|c|c|c|c|c|c|c|c|c|c|c|c|c|c|c|c|c|}
\hline Site & Context & 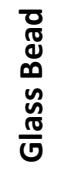 & 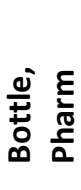 & 。. & & 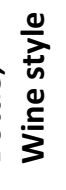 & $\begin{array}{l}\frac{0}{\mathrm{i}} \\
\mathrm{D}\end{array}$ & 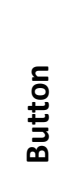 & 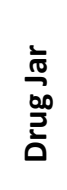 & 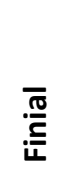 & $\begin{array}{l}\frac{0}{5} \\
\frac{5}{5} \\
i \frac{\pi}{4}\end{array}$ & 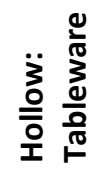 & 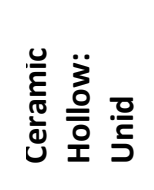 & 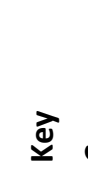 & $\begin{array}{l}\frac{n}{ \pm} \\
\frac{\pi}{0} \\
\frac{0}{0} \\
0 \\
0\end{array}$ & 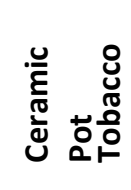 & $\stackrel{0}{\frac{0}{2}}$ & 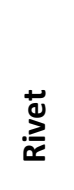 & 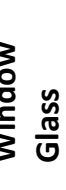 & 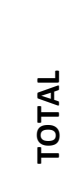 \\
\hline \multirow[t]{6}{*}{ Adlavik } & House 1 & 18 & 1 & & 3 & 4 & & 1 & 2 & & & & 3 & & 1 & & & & & 33 \\
\hline & House 1Mid & 10 & & & 1 & 3 & & 1 & & & & 1 & 19 & & & & 4 & 1 & 4 & 44 \\
\hline & House 2 & 2 & & & 1 & 2 & & & & & & & & & & & & & & 5 \\
\hline & House 3 & 12 & & & 4 & 3 & & & & 1 & & $\epsilon$ & 11 & & & & 11 & 1 & & 49 \\
\hline & House 4 & 2 & & & 1 & 1 & & & & & & 1 & 1 & & 1 & & 1 & & & 8 \\
\hline & House 4Mid & 6 & & & 3 & 3 & & & & & & & 3 & & & & & & & 15 \\
\hline \multirow[t]{5}{*}{ Anniowaktook } & House 1 & 2 & 1 & & 1 & 2 & 1 & & & & & & 7 & & & & 2 & & 1 & 17 \\
\hline & House 1Mid & 2 & & & & & & & & & & & 3 & & 1 & & & & & 6 \\
\hline & House 3 & & & & & & & & & & 2 & & & & & & & & & 2 \\
\hline & House 4 & & & & 2 & & & & & & & & 7 & & 1 & 1 & 1 & & & 12 \\
\hline & House 4Mid & & & & & 1 & & & & & & & 18 & & & & & & & 19 \\
\hline \multirow[t]{2}{*}{ Avertôk } & House 4 & & & & & & & & & & & & 1 & & & & & & & 1 \\
\hline & Midden & & & & & & & & & & & & & 1 & & & & & & 1 \\
\hline TOTAL & & 54 & 2 & 1 & 16 & 19 & 1 & 2 & 2 & 1 & 2 & $\varepsilon$ & 73 & 1 & 4 & 1 & 19 & 2 & 5 & 212 \\
\hline
\end{tabular}

Table 7.5: Raw counts of artifacts included in the trade category. 


\begin{tabular}{|ll|cccc|}
\hline & & $\begin{array}{c}\text { Trade/m } \\
\mathbf{3}\end{array}$ & $\begin{array}{c}\text { Hunting/ } \\
\mathbf{m}^{\mathbf{3}}\end{array}$ & $\begin{array}{c}\text { Manufacturing/ } \\
\mathbf{m}^{\mathbf{3}}\end{array}$ & $\begin{array}{c}\text { Domestic/ } \\
\mathbf{~ m}^{\mathbf{3}}\end{array}$ \\
\hline Adlavik & House 1 & 0.16 & 0.03 & 1.02 & 0.06 \\
& House 1 & & & & \\
Mid & 1.46 & 0.91 & 9.61 & 0.03 \\
& House 2 & 1.27 & 1.06 & 12.29 & 2.97 \\
& House 3 & 3.03 & 0.74 & 17.09 & 0.56 \\
& House 4 & 0.29 & 0.07 & 2.50 & 0.11 \\
Anniowaktook 4 & & & & \\
& House & 1.56 & 0.52 & 9.28 & 1.25 \\
& House 1 & 0.18 & 0.03 & 2.47 & 1.05 \\
& House 1 & & & & \\
& Mid & 1.94 & 2.26 & 35.81 & 3.87 \\
& House 4 & 0.19 & 0.14 & 1.44 & 0.07 \\
& House 4 & & & & \\
Mid & 4.57 & 0.65 & 11.30 & 0.65 \\
\hline
\end{tabular}

Table 7.6: Average number of items by volume excavated in each category at Adlavik and Anniowaktook.

On average, more European items (from both the trade and manufacturing categories) were found in the Adlavik deposits $\left(\bar{x}=7.77 / \mathrm{m}^{3}\right)$ than at Anniowaktook deposits $\left(\bar{x}=6.86 / \mathrm{m}^{3}\right)$ suggesting the residents at Adlavik accumulated more foreign goods perhaps as a result of greater availability. The majority of the trade items were found in the midden, with Adlavik House $3\left(\bar{x}=3.03 / \mathrm{m}^{3}\right)$ and the post abandonment midden in Anniowaktook House $4\left(\bar{x}=4.57 / \mathrm{m}^{3}\right)$ averaging the most trade items found per $\mathrm{m}^{3}$ (Table 7.6). Furthermore, trade and manufacturing items are found at a higher rate than hunting and domestic items, suggestive of Inuit placing a new emphasis on accumulating foreign materials. While the manufacturing category will be discussed in greater detail in the following section, it is worth mentioning here that manufacturing items are found at a significantly higher rate at all house deposits. 
Sherds of European vessels were found at each site, though not evenly distributed probably a result of fragmentation. Identifiable ceramic types primarily came from the English and French, as they maintained the most continuous presence along the coast that extended into the historic period. Most notable were British Stoneware and North Devon Coarseware from England, and Normandy stoneware and Rouen Plain Faience from France. Specific forms were not always identifiable, but the most common type of vessel was hollow. Only four fragments from flat vessels were found at Adlavik and Anniowaktook; two fragments from an unidentified flat coarseware vessel were found at Anniowaktook House 3, one flat pearlware teaware fragment was found on the surface of Adlavik House 3, and a whiteware saucer fragment was found on the surface of Adlavik House 1. The two fragments were not included in this analysis since they were found on the surface and may be associated with a later occupation. The fact that no other flat vessels were identified within any of the assemblages highlights Inuit preference for hollow forms.

The predominant hollow forms were used for liquid or liquid based foods as cooking vessels or the transportation of fresh water or snow and were found in all of the deposits except Adlavik House 2. The prevalence of hollow ceramic forms among Inuit houses follows consumption trends similar to those at other Labrador Inuit sites with a preference for stewed and boiled foods and hot beverages. Archaeological evidence from nineteenth-century Moravian-Inuit sites at Nain and Hebron showed hollow vessels dominated the ceramic assemblages, demonstrating that Inuit continued to consume 
traditional liquid-based foods (Arendt 2010; Cabak 1991; Cabak and Loring 2000; Loring and Arendt 2009).

Some ceramics found within the house served a function other than cooking. A large number of redware sherds $(n=54)$ were found placed in a circle into the sand of the sleeping platform in Anniowaktook House 1, perhaps serving as a possible post-mold (Figure 7.15). The arrangement of sherds suggests they may have been used as supports to shore up a roof post. The durable and rigid sherds would have served to stabilize the structural post dug into soft sand.

Another example of European ceramics being adopted into Inuit contexts includes two fragments from a stoneware drug jar found at the occupation levels in Adlavik House 1 and approximately eighteen fragments from a North Devon pot found in the postabandonment midden associated with Anniowaktook House 4. Both vessels were small, but heavily encrusted with burned blubber on the interior and evidence of burning on the exterior. The heavy burning and incrustation suggests that both vessels were exposed to fire and may have been used as lamps, as seal blubber rendered into oil was the fuel for Inuit lamps.

At Anniowaktook, a ceramic vessel was also found associated with a burial offering. North of the sod house settlement on Anniowaktook Island, a broken Normandy stoneware hollow vessel was found placed on a large boulder outside a cave entrance. The cave had evidence of a burial with stones laid in a semicircle, although the human remains were missing (Figure 7.16). The placement of the ceramics outside of the cave may have been a later offering. Some Inuit of the Central Arctic buried their dead 
with many valuable tools and objects to join the dead in their spirit world. Vessels also may have served as tokens from mourners (Way 1978:69). Evidence from earlier Thule Inuit suggests Labrador Inuit typical burial practices included placing the body in a cairn or cave-like overhang, such as the one described above, with a separate cache of associated goods. The presence of the French Normandy stoneware vessel indicated that island occupants at least recognized the burial even if it was not contemporaneous. While the ceramic sherds found near the burial were not included in this analysis since there was insufficient evidence to suggest that the burial was related to the eighteenthcentury sod house settlement, the use of ceramic vessels as burial offerings reveals the extent that Inuit used European ceramics for traditional means.

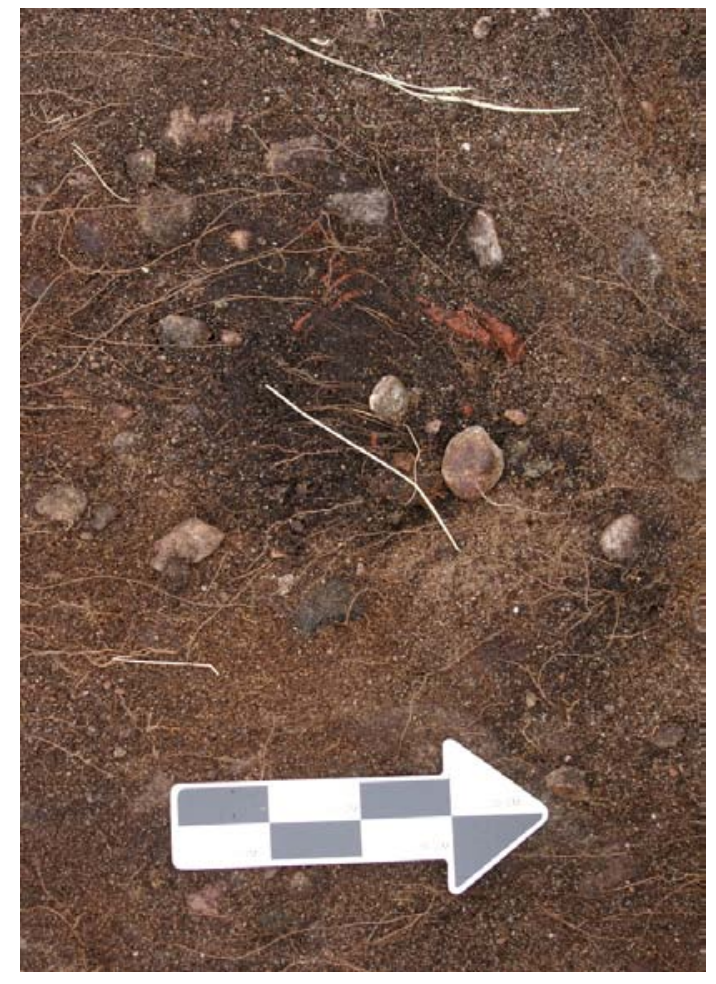

Figure 7.15: Feature 1 on the sleeping platform in Anniowaktook House 1. Note fragments of redware around the edge of the posthole. 
The other ceramic form found within all of the houses at Adlavik, in Houses 1 and 4 at Anniowaktook, and at Avertôk Houses 3 and 9 was the tobacco pipe. The presence of the tobacco pipe fragments may also point to gendered distinctions within the household. Archaeologist Peter Whitridge (1999) argued that during the historic period tobacco use differed between men and women; women took snuff and men smoked tobacco. However, the historical record showed a different pattern by the twentieth century as women were photographed with tobacco pipes (Figure 7.17). Furthermore, early ethnographies identify elaborately constructed and decorated tobacco bags worn by both men and women (Hawkes 1916:54-55). While regarding smoking as a male gendered activity might be too presumptive, the presence of tobacco pipe fragments does point to the prevalence of smoking in households.

Native use of tobacco for religious or spiritual purposes has been associated with western Inuit in Siberia and northern Alaska; however, Labrador Inuit do not appear to be using tobacco for ritual purposes (Winter 2000:11). No mention of the plant product appears in Inuit mythology, and shamans were not using tobacco to achieve trances or to aid in acts of healing. Nevertheless, Inuit found tobacco to be an important and highly used commodity for its medicinal purposes and ability to deaden hunger. As a result, tobacco was heavily sought after and traded by the eighteenth century.

Alcohol was an item the traders brought over in large quantities and the missionaries tried to prohibit increasingly through time. Green wine-style bottles and pharmaceutical bottles were found in all of the Adlavik and Anniowaktook deposits, except Anniowaktook House 4. Of the 30 glass bottle fragments identified at Adlavik, 17 
were green wine-style bottles which may have contained alcohol. Although speculation regarding use of the bottles can be problematic without a residue analysis, historical evidence showed that southern European traders, not missionaries, would freely trade alcohol with Inuit. The Moravians forbade the consumption of alcohol by Inuit at the mission, identifying it as one of the evil consequences of their continued travels south to visit the traders. The desire for alcohol and the Moravians' reluctance to sell it was one of the many reasons Inuit continued traveling south after the Moravian’s arrival (Hiller 1971a; Packard 1891).

The least frequent type of European traded goods was window glass, which was only found in the Adlavik House 1 midden $(n=4)$ and Anniowaktook House $1(n=1)$. Its presence in these two deposits can only suggest that Inuit were incorporating glass windows to replace the seal intestine window that were normally used to allow natural light into the otherwise dark sod house interior. The shift to using flat window glass may have served a practical purpose rather than an aesthetic role; the clear glass let in more light and was more durable than the seal intestine which was susceptible to tearing (Figure 7.18). Flat glass also served another role as a valuable cutting tool. Regardless, the low quantities of window glass in the Adlavik House 1 midden, and Anniowaktook House 1 suggests that if flat glass was available, it was highly preserved and not discarded even after the houses were abandoned. 


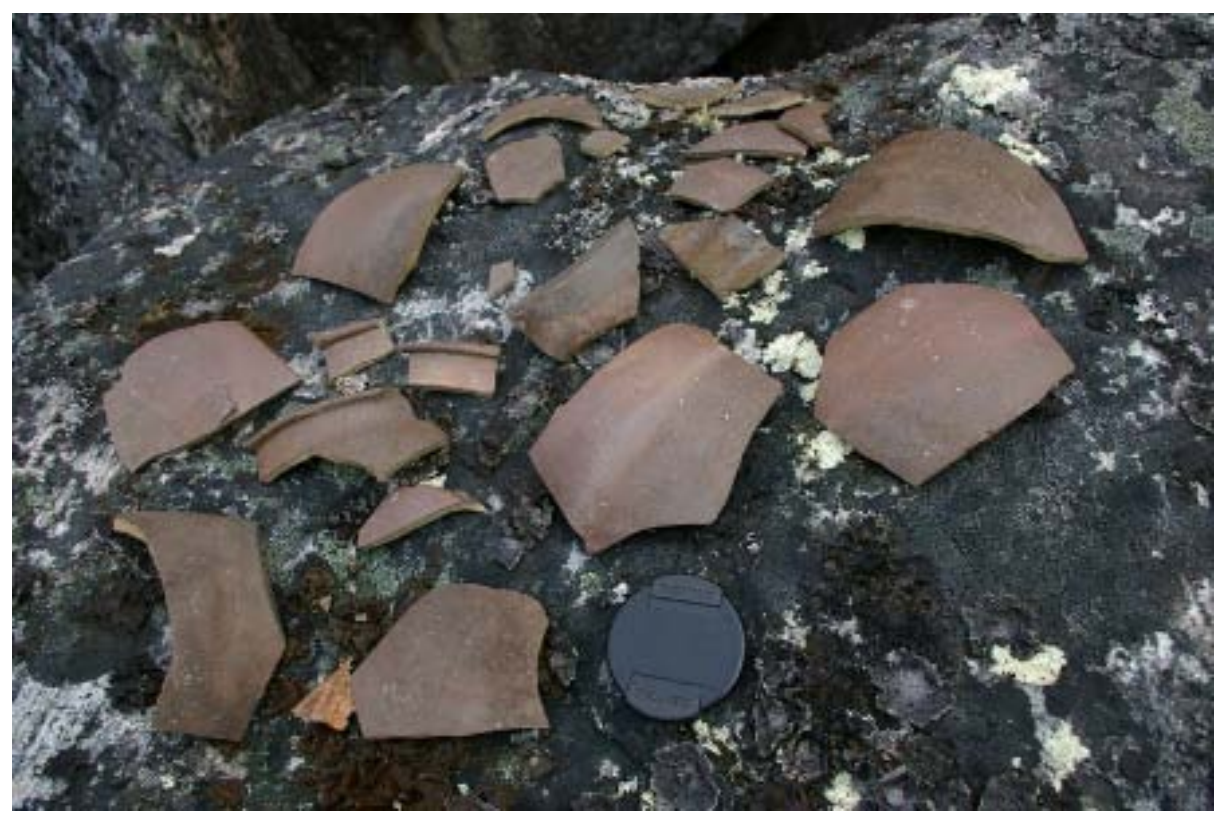

Figure 7.16: Normandy stoneware fragments found on rock located approximately 100 meters east of a cave burial on Anniowaktook Island.

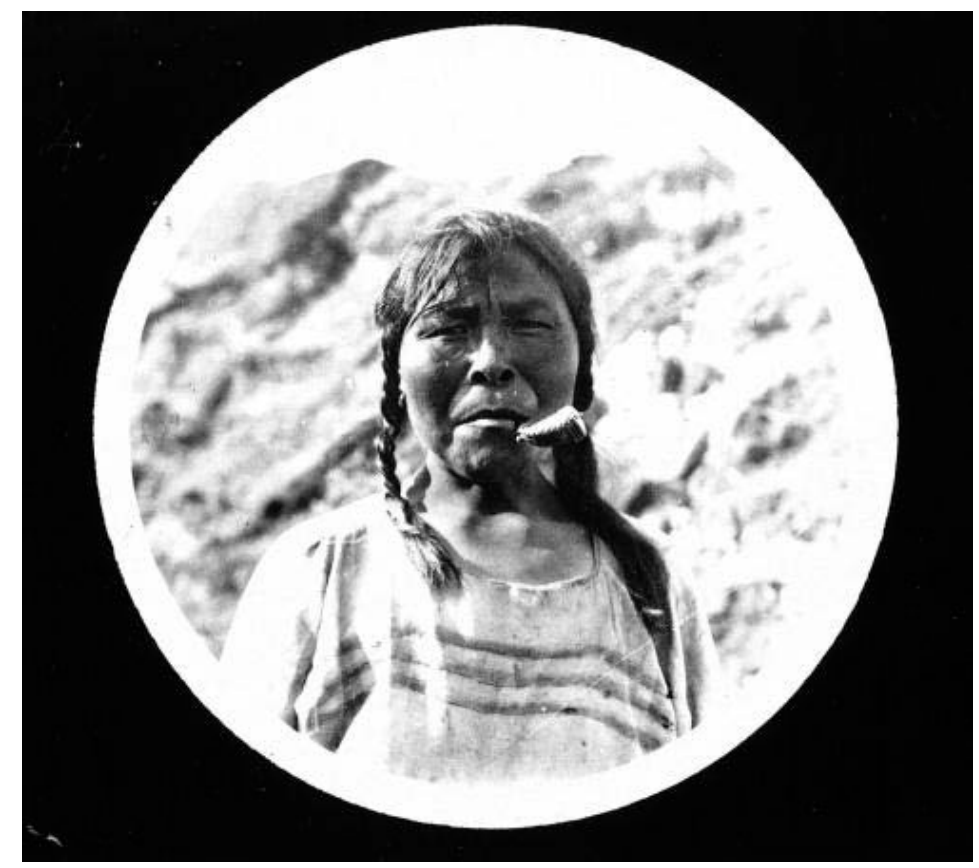

Figure 7.17: Photograph of an Inuit woman smoking a pipe. Photo taken by Paul Hettasch collection, circa 1900. (Source: Labrador Inuit Through Moravian Eyes http://link.library.utoronto.ca/inuitmoravian/index.cfm) 
The window glass may also represent trade with the Moravians, who shipped over most of their construction material, including lumber and window glass. The Moravian constructed missions as part of a larger settlement plan that they hoped would incorporate their growing Inuit congregation. Although the request lists for the trade store or probate lists for the general mission did not include window glass in their inventories, the Moravians were receiving assorted building materials including window glass from Okkak and sources in Newfoundland (LaTrobe 1774:6).

Inuit found glass useful even if when fragmentary. Sherds were retouched to make cutting tools such as scrapers; however, few examples of flaking and retouching tools made of glass appear in Labrador. Glass use by Native Americans is quite a widespread phenomenon probably because glass is mineralogically similar to stone materials (Martindale and Jurakic 2006:416-417). In a nineteenth century post-contact Tsimshian village located in British Columbia, Canada, archaeologists identified a number of glass scrapers and knives among ground stones and traditional stone tools (Martindale and Jurakic 2006). The collection of glass tools among the stone tools may have been a utilitarian response by the Tsimshian to incorporate glass as just another lithic resource, yet it represents the economic resourcefulness and adaptability within a developed technological tradition (Martindale and Jurakic 2006:425). 


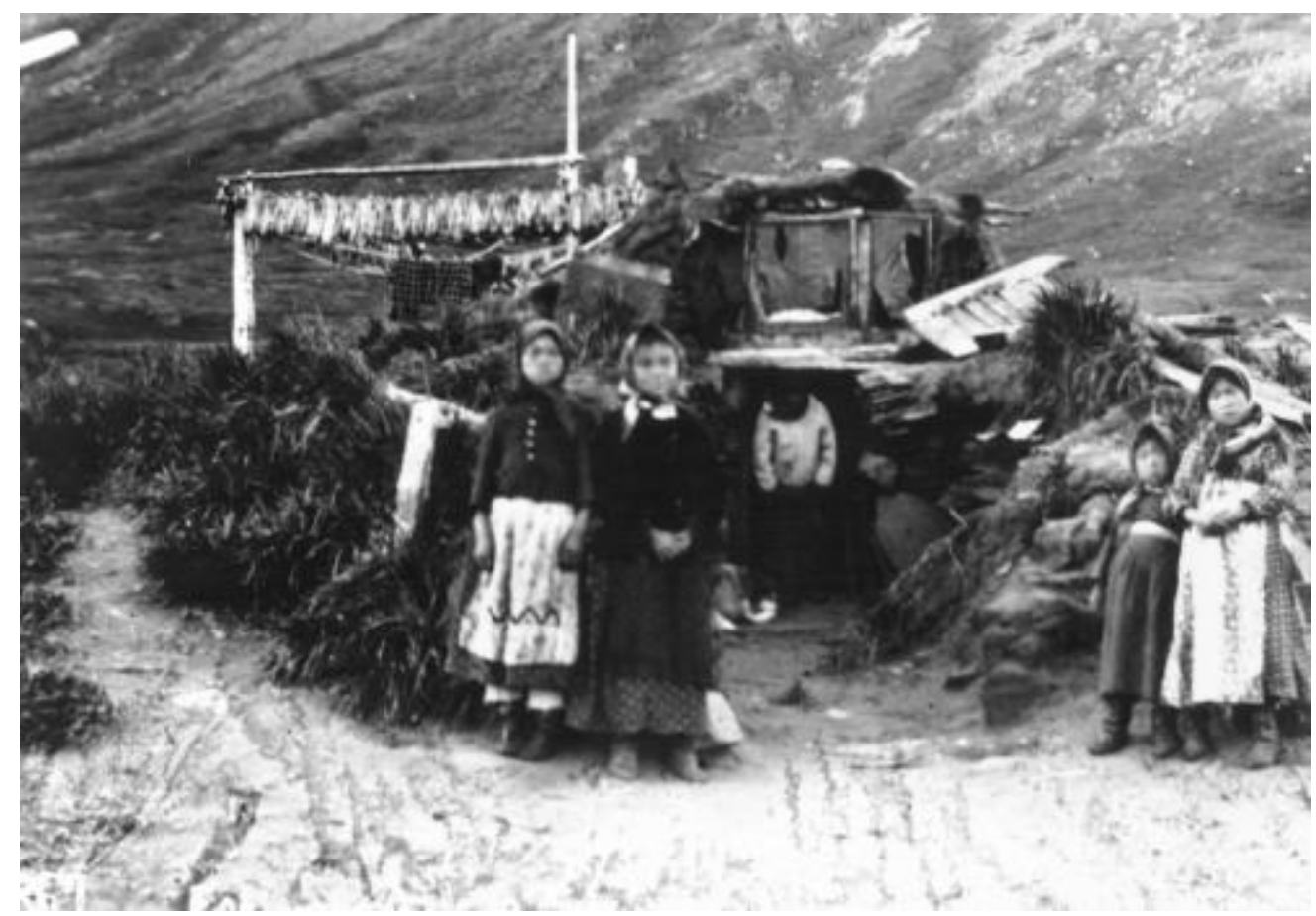

Figure 7.18: Black and white photograph of an Inuit winter house with several children standing out front. The window above the door was made of seal gut. Location probably Ramah. Photo from the Fotosammlung zu Labrador und Grönland, circa 1900. (Source: Labrador Inuit Through Moravian Eyes http://link.library.utoronto.ca/inuitmoravian/index.cfm).

Only one example of a reworked glass sherd was found at the sod level of Adlavik House 4. Unfortunately, its location on the surface and the sample size of one does not allow for any definitive conclusions about the incorporation of worked glass sherds into the Inuit toolkit; however, its presence coincides with other material shifts and historical developments that can be attributed to changes in aesthetic tastes (Stahl 2002).

The final glass form found at Adlavik and Anniowaktook that played an important role in European trade with Native peoples worldwide was beads. Initially given as gifts and trade items by European explorers, glass beads quickly became popular in Inuit culture and were traded among groups. Their use by Native groups may have been 
influenced by other social variables including status and preference in ornamentation (Bundy et al. 2003:31; Graeber 1996).

Beads make up less than 5\% of the assemblages and were found in all the Adlavik and Anniowaktook deposits except Anniowaktook Houses 3 and 4. The majority of the collections contain blue and white drawn beads and red-on-clear beads, and a few unique beads such as two gooseberry beads and an A. Speo black opaque bead discussed in greater detail in Chapter 6. Despite the small sample of beads found in each deposit, the presence of beads in the houses reflects patterns regarding use and loss, preferences, bead availability, and ornamentation (Bundy et al. 2003:31). Most likely, the beads found in the Adlavik and Anniowaktook houses were used for decorative purposes, sewn onto clothing and bags, as well as worn as necklaces or earrings (Figure 7.19). The beads may have also served as currency as this was common among other colonial sites in the Arctic and Alaska, yet such use remains only speculative in this context. Nonetheless, the relatively low frequency of beads in the houses suggests that beads were carefully retained due to their value. The presence of a few unique bead forms in Adlavik Houses 1 and 2 further suggest that residents had access to a diverse trade market either with other Inuit or Europeans themselves. Although the amount of beads does not compare to the amount found at Eskimo Island in Hamilton Inlet as described in Chapter 2, the presence of at least a few glass beads indicates that trade with Europeans was becoming a significant element of the eighteenth century Inuit cultural and social landscape.

Evidence from Adlavik and Anniowaktook suggests that Inuit living at both sites were accumulating European artifacts through trade. The relatively high rate of 
consumption and discard of trade items in all deposits highlights the intensity of such accumulations. European materials must have carried some aesthetic value beyond their practical use.

In a 1794 letter published in the Periodical Accounts from the Moravian missionaries at Nain, the missionaries described an interaction with a particularly prominent Inuit leader and shaman named Tuglavina. After returning from a trip to Chateau Bay to engage in trade, Tuglavina had collected a number of European goods including clothing, weapons and a boat. He entered the mission house "dressed in an old officer's coat, with a bob wig and a huge laced hat on his head, a sword to his side, and altogether in the habit of an European officer; threatening what he would do, and boasting of his valiant deeds in the South” (PA 1794:255). Tuglavina’s display of the European trade goods served to signal his prowess as a trader, and perhaps his performance was done in jest. While the Moravians were not amused with his antics and proceeded to humiliate and chastise Tuglavina for attempting to impersonate Europeans, it was clear by his actions that his ability to collect and wear these trade goods was intended to be a strong statement. Clearly, European trade items carried some value and level of prestige. 


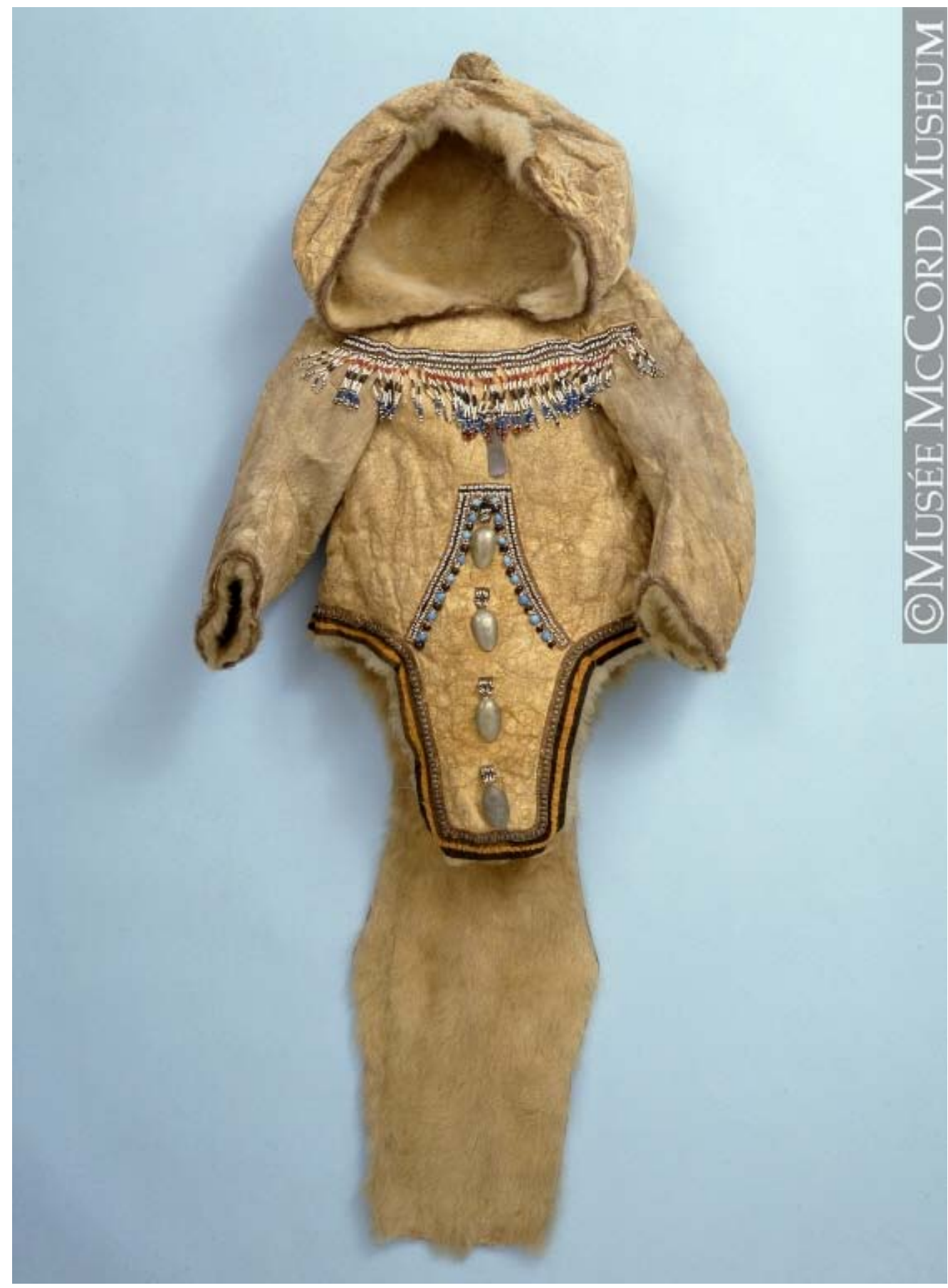

Figure 7.19: Inuit woman's seal skin parka decorated with glass beads and pewter spoon bowls. Courtesy of the Museé McCord Museum in Montreal, Canada. Artifact identification number M5836. 
Anniowaktook House 1, the Avertôk midden and Adlavik House 1 all had a variety of European artifacts such as a pewter button face, a key, and a copper buckle suggesting the household interests in collecting European objects, and using them for both decorative or functional purposes. For instance, buttons may have also been used as part of the woman's needle kit (Hawkes 1912:99). When tied to the end of the skin that held the needles, it would help to pull the hide out from the case. Other European objects such as the copper alloy finial found in Adlavik House 3's entrance tunnel may have been collected solely for its novelty or potential use as a raw material rather than serving any decorative function.

\section{Validating the Categories}

The preceding description of the artifacts types found in the excavations provide an image for what activities occurred in Inuit household and what elements were consumed, used and discarded by eighteenth century Inuit. I explored the implications of the categorical determinations described above by studying the occurrence of the artifact types and assemblages by employing a correspondence analysis (CA) on the artifact type frequencies across the 21 house and midden deposits from Adlavik, Anniowaktook and Avertôk. CA is a non-parametric comparative statistical technique that analyzes a twoway (rows and columns) data matrix (Greenacre 1993; Shennan 1988). It is an exploratory data analytic technique used to graphically depict the table of numerical data and identify patterns of relationships between the rows and columns, in this case, the 
individual assemblages and the artifact type frequencies, in two or three dimensions (K. Smith and Neiman 2007:20).

The CA measures the distance between two assemblages or artifact types by using chi-square distances, where the inertia, or the total Pearson's chi-squared for the two-way matrix divided by the total sum, is the total amount of variation in the original dataset. My intention in calculating a CA is to determine whether my separation of types into categories based on ethnohistorical data can be independently verified. As such, CA is only a descriptive process and is not used to test the hypotheses. SAS code used to perform the CA on all the assemblages was provided by UCLA Academic Technology Services, which I modified (Academic Technology Services, Statistical Consulting Group from http://www.ats.ucla.edu/stat/sas/code/casummary.htm (accessed February 24, 2011)).

For reasons described in more detail in Appendix B, the Avertôk assemblages and Anniwokatook House 3 were removed from the analysis, as assumptions regarding the distribution of samples along gradients could not be met (K. Smith and Neiman 2007:24). The primary problem with the Anniowaktook House 3 and Avertôk assemblages is Bird’s decision to focus on prehistoric items and not collect a representative sample of all artifact types, including European artifact types. 


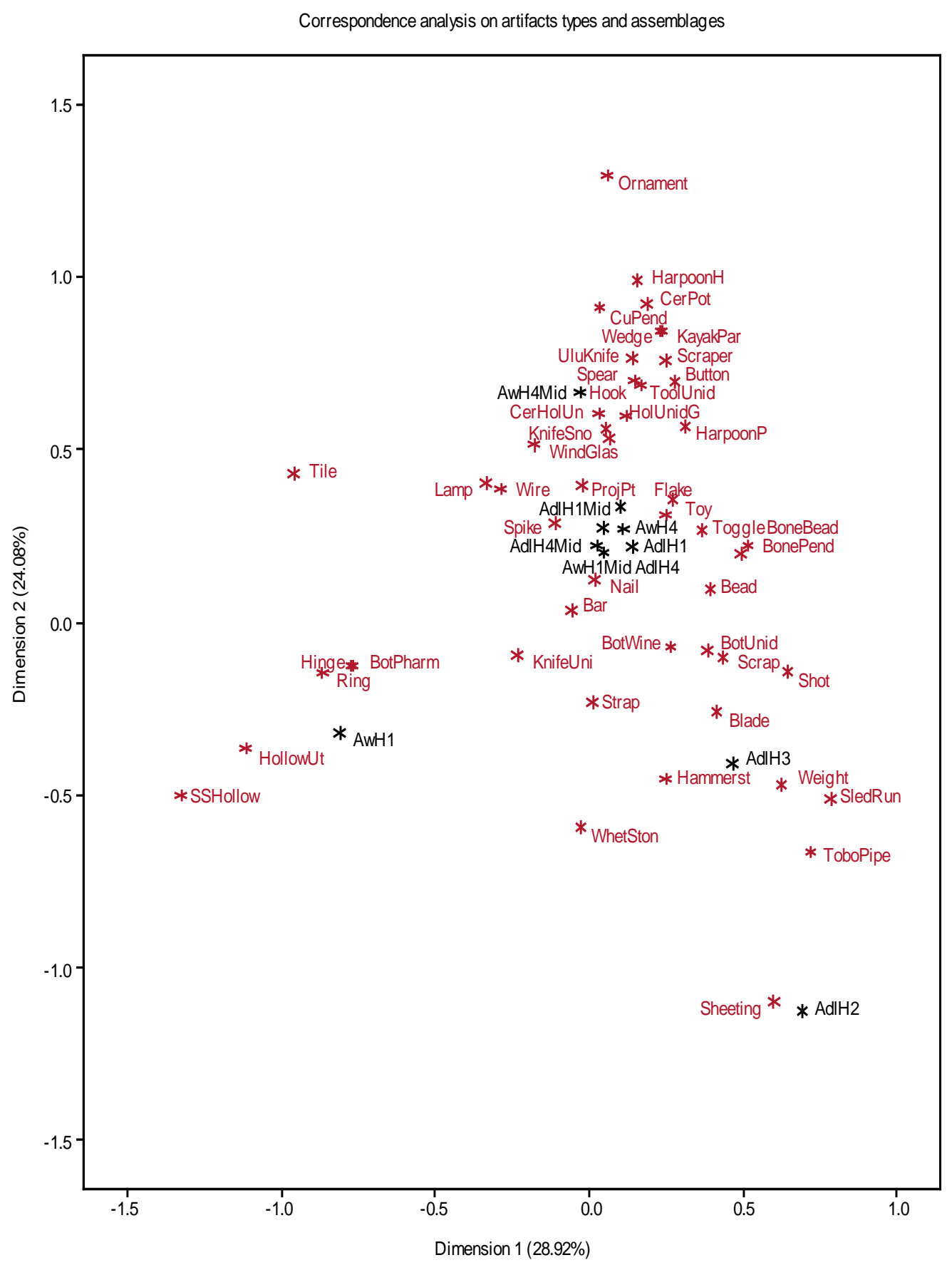

Figure 7.20: Correspondence analysis of artifact types and assemblages from Anniowaktook and Adlavik. 
Figure 7.20 represents the distribution of artifact types and assemblages along the first two CA dimensions for the remaining Anniowaktook and Adlavik sites. The graph reveals what initially looks like an arch, which is caused by a unimodal distribution. The shape of the curve, or the arch effect, represents a non-linear pattern in a Euclidian space as a two-dimensional plot (i.e., representing three dimensions in two dimensions) (Legendre and Legendre 1998:469). The arch simply means that an artifact type frequency will either increase or decrease as a function of a specific variable, such as change over time; however, the plot of the assemblages do not appear to follow a temporal pattern based on the EMDs for each assemblage established in Chapter 6 . Further, the plot of the artifact types reveals that the distribution is heavily influenced by soapstone hollow vessels (SSHollow). Additionally, a plot of the inertia values for each artifact type against the site confirms that soapstone hollow vessels are indeed an outlier type (Figure 7.21). The plot shows that sheet metal (sheeting) also greatly influences the calculation and should be considered an outlier. Soapstone hollow vessels and sheet metal are so distinctive relative to the other artifact types that in seeking to maximize inertia, Axis 1 contrasts these two artifact types (Ramenofsky et al. 2009).

In the subsequent CA (Figure 7.22), I omitted sheet metal and soapstone hollow vessels. This time the artifact types appear to be more evenly distributed across the two axes, with Axis 1 accounting for $22.63 \%$ of the variance among the types and assemblages. Again the plot appears in an arch shape caused by unimodal distribution. While the artifact types do not appear to fall along a functional gradient (according to my categorical definitions), the CA does appear to represent some level of function. For 
instance, the artifact types located around the Anniowaktook House 4 midden are mostly hunting tools, such as harpoon parts, projectile points and kayak parts. The presence of European ceramic hollow vessels (CerHolUn) may be a product of a household that collected or traded for a few European items while out hunting.

Additionally, a small group of artifacts located at the top of the graph are all items I originally characterized as part of the domestic space, including a ring, pharmaceutical bottle (BotPharm), whet stone, and a ceramic hollow utilitarian vessel (HollowUt) similar to that of a pot. The hinge, which is also found in the vicinity of the group, may have held a domestic function or it may just be an outlier. While these two groups do emerge, the majority of the assemblages are surrounded by a variety of artifact types that suggest a wide range of activities occurred at each household, including trading, hunting and cooking; no single house was dominated by a single activity.

It is unclear whether the distribution of the assemblages follows a temporal gradient, as early sites such as Adlavik House 1 fall between two later sites, Adlavik House 3 and Anniowaktook House 4 midden; however, the confidence intervals for the MCDs calculated in Chapter 6 for many of the sites were wide, thus indicating statistical imprecision. The CA may highlight that artifact types are not the best source for dating Inuit sites. Inuit often scavenged old abandoned European sites where items were often left behind or cached. Further, traders likely used earlier material that was no longer fashionable among Europeans to trade with Inuit thus skewing estimated occupation dates earlier. The CA does provide some support that artifacts falling within the hunting and domestic categories I created; however, it does not distinguish differences between 
trading and manufacturing. I believe the CA highlights the degree to which those categories overlap at most of the deposits.

To test the degree to which these categories of artifact types are correlated, I calculated Kendal tau correlation coefficients, as described in Chapter 5, of the four category types using all of the Adlavik, Anniowaktook and Avertôk assemblages. Kendal tau will help identify the strength of relationship between each category, particularly between trading and hunting items which I expect to be strong (Table 7.7). Strong correlations will further support the suggestion that prominent Inuit men who were hunters were also traders and were able to accumulate more of those objects.

A log-transformation of the counts of the hunting and manufacturing category did not allow for the null hypothesis of zero correlation to be rejected at $\alpha=0.1, \tau=0.3(p=$ 0.21); instead, a moderate correlation between the manufacturing and trading category did occur at $\alpha=0.1, \tau=0.64(p=0.04)$. Again, these correlations are skewed by the Avertôk deposits. To test the degree Bird's methodology may have also distorted the correlation calculation; I recalculated the Kendall's tau omitting the Avertôk deposits again (Table 7.8). 


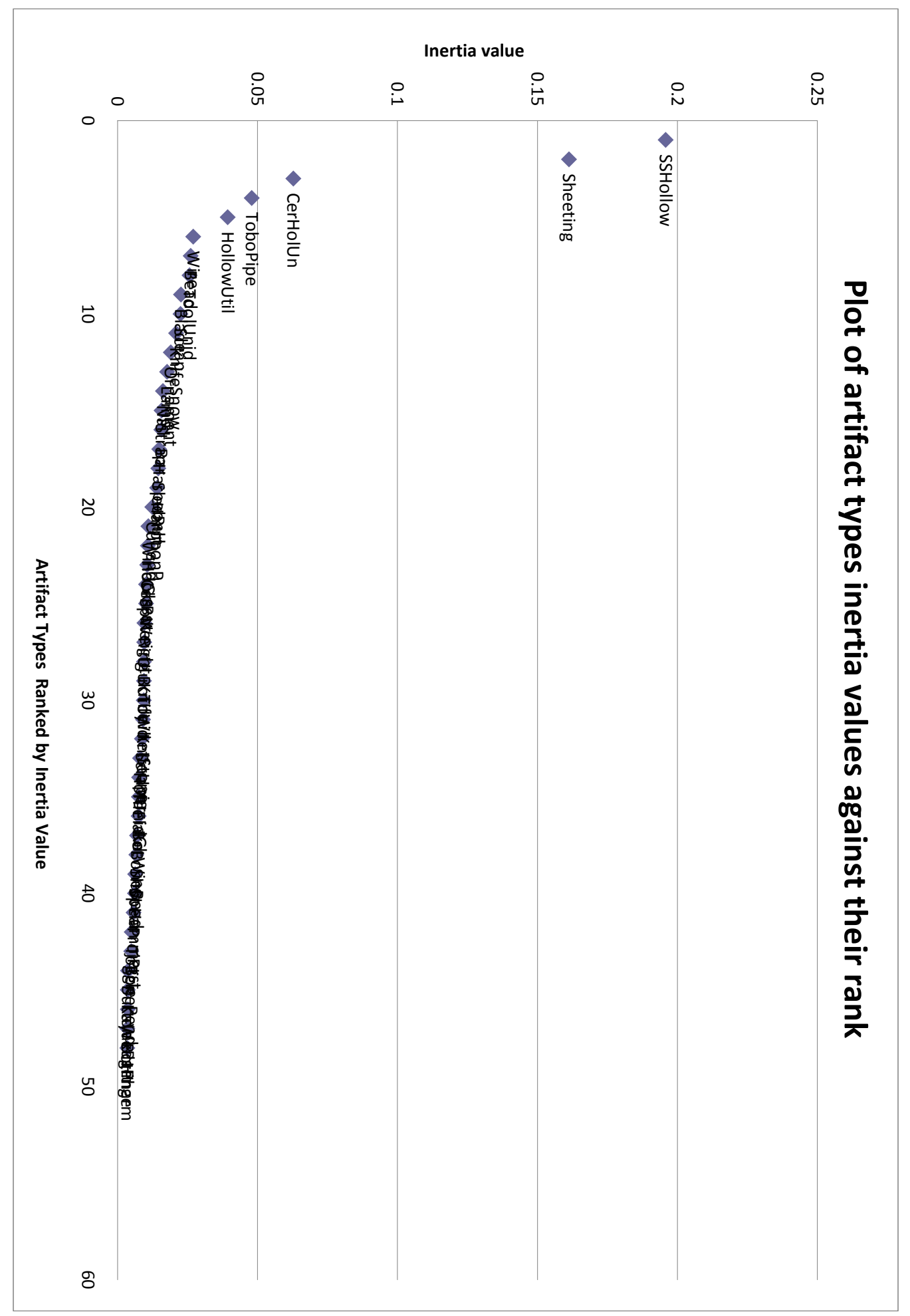

Figure 7.21: Plot of the artifact types inertia values against their rank. 


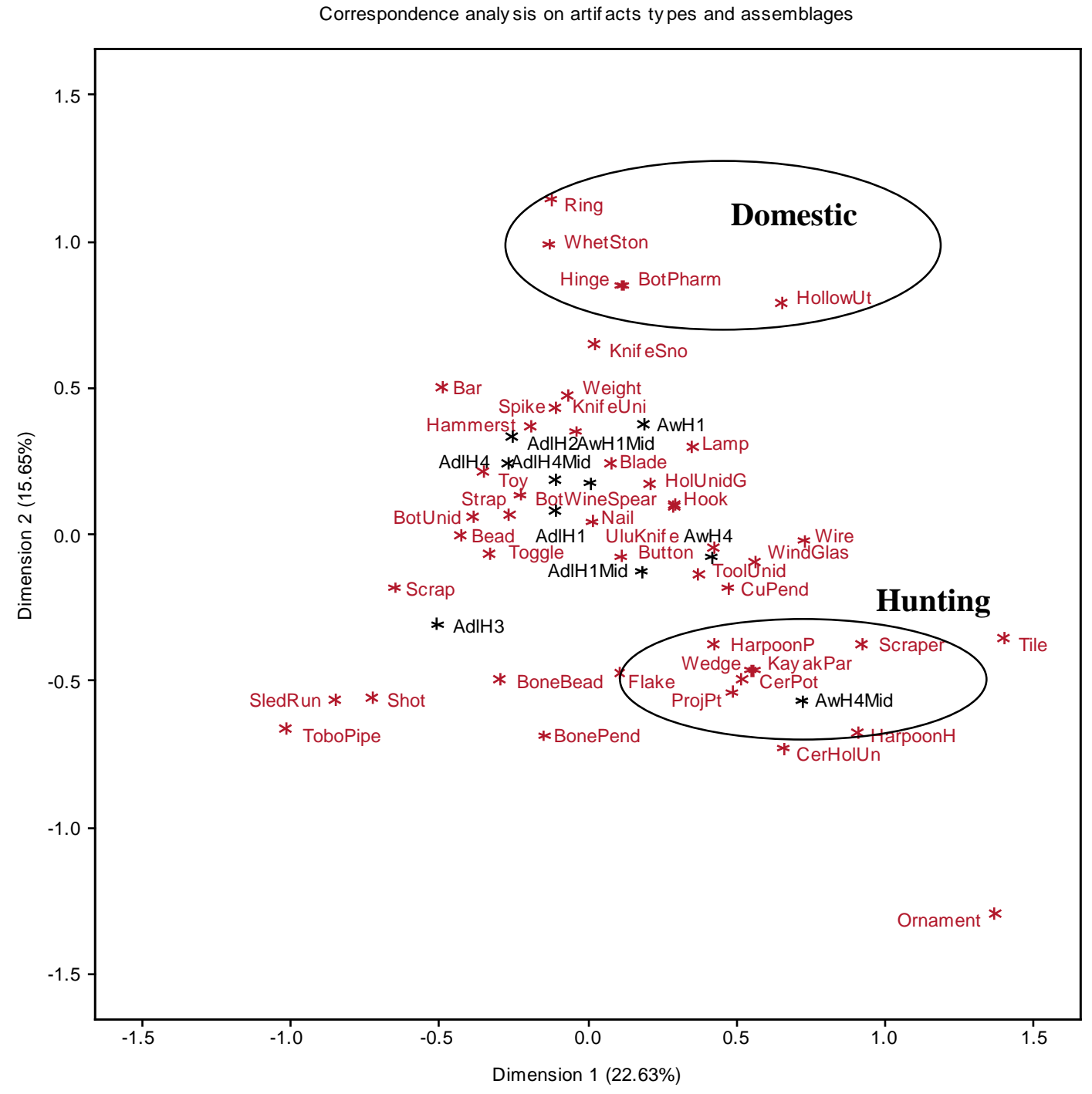

Figure 7.22: Plot of correspondence analysis of Anniowaktook and Adlavik with sheet metal and soapstone hollow vessels removed. The two circles highlight groupings of artifacts that align with my domestic and hunting categorizations. 
As before, a moderate correlation between the manufacturing and trade categories occur with $\tau=0.6$ at $\alpha=0.1(p=0.01)$; however, the manufacturing and hunting categories at Adlavik and Anniowaktook are more moderately correlated at $\alpha=$ $0.1, \tau=0.49(p=0.04)$. Additionally, the manufacturing category also moderately correlates with the domestic category at $\alpha=0.1, \tau=0.57(p=0.01)$. The significance of the concordant pairs between the manufacturing and hunting and domestic categories appears to be due to an overlap of materials, particularly faunal, used in tool construction for hunting and domestic items. Nevertheless, the strong correlation between the trading and manufacturing categories does not necessarily imply how Inuit were accumulating the strap metal and nails (i.e. via trade with Europeans or raiding abandoned European sites); instead, it simply shows that all of these materials were coming from Europe.

The correlation calculation of the hunting, domestic and trading categories indicates that the null hypothesis of zero correlation cannot be rejected. I expected a lack of correlation between domestic versus hunting and trading activities, as these activities were believed to be tied to gendered divisions of labor and spaces, particularly of women's association with food processing and clothing manufacture, and men's role as hunter and trader (Whitridge 1999). Instead, the domestic category is not a good predictor for the presence of items from the hunting or trading categories, as all households required and used domestic elements regardless of status. Ultimately, the data are inconclusive regarding whether there is any type of correlation between the hunting, trading, and domestic pairs. 
The most surprising result was the correlation scores between hunting and trading; the low positive association of 0.34 and that $p$ exceeds $\alpha=0.1(p=0.16)$, again indicates that the null hypothesis of zero correlation cannot be rejected. Given the ethnographic evidence that prominent hunters were also traders, I expected to see a moderate or strong correlation between the two categories. The results suggest that earlier models that assigned similar levels of social value to trading and hunting activities may not be accurate for all settlements. For instance, some households may have expended more resources on developing trade relationships or hunting, but not both simultaneously. To survive the harsh and unpredictable Arctic environment, every household needed to be associated with a hunter. If a hunter was not successful then trade may have served as an alternative approach by either accumulating food directly from the Europeans, or using European goods to trade for food with other Inuit.

However, rank correlations cannot model the entire complexity of this situation. To determine Inuit social differentiation, I explore the archaeological and faunal record as potential indicators for status in historic Inuit culture and to construct a testable archaeological model. The model that historic Inuit social organization was based on a hierarchy where Inuit settled around prominent Inuit who were hunters and traders is evaluated further in the following chapter. 


\begin{tabular}{|c|c|c|c|c|}
\hline \multicolumn{5}{|c|}{$\begin{array}{c}\text { Anniowaktook, Adlavik and Avertôk Deposits } \\
\text { Kendall Tau b Correlation Coefficients using the } \log (\text { counts) } \\
\text { Prob }>\mid \text { tau| under } \mathrm{H}_{0} \text { : Tau=0 } \\
\text { Number of Observations }\end{array}$} \\
\hline & Hunting & Trade & Manuf. & Domestic \\
\hline Hunting & $\begin{array}{l}1.00000 \\
20\end{array}$ & & & \\
\hline Trade & $\begin{array}{l}0.08047 \\
0.7799 \\
14\end{array}$ & $\begin{array}{l}1.00000 \\
14\end{array}$ & & \\
\hline Manuf. & $\begin{array}{l}0.29794 \\
0.1132 \\
16\end{array}$ & $\begin{array}{l}0.63636 \\
0.004 \\
12\end{array}$ & $\begin{array}{l}1.00000 \\
17\end{array}$ & \\
\hline Domestic & $\begin{array}{l}0.12809 \\
0.4580 \\
19\end{array}$ & $\begin{array}{l}0.14379 \\
0.4998 \\
13\end{array}$ & $\begin{array}{l}0.03718 \\
0.8364 \\
17\end{array}$ & $\begin{array}{l}1.00000 \\
20\end{array}$ \\
\hline
\end{tabular}

Table 7.7: Kendall Tau correlation using the transformed (log) counts of the domestic, hunting, manufacturing and trading categories from all deposits at Anniowaktook, Adlavik and Avertôk. Note that the Trade and Manufacturing categories strongly correlate at a significance of 0.1 .

\begin{tabular}{|c|c|c|c|c|}
\hline \multicolumn{5}{|c|}{$\begin{array}{c}\text { Anniowaktook and Adlavik Deposits } \\
\text { Kendall Tau b Correlation Coefficients using the } \log (\text { counts }), \mathrm{N}=11 \\
\text { Prob }>\mid \text { tau } \mid \text { under } \mathrm{H}_{0} \text { : Tau }=0\end{array}$} \\
\hline \multirow[b]{2}{*}{ Hunting } & Hunting & Trade & Manuf. & Domestic \\
\hline & 1.00000 & & & \\
\hline \multirow[t]{2}{*}{ Trade } & 0.33658 & 1.00000 & & \\
\hline & 0.1573 & & & \\
\hline \multirow[t]{2}{*}{ Manuf. } & 0.48617 & 0.60000 & 1.00000 & \\
\hline & 0.0411 & 0.0102 & & \\
\hline \multirow[t]{2}{*}{ Domestic } & 0.22858 & 0.31487 & 0.57417 & 1.00000 \\
\hline & 0.3429 & 0.1830 & 0.0152 & \\
\hline
\end{tabular}

Table 7.8: Kendall Tau correlation using the transformed (log) counts of the domestic, hunting, manufacturing and trading categories from all deposits at Anniowaktook and Adlavik, with the Avertôk deposits omitted. Note that the Trade and Manufacturing categories strongly correlate, while the Domestic and Manufacturing categories moderately correlate. 


\section{Chapter 8: Locating Evidence for Inuit Social Differentiation in the Material Remains}

This chapter focuses on studying patterns of archaeological material within and among Inuit households, and demonstrates that distinct distributions and associations of material culture can help identify households experiencing greater economic success.

The four categories identified in the previous chapter will be used to evaluate a series of hypotheses. I am interested in determining whether Labrador Inuit converting and moving to Moravian missions were motivated by an existing Inuit economic and social system that privileged Inuit who were successful hunters and traders. Analysis focuses on the type and distribution of archaeological material at Anniowaktook, Adlavik and Avertôk to test whether social stratification was apparent at earlier eighteenth-century Inuit sod house villages via indicators of higher status, such as highly valued resources including food and exotic goods and raw materials. While I determined in the previous chapter that the trade and hunting categories are not correlated, here I focus more specifically on individual assemblages to suggest that only those deposits related to prominent Inuit leaders who were traders or hunters or a combination of the two will exhibit uneven distribution or artifact and faunal material. Inequities in the distribution of goods may reflect status within settlements, suggesting that access of material goods reflect social differentiation.

To identify evidence for Inuit social differentiation in the archaeological record, I return to the two of the three areas identified in Chapter 2, hunting strategies and the acquisition of exotic raw materials and manufactured products. I focus the following discussion on testing four hypotheses. They are: (1) household assemblages will be 
differentiated by the degree of participation in hunting as reflected in relative abundance of prized faunal portions; (2) households with a prominent hunter will have a greater abundance of hunting tools; (3) household participation in a trading network will correlate with heightened consumption of European materials; and (4) households exhibiting an abundance of trade items will correlate with households that have the highest rates of hunting tools.

\section{Hunting Strategies}

Faunal remains were only collected from the Anniowaktook and Adlavik houses as Bird did not preserve a faunal sample from Avertôk. Nevertheless, the prevalence of whale bone and baleen tools in all Avertôk houses suggest that whale hunting was still practiced by the residents of Avertôk into the historic period either through coordinated hunting or scavenging (Bird 1945; J. G. Taylor 1974). Bird does not discuss the presence of faunal material or identify species of any bone in the houses or middens. Bird does note the presence of a "meat pit” near the entrance tunnel and a heavy density of mussel shells and bones (8 inches thick) covering the floor of Avertôk House 3. Earlier researchers (i.e., J.G. Taylor 1974) believed that a dense deposit of mussels found in a house was evidence for a starving or a less-productive household, as mussels were considered a low-status food eaten only in dire cases. However, recent research (i.e., Woollett 2003) has determined that mussels were consumed as a welcomed change to the Inuit diet. The presence of mussels simply suggests residents were diversifying their diet. 
More information regarding species identification and distribution among houses is available for the Anniowaktook and Adlavik houses. Faunal analysis for the Anniowaktook midden was conducted by zooarchaeology graduate students Céline Dupont-Hébert, Félix Gagné and Lindsay Swinarton at Université Laval in Quebec City, Canada, under the supervision of Dr. James Woollett, while the faunal analysis for the Adlavik House 1 midden was conducted by research collaborator Sarah Lansing of the Smithsonian Institution in Washington, DC. Each specimen was counted and identified according to taxon, species, and element when available, and the number of specimens identifiable to species (NISP) was calculated. Complete summaries of these data can be found in Appendix C. Tables 8.1, 8.2, and 8.3 summarize frequency of seal, caribou, whale and walrus according to individual context. Although a full species and faunal element analysis was not completed for both sites at time of publication, the following discussion presents preliminary results from those analyses.

Over 14,700 faunal specimens were recovered from both Anniowaktook Houses 1 and 4, and the Adlavik House 1 midden. 1342 specimens were recovered from a 1 x $1 \mathrm{~m}$ test unit located in the midden of Anniowaktook House 1; 642 specimens were recovered from a 1 x 1 m test unit located at the eastern most end of the entrance tunnel of House 4, and 2785 specimens were recovered inside House 4 from the post-abandonment midden and house floor; and 9951 specimens were recorded from six units in the midden of Adlavik House 1 (three 1 x $1 \mathrm{~m}$ units, one 1 x $0.67 \mathrm{~m}$ unit, one 1 x $0.4 \mathrm{~m}$ unit, and one 1 x 0.8 m unit). Only faunal elements have been identified for Adlavik House 1 midden at this time, and additional faunal element analysis for the material found within 
Anniowaktook House 4 is currently underway. Thus the following summary will provide only a preliminary analysis of the zooarchaeological data.

\begin{tabular}{|l|cc|cc|}
\hline & \multicolumn{3}{|l|}{ House 1 TP } & \multicolumn{2}{|l|}{ House 4 TP } \\
\hline Taxniowaktook & NISP & Percent & NISP & Percent \\
\hline Indeterminate & 647 & 51.27 & 451 & 62.12 \\
Seal Species & 5 & 0.40 & 9 & 1.24 \\
Small Seal & 459 & 36.37 & 256 & 35.26 \\
Large Seal & 92 & 7.29 & 4 & 0.55 \\
Cetacean Species & 6 & 0.48 & 2 & 0.28 \\
Small terrestrial mammal & & & 1 & 0.14 \\
Medium Terrestrial Mammal & 15 & 1.19 & & \\
Caribou & 3 & 0.24 & & \\
\hline TOTAL & 1227 & 97.24 & 723 & 99.59 \\
\hline
\end{tabular}

Table 8.1: Table of NISP of the seal, caribou and whale faunal material identified in the test units at Anniowaktook House 1 and House 4. Additional data of other species identified can be found in Appendix C.

\begin{tabular}{|lrr|}
\hline Anniowaktook & & \\
House 4 & NISP & Percent \\
\hline Taxon & 14 & 0.5 \\
\hline Caribou & 1 & $<0.1$ \\
Terrestrial mammal & 2 & $<0.1$ \\
Seal unknown & 777 & 27.9 \\
Small Seal & 4 & $<0.1$ \\
Large Seal & 13 & 0.5 \\
Ringed/Harbour seal & 2 & $<0.1$ \\
Harp/Hooded seal & 60 & 2.2 \\
Ringed seal & 7 & 0.3 \\
Harbour seal & 8 & 0.3 \\
Harp seal & 3 & 0.1 \\
Whale & 891 & 32.2 \\
\hline TOTAL
\end{tabular}

Table 8.2: Table of NISP of the seal, caribou and whale faunal material identified at Anniowaktook House 4. Additional data of other species identified can be found in Appendix C. 


\begin{tabular}{|lcc|}
\hline $\begin{array}{l}\text { Adlavik House 1 } \\
\text { Midden }\end{array}$ & & \\
\hline Taxon & NISP & Percent \\
\hline Unidentified & 2717 & 27.30 \\
Bovid & 1 & 0.01 \\
Caribou & 136 & 1.37 \\
Seal unknown & 6394 & 64.25 \\
Harp Seal & 4 & 0.04 \\
Ringed Seal & 19 & 0.19 \\
Walrus & 4 & 0.04 \\
Whale & 24 & 0.24 \\
\hline TOTAL & 9299 & 93.44 \\
\hline
\end{tabular}

Table 8.3: NISP of seal, caribou, walrus, and whale faunal material from Adlavik House 1 midden. Additional data of other species identified can be found in Appendix C.

Three main problems arose further restricting the analysis of these collections. First, a relatively high degree of fragmentation and mediocre preservation led to limited identification of a majority of the material. Complete bones were infrequently found as the units were placed in the midden or near the entrance tunnel, an area where all traffic entering and leaving the house must pass. Initial fragmentation was the result of trampling by people leaving or entering the house. Fragmentation was further exasperated by damp or wet soils from melting snow and permafrost leaving bones spongy and extremely brittle. Due to these taphonomic factors, a total of 1107 (23.2\%) specimens from Anniowaktook contexts and 2717 (27.3\%) specimen from the Adlavik midden could not be identified.

Second, the majority of the faunal material from Anniowaktook House 4 came from the post-abandonment midden located above the occupation level, yet the stratigraphic distinctions were not made upon the initial faunal overview. Not making 
this stratigraphic distinction omits the subtle differences between earlier and later Inuit hunting strategies. Even so, the data available can provide initial clues to strategies employed by those living at Anniowaktook.

The final problem central to zooarchaeological research particular to the Eastern Arctic is the difficulty in identifying seal to the species level. Seal bones themselves are relatively distinct, yet researchers generally report difficulty in reliably attributing species identification based on the post-cranial skeletons (McCullough 1989; Woollett 2003). Unfortunately, the three species most difficult to differentiate are those most commonly found and hunted in Labrador, including the ringed seal (Pusa hispida), harp seal (Pagophilus groenlandicus), and the harbour seal (Phoca vitulina) (Wilson and Reeder 2005). The analysis conducted for this research did attempt to distinguish seals to the species level yet the majority of specimen was only identified as seal. Identifying various species can provide more information regarding the season or duration of Inuit occupation based on seasonal seal migration patterns. For instances, harbour seals were primarily hunted in the fall and spring as they were commonly associated with open water to feed and pup along the shores (Boles et al. 1980; Woollett 2007:28). The absence of these species from household assemblages indicates that the houses were not occupied in the fall or were abandoned prior to the spring migration. In the following discussion, I only identify species when known; otherwise I refer to the genus (Phocidea). 


\section{Hypothesis 1: Abundance of prized faunal material}

The faunal materials found in all test units represent the variety of species common in Labrador, including ringed, harbour and harp seal, caribou, bear, fox, dog, Arctic hares, rabbits and mice. Labrador Inuit subsistence strategies focused primarily on caribou, whales, and seals, but they hunted all available animals, particularly during the late winter season when productivity was at its lowest. To test whether household assemblages are differentiated by the degree of participation in hunting as reflected in relative abundance of prized faunal portions, I focus the subsequent analysis only on the presence of caribou, whales, and seals. Previous ethnographers identified that Inuit organized hunting groups around the seasonal migration of these animals.

\section{$\underline{\text { Caribou }}$}

Herds of hundreds of caribou (Rangifer tarandus) inhabit the boreal forest and migrate southwest to areas further inland during the late summer (J. G. Taylor 1974:28). Early Moravian diaries document the significance of the autumn caribou hunt in Inuit culture, particularly for skins for winter clothing and the consumption of meat (J. G. Taylor 1974:28). Entire Inuit families or large groups of men would travel as a group to intercept the migration, often staying in tents out on the land from August until midOctober.

The caribou hunt held a significant social function, whereby many Inuit groups came together for a collaborative hunt which served to renew relationships and create a sense of social cohesion. Descriptions from Moravian missionary William Turner's 1780 
journal of a caribou hunt with the Nain Inuit illustrated the highly cooperative hunting method where men and women assembled to surround the caribou herd and drive them into a lake where Inuit in kayaks speared the animals (J. G. Taylor 1969). Turner suggested that tasks were separated by gender where men located and speared the caribou, and women and children were responsible for driving the caribou into the lake.

After such a successful hunt, the meat and skins were shared among all members of the group regardless of gender or one’s role in the hunt (J. G. Taylor 1969:151). However, Turner does not indicate whether there was a hierarchical structure where meat was distributed relative to status (J. G. Taylor 1969:159). Unfortunately, Turner’s description focused more on the journey and did not delve into greater detail regarding the social organization of hunting groups.

While such accounts are invaluable, other ethnographic and historic data offers little evidence for the manner in which caribou was distributed within the Labrador Inuit community. Employing analogy with similar cultural practices within other Inuit groups may provide clues.

Research on the Central Canadian Arctic Copper Inuit sharing system suggests that arrangements once believed to have been reserved for seal also extended to caribou (Damas 1984; Jenness 1922; Rasmussen 1929). Specific social protocols dictating the proper distribution of food among and within households were probably kinship-based but also could extend to entire communities (Collings et al. 1998:301). After a hunt, meat distribution focused primarily on kin but was also given to non-kin with the obligation for reciprocity (Jenness 1922:87). 
Often, communal hunts were associated with feasts. Large communal meals were initiated by the head of a well-provisioned household. If most of the meat was not consumed during the feast, it remained in the possession of the individual hunter (Damas 1972:226).

Since sod houses were likely occupied in the early winter after the main caribou hunt, I do not expect a great amount of caribou or in the near interior year round. Nevertheless, Inuit could have encountered smaller herds or individual caribou that traveled along the coast. If eighteenth-century Labrador Inuit were practicing similar sharing strategies with caribou meat as Central Canadian Arctic Inuit, then the hunter's household who hosted communal meals would exhibit higher frequencies of caribou bones relative to other houses.

As expected, caribou was found in small numbers in all three deposits with NISP $=136(1.37 \%)$ from the Adlavik House 1 midden, NISP = 14 (0.5 \%) from Anniowaktook House 4, and only NISP = 3 (0.24\%) from the Anniowaktook House 1 midden. The extremely small amount of caribou material found in the Anniowaktook House 1 midden and in House 4 suggests that residents were not actively seeking caribou while living in these sod houses. Although faunal element data was not available for both deposits, the low frequency at Anniowaktook suggests that the meat probably came from caches. Thus, hunters in these households did not experience a high rate of encounter or success during their occupation.

Distribution of elements, including long bones, sacrum, vertebrae, and ribs, identified at the Adlavik House 1 midden does support the transport of meat-rich 
elements to the site, consistent with inland hunting (Binford 1978). The majority of meat and hide processing likely occurred at the kill site due to the size of the animal. Only the meat, skins and tendons, and a few bones for tools, weapons and jewelry would be returned to the sod house settlement (Woollett 2003). While the frequency of the caribou was still low, residents of this household benefitted from a larger stored surplus or a winter caribou kill, both suggestive of a successful hunter. Although not much higher than the Anniowaktook deposits, the slightly greater frequency at Adlavik may indicate a household that had a more successful hunter or hunters, since all houses were multifamily.

The limited amount of data can neither confirm nor deny whether a sharing system similar to that of the Copper Inuit occurred among the Labrador Inuit or whether a prominent caribou hunter occupied any of these houses. Further, the lack of evidence suggests that caribou was not actively exploited while the sod houses were occupied. Other winter settlements at Eskimo Island and Uivak Point had similar amounts of caribou suggesting that the lack of the faunal material was more an indication of the winter occupation (Woollett 2003:2010). A better test of social differentiation requires analysis of the faunal data for species more likely to have been hunted during the fall and winter months such as whales and seals.

\section{Whales}

Whale hunting was an important traditional practice that was a significant source of protein and provided other useful material, including bones, skin and blubber for oil 
for lamps. Whale hunts required a cooperative effort where men from a number of households or neighboring communities worked together to kill the large, powerful mammal. The early Moravian diaries suggest that the absolute minimum required for successful whaling was a single umiak or boat crew which consisted of twelve people; however, the presence of multiple crews increased the chances for success (J. G. Taylor 1974:44).

Following a successful hunt, ethnographic evidence suggests that entire communities shared the captured whale, but the distribution of the meat followed a specific structure based on an individual's role in the hunt (Graburn 1969:68; Savelle 1997; J. G. Taylor 1974:44). Understanding this sharing structure as it applies to the whale bones found in the houses may elucidate the degree to which Anniowaktook and Adlavik households participated in the whale hunt and subsequent sharing practices. Nelson Graburn’s (1969) ethnographic work with the Sugluk Inuit in Central Canada identified that parts of whales were distributed among the entire community according to one's role in the hunt and one's association with the successful hunter (Figure 8.1). For instance, the hunter who killed the animal would receive the best parts of the whale including the maktak or blubber and skin of the rear section. The remainder of the meat would be distributed among all members of the community, including dogs as described in Figure 8.1 (Graburn 1969:69).

Similarly, archaeologist James Savelle (1997) noted an analogous distribution pattern of whale parts among historic whale crews in the North Slope of Alaska. The whale boat crew and the captain received the highly valued thoracic, lumbar and tail 
sections, while lesser value portions were distributed to other members who played a minor role in the hunt (Savelle 1997:873).

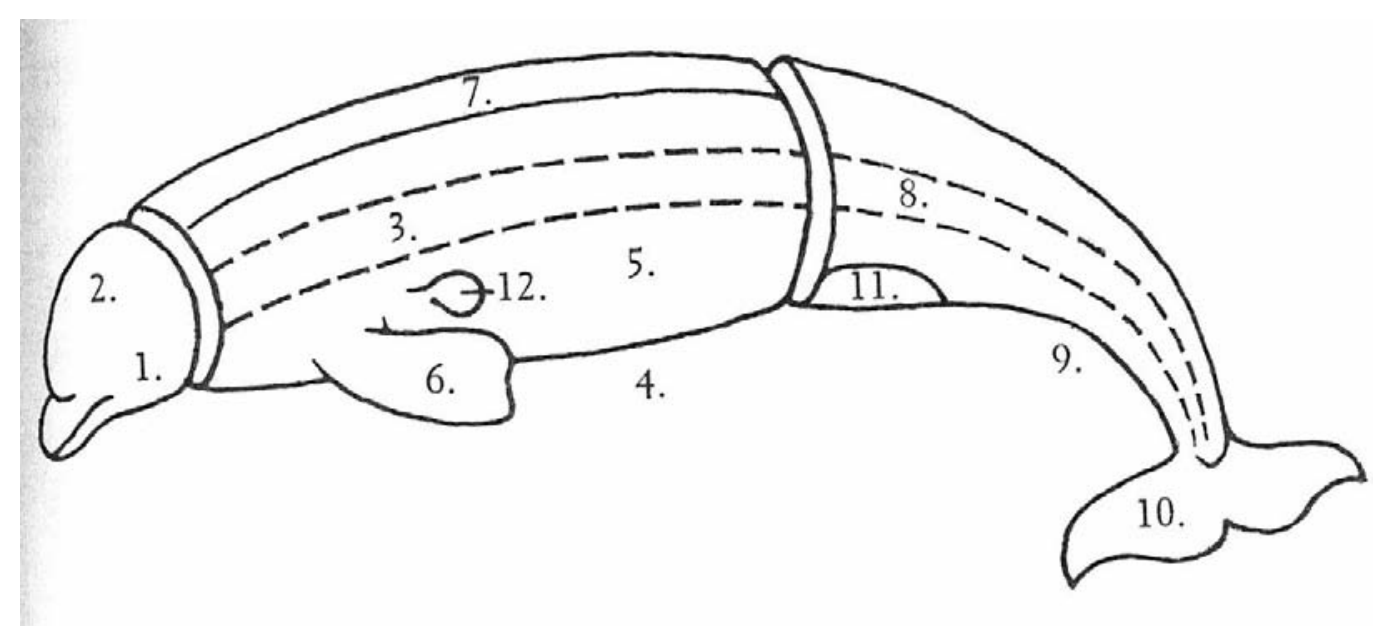

Figure 8.1: Image of a white whale identifying the parts for distribution (Graburn 1969:69). 1. Eyes given to dogs; 2. Head given to men; 3. Thoracic vertebrae and ribs given to everyone in the settlement; 4. Maktak and blubber on lower 2/3 of thoracic section given to women; 5 . Viscera given to the dogs of the hunter who killed the animal; 6. Forelimbs given to everyone at the settlement; 7. Maktak and blubber of upper 1/3 of the thoracic section given to the hunter's household; 8. Lumbar, sacral and caudal vertebrae given to women; 9. Maktak and blubber of rear section given to the hunter who killed the animal; 10. Flukes given to everyone; 11 . Cloaca given to the dogs; 12 . Heart given to men.

Ideally, identifying the uneven distribution of tail or lumbar elements in Labrador Inuit house deposits would serve as evidence for the presence of a hunter; however, two problems arise when analyzing such data. First, hunters also received skins and blubber which do not preserve well and would be harder to identify in the archaeological record. Second, because of the size of the animal most of the butchering of the whale probably 
occurred at the kill site and only meat and blubber was returned to the settlement. Ethnoarchaeological investigations of modern Inuit beluga and narwhal hunting in the Central Canadian Arctic determined that almost no bones were removed from the kill site, unless those bones could not be easily removed from the highly valued maktak, such as the forelimbs (Savelle and Friesen 1996:717). Results also suggested that beluga and narwhals approached the threshold wherein bone transport was not cost effective given the size of the bone, except when architectural utility was relevant, particularly in the case of bowhead whales (McCartney 1980; Savelle and Friesen 1996).

Using certain whale bones as evidence for the presence of social roles is further complicated as these bones may have been easily collected from beached whales or stranded carcasses. Whale bone was often recycled for building or manufacturing materials. Weathered bones still appeared to have been preferable as building material (Savelle 1997; Woollett 2003:590), even though whale bones were not used to the same degree in historic Labrador Inuit house construction as they were in Thule house construction.

Instead, Woollett (2003) found that the presence of phalanges from the flipper, a valued food portion which does not have value as a building material, could represent unequal food distribution at an eighteenth-century northern Labrador Inuit site. Identifying specific bone elements in the households such as tails, forelimbs or phalanges which do not serve an architectural purpose may reveal patterns of distribution according to status. If similar actions were being followed by eighteenth-century Labrador Inuit, then archaeological evidence for a prominent hunter would appear in a higher frequency 
of the tail or lumbar portion found in the household deposits. On the other hand, a lower frequency of bones found with ample evidence of wear serve as evidence for domestic use and may have been collected by scavenging.

Complete whale bone elements were found in all three deposits analyzed. Tools made from whale bone tools were also found at all of the Avertôk, Aldavik and Anniowaktook houses suggesting continued use of the material into the historic period. However, sample sizes at the Adlavik and Anniowaktook houses were small. Anniowaktook House 1 midden had six individual specimens and House 4 only had five individual specimens, which included two scapulae, an unfused vertebral epiphysis, and a larger cut whale bone (approximately 20 x $35 \mathrm{~cm}$ ) found at the floor level in Anniowaktook House 4. The Adlavik House 1 midden had a slightly larger sample with 24 whale bone fragments and four specimens identified as walrus, another large yet highly valued animal for its meat and skins. Of the 24 fragments, only two whale vertebrae were identified, 14 unidentified elements showed cut marks, and the remaining ten were unidentified elements.

Historical evidence attests to a decrease in whale hunting by Inuit during the historic period, likely occurring before the arrival of the missionaries, and a consequence of the over-whaling by Basque during the fifteen and sixteenth centuries in the Strait of Belle Isle. Moravian documents indicated that whaling success varied greatly among places with the most successful located further north (J. G. Taylor 1974:32-33). In fact, the missionaries at Okkak encouraged Inuit to go out whenever whales were available. They were particularly aware that unsuccessful whaling led to severe food shortages, 
frequently forcing mission Inuit to move north to stay with more fortunate, non-converted whalers (J. G. Taylor 1975).

The area surrounding Avertôk and Anniowaktook was considered an excellent location for whale hunting, but the limited amount of archaeological evidence found in the house deposits suggests that residents were not actively hunting the whale to the same degree as earlier hunters. The significance of whaling appears to have diminished by the end of the eighteenth century.

Historical data in the Moravian diaries corroborates whale hunting was less actively pursued by Inuit after Moravian arrival. The Moravian diaries note that at least ten whales were spotted around Hopedale, while only seven were killed or found dead between 1773 and 1789 and four killed near Avertôk from 1774 to 1779 (Table 8.4). In comparison, Inuit living at sites located north of Okkak killed 30 whales during that same period (J. G. Taylor 1974:Table 11). Whales were often spotted near Avertôk, but were not always pursued. Based on the archival records, the number of whales captured near Avertôk dropped precipitously after 1780, and this decrease appears to coincide with increased trading activities further south (J. G. Taylor 1974:34). Whale bone was a valuable commodity on the trade market, and some southern traders appear to have purchased whale bones and baleen from groups north of Nain or harvested it from dead whales that washed up on shore, rather than expend the energy and labor to hunt and process whales (Kennedy 2009:29). 


\begin{tabular}{|cccc|}
\hline Year & $\begin{array}{c}\text { Whales } \\
\text { Spotted }\end{array}$ & $\begin{array}{c}\text { Whales } \\
\text { Killed }\end{array}$ & $\begin{array}{c}\text { Whales } \\
\text { Found Dead }\end{array}$ \\
\hline 1773 & & & 1 \\
1774 & & 1 & \\
1778 & & 1 & \\
1779 & & 2 & \\
1780 & 1 & & \\
1784 & 2 & & \\
1785 & 6 & & \\
1786 & & & 3 \\
1788 & "several" & & 5 \\
1789 & & & \\
\hline TOTAL & $10+$ & 4 & \\
\hline
\end{tabular}

Table 8.4: Table of whales spotted, killed or found by Inuit in the Avertôk/Hopedale area as recorded by the Moravian diaries from J. G. Taylor 1974:Table 8.

The deposits suggest that a limited amount of whale hunting or scavenging occurred at Anniowaktook and Adlavik, yet insignificant evidence points to uneven distribution between houses to suggest social differentiation. If specific meat sharing practices were observed after a successful hunt, then households with prominent hunters should become apparent by their uneven distribution of elements. However, this is not the case. First, the presence of the vertebrae and the lack of tails and forelimbs suggest that these household did not play a lead role in the hunt, thus receiving a non-specialized portion of the animal which was distributed to everyone in the community (Graburn 1969). Second, the whale bone fragments from the Anniowaktook House 4 occupation level and the Adlavik House 1 midden exhibited a significant amount of use-wear including burning and cut marks on the surfaces. This evidence suggests these bones were used for domestic purposes, such as serving as a flat place to sit, a lamp stand, or flooring. Two of the three elements from Anniowaktook House 4 were found in the same 
unit as the hearth, and may have been used as flat surfaces for cooking or chopping. It seems more likely that these bones were collected from a beached whale.

With the data available, the house deposits do not offer definitive evidence for the presence of a social differentiation based on the distribution of whale parts. Historic Inuit still hunted whales, if only on a limited basis, in addition to collecting and using whale bones for material. The whale hunt was no longer prevalent within Labrador Inuit society.

$\underline{\text { Seal }}$

Seal became the primary resource hunted by Historic Inuit (Woollett 2003). The meat and blubber were highly valued, and the skin provided Inuit with waterproof material for clothing and kayaks covers, yet hunting seals did not necessarily require a similar level of cooperation, resource expenditure, or labor as hunting whales; seals could be hunted independently. Nevertheless, some seal hunting did include a level of cooperation and coordination to ensure the greatest success for a settlement.

Based on his research of the Moravian diaries, J. G. Taylor (1974) determined that Labrador Inuit often cooperatively hunted seals from kayaks during the open water season, or captured seals at breathing holes through the ice in winter, or from the shore fast ice at the sina. Although one hunter watched over a single breathing hole - a small hole in the surface of the ice where seals came up for air - several men partook in this kind of hunting because seals used multiple holes. More men could cover the multiple 
holes resulting in the likelihood that someone would get a seal. In all cases, the hunters presumably combined and shared their catches (J. G. Taylor 1974:44).

Cooperative hunts often led to communal sharing or redistribution of the meat. Very limited ethnographic and historic data identifies a sharing system specifically associated with seal hunting. Samuel Hutton, a Moravian doctor that documented his life among the Labrador Inuit during the early 1900s, described two instances when meat was shared after a successful hunt. In both cases, the hunter kept the skin and blubber for himself, saved a small portion of meat and the liver for his family, and shared the remainder of the seal including the blood with the rest of the community (Hutton 1912:224, 251). Hutton's description of the meat distribution did not identify specific elements beyond the skin, blubber and liver, none of which preserve in the archaeological record.

Another valuable portion of the seal was the flipper. Evidence I collected during my residency among Hopedale suggests that the flipper may have been a prized element. Modern day Inuit still consider the seal flipper a valued portion of meat. During my tenure in Hopedale, I was invited for dinner and offered a portion of the flipper meat, which I shared with the hunter and his wife. If similar patterns appeared in historic Inuit households, then phalanges from a flipper would be found in greater quantities in the home of successful hunters.

Seal was the most common species found in all the deposits. The Adlavik House 1 midden had the largest number of seal bones (NISP $=6417$ ), constituting $64.5 \%$ of the entire faunal assemblage. Seal also made up almost half of the faunal assemblage of the 
Anniowaktook House 1 midden at 44.05\% (NISP = 556), and 32.5\% of the Anniowaktook House 4 assemblage (NISP = 269). The significantly larger sample of seal relative to caribou or whale in the three deposits indicates that residents were, indeed, focused on seal hunting.

Seals identified to species include ringed, harp, and harbor seals, found in most house deposits. Of all of these, ringed seal is the most common species in the Arctic region and is considered a stable and staple resource for Inuit communities since they are present year round along the Labrador coast (Woollett 2003). Thus, it is no surprise that ringed seals (Phoca hispida) are the most common species identified in both of the Anniowaktook deposits (House 1 midden NISP = 12; House 4 NISP $=66$ ) and the Adlavik House 1 midden (NSIP = 19).

The other types of seals listed above are not found to the same degree, and their presence can likely be attributed to seasonal migration patterns. For instance, harp seal (Phoca groenlandica) were commonly found at other historic Labrador Inuit sod house settlements, usually comprising of $30 \%$ to $60 \%$ of the entire assemblage (Woollett 2010a:254). They were the second most abundant seal species identified at Anniowaktook, but only accounted for $1 \%$ of the assemblage. Only limited quantities of harp seal were found in the Anniowaktook House 1 midden (NISP = 2) and House 4 (NISP $=8$ ), while the majority was found in the House 1 midden (NISP $=27$ ). The small samples of harp seal found in the Anniowaktook houses may be result of a shorter occupation at the Anniowaktook sod houses that did not extend into the fall southern migration or the spring migration north (Woollett 2010a:255). 
Even when species could not be identified, ascertaining anatomical elements of seals can help determine whether certain parts were distributed unevenly among the households. The prominence of ribs and phalanges from the test units in the Anniowaktook House 1 midden (24 ribs and 60 phalanges) and in the entrance tunnel of Anniowaktook House 4 (20 ribs and 41 phalanges) strongly indicate that whole or nearly whole seals were transported from the kill site to the settlement (Dupont-Hébert and Gagné 2008). All anatomical elements of the seal were also represented in the Adlavik House 1 midden including a higher frequency of rib bones $(\mathrm{n}=969)$ and phalanges $(\mathrm{n}=$ 730). The high frequency of ribs and phalanges seen in all deposits does not represent a special preference for axial skeleton, rather ribs and phalanges are the most common elements in a whole seal skeleton (Dupont-Hébert and Gagné 2008). The relative evenness of skeletal elements at the three deposits is that whole seals are easier to transport back to the settlement than whales.

Although NISP is sensitive to effects of fragmentation, the relative even distribution of skeletal elements indicates that a large number of whole seal skeletons were in the middens. Insufficient data limits calculating minimum number of individuals (MNI); however, I chose to estimate the number of seals in the deposit by calculating rib and phalanges frequency as a very rough estimate of the number of seals in the deposits. Not identifying whether the ribs or phalanges came from the right or left side of the individual may severely under represent the number of actual species included in the deposit. 
Since blubber, skin and the liver do not preserve well or at all, household deposits with greater frequencies of phalanges may be the mark of a successful hunter. Estimating that a seal (Phocidea) has 28 rib bones and 56 phalanges (14 phalanges per flipper), the data suggest that both Anniowaktook houses only had enough elements to be equivalent to at least a single seal in multiple deposits in both houses. On the other hand, the quantity of bones at Adlavik indicates that there could be enough phalanges for at least 13 seals in the midden. There are twice as many rib bones as phalanges in the midden deposit, suggesting there may have up to 34 seals; however, ribs are much more subject to fragmentation as a result of trampling than the more compact phalanges, even though phalanges are more easily separated from the body. The inflated number of ribs may be reflecting fragmentation differences rather than whole seal quantities.

Despite the wide range of the possible number of seals in the midden, the quantity still suggests that the inhabitants of Adlavik House 1 experienced considerable hunting success. The quantity of phalanges may indicate the presence of a hunter who often received prized portions of meat; however, there were fewer phalanges than expected given the high quantity of rib bones. The variation in faunal elements suggests that meat distribution did occur at this house, as various parts of the seal were identified. The lack of comparable faunal materials from other Adlavik houses makes it impossible to determine whether occupants of House 1 enjoyed the benefits of living with a successful hunter, or if all household faunal assemblages resembled similar distribution patterns suggesting even distribution, rather than a specific social structure tied to cuts of meat. 


\section{Discussion of Faunal Material}

This analysis provides a preliminary overview of the faunal evidence collected from only three houses at the Adlavik and Anniowaktook sites, only one of which had element data available by time of publication. The data reveal some interesting patterns regarding resource choice associated with caribou, whales and seal. In particular, the relative abundance of seal and limited quantity of caribou and whale suggests Inuit were focusing energy expenditure on seal hunting, as it was the most abundant resource available. This faunal distribution aligns with patterns seen at other historic Labrador Inuit sod house settlements (i.e., Woollett 2003).

The Adlavik House 1 faunal assemblage suggests a prominent hunter and possible leader in comparison to the Anniowaktook houses. The high frequency and distribution of certain seal elements found at Adlavik House 1 suggests residents occupied the house longer and engaged in sharing, which suggests the presence of some level of social differentiation within the household. Additional faunal data from the remaining three Adlavik houses would clarify whether the Adlavik House 1 assemblage was unique. The lower frequencies of faunal remains found at Anniowaktook suggests that either households were not as successful or did not participate in sharing to a great degree. Collecting additional data from the two unexcavated Anniowaktook houses would clarify whether houses were occupied independently or whether sharing occurred between at least two of the four houses. 


\section{Artifactual Evidence for Social Differentiation}

Material evidence for Inuit social order may appear in the variability among eighteenth-century household artifacts found at the sites. Artifact distributions within and between sites can be interpreted in terms of inter-household social and economic status that characterizes a community during peak periods of site occupation. Studying the distribution of artifacts associated with hunting or trading activities may reveal that certain households had greater access to some goods.

The variation in hunting tools or trade items among sites can signal a household's ability to access, use and replace these items. This is best reflected in use and discard rates. For instance, a household that attained more tools would theoretically discard more tools if family size and duration of occupation were similar. Comparing discard rates at all houses and middens will show whether hunting tool and trade item frequencies vary across the sites.

Quantifying this variation requires calculating an index that uses a single artifact class as the denominator value (Galle 2004:45, 2006:173; Neiman et al. 2001). Choosing a single artifact class as the denominator limits each measure to only two artifact classes. Soapstone vessels were chosen as the denominator artifact because soapstone was a fundamental material of the Inuit domestic space used for the construction of pots, lamps, whet stones, and cooking slabs, and was found archaeologically throughout the prehistoric and historic era. In addition, soapstone sources are located near Hopedale and Adlavik, indicating the material was readily accessible to everyone. While the variety 
and density of hunting and trading artifacts may differ between households, consumption of soapstone should be equivalent.

The Artifact Index calculated for each category is the total number of items (i.e., trading, hunting) for each house divided by the hunting item total plus the total number of soapstone hollow vessel fragments for each house (Galle 2004:46).

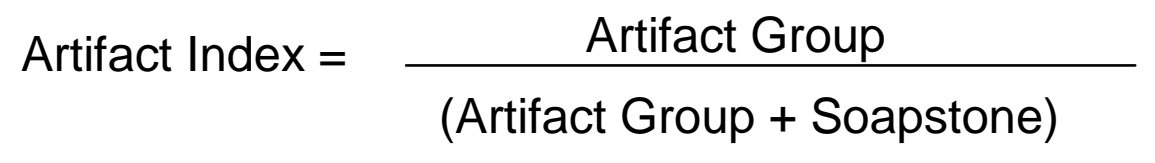

For this study, the Artifact Group is the sum of hunting tools, trade items, or manufacturing items according to the appropriate hypothesis. In each section, the index will be referenced according to the category used, such as the Trade Index, Hunting Index, or Manufacturing Index.

\section{Hypothesis 2: Abundance of hunting tools}

Comparing the discard rates of hunting tools will measure differential participation in hunting. When available, these abundance indices will also be compared to the available faunal assemblages to identify possible correlations between high rates of tool discard and faunal material. The total number of hunting items (artifact group) discarded at each deposit was entered into the above equation and the results are plotted in Figure 8.2. The abundance indices are plotted with $90 \%$ confidence intervals due to generally small sample sizes with each deposit. Adlavik House 4, Anniowaktook House 3, and Avertôk House 7 exhibited extremely wide confidence intervals implying poor precision. As a result, these were removed from this analysis. 
Calculating the Hunting Index for the remaining Anniowaktook, Adlavik and Avertôk deposits helps gauge the use frequency and discard rates of hunting tools and how those differ between sites. As described in Chapter 7, the Hunting category includes tools directly and indirectly associated with hunting such as harpoon parts, kayak parts, men’s knives, sled runners and fishing weights.

The results indicate a high rate of tool use and discard for the Adlavik House 1 midden. The higher index value suggests residents of Adlavik House 1 were discarding into the associated midden and replacing tools at a higher rate than any other house examined in this study. The higher rate of discard of hunting tools aligns with the high rate of discard of seal bone from the same midden deposit as discussed in the previous section. Even if the accumulation of the assemblages occurred over an extended period of time, the corresponding rates of discard of tools and faunal material at Adlavik House 1 and its associated midden suggests that residents were enjoying some level of hunting success.

In contrast, residents of Anniowaktook House 1 discarded three times fewer hunting tools. The midden associated with Anniowaktook House 1 had a slightly higher index value, yet discarded two times fewer hunting tools than Adlavik House 1 midden. These lower rates of hunting tool discard in both House 1 and the associated midden, as well as the low frequency of faunal material identified in the previous section suggests that residents at Anniowaktook House 1 did not achieve a similar level of hunting prosperity. One reason for this difference may be that the Anniowaktook House 1 was occupied for a shorter period of time, resulting in less accumulation and discard of both 
tools and faunal material. This lower rate of discard is also seen at Anniowaktook House 4 and may be linked to shorter occupation periods.

Among the Avertôk deposits, House 3 and the midden exhibit relatively high discard rates. Closer inspection of the tool types comprising the House 3 and midden assemblages reveals different hunting strategies. Avertôk House 3 deposit had higher rates of tool discard particularly associated with winter sea mammal hunting, such as harpoon parts $(n=6)$ and snow knives used to make igloos $(n=4)$. The Avertôk midden exhibited a wider variety of seasonal tools used to hunt a variety of animals, including hooks for fishing ( $n=2)$, a bow part for land mammals $(n=1)$, toggles $(n=3)$, and kayak parts for marine mammal hunting $(n=2)$. However, without additional evidence such as faunal material, we will never know whether residents of these houses were successful in hunting and whether they shared meat from a kill. Nevertheless, the index values indicate that residents associated with these houses used and discarded hunting tools at a greater rate than all other Avertôk houses. 


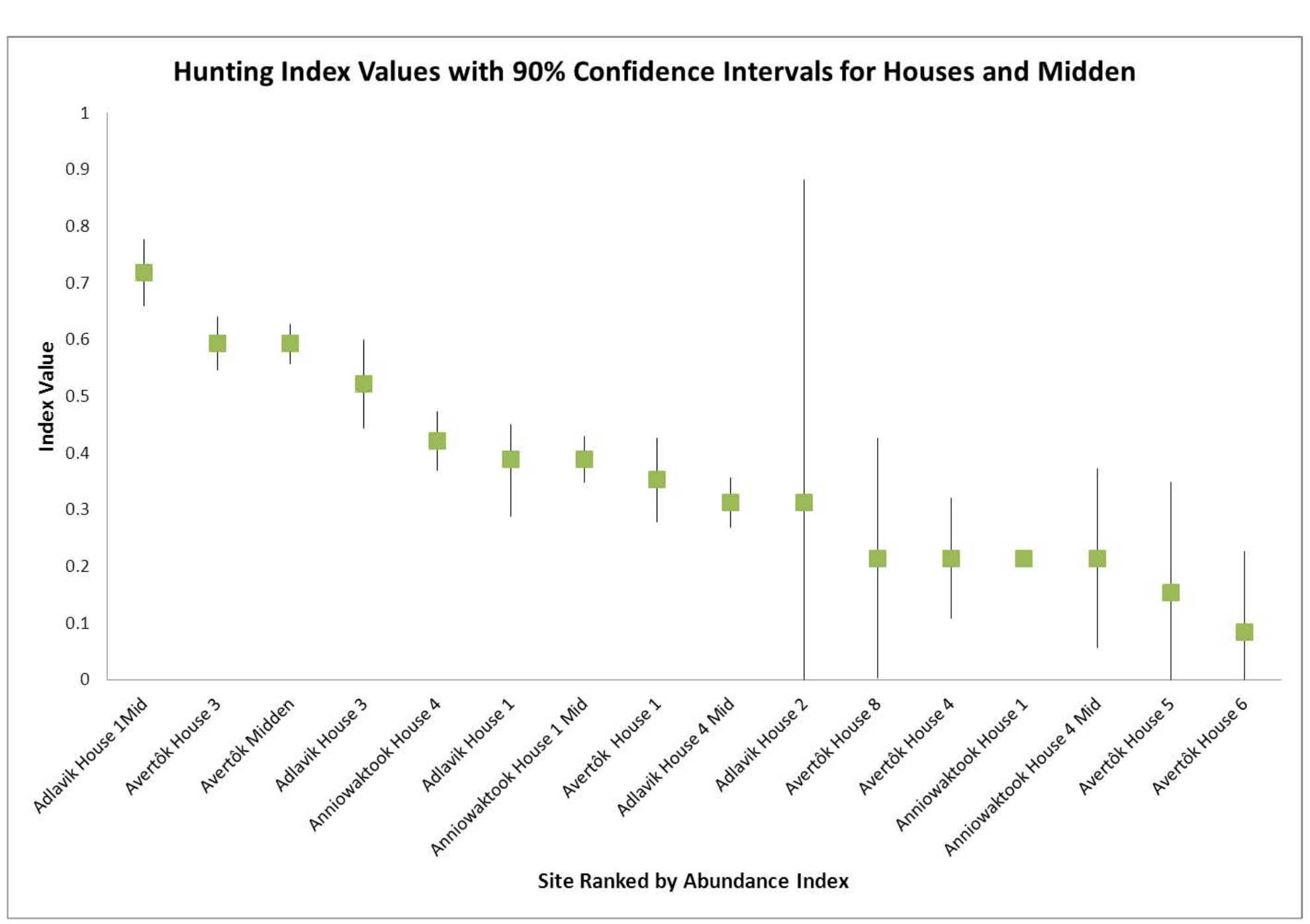

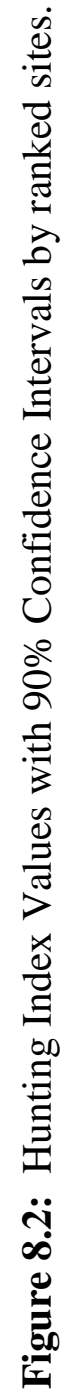


While the raw counts of artifacts from all Avertôk houses must always be framed in terms of Bird's selective collection methods, his interest in early Inuit culture likely led to a relatively even collection of hunting tools. Thus, the smaller number of blades, projectile points, and harpoon parts from the other Avertôk houses suggest that residents participated nominally in hunting activities. Missing data, such as faunal material, would clarify whether the lower rates of discard of hunting tools from Avertôk Houses 1, 4, 5, 6 and 8 was the result of a limited supply of materials, shorter occupations, or the result of looting by earlier researchers.

Historical and Moravian records document Avertôk as a prominent hunting ground where successful Inuit hunters lived. The variable rates of discard of hunting tools at Avertôk suggest otherwise, and that each house participated in hunting activities at different levels. One cause for the differences in household assemblages is seasonal differences in occupation. The array of hunting tools found within the midden indicates that residents were hunting a variety of mammals, fish and birds that migrated at different times of the year, while the hunting assemblage at House 3 included only tools used predominantly to hunt sea mammals. A focused subsistence strategy usually aligns with a winter occupation when only a few resources were available.

Changes to Inuit hunting strategies may have been the result of Inuit adjusting their hunting patterns to meet the rising demand of the newly arriving Europeans. Earlier researchers (Elton 1942; Kleivan 1966) speculated that Inuit shifted some of their energy expenditure by the end of the eighteenth century towards accumulating European products and goods from an ever-increasing European trade market. By focusing on 
hunting animals that were valued in the trade market, such as fish or foxes for their furs, Inuit could accumulate these commodities to achieve better leverage when trading with the Europeans. While Inuit continued to hunt seals and caribou to meet basic subsistence needs, some Inuit began incorporating the collection of fur-bearing animals as part of their subsistence strategies.

One outcome of a shift in subsistence practices that would appear in the archaeological record was the introduction of the fox stone trap (Figure 8.3). Inuit constructed long stone tunnels approximately two to three feet high and four to five feet long with a trap door at one end that would fall and capture the animal (Hawkes 1916:86). Foxes were primarily hunted for their fur which was used to make clothing and traded for European goods (Elton 1942; J. G. Taylor 1974; Woollett 2003). Trapping, rather than hunting with spears, bows or guns, ensured that the pelt would remain pristine. A shift towards hunting foxes may have resulted in a decrease of specific hunting tools over time.

The Anniowaktook House 4 faunal assemblage had a slightly higher amount of foxes than the Adlavik House 1 midden or Anniowaktook House 1 midden as seen in Appendix C; however, the lack of stratigraphic distinction makes it difficult to determine whether the frequency of foxes is associated with the later post-abandonment midden or the earlier occupation. Given the insufficient faunal data, another measure to test whether Inuit shifted resources towards trapping fur-bearing animals would be to track the discard rates of hunting tools over time. One possibility would be if Inuit are 
focusing most of their resources on trapping, which required fewer tools, then hunting tools may decrease over time as the fur trade increased.

When the Hunting Index values from Adlavik and Anniowaktook with 90\% confidence intervals are plotted against the estimated mean dates, no association between time and discard rates appears and that there was no temporal pattern (Figure 8.4). A linear regression confirms the lack of correlation between hunting discard rates and time $(r=0.02)$. The residuals are also plotted in Figure 8.5 to identify outliers influencing the regression, and the pattern again reveals that the majority of the points are situated around the x-axis. The data, instead, indicates that hunting a wide variety of animals remained a vital part of survival in the extreme environmental conditions Labrador presents, and Inuit were not shifting all of their resources to account for a growing trade market. There is, however, an increase in variation among sites that date after 1750 . The five earlier sites are very similar, while the later sites reveal greater variation in tool types, suggesting that hunting strategies may have become more variable among households after 1750 .

Nevertheless, the data indicates that subsistence hunting remained a prominent part of Inuit life, yet it does not reveal the degree to which Inuit were increasing their efforts in trapping foxes, an activity that could be incorporated while Inuit hunted other animals. One area where this difference would be apparent is in the faunal remains; however, fox remains recovered from Anniowaktook House $4(\mathrm{NISP}=90 ; \mathrm{MNI}=5)$ and Adlavik House 1 (NISP = 98), only represented 1\% of the total assemblage, suggesting that foxes did not play a significant role in Inuit subsistence or economic strategies. 


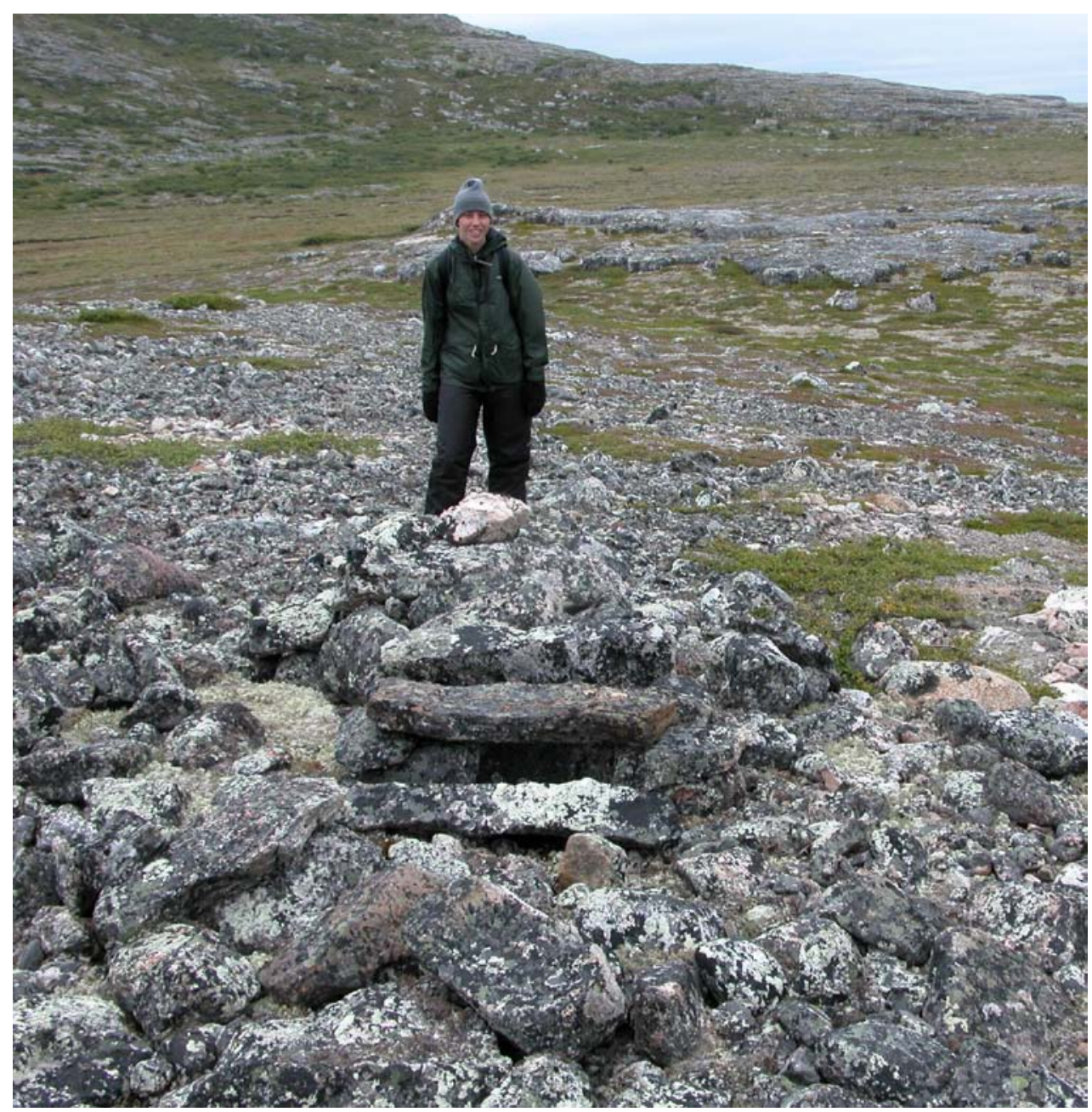

Figure 8.3: Author standing directly behind a stone fox trap near Adalvik (Courtesy S. Loring, photographer, 2005). 


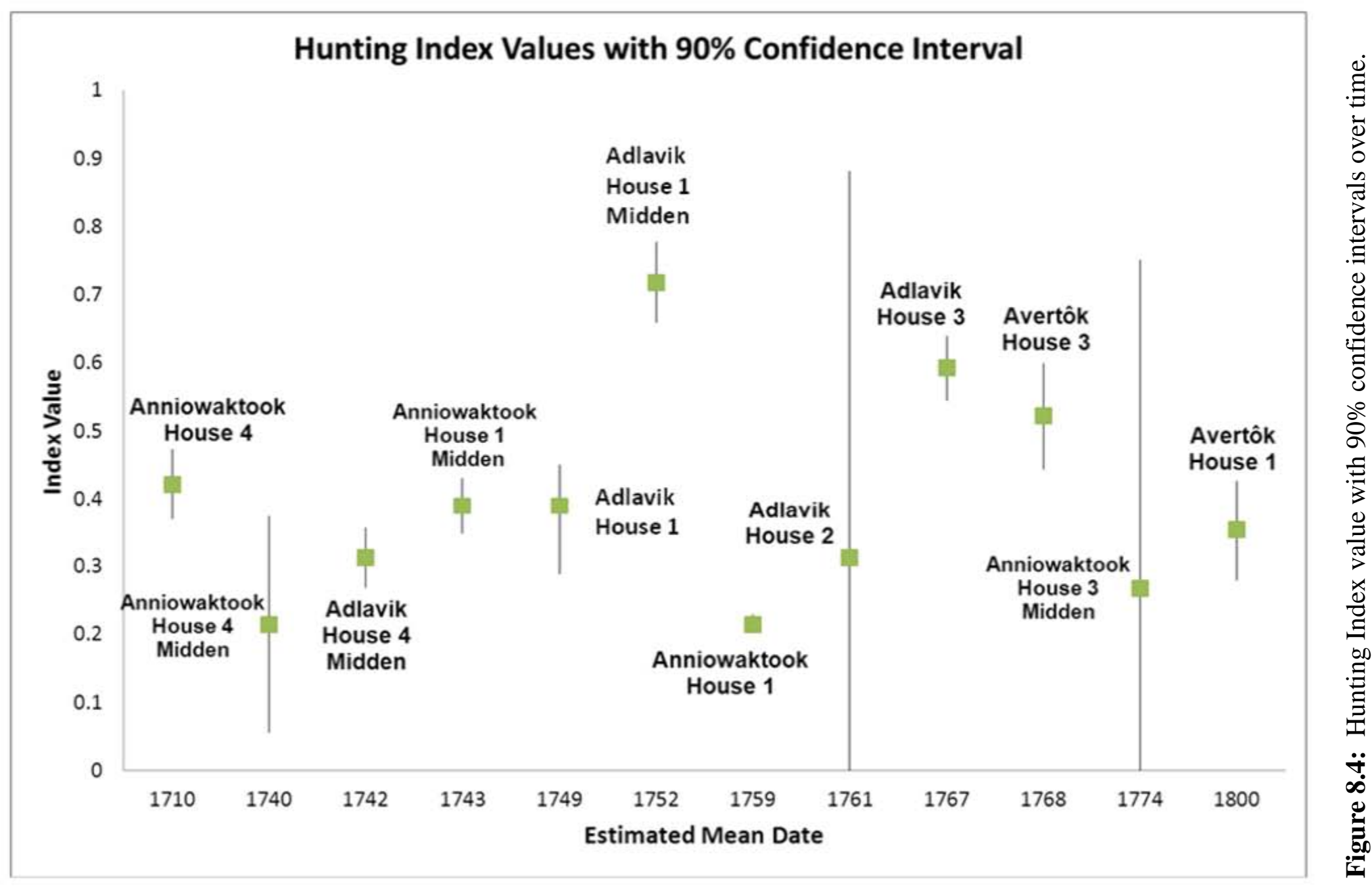




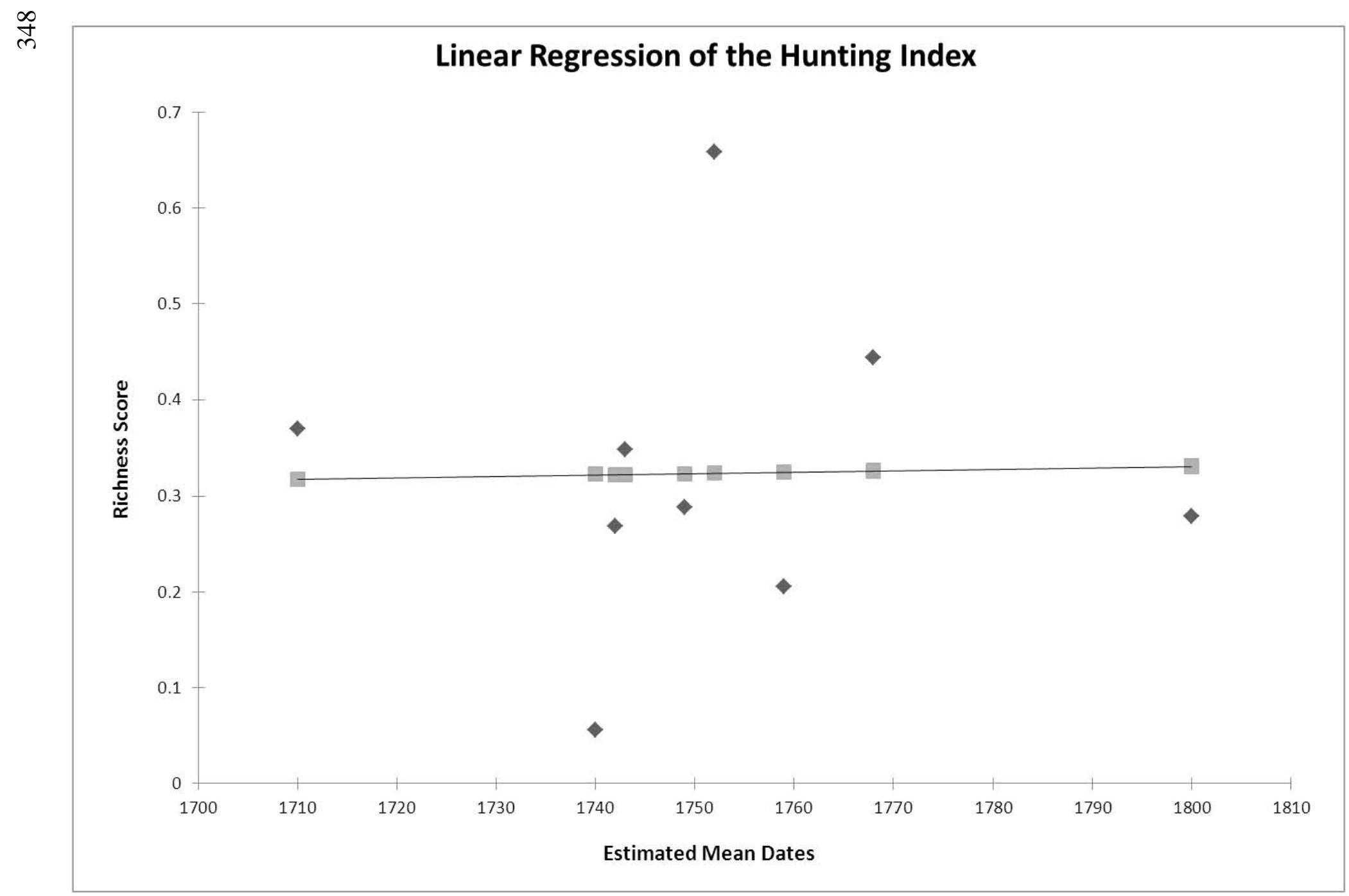

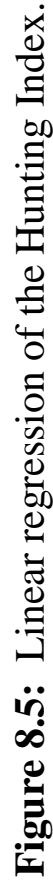


Hypothesis 3: Heightened consumption of European materials and forms.

The distribution of trade items at Adlavik and Anniowaktook demonstrates that the accumulation of European objects was not restricted to a single household; however, differences in raw counts and the variety of European forms and materials suggest that Inuit households had unequal access to European goods. As discussed in Chapter 3, a variety of European and American groups arrived on the coast of Labrador during the seventeenth and eighteenth centuries to access a wide range of resources including whale, fish, and exotic trade goods. The development of many trading relationships between the Native population and the Europeans drew a number of Inuit south to exploit opportunities to access and accumulate various European goods (Kaplan 1983:331). Some researchers argue that the introduction of new trading opportunities and a growing Inuit population in the south led to the development of a competitive market among Inuit, and access and accumulation of European goods became tied to prestige (Kennedy 2009:29; Richling 1998).

Identifying social differentiation based on the accumulation of exotic goods at Adlavik and Anniowaktook demands understanding the spatial distribution of trade items among and between houses, as well as reliable estimates of consumption and discard. Only Adlavik and Anniowaktook were included in the following analysis as the sample size of all trade items collected by Bird at Avertôk totaled three, not enough to provide an accurate picture of consumption practices. Figure 8.6 shows the Artifact Index for trade items, or Trade Index, with 90\% confidence intervals for Anniowaktook and Adlavik. 
Anniowaktook House 4 is not included, however, as it had a wide confidence interval implying statistical imprecision.

Figure 8.6 reveals that the all Adlavik deposits have higher rates of discard of trade items than the Anniowaktook deposits. There is also variation within settlements. The higher rates of discard of trade items seen at Adlavik House 1 suggest residents had more of these objects. If prominent Inuit leaders were both hunter and trader, then it would be expected that houses with high discard rates of hunting tools would also have high discard rates of trade items.

Adlavik was located further south along the Labrador coast, closer to Hamilton Inlet where a majority of trading in Labrador occurred. As described in Chapter 2, the attraction of Hamilton Inlet for Inuit and Europeans alike was its location in a diverse ecosystem, making it an excellent location for hunting seal and fish, as well as a great opportunity to engage in trade. The material found at Eskimo Island in Hamilton Inlet highlights the amount of European objects and raw material being made available to Inuit. The draw may have originally been for subsistence reasons, but the arrival of the Europeans also made Hamilton Inlet a trade destination. 


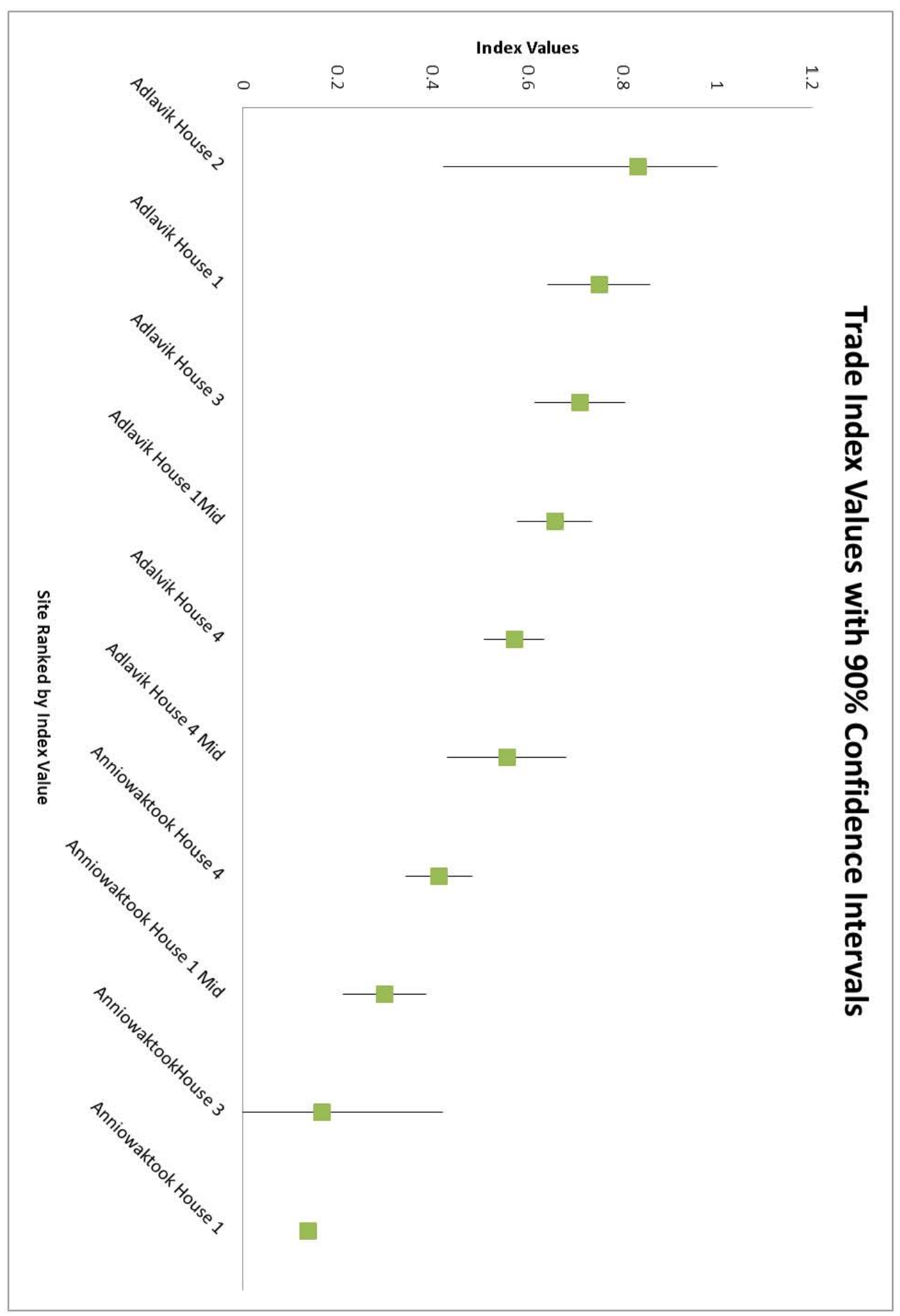

Figure 8.6: Trade Index scores for midden deposits at Anniowaktook and Adlavik plotted over time. 
Adlavik was located approximately 100 km closer to Hamilton Inlet than Avertôk and Anniowaktook. This additional distance required 17 extra days of traveling for the Avertôk and Anniowaktook residents, dependent upon weather (Rollmann 2010:27). In addition to less travel time to the Narrows, Adlavik may have also benefitted because few European traders ventured north to trade with the Inuit. It is not surprising that Adlavik House 1 discarded almost four times more trade items than Anniowaktook House 1 and almost twice as much as Anniowaktook House 4. Although proximity to southern traders may have played a part in limiting the amount of material available to Inuit located further north, it cannot account for all of the variation as northern Inuit did travel south seasonally to partake in trading or raiding expeditions.

Another factor that might explain the different rates of discard may have been a change over time; more Europeans including the Moravian missionaries arrived along the Labrador coast during the late eighteenth century making European goods more widely available. When Trade Index scores are plotted against the EMDs of each deposit, two different trends emerge: Adlavik Trade Index score generally increases over time, while Anniowaktook Trade Index scores decrease over time (Figure 8.7).

The rise of the Trade Index values over time at Adlavik is not surprising given that more Europeans established trading posts in southern Labrador, which simultaneously provided more opportunities for Inuit to accumulate goods, either through trading or raiding abandoned Europeans settlements, as discussed in Chapter 2. However, the decrease in the rate of discard of trade items at Anniowaktook was less expected given its proximity to Avertôk, which Moravian missionary Jens Haven 
identified as the Inuit equivalent to living in London or Paris (Kennedy 2009:29). The abundance index indicates that residents at Anniowaktook were not discarding trade items at a higher rate than soapstone vessels; instead Anniowaktook deposits had more items associated with domestic activities such as cooking and heating (i.e., pots and lamps). The subsequent decrease of trade goods at Anniowaktook suggests Inuit living there were less involved with the trade, choosing to engage with other pursuits, perhaps associated with domestic activities.

A second way that Inuit collected European objects was raiding or the removal of objects after a European site was seasonally abandoned. The most likely cause for the difference of discard rates for manufacturing items among houses was the addition of raiding as a means for Inuit to collect European materials. As discussed in Chapter 3, the archival accounts of European merchant and Moravian missionaries from the eighteenth century note the increasing hostilities between Inuit and Europeans, as Inuit continuously plundered European sites for goods and materials (Rankin 2011; Stopp 2002). Given the location of Adlavik tucked away in a protected harbor, it seems unlikely that Europeans would have happened upon the settlement for trade; instead, trading or raiding caravans likely sought out European sites to gain access to goods. 


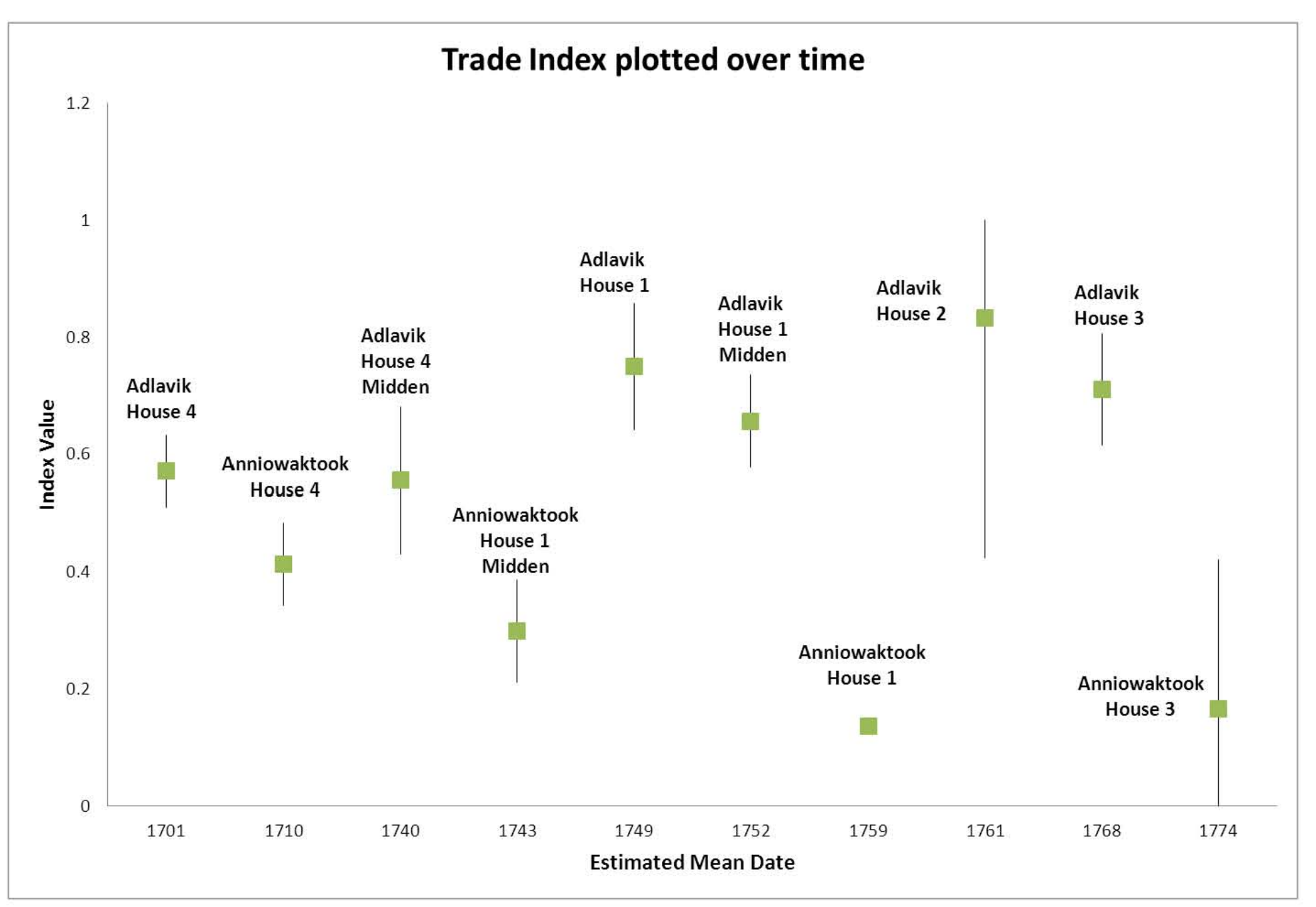

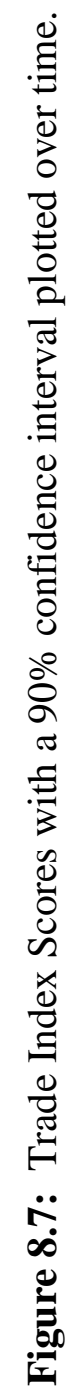


One possible method for identifying whether individuals were raiding is by calculating the amount of manufacturing material (Stephen Loring, personal communication 2010). As discussed in Chapter 2, Europeans often left behind extra strap metal, nails from boxes, and scrap metal that was not needed for the return voyage. Probate lists from 1738 to 1757 from the Hudson Bay Company for trade among the Baffin Island Inuit showed the majority of the items imported for trade were beads, hammers, tobacco, spoons, swords, knives and fish hooks, with only a small unspecified amount of hoop iron included (Barr 1994:240). The inclusion of strap metal, sheet metal, and nails in European inventory lists for the purpose of trade does not appear until later in the eighteenth century when the Moravians requested more of those objects for their Trade Store, possibly as a response to increasing Inuit demand. Prior to the arrival of the Moravians, Inuit may have been accumulating these materials and forms during informal foraging strategies that coincided with other hunting activities. The Manufacturing Index values suggest that the vast amounts of manufacturing items found in the Adlavik and Anniowaktook deposits were collected via means other than trading.

Abundance index scores for manufacturing items minus nails were calculated, since nails disproportionately influenced the overall manufacturing scores at all sites. When the abundance index scores for manufacturing items minus nails are plotted over time, a positive correlation emerges (Figure 8.8). The two outliers, Avertôk House 1 and Anniowaktook House 1, may be a result of certain collection methods and household preferences. For instance, the low score for the Avertôk House 1 index score was the result of selective collection on the part of Bird and his decision to overlook or discard 
most metal, glass and ceramics. The low Anniowaktook House 1 value may be a result of cleaning where damaged or unecessary artifacts were discarded into the midden. The Anniowaktook House 1 midden did exhibit a higher rate in line with the discard rates at Adlavik. The lower abundance index for nails in Anniowaktook House 1 may be directly related to the higher rate seen in the associated midden; House 1 residents discarded unnecessary nails in the midden.

Despite these two outliers, the overall pattern of the Manufacturing Index indicates that Inuit were discarding more manufacturing items over time than soapstone vessels. This implies that trade with Europeans and the raiding or collecting items from abandoned European sites both increased over time. 
Manufacturing Index Values with Nails removed

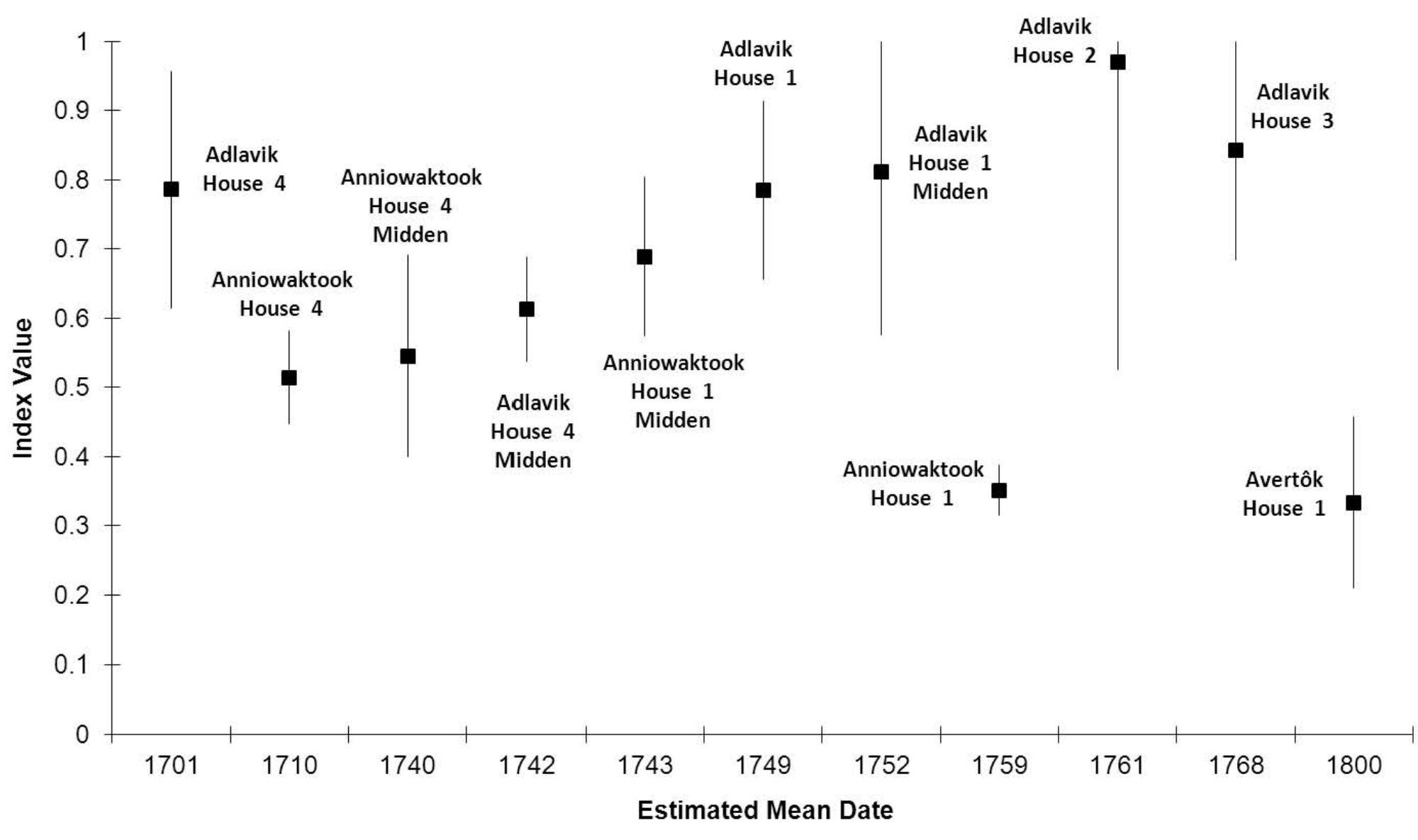


Hypothesis 4: Correlation between Trade and Hunting Index values as indicator for a leader.

Ethnohistorical evidence suggests prominent Inuit men rose to positions of leadership due to their ability to organize hunting and trading groups. Hunting and trading captains would experience greater accessibility to desired trade goods, and, as a result, accumulate more of those items. The previous chapter indicated that there was no correlation between the trade and hunting items across all sites. More focused analysis of each house deposits may reveal that certain deposits had stronger correlation between hunting and trading items than others. It stands to reason that only households with leaders who were hunters and traders would exhibit a correlation, while other households where less prominent individuals resided would have lower correlation between the two categories. To determine how discard rates differ according to each sample, the Trade and the Hunting Indices from each deposit were compared. Figure 8.9 is a scatter-plot of the Trade Index values plotted against Hunting Index values. 


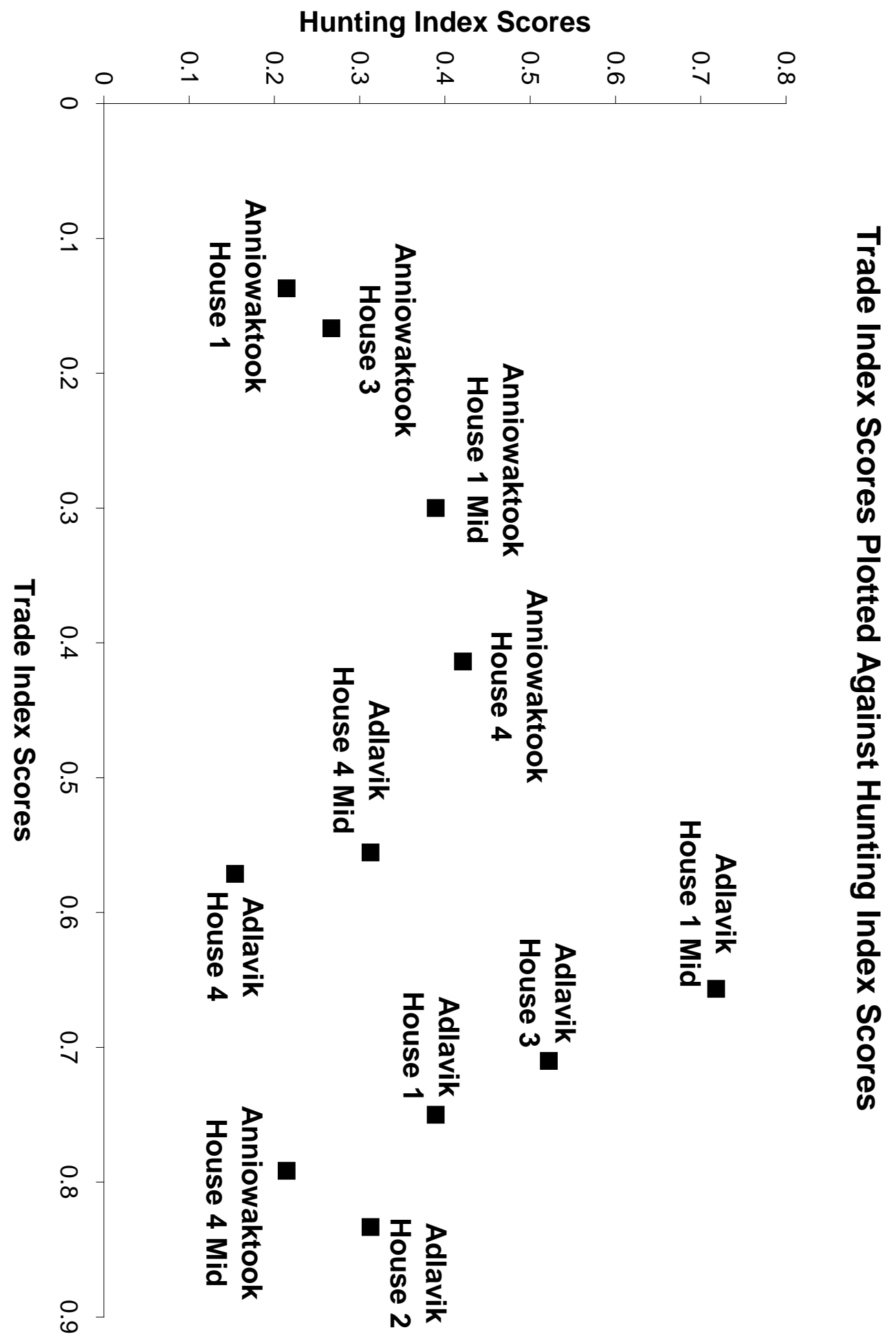

Figure 8.9: Trade Index Values plotted against Hunting Index Values. 
In general, Adlavik deposits exhibited higher rates of discard of trade items than Anniowaktook deposits. As expected, the Adlavik House 1 midden and Adlavik House 1 deposits had the highest rates of discard of hunting tools, while Adlavik House 1 also had the second highest rate of discard of trade items among Adlavik deposits. Thus, Adlavik House 1 residents discarded more of those goods because they possessed more trade items and hunting tools, a sign of a prominent hunter and trader. Additionally, Adlavik residents likely had greater access to engage in trade with Europeans or access European sites for collecting items post-abandonment or raid since Adlavik was located $100 \mathrm{~km}$ further south than Anniowaktook. Conversely, the low rates of discard of hunting and trade items at Anniowaktook may be related to lower encounter rates of both Europeans and certain animals associated with a shorter occupation.

With the exception of Anniowaktook House 4 midden, the low Trade Index scores seen among the Anniowaktook deposits signal that availability of European material was limited. In this case, it may be directly tied to proximity to the Europeans, who remained in southern Labrador until the latter half of the eighteenth century when traders moved north to expand their market, and the Moravians established their missions at Nain, Okkak and Hopedale. Raiding or collecting methods likely served as an alternative approach to trading for European materials. A general increase of manufacturing items over time at Anniowaktook suggests most residents chose to collect European materials from abandoned European sites rather than engage in trade. The trading, hunting and manufacturing abundance indices suggest that residents at 
Anniowaktook were not as adapt in accumulating certain types of resources as Adlavik Inuit, perhaps due to access.

The increase in the accumulation of European items reveals that foreign materials were modified and adopted to meet specific Inuit needs as described in Chapter 7, but does not appear to serve as the lone signifiers for status across all sites. Nevertheless, Adlavik House 1 and the associated midden offer the best evidence for a household with a successful hunter and trader. Although exhibiting a low Hunting Index score, the Anniowaktook House 4 midden has the second highest Trade Index score. Given that the midden was deposited after Anniowaktook House 4 was abandoned and had a later EMD, the deposit may represent an alternative model where an Anniowaktook household exploited the increase European presence along the coast and had greater access to trade items. Differences seen in the Anniowaktook households seem to be more closely related to temporal changes rather than large scale social organization.

Yet the data presented above does not neatly align with the available ethnographic data. For instance, ethnographic data collected by J. Garth Taylor suggests that social organization remained at the household level, with authority falling to the male of the household (J. G. Taylor 1974:80-81). Closely related nuclear families shared winter quarters and multi-household settlements were tied by similar kinship bonds, yet no single figure of authority led an entire community. Taylor suggests that leadership and authority involving larger group activities was weakly developed among the Labrador Inuit and did not extend beyond the household level (J. G. Taylor 1974:84). Yet the Moravian diaries reference a number of men that the Inuit called “captain” who had 
considerable influence as determined by access to boats, kinship network, and personal and physical qualities such as “dexterity, and success in hunting, courage, bodily strength and hardiness” (PA 1794:254; J. G. Taylor 1974:81).

Inuit social differentiation appears to incorporate a more informal approach that was not universal, rather fluctuated between settlements according to resource availability. For instance, meat was more evenly shared throughout the entire community during times of scarcity; otherwise each person was expected to attend to themselves (J.G. Taylor 1974:84). Adlavik represents a site where both European and animal resources were abundant. The greater overall accumulation of those goods in House 1 and its associated midden seems to be associated with a prominent hunter and trader. On the other hand, Anniokwaktook characterizes a site where similar resources were less available, resulting in a more equal distribution of resources and materials. Differences seen in the abundance indices described above may represent availability of resources for the entire community and not just the status of individuals within the village.

\section{Chapter Summary}

The data presented in this chapter are intended to identify archaeological patterns that served to locate hierarchical social organization among Labrador Inuit settlements; however, the limited data available did not provide substantial evidence to support the existence of social differentiation. Instead, four conclusions regarding historic Inuit social differentiation as suggested by consumption practices can be made. 
First, the frequency of hunting tools in households may be determined by the hunter's ability as well as the availability of resources. Despite the known collection discrepancies with the Avertôk assemblages, the rates of discard of hunting tools between houses indicated different subsistence patterns, which may be correlated to season of occupation, and what animals were available. The Avertôk midden had the latest documented occupation but it showed the greatest variety in hunting tools, suggestive of an extended occupation. Unfortunately, the lack of European artifacts makes additional correlations between the status of traders and hunters impossible to determine for the Avertôk deposits.

Second, differences in the abundance of trade, hunting and manufacturing items and faunal material between household deposits did appear between Adlavik and Anniowaktook. Adlavik residents discarded more tools and trade items than the Anniowaktook residents. Located further south than Anniowaktook, Adlavik had more potential access to Europeans and their goods

Third, Inuit were accumulating European items via means other than trade such as raiding or collecting. Given the low frequency of trade items at Anniowaktook, but the high discard rates of manufacturing items, it appears that the inhabitants ofAnniowaktook raided or collected from European sites as a matter of material accumulation. Although the discard rate of trade items is very low at Anniowaktook and decreases over time, the abundance index of the manufacturing category, or items that may indicate raiding or collecting, rose over that same period. On the other hand, residents at Adlavik were 
employing a number of avenues to accumulate European materials, a likely result of their more southerly location.

Finally, the difference between Adlavik and Anniowaktook highlighted by the abundance indices strongly suggests that Adlavik Inuit were more successful in hunting and accumulating European materials. Comparison of discard rates among Adlavik household deposits reveals that variations in the discard of trade and hunting items did emerge within the site. The greater rate of discard of hunting tools, trade items, and seal fauna at Adlavik House 1 and its associated midden suggest that House 1 residents benefitted from greater success in collecting these resources. Yet the degree to which that access extended to multiple households is unknown and requires additional data from the remaining household deposits at Adlavik. The abundance indices suggest some deposits had more trade goods, such as Adlavik House 2 and the Anniowaktook House 4 midden, while other deposits had more hunting tools, including Adlavik Houses 1 and 3. This balance between abundance indices of hunting and trade items suggests that the accumulation and consumption of goods was not reserved for a single household. 


\section{Chapter 9: The Process of Culture Change and Missionization}

This study highlights the challenge of developing a model of culture change, or system of models, to investigate the development of a Christian mission among the Inuit in the remote subarctic. I began this investigation by studying the recent history of two separate cultures moving along very different trajectories. First, there were the Inuit, a group of subsistence based hunters who observed a spiritual association to their natural surroundings upon which they survived. The other group was the German Moravian missionaries, who were founded on a tradition of persecution. The missionaries developed a pious and economic society rooted in a sense of Christian duty and work ethic. The eventual encounter of the Inuit and Moravians in Labrador, Canada in the eighteenth century was based on the missionaries' wish to bring salvation to what they believed were an otherwise forgotten people. What emerges from this interaction is a story of Inuit agency that both accepted and rejected the new materials and ideas based on an Inuit cultural framework. The Inuit did not necessarily resist the Moravian’s propositions, but rather accepted ideas based on shifting individual and communal needs.

This research originated with an examination of early Inuit culture history to understand whether existing social institutions motivated Inuit to choose to convert to Christianity for economic and social reasons. This study differed from previous research on Labrador Inuit and the Moravians by adopting a diachronic approach that considered the influence of pre-contact Thule customs on the interpretation of the material outcome of the interaction between Moravians and Inuit. Rather than just asking how Inuit or 
Moravian culture changed (or remained the same), I sought to locate reasons for why Inuit and Moravians adapted to the new circumstances.

Earlier research suggested that Inuit culture had undergone fundamental changes that coincided with the rise of a European presence along the coast. Archaeological remains indicate Inuit increased their consumption of European materials, and moved south to be closer to the only consistent source of European goods. Our understanding of the development of an elaborate coastal trade system where Inuit accumulated European goods in the south to trade with other Inuit located further north rests primarily on Jordan’s work at Eskimo Island (Jordan n.d.). However, Jordan’s work lacked contextual and stratigraphic distinctions, and offered a limited description of the site and the reasons for his methodologies. Later research conducted by Susan Kaplan (1983; 1985a) sought to refine Jordan's conclusions by exploring eighteenth century sites along the entire Labrador coast to understand Inuit settlement patterns as they related to an expansive eighteenth-century European trade.

I hoped to add to Kaplan’s ground-breaking research by providing a micro-scale investigation of three eighteenth century Inuit sites to offer specific data that could be used to identify patterns of historic Inuit culture and social organization. Based on these earlier works, I expected that archaeological evidence for a hierarchical Inuit social system would appear in the uneven distribution of European goods and faunal material within settlements. I further expected economic motivation led Inuit to engage with the Moravian missionaries and eventually, convert to Christianity. However, limited 
evidence exists to support such a model that posits that status was measured by material wealth and that Inuit were driven by that motivation.

My case study of Inuit sod house settlements at Adlavik, Anniowaktook and Avertôk questioned the existence of a hierarchical model based on the following five conclusions. First, there is insufficient evidence to support the existence of a social organization in which Inuit settlements formed around individuals who were successful hunters and traders. Only Adlavik House 1 exhibited sufficient faunal and artifactual evidence to suggest the presence of a successful hunter and trader. Given the limited excavations and sampling error of the surveys at Adlavik, however, I suggest caution in concluding that House 1 and its associated midden represent an Inuit leader. Even when a clear pattern of differential access to high-valued goods emerged in this study, the lack of similar patterns at comparable sites challenges its pervasiveness in Inuit social organization.

There is a possibility that residents at Adlavik experienced a period of considerable consistency in hunting and contact with Europeans, resulting in communitywide abundance of faunal and European materials. Ethnographic evidence suggests that Inuit accumulated goods in excess when resources were abundant, and shared resources during times of scarcity. This sort of organization would have resulted in a more even distribution of certain types of goods. Rather than a top-down approach, Inuit may have developed a more flexible social organization that utilized a particular individual's strength in engaging in trade relations, or organizing hunting or raiding expeditions. 
Second, the accumulation of European materials (i.e., trade and manufacturing items), is more affected by temporal differences and location than social inequities within settlements. Adlavik was the most southern of all the sites investigated, and it had the highest frequency of European materials — both trade goods and manufacturing items across all house deposits. The variation of trade goods between the Adlavik and Anniowaktook house deposits suggests that Adlavik Inuit were in contact with more Europeans prior to the arrival of the Moravian missionaries. Thus, Adlavik Inuit were able to accumulate more goods over time than their more northerly Anniowaktook neighbors. Access to and accumulation of goods was tied to proximity to European merchant sites, rather than being linked to certain households.

Third, Inuit were accumulating European goods via means other than direct exchange with European traders. Items associated with the manufacturing category, such as nails, spikes and strap metal, were found to have been discarded at high rates at most of the Anniowaktook and Adlavik house deposits. The data suggest most of these items were not accumulated through the normal avenues of trade, but by Inuit visiting abandoned European sites and collecting the discarded items. Metal was a useful material for making tools and ornaments; however, the high density of non-manipulated nails, strap and sheet metal in the middens may be the result of Inuit salvaging boxes and barrels primarily for the wood. Regardless of what was collected, the method of collection raises interesting questions about interpretation of consumption patterns of European goods when direct European contact is removed. 
Since Inuit could accumulate European materials through different channels, engaging with the Moravians must have been for more than just economic purposes. This leads me to my fourth conclusion: the specific approach the Moravians took in converting Inuit was the reason for their success. The Moravians differed from the prior European groups that visited the Labrador coast in that the Moravian missionaries offered economic incentives in combination with an introduction to Christianity and European society. Some methods were overt, such as the land exchange ceremony, the construction of the wooden buildings, and openly demoralizing shamans. Other approaches were more subtle, such as making materials or objects that conveyed a European sensibility more available. For instance, the Moravians presented European cloth and associated adornments as gifts and maintained a surplus in the trade store to encourage Inuit to change their style of dress to resemble Moravian fashion. They also influenced the modification of Inuit subsistence practices to correspond to Moravian economic needs, such as encouraging fishing and surplus storage.

Finally and perhaps most significantly was the evidence of the acceptance of both Inuit and Christian traditions by many Inuit. In general, Inuit did not perceive of conversion as an inevitable consequence where one discarded all previous cultural attributes. For their part, the Moravians did not completely intend for that result as they hoped the Inuit would remain self-sufficient. Inuit were more flexible in accepting both religions as complementary; where one system failed, the other might succeed. It was within this flexibility where culture change occurred for the Inuit. 
I now turn to a discussion of the archaeological and historical data more specifically to consider how changes to nineteenth-century Inuit culture were based on seventeenth and eighteenth-century cultural patterns. I then outline avenues for future work on Inuit social organization that will lead to a better understanding of the process of social and religious conversions at missions.

\section{Review of the Model}

Excavations at Adlavik and Anniowaktook and reanalysis of Avertôk site plans and artifacts revealed that historic Inuit did not have a social organization similar to their Thule ancestors. Differences identified in house settlement patterns, faunal collections, and artifact distributions suggest eighteenth-century Inuit settlements consisted of smaller independent family units that exploited a variety of avenues to accumulate resources. Evaluation of some of the inter-household difference was complicated by the small assemblages from various deposits (i.e., middens, entrance tunnels, floor, fill, etc.), and the need for a more detailed analysis of the faunal material. Nevertheless, some conclusions can still be made regarding inter- and intra-site faunal and artifact data.

Faunal data from Adlavik House 1, Anniowaktook House 1 midden and Anniowaktook House 4 reveal that consumption and discard patterns follow those from other eighteenth-century Inuit sites in northern Labrador; sod houses were occupied during winter months and Inuit focused on hunting seals. A low frequency of whale bone in the three deposits suggests that Inuit continued to exploit whale but in a more limited fashion than their Thule Inuit ancestors. Instead, their emphasis was on seal hunting. 
Although seal were found at the occupation level in the houses, information on faunal elements would be needed to support sharing of seals among households as a result of communal hunting.

The results with respect to artifact distribution also differed slightly from expectations. The Avertôk assemblages showed some differences in hunting tools among households, suggestive of seasonal and temporal occupations. Only the Avertôk midden exhibited a great range of artifact types. The distribution of hunting and European items varied among the house deposits at Anniowaktook and Adlavik; some houses exhibited a high rate of discard of trade items, while others had higher rates of hunting tools. As already discussed, only Adlavik House 1 and its associated midden exhibited evidence for higher rates of discard of both hunting and trade related items.

The data supports a modification to the model; instead of a hierarchical structure, Inuit social organization may have been a more egalitarian organization where power relations shifted as values were ranked and reranked as conditions changed through time (Crumley 1995). Studies have considered status far too materialistically at Inuit sites, often overlooking the nuances of Inuit life during a transitional period. Social power may have been transmitted through resources other than material wealth that are less pervasive in the archaeological record, such as ritual knowledge or kinship. A better understanding of Labrador Inuit social organization would be achieved by gathering more data from other historic Inuit settlements in the Hopedale region to determine how individual household organization that had its own unique set of rules participated in a larger communal settlement that practiced resource and knowledge sharing (Kelly 2010:109). 
How this, or any, model of Inuit social organization can help us understand Inuit decisions to engage with the Moravian also requires analyzing the voluminous historical records kept by the missionaries. The data presented in Chapters 4 and 5 suggest that the missionaries attempted to, on the one hand, engage with and understand Inuit cultural practices in an effort to simultaneously change some of those beliefs, particularly those associated with the shaman. On the other hand, the Moravians imposed a different cultural orientation by deliberately importing items to sell to Inuit that conveyed a particular Moravian ideal — that of a clean, assiduous Christian.

The inclusion of the mission trade store was intended to disrupt Inuit tendencies to travel south and trade with unscrupulous Europeans that resulted, in the eyes of the Moravians, in the perpetuation of sinful activities. By offering a local alternative, the Moravians hoped Inuit would remain near the missions, and as a result learn the Gospel and engage in activities that benefitted the entire Moravian community. The trade store was merely a means to achieving the Christian ideal.

The Moravians initially tried to keep trade separate from religion, but over time the boundaries eroded; by the nineteenth century, missionaries traded European goods with Inuit. Still, they employed other methods to systematically undermine and change Inuit perception of healing, taboos, and the shaman. By providing alternative western medicines, ignoring taboos related to hunting, and challenging the shaman outright, the Moravians presented themselves and Christianity as the alternative to navigating and surviving the Arctic natural and spiritual landscape. 
Despite the rise of Inuit converts in the 1800s, the Moravians remained unsatisfied because Inuit maintained relationships with shamans or continued traditional subsistence patterns that included a summer caribou hunt, as well as the journeys south to trade with merchants. The cause of the Moravians' frustration was that the missionaries did not recognize their role in the flexible Inuit communal structure that relied on sharing and redistribution. Unlike the rigid European worldview, Inuit could adapt to a new social situation that allowed for both Christianity and traditional spirituality to meet individual and communal needs.

The missionaries’ frustration was not novel to the Labrador situation; many European missionaries viewed this Native flexibility as indecision or inconsistencies within Native culture. Other missionaries tried to force conversion aggressively, as evidenced by some of the hostilities documented at Spanish missions in California and American southwest Spanish (Jackson and Castillo 1995; Liebmann 2008; Peelo 2009; Van Buren 2010).

However, even missionaries that engaged in less aggressive methods of conversion — where they learned about Native customs and languages as a way of entry — also encountered impediments to convincing Native peoples to convert. For instance, the Jesuit also sought to incorporate Native symbols in their practices, but their approach was much more premeditated. Similar to the Moravians, the Jesuit missionaries studied the people, their language and their customs prior to establishing missions, even adopting many Native practices themselves. Jesuit missionaries sought to develop a rapport with Native peoples by gaining their confidence and introducing Catholicism by drawing 
parallels to the Native customs. While seemingly sympathetic to Native cultures, this pursuit of learning about indigenous customs was an effort to acquire greater authority and influence over Native populations (Blackburn 2000:134).

An alternative approach used by Spanish missionaries in Peru was to transform local spaces and materials into a hybrid form of Christianity and Incan culture (Wernke 2007). The space or material conveyed both an Incan and Christian sensibility. As with the Jesuit and Moravian missionaries, the syncretism of Christianity and Native religions provided an avenue for introducing new ideas within a familiar form while imposing European authority in a less overt manner.

Regardless of how conversion was approached, the encounter often led to misunderstanding and conflict. In particular, different interpretations of authority and social order led Jesuit and Moravian missionaries to impose strict rules regarding trade, dress, and proper behavior. These rules were intended to guide Native peoples to embrace a Christian, and ultimately a European identity; yet they were perceived by some Native peoples as intrusive and oppressive. The Moravian missionaries initially appeared to be less aggressive than some Spanish missionaries in their pursuit of conversion; however, they remained greatly influential in their role as agents of culture change due to their careful manipulation of meaning and acquisition of objects and control of places.

\section{Future Research}

As with many projects, the collection of more data is needed to better understand the social situation of Labrador in the eighteenth century. The data presented here add to 
a small dataset of eighteenth century Inuit houses previously excavated, providing preliminary results regarding Inuit social organization and the role of the Moravians in changing seen to Inuit culture.

It has been through this narrow investigation that a host of new questions emerge. New questions surround the manner in which Inuit accumulated goods and who among the Inuit chose to convert first. One problem that warrants further investigation is the degree consumption patterns differed when Inuit received goods directly from European traders veresus from missionaries. Anthropologists and archaeologists have demonstrated elsewhere that the materials introduced by missionaries coupled with the particular meaning and significance tied to those objects disrupted Native social systems more so than those from traders who were not interested in civilizing Native peoples (Comaroff and Comaroff 1991; Rothschild 2003). Identifying additional Inuit sites where trade between Inuit and the Moravians occurred can help locate and measure the degree to which Moravian ideals were or were not being incorporated into Inuit households.

The degree to which these foreign ideas were accepted by the Inuit may be associated with settlement proximity and the amount of contact with the missionaries. Presumably, Inuit living closer to the missions had more regular contact with the missionaries, and subsequently had more exposure to the Moravian’s preaching. Most eighteenth- and nineteenth-century Inuit families lived within $60 \mathrm{~km}$ of a mission (BriceBennett 1977:103), but limited research exists on how these surrounding residences were influenced by the missionaries’ arrival. To begin to understand the extent to which 
Moravian influence permeated the Labrador coast, additional surveys are needed within a radius from the Hopedale mission to locate additional eighteenth and nineteenth century Inuit site. Such surveys will add to a broader understanding of Inuit settlement along the Labrador coast and the level of Inuit interaction with missions. Discovering sites within a $30 \mathrm{~km}$ radius would help to clarify how settlement or household discard patterns differed from those identified in this study, and whether trading with Europeans merchants or Moravian missionaries resulted in alternative settlement patterns.

Expanding that radius to include other missions may highlight how Inuit settlement patterns and consumption choices differed among the Labrador missions, thus highlighting the diversity of individual Inuit and missionary choices as well as the mutual cultural transformations that developed. Even at the same time and within the same place, different Inuit understood and related to the landscape in different ways (Bender 1995:2). The Moravians recognized that a mission in central or southern Labrador would be very different from those located near northern communities. Including a regional aspect that follows the temporal trends identified by previous researchers (i.e., Cabak 1991; Fitzhugh 1977; Loring 1990) will help clarify the degree to which inter-regional differences developed and whether alternative traditions or organizations emerged over time.

Future projects on any eighteenth- or nineteenth-century Labrador Inuit sites will require additional research of the extensive Moravian records and the Hudson Bay Company records. Specifically, examining the Moravian baptismal records can identify the first Inuit converts. Early documents identify prominent male shamans who helped 
the Moravians establish their missions, but suggest women, children and elders were the first to settle at the mission and convert (Brice-Bennett 1981:98; Kleivan 1966). Identifying who converted to Christianity may elucidate whether individuals in particularly social categories were choosing to settle at Moravian sites rather than Inuit communal settlements. For instance, widows or older persons who could no longer be provided for by the community may have chosen to move to Moravian sites to gain access to resources otherwise denied to them (Cabak 1991; Hawkes 1916:117). Access to resources including food and trade goods may have served as a motivation for new social alliances.

While I chose not to include a study of the role of the Hudson Bay Company (HBC) in the development of the Labrador trade market because the first store was not opened until the mid-nineteenth century, the HBC built a number of posts along the Labrador coast. It was the only merchant in the area from that time until the twentieth century. This sudden and continual presence created a competitive trading market, ultimately affecting the Moravian missions. With the arrival of both the traders and the missionaries, Inuit subsistence economy turned into a trapping economy that strongly depended on Europeans. Similar to the Moravians, the HBC kept detailed records describing their interactions with Inuit and Innu. Analyzing these documents can provide insight into what specific missionary regulations and restrictions led some Inuit to trade with the HBC and not the Moravians. 


\section{Implications of this Study}

The research presented here led to the development of new models that allow for the identification of flexible social organization, while simultaneously bringing Labrador Inuit history into much greater relief. The significance of this study and the conclusions regarding archaeology in Labrador and the Arctic more generally lies in its implications for research concerning culture change and the economic and social function of the household.

This study has shown that by combining the analysis of the communal house sites at Adlavik, Anniowaktook and Avertôk with previously unpublished historic data, an alternative approach emerges for understanding Inuit and missionary motivations in the process of culture change. This study contributes to the debate regarding the development of an elaborate Inuit coastal trading system and the rise of prominent Inuit men as traders and middlemen by attempting to test such a model. The data that I collected and analyzed challenges previously held assumptions about Inuit social organization that regarded the accumulation of material goods and the conversion to Christianity as solely an economic endeavor. My research supports arguments for a more nuanced understanding of Inuit social organization that moves beyond traditional material expressions for leadership, and point towards identifying relationships within a system where values are flexible and change according to individual and group needs.

Further, the project highlights the need for understanding the effect of numerous social, economic and political factors in the process of colonialism and, more specifically, missionization. It is within the blending of Christian Protestant influences 
with a sacred Inuit geography that reveals that the motivations for grand social change. Inuit culture change resides in a mutual acceptance and rejection of both new and traditional ideas, materials and social structures.

Inuit modified their existing social organization to incorporate new ideas and materials after the arrival of the Moravian missionaries. Employing a diachronic approach captured the subtleties of a colonial situation and showed that change was neither universal nor homogenous. Archaeological research on missions has focused on understanding how Native American groups converted to European Christian practices, but less research has addressed why Native groups chose to convert. By presenting data that moved beyond descriptions of processes of culture change, this project sought to understand indigenous choices based on Native systems and to develop alternative models for long standing questions. 


\section{Appendix A: The Hopedale Archaeology Project}

Each summer from 2007 to 2009, I organized and ran The Hopedale Archaeology Project (HAP), a community archaeology project based in the northern Labrador town of Hopedale, Canada. HAP was a community-oriented program that worked with the local population at all levels of research and development. As part of this program, local Inuit students were hired to assist with the excavation, and participate in Community Days and Archaeology Open Houses which shared our findings with the entire Hopedale community. This appendix presents the activities and events employed during this three year tenure in Hopedale and subsequent discussion about the successes and failures of the project. For each year, I discuss the steps taken to ensure the participation of community involvement at multiple levels and the lessons learned from that summer. I conclude with final thoughts on the project and potential future directions for community archaeology in Labrador more generally.

2007 Season

The 2007 field season in Hopedale was a preliminary survey of Inuit sod houses and middens in and around the Moravian mission. Working with Nunatsiavut Government archaeologist, Lena Onalik, and director of the Moravian Museum in Hopedale, David Igloliorte, we hired five local high school students to participate in the archaeological excavation of an eighteenth century Moravian midden, and surveys on Anniowaktok Island (Big Island), Ellen Island, and Kannertaluk Island (Black Island). Students were trained in proper archaeological techniques including survey, excavation, 
screening, and data recording, as well as artifact identification. The six students hired for the inaugural year were Ben Abel, James Karpik, Martin Nochasak, Amalia Jararuse, Selma Jararuse, and Bobby Nochasak.

This project was the continuation of the work begun by Dr. Stephen Loring of the Smithsonian Institution called the Central Coast of Labrador Community Archaeology Project (CCLAP). Since 1999, the Arctic Studies Center of the Smithsonian Institution and institutions in Labrador and the United States have been conducting an annual summer field school centered on the coastal Inuit communities. The community goals of the program include providing training and employment opportunities for Inuit students in the field of archaeology, working with local communities and historical societies to identify archaeological and historical resources, working with local Labrador teachers to incorporate archaeology into the curriculum, and help foster pride in Labrador culture and heritage.

The HAP field season was divided into two stages that included excavation and survey during July and August 2007. The first stage was a three-week excavation in search of the Moravian midden located near the Moravian mission buildings; the second stage was a ten-day survey and excavation project on Anniowaktok Island (aka Big Island) located approximately $7.5 \mathrm{~km}$ east of Hopedale, and a two-day survey of Kannertaluk Island location approximately $15 \mathrm{~km}$ north. After discussing the work conducted, I review the additional community outreach activities including an Archaeology Open House. 


\section{$\underline{\text { Excavations at the Hopedale Moravian Midden }}$}

The first half of the season sought to relocate a nineteenth-century midden associated with the Moravian missionary occupation. This excavation was based on Dr. Loring's identification in 2002 of some nineteenth century ceramics unearthed during the erection of a new telephone pole. Dr. Loring noted the appearance of these artifacts and suggested this might be the location of a Moravian midden but did not conduct additional testing.

Based on Loring's findings, two $1 \mathrm{x} 1 \mathrm{~m}$ units were placed behind the missionary buildings, across the road from the telephone pole and near some bedrock (Figure A.1). An additional unit was later added to the area behind the telephone pole, when a home owner unearthed some twentieth-century ceramics while digging a hole for her laundry line. Two additional exploratory $1 \times 1 \mathrm{~m}$ units were placed five $\mathrm{m}$ north of the museum building along a slope, since it exhibited potential for an over-the-bank midden as seen at other Moravian missions in Labrador (Cabak 1991; Cabak and Loring 2000). Excavation and data recording for these five units was conducted over a period of three-weeks by me and a team of five Hopedale students.

Most students were generally attentive to their duties, which included excavation, screening, paper-work and washing artifacts. Motivation dropped and worked slowed usually on hot days when the flies were particularly bad or on Fridays. One younger student was not very interested in archaeology and did not activitely participate in the work. As a result, he often disrupted the other students, arrived late to work, or avoided work altogether. When I attempted to appease his interest by assigning him to other 
activities such as cleaning artifacts, his work was careless and even destructive. After discussing the matter with HAP co-director, David Igloliorte and other members of the Town Council, it was decided the best plan of action was to relieve him of his duties and implement a minimum age of employment at 16 years for all future archaeological projects. Selma Jararuse was hired replace him.

Excavations in the center of town brought a lot of good and bad attention by local residents. It raised awareness for archaeology and the history of the mission. Hopedale residents walking by would often inquire into our findings, offer their insights, and reminisce about the past. For instance, Test Unit \#4 was located just north of the mission building. Test Unit \#4 differed from the other units in the area in that the deposit was not a brown sandy loam but rather a black, wet loam, it was over a meter deep, and had few artifacts. Although some evidence suggested that the area was used a twentieth-century midden, elders passing by claimed the Moravians built a small sod house in this location to store potatoes. Due to the discussion with the neighbors, Mr. Igloliorte and I returned to the historical documents and located a small sod house in a 1920s photograph of the Moravian Church.

Although most of the attention we received was positive, a few citizens did express their concern that I, the foreign archaeologist, would take away any artifacts found. Provincial protocol does require that all objects are returned to the Province if removed for research; however, artifacts are returned to the Rooms Museum in St. John’s Newfoundland and not Hopedale. Understandably, local residents were hesitant to show me artifacts they found in the area, fearing I might confiscate these objects. Only after 
numerous reassurances that I only want to photograph objects, did residents welcome me into their homes to share their objects and stories. All of the artifacts from this portion of the survey were recorded and many were photographed. Some of the twentieth century artifacts were reburied after being recorded and photographed. All remaining historic and prehistoric objects are currently being stored at the Hopedale Moravian Museum and eventually will be sent to St. John’s for permanent storage.

Another surprising source of both joy and discontentment were the local children who visited our site daily to inquire about our work. The children's visits offer the HAP students an opportunity to show their work and discuss their finds; however, the children were also disruptive by stealing tools, equipment, and throwing stones at the field workers. As a result, all equipment, including nails and lines to outline the units had to be removed at the end of each day or risk being stolen. The children's visits were initially welcomed by the students, but after a week of disruption, they quickly expressed their concern and annoyances, leading me to request the children only visit during certain hours of the day. Over time, the children lost interest in our project, and soon no longer visited.

In addition to the archaeological excavations, HAP included a museum studies component where students worked with museum director David Igloliorte. Students were asked to pick an artifact on display in the museum and conduct research on its function in nineteenth-century mission life. The result of the students’ research was used to write new object labels for the museum with students’ work acknowledged in the display. Access to the school's computer was arranged; however, students were less interested in 
the research aspect and often explored the internet, played games, or IM chatted with other friends.

The first half of the field season taught me a few valuable lessons, including limiting the age of student workers and employing more hands-on and less researchbased activities. The excavations also spurred a dialogue within the community, regarding the significance of archaeology and the preservation of local heritage projects. As a result of this work, future excavation projects were met with more enthusiasm. 

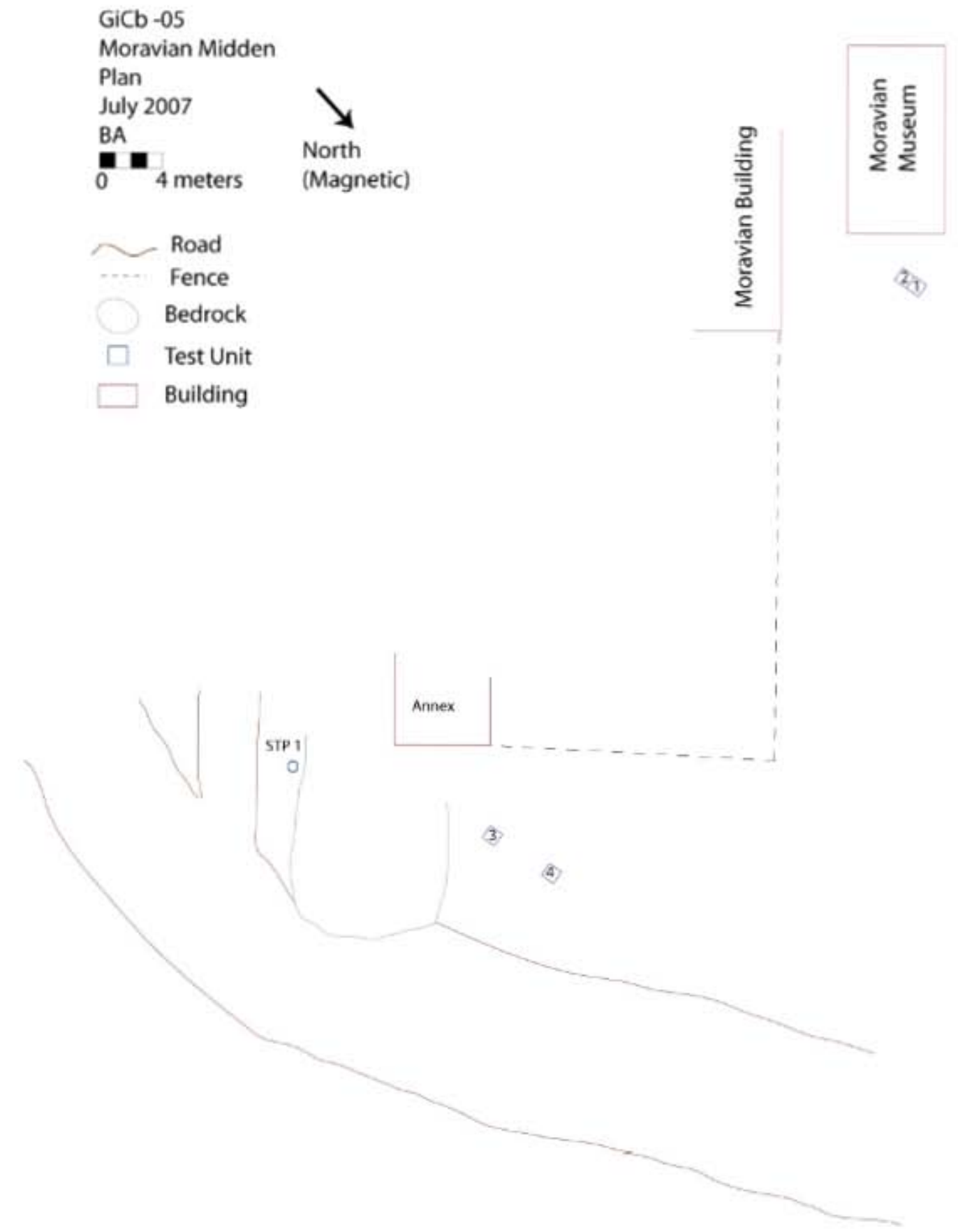

Figure A.1: Plan map of the Hopedale Moravian mission and unit locations. 
$\underline{\text { Kernertaluk and Anniowaktok Islands }}$

The second part of the 2007 project included surveying nearby islands to locate previously unrecorded Inuit sites. With the help of the five Hopedale students, we surveyed two islands in the Hopedale region, Kernertaluk and Anniowaktok.

A one-day pedestrian survey was conducted on Kernertaluk Island located approximately $15 \mathrm{~km}$ north of Hopedale. The island was chosen for its archaeological potential based on community members' description of burials and their identification of possible sod houses. The Hopedale students and I hiked across the island recording burials, tent rings, fox traps, and hunting blinds. Students were responsible for measuring and photographing many of these features. As a result, we identified eight features including a large burial, three features (possible hunting blinds), and a series of tent rings and fox traps along the northern coast of the island. The evidence for occupation at Kernertaluk Island suggests it was a prominent spring and summer hunting ground during the historic period. The island is still known as an excellent location for seal hunting in the present Hopedale community.

Surveys conducted on Anniowaktok Island sought to relocate the Inuit sod house settlement Bird identified in 1934, as well as identify previously unrecorded Inuit sites. A two-day pedestrian survey located twenty-two possible features and sites, including a number of tent rings, caches, above-ground burials, and a possible cave burial located on the north side of the island. Students were asked to identify, record, and photograph any possible features. Each student was given my camera for 20 to 30 minutes to record possible features as well as anything else they found interesting. As a result, students 
helped identify previously undocumented cave burials and tent rings. In addition, a photo journal of the students' journey across the island was created. At the end of the season, all students received digital copies of the images taken.

Unfortunately, we found little material evidence to assist in the dating of the sites located on Anniowaktook. Only fragments of an eighteenth-century French Normandy stoneware jug were found in the vicinity of the cave burial as described in Chapter 6, but it remained unclear whether the stoneware jug and the cave burial were related.

The team was successful in relocating the four-sod house settlement originally described by Bird. The students mapped and photographed all of the houses and recorded any surface finds. I returned the following week with Nunatsiavuk archaeologist Lena Onalik and Hopedale student James Karpik to test the hypothesis that the houses were occupied during the late eighteenth century. We completed the excavation of two $1 \mathrm{x} 1 \mathrm{~m}$ test units near the entrance tunnels of two of the four sod houses. This survey and subsequent test units served as the basis for this dissertation.

\section{Community Outreach}

In addition to hiring students and teaching them about Labrador history and archaeology, sharing our findings with the entire Hopedale community was an important element of HAP. Following the completion of the 2007 summer field season, an Archaeology Open House was held for the community in the Moravian Church building. The community was invited to view artifacts and photographs from that summer's excavations in town and on the islands (Figures A.2 and A.3). Nunatsiavut archaeologist, 
Lena Onalik, Moravian Museum Director, David Igloliorte, Hopedale student, James Karpik, and I were on hand to discuss our findings and answer questions. Many from the community visited our display and asked interesting questions about the artifacts and our findings.

I also followed up with meetings with the Town Council and the Moravian Church Council. Upon arriving in Hopedale in July, I arranged to meet with both groups separately to discuss my intentions and goals regarding the project and hear their questions and concerns. The follow-up meetings discussed the team's findings and conclusions. I discussed with them the potential for a similar archaeological project in the summer of 2008 and 2009. Again, the only dissatisfaction expressed was regarding Provincial protocol to remove artifacts for conservation and storage at the Newfoundland museum in St. John's. However, both groups conveyed satisfaction with the 2007 project and the potential for future community archaeological projects in Hopedale.

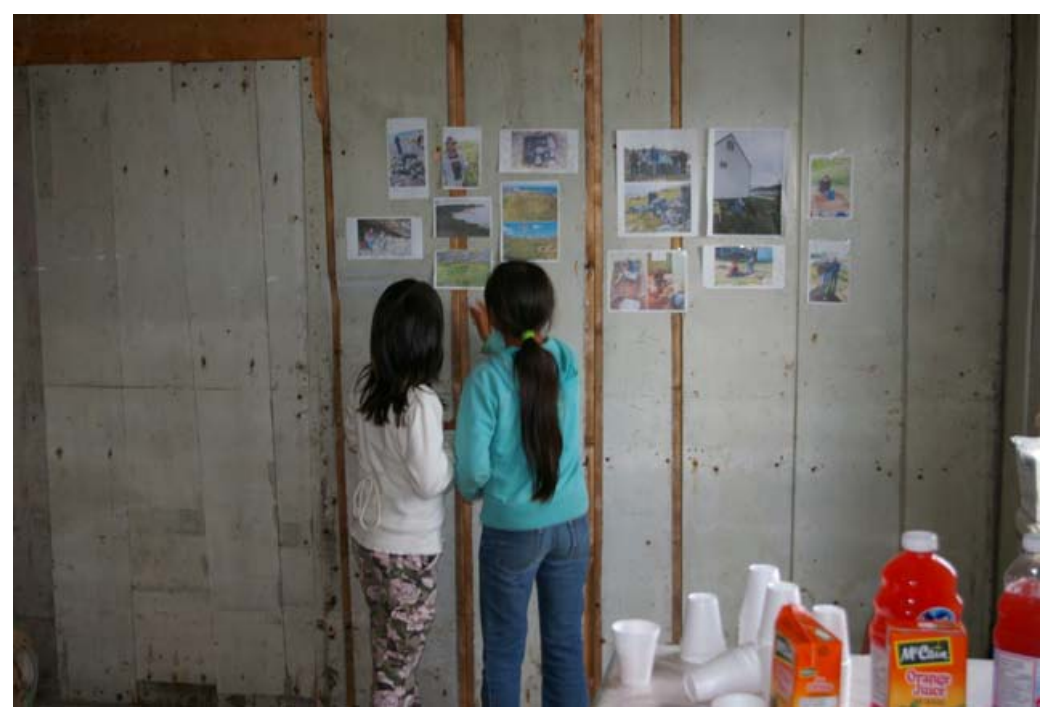

Figure A.2: Students viewing photographs at the Archaeology Open House. 


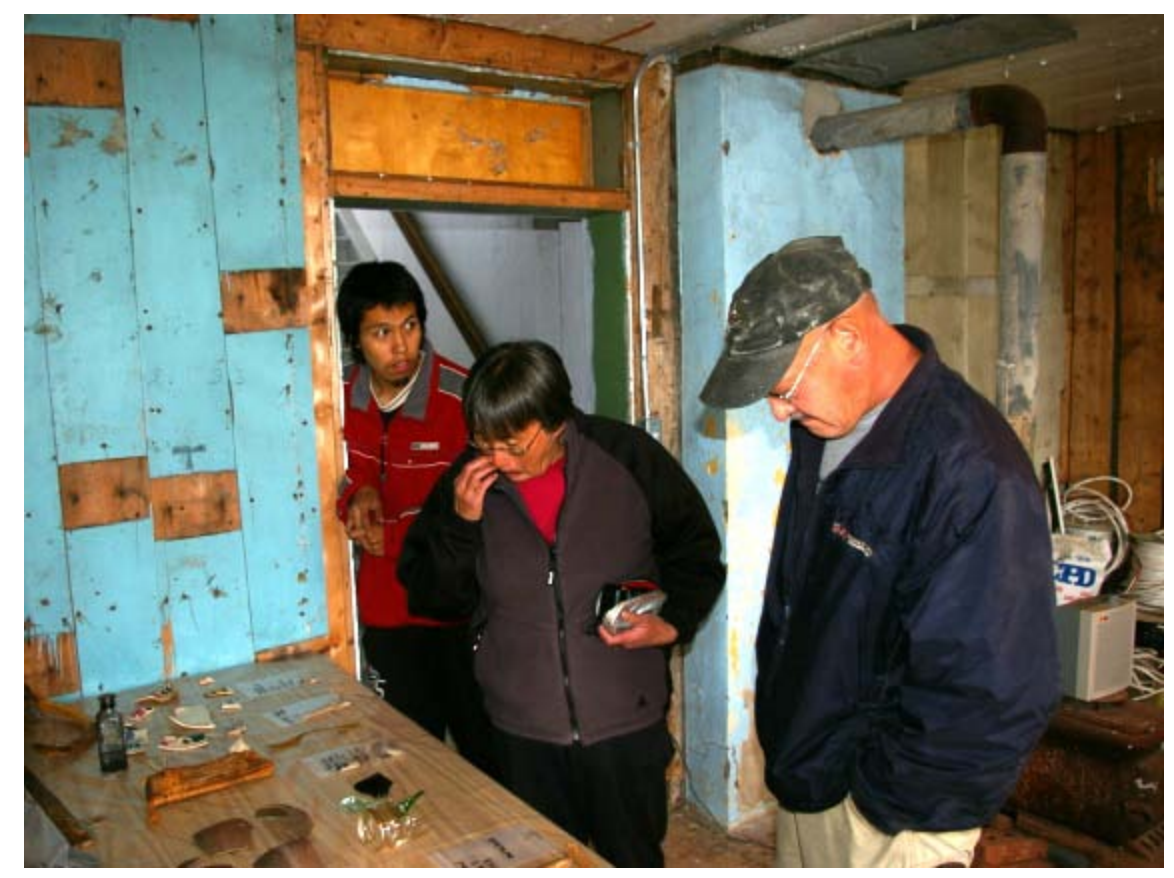

Figure A.3: Community members viewing artifacts from the summer's excavation at the Archaeology Open House.

As a result of my work in 2007, I was invited to return to Labrador in November to be part of the Labrador Creative Arts Festival as a "Visiting Artist." The Festival is an annual event that brings international artists to Labrador to teach students about the Arts, including culture, dance, music, and theater. This year’s theme was “Landmarks,” based on my previous conversation with the Festival Organizer regarding archaeology of sod houses. Although not a traditional artist, my role was to teach students about culture and historical significance. For one-week, I visited schools in Goose-Bay-Happy Valley and Northwest Valley area and returned to Hopedale to conduct workshops with students. I conducted archaeological workshops teaching students from K-12 about archaeology in Labrador. Younger students were asked to "mend” artifacts (cut photographs of artifacts 
printed on magnetic paper) and then write a book about who used the artifacts. Older students were given bags from a "midden" and asked to identify the artifacts. From the artifacts identified, students were asked to describe the people who made the trash. My workshops were well received, and served as the basis for the development of an archaeological activity handbook in 2009.

\section{Season}

This season focused on full scale excavations of one of the sod houses identified during the 2007 survey on Anniowaktook Island. My intension was to hire five local students to assist in the daily excavation of the sod houses and all related paperwork. Upon arriving in Hopedale, I met with Juliana Flowers of the Hopedale Town Council and David Igloliorte of the Agvituk Historical Society and director of the Moravian Museum to discuss the 2008 field season. Given that the project was going to occur outside of town, the Committee expressed two concerns. First, there was a possibility of a bear on the island, since a bear had been spotted on Anniowaktook Island earlier that spring. To accommodate their concerns, I discussed the potential of a bear encounter and methods to protect ourselves with Hopedale’s Environmental and Fisheries expert, Ian Flowers. Mr. Flowers conducted a survey of the island but did not find any evidence to suggest the bear was still on the island. Nevertheless, the Mr. Flowers recommended that I hire a bear monitor to constantly monitor the area and provide protection for my and the students' safety. 
The second issue discussed was the hiring process of four additional students. All five positions (including the bear monitor) were funded by the Student Summer Employment Opportunity sponsored by the Youth Employment Strategy (YES) which required employees to be returning students. Due to the success of the previous season, we had more applicants than positions. Two potential employees included a local student who dropped out of school and another non-local student. The Committee requested I offer the position to the local student first.

Despite this decision, a community member who was housing the non-local student expressed her frustration with this decision. She argued that hiring the local student who did not finish school went against Nunatsiavut policy (students must complete a full school year in order to be considered for summer employment), thus punishing good students. She expressed her dissatisfaction with me, members of Town Council, and the Nunatsiavut Government. After discussing the situation with representatives from Nunatsiavut and Town Council, they advised that I not hire the local student who did not complete school in accordance to government policy; however, they requested I reopen the job to promote community involvement of local heritage projects. If no acceptable candidates from Hopedale applied after a week, then the job would be offered to the non-local student. Five Hopedale students were hired and they were James Karpik, Nathan Karpik, Trevor Broomfield, Kelsey Hunter and Delano Torarak as the bear monitor.

Even though the job was filled eventually by another Hopedale student, the process required that I navigate personal and political waters very carefully, particularly 
as a foreign researcher. While the end result was not well received by the one community member or the non-local student, many of the Hopedale students and local parents appreciated that the project remained for Hopedale. I recognize the exclusivity I presented by only hiring Hopedale students, but my intension was to build trust and a relationship within the community. By showing my commitment to the education of the Hopedale community, I hoped it would reflect well in other communities along the coast.

All five students participated in the excavation of the sod house, completed paperwork, mapped house architecture, cleaned artifacts, and took many field photographs. One of the field assistants, James Karpik, worked on the 2007 survey team, and showed a particular interest in both archaeology and photography. As a result of James interest and hard work the previous season, I asked James to return as my assistant. His previous experience proved invaluable as he assisted in setting up the site, photographed and mapped the house, supervised other students, and helped make some critical field decisions.

Towards the end of the season, I coordinated with Maria Igloliorte, president of the Kamatsiatet Committee to arrange for a Community Archaeology Day on the island. The Archaeology Day intended to allow residents to visit the site as the students worked, ask questions, and view artifacts. I worked with Ms. Igloliorte to coordinate the rental of three speed boats to serve as shuttles between town and the island for those who did not own boats. In addition to word of mouth, flyers were placed around town and an announcement was made on the local radio station. Despite all efforts, the Archaeology Day was cancelled due to poor weather. Instead, an Archaeology Open House was held 
in the Moravian building showcasing the students' photographs and artifacts from the excavation.

As in the previous year, I conducted follow-up meetings at the end of the summer. I met with Julianna Flowers, David Igloliorte, and other members of the Town Council to summarize the project, and discuss ideas for the following summer. Three points were raised for future consideration. First, we agreed that a bear monitor was a necessary precaution and should be included in all future projects. Second, I would organize multiple community archaeology days to offer several opportunities for the community to see the excavations in the hopes of avoiding similar disappointment. Lastly, David and I would work on developing a new exhibition for the Moravian Museum highlighting the excavations on Anniowaktook Island.

2009 Season

For the final season of HAP, I returned to Anniowaktook to conduct additional excavations on a second sod house. Prior to excavation, I met with the new head of Town Council, Judy Dicker, to discuss the goals of the summer project, student applicants, and the inclusion of three Community Days on the island. I also arranged for Hopedale’s Environmental and Fisheries expert, Ian Flowers, to conduct a boat survey of Anniowaktook Island prior to the team's arrival to ensure there were no bears currently on the island.

Five students were hired to participate in the excavation of eighteenth century Inuit house. Two students, James Karpik and Nathan Karpik, worked on the 2008 
excavation of House 1, while the other two students, Mary Jararuse and Christopher Abel were new to the project. One student, Trevor Broomfield, who also worked on the 2008 excavation, returned as the bear monitor and occasionally helped with the excavation. Unfortunately, James missed too many days of work and had to be let go early on in the season. He was replaced by Ashley Abel who had worked on a 2005 archaeological project on Napatilk Island project with Dr. Loring. Her previous excavation experience proved very valuable.

The Agvituk Historical Society funded boat transportation costs for three Community Days. Three speed boats were hired to serve as shuttles between town and the island for those who did not own boats. Announcements were made on the radio and flyers were placed around town. Unfortunately, two Community Days were canceled due to poor weather; we did have one successful visit to the island. Ten community members traveled to the island. Upon our arrival, a sudden storm forced us to huddle in a small canvas tent that was used to store the archaeological equipment. As we waited for the storm to pass, I took the opportunity to discuss the history of the site, the goal of the project, and show a few of our most significant finds.

Once the storm subsided, I led a tour of the entire site identifying all four houses, related architectural features, including the entrance tunnels, paved stone floors, and the cooking areas (Figure A.4). In addition to taking visitors' questions, I also showed some stones and artifacts I could not identify and asked for their insights. As a result of this dialogue, I believe we identified the cooking area in House 4 as discussed in Chapter 6. 
Inuit living in this house were using a different cooking method where they placed meat directly onto a heated soapstone slab as opposed to cooking over an open hearth.

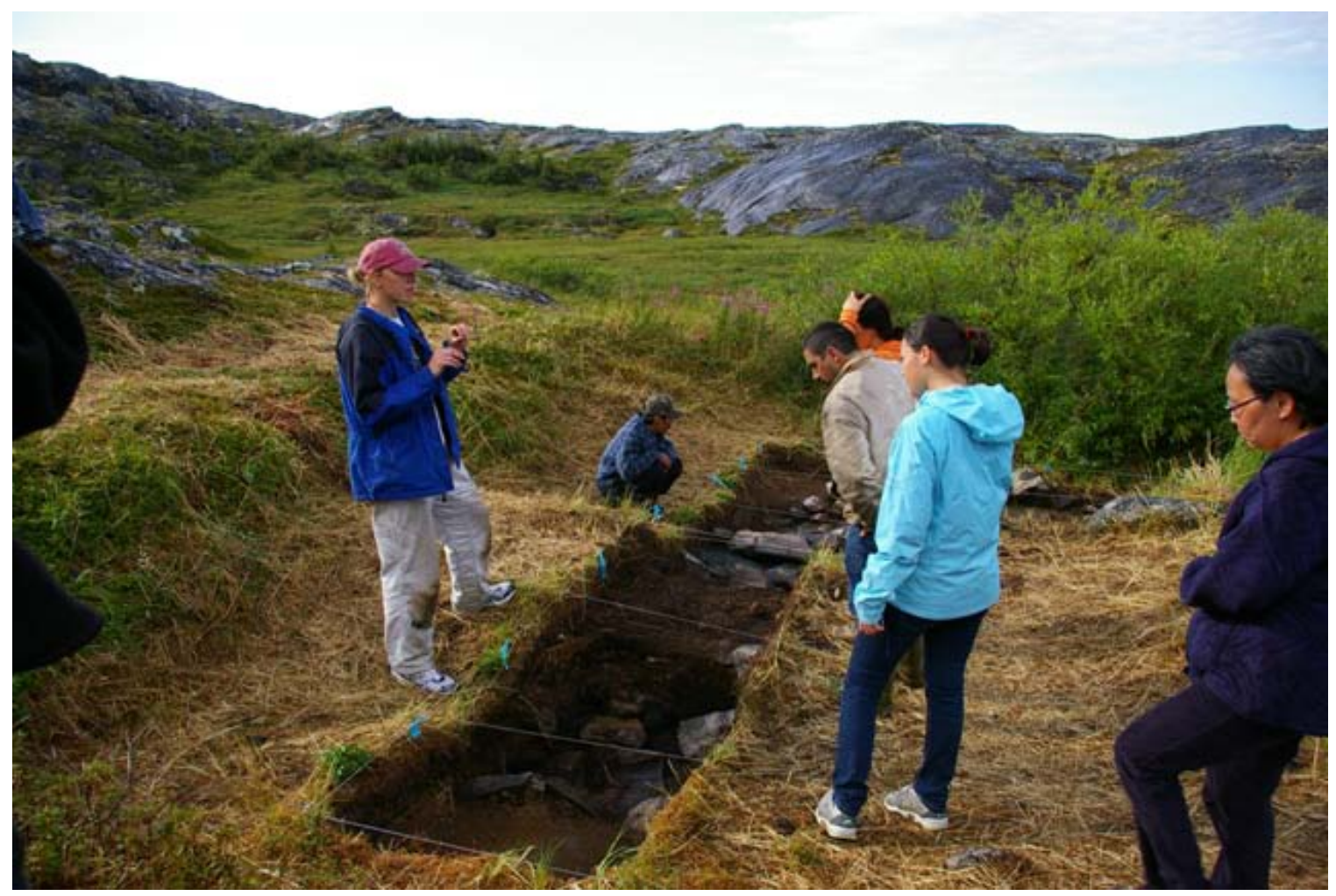

Figure A.4: Community Day on Anniowaktook Island, 2009.

On the final day of the season, I also arranged for an Archaeology Open House in the Moravian mission building to accommodate people who had schedule conflicts and were not able to visit the excavations at Anniowaktook. Again, students' photographs were showcased, as well as artifacts found. Approximately 20 visited the display to view the objects and images on display and ask questions about the site. Student Trevor Broomfield assisted with the Open House by answering questions, and offering his perspective of the excavation and project as a whole. 
Before my departure, I was able to provide the community with a final presentation summarizing the three-year project at a public Town Council meeting. I discussed our findings, the significance of the students' participation, as well as address the town's concerns, regarding the final storage of the artifacts.

A final component to HAP was developing resources based on our project to continue dialogue about the history of the region, the role of archaeology, and the significance of conserving and preserving a rich heritage. I provided the school with two posters and a teacher's handbook that showcased Hopedale’s archaeological history and the work we had done together over the last three seasons.

As part of my predoctoral fellowship at the Smithsonian Institution in Washington, D.C., I worked with summer intern Sarah Dickey to develop and publish two posters on the archaeology of Hopedale and Anniowaktook and develop a teacher's handbook with in-class activities for the Hopedale School (Figures A.5 and A.6). The 3' x 2' posters serve as teaching tools for Hopedale teachers during the school's Heritage Festival in the spring and was designed to be used with the teacher's handbook. Three hard copies and three CDs of the teacher's handbook with over 10 in-class activities specific to the Hopedale region were also donated to the school. 


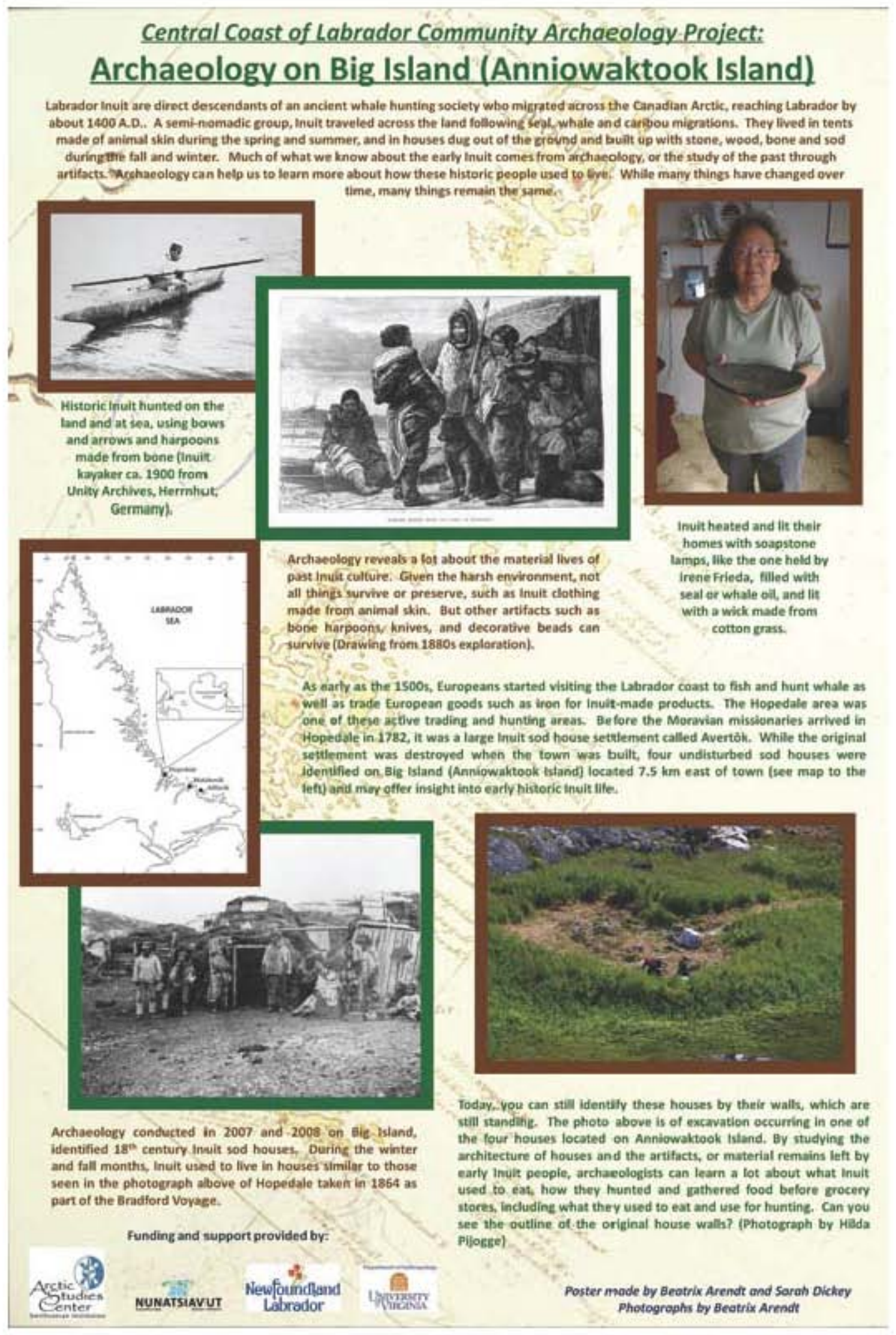

Figure A.5: Poster 1 donated to the Hopedale School 


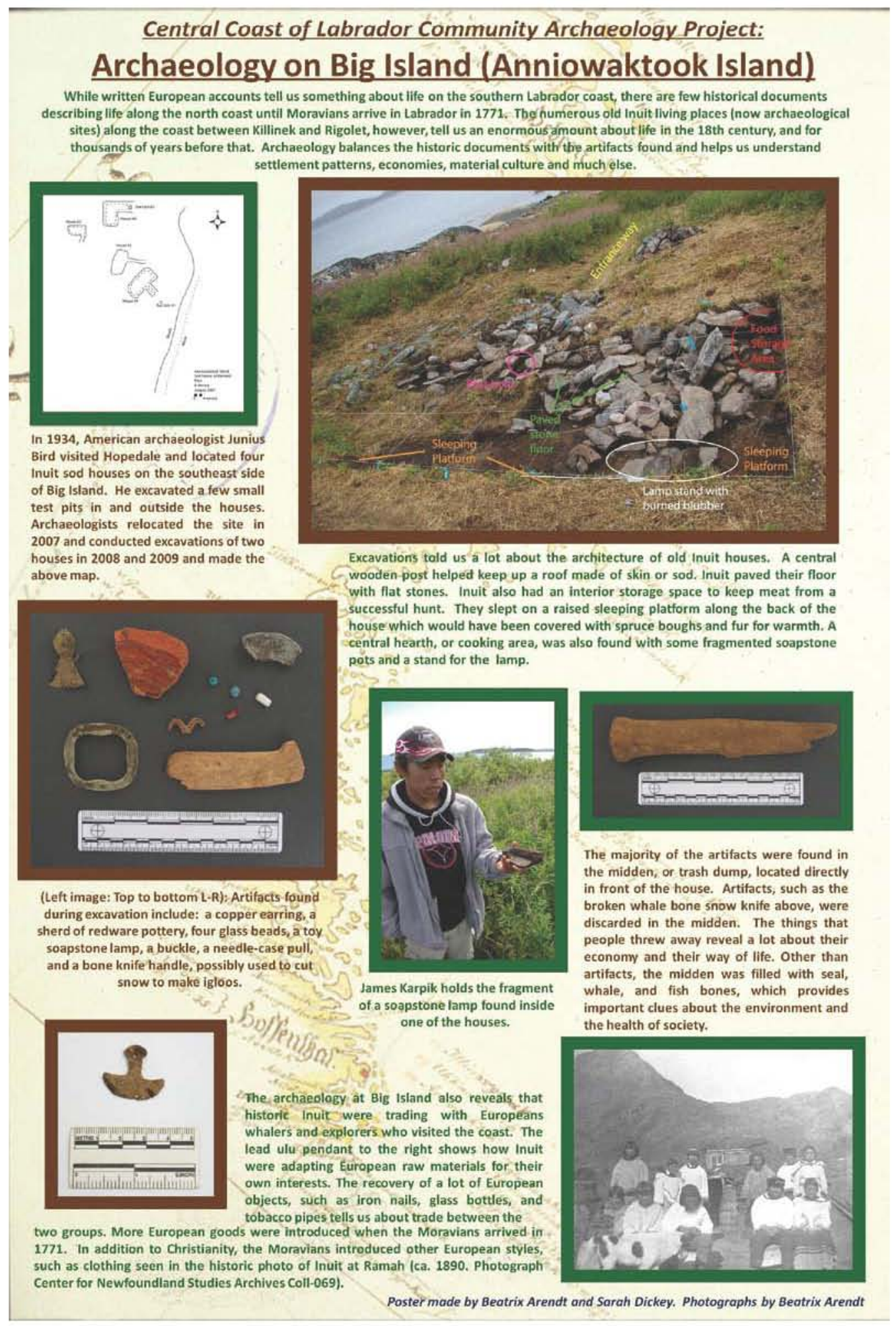

Figure A.6: Poster 2 donated to the school. 


\section{Final Thoughts}

For decades, archaeologists have conducted research on the prehistory of Labrador Inuit, offering insights into the architecture, culture and social organization of the region's earliest ancestors; yet the indigenous voice and perspective were often alienated from this interpretation of the past (Loring 2007). However, current research of Inuit history and material culture is greatly informed by the communities themselves, and involving indigenous communities is necessary to promote cultural diversity and heritage internationally.

The community goals of the HAP included providing training and employment opportunities for Inuit students in the field of archaeology, working with local communities and historical societies to identify archaeological and historical resources, and help foster pride in Labrador culture and heritage. The development of HAP was an attempt to proactively include the Hopedale Inuit community at all levels of research creating a dialogue where we would both benefit from the other's scientific, cultural, and historical knowledge. It was also an effort to decentralize the archaeologist as the sole source of historic “truth,” and incorporate a community archaeology program that provided younger Inuit with tools to help piece together their own history which has for so long been constructed by others.

The archaeology of this area is considered of vital interest of a relatively new Nunatsiavut government (est. 2005) that promotes the sustainability of its people who have endured centuries of change as the result of colonialism, dislocation and resettlement. As a result of cultural changes, many in Labrador emerged with two 
identities; one that related directly to European colonization and a global market, while the other remains part of a sacred Inuit geography (Fienup-Riorden 1994:9). What makes Hopedale unique is that these two identities continue to exist simultaneously for descendant and community members.

As archaeologists, we must recognize that these past encounters contribute to the development of new understandings of Native identities and relationships that emphasize the ongoing effects of colonialism that began when the first Europeans arrived in the fifteenth century (Lightfoot 1995). Archaeology allows for the exploration of this diverse past and places these issues into a historic context highlighting that these problems are part of a longer historical trajectory (Shackel 2004:9).

Part of the reality of this project included living and working in a community where many continue to feel disempowered and hopeless. Reconnecting communities to their cultural heritage is increasingly seen as an empowering experience promoting cultural pride and confidence in a Native population that otherwise experiences serious social dislocation, including a high rate of teenage suicide, alcoholism, and drug-use. Only by acquiring new skills, new experiences, and creating a connection between the local community and archaeological landscape could this type of project be sustainable and successful. Unfortunately, for many students, at the end of the day this was still just a job.

Perhaps my failure to develop a permanent, sustainable archaeology program in Hopedale was not working more closely with the Nunatsiavut government to establish permanent funding to pay students, acquire equipment, and ensure future training. I may 
have led too much without providing sufficient training to older students or local leaders for running similar projects. In developing a program that enhanced current community goals but bypassed a bureaucratic system to quickly implement a summer project for local students, I may have unintentionally undercut my long-term goal in making archaeology an essential part of the Hopedale community consciousness.

On the other hand, perhaps my definition of a successful, long-term project is different from those who live in Hopedale. Rather than archaeology become part of the institutionalized process, the archaeological project spurred a conversation and heightened awareness that enable the community to recognize sod houses, burials, and caches as footprint of their ancestors.

The Central Coast of Labrador Community Archaeology Project developed and run by Dr. Loring serves as the best example of a program that continues to influence and promote archaeology at all levels. Students that worked on summer projects with Dr. Loring have gone on to the university to pursue a degree in archaeology and even get jobs as archaeologists. His co-authored book “Anguti’s Amulet” (Loring and Rosenmeier 2005) was based on the archaeology at Adlavik and is a fixture in all Labrador and Newfoundland schools. The book also continues to serve as a revenue source for the White Elephant, the Makkovik historic museum. This model demonstrates that successful community archaeology projects require long-term commitment by both communities and researchers where individual projects are gradually implement and executed over time. The success of HAP lies not in the development of a full-scale 
archaeological institute, but rather in its function in establishing a foundation for all future projects based on respect, awareness, collaboration.

Working with the Hopedale community has been a wonderful and challenging experience I hope to continue in the future. I am grateful for the community’s willingness to work with me and feel that my thanks are inadequate for all that Hopedale has given and taught me. My only hope is that the work we completed together can serve to inspire a new generation of young Inuit scholars, since the fate of Hopedale and the future of the past will come to reside in the next generation. 


\section{Appendix B: Explanation for the removal of Anniowaktook House 3 and the Avertôk houses from the correspondence analysis}

The correspondence analysis conducted in Chapter 7 sought to measure distance among artifact types and assemblages along a functional gradient. The following Appendix will discuss the rationale for removing the Avertôk and Anniowaktook House 3 assemblages from the analysis.

Figure B.1 shows a scatter plot of assemblages and artifact types on the first two CA axes when all assemblages and artifact types are included. The CA is a descriptive ordination technique that helps to visualize the overall structure of variation in the data and identify outliers. Figure B.1 shows that there is a single cluster of types and assemblages, with other assemblages and types scattered along the edges. The assemblages not included the cluster were the Avertôk assemblages and the Anniowaktook House 3 assemblages, all of which were excavated by Junius Bird.

As noted in Chapter 6, Junius Bird was interested in the prehistoric element of Inuit sites in Labrador and appeared to only collect a small sample of the European materials when they were present. Unfortunately, his collection method does not appear to be consistent; many European artifacts were not collected. Avertôk likely had a substantial amount of European materials — at least more than Bird collected — since the site was occupied into the eighteenth century and overlaps with the earliest part of the Moravian tenure in Hopedale. Further, Moravian historic documents denote that Inuit living at the site actively traded with them and European traders further south. Figure B.1 shows that Avertôk assemblages are more closely associated with traditional Inuit 
artifact types and none of the European trade items, such as tobacco pipes and wine bottles. I argue that the unique feature of the Avertôk assemblages is due to Bird's specific collection methods.

To validate this, I plot the inertia values for assemblages. The proportion of inertia, or variability, accounted for by each axis indicates whether the CA has identified a meaningful gradient, or dimension (K. Smith and Neiman 2007:24; ter Braak 1985). However, a scatterplot of the inertia values of the assemblages plotted against their rank order do not show a large gap between the assemblages (Figure B.2). Instead, a scatterplot of the inertia values of the artifact types does indicate that certain types are influencing the inertia more greatly, specifically, the gap between hollow soapstone vessels (SSHollow) and the rest of the types. A second group of artifact types including lamps, whet stones, strap and sheet metal seem also to be affecting the placement of the types along the axes (Figure B.3). Rather than remove all five types simultaneously, I ran another CA on the remaining assemblages and types when just removing soapstone hollow vessels (listed on graph as SSHollow) ${ }^{17}$ as it had the greatest influence on the distribution (Figure B.3).

The distribution of the assemblages and types again reveals a central cluster with the Avertôk sites and Anniowaktook House 3 scattered away from the cluster. Yet a scatterplot of the inertia values of all of the assemblages does not identify any great difference between each assemblage from the average assemblage, or the centroid of the assemblage point scatter (Figure B.4); yet, a scatterplot of the inertia values of the types

\footnotetext{
${ }^{17}$ All soapstone hollow vessels were returned to the correspondence analysis displayed in Chapter 7 since collections methods were relatively uniform at the Adlavik and Anniowaktook sites. I expected it would help identify an element of the functional gradient.
} 
reveal that different types are influencing the uneven distribution. In this case, these are whet stones, soapstone lamps, and weights (Figure B.5); however, even when all of these types are eliminated, a central cluster of types and assemblages with a few outliers from Avertôk appear (Figure B.6). But eliminating too many types is problematic, given that my intent in using CA is to identify whether types fall along a functional gradient to support the categorical divisions identified in Chapter 7.

Returning to Figure B.3, the biplot reveals the nine Avertôk assemblages and the Anniowaktook House 3 sit at a distance from a large cluster of assemblages and types. These assemblages are so distinctive that they are contrasted against the other Adlavik and Anniowaktook assemblages. Figure B.4 reveals that it is not any single site that is influencing the inertia, rather the distinctiveness of the Anniowaktook House 3 assemblage and all of the Avertôk assemblages in combination. As shown above, removing the types does not improve upon the overall distribution. Unfortunately, the two axes only account for $39.65 \%$ of the variation, suggesting that the data includes a significant amount of unstructured variation and does not fit well into the model that artifact types fall along a functional gradient.

For these reasons, I chose not to include Avertôk or Anniowaktook House 3 assemblages in the CA. Figure 7.20 in Chapter 7 represents the distribution of artifact types and assemblages only for the remaining Anniowaktook and Adlavik sites. 


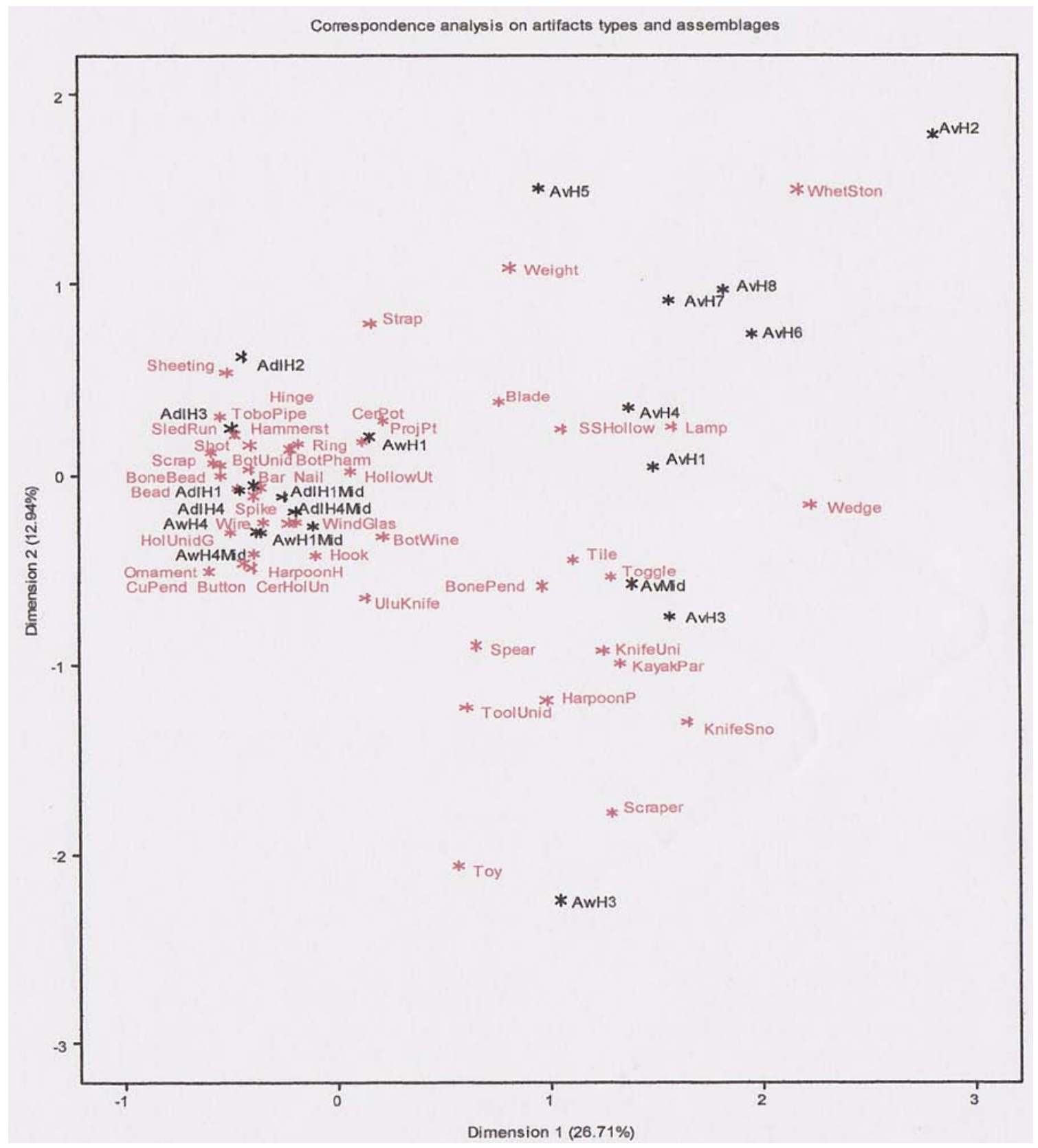

Figure B.1: Correspondence Analysis plot of all assemblages and artifact types. 


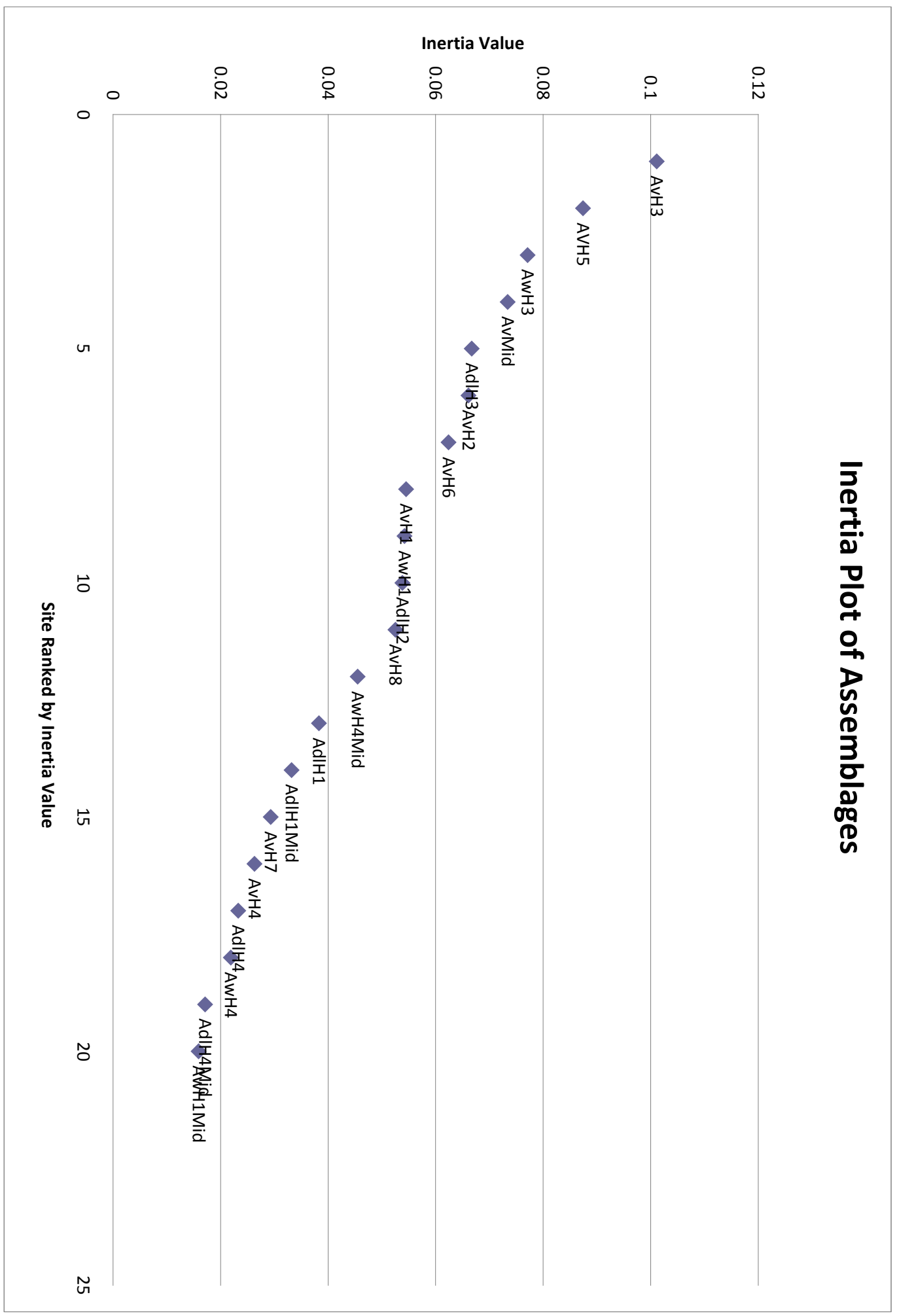

Figure B.2: Scatterplot of Inertia values of assemblages. 


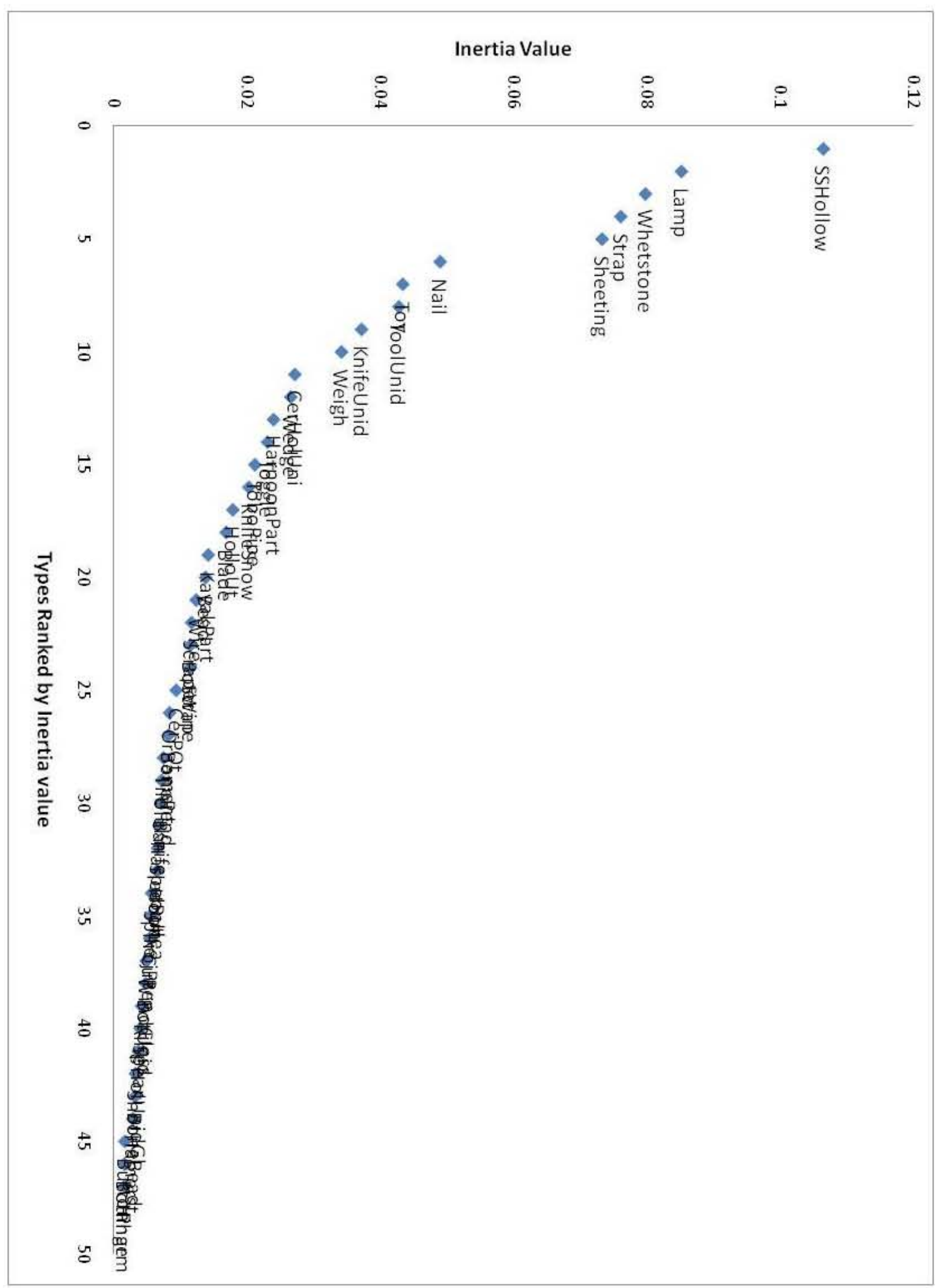

Figure B.3: Scatter plot of inertia values of all artifact types. 


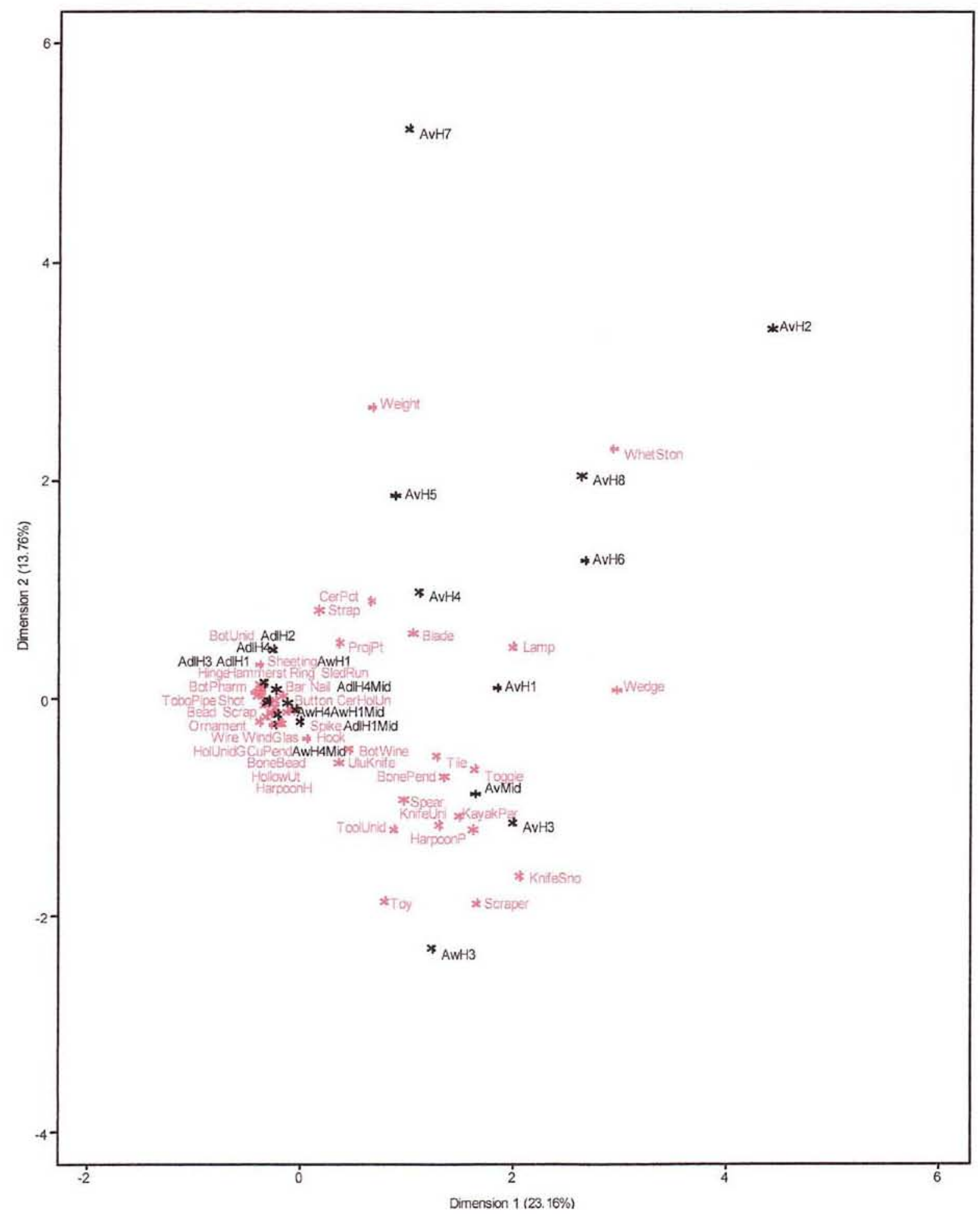

Figure B.4: CA scatterplot after soapstone hollow vessels (SSHollow) were removed. 


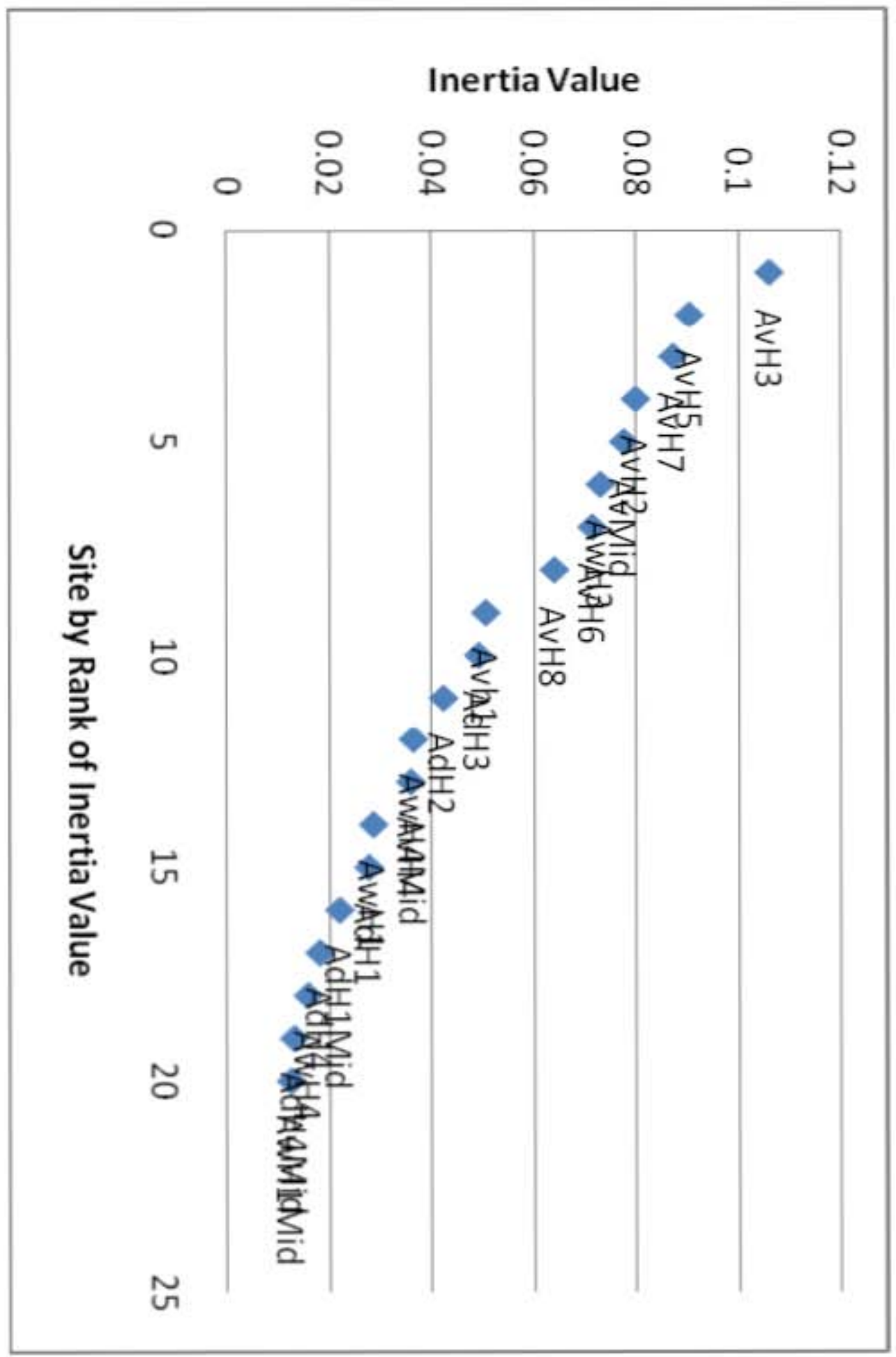

Figure B.5: Scatter plot of inertia values of all assemblages after soapstone hollow vessels were removed (SSHollow). 


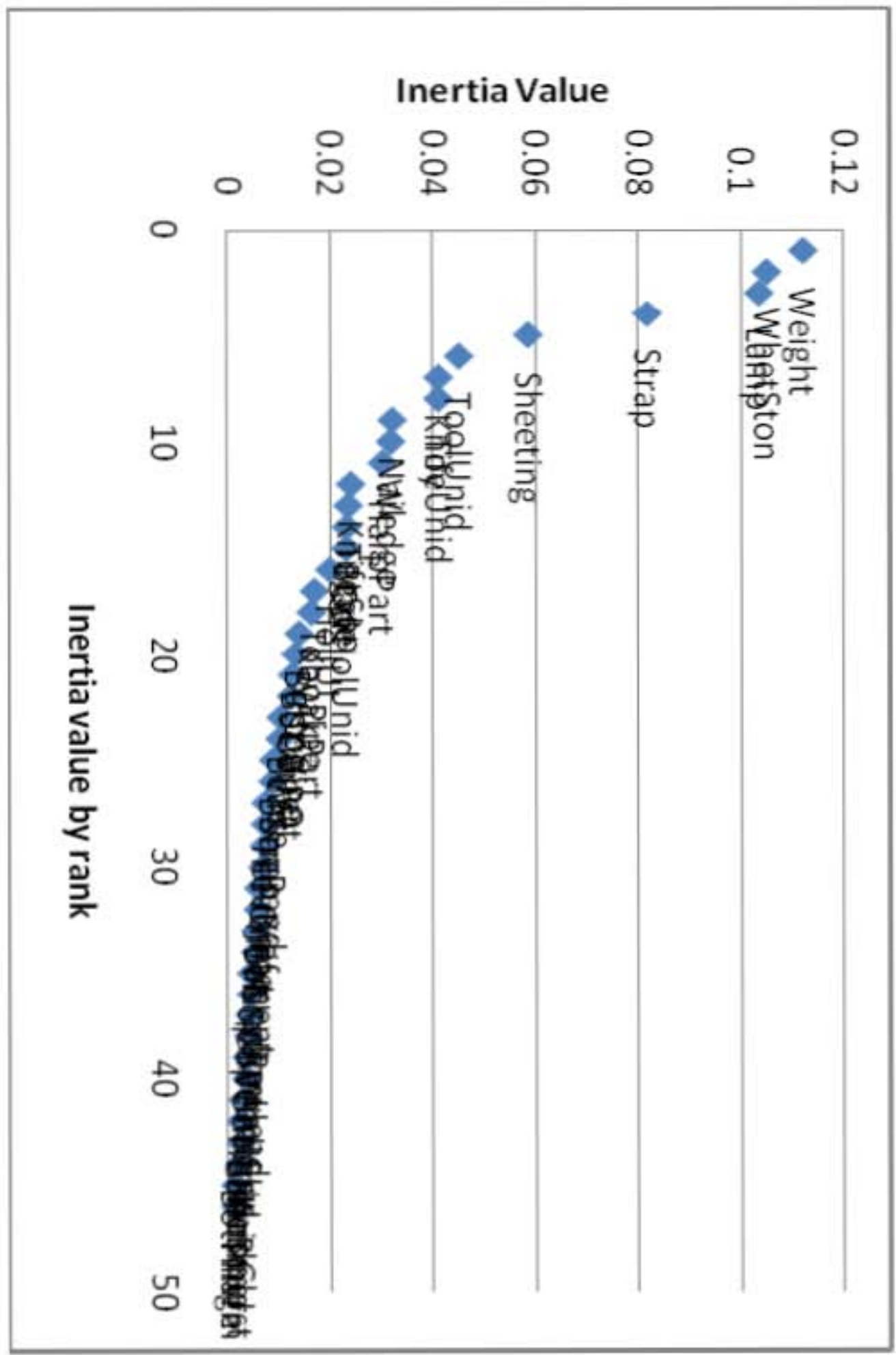

Figure B.6: Scatter plot of inertia values of all artifact types once soapstone hollow vessels removed (SSHollow). 


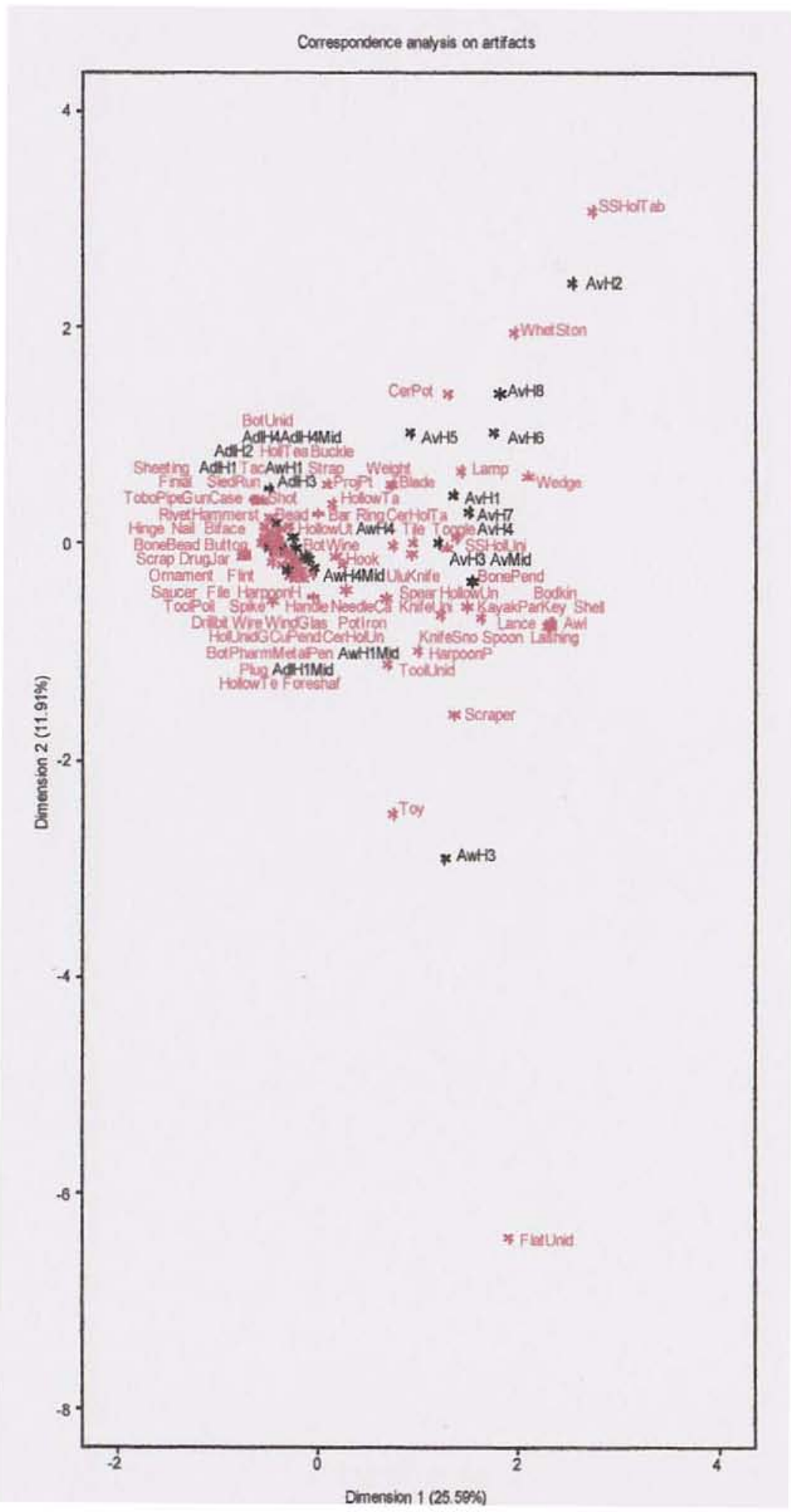

Figure B.7: CA scatterplot after weights, whet stones, lamps and soapstone hollow vessels were removed. 


\section{Appendix C: Faunal Data}

Table C.1: NISP of faunal material from Adlavik House 1 midden.

\begin{tabular}{|lcc|}
\hline Adlavik House 1 & & \\
Midden & & \\
\hline Taxon & NISP & Percent \\
\hline Unidentified & 2717 & 27.30 \\
Unknown Fish & 144 & 1.45 \\
Unknown Bird & 259 & 2.60 \\
Sea bird unknown & 2 & 0.02 \\
Duck species & 23 & 0.23 \\
Raptor & 1 & 0.01 \\
Auks & 2 & 0.02 \\
Bovid & 1 & 0.01 \\
Caribou & 136 & 1.37 \\
Lemming & 1 & 0.01 \\
Hare & 11 & 0.11 \\
Fox & 98 & 0.98 \\
Dog/Wolf & 107 & 1.08 \\
Bear unknown & 3 & 0.03 \\
Otter & 1 & 0.01 \\
Seal unknown & 6394 & 64.25 \\
Harp Seal & 4 & 0.04 \\
Ringed Seal & 19 & 0.19 \\
Walrus & 4 & 0.04 \\
Whale & 24 & 0.24 \\
\hline TOTAL & 9951 & 100.00 \\
\hline
\end{tabular}




\begin{tabular}{|c|c|c|c|c|c|c|}
\hline \multirow[t]{3}{*}{ Class } & \multicolumn{6}{|c|}{ Number of Specimens } \\
\hline & \multicolumn{2}{|c|}{ House 1} & \multicolumn{2}{|c|}{ House 1 midden } & \multicolumn{2}{|c|}{ House 4} \\
\hline & & $\%$ & & $\%$ & $\mathbf{n}$ & $\%$ \\
\hline Mammalia & 604 & $(70 \%)$ & 3,442 & (98 \%) & 8,360 & (94\%) \\
\hline Aves & 2 & $(<1 \%)$ & & $(<1 \%)$ & & $(1 \%)$ \\
\hline Osteicthythes & & & & & 3 & $(<1 \%)$ \\
\hline Bivalvia & 256 & (30 \%) & 38 & $(1 \%)$ & 477 & $(5 \%)$ \\
\hline Gastropoda & & $(<1 \%)$ & & $(<1 \%)$ & 3 & $(<1 \%)$ \\
\hline Indeterminate & & & & $(<1 \%)$ & 22 & $(<1 \%)$ \\
\hline TOTAL & 864 & $(100 \%)$ & 3,497 & $(100 \%)$ & 8,924 & $(100 \%)$ \\
\hline
\end{tabular}

Table C.2: Distribution of specimens by class at Anniowaktook. 
Table C.3: NISP and MNI of identified specimens at Anniowaktook by house and midden.

\begin{tabular}{|c|c|c|c|c|c|c|}
\hline \multirow[t]{2}{*}{ Taxa } & \multicolumn{2}{|c|}{ House 1} & \multicolumn{2}{|c|}{ House 1 midden } & \multicolumn{2}{|c|}{ House 4} \\
\hline & NISP & MNI & NISP & MNI & NISP & MNI \\
\hline MAMMAL & & & & & & \\
\hline \begin{tabular}{|l} 
TERRESTRIAL \\
Hare sp. - Lepus sp. \\
Dog - Canis familiaris \\
Dog/Wolf - C. familiaris or C. \\
$\quad$ Lupus \\
Arctic fox -Vulpes lagopus \\
Red fox - Vulpes vulpes \\
Fox sp. - Vulpes sp. \\
Canid \\
Bear sp. - Ursus sp. \\
Caribou - Rangifer tarandus \\
Cervid sp. \\
Large terrestrial mammal \\
Medium terrestrial mammal \\
Terrestrial mammal
\end{tabular} & $\begin{array}{l}1 \\
1\end{array}$ & 1 & $\begin{array}{c}44(1 \%) \\
1\end{array}$ & $\begin{array}{c}4 \\
\text { (L. } \\
\text { nandible) }\end{array}$ & $\begin{array}{l}11 \\
1 \\
78(1 \%) \\
4 \\
3 \\
25\end{array}$ & $\begin{array}{c}1 \\
5 \\
\text { (R. humerus) } \\
\\
2 \\
\text { (L. humerus) } \\
1 \\
2^{*} \\
\text { (L. humerus) } \\
1 \\
1\end{array}$ \\
\hline $\begin{array}{l}\text { MARINE } \\
\text { Whale sp. } \\
\text { Bearded seal - Erignathus } \\
\text { Barbatus } \\
\text { Harp seal - Phoca } \\
\text { Groenlandica } \\
\text { Harp/Hooded seal - } \\
\text { P. groenlandica or } \\
\text { C. cristata } \\
\text { Harp/Harbour seal - } \\
\text { P. groenlandica or } \\
\text { P. vitulina }\end{array}$ & 1 & 1 & $\begin{array}{c}5 \\
27(1 \%) \\
7\end{array}$ & $\begin{array}{c}2 \\
\text { (L. } \\
\text { andible) } \\
8 \\
\text { R. bulla) }\end{array}$ & $\begin{array}{l}26 \\
8\end{array}$ & $\begin{array}{c}5 \\
\text { (L. bulla) }\end{array}$ \\
\hline
\end{tabular}




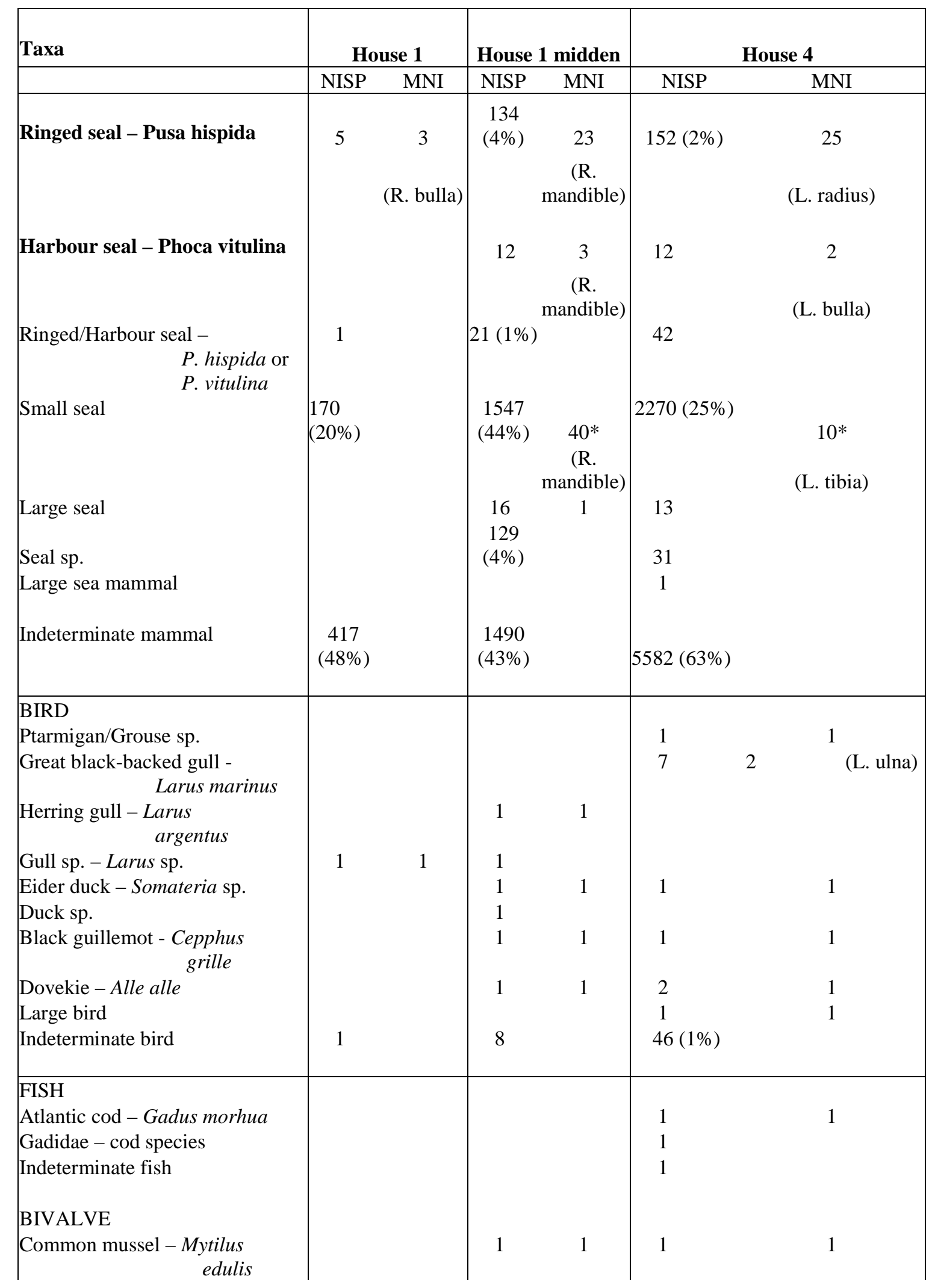




\begin{tabular}{|c|c|c|c|c|c|c|}
\hline \multirow[t]{2}{*}{ Taxa } & \multicolumn{2}{|c|}{ House 1} & \multicolumn{2}{|c|}{ House 1 midden } & \multicolumn{2}{|c|}{ House 4} \\
\hline & NISP & MNI & NISP & MNI & NISP & MNI \\
\hline $\begin{array}{l}\text { Mussel sp. } \\
\text { Indeterminate bivalve }\end{array}$ & $\begin{array}{c}256 \\
(30 \%)\end{array}$ & & $37(1 \%)$ & & $\begin{array}{l}446(5 \%) \\
30\end{array}$ & \\
\hline $\begin{array}{l}\text { GASTROPOD } \\
\text { Indeterminate gastropod }\end{array}$ & 2 & 1 & 1 & 1 & 3 & 3 \\
\hline INDETERMINATE CLASS & & & 2 & & 22 & \\
\hline TOTAL & $\begin{array}{c}864 \\
(100 \%)\end{array}$ & 10 & $\begin{array}{c}3497 \\
(100 \%)\end{array}$ & 89 & $\begin{array}{c}8924 \\
(100 \%)\end{array}$ & 69 \\
\hline
\end{tabular}


Table C.4: Faunal frequencies at Anniowaktook by context and level.

\begin{tabular}{|c|c|c|c|c|c|c|}
\hline Level & Species & |House 1|| & $\begin{array}{c}\text { House } 1 \\
\text { backdirt }\end{array}$ & $\begin{array}{l}\text { House } 1 \\
\text { midden }\end{array}$ & $\begin{array}{c}\text { House } 1 \\
\text { midden } \\
\text { wall }\end{array}$ & $\begin{array}{c}\text { House } \\
4\end{array}$ \\
\hline$?$ & dog & & 4 & & & \\
\hline ? & gull sp. & & 1 & & & \\
\hline ? & indeterminate & & 94 & & & \\
\hline ? & mussel sp. & & 1 & & & \\
\hline$?$ & ringed seal & & & & $\overline{1}$ & \\
\hline ? & small seal sp. & & 23 & & 17 & \\
\hline$\overline{\mathrm{A}}$ & $\overline{\text { arctic fox }}$ & & & & & 2 \\
\hline A & bearded seal & 1 & & 2 & & \\
\hline A & caribou & & & & & 7 \\
\hline A & dog & & & 8 & & 1 \\
\hline A & fox sp. & & & & & 4 \\
\hline A & harbour seal & & & & & 1 \\
\hline $\bar{A}$ & harp or hooded seal & & & 1 & & \\
\hline A & harp seal & & & 6 & & 1 \\
\hline$\overline{\mathrm{A}}$ & indeterminate & 18 & & 473 & & 777 \\
\hline A & large seal sp. & & & 6 & & 1 \\
\hline A & mussel sp. & & & 24 & & 17 \\
\hline A & ringed or harbour seal & 1 & & 6 & & 1 \\
\hline$\overline{\mathrm{A}}$ & |ringed seal & 1 & & 35 & & $\overline{\overline{4}}$ \\
\hline A & seal sp. & & & 47 & & \\
\hline A & small seal sp. & 15 & & 409 & & 51 \\
\hline A & whale sp. & & & & & 1 \\
\hline $\bar{B}$ & $\overline{\text { arctic fox }}$ & & & & & $\overline{44}$ \\
\hline $\mathrm{B}$ & bearded seal & & & 3 & & \\
\hline B & canid & & & 3 & & 1 \\
\hline B & caribou & & & 1 & & 6 \\
\hline$B$ & common mussel & & & $1 \|$ & & 1 \\
\hline $\mathrm{B}$ & dog & & & 24 & & 22 \\
\hline B & dog or wolf & & & 1 & & \\
\hline B & duck sp. & & & $1 \|$ & & \\
\hline B & eider duck & & & 1 & & \\
\hline
\end{tabular}




\begin{tabular}{|c|c|c|c|c|c|c|}
\hline Level & Species & House 1 & $\begin{array}{l}\text { House } 1 \\
\text { backdirt }\end{array}$ & $\begin{array}{l}\text { House } 1 \\
\text { midden }\end{array}$ & $\begin{array}{c}\text { House } 1 \\
\text { midden } \\
\text { wall }\end{array}$ & $\mid \begin{array}{c}\text { House } \\
4\end{array}$ \\
\hline $\mathrm{B}$ & fox sp. & & & 1 & & 14 \\
\hline $\mathrm{B}$ & great black backed gull & & & & & 3 \\
\hline $\mathrm{B}$ & harbour seal & & & 5 & & 2 \\
\hline $\mathrm{B}$ & harp or hooded seal & & & 6 & & 2 \\
\hline B & harp seal & & & 17 & & 8 \\
\hline $\mathrm{B}$ & indeterminate & 54 & & 779 & & 540 \\
\hline $\mathrm{B}$ & large seal sp. & & & 7 & & 6 \\
\hline $\mathrm{B}$ & mussel sp. & 9 & & 12 & & 134 \\
\hline $\mathrm{B}$ & ringed or harbour seal & & & 8 & & 10 \\
\hline $\mathrm{B}$ & ringed seal & 3 & & 67 & & 39 \\
\hline $\mathrm{B}$ & seal sp. & & & 57 & & 4 \\
\hline $\mathrm{B}$ & small seal sp. & 35 & & 820 & & 362 \\
\hline $\mathrm{B}$ & terrestrial & & & & & 1 \\
\hline $\mathrm{B}$ & whale sp. & & & & & 2 \\
\hline $\mathrm{C}$ & arctic fox & & & & & 1 \\
\hline $\mathrm{C}$ & black guillemot & & & 1 & & \\
\hline $\mathrm{C}$ & canid & & & & & 3 \\
\hline $\mathrm{C}$ & caribou & 1 & & 2 & & 2 \\
\hline $\mathrm{C}$ & cervid & 1 & & & & \\
\hline C & $\operatorname{dog}$ & & & 7 & & 10 \\
\hline $\mathrm{C}$ & dovekie & & & 1 & & \\
\hline C & fox sp. & & & & & 22 \\
\hline C & great black backed gull & & & & & 3 \\
\hline $\mathrm{C}$ & gull sp. & & & 1 & & \\
\hline $\mathrm{C}$ & harbour seal & & & 4 & & 2 \\
\hline $\mathrm{C}$ & harp or hooded seal & & & & & 1 \\
\hline C & harp seal & & & 4 & & 4 \\
\hline $\mathrm{C}$ & herring gull & & & 1 & & \\
\hline $\mathrm{C}$ & indeterminate & 61 & & 209 & & 903 \\
\hline $\mathrm{C}$ & large seal sp. & & & 2 & & 1 \\
\hline C & large terrestrial & & & 1 & & \\
\hline C & medium terrestrial & & & 1 & & \\
\hline $\mathrm{C}$ & mussel sp. & 32 & & 1 & & 51 \\
\hline
\end{tabular}




\begin{tabular}{|c|c|c|c|c|c|c|}
\hline Level & Species & House 1 & $\begin{array}{l}\text { House } 1 \\
\text { backdirt }\end{array}$ & $\begin{array}{l}\text { House } 1 \\
\text { midden }\end{array}$ & $\begin{array}{c}\text { House } 1 \\
\text { midden } \\
\text { wall }\end{array}$ & $\mid \begin{array}{c}\text { House } \\
4\end{array}$ \\
\hline$C$ & ringed or harbour seal & & & 7 & & 8 \\
\hline $\mathrm{C}$ & ringed seal & & & 25 & & 22 \\
\hline C & seal sp. & & & 10 & & 2 \\
\hline$C$ & small seal sp. & 36 & & 262 & & 435 \\
\hline$C$ & whale sp. & & & & & 2 \\
\hline clean up & dog & & & & & 1 \\
\hline clean up & indeterminate & & & & & 38 \\
\hline clean up & mussel sp. & & & & & 14 \\
\hline clean up & small seal sp. & & & & & 4 \\
\hline $\mathrm{D}$ & bear sp. & & & & & 1 \\
\hline $\mathrm{D}$ & caribou & & & & & 1 \\
\hline $\mathrm{D}$ & cod & & & & & 1 \\
\hline $\mathrm{D}$ & dog & & & & & 18 \\
\hline $\mathrm{D}$ & fox sp. & 2 & & & & 15 \\
\hline $\mathrm{D}$ & great black backed gull & & & & & 1 \\
\hline $\mathrm{D}$ & harbour seal & & & & & 2 \\
\hline $\mathrm{D}$ & hare sp. & & & & & 1 \\
\hline $\mathrm{D}$ & harp seal & 1 & & & & 4 \\
\hline $\mathrm{D}$ & indeterminate & 71 & & & & 1185 \\
\hline $\mathrm{D}$ & large sea mammal & & & & & 1 \\
\hline $\mathrm{D}$ & large seal sp. & & & & & 2 \\
\hline $\mathrm{D}$ & mussel sp. & 110 & & & & 106 \\
\hline $\mathrm{D}$ & ptarmigan/grouse & & & & & 1 \\
\hline $\mathrm{D}$ & red fox & & & & & 1 \\
\hline $\mathrm{D}$ & ringed or harbour seal & & & & & 7 \\
\hline $\mathrm{D}$ & ringed seal & 1 & & & & 28 \\
\hline $\mathrm{D}$ & seal sp. & & & & & 2 \\
\hline $\mathrm{D}$ & small seal sp. & 22 & & & & 458 \\
\hline $\mathrm{D}$ & whale sp. & & & & & 2 \\
\hline$E$ & arctic fox & & & & & 4 \\
\hline E & bear sp. & & & & & 1 \\
\hline$E$ & bearded seal & & & & & 1 \\
\hline$E$ & black guillemot & & & & & 1 \\
\hline
\end{tabular}




\begin{tabular}{|c|c|c|c|c|c|c|}
\hline Level & Species & House 1| & $\begin{array}{l}\text { House } 1 \\
\text { backdirt }\end{array}$ & $\begin{array}{l}\text { House } 1 \\
\text { midden }\end{array}$ & $\begin{array}{c}\text { House } 1 \\
\text { midden } \\
\text { wall }\end{array}$ & \begin{tabular}{|c} 
House \\
4
\end{tabular} \\
\hline $\mathrm{E}$ & caribou & & & & & 1 \\
\hline $\mathrm{E}$ & dog & & & & & 14 \\
\hline $\mathrm{E}$ & dovekie & & & & & 2 \\
\hline $\mathrm{E}$ & fox sp. & & & & & 10 \\
\hline E & harp or hooded seal & & & & & 1 \\
\hline$E$ & harp seal & 1 & & & & 4 \\
\hline $\mathrm{E}$ & indeterminate & 106 & & & & 1048 \\
\hline $\mathrm{E}$ & large seal sp. & & & & & 1 \\
\hline $\mathrm{E}$ & mussel sp. & 104 & & & & 26 \\
\hline $\mathrm{E}$ & ringed or harbour seal & & & & & 4 \\
\hline $\mathrm{E}$ & ringed seal & & & & & 28 \\
\hline $\mathrm{E}$ & seal sp. & & & & & 5 \\
\hline E & small seal sp. & 39 & & & & 416 \\
\hline $\mathrm{F}$ & caribou & & & & & 2 \\
\hline $\mathrm{F}$ & dog & & & & & 12 \\
\hline F & eider duck & & & & & 1 \\
\hline $\mathrm{F}$ & fox sp. & & & & & 3 \\
\hline $\mathrm{F}$ & gadidae & & & & & 1 \\
\hline $\mathrm{F}$ & harbour seal & & & & & 1 \\
\hline $\mathrm{F}$ & harp or harbour seal & & & & & 1 \\
\hline $\mathrm{F}$ & harp or hooded seal & & & & & 3 \\
\hline $\mathrm{F}$ & indeterminate & 16 & & & & 517 \\
\hline $\mathrm{F}$ & mussel sp. & & & & & 33 \\
\hline $\mathrm{F}$ & ringed or harbour seal & & & & & 6 \\
\hline F & ringed seal & & & & & 12 \\
\hline $\mathrm{F}$ & seal sp. & & & & & 5 \\
\hline $\mathrm{F}$ & small seal sp. & & & & & 150 \\
\hline $\bar{G}$ & caribou & & & & & 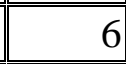 \\
\hline $\bar{G}$ & dog & & & 5 & & 5 \\
\hline $\mathrm{G}$ & fox sp. & & & & & 3 \\
\hline $\mathrm{G}$ & harbour seal & & & 3 & & 1 \\
\hline $\bar{G}$ & hare sp. & & & & & 1 \\
\hline $\bar{G}$ & harp or hooded seal & & & & & 1 \\
\hline
\end{tabular}




\begin{tabular}{|c|c|c|c|c|c|c|}
\hline Level & Species & House 1 & $\begin{array}{l}\text { House } 1 \\
\text { backdirt }\end{array}$ & $\begin{array}{l}\text { House } 1 \\
\text { midden }\end{array}$ & $\begin{array}{c}\text { House } 1 \\
\text { midden } \\
\text { wall }\end{array}$ & $\begin{array}{c}\text { House } \\
4\end{array}$ \\
\hline $\mathrm{G}$ & harp seal & & & & & 1 \\
\hline$G$ & indeterminate & & & 40 & & 468 \\
\hline$G$ & large seal sp. & & & 1 & & 2 \\
\hline $\mathrm{G}$ & mussel sp. & & & & & 21 \\
\hline $\mathrm{G}$ & ringed or harbour seal & & & & & 2 \\
\hline$G$ & ringed seal & & & 6 & & 6 \\
\hline $\mathrm{G}$ & seal sp. & & & 15 & & 3 \\
\hline$G$ & small seal sp. & & & 39 & & 134 \\
\hline $\mathrm{G}$ & whale sp. & & & & & 1 \\
\hline $\mathrm{H}$ & bear sp. & & & & & 1 \\
\hline $\mathrm{H}$ & dog & & & & & 2 \\
\hline $\mathrm{H}$ & fox sp. & & & & & 3 \\
\hline $\mathrm{H}$ & hare sp. & & & & & 1 \\
\hline $\mathrm{H}$ & harp seal & & & & & 2 \\
\hline $\mathrm{H}$ & indeterminate & & & & & 409 \\
\hline $\mathrm{H}$ & large bird & & & & & 1 \\
\hline $\mathrm{H}$ & mussel sp. & & & & & 28 \\
\hline $\mathrm{H}$ & ringed or harbour seal & & & & & 2 \\
\hline $\mathrm{H}$ & ringed seal & & & & & 5 \\
\hline $\mathrm{H}$ & seal sp. & & & & & 1 \\
\hline $\mathrm{H}$ & small seal sp. & & & & & 113 \\
\hline $\mathrm{J}$ & dog & & & & & 2 \\
\hline $\mathrm{J}$ & fox sp. & & & & & 4 \\
\hline $\mathrm{J}$ & harbour seal & & & & & 3 \\
\hline $\mathrm{J}$ & harp seal & & & & & 2 \\
\hline $\mathrm{J}$ & indeterminate & & & & & 499 \\
\hline $\bar{J}$ & mussel sp. & & & & & 16 \\
\hline $\mathrm{J}$ & ringed or harbour seal & & & & & 2 \\
\hline $\mathrm{J}$ & ringed seal & & & & & 8 \\
\hline $\mathrm{J}$ & seal sp. & & & & & 9 \\
\hline $\mathrm{J}$ & small seal sp. & & & & & 147 \\
\hline
\end{tabular}




\section{Bibliography}

Arendt, Beatrix

20082007 Season Report: Hopedale Archaeology Project. Provincial Archaeology Office 2007 Archaeology Review 6: 3-6.

2010 Caribou to Cod: Moravian Missionary Influence on Inuit Subsistence Strategies. Historical Archaeology 44(3): 81-101.

Auger, Reginald

1989 Labrador Inuit and Europeans in the Strait of Belle Isle: From the written sources to the archaeological evidence. $\mathrm{PhD}$, University of Calgary, Calgary.

Baer, K., and H. Rudinger

1958 Architecture of the California missions. University of California Press, Berkeley.

Balikci, Asen

1984 Netsilik. In Handbook for North American Indians Arctic, edited by William C. Sturtevant, Volume 5. Smithsonian Institution, Washington, D.C.

Barkham, Selma

1978 The Basques: filling a gap in our history between Jacques Cartier and Champlain. Canadian Geographical Journal 96: 8-19.

1980 Notes of Straits of Belle Isle. Etudes/Inuit/Studies 4(1-2): 51-58.

1984 The Basque Whaling Establishments in Labrador 1536-1632 - A Summary. Arctic 37(4): 515-518.

Barr, William

1994 The Eighteenth Century Trade between the Ships of the Hudson's Bay Company and the Hudson Strait Inuit. Arctic 47(3): 236-246.

Bender, Barbara

1995 Landscape: Politics and Perspectives. Berg, Oxford.

Benham, Daniel

1856 Memoirs of James Hutton Comprising the Annals of His Life and Connection with the United Brethren. BiblioBazaar, LLC.

Bhabha, Homi K.

1994 The Location of Culture. 1st ed. Routledge, New York. 
Billeck, William

2008 Red-on-White Drawn or Cornelian Beads: A 19th-century Temporal Marker for the Plains. Beads 20: 49-61.

Billson, Janet Mancini, and Kyra Mancini

2007 Inuit women: their powerful spirit in a century of change. Rowman \& Littlefield, Lanahman, Maryland.

Binford, Lewis

1962 A New Method of Calculating Dates from Kaolin Pipe Stem Fragments. Southeastern Archaeological Conference Newsletter 9(1): 19-21.

1978 Nunamiut Ethnoarchaeology. Academic Press, New York.

1980 Willow Smoke and Dogs’ Tails: Hunter-Gatherer Settlement Systems and Archaeological Site Formation. American Antiquity 45(1): 4-20.

Bird, Junius

n.d. Junius Bird's hand-written notes from Anniowaktook. American Museum of Natural History, On file at the American Museum of Natural History.

1945 Archaeology of the Hopedale Area, Labrador. Anthropological Papers of the American Museum of Natural History. American Museum of Natural History, New York.

Birket-Smith, Kaj

1959 The Eskimos. Methuen \& Co. Ltd, London.

Blackburn, Carole

2000 Harvest of souls: the Jesuit missions and colonialism in North America, 16321650. McGill-Queen's Press - MQUP, Quebec.

Boas, Franz

1964 The Central Eskimo. University of Nebraska Press, Lincoln.

Bodenhorn, Barbara

1990 “I'm Not the Great Hunter, My Wife Is": Inupiat and anthropological models of gender. Etudes/Inuit/Studies 14(1-2): 55-74.

Boles, B., G. J. Chaput, and F. Phillips

1980 Offshore Labrador Biological Studies, 1979: Seals. A Study and Review of the Distribution of Pinnipeds in Labrador. Report by Atlantic Biological Services Ltd, St. John’s, Newfoundland. Total Eastcan Explorations, Calgary. 
Brice-Bennett, Carol

1981 Two Opinions: Inuit and Moravian Missionaries in Labrador 1804-1860. MA, Memorial University of Newfoundland, St. John's, Newfoundland.

2003 Hopedale: Three ages of a community in northern Labrador. Historical Sites Association of Newfoundland and Labrador, St. John's.

Briggs, Jean L.

1971 Never in Anger: Portrait of an Eskimo Family. Harvard University Press, Cambridge.

Buchwald, Vagn Fabritius

2005 Iron and steel in ancient times. Kgl. Danske Videnskabernes Selskab.

Bundy, Barbara E., Allen P. McCartney, and Douglas W. Veltre

2003 Glass Trade Beads from Reese Bay, Unalaska Island: Spatial and Temporal Patterns. Arctic Anthropology 40(1): 29-47.

Burgess, Laurie, and Laure Dussubieux

2007 Chemical Composition of late 18th- and 19th-Century Glass Beads from Western North America: Clues to Sourcing Beads. Beads: Journal of the Society of Bead Researchers 19: 58-73.

Burgess, Laurie, and Christopher Sperling

2008 Glass Beads from Gloucester Point. In Beads and More Beads: Studies in Historical Archaeology. Albuquerque.

Bury, John Bagnell

2004 The Idea of Progress. Kessinger Publishing, Cambridge.

Cabak, Melanie

1991 Inuit Women as catalysts of Change: An archaeological study of 19th century Northern Labrador. MA, University of South Carolina, Columbia.

Cabak, Melanie, and Stephen Loring

2000 "A set of very fair cups and saucers": Stamped Ceramics as an example of Inuit incorporation. International Journal of Historical Archaeology 4(1): 1-34.

Cadigan, Sean T.

2009 Newfoundland and Labrador: A History. University of Toronto Press, Toronto. 
Cartwright, George

1792 A journal of transactions and events, during a residence of nearly sixteen years on the coast of Labrador: containing many interesting particulars, both of the country and its inhabitants, not hitherto known. Allin and Ridge, Newark.

Cary, Hary

2004 Hoffnungsthal: The Archaeology and Architecture of the First Moravian Mission to the Labrador Inuit, 1752. MA, Memorial University of Newfoundland, St. John's Newfoundland.

Chaney, Edward, and Kathleen Deagan

1989 St. Augustine and the La Florida colony: new life-styles in a new land. In First Encounters: Spanish Exploration in the Caribbean and the United States, 1492157, edited by Jerald Milanich and Susan Milbrath, pp166-182. University Press of Florida Press, Gainesville.

Clark, Brenda

1979 Thule Occupation of West Hudson Bay. In Thule Eskimo Culture: An Anthropological Retrospective, pp. 89-99. Mercury Series 88. National Museum of Canada, Ottawa.

Collings, Peter, George Wenzel, and Richard Condon

1998 Modern Food Sharing Networks and Community Integration in the Central Canadian Arctic. Arctic 51(4): 301-314.

Coltrain, Joan Brenner, M. Geoffrey Hayes, and Dennis H. O’Rourke 2004 Sealing, whaling and caribou: the skeletal isotope chemistry of Eastern Arctic foragers. Journal of Archaeological Science 31(1): 39-57.

Comaroff, John, and Jean Comaroff

1991 Of Revelation and Revolution: Christianity, Colonialism and Consciousness in South Africa. University of Chicago Press, Chicago.

1992 Ethnography and the Historical Imagination. Westview Press, Inc., Boulder.

Conover, W.J.

1980 Practical Non-Parametric Statistics. John Wiley and Sons, New York.

Coupland, Gary

1996 The Evolution of Multi-Family Households on the Northwest Coast of North America. In People Who Lived in Big Houses: Archaeological Perspectives on Large Domestic Structures, edited by Gary Coupland and E.B. Banning, pp. 121150. Monographs in World Archaeology 27. Prehistory Press, Madison. 
Cox, Stephen

1977 Prehistoric Settlement and Culture Change at Okak, Labrador. PhD, Department of Anthropology, Harvard University, Boston.

Crumley, Carole

1995 Heterarchy and the Analysis of Complex Societies. Heterarchy and the Analysis of Complex Societies 6(1). Archaeological Papers of American Anthropological Association: 1-5.

Cusick, James

1998 Historiography of Acculturation: An Evaluation of Concepts and their Application in Archaeology. In Studies in Culture Contact: Interaction, Culture Change and Archaeology, edited by James Cusick, pp. 126-145. Southern Illinois University, Carbondale.

Damas, David

1972 Central Eskimo System of Food Sharing. Ethnology 11(3): 220-240.

1984 Copper Eskimo. In Arctic, edited by W.C. Sturtevant, 5: Handbook of North American Indians. Smithsonian Institution, Washington, D.C.

Davey, J. W.

1905 The Fall of Torngak. S. W. Partridge and Co., London.

Dawson, Peter C.

2001 Interpreting Variability in Thule Inuit Architecture: A Case Study from the Canadian High Arctic. American Antiquity 66(3): 453-470.

Deagan, Kathleen

1974 Sex, status and role in the mestizaje of Spanish colonial Florida. PhD, University of Florida, Gainesville.

1983 Spanish St. Augustine: The Archaeology of a Colonial Creole Community. Academic Press, April.

1985 The archaeology of sixteenth century St. Augustin. The Florida Anthropologist 38: 6-33.

1987 Ceramics, Glassware, and Beads. Smithsonian Institution Press, Washington, D.C. 
Deetz, James

1991 Introduction: Archaeological Evidence of Sixteenth- and Seventeenth-Century Encounters. In Historical Archaeology in Global Perspective, edited by Lisa Falk, 1-9. Smithsonian Institution Press, Washington, D.C.

Delanglez, Jean

1948 Life and voyages of Louis Jolliet, 1645-1700. English. Institute of Jesuit History, Chicago.

Dempsey, Paul, and Martin Baumhoff

1963 The Statistical Use of Artifact Distributions to Establish Chronological Sequence. American Antiquity 28: 496-509.

Dommelen, Peter van

1997 Colonial constructs: colonialism and archaeology in the Mediterranean. World Archaeology 28(3): 305-323.

Drennan, Robert

1996 Statistics for Archaeologists: A common Approach. Kluwer Academic/Plenum Publishers, New York.

Dunnell, Robert C.

1970 Seriation Method and Its Evaluation. American Antiquity 35(3): 305-317.

Dupont-Hébert, Celine, and Felix Gagné

2008 Preliminary Zooarchaeological Analysis of the Big Island Site (GiCa-02), Hopedale Area, Labrador-Newfoundland. Cahiers du laboratoire de zooarcheologie. University Laval, Quebec City.

Durkheim, Emile

1912 The Elementary Forms of Religious Life. Oxford University Press, New York.

Ellis, Henry

1748 A voyage to Hudson's-Bay by the "Dobbs Galley" and "California" in the years 1746 and 1747 for discovering a North West Passage. Library MARC record. Printed for H. Whitridge, London.

Elton, Charles

1942 Voles, Mice and Lemmings. Clarendon Press, Oxford.

Fagan, Brian

1984 Clash of Cultures. W. H. Freeman and Company, New York. 
Farnsworth, Paul

1992 Missions, Indians, and Cultural Continuity. Historical Archaeology 26(1): 22-36.

Ferguson, Leland

1992 Uncommon Ground: Archaeology and early African America, 1650-1800.

Smithsonian Institution Press, Washington, D.C.

Ferguson, Rob

2003 Archaeological Research at the Moravian Mission, Hopedale, 2001.

Archaeological Report. Parks Canada.

Ferris, Neal

2011 The Archaeology of Native-Lived Colonialism: Challenging History in the Great Lakes. University of Arizona Press, Tucson.

Fienup-Riordan, Ann

1991 The Real People and the Children of Thunder: The Yup'Ik Eskimo Encounter With Moravian Missionaries John and Edith Kilbuck. University of Oklahoma Press, Norman.

1994 Boundaries and Passages: Rule and Ritual in Yup'ik Eskimo Oral Tradition. University of Oklahoma Press, Norman.

Finkelstein, S. A., J. M. Ross, and J. K. Adams

2009 Spatiotemporal Variability in Arctic Climates of the Past Millennium: Implications for the Study of Thule Culture on Melville Peninsula, Nunavut. Arctic, Antarctic, and Alpine Research 41(4): 442-454.

Fitzhugh, William W.

1972 Environmental Archeology and Cultural Systems in Hamilton Inlet, Labrador. Smithsonian Contribution to Anthropology 16. Smithsonian Institution, Washington, D.C.

1977 Indian and Eskimo/Inuit Settlement History in Labrador: An Archaeological View. In Our Footsteps are Everywhere: Inuit Land Use and Occupancy in Labrador, pp. 1-41. Labrador Inuit Association, Nain.

1980 Preliminary Report on the Torngat Archaeological Project. Arctic 33(3): 585-606.

1981 Smithsonian Archaeological Surveys Central and Northern Labrador, 1980. Archaeology in Newfoundland and Labrador 1980. Department of Tourism and Culture, St. John's, February. 
1994 Staffe Island I and the northern Labrador Dorset-Thule succession. In Threads of Arctic Prehistory: Papers in honour of William E. Taylor, Jr., edited by David A. Morrison and Jean-Luc Pilon. Archaeological Survey of Canada Mercury Series 149. Canadian Museum of Civilization, Ottawa.

2009 Exploring Cultural Boundaries: The Less "Invisible” Inuit of Southern Labrador and Quebec. In On the Track of the Thule Culture From Bering Strait to East Greenland, 15:129-148. Studies in Archaeology and History. The National Museum of Denmark, Copenhagen.

Fitzhugh, William W., and Aaron Crowell

2009 Ancestors and Ivories: Art of the Ancient Bering Sea. In Gifts for the Ancestors: Ancient Ivories from Bering Sea, edited by Julie Hollowell and Aaron Crowell, pp. 18-41. Princeton University Press, Princeton.

Fitzhugh, William W., and Ben Ford

2008 The Gateways Project 2008: Land and Underwater Excavations at Hare Harbor, Mécatina. Smithsonian Institution, Washington, D.C.

Fitzhugh, William W., and Jacqueline Olin (editors).

1993 Archaeology of the Frobisher Voyages. illustrated edition. Smithsonian Institution Press, Washington, D.C.

Fitzhugh, William W., and Erik Phaneuf

2008 The Gateways Project 2007: Land and Underwater Excavations at Hare Harbor, Mécatina. Smithsonian Institution Press, Washington D.C.

Fitzhugh, William W., Anja Herzog, and Sophia Perdikaris

2011 Ship to Shore: Inuit, Early Europeans, and Maritime Landscapes in the Northern Gulf of St. Lawrence. In The Archaeology of Maritime Landscapes, edited by Ben Ford, 2: When the Land Meets the Sea. Springer, New York.

Foster, George

1960 Culture and Conquest: America’s Spanish Heritage. Anthropology 27. Viking Fund Publications, New York.

Friesen, T. Max, and Charles Arnold

2008 The Timing of the Thule Migration: New Dates from the Western Canadian Arctic. American Antiquity 73(3): 491-538.

Frink, Lisa

2003 A Tale of Three Villages: Archaeological Investigation of Late Prehistoric and Historic Change in Western Alaska. PhD, University of Wisconsin, Madison. 
Galle, Jillian E.

2004 Designing Women: Measuring Acquisition and Access at the Hermitage Plantation. In Engendering African American Archaeology, edited by Jillian E. Galle and Amy L. Young, pp. 39-72. The University of Tennessee Press, Knoxville.

2006 Strategic Consumption: Archaeological Evidence for Costly Signaling among Enslaved Men and Women in the Eighteenth-Century Chesapeake. PhD, University of Virginia, Charlottesville.

Giddings, J. Louis

1952 The Arctic Woodland Culture of the Kobuk River. University Museum Monograph. 8. University of Pennsylvania.

Gollin, Gillian

1967 Moravians in Two Worlds: A Study of Changing Communities. Columbia University Press, New York.

Gosden, Chris

2001 Postcolonial Archaeology: Issues of Culture, Identity, and Knowledge. In Archaeological Theory Today, edited by Ian Hodder, pp. 241-261. Blackwell Publishing Inc., Malden.

Gosling, William G.

1910 Labrador: Its discovery, exploration and development. Alston Rivers, Ltd., London.

Graburn, Nelson

1969 Eskimos without Igloos. Little, Brown and Co., Boston.

Graham, Elizaaeth

1998 Mission Archaeology. Annual Review of Anthropology 27: 25-62.

Greenacre, Michael J.

1993 Correspondence Analysis in Practice. Academic Press, London.

Grier, Colin

2000 Labor Organization and Social Hierarchies in North American Arctic Whaling Societies. In Hierarchies in Action: Cui Bona?, edited by Diehl, pp. 264-283. Center for Archaeological Investigations Occasional Paper 27. Southern Illinois University, Carbondale. 
Grier, Colin, and James M. Savelle

1994 Intrasite spatial patterning and Thule Eskimo social organization. Arctic Anthropology 31(2): 95-107.

Gulløv, H., and Robert McGhee

2006 Did Bering Strait People Initiate the Thule Migration? Alaskan Anthropological Journal 4(1-2): 254-263.

Hanson, Lee

1969 Kaolin Pipestems — Boring in on a fallacy. Historical Site Archaeology 4:2-15.

1971 A Few Cents More. The Conference on Historic Site Archaeology Papers 6: 254257.

Hantman, Jeffrey

1990 Between Powhatan and Quirank: Reconstructing Monacan Culture and History in the Context of Jamestown. American Anthropologist 92(3): 676-690.

Harrington, J. C.

1951 Tobacco Pipes from Jamestown. Bulletin of the Archaeological Society of Virginia 5(4): 2-8.

1954 Dating Stem Fragments of Seventeenth and Eighteenth Century Clay Tobacco Pipes. Quarterly Bulletin of the Archaeological Society of Virginia 9(1): 10-14.

Haven, Jens

n.d. Memoir of the Life of Br. Jens Haven, the First Missionary of the Brethren's Church to the Esquimaux, on the Coast of Labrador. Periodical Accounts II. London. http://www.mun.ca/rels/morav/texts/jhaven.html.

1797 Account of the life of Brother Jens Haven, the first missionary sent by the Brethren to the Esquimaux Indians on the Coast of Labrador. Periodical Accounts Relating to the Missions of the Church of the United Brethren, established among the Heathn, vol. 2 (1798).

Hawkes, Earnest William

1916 The Labrador Eskimo. Anthropological Series 14. Johnson Reprint Corporation, New York.

Henshaw, Anne

2000 Central Inuit Household Economies: Zooarchaeological, Environmental, and Historical Evidence from Outer Frobisher Bay, Baffin Island, Canada. Archaeopress, Oxford. 
Hiller, James K.

1967 The Foundation and the Early Years of the Moravian Missions in Labrador 17521805. MA, Memorial University of Newfoundland and Labrador, St. John's Newfoundland.

1971a The Moravians in Labrador, 1771-1805. The Polar Record 15(99): 839-854.

1971b Early Patrons of the Labrador Eskimos: The Moravian Mission in Labrador, 1764-1805. In Patrons and Brokers in the East Arctic, edited by Robert Paine. Newfoundland Social and Economic Papers 2. University of Toronto Press, Toronto.

Hood, Bryan

2008 Towards an Archaeology of the Nain Region, Labrador. Contributions to Circumpolar Anthropology 7. Smithsonian Institution Press, Washington, D.C.

Huntington, Patricia

2002 Robert E. Peary and the Cape York Meteorites. Polar Geography 26(1): 53-65.

Hutchings, Jeffrey A., and Ransom A. Myers

1995 The Biological Collapse of Atlantic Cod off Newfoundland and Labrador: An exploration of Historical Changes in Exploitation, Harvesting Technology, and Management. In The North Atlantic Fisheries: Success, Failures, and Challenges, 39-93. The Institute of Island Studies, Charlottestown, Prince Edward Island.

Hutton, Joseph E.

1922 A History of Moravian Missions. Moravian Publication Office, London.

Hutton, Samuel K.

1912 Among the Eskimos of Labrador: A Record of Five Years Close Intercourse with the Eskimo Tribes of Labrador. Seeley, Service and Co. Limited, London.

Innis, Harold A.

1940 The Cod Fisheries: the History of an International Economy. Yale University Press, New Haven.

Jackson, Robert, and Edward Castillo

1995 Indians, Franciscans, and Spanish Colonization. University of New Mexico Press, Albuquerque.

Jacobs, John

1979 Climate and the Thule Ecumene. In Thule Eskimo Culture: An Anthropological Retrospective, edited by Allen McCartney, 528-534. Mercury Series 88. National Museum of Canada, Ottawa. 
Jaenen, Cornelius

1991 French Sovereignty and Native Nationhood during the French Régime. In Sweet Promises: A reader on Indian-White Relations in Canada, edited by J.R. Miller, 19-41. University Press of Toronto, Toronto.

Jenness, Diamond

1922 The Life of the Copper Eskimo. Report of the Canadian Arctic Expeditions, 19131918. Ottawa.

Jordan, Richard

n.d. Field notes of excavations at Eskimo Island, Labrador, 1973-1975. Unpublished report on file at the Peary-MacMillan Arctic Museum and Arctic Studies Center, Bowdoin College, Brunswick, Maine.

1974 Preliminary Report on Archaeological Investigations of the Labrador Eskimo in Hamilton Inlet in 1973. Man in the Northeast 8(1).

1977 Inuit Occupation of the Central Labrador Coast since 1600 AD. In Our Footsteps are Everywhere: Inuit Land Use and Occupancy in Labrador, edited by Carol Brice-Bennett, 43-48. Labrador Inuit Association, Nain.

1978 Archaeological investigations of the Hamilton Inlet Labrador Eskimo: Social and economic responses to European contact. Arctic Anthropology 15(2): 175-185.

Jordan, Richard, and Susan Kaplan

1980 An archaeological view of the Inuit/European contact period in central Labrador. Etudes/Inuit/Studies 4(1-2): 35-45.

Kaplan, Susan

1983 Economic and social change in Labrador Neo-Eskimo culture. PhD, Bryn Mawr College, Bryn Mawr.

1985a European Goods and Socio-Economic Change in Early Labrador Inuit Society. In Cultures in Contact: The Impact of European Contacts on Native American culture Institutions A.D. 1000-1800, edited by William W. Fitzhugh, 45-69. Smithsonian Institution Press, Washington, DC.

1985b Early Neoeskimo sites in central Labrador. Archaeology in Newfoundland and Labrador 1984, Annual Report No. 5. Historical Resources Division, Department of Culture, Recreation and Youth, St. John's,, Newfoundland. 
Kaplan, Susan, and James Woollett

2000 Challenges and Choices: Exploring the Interplay of Climate, History and Culture on Canada's Labrador Coast. Arctic, Antarctic, and Alpine Research 32(3): 351359.

Karklins, Karlis

1985 Guide to the Description and Classification of Glass Beads. In Glass Beads. Studies in Archaeology, Architecture and History. Parks Canada, Ottawa.

1993 The A. Speo Method of Heat Rounding Drawn Glass Beads and its Archaeological Manifestations. Beads: Journal of the Society of Bead Researchers 5: 27-36.

Kelly, Robert L.

2010 A Good Start. Current Anthropology 51(1): 109-110.

Kennedy, John

1995 People of the Bays and Headlands: Anthropological History and Fate of Communities in the Unknown Labrador. University of Toronto Press, Toronto.

2009 Two Worlds of Eighteenth-Century Labrador Inuit. In Moravian Beginnings in Labrador: Papers from a Symposium held in Makkovik and Hopedale, edited by Hans Rollmann, 23-36. Newfoundland and Labrador Studies, Occasional Publication 2. Memorial University, St. John’s, Newfoundland.

Kidd, Kenneth E., and Martha Ann Kidd

1970 A Classification System for Glass Beads for the Use of Field Archaeologists. Canadian Historic Sites, Occasional Papers in Anthropology and History 1. Ottawa.

Kleivan, Helga

1966 The Eskimos of Northeast Labrador: A History of Eskimo-White Relations, 17711955. Norsk Polarinstitutt, Oslo.

Kristiansen, Kristian

2004 Genes versus agents. A discussion on the widening theoretical gap in archaeology. Archaeological Dialogues 11(2): 77-99.

Kubler, George

1940 The religious architecture of New Mexico in the colonial period and since the American occupation. The Taylor Museum, Colorado Springs.

1948 Mexican Architecture of the Sixteenth Century. Greenwood Press. 
Kupp, Jan, and Simon Hart

1976 The Dutch in the Strait of Davis and Labrador during the 17th and 18th Centuries. Man in the Northeast Spring(11): 3-20.

Lapham, Heather

2001 More than “A Few Blew Beads": The Glass and Stone Beads from Jamestown Rediscovery’s 1994-1997 Excavations. The Journal of the Jamestown Rediscovery Center 1.

LaTrobe, Benjamin

1774 A Brief Account of the Mission established among the Esquimaux Indians, on the Coast of Labrador by the Church of the Brethren. The Brethren's Society for the Furtherance of the Gospel, London. The Moravian Archives, London.

1800 Religious Intelligence: General State of the Missions of the United Brethren. In The Missionary Magazine, for 1800, a Periodical Monthly Publication Intended as a Repository of Discussion, and Intelligence Respecting the Progress of the Gospel throughout the World, V: J. Pillans and Sons, Edinburgh.

Legendre, Pierre, and Louis Legendre

1998 Numerical ecology. Elsevier Science B.V., Amsterdam.

LeMoine, Genevieve

2001 Woman of the House: Gender, Architecture and Ideology in Dorset Prehistory. Arctic Anthropology 40(1): 121-138.

Lewis, Kingsley

1985 The Moravian Mission in Barbados 1816-1886: A Study of the Historical Context and Theological Significance of a Minority Church Among Oppressed People. Peter Lang Publishing Inc, Frankfurt.

Liebmann, Matthew

2008 The Innovative Materiality of Revitalization Movements: Lessons from the Pueblo Revolt of 1680. American Anthropologist 110(3): 360-372.

Liebmann, Matthew, and Robert Preucel

2007 The Archaeology of the Pueblo Revolt and the Formation of the Modern Pueblo World. Kiva: The Journal of Southwestern Anthropology and History 73(2): 195217.

Lightfoot, Kent G.

1995 Culture contact studies. American Antiquity 60(2): 199-217. 
2005 Mission, Gold, Furs, and Manifest Destiny: Rethinking an Archaeology of Colonialism for Western North America. In Historical Archaeology, edited by Martin Hall and Stephen W. Silliman, pp. 272-292. Blackwell Publishing Ltd, Oxford.

2006 Indians, Missionaries, and Merchants: The Legacy of Colonial Encounters on the California Frontiers. 1st ed. University of California Press, Berkley.

Lipo, Carl

2001 Science, Style and the Study of Community Structure: An Example from the Central Mississippi River Valley. British Archaeological Reports, International Series. Oxford.

Loring, Stephen

1990 The "Heathen Eskimos" of northern Labrador: Inuit sovereignty in the Torngats. A report on the 1989 archaeological fieldwork at Eskimo Hutte (IkDb-2). Government of Newfoundland and Labrador, Department of Tourism, Culture \& Recreation, Division of Historic Resources, St. John’s, Newfoundland.

1992 Princes and princesses of ragged fame: Innu archaeology and ethnohistory in Labrador. PhD, University of Massachusetts.

1998a In Torngak’s Realm: The Nineteenth-Century Photography of Moravian Missionaries in Labrador. In Imaging the Arctic, edited by J. C. H. King and H. Lidchi, 207-220. University of Washington Press, Seattle.

1998b The archaeology of Eskimo Hütte (IkDb-2): Inuit sovereignty in the Torngat. Etudes/Inuit/Studies 22(2): 53-76.

2007 The Wind Blows Everything off the Ground: New Provisions and New Directions in Archaeological Research in the North. In Opening Archaeology: Repatriation's Impact on Contemporary Research and Practice, edited by Thomas Killion, pp. 181-208. School for Advanced Research Advanced Seminar Series. School for Advanced Research, Santé Fe, New Mexico.

Loring, Stephen, and Beatrix Arendt

2009 “...they gave Hebron, the city of refuge...” (Joshua 21:13): an archaeological reconnaissance at Hebron, Labrador. Journal of the North Atlantic: Archaeologies of the Early Modern North Atlantic Special Volume (1):33-56.

Loring, Stephen, and Leah Rosenmeier

2005 Anguti's Amulet/Angutiup ânguanga. Eastern Woodland Publishing, Millbrook First Nation, Truro, Nova Scotia. 
Lydon, Jane

2009 Fantastic Dreaming: The Archaeology of an Aboriginal Mission. AltaMira Press, Plymouth.

Lyons, Claire, and John Papadopoulos

2002 The Archaeology of Colonialism. Getter Research Institute Press, Santa Monica.

Marchani, E.E., A.R. Rogers, and Dennis H. O’Rourke

2007 Brief communication: The Thule migration: Rejecting population histories using computer simulation. American Journal of Physical Anthropology 134(2): 281284.

Martijn, Charles

1980 La présence inuit sur la côte-nord du golfe St. Laurent à l'époque historique. Etudes/Inuit/Studies 4(1-2): 105-125.

Mary-Rousselière, Guy

1979 The Thule Culture on North Baffin Island: Early Thule Characteristics and the Survival of the Thule Tradition. In Thule Eskimo Culture: An Anthropological Retrospective, edited by Allen McCartney, pp. 54-75. Mercury Series 88. National Museum of Canada, Ottawa.

Mason, J. C. S.

2001 The Moravian Church and the Missionary Awakening in England 1760-1800. Royal Historical Society, Suffolk.

Maxwell, Moreau

1985 Prehistory of the Eastern Arctic. Academic Press, Inc., Orlando.

McCartney, Allen

1979 Thule Eskimo Prehistory Along Northwestern Hudson Bay. Mercury Series Paper 70. Canadian Museum of Civilization, Ottawa.

1980 The nature of Thule Eskimo whale use. Arctic 33(3): 571-541.

1988 Late Prehistoric Metal Use in the New World Arctic. In The Late Prehistoric Development of Alaska's Native People, edited by R. D. Shaw, pp. 57-79. Alaska Anthropological Association Monograph 4. Alaska Anthropological Association, Anchorage.

McCartney, Allen, and D. J. Mack

1973 Iron Utilization by Thule Eskimos of Central Canada. American Antiquity 38(3): 328-339. 
McCullough, Karen

1989 The Ruin Islanders. Mercury Series 141. Canadian Museum of Civilization, Hull, Quebec.

McGhee, Robert

1977 Ivory for the Sea Woman: The Symbolic Attributes of a Prehistoric Technology. Canadian Journal of Archaeology 1: 141-149.

1984 Contact between Native North Americans and the Mediaeval Norse: a Review of the Evidence. American Antiquity 49(1): 4-26.

1994 Disease and the Development of Inuit Culture. Current Anthropology 35(5): 565594.

2007 Last Imaginary Place: A Human History of the Arctic World. University of Chicago Press, Chicago.

2009 The Population Size and Temporal Duration of Thule Culture in Arctic Canada. In On the Track of the Thule Culture From Bering Strait to East Greenland, 15:75-89. Studies in Archaeology and History. The National Museum of Denmark, Copenhagen.

McMillan, Lauren

2010 Put This In Your Pipe and Smoke It: An Evaluation of Tobacco Pipe Stem Dating Methods. MA, Eastern Carolina University, Greenville.

Merbs, Charles

1997 Eskimo Skeleton Taphonomy with Identification of Possible Polar Bear Victims. In Forensic Taphonomy: the Postmortem Fate of Human Remains, edited by William D. Haglund and Marcella H. Sorg, pp. 249-262. CRC Press, Boca Raton.

Miller, Henry, Dennis Pogue, and Michael Smolek

1983 Beads from the Seventeenth Century Chesapeake. In Proceedings of the 1982 Glass Bead Conference, edited by Charles F. Hayes, pp. 127-144. Research Records 16. Rochester Museum and Science Division, Rochester.

Morrison, David

1981 A Preliminary Statement on Neo-Eskimo Occupations in Western Coronation Gulf, N.W.T. Arctic 34(3): 261-269.

1983 Thule Culture in Western Coronation Gulf, N.W.T. Mercury Series Paper 116. Canadian Museum of Civilization, Ottawa. 
1987 Thule and Historic Copper Use in the Copper Inuit Area. American Antiquity 52(1): 3-12.

1991 The Copper Inuit Soapstone Trade. Arctic 44(3): 239-246.

Le Mouël, Jean-François, and Maryke Le Mouël

2002 Aspects of Early Thule Culture as Seen in the Architecture of a Site on Victoria Island, Amundsen Gulf Area. Arctic 55(2): 167-189.

Neiman, Fraser, Leslie McFaden, and Derek Wheeler

2001 Archaeological Investigations of the Elizabeth Hemmings Site (44AB438).

Monticello Deparment of Archaeology Technical Report. Charlottesville.

Obeyesekere, Gananath

1997 The Apotheosis of Captain Cook: European Mythmaking in the Pacific. Princeton University Press, Princeton.

Omwake, H. Geiger

1956 Date-Bore Diameter Correlation In English White Kaolin Pipe Stems. Quarterly Bulletin of the Archaeological Society of Virginia 2(1): 3-5.

Oosten, J.G.

1976 The Theoretical Structure of the Religion of the Netsilik and Iglulik. Krips Repro, Meppel.

P.A.

1790-1813 Periodical Accounts Relating to the Missions of the Church of the United Brethren Established Among the Heathen. J. Marshall, London.

Packard, Alpheus Spring

1891 The Labrador coast: A journal of two summer cruises to that region. N.D.C. Hodges.

Park, Robert W.

1988 "Winter Houses” and Qarmat in Thule and Historic Inuit Settlement Patterns: Some Implications for Thule Studies. Canadian Journal of Archaeology 12: 163175.

1997 Thule winter site demography in the high Arctic. American Antiquity 62(2): 273284.

1999 Seal use and storage in the Thule culture of Arctic North America. Revista de Arqueologia Americana. 
Pastore, Ralph

1994 The Sixteenth Century: Aboriginal Peoples and European Contact. In The Atlantic Region to Confederation: a history, pp. 22-39. University of Toronto Press, Toronto.

Patterson, Stephen E.

1994 1744-1763 Colonial Wars and Aboriginal Peoples. In The Atlantic region to Confederation: a history, pp. 125-155. University Press of Toronto, Toronto.

Pearce, Susan

1987 Ivory, Antler, Feather and Wood: Material Culture and the Cosmology of the Cumberland Sound Inuit, Baffin Island, Canada. The Canadian Journal of Native Studies 8(2): 307-321.

Peelo, Sarah

2009 Baptism among the Salinan Neophytes of Mission San Antonio de Padua: Investigating the Ecological Hypothesis. Ethnohistory 56(4): 589-624.

Penney, Gerald

2002 Historic Resource Overview Assessment (Stage 1): Water and Sewer Projectphase 7, Hopedale, Labrador. Gerald Penny and Associates Ltd, Newfoundland.

Petrone, Penny

1992 Northern Voices: Inuit Writing in English. University of Toronto Press.

Plog, Stephen

1990 Agriculture, Sedentism and Environment in the Evolution of Political Systems. In The Evolution of Political Systems, edited by Steadman Upham, pp. 177-199.

Cambridge University Press, Cambridge.

Plog, Stephen, and Michelle Hegmon

1993 The sample size-richness relation: The relevance of research questions, sample strategies and behavioral variation. American Antiquity 58(3): 489-496.

Podmore, Colin

1998 The Moravian Church in England, 1728-1760. Clarendon Press, Oxford.

2007 Zinzendorf and the English Moravians. Journal of Moravian History(3): 31-50.

Pope, Peter

2004 Fish Into Wine: The Newfoundland Plantation in the Seventeenth Century. The University of North Carolina Press, Chapel Hill. 
Pringle, Heather

1997 New Respect for Metal's Role in Ancient Arctic Cultures. Science 277(5327): 766-767.

Proulx, Jean-Pierre

1993 Basque Whaling in Labrador in the 16th century. National Historic Sites, Parks Service, Ottawa.

Prowse, Daniel Woodley

1895 A history of Newfoundland from the English, colonial, and foreign records. Macmillan and Co., New York.

Ramenofsky, Ann F., Fraser Neiman, and Christopher D. Pierce

2009 Measuring Time, Population, and Residential Mobility From the Surface at San Marcos Pueblo, North Central New Mexico. American Antiquity 74(3): 505-530.

Ramsden, Peter, and Lisa Rankin

2010 Thule Radiocarbon Chronology and its Implications for Early Inuit-European Interaction in Labrador. In St. John's, Newfoundland.

Rankin, Lisa

2011 A People for All Seasons: Expression of Inuit Identity over the past 500 years in Southern Labrador. In Identity: Archaeological Perspectives on Social Identity, edited by Lindsay Amundsen-Pichering, Nicole Engel, and Sean Pickering, pp. 332-340. Proceedings of the 42nd (2010) Annual Chacmool Archaeology Conference. Chacmool Archaeological Association, University of Calgary, Calgary.

Rasmussen, Knud

1929 Intellectual Culture of the Iglulik Eskimos. Report of the Fifth Thule Expedition. Vol. 7. 1 vols. Gyldendalske Boghandel, Copenhagen.

Reedy-Maschner, Katherine, and Herbert Maschner

1999 Marauding Middlemen: Western Expansion and Violent Conflict in the Subarctic. Ethnohistory 46(4): 703-743.

Rich, E. E.

1960 Hudson’s Bay Company 1670-1870. Vol. 1. 3 vols. MacMillian Company, New York.

Richling, Barnett

1993 Labrador's “Communal House Phase” Reconsidered. Arctic Anthropology 30(1): 67-78. 
1998 Hard times them times: An interpretative ethnohistory of Inuit and settlers in Hopedale District of Northern Labrador. PhD, McGill University, Montreal.

Rollmann, Hans

2002 Labrador Through Moravian Eyes: 250 Years of Art, Photographs, and Records. Department of Tourism, Culture and Recreation, St. John’s, Newfoundland.

2009a Johann Christian Erhardt and the First Moravian Exploration of Labrador in 1752. In Moravian Beginnings in Labrador: Papers from a Symposium held in Makkovik and Hopedale, edited by Hans Rollmann, pp. 53-68. Newfoundland and Labrador Studies, Occasional Publication 2. Memorial University, St. John’s.

2009b The Labrador Land Grants for 1769 and 1774. In Moravian Beginnings in Labrador: Papers from a Symposium held in Makkovik and Hopedale, edited by Hans Rollmann, pp. 104-131. Newfoundland and Labrador Studies, Occasional Publication 2. Memorial University, St. John's.

2010 Moravians in Central Labrador: The Indigenous Inuit Mission of Jacobus and Salome at Snooks Cove. Journal of Moravian History 9: 7-40.

Rompkey, Bill

2003 The Story of Labrador. McGill-Queen’s Press, Montreal.

Rothschild, Nan

2003 Colonial Encounters in a Native American Landscape. Smithsonian Books, Washington, D.C.

Rowe, Frederick

1980 A History of Newfoundland and Labrador. McGraw Hill Ryerson Ltd., Toronto.

Rowley, Susan

1994 Comment to Disease and the Development of Inuit Culture. American Antiquity 35(5): 582-583.

Sabathy-Judd, Linda

2009 Winning Souls for Jesus: Moravians in Nain, Labrador, 1771-1781. In Moravian Beginnings in Labrador: Papers from a Symposium held in Makkovik and Hopedale, edited by Hans Rollmann, pp. 132-142. Newfoundland and Labrador Studies, Occasional Publication 2. Memorial University, St. John’s. 
Sabo, George

1991 Long Term Adaptations among Arctic Hunter-Gatherers: a case study from southern Baffin Island. Evolution of North American Indian. Garland Publishing, New York.

Sabo, George, and John Jacobs

1980 Aspects of Thule Culture Adaptations in Southern Baffin Island. Arctic 33(3): 487-504.

Sahlins, Marshall

1985 Islands of History. The University of Chicago Press, Chicago.

Said, Edward W.

1978 Orientalism. Vintage Books, New York.

Saunders, Rebecca

1998 Forced Relocation, Power Relations, and Culture Contact in the Missions of La Florida. In Studies in Culture Contact: Interaction, Culture Change and Archaeology, edited by James Cusick, pp. 402-429. Southern Illinois University, Carbondale.

Savelle, James M.

1984 Cultural and Natural Formation Processes of a Historic Inuit Snow Dwelling Site, Somerset Island, Arctic Canada. American Antiquity 49(3): 508-524.

1987 Collectors and Foragers: Subsistence-Settlement System Change in the Central Canadian Arctic, A.D. 1000-1960. Vol. 358. BAR International Series. BAR, Oxford.

1997 The role of architectural utility in the formation of zooarchaeological whale bone assemblages. Journal of Archaeological Science 24: 869-885.

2002 Complexity, and the Collapse of Prehistoric Thule Whaling Societies in the Central Canadian Arctic Archipelago. In Beyond Foraging and Collecting, edited by Ben Fitzhugh and Junko Habu, pp. 73-90. Springer, New York.

Savelle, James M., and Max T. Friesen

1996 An Odontocete (Cetacea) Meat Utility Index. Journal of Archaeological Science 23(5): 713-721. doi:10.1006/jasc.1996.0067. 
Schattschneider, David

2009 Moravians Approach the Inuit: Theories and Realities. In Moravian Beginnings in Labrador: Papers from a Symposium held in Makkovik and Hopedale, edited by Hans Rollmann, pp. 143-151. Newfoundland and Labrador Studies, Occasional Publication 2. Memorial University, St. John's.

Schledermann, Peter

1971 The Thule Tradition in Northern Labrador. MA, Memorial University of Newfoundland.

1976 Thule Culture Communal Houses in Labrador. Arctic 29(1): 27-37.

Schledermann, Peter and Karen McCullough

1980 Western Elements in the Early Thule Culture of the Eastern High Arctic. Arctic 33(4): 833-841.

2003 Late Thule Culture Developments on the central east coast of Ellesmere Island. Danish Polar Center 12. Danish Polar Center, Copenhagen.

de Schweinitz, E.

1859 The Moravian Manual: Containing an Account of the Protestant Church of the Moravian United Brethren, or Unitas Fratrum. Lindsay and Blakiston, Philadelphia.

Sensbach, Jon F.

1998 A Separate Canaan: The Making of an Afro-Moravian World in North Carolina, 1763-1840. The University of North Carolina Press, Chapel Hill.

2005 Rebecca's Revival: Creating Black Christianity in the Atlantic World. Harvard University Press, Cambridge.

Shackel, Paul A.

2004 Introduction: Working with Communities Heritage Development and Applied Archaeology. In Places in Mind: Public Archaeology as Applied Anthropology, edited by Paul A. Shackel and Erve J. Chambers, pp. 1-18. Routledge, New York.

Shennan, Stephen

1988 Quantifying Archaeology. University Press, Edinburgh.

Singleton, Theresa A.

1999 I, too, am America. University of Virginia Press, Charlottesville. 
Smith, Karen, and Fraser Neiman

2007 Frequency Seriation, Correspondence Analysis, and Woodland Period Ceramic Assemblage Variation in the Deep South. Southeastern Archaeology 26(1): 47-72.

Smith, Karen, Fraser Neiman, and Jillian Galle

2008 Building a continuous chronology for studying early-modern Atlantic slavery. Poster presented at the Society for American Archaeology Meetings, Vancouver, B.C.

Smith, Marvin

1976 The Chevron Trade Bead in North America. The Bead Journal 3(1): 15-17.

1983 Chronology from Glass Beads: The Spanish Period in the Southeast, c. A.D. 1513-1670. In Proceedings of the 1982 Glass Trade Bead Conference, edited by Charles F. Hayes. Research Records 16. Rochester Museum and Science Division, Rochester.

Sommer, Elisabeth W.

2000 Serving Two Masters : Moravian Brethren in Germany and North Carolina, 1727-1801. University Press of Kentucky, Lexington.

South, Stanley A.

1977 Method and Theory in Historical Archaeology. Academic Press, New York.

1999 Historical archaeology in Wachovia: excavating eighteenth-century Bethabara and Moravian pottery. Kluwer Academic/Plenum Publishers, November 30.

Spicer, Edward

1961 Cycles of Conquest. University of Arizona Press, Tucson.

Spivak, Gayatri Chakravorty

1987 In Other Worlds: Essays in Cultural Politics. New edition. Routledge, New York.

Stahl, Ann

1993 Concepts of Time and Approaches to Analogical Reasoning in Historical Perspective. American Antiquity 58: 235-260.

Stopp, Marianne P.

2002 Reconsidering Inuit presence in southern Labrador. Etudes/Inuit/Studies 26(2): 71-106.

2008 The New Labrador Papers of Captain George Cartwright. McGill-Queen's University Press, Montreal, June. 
2009 Eighteenth Century Labrador Inuit in England. Arctic 62(1): 45-64.

Sturtevant, W.C.

1980 The first Inuit depiction by Europeans. Etudes/Inuit/Studies 4(1-2): 47-49.

Taylor, J. Garth

1969 William Turner's Journeys to the Caribou Country with the Labrador Eskimos in 1780. Ethnohistory 16(2): 141-164.

1972 Answers to an Eighteenth Century Questionnaire. Ethnohistory 19(2): 135-145.

1974 Labrador Eskimo Settlements of the Early Contact Period. Ethnology 9. National Museum of Man, National Museums of Canada, Ottawa.

1975 Moravian Mission influence on Labrador Inuit Subsistence: 1776-1830. Approaches to Native History in Canada. National Museum of Man, National Museums of Canada, Ottawa.

1977 Traditional Land Use and Occupancy by the Labrador Inuit. In Our Footsteps are Everywhere: Inuit Land Use and Occupancy in Labrador, edited by Carol BriceBennett, 49-51. Labrador Inuit Association, Nain.

1983 The Two Worlds of Mikak I. The Beaver 314(3): 4-13.

1984 The Two Worlds of Mikak II. The Beaver 314(4): 18-25.

1988 Labrador Inuit whale use in the early contact period. Arctic Anthropology 25(1): 120-130.

2009 In the Wake of the Hope: Jens Haven’s 1764 Reconnaissance Journey in Northern Newfoundland and Southern Labrador. In Moravian Beginnings in Labrador: Papers from a Symposium held in Makkovik and Hopedale, edited by Hans Rollmann, 87-103. Newfoundland and Labrador Studies 2. Memorial University, St. John's.

Taylor, William

1966 An archaeological perspective on Eskimo economy. Antiquity 40: 114-20.

Taylor, William, and Robert McGhee

1979 Archaeological Material from Cresell Bay, N.W.T., Canada. Mercury Series Paper 85. Canadian Museum of Civilization, Ottawa. 
ter Braak, Cajo J. F.

1985 Correspondence Analysis of Incidence and Abundance Data: Properties in Terms of a Unimodal Response Model. Biometrics 41(4): 859-873.

The Moravians in Labrador

1835 The Moravians in Labrador. William Oliphant and Son, Edinburgh, Scotland.

Tocque, Philip

1895 Kaleidoscope echoes, being historical, philosophical, scientific and theological sketches from the miscellaneous writings of the Rev. Philip Tocque. The Hunter, Rose Company, Ltd., Toronto.

Trigger, Bruce G.

1991 Distinguished Lecture in Archeology: Constraint and Freedom - A New Synthesis for Archeological Explanation. American Anthropologist 93(3). New Series: 551569.

Trudel, Francois

1978 The Inuit of Southern Labrador and the development of French sedentary fisheries (1700-1760). In Canadian Ethnology Service Paper, edited by R Preston, 40:99121.

Tuck, James

1982 Prehistoric archaeology in Atlantic Canada since 1975. Canadian Journal of Archaeology(6): 201-223.

Tuck, James, and Robert Grenier

1981 A 16th-Century Basque Whaling Station in Labrador. Science 245(5): 180-189.

Turgeon, Laurier

1998 French Fishers, Fur Traders, and Amerindians during the Sixteenth Century: History and Archaeology. The William and Mary Quarterly 55(4): 585-610.

Turner, Lucien

2001 Ethnology of the Ungava District, Hudson Bay Territory. Smithsonian Institution Press, Washington, D.C.

Van Buren, Mary

2010 The Archaeological Study of Spanish Colonialism in the Americas. Journal of Archaeological Research 18(2): 151-201.

Vogt, Evon

1969 Zinacantan: A Maya Community in the Highlands of Chiapas. The Belknap Press, Cambridge. 
Voss, Barbara

2008 The Archaeology of Ethnogenesis: Race, Sexuality, and Identity in Colonial San Francisco. University of California Press, Berkeley.

Wallace, Birgitta Linderoth

2006 Westward Vikings: The Saga of L'Anse aux Meadows. Historic Sites Association of Newfoundland and Labrador in association with Parks Canada, St. John's, Newfoundland.

Way, Jacob E.

1978 An Osteological Analysis of a Transitional Late Thule/ Early Historic Labrador Eskimo Population. PhD, Department of Anthropology, University of Toronto, Toronto.

Weber, Max

1958 The Protestant Ethic and the Spirit of Capitalism. Charles Scribner and Sons., New York.

Weinlick, John R., and Albert H. Frank

1989 The Moravian Church Through the Ages. Moravian Church in America, WinstonSalem.

Wenzel, George

1994 Recent Change in Inuit Summer Residence Patterning on East Baffin Island. In Issues in Hunter-Gatherer Research, edited by Ernest S. Burch and Linda J. Ellanna, pp. 289-310. Berg Publishers, Oxford.

Wernke, Steven

2007 Analogy or Erasure? Dialectics of Religious Transformation in the Early Doctrinas of the Colca Valley, Peru. International Journal of Historical Archaeology 11(2): 152-182. doi:10.1007/s10761-007-0027-5.

Whitbourne, Richarad

1620 A Discourse and Discovery of New-Found-Land. London.

Whiteley, William H.

1964 The Establishment of the Moravian Mission in Labrador and British Policy, 17631783. Canadian Historical Review 45(1): 29-50.

1966 The Moravian Missionaries and the Labrador Eskimos in the Eighteenth Century. Church History 35(1): 76-92.

Whiteman, Darrell

1986 Using Missionary Documents in Ethnohistorical Research. In Ethnohistory: A 
Researcher's Guide, edited by Dennis Wiedman, pp. 25-60. Department of Anthropology, College of William and Mary, Williamsburg.

Whitridge, Peter

1999 The Construction of Social Difference in A Prehistoric Inuit Whaling Community. PhD, Arizona State University.

2004a Nachvak Fjord: Summary of 2003 Fieldwork. Provincial Archaeology Office Newsletter 2(1): 14.

2004b Landscapes, Houses, Bodies, Things: "Place” and the Archaeology of Inuit Imaginaries. Journal of Archaeological Method and Theory 11(2): 213-250.

2007 Summary of 2006 Fieldwork at Nachvak Fiord. Provincial Archaeology Office 2006 Archaeology Review 5: 42-44.

2008 Reimagining the Iglu: Modernity and the Challenge of the Eighteenth Century Labrador Inuit Winter House. Archaeologies 4(2): 288-309.

Whitridge, Peter, and James Woollett

2008 Summary of 2007 Fieldwork at Iglosiatik and Komaktorvik Fiord. Provincial Archaeology Office 2008 Archaeology Review 6: 60-61.

Williamson, H. Anthony

1964 The Moravian Mission and Its Impact on the Labrador Eskimo. Arctic Anthropology 2(2): 32-36.

Wilson, Don E., and DeeAnn M. Reeder

2005 Mammal Species of the World : A Taxonomic and Geographic Reference, 2volume set. 3rd ed. The Johns Hopkins University Press, Baltimore

Winter, Joseph C.

2000 Tobacco use by Native North Americans: sacred smoke and silent killer. University of Oklahoma Press, Norman.

Wolf, Eric

1982 Europe and the People Without History. 1st ed. University of California Press, Berkeley.

Woollett, James

1999 Living in the Narrows: Labrador Inuit Subsistence in Hamilton Inlet. World Archaeology 3(1): 370-387.

2003 An Historical Ecology of Labrador Inuit Culture Change. PhD, City University of 
New York.

2007 Labrador Inuit Subsistence in the Context of Environmental Change: An Initial Landscape History Perspective. American Anthropologist 109(1): 69-84.

2010a Oakes Bay 1: A Preliminary Reconstruction of a Labrador Inuit Seal Hunting Economy in the Context of Climate Change. Geografisk Tidsskrift-Danish Journal of Geography 110(2): 245-259.

Worth, John

2002 Spanish Missions and the Persistence of Chiefly Power. In The Transformation of the Southeastern Indians, 1540-1760, edited by R. Ethride and C. Hudson, 39-64. University Press of Mississippi, Jackson.

Zimmerly, David

1975 Cain's Land Revisited: Culture change in Central Labrador. Newfoundland Social and Economic Studies 16. 